\author{
UNIVERSIDADE DE SÃO PAULO \\ ESCOLA DE ENGENHARIA DE SÃO CARLOS \\ DEPARTAMENTO DE HIDRÁULICA E SANEAMENTO \\ PROGRAMA DE PÓS-GRADUAÇÃO EM ENGENHARIA \\ HIDRÁULICA E SANEAMENTO
}

\title{
AVALIAÇÃO DA QUALIDADE DO AR EM AMBIENTES INTERNOS: BIBLIOTECA PÚBLICA
}

Guilherme Caetano do Nascimento

São Carlos, SP

2011 


\section{AVALIAÇÃO DA QUALIDADE DO AR EM AMBIENTES INTERNOS: BIBLIOTECA PÚBLICA}

Guilherme Caetano do Nascimento

Dissertação apresentada à Escola de Engenharia de São Carlos, da Universidade de São Paulo, como parte dos requisitos para obtenção do título de Mestre em Hidráulica e Saneamento.

Orientador: Prof. Dr. Wiclef Dymurgo Marra Junior

[VERSÃO CORRIGIDA]

São Carlos, SP

2011 
AUTORIZO A REPRODUÇÃO E DIVULGAÇÃO TOTAL OU PARCIAL DESTE TRABALHO, POR QUALQUER MEIO CONVENCIONAL OU ELETRÔNICO, PARA FINS DE ESTUDO E PESQUISA, DESDE QUE CITADA A FONTE.

Ficha catalográfica preparada pela Seção de Tratamento da Informação do Serviço de Biblioteca - EESC/USP

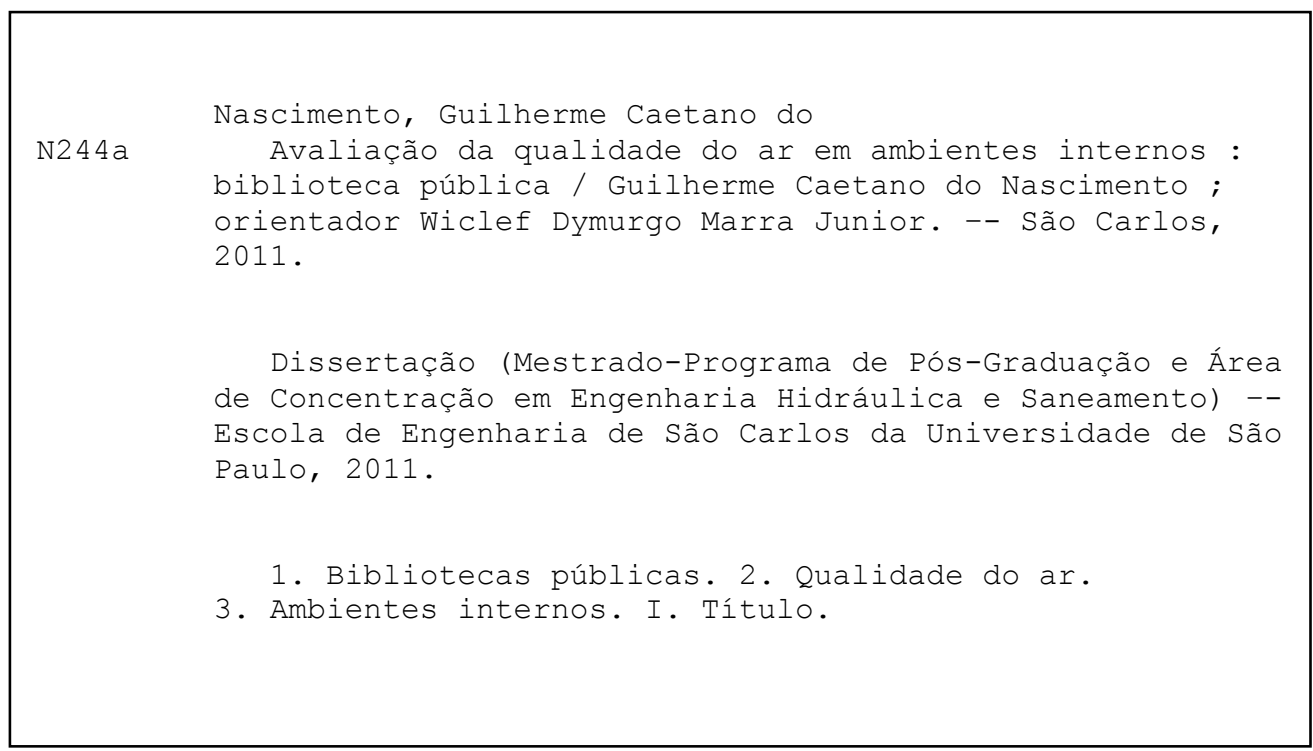


Candidato: Engenheiro GUILHERME CAETANO DO NASCIMENTO.

Dissertação defendida e julgada em 01/04/2011 perante a Comissão Julgadora:

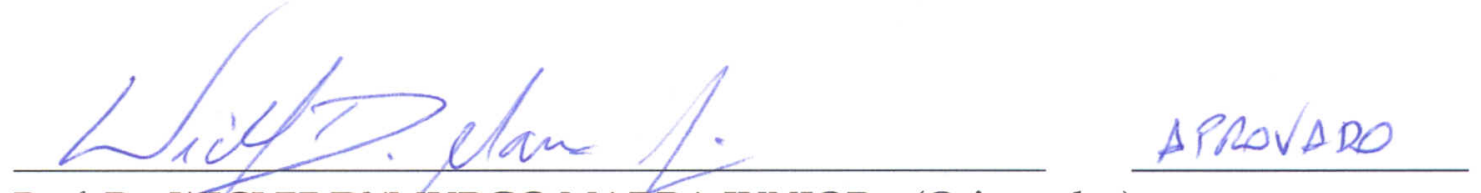

Prof. Dr. WICLEF DYMURGO MARRA JUNIOR - (Orientador)

(Escola de Engenharia de São Carlos/USP)

Hoómica Lopes Afinian Aprovado Prof ${ }^{\text {. Dria }}$. MONICA LOPES AGUIAR

(Universidade Federal de São Carlos/UFSCar)

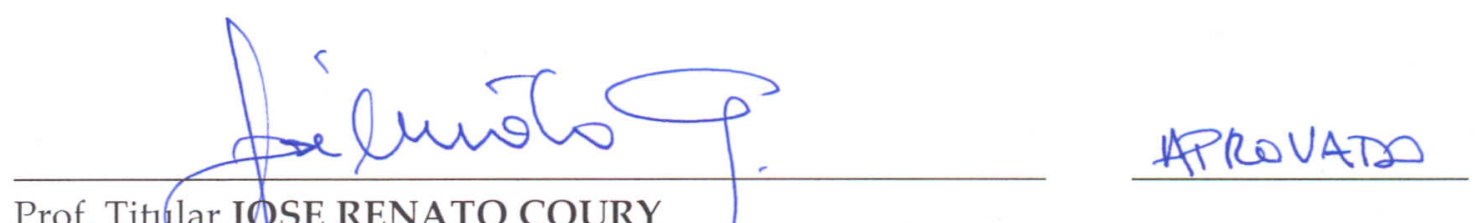

(Universidade Federal de São Carłos/UFSCar)

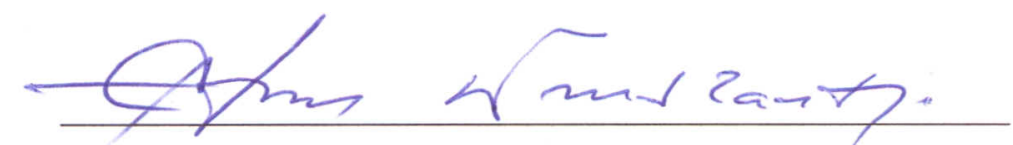

Prof. Titular EDSON CEZAR WENDLAND

Coordenador do Programa de Pós-Graduação em Engenharia Hidráulica e Saneamento

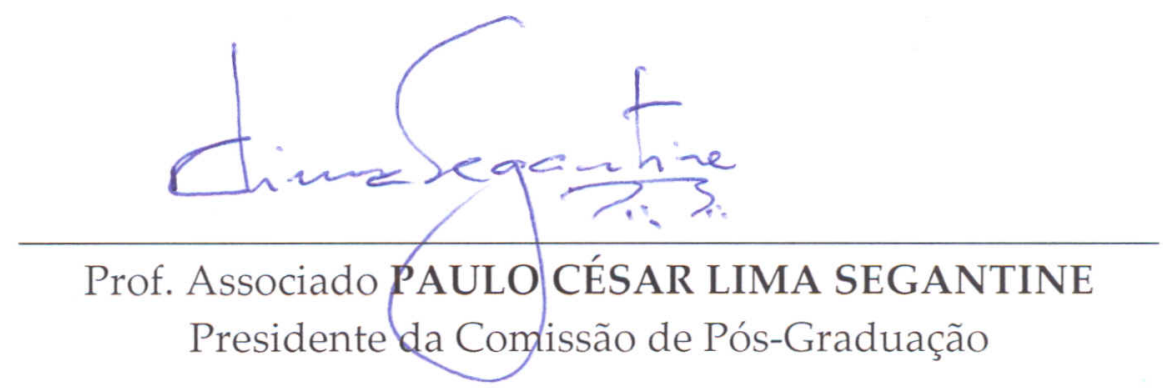


A toda minha familia, por todos os valiosos ensinamentos, pelo eterno apoio e base de toda a minha moral. Sem vocês, esse trabalho não seria completo. 


\section{AGRADECIMENTOS}

Primeiramente, a Deus, pelo primordial dom da vida e por possibilitar vivenciar as diversas experiências e adversidades;

Ao Prof. Dr. Wiclef Dymurgo Marra Junior, pela orientação e parceria desde 2007, pela confiança em mim depositada, pelas oportunidades de aprendizado a mim confiadas e pela colaboração com idéias para superar todas as dificuldades encontradas no caminho;

À Profa. Dra. Mônica Lopes Aguiar, da UFSCar, pelo cuidado especial com o projeto e a pesquisa, pela presença e sugestões na qualificação, pelo auxílio ao longo desses anos, pelo apoio técnico e instrumental e pela disponibilidade em participar da banca julgadora;

Ao Prof. Dr. José Renato Coury, pela oportunidade de conhecer novas áreas do conhecimento, pelas sugestões apresentadas na qualificação, pelos conselhos e dúvidas resolvidas, pelo apoio técnico e instrumental e por aceitar compor a banca julgadora;

A todo o pessoal do Laboratório de Processos Biológicos da EESC/USP, na Área 2 do Campus da USP de São Carlos, e do Laboratório de Controle Ambiental do Departamento de Engenharia Química da UFSCar, técnicos e alunos de pós-graduação, pelo auxílio experimental prestado, pela oportunidade de aprendizado e pelo companheirismo;

Aos companheiros de pesquisa Lênin, Elaine, Mayumi, Tati, Beatriz, Ana Flávia, Cristiane e Janaína, pelos momentos e experiências compartilhadas, pela companhia e dicas nas coletas, fazendo com que os laços ficassem mais estreitos e contribuindo com muito orgulho para a extensão dos meus vínculos de amizade;

Aos usuários e, principalmente, aos funcionários da Biblioteca, que ao longo de dois anos fizeram com que o desenvolvimento da pesquisa fosse cada vez mais interessante e colaborando para um clima gostoso de trabalho;

À Sra. Claudete Cury Sacomano, diretora da Biblioteca Municipal Amadeu Amaral, por autorizar a realização da pesquisa no local em questão e depositar confiança na execução do estudo; 
Ao Sr. Edson, Sr. Carlos e ao Camilo, pelo apoio técnico com os imprevistos com os equipamentos e pela confiança construída ao longo da minha estadia no prédio da Engenharia Ambiental;

Aos amigos do curso de pós-graduação em Engenharia Hidráulica e Saneamento da EESC/USP, pela companhia durante as aulas e nos momentos de descontração;

Aos amigos e companheiros Engenheiros Ambientais, pela motivação sempre presente;

A toda minha família, especialmente aos meus pais, Henrique e Maria José, e aos irmãos, Marcos e Rafael;

Aos meus pais, por sempre apoiarem as minhas decisões de forma irrestrita e incondicional, me sinto extremamente feliz e completo por poder contar com essas pessoas, razão do meu sentimento profundo e verdadeiro;

Aos meus irmãos, meus melhores amigos e sempre me apoiando nas minhas decisões, dando conselhos e fazendo meu olhar se voltar para outros horizontes e por isso os considero um exemplo de vida, dignidade e honra;

A toda minha família, pelas experiências passadas, pelo amor, pela fé, pela esperança sempre depositada em mim, pelo apoio às minhas atitudes e pelos momentos de descontração e diversão, fundamentais na minha vida;

A todos os amigos da cidade de Ituverava, por sempre estarem presentes, desde a infância até os dias atuais, e pelo sentimento de felicidade extrema em compartilhar os momentos de alegria com essas pessoas ímpares e fundamentais na minha vida;

Aos amigos da cidade de São Carlos, que ao longo de sete anos, passei a conhecer pessoas diferenciadas, e fui capaz de vivenciar oportunidades únicas de conhecimento e amadurecimento, constituindo parte essencial da minha índole e personalidade;

Não irei colocar os nomes de todas as pessoas que me motivaram a seguir nessa carreira e área de pesquisa, porém, eles estão todos muito bem guardados na minha lembrança e sou eternamente grato a existência dessas peças em minha vida.

Muito obrigado! 
Eu sou apenas um rapaz, Latino-americano, sem dinheiro no banco,

Sem parentes importantes,

$E$ vindo do interior.

Mas trago de cabeça uma canção do rádio, Em que um antigo compositor baiano me dizia, Tudo é divino, tudo é maravilhoso Belchior - Apenas uma rapaz latino-americano 
SUMÁRIO

LISTA DE ABREVIATURAS E SIGLAS ......................................................................... i

LISTA DE FIGURAS..................................................................................................................iii

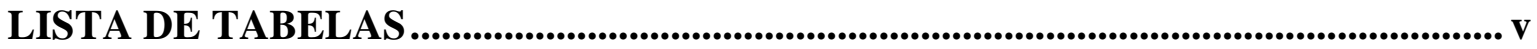

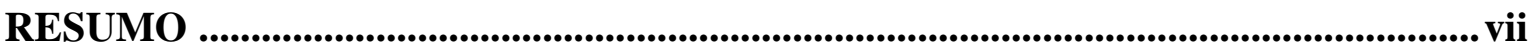

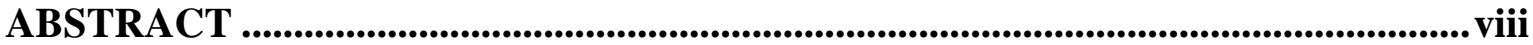

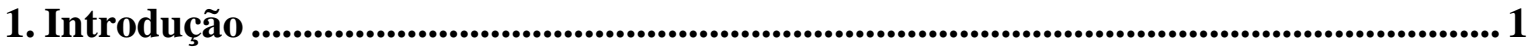

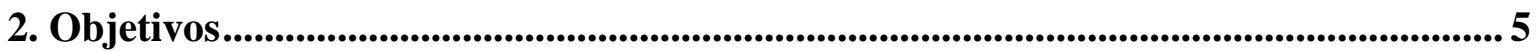

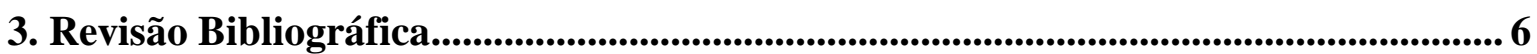

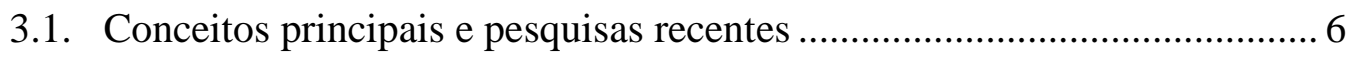

3.2. Legislação e Normas ......................................................................... 18

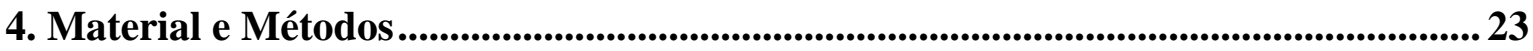

4.1. Biblioteca Pública Amadeu Amaral ...................................................... 23

4.2. Análise de gás carbônico ....................................................................... 28

4.3. Intensidade luminosa, ruído, umidade e temperatura ..............................2 29

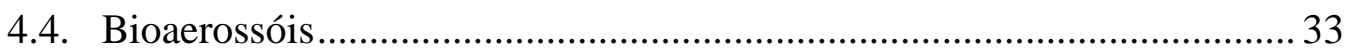

4.4.1. Preparação dos meios de cultura e placas................................ 34

4.4.2. Coleta de bioaerossol ................................................................. 34

4.4.3. Microscopia com coloração de Gram ……............................... 37

4.4.4. Concentração de microrganismos............................................ 38

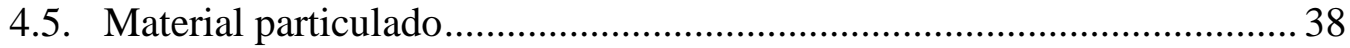

4.6. Taxa de ocupação e ventilação ................................................................ 39

4.7. Aplicação de questionário .................................................................. 42

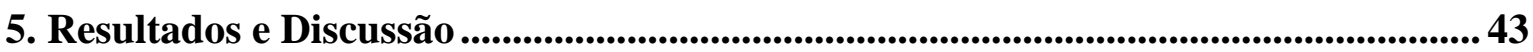

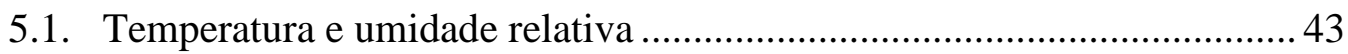

5.2. Material particulado............................................................................. 54

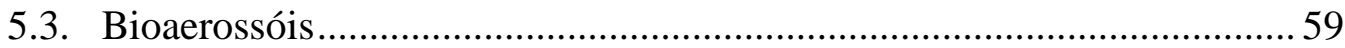

5.3.1. Análise da concentração de bioaerossóis ................................. 59

5.3.2. Coloração de Gram das bactérias ............................................ 63

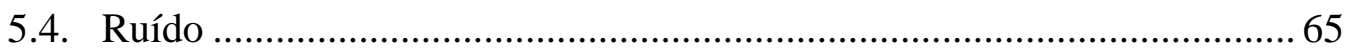

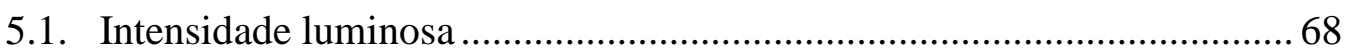

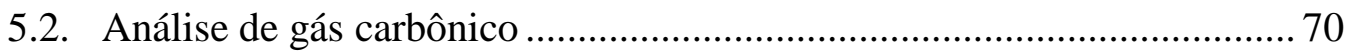

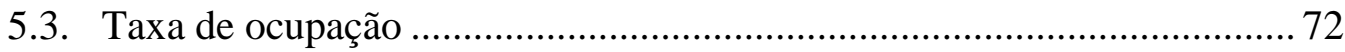




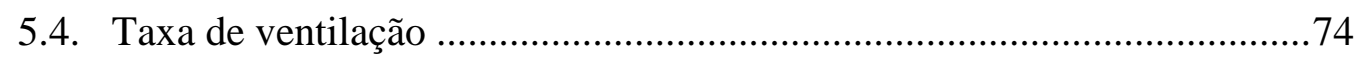

5.5. Aplicação de questionário.................................................................76

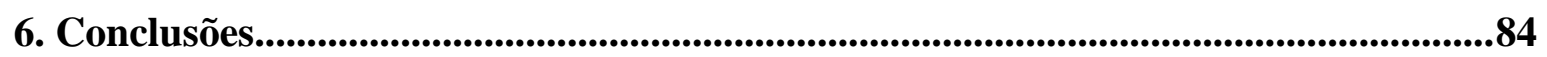

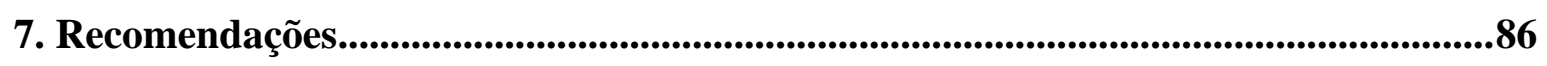

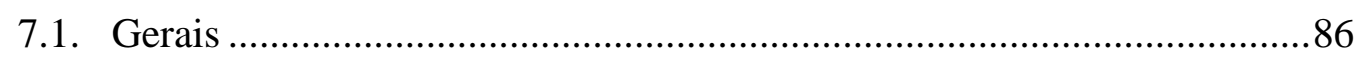

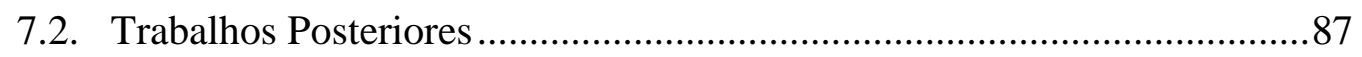

8. Referências Bibliográficas ...................................................................................88

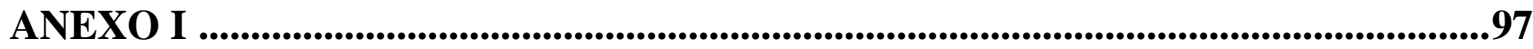

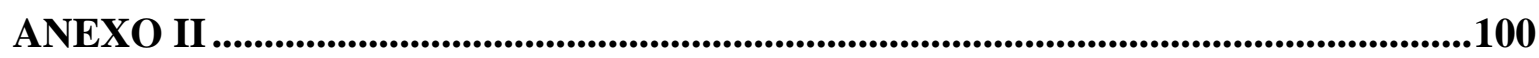

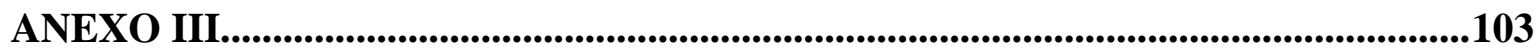

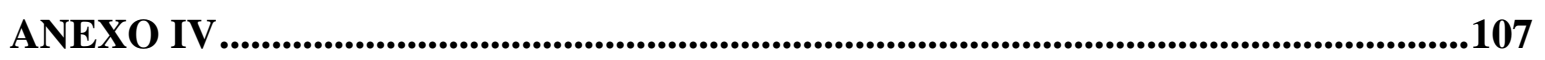

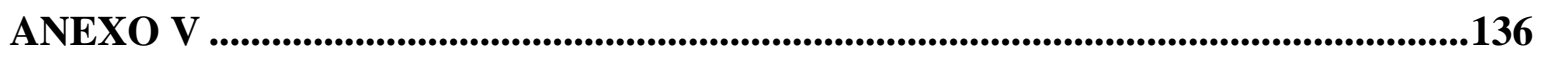




\section{LISTA DE ABREVIATURAS E SIGLAS}

ABNT - Associação Brasileira de Normas Técnicas

ABRAVA - Associação Brasileira de Refrigeração, Ar Condicionado, Ventilação e Aquecimento

ANVISA - Agência Nacional de Vigilância Sanitária

ASHRAE - American Society of Heating, Refrigerating and Air Conditioning Engineers

CETESB - Companhia de Tecnologia de Saneamento Ambiental do Estado de São

Paulo

CO - Monóxido de carbono

$\mathrm{CO}_{2}$ - Dióxido de carbono (gás carbônico)

CONAMA - Conselho Nacional de Meio Ambiente

COV - Composto Orgânico Volátil

Índice I/E - Razão entre concentrações de compostos em ambientes internos sobre a de externos

MP - Material Particulado

$\mathrm{MP}_{1}$ - Fração do material particulado total em suspensão com partículas de tamanho menor que $1 \mu \mathrm{m}$

$\mathrm{MP}_{2,5}$ - Fração do material particulado total em suspensão com partículas de tamanho menor que $2,5 \mu \mathrm{m}$

$\mathrm{MP}_{7}$ - Fração do material particulado total em suspensão com partículas de tamanho menor que $7 \mu \mathrm{m}$

$\mathrm{MP}_{10}$ - Fração do material particulado total em suspensão com partículas de tamanho menor que $10 \mu \mathrm{m}$ 
MPT - Material Particulado Total em Suspensão

$\mathrm{NO}_{2}$ - Dióxido de nitrogênio

$\mathrm{NO}_{\mathrm{x}}$ - Óxidos de Nitrogênio

$\mathrm{O}_{3}$ - Ozônio

OMS - Organização Mundial de Saúde

PRONAR - Programa Nacional de Controle da Qualidade do Ar

QAI - Qualidade do ar de interiores

$\mathrm{SO}_{\mathrm{x}}$ - Óxidos de Enxofre

UFC - Unidades Formadoras de Colônias

VMR - Valor Máximo Recomendável 


\section{LISTA DE FIGURAS}

Figura 1. Fachada externa do prédio no cruzamento da Av. São Carlos com a Rua 13 de Maio.

Figura 2. Fachada externa do prédio, vista por quem transita na Av. São Carlos; em destaque, as janelas do Acervo

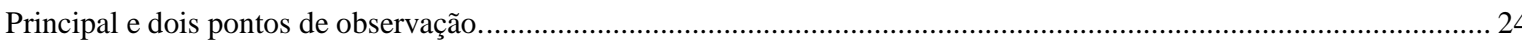

Figura 3. Perfil da rua para a fachada externa da Biblioteca com a Av. São Carlos................................................... 25

Figura 4. Porção exterior da Biblioteca Pública Amadeu Amaral, utilizada para coleta de dados de qualidade do ar. ...... 25

Figura 5. Principais dimensões, em metros, do Piso 1 e localização do ponto de amostragem....................................... 26

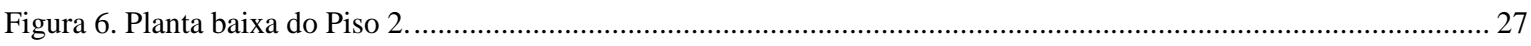

Figura 7. Principais dimensões, em metros, do Piso 2 e localização do ponto de amostragem....................................... 27

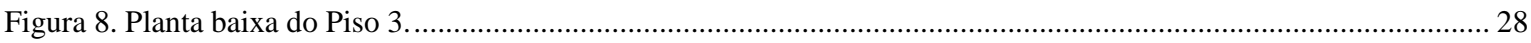

Figura 9. Principais dimensões, em metros, do Piso 3 e localização do ponto de amostragem....................................... 28

Figura 10. Monitor de gases portátil da RAE Systems, modelo MultiRAE IR - PGM54. ...............................................29

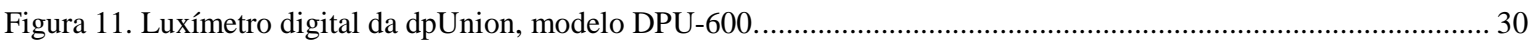

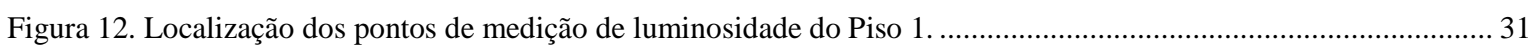

Figura 13. Localização dos pontos de medição de luminosidade do Piso 2. ...................................................................... 31

Figura 14. Localização dos pontos de medição de luminosidade do Piso 3 ................................................................. 32

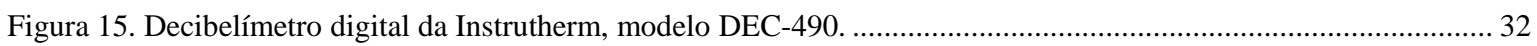

Figura 16. Termohigrômetro digital, marca Rotronic, modelo Hygropalm 0 ................................................................ 33

Figura 17. Sistema de filtração para avaliação de bactérias e fungos........................................................................... 35

Figura 18. Detalhamento do sistema de filtração empregado: (a) painel com rotâmetro e válvula reguladora; (b) funil com garra para suporte de membrana filtrante em haste regulável; (c) bomba de vácuo..................................................... 36

Figura 19. Contador de material particulado AEROCET 531, da marca Met One........................................................ 38

Figura 20. Diagrama esquemático do balanço de massa na sala de aula e suas principais variáveis................................ 41

Figura 21. Perfil da concentração de material particulado fracionado em uma medição no Piso 3, no dia 11/11/2009..... 55

Figura 22. Perfil da concentração de material particulado total em uma medição no Piso 3, no dia 11/11/2009............... 55

Figura 23. Concentração média de material particulado no Piso 1 para cada dia de análise. ............................................56

Figura 24. Concentração média de material particulado no Piso 2 para cada dia de análise........................................... 56

Figura 25. Concentração média de material particulado no Piso 3 para cada dia de análise. ...........................................56

Figura 26. Concentração média de material particulado no Ambiente Externo para cada dia de análise...........................57

Figura 27. Acúmulo de material particulado em membrana de $47 \mathrm{~mm}$ de Teflon® após coleta de 4 horas......................5 59

Figura 28. Desenvolvimento das colônias de bactérias em função do tempo de incubação para a coleta do dia 09/06/2009.

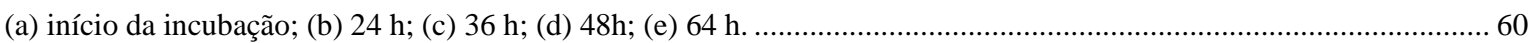

Figura 29. Contaminação biológica no Piso 1 com análise por filtração em membrana. ................................................. 61

Figura 30. Contaminação biológica no Piso 2 com análise por filtração em membrana. ................................................ 61

Figura 31. Contaminação biológica no Piso 3 com análise por filtração em membrana. .............................................. 62

Figura 32. Contaminação biológica no ambiente externo com análise por filtração em membrana.................................. 62

Figura 33. Presença de bacilos Gram positivos, em coleta do dia 07/10/2009; presença de esporos. ................................64

Figura 34. Presença de bacilos e cocos Gram positivos, em coleta do dia 21/10/2009. ................................................. 64

Figura 35. Perfil de ruído em dB(A) durante 4 horas de coleta no Piso 3 no dia 17/08/2010 .........................................66

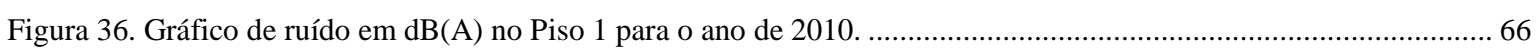

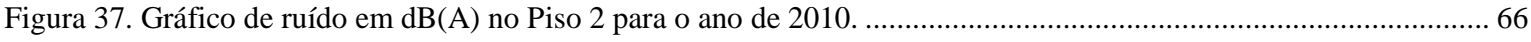

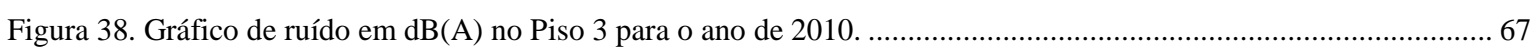


Figura 39. Gráfico de ruído em dB(A) no Ambiente Externo para o ano de 2010.

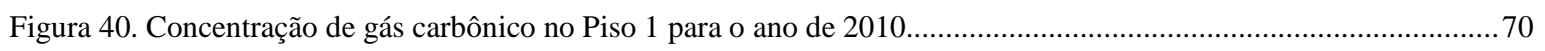

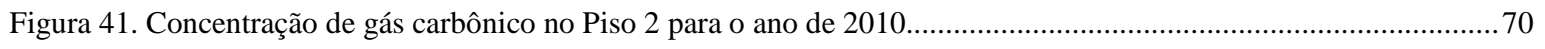

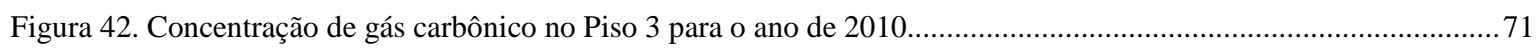

Figura 43. Concentração de gás carbônico no Ambiente Externo para o ano de 2010.................................................71

Figura 44. Concentração de gás carbônico para determinação da taxa de ventilação; Amostra 1................................75

Figura 45. Concentração de gás carbônico para determinação da taxa de ventilação; Amostra 2.................................75

Figura 46. Respostas para a proximidade do questionado a um ponto de desconforto..................................................77

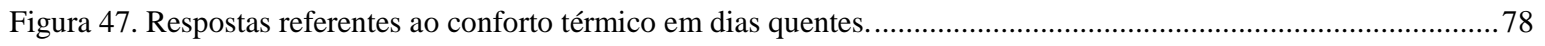

Figura 48. Respostas referentes ao conforto térmico em dias frio. ......................................................................... 78

Figura 49. Respostas referentes ao conforto térmico em geral. ......................................................................... 78

Figura 50. Influência do conforto térmico na realização das atividades do questionado. ...........................................79

Figura 51. Classificação do ar no local de atividade do questionado......................................................................... 80

Figura 52. Sintomas relacionados à má qualidade do ar, identificados pelos questionados..........................................8 80

Figura 53. Influência do ruído no desempenho dos questionados.................................................................... 81

Figura 54. Interferência do ruído na comunicação interpessoal dos entrevistados. .......................................................81

Figura 55. Necessidade de adoção de medidas para controle do ruído................................................................. 81 


\section{LISTA DE TABELAS}

Tabela 1 - Classificação dos poluentes do ar (Fonte: Bernstein, 2004) .......................................................................... 7

Tabela 2 - Poluentes em ambientes internos e seus efeitos adversos na saúde............................................................. 8

Tabela 3 - Poluentes do ar de interiores e suas fontes de emissão (Fonte: EPA, 2002).............................................. 9

Tabela 4 - Índices I/E de salas de aula (Fonte: Blondeau et al., 2005).......................................................................... 12

Tabela 5 - Distribuição de tamanhos e concentração de material particulado nas 60 casas de Hong Kong. (Fonte: Chao et al., 2002).

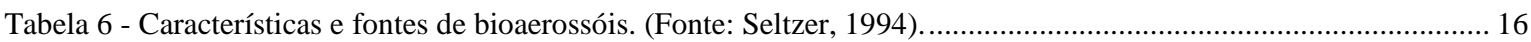

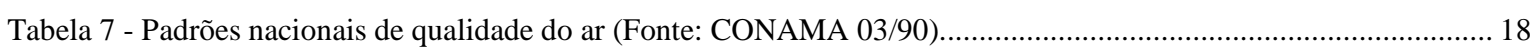

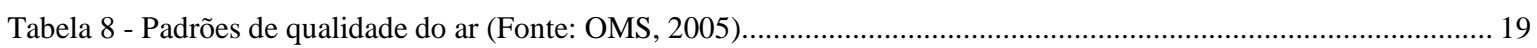

Tabela 9 - Possíveis fontes de poluentes biológicos (Fonte: RE/ANVISA No9) ......................................................... 20

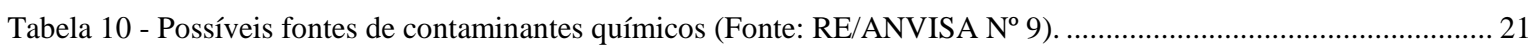

Tabela 11 - Valores médios da temperatura interna (TI) no Piso 1 e da temperatura externa (TE)................................. 44

Tabela 12 - Valores médios da temperatura interna (TI) no Piso 2 e da temperatura externa (TE)................................. 45

Tabela 13 - Valores médios da temperatura interna (TI) no Piso 3 e da temperatura externa (TE).............................. 47

Tabela 14 - Valores médios de umidade relativa interna (URI) no Piso 1 e umidade relativa externa (URE)................. 48

Tabela 15 - Valores médios de umidade relativa interna (URI) no Piso 2 e umidade relativa externa (URE).................. 50

Tabela 16 - Valores médios de umidade relativa interna (URI) no Piso 3 e umidade relativa externa (URE)...................51

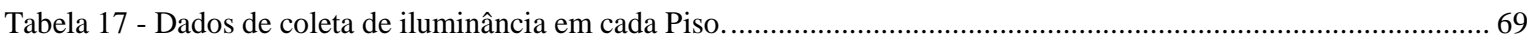

Tabela 19 - Dados utilizados para determinação da taxa de ventilação no Piso 1 . ........................................................ 76

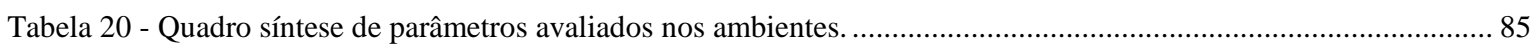




\section{RESUMO}

Ao longo de quinze meses, foram monitorados na Biblioteca Pública Amadeu Amaral, da cidade de São Carlos, SP, os níveis de temperatura, umidade relativa, ruído, intensidade luminosa, contaminação por dióxido de carbono, material particulado total (MPT) e suas frações respiráveis $\left(\mathrm{MP}_{1}, \mathrm{MP}_{2,5}, \mathrm{MP}_{7}\right.$ e $\left.\mathrm{MP}_{10}\right)$, avaliação da taxa de ventilação e ocupação, concentração de bioaerossóis e sua identificação. Além disso, foi aplicado um questionário aos ocupantes do local com o intuito de levantar as principais reclamações e queixas relacionadas à qualidade do ar interior. Os resultados mostraram o desconforto térmico do local em todas as salas monitoradas, altos níveis de ruído proveniente do ambiente externo, inadequações relativas à iluminação do local e necessidade de uma atenção especial à taxa de ocupação do prédio. Durante alguns momentos das medições, os níveis de ruído ultrapassaram a barreira dos $80 \mathrm{~dB}(\mathrm{~A})$, que é um valor bem acima do recomendado em normas, revelando-se um fator de risco para seus usuários e funcionários. Não foram encontrados problemas relacionados à contaminação biológica do local, analisando a concentração de bactérias e fungos. A taxa de ventilação possui valor adequado para o Piso 1 e a concentração de gás carbônico se manteve de acordo com os padrões estabelecidos em normas. As respostas dos questionários confirmam os principais resultados encontrados para a Biblioteca, como os altos níveis de ruído, o desconforto térmico do local e as inadequações da iluminação. As recomendações são pautadas na necessidade de realização de ensaios gravimétricos da concentração de material particulado e o desenvolvimento de estudos específicos para a adoção de medidas mitigadores da poluição sonora e, também, da adequação das salas para o conforto térmico dos ocupantes. 


\begin{abstract}
Over fifteen months, levels of temperature, humidity, noise, light intensity, contamination by carbon dioxide, total suspended particles (TSP) and respirable fractions $\left(\mathrm{PM}_{1}, \mathrm{PM}_{2.5}, \mathrm{PM}_{7}\right.$ and $\left.\mathrm{PM}_{10}\right)$ were monitored at the Public Library Amadeu Amaral at São Carlos, SP. Investigation of the ventilation rate and occupancy, concentration of bioaerosols and identification were also performed. In addition, a questionnaire was handed over to the occupants of the site in order to raise the main complaints related to indoor air quality. The results showed the discomfort of the place at all rooms monitored, high levels of noise from the outside environment, inadequacies relating to the site illumination and special attention to the building occupancy. During some measurements, the noise levels exceeded the barrier of $80 \mathrm{~dB}(\mathrm{~A})$, which is above the recommended standards and proved to be a risk factor for its users and employees. No problems were found related to the site biological contamination, analyzing the concentration of bacteria and fungi. The ventilation rate has adequate value to the First Floor and carbon dioxide concentration was maintained in accordance with the standards. The questionnaire responses confirm the main findings to the Library, such as high noise levels, thermal discomfort and the illumination problem. The main recommendations are based on the need of gravimetric particulate matter investigation and development of specific studies for the adoption of mitigation measures on noise pollution and also the suitability of the rooms to the thermal comfort of occupants.
\end{abstract}




\section{Introdução}

A qualidade do ar de interiores (QAI) é uma recente área de estudo no Brasil e em todo o mundo. Pesquisadores relatam que o interesse por esse assunto começou a prosperar por volta da década de 1970 e, mais especificamente no Brasil, na década de 1990. Eles ainda destacam a multidisciplinaridade do assunto, que deve reunir químicos, microbiologistas, engenheiros, arquitetos e toxicologistas. As inúmeras variáveis monitoradas para avaliação da QAI exigem uma interpretação abrangente e por isso englobam as diversas áreas de estudo acima destacadas (BRICKUS e AQUINO NETO, 1999).

O ser humano começou, originalmente, a se desenvolver no mundo em regiões tropicais e em seus arredores. A fim de ocupar as regiões mais frias e distantes dos trópicos, foram elaboradas várias adaptações, como a utilização de roupas, a construção de casas e o aperfeiçoamento do uso do fogo (SUNDELL, 2004). Sendo assim, os ambientes internos começaram a ser construídos e habitados, tendo suas condições climáticas alteradas e diversificadas das condições externas.

O interesse nessa área de pesquisa surgiu com a descoberta de que baixas taxas de troca de ar entre o ambiente interno e o externo ocasionam um aumento considerável na concentração de poluentes químicos e biológicos. Tal fato foi agravado a partir da década de 70, quando o movimento mundial de conservação de energia ganhou notoriedade e seus conceitos foram aplicados em projetos de uma forma abrangente (BRICKUS e AQUINO NETO, 1999).

Com essa evolução, as edificações foram projetadas com a intenção de serem mantidas mínimas as trocas com o ambiente externo, a fim de diminuir perdas de cargas térmicas. A partir da aplicação desses conceitos, a concentração de poluentes no ambiente interno pode atingir níveis elevados se comparados com os do ambiente externo e agravar o desconforto dos usuários (MORAES, 2006).

Uma série de fatores interfere nas condições de um ambiente interno; dentre eles, destacam-se as características do ambiente externo, aspectos construtivos do prédio, a rotina dos ocupantes do prédio, além das atividades realizadas pelos ocupantes do local. Cada edificação possui variáveis a serem monitoradas e que se comportam distintamente se comparadas com outros prédios. O conhecimento das características do ar em ambientes internos é fundamental, pois ele é o meio pelo qual se realiza a interação entre clima, prédio e 
pessoas; é também fator determinante da saúde e bem-estar dos ocupantes; além de ser peça fundamental para controle e racionalização da QAI (MEYER, 1983).

Segundo a Organização Mundial de Saúde (OMS), a poluição do ar interior é considerada como um dos principais problemas ambientais e de saúde pública. Estima-se que cerca de metade da população mundial, ou seja, quase três bilhões de pessoas sofram com a má qualidade do ar interior, principalmente para as pessoas nos países subdesenvolvidos e em desenvolvimento (BRUCE, 2000).

Ainda segundo o mesmo autor, os efeitos adversos da poluição do ar comprometem não só o sistema respiratório, mas também o sistema cardiovascular. As enfermidades estão relacionadas à exposição aos diversos poluentes presentes no ar e ao tempo que a população ficou exposta a estes compostos nocivos, podendo os efeitos variar desde uma reação inflamatória pulmonar até a uma diminuição da capacidade pulmonar, a redução da expectativa de vida e o câncer.

Saldiva (2008), em seu trabalho, faz uma breve revisão dos principais acontecimentos sobre a poluição atmosférica e os efeitos na saúde, discutindo, também, aspectos legislativos e seu embasamento teórico no Brasil e na Europa. Por fim, ele faz um apelo aos médicos pneumologistas para uma investigação detalhada deste assunto e a realização de estudos mais específicos no Brasil, salientando a importância da qualidade do ar na saúde respiratória e cardiovascular da população.

O estudo de Lahtinen et al. (2002) investiga a solução de problemas relativos à qualidade do ar interior e sua relação com a saúde psicológica dos ocupantes. O bem-estar do ambiente de trabalho é comparado com a qualidade do ar interior, tanto em seus aspectos químicos, quanto no conforto térmico do local. Destaca-se a manutenção da boa qualidade do ar interior para um ambiente psicológico saudável de trabalho, aumentando a satisfação e o rendimento dos trabalhadores inseridos neste contexto. O grau de satisfação dos usuários é diretamente ligado às condições do ambiente de trabalho.

Evidencia-se a publicação de pesquisas sobre QAI, em diferentes tipos de ambientes. Estudos foram dirigidos em salas de aula, escolas, hotéis, escritórios, shoppings, galerias de artes, restaurantes, museus, estações de metrô, salões de cabeleireiros, casas, entre outras localidades em várias partes do mundo (LEE e CHANG, 2000; SCHEFF et al., 2000; LEE et al., 2002; BARTLETT et al., 2004; BLONDEAU et al., 2005; REDDY et al., 2005; EVCI et al., 2007; CHAN et al., 2009; CAI et al., 2010; YE et al., 2010). Nota-se um foco de 
estudos na Europa e Ásia, sendo que, na América Latina, há uma escassez de trabalhos sobre o tema, evidenciando a importância do desenvolvimento de estudos nesta área.

A existência de uma legislação específica sobre QAI serve de indicador para o grau relevância do assunto em cada país. No Brasil, existem leis e normas publicadas pelo governo e por instituições a fim de regulamentar as características físicas e químicas do ar em ambientes internos. Porém, alguns avanços fundamentais ainda são necessários, principalmente devido às peculiaridades do clima no país e sua influência nesse tipo de ambiente. Estudos relacionados a esse tema são essenciais para o avanço e aprimoramento dos aspectos legais e normativos.

Seguindo essa linha de pensamento, Brickus et al. (1998) ressaltam que a maioria das pesquisas relativas à QAI em países desenvolvidos devem ser avaliadas com ressalvas importantes em países como o Brasil, devido às diferenças das características climáticas, habitacionais e socioeconômicas entre esses tipos de nações.

Na cidade de Modena, na Itália, uma pesquisa sobre QAI e bem-estar dos ocupantes em bibliotecas foi dirigida por Righi et al. (2002). Os principais parâmetros observados foram poeira total, formaldeído, outros compostos orgânicos voláteis, como benzeno, tolueno e xileno, e a percepção do bem-estar dos usuários. Os resultados evidenciaram que, apesar das concentrações dos compostos estarem em patamares aceitáveis, os usuários reclamaram sobre o desconforto do local. Para uma análise específica, foi realizada uma avaliação das condições microclimáticas do local para levantar as possíveis causas do desconforto.

Ito e Aguiar (2007) realizaram um estudo em bibliotecas na cidade de São Paulo e uma fundamental motivação para o seu desenvolvimento foi o fato da população passar cerca de $90 \%$ do tempo em ambientes internos (OMS, 2005), destacando a relevância da QAI para os funcionários e outros ocupantes. Essa alta porcentagem realça a significância do controle dos poluentes encontrados no interior de casas, automóveis, escritórios, salas de aula, bibliotecas e qualquer outro ambiente interior.

As bibliotecas necessitam de condições específicas para a conservação do acervo. Além disso, este tipo de ambiente possui características peculiares devido à presença de livros e revistas. Este tipo de conteúdo pode ser o responsável por emissões de material particulado, entre outros compostos químicos. Outro fator importante é a quantidade de pessoas que freqüenta este tipo de ambiente e o seu tempo de permanência. Nestes locais, principalmente quando são evidenciadas más condições de QAI, os ocupantes são os principais prejudicados 
e são responsáveis por fazerem queixas para a adoção de medidas mitigadoras dos impactos causados por esse tipo de degradação. A solicitação de estudos por parte dessa parcela da população é fundamental e levanta os principais problemas a serem investigados e verificados. Esses são alguns fatores relevantes para o desenvolvimento do estudo da QAI neste local. 


\section{Objetivos}

O presente estudo buscou obter informações sobre a qualidade ambiental interior e sua comparação com a situação externa. Sob esse aspecto, a Biblioteca Pública Amadeu Amaral, situada na cidade de São Carlos (SP) foi escolhida para o monitoramento. Além disso, enfocou-se a identificação dos agentes causadores de desconforto e agravos à saúde dos ocupantes, relacionando com as características atmosféricas do ambiente.

As variáveis escolhidas para o monitoramento foram representadas pela análise da concentração de material particulado em suspensão $\left(\mathrm{MP}_{1}, \mathrm{MP}_{2,5}, \mathrm{MP}_{7}, \mathrm{MP}_{10}\right.$ e Material Particulado Total), avaliação dos níveis de temperatura, umidade relativa, intensidade luminosa e ruído, concentração de bioaerossóis, concentração de dióxido de carbono $\left(\mathrm{CO}_{2}\right)$, verificação da taxa de ventilação e ocupação. 


\section{Revisão Bibliográfica}

\subsection{Conceitos principais e pesquisas recentes}

Para tratar sobre a poluição atmosférica, é fundamental a definição do que vem a ser um poluente atmosférico. No Brasil, a Resolução do Conselho Nacional de Meio Ambiente (CONAMA) n 3, de 28 de junho de 1990, define como "poluente atmosférico qualquer forma de matéria ou energia com intensidade e em quantidade, concentração, tempo ou características em desacordo com os níveis estabelecidos, e que tornem ou possam tornar o ar impróprio, nocivo ou ofensivo à saúde, inconveniente ao bem-estar público, danoso aos materiais, à fauna e à flora ou prejudicial à segurança, ao uso e gozo da propriedade e às atividades normais da comunidade".

Como já salientado, a QAI é condicionada por uma série de fatores que interagem entre si e cada um deve ser analisado com um grau de detalhamento específico.

Dentre os vários níveis de análise, há uma combinação de agentes que devem ser analisados na poluição do ar interior. Em uma perspectiva física, a concentração de uma substância no interior de um ambiente depende das fontes e das condições de dispersão, dos níveis de temperatura e pressão, e do tempo de exposição a esses fatores. Sob um foco químico, a importância é voltada para a determinação das substâncias presentes no ambiente em análise com a finalidade de verificar qual a concentração de determinado composto no local. Já, para um ponto de vista biológico, a concentração dos compostos químicos deve ser avaliada com ênfase nos efeitos na saúde (WALSH et al., 1984).

Brickus e Aquino Neto (1999) fizeram uma retrospectiva dos primeiros estudos relativos à QAI. As preocupações atuais para com o tema em discussão surgiram com o desenvolvimento do movimento mundial de conservação de energia, a partir da década de 70. Essa vertente torna-se prioritária desde então nas concepções de projetos, sugerindo uma vedação térmica mais eficiente dos prédios com a finalidade de otimizar o funcionamento de refrigeradores e aquecedores do ar interno. Tal visão foi vastamente aplicada nos países de clima frio e, no Brasil, devido às altas temperaturas, tal modelo foi analogamente incorporado.

As fontes de poluentes do ar interior podem ser classificadas em dois grandes grupos, sendo um deles as fontes externas, como automóveis, construção civil e indústrias, e o outro as fontes internas, como mobiliário, produtos químicos de limpeza, cigarros, equipamentos 
eletrônicos e a própria atividade humana. Como exemplos de poluentes biológicos do ar em interiores, também denominados bioaerossóis, encaixam-se no perfil os fungos, bactérias, vírus, pólen, escamações de pele, excrementos, entre outros. Já os compostos orgânicos voláteis (COV's), os óxidos de enxofre e nitrogênio $\left(\mathrm{SO}_{\mathrm{x}}\right.$ e $\mathrm{NO}_{\mathrm{x}}$, respectivamente), ozônio $\left(\mathrm{O}_{3}\right)$ e produtos da combustão são alguns exemplos de poluentes químicos. Os aerossóis são as partículas sólidas ou líquidas, provenientes de diversas atividades humanas e que também são considerados poluentes do ar (BERNSTEIN, 2004).

$\mathrm{Na}$ Tabela 1 são apresentados os principais poluentes do ar e sua respectiva classificação.

Tabela 1 - Classificação dos poluentes do ar (Fonte: Bernstein, 2004).

A - Poluentes primários/secundários

(i) Primários: poluentes emitidos diretamente na atmosfera (ex. $\mathrm{SO}_{2}, \mathrm{NO}_{\mathrm{x}}, \mathrm{CO}, \mathrm{MP}$ )

(ii) Secundários: poluentes formados como resultado de reações químicas com outros poluentes e gases (ex. $\mathrm{O}_{3}, \mathrm{NO}_{\mathrm{x}}, \mathrm{MP}$ )

$\mathrm{B}$ - Poluentes exteriores/interiores

(i) Interiores

(a) Fontes: combustão, ressuspensão de particulado, materiais de construção, condicionamento de ar, tabagismo, agentes biológicos.

(b) Produtos: produtos da combustão (ex. fumaça de cigarro), $\mathrm{CO}, \mathrm{O}_{2}, \mathrm{COV}$ 's (ex: aldeídos, álcoois, alcanos, cetonas), agentes microbiológicos e partículas orgâncias.

(ii) Exteriores

(a) Fontes: industrial, comercial, móvel, urbana, regional, agrícola, natural.

(b) Produtos: $\mathrm{SO}_{2}, \mathrm{O}_{3}, \mathrm{NO}_{\mathrm{x}}, \mathrm{CO}, \mathrm{MP}, \mathrm{COV}$ 's.

$\mathrm{C}$ - Poluentes gasosos/particulados

(i) Gasosos: $\mathrm{SO}_{2}, \mathrm{NO}_{\mathrm{x}}, \mathrm{O}_{3}, \mathrm{CO}, \mathrm{COV}$ 's (ex: benzeno, aldeídos, dioxinas).

(ii) Particulado: material grosso $\left(2,5-10 \mu \mathrm{m}\right.$; padrão legal $\left.=\mathrm{MP}_{10}\right)$; material fino $(0,1-2,5 \mu \mathrm{m}$; padrão legal $\left.=\mathrm{MP}_{2,5}\right)$; material ultrafino $(<0,1 \mu \mathrm{m}$; não regulamentado $)$.

A identificação dos poluentes faz-se útil para estimar sua origem e identificar sua provável fonte. Sendo assim, a classificação apresentada acima é importante para tentativa de identificação do tipo e origem dos compostos encontrados no ar, além de fornecer um panorama geral dos parâmetros. As fontes de poluentes devem ser localizadas e controladas para a manutenção de uma boa qualidade do ar interior, e algumas ações podem ser adotadas, como por exemplo, isolamento da fonte, minimização do tempo de exposição das pessoas, diluição e remoção dos poluentes do ambiente com aumento da ventilação, adoção de equipamentos de filtragem e outras. 
Estudos científicos evidenciam a associação do aparecimento de algumas doenças e o aumento da mortalidade infantil com a exposição ao ar contaminado com determinados poluentes (PETERS et al., 1999; WHEELER et al., 2000; BERNSTEIN, 2004; SUNDELL, 2004; MYERS, 2005; FREW, 2005). Alguns trabalhos revelam que doenças, como asma (RICHARDSON et al., 2005) e catarata (POKHREL et al., 2005) estão associadas à má QAI. A avaliação da QAI em alguns ambientes, a comparação com a qualidade do ar exterior e os possíveis malefícios causados pela exposição a alguns poluentes específicos estão relatados em estudos reunidos na Tabela 2.

Tabela 2 - Poluentes em ambientes internos e seus efeitos adversos na saúde.

\begin{tabular}{|c|c|c|c|}
\hline Poluente & Ambiente & Efeito Adverso & Referência \\
\hline $\begin{array}{l}\text { Produtos da degradação de } \\
\text { revestimentos de PVC, } \\
\text { usados em mobiliário e pisos }\end{array}$ & $\begin{array}{l}\text { Edifícios e } \\
\text { escritórios }\end{array}$ & Asma brônquica & TUOMAINEN, 2004 \\
\hline $\begin{array}{c}\text { Éter difenílico polibromado - } \\
\text { PBDE. Agente antichama } \\
\text { usado em mobiliário e } \\
\text { eletrônicos }\end{array}$ & Residências & $\begin{array}{l}\text { Pode afetar a memória e } \\
\text { o aprendizado, alterar o } \\
\text { comportamento e retardar } \\
\text { o desenvolvimento sexual }\end{array}$ & $\begin{array}{c}\text { JONES- } \\
\text { OTAZO,2005 }\end{array}$ \\
\hline Benzeno & Residências & Carcinogênico & CHATZIS, 2005 \\
\hline $\begin{array}{l}\text { Hidrocarbonetos aromáticos } \\
\text { policíclicos }\end{array}$ & Residências & Carcinogênico & LI, 2005 \\
\hline COV's & $\begin{array}{l}\text { Escritórios, } \\
\text { residências e } \\
\text { escolas }\end{array}$ & Carcinogênico & $\begin{array}{l}\text { GUO, 2004; } \\
\text { KOTZIAS, } 2005\end{array}$ \\
\hline $\begin{array}{c}\text { Emissões de computadores } \\
\text { (fenol, tolueno, formaldeído, } \\
\text { estireno) }\end{array}$ & Escritórios & $\begin{array}{l}\text { Câncer, irritação à pele, } \\
\text { olhos e trato respiratório }\end{array}$ & BAKÓ-BIRÓ, 2004 \\
\hline Ozônio & - & Irritante & WESCHLER, 2000 \\
\hline $\begin{array}{c}\text { Material Particulado }\left(\mathrm{MP}_{2,5}\right. \\
\left.\mathrm{MP}_{10} \text { e MPT }\right)\end{array}$ & Diversos & $\begin{array}{l}\text { Problemas respiratórios, } \\
\text { alergias, doenças } \\
\text { pulmonares }\end{array}$ & $\begin{array}{l}\text { KAGAWA, 2002; } \\
\text { GERRITY, 1995; } \\
\text { MENG, 2005; } \\
\text { MATSON, 2005; } \\
\text { NAZAROFF, 2004; } \\
\text { HUSSEIN, } 2005\end{array}$ \\
\hline $\begin{array}{l}\text { Bioaerossol (bactérias e } \\
\text { fungos) }\end{array}$ & $\begin{array}{l}\text { Escritórios e } \\
\text { residências }\end{array}$ & $\begin{array}{c}\text { Problemas respiratórios, } \\
\text { alergias, doenças } \\
\text { pulmonares } \\
\end{array}$ & $\begin{array}{l}\text { KALOGERAKIS, } \\
2005\end{array}$ \\
\hline
\end{tabular}


A Tabela 3 apresenta os poluentes do ar e identifica suas principais fontes de emissão.

Tabela 3 - Poluentes do ar de interiores e suas fontes de emissão (Fonte: EPA, 2002).

Poluentes do ar

Fontes de Emissão

\begin{tabular}{cl}
\hline Fuligem de fumaça de cigarro & Acender ou fumar cigarros \\
\hline Contaminação pela combustão & $\begin{array}{l}\text { Fornalhas, geradores, aquecedores a gás ou querosene, } \\
\text { produtos derivados do tabaco, ar externo, veículos }\end{array}$ \\
\hline Contaminação biológica & $\begin{array}{l}\text { Materiais molhados ou úmidos, ar-condicionado, } \\
\text { umidificadores, manta de isolação de dutos, respiros da } \\
\text { tubulação de esgotos, excremento de pássaros, de baratas } \\
\text { ou de roedores, odores do corpo }\end{array}$ \\
\hline \multirow{2}{*}{ Compostos Orgânicos Voláteis } & $\begin{array}{l}\text { Pinturas, vernizes, solventes, pesticidas, adesivos, ceras, } \\
\text { produtos de limpeza, lubrificantes, purificadores de ar, } \\
\text { (COV's) } \\
\text { combustíveis, plásticos, copiadoras, impressoras, produtos } \\
\text { derivados do tabaco, perfumes }\end{array}$ \\
\hline Gases & $\begin{array}{l}\text { Chapas e compensados de madeira, aglomerados, carpetes } \\
\text { de madeira, móveis, forros }\end{array}$ \\
\hline Pesticidas & $\begin{array}{l}\text { Solo e rochas (radônio), ventilação da tubulação de esgoto, } \\
\text { ralos com fecho hídrico seco, reservatórios subterrâneos } \\
\text { com vazamento }\end{array}$ \\
\hline Partículas e fibras & $\begin{array}{l}\text { Termiticidas, inseticidas, rodenticidas, fungicidas, } \\
\text { desinfetantes, herbicidas }\end{array}$ \\
\hline $\begin{array}{l}\text { Impressoras, combustão em geral, ar externo, deterioração } \\
\text { dos materiais, construção/reforma, limpeza, isolação }\end{array}$ \\
\hline
\end{tabular}

Os ambientes internos e externos podem diferir, significativamente, em relação aos níveis e tipos de poluentes comuns a ambos. Poluentes com fontes predominantemente externas incluem $\mathrm{SO}_{2}, \mathrm{O}_{3}$, pólen, e vários compostos orgânicos. Poluentes gerados originalmente de fontes internas incluem formaldeído, amônia, compostos orgânicos, e bioaerossóis. Material particulado, compostos orgânicos, esporos, $\mathrm{CO}, \mathrm{NO}_{\mathrm{x}}$ e $\mathrm{CO}_{2}$, são poluentes comuns a ambos os ambientes. Diferenças nos níveis de poluentes interiores e exteriores são resultado da reatividade química de alguns poluentes, de sua mobilidade entre os ambientes, da presença de fontes internas, das práticas de construção e manutenção das edificações que reduzem a troca de ar (ventilação) entre os ambientes internos e externos. A razão entre os níveis de concentração interna e externa (índice $\mathrm{I} / \mathrm{E}$ ) de um determinado poluente é um parâmetro importante na avaliação da QAI (GODISH, 1991).

Há uma notável contribuição das pessoas e suas respectivas atividades ocupacionais para a poluição do ar em ambientes fechados. As atividades metabólicas, tanto a respiração quanto a transpiração, liberam substâncias químicas para a atmosfera e, além disso, facilitam 
o transporte de microrganismos. O hábito de fumar e outras atividades domésticas de rotina (cozinhar, limpar, pintar) contribuem para a depreciação da qualidade do ar. Partículas grandes em suspensão são removidas com simples processos de limpeza, como varrer, aspirar e espanar a poeira. Mas, devido à ressuspensão de partículas pequenas, a concentração dessas substâncias frequentemente aumenta (BRICKUS e AQUINO NETO, 1999).

A partir da concentração máxima admissível de um poluente no ambiente e da quantidade de ar externo necessário para sua diluição, é possível garantir o controle da fonte do composto nocivo. Porém, a diluição exige grandes volumes de ar externo e, consequentemente, maiores gastos com energia. Por esse e outros motivos, torna-se correto e mais econômico evitar a dispersão dos poluentes químicos, físicos e biológicos, do que adotar ações corretivas (MORAES, 2006).

O conforto e o clima são parâmetros influentes na QAI e necessitam de estudos aprofundados, pois envolve fatores físicos, fisiológicos e psicológicos. O conforto químico consiste na ausência de odores indesejados, além da manutenção de níveis aceitáveis de contaminantes atmosféricos. O conforto relacionado a sistemas de aquecimento e resfriamento é uma análise do balanço de calor entre o ocupante e o ambiente interno. O conforto térmico depende da temperatura do ambiente, do tipo de roupas e das atividades metabólicas. Um indivíduo sente-se confortável quando a energia do metabolismo é dissipada na mesma razão em que é produzida. Fica claro que o conforto térmico é uma medida complexa de ser estimada, devido à extensão e variedade de fatores envolvidos (MEYER, 1983).

A QAI pode ser influenciada pelo ruído no ambiente externo, pois, se este atingir níveis elevados, o ambiente interno deverá ser projetado e preparado para amortecer os seus efeitos nocivos. Em geral, a medida tomada é o fechamento de janelas e portas, implicando em uma diminuição da taxa de ventilação no local e ocasionando outros prejuízos, como aumento concentração de poluentes e diminuição do conforto térmico.

Os sons são formados por vibrações com frequiências harmônicas, enquanto o ruído é um conjunto superposto de vibrações com freqüências e intensidades diferentes. Em geral, o ruído pode ser definido como toda sensação auditiva insalubre e/ou como fenômeno acústico não periódico sem componentes harmônicos definidos e, desde 1980, passou a ser tratado como problema de saúde pública pela OMS (RIOS, 2003). Sendo assim, além de ser uma variável importante para a saúde dos frequientadores de um local, é um fator de influência na QAI. 
Os ruídos podem ser classificados de acordo com a variação do seu nível de intensidade com o tempo de exposição, sendo as categorias denominadas: contínuos, intermitentes e de impacto ou impulso (RIOS, 2003).

Os níveis de ruído em uma empresa de impressão na Sérvia foi investigado por Mihailovic et al. (2010). Buscou-se analisar o impacto do tipo de ruído proveniente das impressoras sobre os funcionários, partindo-se do conceito de que o tipo de ruído emitido por essa máquina é peculiar e altamente nocivo ao sistema auditivo dos funcionários. Esse trabalho destaca a importância da saúde dos ocupantes e trabalhadores próximos a uma fonte de ruído. A média encontrada nesse ambiente foi próxima a $87 \mathrm{dBA}$.

O conforto ambiental nas bibliotecas é pouco estudado no Brasil, principalmente no que se refere aos níveis de ruídos, seu controle, avaliação dos projetos e das edificações, influência da localização da biblioteca e a satisfação do usuário. Estas preocupações enunciadas acima são frequentemente negligenciadas no país. No entanto, sabe-se que altos níveis de ruídos causados por veículos, carros de propaganda, atividades de lazer, dentre outros, provocam perturbações psicológicas (LEITE et al., 1997).

A adequada iluminação de interiores é um aspecto influente na melhora das ambientais de trabalho e evidencia-se a importância dessa vertente na QAI. Em um trabalho realizado por Jaglbauer (2007), efetuou-se uma análise da melhora das condições ambientais e de higiene do trabalho em pátios cobertos da indústria mineral, sendo destacada a relevância do projeto adequado do sistema de iluminação à minimização do risco de explosão do material reservado. Como resultado, chegou-se a uma conclusão de que há uma melhora significativa na produção apenas com a instalação de sistemas de iluminação nos galpões. A manutenção apropriada e a troca por equipamentos capazes de atingir padrões estabelecidos por normas mostraram-se como ferramentas essenciais para tal meta ser atingida.

No espaço de uma biblioteca, a iluminação deve ser adequada para que o usuário consiga realizar a leitura, geralmente em um livro ou na tela de um computador, por longos intervalos de tempo, sem que ocorra cansaço. Além dos próprios usuários, as condições de iluminação são essenciais para os próprios funcionários da biblioteca. Em muitos edifícios educacionais, as condições de leitura são geralmente inadequadas (RODRIGUES, 2009).

Muitos estudos sobre qualidade do ar em diferentes tipos de ambientes interiores são realizados atualmente. Em Hong Kong, Lee e Chang (2000) avaliaram a QAI em salas de aula de cinco escolas, localizadas em diferentes pontos da cidade e com distintas características de 
condicionamento de ar. O maior problema encontrado foi em relação ao material particulado, uma vez que o pico de concentração excedeu em mais de três vezes o limite estabelecido em norma. Outro problema detectado foi a respeito da concentração de gás carbônico, já que o valor aferido no interior das salas de aula excedeu o limite estabelecido por normas internacionais.

Lee et al. (2002) avaliaram a QAI em residências, escritórios, escolas, "shoppings centers" e restaurantes, avaliando os níveis de $\mathrm{CO}_{2}, \mathrm{MP}_{10}, \mathrm{COV}$ 's e bactérias. Todos os níveis encontrados de poluentes excederam os níveis aceitos na legislação do país (China), evidenciando deficiências na ventilação dos ambientes, ocupação inadequada, presença de fumantes, uso de materiais de construção e de mobiliário com emissões de poluentes (COV's). Os estudos de Keller-Olaman et al. (2005) demonstram a má qualidade do ar interior de 300 residências da cidade de Hamilton (Canadá) e sua possível influência na qualidade de vida de seus ocupantes.

Blondeau et al. (2005) conduziram um projeto que visa avaliar o impacto dos contaminantes encontrados no ambiente externo em locais fechados. A partir da análise de concentrações de $\mathrm{NO}_{\mathrm{x}}, \mathrm{O}_{3}$ e material particulado, foi realizada uma comparação entre as concentrações no ambiente interno e externo (índice I/E) com a finalidade de serem obtidos parâmetros de QAI. O estudo foi realizado em oito escolas francesas e alguns resultados dos índices I/E são apresentados na Tabela 4.

Tabela 4 - Índices I/E de salas de aula (Fonte: Blondeau et al., 2005).

\begin{tabular}{ccccccc}
\hline \multirow{2}{*}{ Escola } & \multirow{2}{*}{$\boldsymbol{O}_{3}$} & \multirow{2}{*}{$\boldsymbol{N O}$} & \multirow{2}{*}{$\boldsymbol{N O}_{\mathbf{2}}$} & \multicolumn{4}{c}{ Material Particulado } \\
\cline { 5 - 7 } & & & $\mathbf{0 , 3}-\mathbf{0 , 4} \boldsymbol{\mu m}$ & $\mathbf{1 , 0}-\mathbf{1 , 6} \boldsymbol{\mu m}$ & $\mathbf{5 , 0}-\mathbf{7 , 5} \boldsymbol{\mu m}$ \\
\hline 1 & 0,28 & 0,98 & 0,93 & 1,11 & 2,76 & 4,12 \\
2 & 0,14 & 0,5 & 0,88 & 0,7 & 1,9 & 9 \\
3 & 0,45 & 0,57 & 0,93 & 0,58 & 1,76 & 4,97 \\
4 & 0,28 & 0,97 & 0,94 & 1,18 & 1,05 & 4,02 \\
\hline
\end{tabular}

Com o intuito de inspecionar diversas variáveis sobre qualidade do ar interior, Valavanidis e Vatista (2006) escolheram laboratórios de graduação e pós-graduação no Departamento de Química da Universidade de Atenas, na Grécia, para realizar tais amostragens. Foram avaliados gases como dióxido de carbono, formaldeído, ozônio, entre outros, temperatura, ruído e outras variáveis. Também foi aplicado um questionário para os ocupantes do local, com o intuito de levantar possíveis problemas. Nenhum grave problema 
em relação aos componentes pesquisados foi encontrado, mas o estudo mostra a importância e necessidade de aprofundamento no tema. A concentração de $\mathrm{CO}_{2}$ manteve-se abaixo dos 1000 ppm e a concentração de material particulado total em alguns laboratórios ficou na faixa de 0,1 e $0,7 \mathrm{mg} / \mathrm{m}^{3}$.

Ito e Aguiar (2007) realizaram um monitoramento de $\mathrm{MP}_{2,5}$ e $\mathrm{MP}_{10}$ em duas bibliotecas na cidade de São Paulo, com a finalidade de estabelecer a razão I/E. Como resultado, na Biblioteca Monteiro Lobato, o índice $\mathrm{I} / \mathrm{E}$ para $\mathrm{MP}_{2,5}$ foi da ordem de 3, enquanto na Biblioteca da Química da USP de São Paulo, a razão I/E para $\mathrm{MP}_{10}$ assumiu valor 2. Os valores mais altos foram observados nos meses de agosto e setembro, quando há um período de seca, propiciando um aumento na concentração de partículas dispersas no ar. Além disso, um motivo apontado para a alta concentração de MP no interior das bibliotecas avaliadas foi a alta concentração desse material no ar do entorno.

Na cidade de Agra, na Índia, Taneja et. al (2008) dirigiram um estudo no interior de casas, avaliando as concentrações de compostos químicos gasosos dentro e fora do ambiente interno, além de uma análise sazonal, comparando com diferentes estações do ano. O objetivo principal é a investigação da influência dos poluentes encontrados no ar externo no interior das casas e também a identificação das principais fontes de poluentes do ar interior, com base em uma caracterização dos compostos registrados. As conclusões do trabalho são pautadas nas diferenças entre as concentrações internas e externas no verão e no inverno e a adequação ou não desses valores com normas da OMS. Neste caso, evidenciou-se que o ar interior possui uma qualidade pior do que o exterior, devido a fontes de emissão situadas no ambiente interno.

Chan et. al (2009) realizou um estudo em um tipo de ambiente interior diferenciado. Avaliaram-se as concentrações de COV's, o nível de temperatura, umidade relativa e taxa de ventilação em quartos de hotéis na região de Guangdong, na China. A partir dos valores observados, contatou-se que as condições de qualidade do ar interior poderiam ser melhoradas para um conforto melhor dos hóspedes. Medidas como a escolha mais adequada da decoração dos quartos pode diminuir a emissão de gases poluentes e, dessa forma, garantir uma maior pureza do ar no interior do ambiente.

No que tange o material particulado em salas de aula, Janssen et al. (1999) publicaram um estudo sobre a concentração e composição desse material neste tipo de ambiente, em Amsterdã (Holanda). A composição do $\mathrm{MP}_{10}$ coletado no local é resultado da ressuspensão do 
material grosseiro depositado e poeira, devido às atividades exercidas. Não houve comparação da concentração do material em suspensão com guias de qualidade do ar, porém, fica destacada a relevância da análise da composição do material particulado em suspensão.

O projeto desenvolvido por Chao el at. (2002) buscou avaliar a distribuição do material particulado no interior de 60 casas na cidade de Hong Kong. Além do material particulado, foram investigados parâmetros de temperatura, umidade relativa e taxa de renovação do ar. Com um impactador de cascata de oito estágios, as amostragens nas casas de Hong Kong foram efetuadas e os resultados encontram-se destacados na Tabela 5.

Tabela 5 - Distribuição de tamanhos e concentração de material particulado nas 60 casas de Hong Kong. (Fonte: Chao et al., 2002).

\begin{tabular}{|c|c|c|c|c|c|c|}
\hline \multirow[b]{2}{*}{$\begin{array}{c}\text { Diâmetro } \\
\text { de corte } \\
(\mu \mathrm{m})\end{array}$} & \multicolumn{3}{|c|}{ Interior } & \multicolumn{3}{|c|}{ Exterior } \\
\hline & $\begin{array}{l}\text { Concentração } \\
\text { média }\left(\mu \mathrm{g} / \mathbf{m}^{3}\right)\end{array}$ & $\begin{array}{c}\text { Faixa de } \\
\text { variaçãão } \\
\left(\mu \mathrm{g} / \mathbf{m}^{3}\right)\end{array}$ & $\begin{array}{c}\text { Desvio } \\
\text { Padrão } \\
\left(\mu \mathrm{g} / \mathbf{m}^{3}\right)\end{array}$ & $\begin{array}{l}\text { Concentração } \\
\text { média }\left(\mu \mathrm{g} / \mathrm{m}^{3}\right)\end{array}$ & $\begin{array}{c}\text { Faixa de } \\
\text { variaçãão } \\
\left(\mu \mathrm{g} / \mathbf{m}^{3}\right)\end{array}$ & $\begin{array}{l}\text { Desvio } \\
\text { Padrão } \\
\left(\mu \mathrm{g} / \mathrm{m}^{3}\right) \\
\end{array}$ \\
\hline $10,0-9,0$ & 3,6 & $0,9-12,6$ & 2,3 & 5,1 & $0,6-32,4$ & 4,8 \\
\hline $9,0-5,8$ & 4,3 & $1,1-10,2$ & 2,0 & 5,5 & $0,5-22,1$ & 3,4 \\
\hline $5,8-4,7$ & 3,3 & $0,2-10,1$ & 2,0 & 4,3 & $0,3-10,3$ & 2,3 \\
\hline $4,7-3,3$ & 5,2 & $0,3-25,5$ & 3,8 & 6,9 & $1,5-18,3$ & 4,0 \\
\hline $3,3-2,1$ & 4,2 & $0,2-13,9$ & 2,9 & 5,6 & $1,2-16,2$ & 3,7 \\
\hline $2,1-1,1$ & 7,5 & $0,3-28,3$ & 6,1 & 8,3 & $0,3-26,9$ & 6,1 \\
\hline $1,1-0,7$ & 10,3 & $0,6-29,6$ & 7,7 & 10,1 & $0,5-22,4$ & 6,5 \\
\hline $0,7-0,4$ & 8,5 & $1,6-32,2$ & 5,4 & 8,8 & $1,1-18,8$ & 4,6 \\
\hline $0,4-0,0$ & 17,5 & $6,7-57,9$ & 8,3 & 15,8 & $5,7-33,7$ & 5,9 \\
\hline $\mathrm{MP}_{2,1}$ & 43,7 & $12,6-121,9$ & 22,6 & 42,9 & $7,9-93,6$ & 19,6 \\
\hline $\mathrm{MP}_{10}$ & 64,1 & $22,6-137,2$ & 29,6 & 70,1 & $13,1-152,1$ & 31,9 \\
\hline
\end{tabular}

Os principais parâmetros de interferência na variação da concentração de material particulado também foram destacados por Chao et al. (2002). Eles consideraram como fatores que aumentaram as concentrações nos ambientes internos atividades como fumar cigarros e realização de faxina. Para justificar a ocorrência de concentrações relativamente baixas, a chuva foi indicada como principal fator interveniente.

Uma caracterização do material particulado na cidade de São Carlos, a partir do estudo de séries temporais, foi realizada por Pozza (2009). A contextualização do tema foi agrupada com uma análise detalhada sobre a concentração de $\mathrm{MP}_{10}$ e $\mathrm{MP}_{2,5}$ na atmosfera da cidade. A variação temporal dos valores na estação instalada no centro da cidade, entre os anos de 1998 e 2003, situou-se na faixa de 20 a $60 \mu \mathrm{g} / \mathrm{m}^{3}$. É importante salientar que trata-se de um trabalho sobre o material particulado correspondente ao ambiente externo. 
Godwin e Batterman (2006) avaliaram parâmetros do ar interior em 64 salas de aula de escolas na cidade de Michigan, nos EUA e relevam a importância da taxa de renovação do ar interior neste ambiente. Houve coleta de dados relativos à concentração de $\mathrm{COV}$ 's, $\mathrm{CO}_{2}$, bioaerossóis, níveis de temperatura e umidade relativa, além de mensuração de taxas de ventilação. Como conclusão, os autores identificaram emissões locais nos ambientes com base na avaliação de parâmetros internos e externos. Eles destacam a importância da renovação do ar interior devido à contaminação proveniente de emissões com fontes internas, como utilização de tintas em aulas de arte ou determinados compostos nas aulas de ciências. A renovação do ar interior mostra-se essencial para evitar altas concentrações desses compostos prejudiciais à saúde humana.

Outra variável interveniente na QAI é a concentração de microrganismos em suspensão, também denominados, bioaerossóis. A Agência de Proteção Ambiental dos Estados Unidos da Améria (EPA) declarou que os contaminantes biológicos são importantes para a caracterização da QAI e pode ser o principal problema em alguns prédios e escritórios, devido ao fato de serem os principais causadores de alergias e doenças infecciosas. Porém, a tarefa de detectar, identificar, relacionar contaminantes específicos com doenças humanas, remover efetivamente e prevenir a recorrência não é nada simples e direta (SELTZER, 1994).

Estudos específicos sobre a identificação das colônias de bactérias dispersas no ar são escassos. Williams et al. (1956) fizeram uma classificação inicial dos principais componentes microbiológicos do ar em análises em salas de aula na Inglaterra. A presença predominante foi de micrococos $(81,6 \%)$, seguido por organismos difteróides $(6,8 \%)$, aerococos $(3,3 \%)$, streptococos $(3,1 \%)$, organismos coliformes $(2,7 \%)$, organismos aeróbios de esporos $(1,0 \%)$, Staph. aureus $(0,3 \%)$ e outros $(1,0 \%)$.

Com o intuito de verificar os níveis de bactérias e fungos dispersos no ar, na cidade de Ancara, na Turquia, Mentese et al. (2009) selecionaram diferentes tipos de ambientes internos e seus ambientes externos para a realização das amostragens. Para a coleta de bioaerossóis viáveis, utilizou-se um impactador Andersen de único estágio e meios de cultura específicos para bactérias e fungos para a incubação. Os resultados para as bibliotecas em Ancara estiveram na média de $113 \mathrm{UFC} / \mathrm{m}^{3}$, com desvio padrão de $97 \mathrm{UFC} / \mathrm{m}^{3}$, valor mínimo de 53 e máximo de $362 \mathrm{UFC} / \mathrm{m}^{3}$ para a contagem de bactérias e média de $18 \mathrm{UFC} / \mathrm{m}^{3}$, com desvio padrão de $13 \mathrm{UFC} / \mathrm{m}^{3}$ e valor máximo de $44 \mathrm{UFC} / \mathrm{m}^{3}$ para fungos. Como conclusão, a 
variação da concentração de bioaerossóis nos ambientes internos selecionados está na faixa de 10 a $1000 \mathrm{UFC} / \mathrm{m}^{3}$, em função do tipo de ambiente e a atividade desenvolvida.

Autores pesquisam sobre as concentrações específicas bactérias e fungos no ar em diferentes ambientes, como casa, escritórios, orfanatos, restaurantes, entre outros locais (PASTUSZKA et al., 2000; BHATTACHARYA et al., 2001; ROSS et al., 2004; KIM e KIM, 2007; BONETTA et al., 2010; SEN e ASAN, 2009; AYDOGDU et al., 2010). Nestes trabalhos, as concentrações de bactérias e fungos variam da ordem de 10 a $1000 \mathrm{UFC} / \mathrm{m}^{3}$ e a metodologia de coleta é basicamente fundamentada na coleta de aerossóis com um impactador Andersen e a posterior incubação em meios de cultura específicos.

A Tabela 6 lista as principais características, fontes e potenciais efeitos adversos causados por bioareossóis.

Tabela 6 - Características e fontes de bioaerossóis. (Fonte: Seltzer, 1994).

\begin{tabular}{|c|c|c|c|c|c|}
\hline $\begin{array}{c}\text { Tipo de } \\
\text { microrganismo }\end{array}$ & $\begin{array}{c}\text { Unidade de } \\
\text { transmissãa }\end{array}$ & Exemplo de fonte & $\begin{array}{c}\text { Efeito primário } \\
\text { nos homens }\end{array}$ & $\begin{array}{l}\text { Tipo de } \\
\text { vida }\end{array}$ & $\begin{array}{l}\text { Principal fonte no } \\
\text { ambiente interno }\end{array}$ \\
\hline \multirow[t]{4}{*}{ Bactéria } & Organismos & Legionella & Pneumonia & $\begin{array}{c}\text { Parasita } \\
\text { facultativo }\end{array}$ & $\begin{array}{c}\text { Torres de } \\
\text { resfriamento }\end{array}$ \\
\hline & Esporos & Thermoactinomyces & $\begin{array}{l}\text { Hipersensitividade } \\
\text { para pneumonia }\end{array}$ & Saprófita & $\begin{array}{c}\text { Fonte de água } \\
\text { quente, superfícies } \\
\text { quentes e úmidas }\end{array}$ \\
\hline & \multirow{2}{*}{ Produtos } & Endotoxina & Febre, calafrios & - & $\begin{array}{l}\text { Reservatórios com } \\
\text { água parada }\end{array}$ \\
\hline & & Proteases & Asma & - & $\begin{array}{l}\text { Processos } \\
\text { industriais }\end{array}$ \\
\hline \multirow[t]{6}{*}{ Fungos } & Organismos & Sporobolomyces & $\begin{array}{c}\text { Hipersensitividade } \\
\text { para pneumonia }\end{array}$ & Saprófita & $\begin{array}{c}\text { Superfícies } \\
\text { úmidas }\end{array}$ \\
\hline & Esporos & Alternaria & Asma, rinite & Saprófita & $\begin{array}{c}\text { Ar exterior, } \\
\text { superfícies úmidas }\end{array}$ \\
\hline & Esporos & Histoplasma & Infecção sistêmica & $\begin{array}{l}\text { Parasita } \\
\text { facultativo }\end{array}$ & $\begin{array}{l}\text { Excrementos de } \\
\text { pássaros }\end{array}$ \\
\hline & Antígenos & Glicoproteínas & Asma, rinite & - & Ar exterior \\
\hline & Toxinas & Aflatoxinas & Câncer & - & $\begin{array}{l}\text { Superfícies } \\
\text { úmidas }\end{array}$ \\
\hline & Voláteis & Aldeídos & $\begin{array}{c}\text { Dor de cabeça, } \\
\text { irritação das } \\
\text { mucosas }\end{array}$ & - & $\begin{array}{c}\text { Superfícies } \\
\text { úmidas }\end{array}$ \\
\hline \multirow[t]{2}{*}{ Protozoários } & Organismos & Naegleria & Infecção & $\begin{array}{c}\text { Parasita } \\
\text { facultativo }\end{array}$ & $\begin{array}{l}\text { Reservatórios com } \\
\text { água contaminada }\end{array}$ \\
\hline & Antígenos & Acanthamoeba & $\begin{array}{c}\text { Hipersensitividade } \\
\text { para pneumonia }\end{array}$ & - & $\begin{array}{l}\text { Reservatórios com } \\
\text { água contaminada }\end{array}$ \\
\hline Vírus & Organismos & Influenza & $\begin{array}{l}\text { Infecção } \\
\text { respiratória }\end{array}$ & $\begin{array}{c}\text { Parasita } \\
\text { obrigatório }\end{array}$ & Fezes humanas \\
\hline \multirow{5}{*}{$\begin{array}{c}\text { Algas } \\
\text { Plantas } \\
\text { Artrópodes } \\
\text { Mamíferos }\end{array}$} & Organismos & Chlorococus & Asma, rinite & Autrotófico & Ar exterior \\
\hline & Pólen & Ambrosia & Asma, rinite & Autotrófico & Ar exterior \\
\hline & Fezes & Dermatophagoides & Asma, rinite & Fagotófico & \\
\hline & $\begin{array}{l}\text { Escamas da } \\
\text { pele }\end{array}$ & Cavalos & Asma, rinite & Fagotrófico & Cavalos \\
\hline & Saliva & Gatos & Asma, rinite & Fagotrófico & Gatos \\
\hline
\end{tabular}


Trabalhos versam sobre a relação entre a concentração de $\mathrm{CO}_{2}$, taxa de ventilação e ar interior. Mysen et al. (2005) analisaram o sistema de ventilação empregado e densidade de ocupação em escolas primárias da Noruega, com foco no desempenho energético dos sistemas utilizados. Em escolas nos estados norte-americanos de Washington e Idaho, pesquisadores estudaram a influência da presença dos alunos nas salas de aula com a concentração de $\mathrm{CO}_{2}$ no ambiente, correlacionando esses parâmetros em função do sistema de ventilação instalado no local (SHENDELL et al., 2004). Verificou-se como são avaliadas a importância das taxas de renovação do ar em ambientes internos e a relação com o sistema de ventilação utilizado.

A concepção de um sistema de distribuição do ar exterior em salas de aula é um parâmetro fundamental na determinação da QAI e no conforto térmico dos estudantes. A partir desse pressuposto, Karimipanah et al. (2007) propuseram uma modelagem dessa distribuição e o monitoramento de parâmetros como temperatura do ar, velocidade do ar e concentrações de alguns gases atuando como traço, considerando diferentes situações. O trabalho faz uma análise comparativa entre o sistema de distribuição de ar e a QAI a partir de um programa capaz de modelar as correntes de ar, evidenciando, assim, a importância das taxas e condições de ventilação na determinação do conforto térmico.

A verificação da concentração de COV's em bibliotecas é uma área de pesquisa divulgada no cenário mundial. Devido à presença de livros e revistas, a avaliação deste tipo de composto gasoso é particularmente importante para o tipo de ambiente, uma vez que eles são produtos da degradação do papel e arquivos (FENECH et al., 2010). Pesquisadores realizaram diversos estudos em bibliotecas com o intuito de avaliar tais compostos (AL-REHALI, 2001; RIGHI et al., 2002; CAVALCANTE et al., 2005; HANOUNE et al., 2006; MARCHAND et al., 2006; CHAN et al., 2007; ALLOU et al., 2008; BRUNO et al., 2008; JIA et al., 2010;).

Em um panorama internacional, a avaliação da QAI de bibliotecas é um assunto pouco estudado e trabalhado por pesquisadores. As pesquisas encontradas são, geralmente, pautadas no tema relativo à concentração de COV's no ar e há poucas pesquisas que realizam um monitoramento mais amplo, envolvendo diversas variáveis de QAI. As revistas com pesquisas sobre o tema mostram que a maioria desses estudos foi conduzida em países da Europa e Ásia, onde as condições climáticas são bem distintas se comparadas ao Brasil. Por isso, tornase relevante salientar que as comparações entre esses ambientes também é diferente, visto que o clima é um fator determinante nos projetos civis. No Brasil, especificamente, há casos de bibliotecas projetadas com ventilação natural, como acontece na cidade de São Carlos, 
enquanto que o padrão das bibliotecas avaliadas pelas pesquisas apresenta locais com sistemas artificiais de ventilação. Esse fator é preponderante para a realização de comparações e isso merece um destaque no presente estudo.

Diante todos esses aspectos levantados, é relevante a avaliação da QAI desse tipo de ambiente, devido à circulação de pessoas no local e essa investigação interfere diretamente no bem-estar dos funcionários e usuários.

\subsection{Legislação e Normas}

A poluição atmosférica começou a ser regulamentada juridicamente no Brasil com a publicação da Resolução CONAMA nº 5, de 15 de junho de 1989. Ela foi a responsável por instituir o Programa Nacional de Controle da Qualidade do Ar (PRONAR), como um dos instrumentos básicos da gestão ambiental para a proteção da saúde e bem-estar das populações e melhoria da qualidade de vida, limitando os níveis de emissão de poluentes por fontes de poluição atmosférica. Contudo, esta Resolução versa sobre fontes poluidoras externas e qualidade do ar na atmosfera (ambientes externos). Sob o mesmo foco, a Resolução CONAMA n ${ }^{\circ}$ 3, de 28 de junho de 1990, estabelece os padrões de qualidade do ar e os limites de concentração para os poluentes: partículas totais em suspensão, fumaça, partículas inaláveis, dióxido de enxofre, monóxido de carbono, ozônio e dióxido de nitrogênio.

Os padrões de qualidade do ar exterior adotados pela Companhia de Tecnologia de Saneamento Ambiental do Estado de São Paulo (CETESB), baseados na Resolução CONAMA 03/1990, para os poluentes $\mathrm{SO}_{2}, \mathrm{MP}_{10}, \mathrm{NO}_{2}, \mathrm{CO}$ e $\mathrm{O}_{3}$ estão exibidos na Tabela 7.

Tabela 7 - Padrões nacionais de qualidade do ar (Fonte: CONAMA 03/90).

\begin{tabular}{ccc}
\hline Poluente & \multicolumn{2}{c}{ Padrão diário de qualidade do ar } \\
\hline $\mathrm{SO}_{2}$ & $365 \mu \mathrm{g} / \mathrm{m}^{3}$ & média de 24 horas \\
$\mathrm{MP}_{10}$ & $150 \mu \mathrm{g} / \mathrm{m}^{3}$ & média de 24 horas \\
$\mathrm{CO}$ & $9 \mathrm{ppm}$ & média de 8 horas \\
$\mathrm{NO}_{2}$ & $150 \mu \mathrm{g} / \mathrm{m}^{3}$ & máximo de 1 hora \\
$\mathrm{O}_{3}$ & $160 \mu \mathrm{g} / \mathrm{m}^{3}$ & máximo de 1 hora \\
\hline
\end{tabular}

No ano de 2005, a OMS divulgou um documento com atualizações sobre padrões de qualidade do ar para material particulado, ozônio, dióxido de nitrogênio e dióxido de enxofre, 
tendo como base os efeitos desses poluentes atmosféricos na saúde humana. Os valores recomendados encontram-se dispostos na Tabela 8.

Tabela 8 - Padrões de qualidade do ar (Fonte: OMS, 2005).

\begin{tabular}{ccc}
\hline Poluente & \multicolumn{2}{c}{ Padrão de qualidade do ar } \\
\hline $\mathrm{MP}_{2,5}$ & $\begin{array}{c}10 \mu \mathrm{g} / \mathrm{m}^{3} \\
25 \mu \mathrm{g} / \mathrm{m}^{3}\end{array}$ & $\begin{array}{c}\text { média anual } \\
\text { média de } 24 \text { horas }\end{array}$ \\
\hline $\mathrm{MP}_{10}$ & $\begin{array}{c}20 \mu \mathrm{g} / \mathrm{m}^{3} \\
50 \mu \mathrm{g} / \mathrm{m}^{3}\end{array}$ & $\begin{array}{c}\text { média anual } \\
\text { média de } 24 \text { horas }\end{array}$ \\
\hline $\mathrm{O}_{3}$ & $100 \mu \mathrm{g} / \mathrm{m}^{3}$ & média de 8 horas \\
$\mathrm{NO}_{2}$ & $\begin{array}{c}40 \mu \mathrm{g} / \mathrm{m}^{3} \\
200 \mu \mathrm{g} / \mathrm{m}^{3}\end{array}$ & $\begin{array}{c}\text { média anual } \\
\text { média de } 1 \text { hora }\end{array}$ \\
\hline $\mathrm{SO}_{2}$ & $\begin{array}{c}20 \mu \mathrm{g} / \mathrm{m}^{3} \\
500 \mu \mathrm{g} / \mathrm{m}^{3}\end{array}$ & $\begin{array}{c}\text { média de } 24 \text { horas } \\
\text { média de } 10 \text { minutos }\end{array}$
\end{tabular}

Comparando as Tabelas 7 e 8 acima, observa-se que a concentração de $\mathrm{MP}_{10}$ da $\mathrm{OMS}$ são mais restritivas comparativamente com a da CONAMA. Além disso, é importante identificar que a OMS recomenda valores para o $\mathrm{MP}_{2,5}$, enquanto a norma brasileira não possui referência para este parâmetro. Esse parâmetro é relevante, devido ao fato que ele representa a porção do material particulado em suspensão que atravessa todo o trato respiratório, entra em contato e pode ser acumulado nos alvéolos pulmonares, tornado-se potenciais responsáveis por doenças respiratórias (EPA, 2003).

A preocupação com QAI aparece, pela primeira vez, na Portaria $n^{\circ} 3.523$, de 28 de agosto de 1998, da Agência Nacional de Vigilância Sanitária (ANVISA), que aprovou Regulamento Técnico para manutenção e limpeza de sistemas de climatização de ambientes.

Em 16 de janeiro de 2003, a ANVISA publicou a Resolução - RE/ANVISA nº 9, revisando e atualizando a RE/ANVISA $n^{\circ} 176$, de 24 de outubro de 2000, e regulamentando os padrões referenciais de qualidade do ar interior, em ambientes climatizados artificialmente de uso público e coletivo. Esta Resolução recomenda que sejam adotadas para fins de pesquisa e com o propósito de levantar dados sobre a realidade brasileira, assim como para avaliação e correção das situações encontradas, as possíveis fontes de poluentes informadas nas Tabelas 9 e 10. 
Tabela 9 - Possíveis fontes de poluentes biológicos (Fonte: RE/ANVISA Nº9).

\begin{tabular}{|c|c|c|}
\hline $\begin{array}{c}\text { Agentes } \\
\text { Biológicos }\end{array}$ & $\begin{array}{l}\text { Principais fontes em ambientes } \\
\text { internos }\end{array}$ & $\begin{array}{c}\text { Principais medidas de correção em } \\
\text { ambientes interiores }\end{array}$ \\
\hline Bactérias & $\begin{array}{l}\text { Reservatórios com água } \\
\text { estagnada, torres de } \\
\text { resfriamento, bandejas de } \\
\text { condensado, desumidificadores, } \\
\text { umidificadores, serpentinas de } \\
\text { condicionadores de ar e } \\
\text { superfícies úmidas e quentes. }\end{array}$ & $\begin{array}{l}\text { Realizar a limpeza e a conservação das } \\
\text { torres de resfriamento; higienizar os } \\
\text { reservatórios e bandejas de condensado } \\
\text { ou manter tratamento contínuo para } \\
\text { eliminar as infiltrações; higienizar as } \\
\text { superfícies. }\end{array}$ \\
\hline Fungos & $\begin{array}{l}\text { Ambientes úmidos e demais } \\
\text { fontes de multiplicação fúngica, } \\
\text { como materiais porosos } \\
\text { orgânicos úmidos, forros, } \\
\text { paredes e isolamento úmidos; ar } \\
\text { externo, interior de } \\
\text { condicionadores e dutos sem } \\
\text { manutenção, vasos de terras } \\
\text { com plantas. }\end{array}$ & $\begin{array}{l}\text { Corrigir a umidade ambiental; manter } \\
\text { sob controle rígidos vazamento, } \\
\text { infiltrações e condensação de água; } \\
\text { higienizar os ambientes e componentes } \\
\text { do sistema de climatização ou manter } \\
\text { tratamento contínuo para eliminar as } \\
\text { fontes; eliminar materiais porosos } \\
\text { contaminados; eliminar ou restringir } \\
\text { vasos de plantas com cultivo em terra, ou } \\
\text { substituir pelo cultivo em água } \\
\text { (hidroponia); utilizar filtros G-1 na } \\
\text { renovação do ar externo. }\end{array}$ \\
\hline Protozoários & $\begin{array}{l}\text { Reservatórios de água } \\
\text { contaminada, bandejas e } \\
\text { umidificadores de } \\
\text { condicionadores sem } \\
\text { manutenção. }\end{array}$ & $\begin{array}{l}\text { Higienizar o reservatório ou manter } \\
\text { tratamento contínuo para eliminar as } \\
\text { fontes. }\end{array}$ \\
\hline Vírus & Hospedeiro humano. & $\begin{array}{l}\text { Adequar o número de ocupantes por } \mathrm{m}^{2} \\
\text { de área com aumento da renovação de } \\
\text { ar; evitar a presença de pessoas } \\
\text { infectadas nos ambientes climatizados. }\end{array}$ \\
\hline Algas & $\begin{array}{l}\text { Torres de resfriamento e } \\
\text { bandejas de condensado. }\end{array}$ & $\begin{array}{l}\text { Higienizar os reservatórios e bandejas de } \\
\text { condensado ou manter tratamento } \\
\text { contínuo para eliminar fontes. }\end{array}$ \\
\hline Pólen & Poeira caseira. & $\begin{array}{l}\text { Manter filtragem de acordo com NBR- } \\
6401 \text { da ABNT. }\end{array}$ \\
\hline Artrópodes & Poeira caseira. & $\begin{array}{l}\text { Higienizar as superfícies fixas e } \\
\text { mobiliários, especialmente, os revestidos } \\
\text { com tecidos e tapetes; restringir ou } \\
\text { eliminar o uso desses revestimentos. }\end{array}$ \\
\hline Animais & Roedores, morcegos e aves. & $\begin{array}{l}\text { Restringir o acesso, controlar os } \\
\text { roedores, os morcegos, ninhos de aves e } \\
\text { respectivos excrementos. }\end{array}$ \\
\hline
\end{tabular}


Tabela 10 - Possíveis fontes de contaminantes químicos (Fonte: RE/ANVISA No 9).

\begin{tabular}{|c|c|c|}
\hline $\begin{array}{l}\text { Agentes } \\
\text { químicos }\end{array}$ & $\begin{array}{l}\text { Principais fontes em } \\
\text { ambientes interiores. }\end{array}$ & Principais medidas de correção em ambientes interiores \\
\hline $\mathrm{CO}_{2}$ & $\begin{array}{l}\text { Produtos do metabolismo } \\
\text { humano e combustão. }\end{array}$ & $\begin{array}{l}\text { Aumentar a renovação de ar externo; restringir as fontes de } \\
\text { combustão e o tabagismo em áreas fechadas; eliminar a } \\
\text { infiltração de fontes externas. }\end{array}$ \\
\hline Formaldeído & $\begin{array}{l}\text { Materiais de } \\
\text { acabamentos, mobiliário, } \\
\text { cola, produtos de limpeza } \\
\text { domissanitários. }\end{array}$ & $\begin{array}{l}\text { Selecionar os materiais de construção, acabamento e } \\
\text { mobiliário que possuam ou emitam menos formaldeído; usar } \\
\text { produtos domissanitários que não contenham formaldeído. }\end{array}$ \\
\hline $\begin{array}{l}\text { Material } \\
\text { Particulado }\end{array}$ & Poeiras e fibras & $\begin{array}{l}\text { Manter filtragem de acordo com NBR-6402 ABNT; evitar } \\
\text { isolamento termo acústico que possa emitir fibras minerais, } \\
\text { orgânicas ou sintéticas para o ambiente climatizado; reduzir as } \\
\text { fontes internas e externas; higienizar as superfícies fixas e } \\
\text { mobiliários sem o uso de vassouras, escovas ou espanadores; } \\
\text { selecionar os materiais de construção e acabamento com } \\
\text { menor porosidade; adotar medidas específicas para reduzir a } \\
\text { contaminação dos ambientes interiores (vide biológicos); } \\
\text { restringir o tabagismo em áreas fechadas. }\end{array}$ \\
\hline $\begin{array}{l}\text { Fumo de } \\
\text { Tabaco }\end{array}$ & $\begin{array}{l}\text { Queima de cigarro, } \\
\text { charuto, cachimbo, etc. }\end{array}$ & $\begin{array}{l}\text { Aumentar a renovação do ar externo; restringir o tabagismo } \\
\text { em áreas fechadas. }\end{array}$ \\
\hline $\mathrm{COV}$ & $\begin{array}{l}\text { Cera, mobiliário, } \\
\text { produtos usados em } \\
\text { limpeza e } \\
\text { domissanitários, } \\
\text { solventes, materiais de } \\
\text { revestimento, tintas, } \\
\text { colas, etc. }\end{array}$ & $\begin{array}{l}\text { Selecionar os materiais de construção, acabamento, } \\
\text { mobiliário; usar produtos de limpeza e domissanitários que } \\
\text { não contenham COV ou que não apresentem alta taxa de } \\
\text { volatilização e toxicidade. }\end{array}$ \\
\hline COS-V & $\begin{array}{l}\text { Queima de combustíveis } \\
\text { e utilização de pesticidas }\end{array}$ & $\begin{array}{l}\text { Eliminar a contaminação por fontes pesticidas, inseticidas e a } \\
\text { queima de combustíveis; manter a captação de ar exterior } \\
\text { afastada de poluentes. }\end{array}$ \\
\hline
\end{tabular}

A Associação Brasileira de Refrigeração, Ar Condicionado, Ventilação e Aquecimento (ABRAVA) publicou, em 2003, uma Resolução Normativa, RN 02, cancelando e substituindo a RENABRAVA II, publicada em 2000, e estabelecendo diretrizes de projeto, operação e manutenção para a obtenção de ar interior de qualidade aceitável em locais providos de sistema de condicionamento de ar e ventilação para conforto

A respeito do conforto térmico, já foi salientado que esta é uma variável de difícil valoração devido a sua vasta e complexa teia de parâmetros envolvidos, dentre eles, o metabolismo humano. Contudo, do ponto de vista de temperatura adequada para o conforto térmico, a RE/ANVISA no 9 de 2003 estabeleceu limites para a temperatura e umidade, em diferentes estações do ano. A faixa de temperatura considerada "confortável" está entre 23 e $26^{\circ} \mathrm{C}$ no verão, e 20 e $22^{\circ} \mathrm{C}$ no inverno. Os níveis de umidade relativa devem estar no intervalo de 40 a $65 \%$ no verão, e 35 e $65 \%$ no inverno.

Ainda sobre a RE/ANVISA $n^{\circ}$, ela estabelece limites da quantidade de $\mathrm{CO}_{2}$ no ambiente. A RN02 de 2003 da ABRAVA também impõe valores limites para a concentração 
desse gás no ambiente interno, entretanto, as recomendações para avaliação e controle contidas nessa norma seguem as mesmas já adotadas na RE/ANVISA $n^{\circ}$ 9. A diferença das duas publicações dá-se na imposição dos valores limites do gás. A RN02 de 2003 recomenda valores menores do que 3500 ppm em ambientes fechados, e a RE/ANVISA n 9 estipula um limite de 1000 ppm.

Há um Valor Máximo Recomendável (VMR) para a contaminação biológica, que se caracteriza por estabelecer um valor limite recomendável que separa as condições de ausência e presença do risco de agressão à saúde humana. A RE/ANVISA nº 9 e a RN02 de 2003 estipulam os mesmos limites para contaminação biológica. O VMR deve ser de $750 \mathrm{UFC} / \mathrm{m}^{3}$, para relação I/E menor do que 1,5, em que UFC é a sigla de Unidades Formadoras de Colônias, I é a quantidade de fungos no ambiente interno e E é a quantidade de fungos no ambiente exterior. É inaceitável a presença de fungos patogênicos e toxigênicos.

A Associação Brasileira de Normas Técnicas (ABNT) possui normas a respeito do monitoramento dos níveis de ruído em ambientes. A NBR-10151 de 2000 dá os direcionamentos para verificação dos valores nos ambientes, enquanto a NBR-10152 de 2000 versa sobre os limites para cada tipo de ambiente. Para bibliotecas, a NBR-10152 estipula um intervalo entre 35 a $45 \mathrm{~dB}$ como faixa recomendável.

Para a avaliação da intensidade luminosa e seus valores máximos aceitáveis, há duas normas da ABNT sobre o tema. A NBR 5382 informa o procedimento de verificação da iluminância em interiores e a NBR 5413 estipula os valores de iluminância de interiores a partir da aplicação da primeira. O valor médio, em LUX, determinado pela norma para as Bibliotecas é de 300 LUX para o recinto das estantes e de 500 LUX para a sala de leitura.

A taxa de ventilação em salas de aula, tanto como a ocupação deste ambiente, são fatores determinantes da QAI. A American Society of Heating, Refrigerating and Air Conditioning Engineers (ASHRAE) publicou uma norma contendo valores recomendados para estes valores citados, dando diretrizes para o dimensionamento, operação e manutenção dos sistemas de ventilação, além de uma faixa recomendada de ocupação em função da área utilizada. Esses valores são encontrados na norma ASHRAE 62, com o título de Ventilation for Acceptable Indoor Air Quality. No Brasil, a RN 02 da ABRAVA traz como referência a norma da ASHRAE e indica os valores a serem adotados tanto para taxa de ocupação quanto para de ventilação. 


\section{Material e Métodos}

Este capítulo apresenta os principais procedimentos e equipamentos selecionados para a coleta de amostras e avaliação dos parâmetros propostos. A Biblioteca Pública Amadeu Amaral também é descrita, bem como sua localização e características relevantes para o desenvolvimento do estudo.

\subsection{Biblioteca Pública Amadeu Amaral}

A Biblioteca Pública Municipal Amadeu Amaral foi escolhida para o monitoramento devido à solicitação dos funcionários, por meio do contato com a Profa. Dra. Mônica Lopes Aguiar, da Universidade Federal de São Carlos. Devido à sua localização e sua grande circulação e permanência de pessoas, o local foi considerado relevante para o estudo de sua qualidade do ar. No ano de 2010, a biblioteca teve uma movimentação de cerca de 35.200 empréstimos de livros pelos usuários cadastrados, em 289 dias úteis. O fluxo de pessoas que vão ao local para estudar e ler livros e jornais não é contabilizado nesse cadastro. Portanto, na realidade, há indícios de que o número de frequentadores da Biblioteca é maior do que o contabilizado a partir do empréstimo de livros.

A Biblioteca Pública situa-se na cidade de São Carlos (SP), na região central do município, na esquina entre a Rua 13 de Maio e a Avenida São Carlos. As ruas próximas à sua localização são caracterizadas por intenso tráfico de veículos e pessoas. Essa é uma característica relevante, pois o ruído devido a essas características é elevado e inapropriado para um local de leitura e estudos. A Biblioteca está instalada no edifício Casa da Cultura "Dr. Vicente de Arruda Camargo", inaugurada em 1982. As Figuras 1 e 2 mostram as fachadas externas do prédio, em diferentes ângulos de observação. 


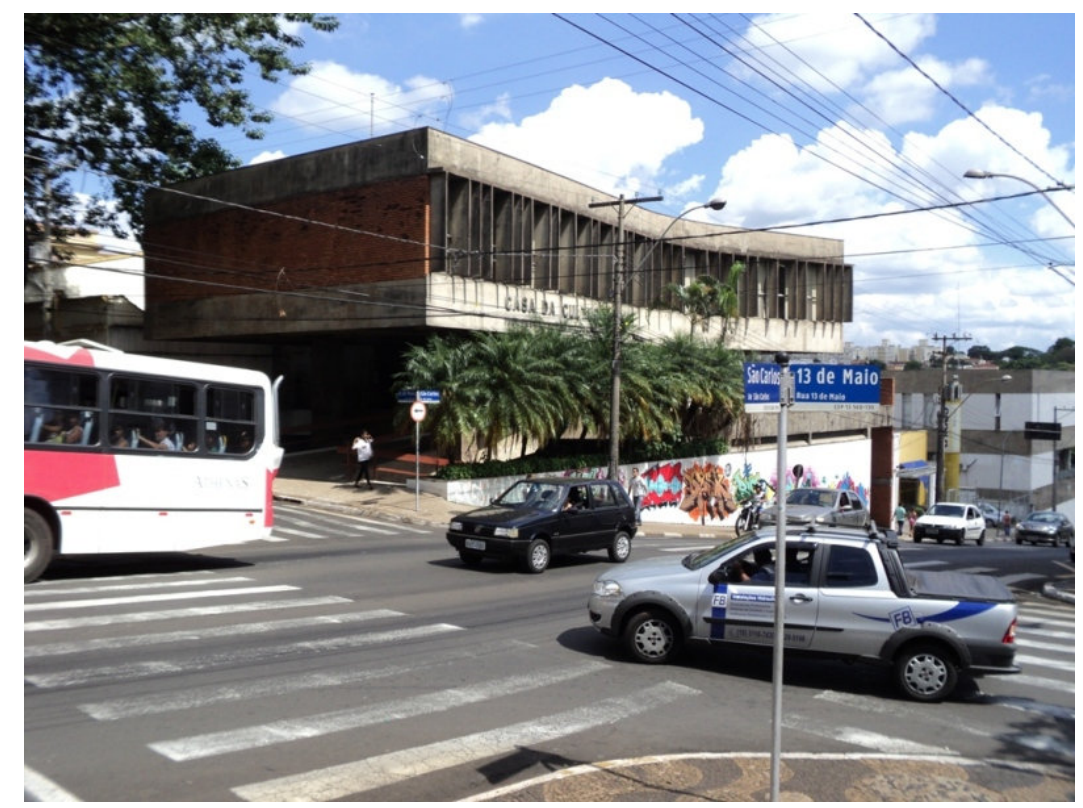

Figura 1. Fachada externa do prédio no cruzamento da Av. São Carlos com a Rua 13 de Maio.

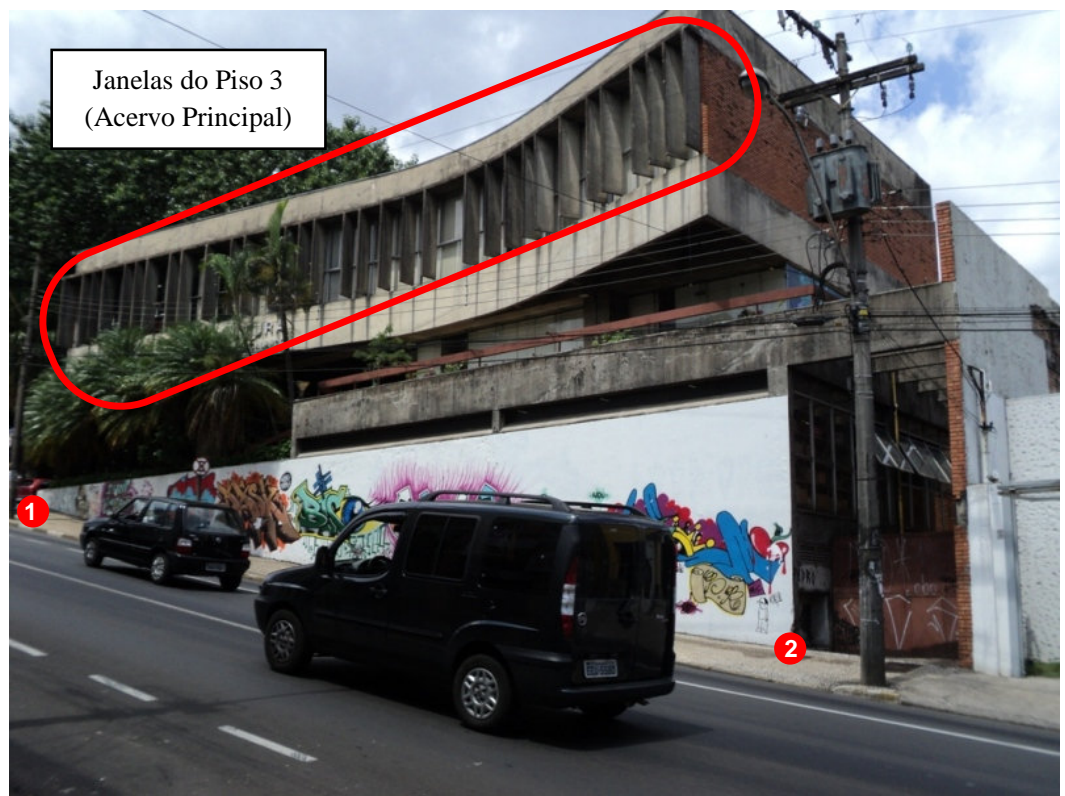

Figura 2. Fachada externa do prédio, vista por quem transita na Av. São Carlos; em destaque, as janelas do Acervo Principal e dois pontos de observação.

A partir da observação da Figura 2 acima, é possível notar que o piso em que está localizado o Acervo Principal da Biblioteca possui as janelas voltadas para um trajeto ascendente da Avenida São Carlos. Para ganhar impulso na subida, os automóveis buscam alcançar altas rotações dos motores e atingirem a velocidade desejada neste trecho. A diferença de altura entre os pontos 1 e 2 destacados na Figura 2 é de 5 metros, para uma distância na horizontal de aproximadamente 27 metros. Para este trecho, a declividade é bem elevada e é da ordem de $18,5 \%$. 
A Figura 3 esquematiza o perfil da rua, tendo como referência os pontos 1 e 2 destacados na Figura 2 acima.

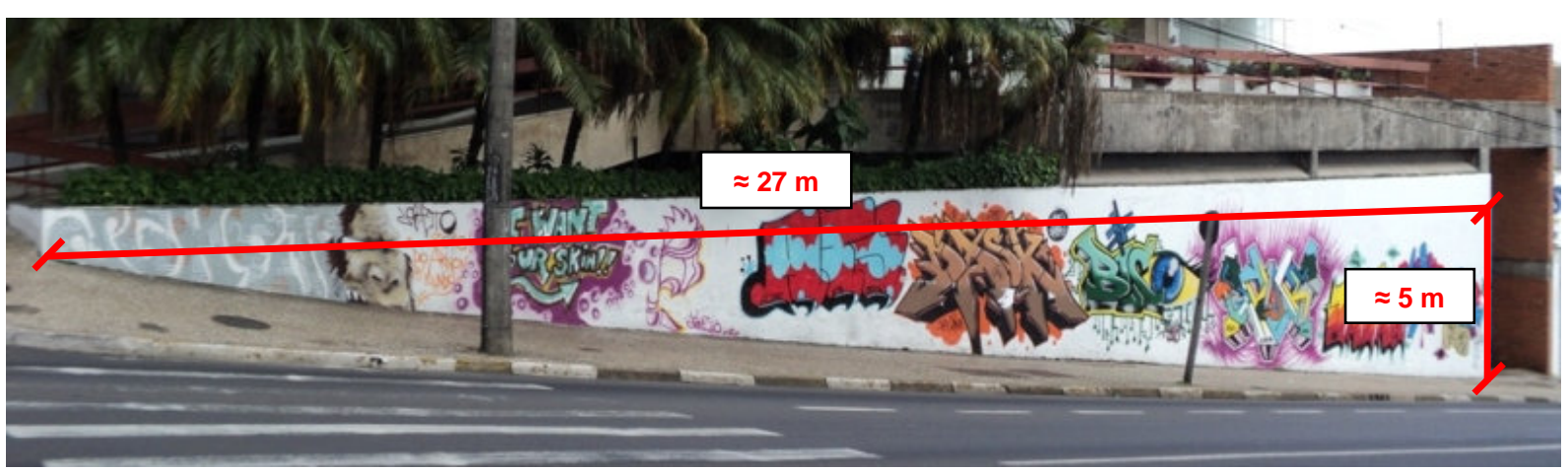

Figura 3. Perfil da rua para a fachada externa da Biblioteca com a Av. São Carlos.

A Biblioteca é composta por três pisos, onde estão situados os três ambientes internos monitorados, denominados Piso 1, Piso 2 e Piso 3. Vale ressaltar que o ambiente externo também foi investigado, sendo este representado por um ponto de análise na porção exterior do próprio prédio. A Figura 4 apresenta o local onde foram realizadas as medições externas.

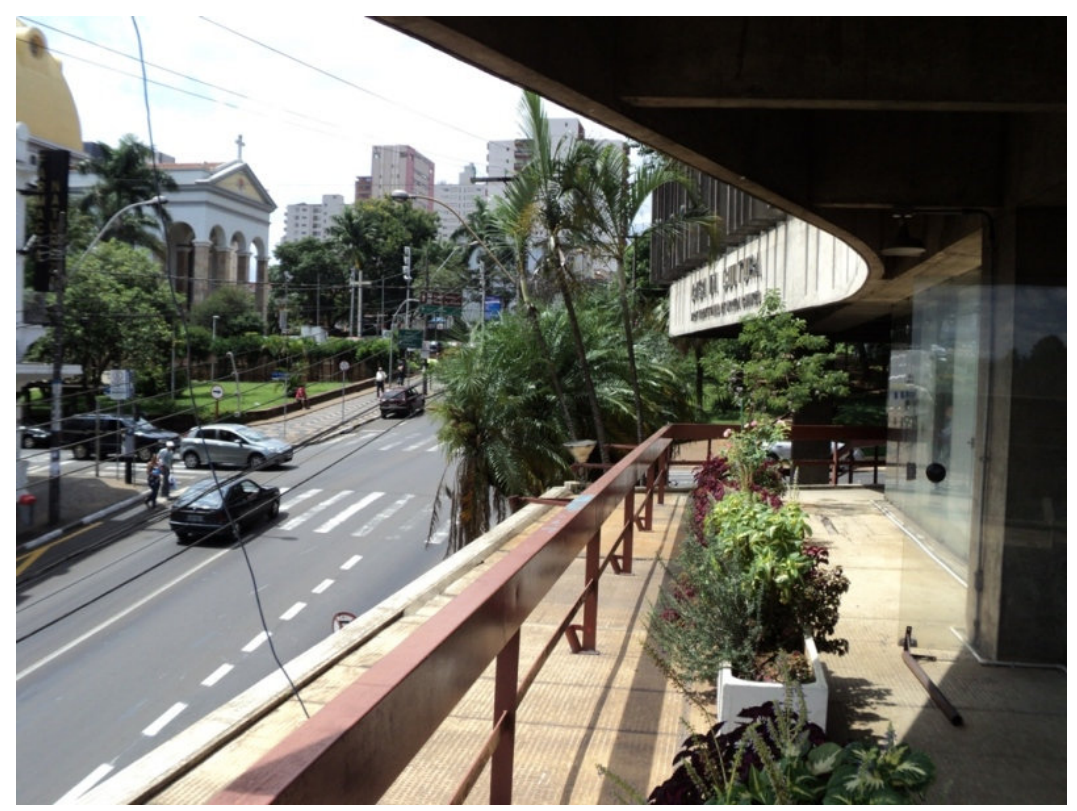

Figura 4. Porção exterior da Biblioteca Pública Amadeu Amaral, utilizada para coleta de dados de qualidade do ar.

No Piso 1, localiza-se o setor de processamento técnico e ação cultural, em uma área de aproximadamente 134,4 $\mathrm{m}^{2}$. Neste piso, o local é prioritariamente ocupado por funcionários públicos. Há, também, um acervo de livros armazenados do Projeto "Barganha- 
Book" da Prefeitura de São Carlos, onde livros são trocados por outros em finais de semana do mês. Este ambiente possui apenas uma porta de acesso e possui também dez janelas basculantes, de 1,00 m de largura por 1,10 $\mathrm{m}$ de altura, sem possuir suas faces voltadas para a Av. São Carlos.

No segundo semestre do ano de 2010, houve uma mudança significativa nas condições do Piso 1. Anteriormente a esta data, estava instalado no local o Setor de Informática da Prefeitura de São Carlos. Havia, portanto, um maior número de ocupantes do local. Após o mês de julho de 2010, este setor foi alocado em outro prédio, e a taxa de ocupação do local resultou na metade de funcionários. Esse fator é importante para as características do ar no ambiente em questão, principalmente no que tange a taxa de ocupação.

A Figura 5 apresenta esquematicamente as dimensões do ambiente em questão e a localização do ponto de amostragem.

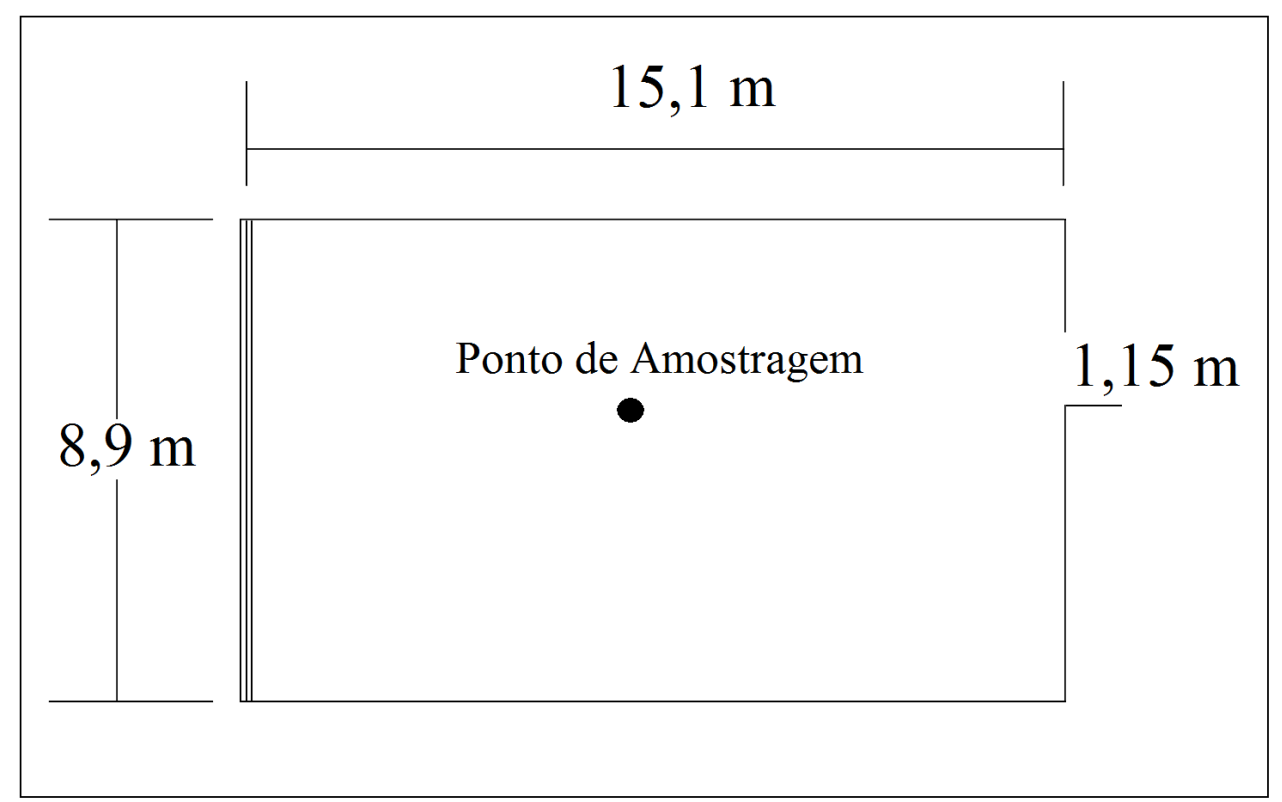

Figura 5. Principais dimensões, em metros, do Piso 1 e localização do ponto de amostragem.

No Piso 2, estão instaladas três unidades: a administração, o acervo infantil e um posto de internet gratuita (Acessa São Paulo), totalizando uma área de aproximadamente 127,5 m². Neste local, os ocupantes são compostos por funcionários e pelo público interessado nos serviços dispostos. Este ambiente não possui janelas nem ventiladores. O Piso 2 possui duas portas, sendo uma a Entrada Principal, e a outra um acesso para a parte exterior do prédio, face à Av. São Carlos. As dimensões principais desta sala, a disposição das mesas e 
prateleiras e o local de instalação dos equipamentos para amostragem estão indicadas nas Figuras 6 e 7 abaixo.

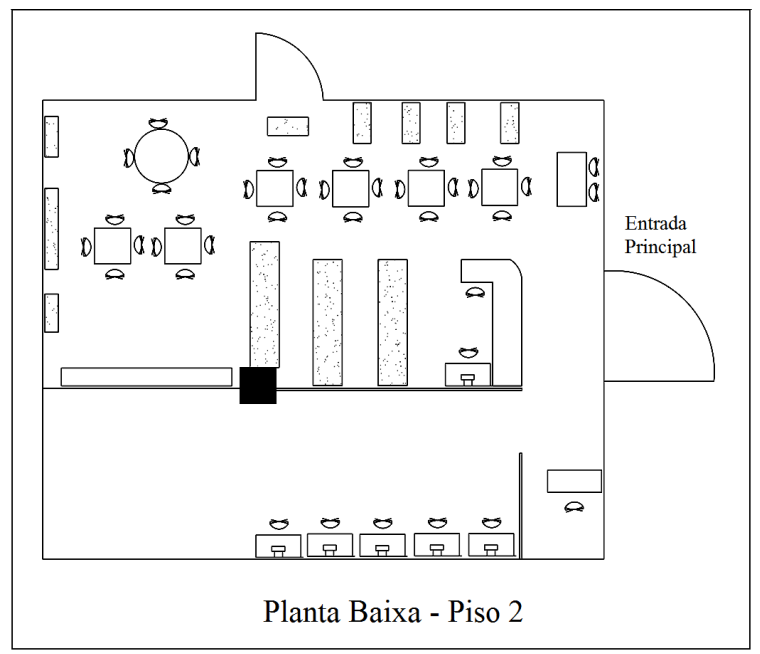

Figura 6. Planta baixa do Piso 2.

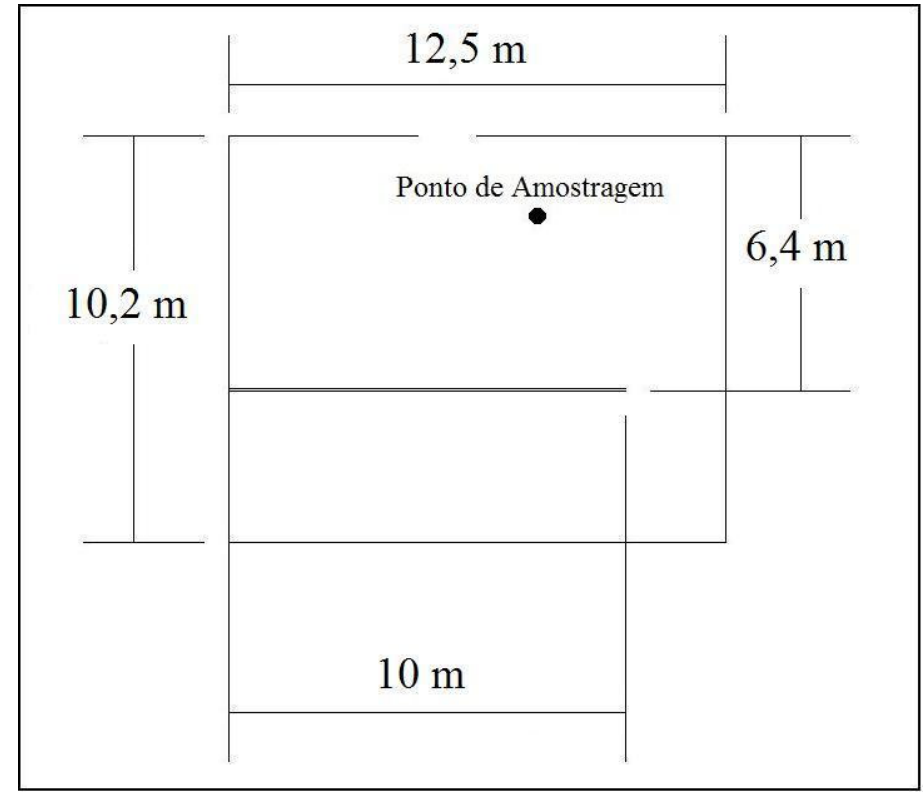

Figura 7. Principais dimensões, em metros, do Piso 2 e localização do ponto de amostragem.

Já no Piso 3, encontra-se o acervo principal, a sala de periódicos e a "sala verde", distribuídos em uma área de, aproximadamente, $285 \mathrm{~m}^{2}$. Os livros são expostos tanto para a locação, quanto para a consulta no próprio local. Há a circulação de funcionários públicos e dos leitores. A sala conta uma porta de acesso principal, um ventilador móvel, 4 janelas (1,9 $\mathrm{m}$ de altura por 1,5 $\mathrm{m}$ de largura) voltadas para uma abertura interior ao prédio e 14 janelas 
(1,5 m de altura e 0,85 m de largura) voltadas para a Av. São Carlos. As Figuras 8 e 9 demonstram as principais características deste local.

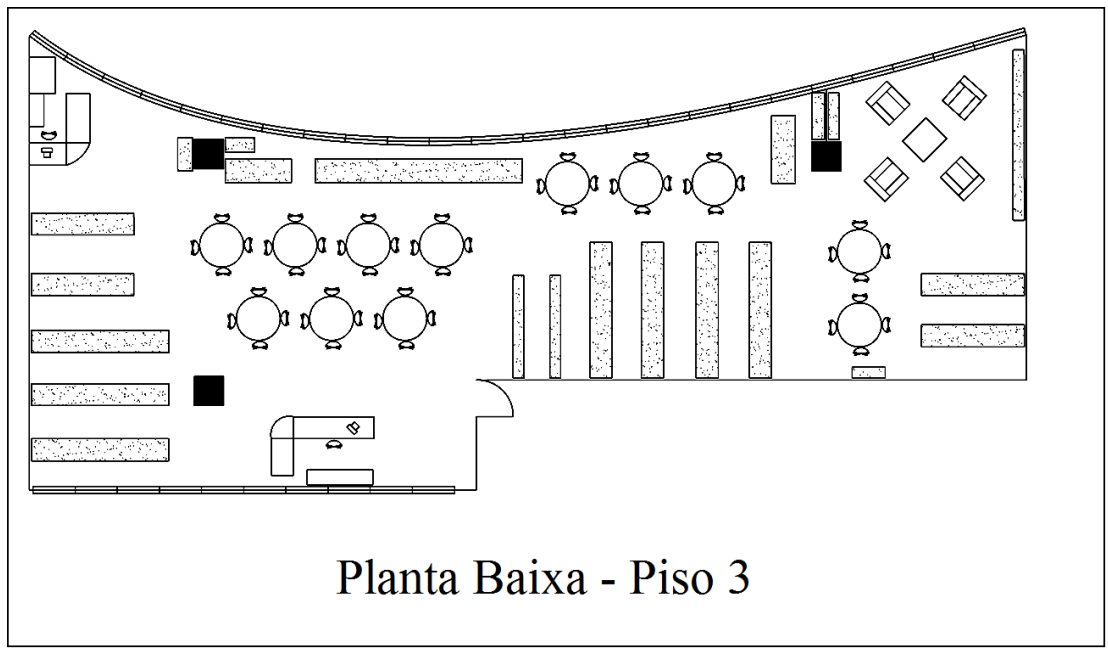

Figura 8. Planta baixa do Piso 3.

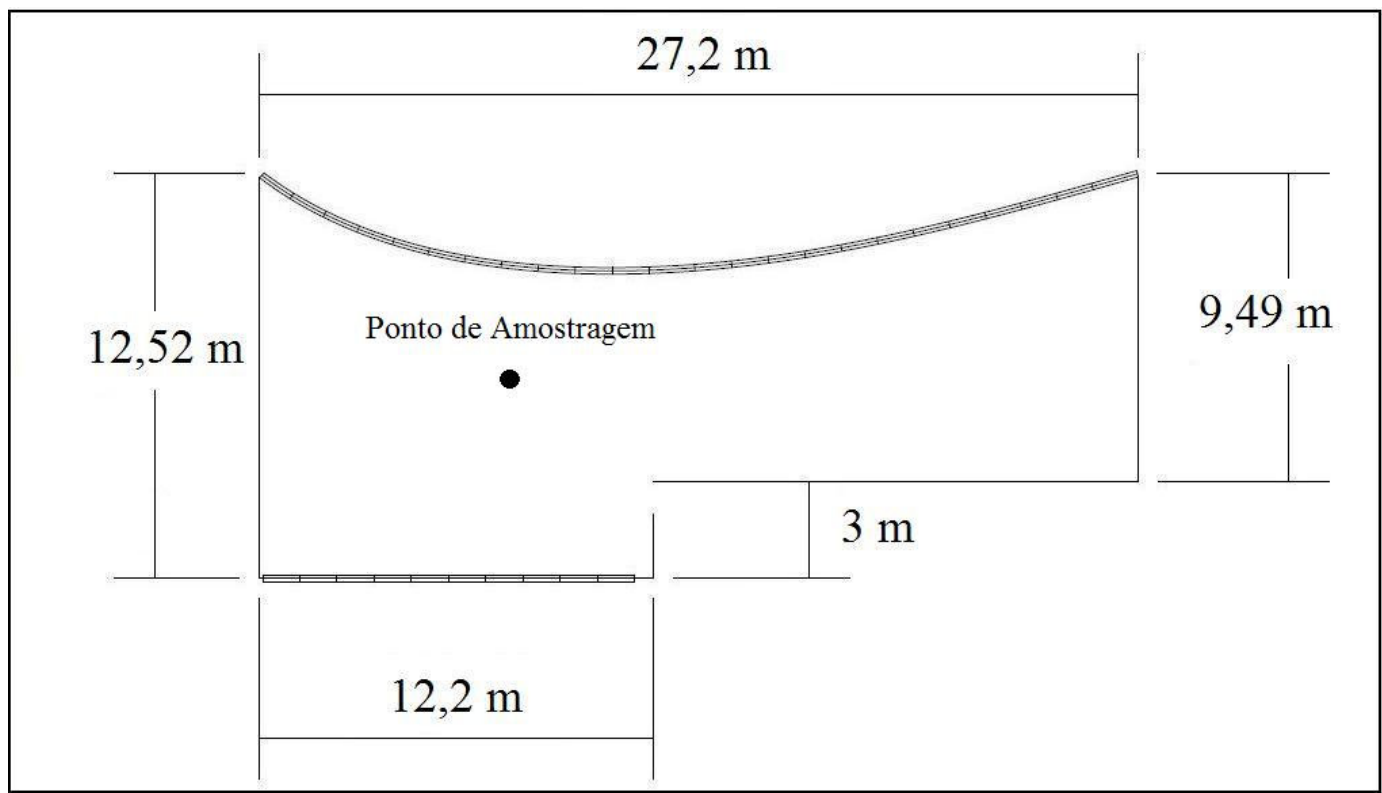

Figura 9. Principais dimensões, em metros, do Piso 3 e localização do ponto de amostragem.

\subsection{Análise de gás carbônico}

A concentração de dióxido de carbono foi avaliada com um analisador digital programável de gases, marca RAE Systems, modelo MultiRAE IR - PGM54, conforme apresenta a Figura 10. Este equipamento é de fácil utilização e seu funcionamento consiste, basicamente, na sucção do ar e análise em sensor interno. A concentração de $\mathrm{CO}_{2}$ é exibida, 
de forma contínua, diretamente no painel do equipamento, na unidade de ppm (partes por milhão). Os dados são armazenados em uma memória e, posteriormente, descarregados em um computador.

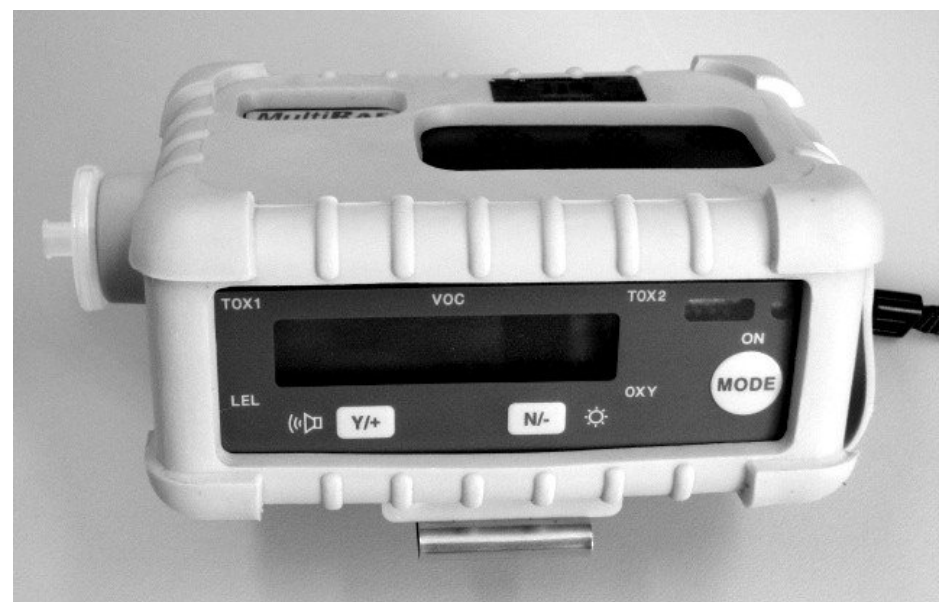

Figura 10. Monitor de gases portátil da RAE Systems, modelo MultiRAE IR - PGM54.

A RN02 de 2003 da ABRAVA relaciona as avaliações e controles da concentração de $\mathrm{CO}_{2}$ no ar com as recomendações da Resolução ${ }^{\circ} 9$ de 16 de janeiro de 2003 da ANVISA. Na RE/ANVISA $n^{\circ}$ 9, há a Norma Técnica 002 que fornece as recomendações de como deverá ser feita a coleta dos dados de concentração de dióxido de carbono nesse ambiente. Por se tratar de um ambiente interior de uso coletivo, a Norma Técnica 002 sugere um equipamento de leitura direta para a amostragem, com uma periodicidade semestral, para uma faixa de concentração de 0 a 5000 ppm. Tendo em vista que cada piso da Biblioteca possui menos de $1000 \mathrm{~m}^{2}$ de área construída, o número mínimo de amostra indicado por essa Norma é de apenas uma. Esta condição foi observada e apenas um ponto de coleta fui selecionado, sendo o mesmo situado a $1,5 \mathrm{~m}$ de distância do piso, no ponto central do local. Essa Norma Técnica foi tomada como base para a coleta dos dados referentes à concentração de $\mathrm{CO}_{2}$.

\subsection{Intensidade luminosa, ruído, umidade e temperatura}

Para a avaliação de intensidade luminosa no ambiente, empregou-se um luxímetro digital, marca dpUnion, modelo DPU-600. O equipamento apresenta uma faixa de medição que vai de 0,1 a 200.000 LUX. A Figura 11 demonstra o instrumento utilizado para tal medição. 


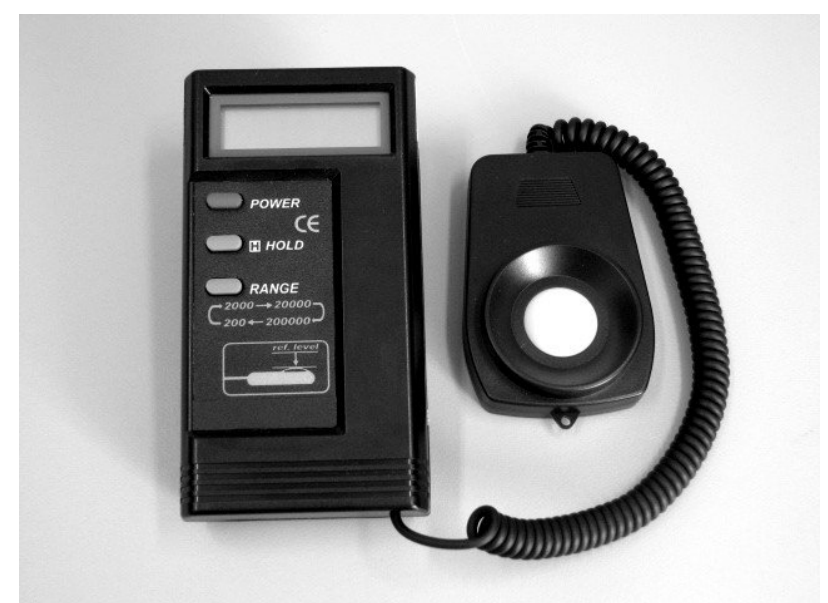

Figura 11. Luxímetro digital da dpUnion, modelo DPU-600.

Em relação às normas existentes sobre intensidade luminosa, a Associação Brasileira de Normas Técnicas (ABNT) publicou duas normas referentes a esse tema. Uma delas é a NBR 5382 que descreve como deve ser realizado o procedimento de Verificação da Iluminância em Interiores. A outra é a NBR 5413, que traz os valores recomendados para a Iluminância de Interiores para cada tipo de ocupação do ambiente interno, baseado nos resultados da aplicação da primeira norma.

A NBR 5382 possui informações sobre como deve ser o procedimento para coleta dos valores de intensidade luminosa, a partir da determinação dos pontos de medição em relação ao posicionamento das luminárias. Todos os Pisos da Biblioteca Municipal possuem linhas contínuas de luminárias e, de acordo com a norma, a medição seguiu a metodologia descrita.

A partir da identificação do tipo de configuração das luminárias nas salas, pontos de coleta denominados $\mathrm{r}_{1}, \mathrm{r}_{2}, \mathrm{r}_{3}, \mathrm{r}_{4}, \mathrm{q}_{1}, \mathrm{q}_{2}, \mathrm{t}_{1}, \mathrm{t}_{2}, \mathrm{t}_{3}, \mathrm{t}_{4}, \mathrm{p}_{1}$ e $\mathrm{p}_{2}$ foram projetados em cada piso. Para cada ponto de coleta, um valor foi medido com o luxímetro e, depois, aplicado na equação destacada a seguir:

$\mathrm{IM}($ Iluminância Média $)=\frac{\text { R.N.(M - 1) + Q.N + T.(M - 1) + P }}{M \cdot(\mathrm{N}+1)} \quad$ Equação (1)

em que,

$\mathrm{R}=$ Média aritmética das leituras dos pontos $\mathrm{r}_{1}, \mathrm{r}_{2}, \mathrm{r}_{3}$ e $\mathrm{r}_{4}$ (LUX);

$\mathrm{N}$ = Número de luminárias por fila;

$\mathrm{M}$ = Número de filas de luminárias; 
$\mathrm{Q}=$ Média aritmética das leituras dos pontos $\mathrm{q}_{1}$ e $\mathrm{q}_{2}$ (LUX);

$\mathrm{T}=$ Média aritmética das leituras dos pontos $\mathrm{t}_{1}, \mathrm{t}_{2}, \mathrm{t}_{3}$ e $\mathrm{t}_{4}$ (LUX);

$\mathrm{P}=$ Média aritmética das leituras dos pontos $\mathrm{p}_{1}$ e $\mathrm{p}_{2}$ (LUX).

As Figuras 12, 13 e 14 apresentam esquematicamente a localização dos pontos de coleta e sua identificação para aplicação na Equação (1).

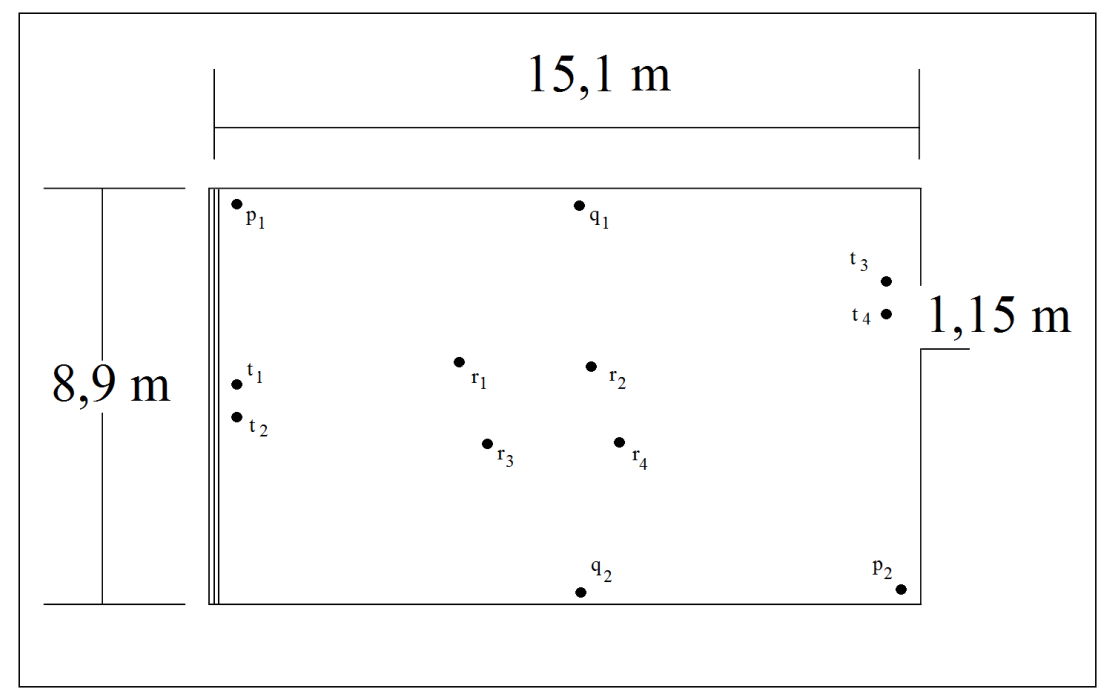

Figura 12. Localização dos pontos de medição de luminosidade do Piso 1.

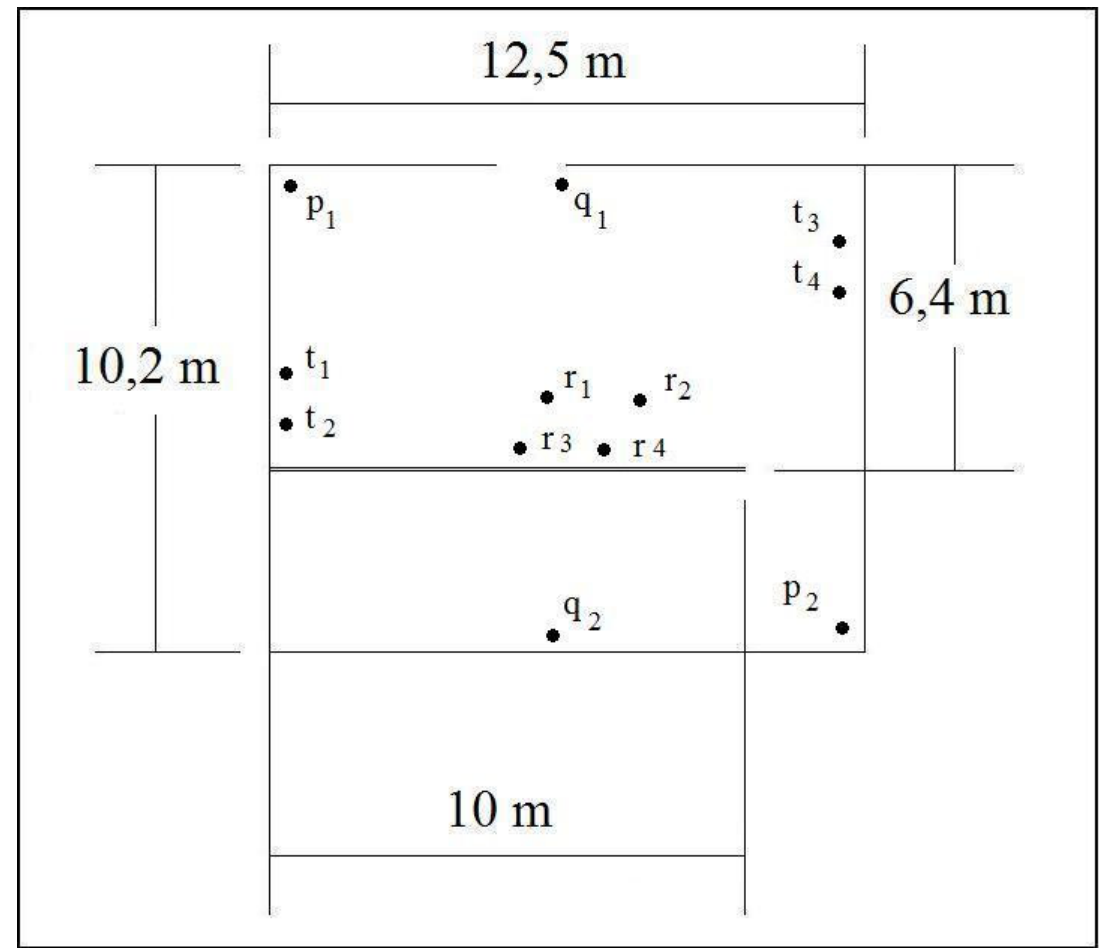

Figura 13. Localização dos pontos de medição de luminosidade do Piso 2. 


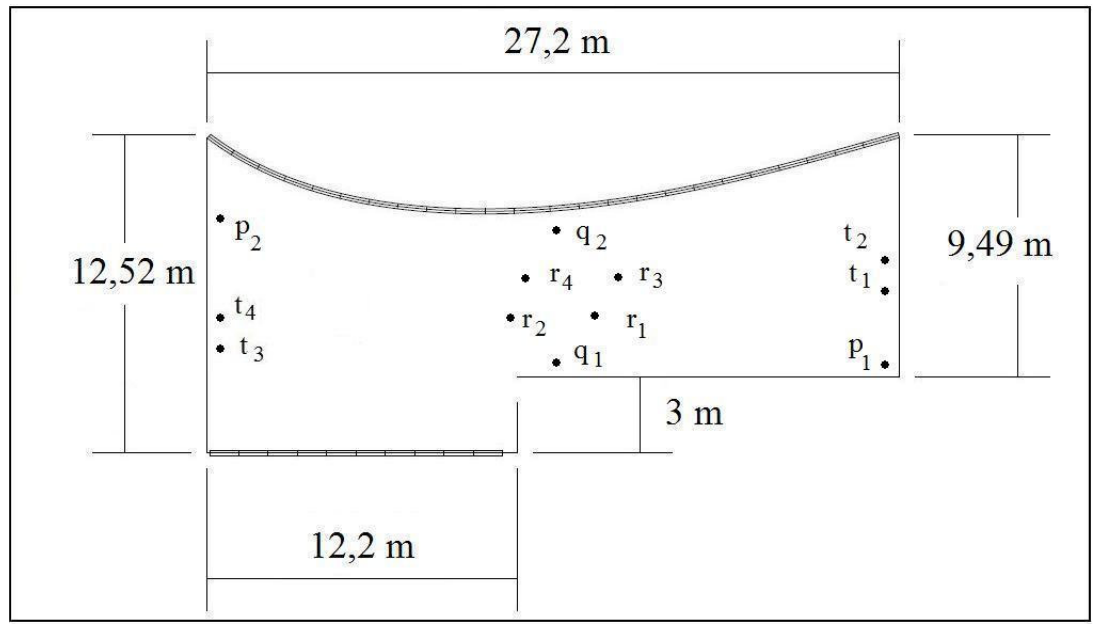

Figura 14. Localização dos pontos de medição de luminosidade do Piso 3.

O ruído dentro do ambiente foi analisado com um decibelímetro digital, marca Instrutherm, modelo DEC-490, com escala de medição de 30 a 130 db. O equipamento é capaz de armazenar uma sequência de medições de ruído, ao longo do tempo. Dessa forma, um perfil desse parâmetro ao longo do período de amostragem no local pode ser elaborado. Este equipamento foi gentilmente cedido pelo Prof. Dr. José Renato Coury, do Departamento de Engenharia Química da UFSCar. O instrumento utilizado para as medições está apresentado na Figura 15.

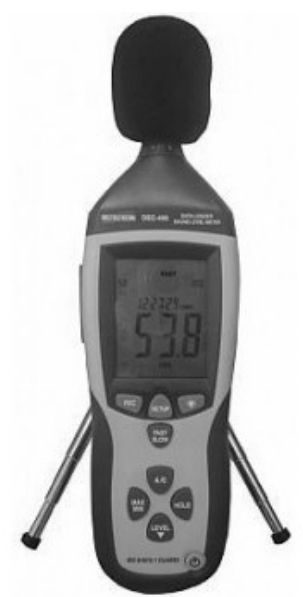

Figura 15. Decibelímetro digital da Instrutherm, modelo DEC-490.

Para as medições do nível de ruído dentro da Biblioteca Municipal, a NBR-10151 de 2000 fornece os requisitos a serem obedecidos para execução nesta etapa. Sendo assim, as medições realizadas no interior da edificação foram realizadas a uma distância maior que um metro em relação a qualquer superfície. Esta norma não faz especificações em relação à 
quantidade de pontos de amostragem no ambiente e também não recomenda o período de coleta a ser fixado durante o monitoramento.

Empregou-se um termohigrômetro digital, marca Rotronic, modelo Hygropalm 0 para a avaliação dos níveis de umidade relativa e temperaturas ambientes. Além disso, o aparelho também fornece os valores de temperatura bulbo úmido e de ponto de orvalho, possibilitando o cálculo da umidade absoluta. A Figura 16 mostra a foto do instrumento descrito.

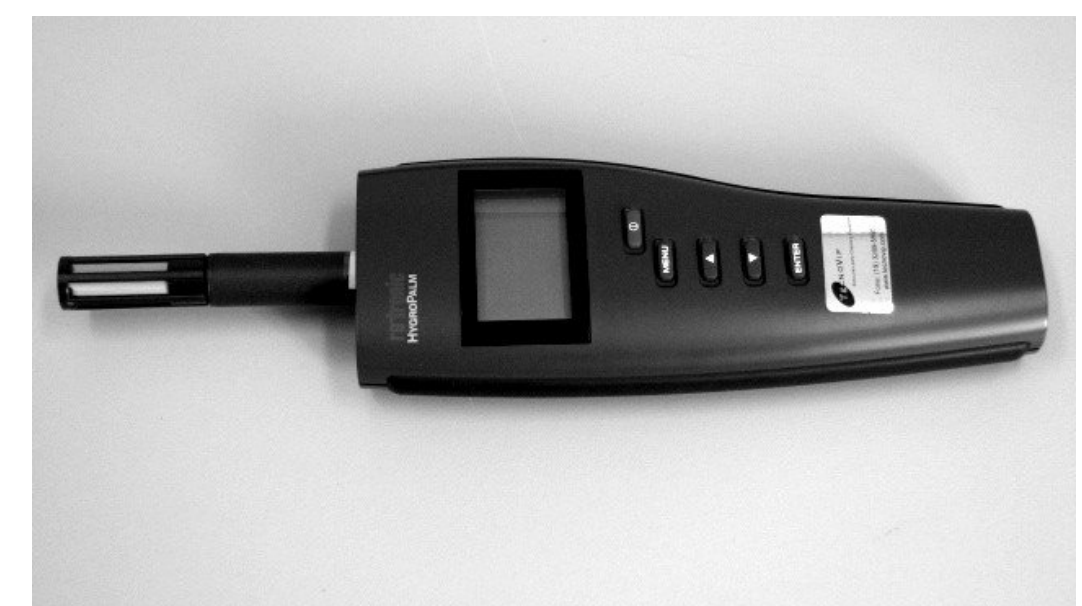

Figura 16. Termohigrômetro digital, marca Rotronic, modelo Hygropalm 0.

Para a coleta de dados de temperatura, servirá de referência a Norma Técnica 003 da RE/ANVISA n 9 de 2003. Essa recomenda a utilização de um amostrador de leitura direta, do tipo termohigrômetro com faixa de temperatura de $0^{\circ} \mathrm{C}$ a $70^{\circ} \mathrm{C}$ e umidade de $5 \%$ a $95 \%$. $\mathrm{O}$ número de pontos de amostras de ar interior é indicado com base na área construída e resultou em apenas um ponto, dado que a área construída é menor do que $1000 \mathrm{~m}^{2}$. Este único ponto de coleta deve ser situado a 1,5 $\mathrm{m}$ do piso do ambiente, no centro do local. Esses aspectos foram atendidos para a coleta de dados referentes à temperatura e umidade relativa.

\subsection{Bioaerossóis}

A coleta do material biológico em suspensão (bioaerossóis) seguiu uma série de etapas detalhadamente descritas nos tópicos abaixo. A metodologia utilizada, bem como toda aparelhagem envolvida nesta parte do trabalho, apresenta-se a seguir. 


\subsubsection{Preparação dos meios de cultura e placas}

O meio de cultura do tipo Agar Nutriente, marca Merck, série Mikrobiologie, foi empregado para a cultura de bactérias e sua preparação foi efetuada de acordo com as recomendações indicadas no rótulo, sendo necessária uma quantidade de $20 \mathrm{~g}$ do produto para cada litro de água destilada. Em seguida, o meio foi vertido em frascos Duran com capacidade de $400 \mathrm{~mL}$ e o material foi esterilizado em uma autoclave vertical durante 20 minutos a $120^{\circ} \mathrm{C}$. O meio ficou estocado em geladeira após o resfriamento do mesmo. A preparação usual era de $200 \mathrm{~mL}$ em cada oportunidade para que seu uso fosse o mais breve possível, contribuindo para diminuir os riscos de contaminação durante o manuseio.

Para a utilização do meio de cultura no experimento, fundiu-se o conteúdo do frasco Duran armazenado na geladeira em um forno microondas e cerca de $20 \mathrm{~mL}$ do meio estéril foram transferidos para placas de petri estéreis, sendo esse procedimento realizado próximo a uma chama. Após essa etapa, as placas eram tampadas e seladas com filme plástico para evitar riscos de contaminação e manter a frescura do meio de cultura.

Para a cultura de fungos, o procedimento realizado foi análogo, porém o meio de cultura empregado é o do tipo Sabouraud Dextrose Agar, marca Acumedia, sendo empregado $65 \mathrm{~g}$ do meio para cada litro de água destilada para a preparação do mesmo.

\subsubsection{Coleta de bioaerossol}

Os bioaerossóis foram coletados com um sistema de filtração empregado para a análise do crescimento de colônias de microrganismos sobre uma membrana.

Para coletar e determinar o número de microorganismos viáveis foi realizada uma filtração do ar do ambiente com uso do sistema de filtração especialmente construído para tal finalidade, de acordo com Catranis et al. (2006). Ele é composto por um funil com garra, marca Nalgene, modelo 315-0047; um medidor de vazão tipo rotâmetro, marca Conaut, modelo 440, escala de 140 a $1400 \mathrm{~L} / \mathrm{h}$; uma válvula tipo globo e uma bomba de vácuo, da marca Fisatom, modelo 820, conforme observado na Figura 17. O funil com a garra é fixado em uma haste, cuja altura em relação ao solo é ajustável. Os componentes do sistema de filtração descrito acima com maiores detalhes são apresentados na Figura 18. 


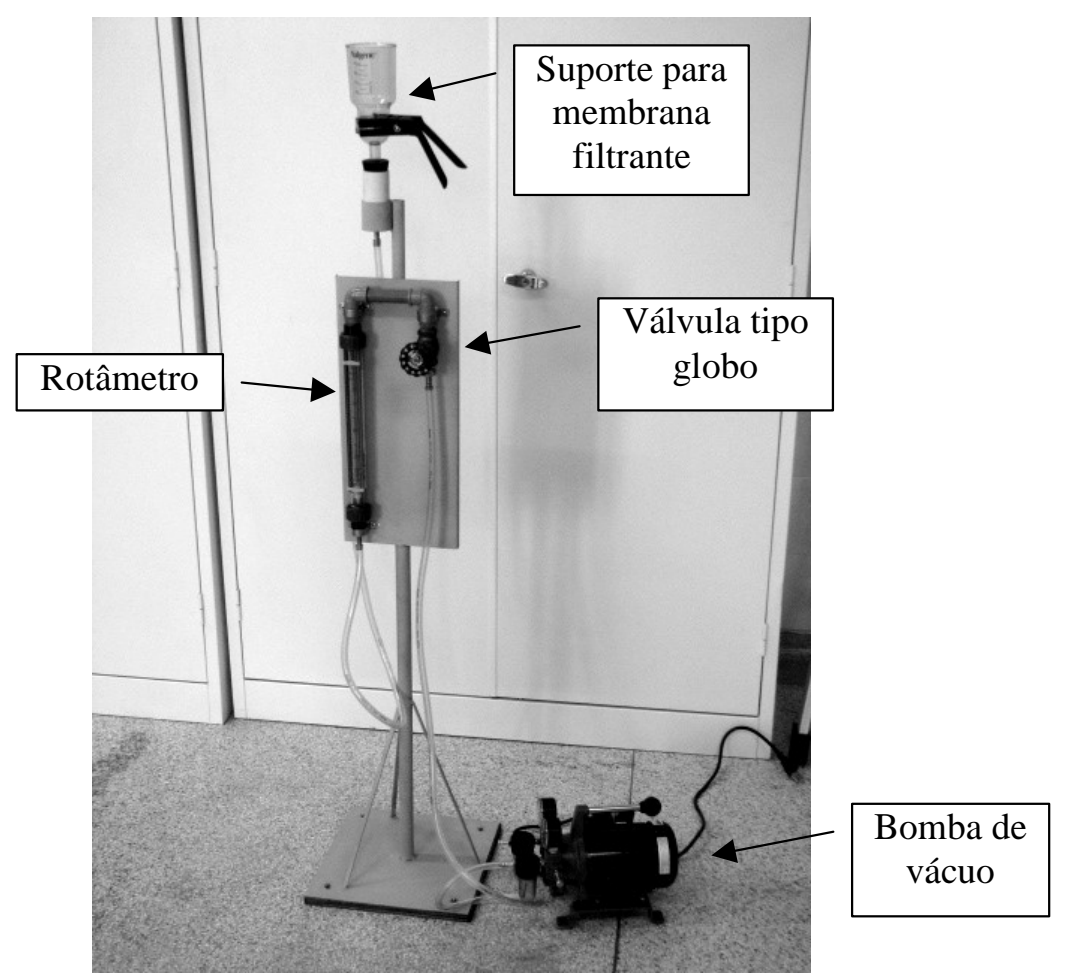

Figura 17. Sistema de filtração para avaliação de bactérias e fungos.

As membranas utilizadas como meio filtrante para a coleta desse material foram as de acetato de celulose, marca Sartorius, com diâmetro de membrana de $47 \mathrm{~mm}$ e diâmetro de poro de $0,2 \mu \mathrm{m}$. Este tipo de membrana foi escolhido para as amostras, pois apresentou uma melhor absorção quando em contanto com o meio de cultura se comparada a outros materiais de membranas existentes. As membranas de acetato de celulose foram esterilizadas, juntamente com os componentes que entram em contanto com a mesma, na autoclave vertical. A temperatura alcançada pela autoclave era em torno de $100^{\circ} \mathrm{C}$, enquanto a membrana empregada possui resistência máxima até o limite máximo de $130^{\circ} \mathrm{C}$. 


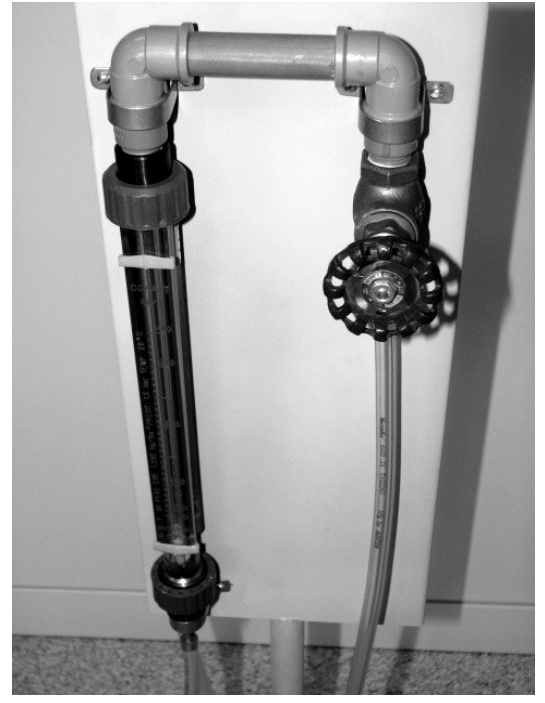

(a)

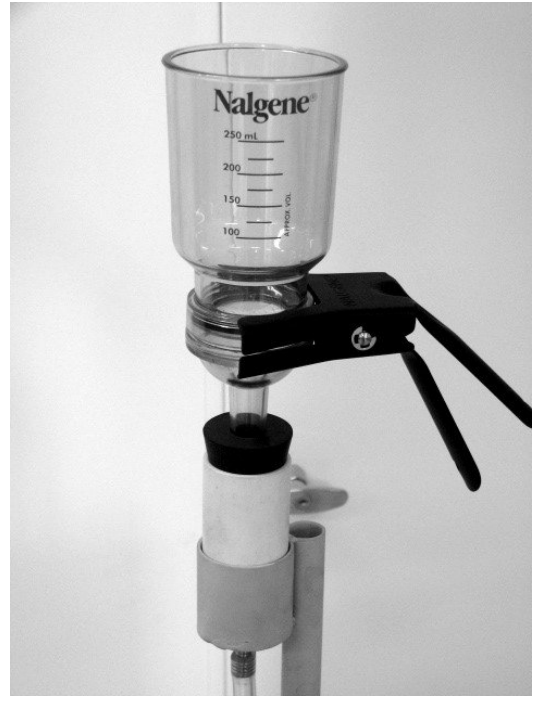

(b)

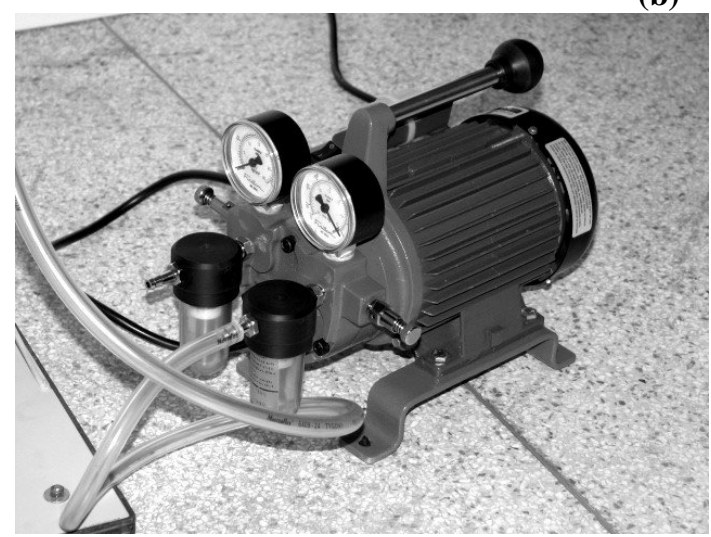

(c)

Figura 18. Detalhamento do sistema de filtração empregado: (a) painel com rotâmetro e válvula reguladora; (b) funil com garra para suporte de membrana filtrante em haste regulável; (c) bomba de vácuo.

A vazão de ar coletada foi fixada em $1.000 \mathrm{~L} / \mathrm{h}$ e o tempo de coleta foi de 120 minutos. Estes valores foram fixados após a realização de testes anteriores. Inicialmente, foi verificada a vazão de $600 \mathrm{~L} / \mathrm{h}$, com período de amostragem de 60 minutos. Essa vazão corresponde à capacidade média de respiração do ser humano. Porém, com o intuito de aperfeiçoar as amostras e armazenar uma quantidade maior de material particulado nas membranas, optou-se por aumentar a vazão e o tempo de coleta, sem que ocorresse interferência na contagem final dos microrganismos. Após testes, esses valores foram fixados para a avaliação do número de colônias nas membranas.

Decorrido o tempo de filtração, a membrana filtrante será retirada do funil suporte, com auxílio de uma pinça esterilizada e já depositada em uma placa de petri com meio de 
cultura previamente preparado. As placas foram incubadas à temperatura ambiente, e a contagem de colônias de microrganismos formados foi realizada 48h após a coleta.

\subsubsection{Microscopia com coloração de Gram}

Para identificação preliminar dos microorganismos coletados nas amostragens, foram realizados ensaios de microscopia, para verificação de suas morfologias e também a coloração de Gram das bactérias. Primeiramente, será realizada a coloração das bactérias para, posteriormente, serem analisadas em microscópio eletrônico.

Após o período de incubação, uma amostra de cada colônia de bactérias será transferida para tubos inclinados com meio ágar nutriente. Após o crescimento das colônias nos tubos, uma amostra de cada colônia foi raspada superficialmente ao ágar, com uma alça de platina. Com essa porção da amostra, foi realizada a coloração de Gram. A seguir, encontra-se destacado os passos da coloração, segundo o método da DSM (1991):

- Fazer um esfregaço com uma gota da amostra a ser analisada;

- Deixar secar;

- Cobrir a lâmina com metanol e deixar evaporar a temperatura ambiente;

- Cobrir a amostra por 1 minuto com solução violeta cristal;

- Lavar por 5 segundos a lâmina em água corrente;

- Lavar o excesso com solução de iodo;

- Cobrir a amostra por 1 minuto com solução de iodo recente;

- Lavar por 5 segundos a lâmina em água corrente;

- Descolorir a lâmina úmida com a aplicação por 1 minuto de n-propanol;

- Lavar por 5 segundos a lâmina em água corrente;

- Lavar o excesso de água com solução de safranina;

- Mergulhar por 1 minuto a lâmina em solução de safranina recente;

- Lavar por 5 segundos em água corrente;

- Secar a lâmina ao ar.

Após a secagem da lâmina, foi realizada a microscopia. Será empregado um microscópio Leica DM LB, acoplado a câmara Leica DC 200 e software Image-Pro plus (versão 4.5.0.19). Serão usadas as seguintes condições de aumento: ocular 10, objetiva 100 e zoom de 2. 


\subsubsection{Concentração de microrganismos}

A razão entre o número de colônias formadas na membrana sobre o meio de cultura e o volume de ar coletado fornece o valor da concentração de microrganismos viáveis para cada amostra considerada. Essa unidade é utilizada para comparação com valores recomendados em normas vigentes no país, e sua formulação está disposta de acordo com a equação a seguir:

$$
\mathrm{UFC} / \mathrm{m}^{3}=\frac{\text { número de colônias observadas }}{[\text { tempo de coleta }(\mathrm{h})] \mathrm{x}\left[\text { vazão de } \operatorname{ar}\left(\mathrm{m}^{3} / \mathrm{h}\right)\right]} \quad \text { Equação (2) }
$$

em que UFC é o número de unidades formadores de colônias.

Para a determinação da concentração total de microrganismos na amostra de ar coletada, somava-se a concentração de bactérias e fungos, uma vez que cada tipo de microrganismo era cultivado em separado. $\mathrm{O}$ valor estabelecido em normas é referente ao material biológico em suspensão, não havendo distinção entre o tipo de microrganismo coletado.

\subsection{Material particulado}

Para a determinação do material particulado na Biblioteca Municipal, um equipamento gentilmente fornecido pela Profa. Dra. Mônica Lopes Aguiar, da UFSCar, foi empregado. A Figura 19 apresenta uma ilustração do contador de partículas, modelo AEROCET 531, da marca Met One.

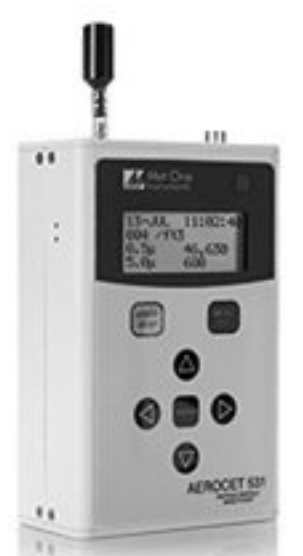

Figura 19. Contador de material particulado AEROCET 531, da marca Met One. 
Este equipamento fornece dois tipos de dados, porém de forma independente: a quantidade de partícula em dois tamanhos (0,5 e $5 \mu \mathrm{m})$; concentração, em $\mathrm{mg} / \mathrm{m}^{3}$, nas frações $\mathrm{MP}_{1}, \mathrm{MP}_{2,5}, \mathrm{MP}_{7}, \mathrm{MP}_{10}$ e material particulado total em suspensão (PTS). Para as amostras em contagem de partículas, ele faz amostragens de um minuto de duração e armazena o valor final com a quantidade de material coletado ao final do período. Já para a análise de concentração de partículas, ele faz uma coleta de dois minutos e, depois de decorrido esse tempo, ele armazena o dado correspondente.

De acordo com a OMS (2005), o $\mathrm{MP}_{10}$ corresponde às partículas que são capazes de adentrar o trato respiratório e, além disso, inclui as partículas grosseiras (entre a faixa de tamanho de partículas de 2,5 a $10 \mu \mathrm{m}$ ) e as partículas finas (com partículas de tamanho menor a 2,5 $\mu \mathrm{m}, \mathrm{MP}_{2,5}$ ). Este equipamento faz uma conversão automática da leitura feita para o valor correspondente ao $\mathrm{MP}_{10}$ da amostra de ar succionada.

O instrumento é capaz de armazenar uma grande sequiência de valores, o que viabiliza sua utilização durante horas, porém, a apresentação dos resultados é feita para cada intervalo de tempo selecionado, ou seja, para a contagem de partículas em uma hora, há sessenta valores armazenados de minuto em minuto. A concentração de partículas é calculada por dois fatores, sendo um a contagem de material por meio de um laser espelhado e um algoritmo específico retorna o valor correspondente à concentração, na unidade de $\mathrm{mg} / \mathrm{m}^{3}$. Esse algoritmo próprio é capaz de converter o valor da contagem de partículas para a sua concentração, de acordo com sua faixa de diâmetro (frações $\mathrm{MP}_{1}, \mathrm{MP}_{2,5}, \mathrm{MP}_{7}$ e $\mathrm{MP}_{10}$, além do PTS). Ele ainda possui uma opção para entrada de um termômetro com a finalidade de registrar os valores de temperatura enquanto o experimento é realizado.

\subsection{Taxa de ocupação e ventilação}

A norma utilizada como base para os valores recomendados de ocupação e ventilação dos pisos da Biblioteca foi a RN02 de 2003 da ABRAVA.

Para determinação da taxa de ocupação, a norma descreve uma relação entre a área construída e o número de ocupantes do local. Segundo a mesma, para o ambiente definido como biblioteca, o número adequado é de 20 pessoas por $100 \mathrm{~m}^{2}$ de área. Dessa forma, há uma recomendação do número ideal de ocupantes para uma área considerada, no caso, a área correspondente a cada sala da biblioteca. 
No que tange a taxa de ventilação, a norma não fornece parâmetros para determinação de seu valor e apenas apresenta o valor recomendado para cada tipo de ambiente interno.

No Piso 1 da Biblioteca Municipal, avaliou-se a taxa de ventilação a partir de um método análogo ao desenvolvido por Heinsohn e Cimbala (2003). Neste livro, há um capítulo a respeito da ventilação em um aspecto geral e o conceito de mistura perfeita do ambiente, com balanços, fórmulas e simulações de problemas que envolvem o tema.

Em um primeiro momento, houve uma caracterização do problema a partir das variáveis: volume do ambiente considerado, concentração de $\mathrm{CO}_{2}$ e vazão de ar. Sendo assim, configurou-se um balanço de massa a fim de determinar a vazão de ar que circula pela sala em questão durante um evento.

Para tanto, foi simulado um problema na sala, em que a concentração de $\mathrm{CO}_{2}$ foi elevada com um cilindro de gás carbônico puro e um perfil do comportamento dessa concentração ao longo do tempo foi monitorado com o equipamento portátil da RAE Systems, modelo MultiRAE IR - PGM54, já ilustrado anteriormente. Portanto, com o volume do Piso 1 e o perfil da concentração gás carbônico durante o período avaliado, a vazão de ar no ambiente foi obtida com a resolução de uma equação proveniente de um balanço de massa.

Com a finalidade de montar essa equação para determinação da vazão de ar, algumas suposições foram feitas para o balanço de massa. As considerações estão descritas a seguir:

- A concentração no interior na sala de aula está igualmente distribuída em todo o ambiente e é a mesma da porção de saída;

- O volume da sala de aula é fixo;

- Não há fonte de emissão de $\mathrm{CO}_{2}$ no interior da sala de aula;

- Dentro e fora das salas de aula, a densidade do ar possui o mesmo valor e é constante;

- A vazão de entrada do ar é igual à de saída.

Sendo assim, a partir da Figura 20, a fórmula para determinação da vazão de ar na situação proposta é estimada. 


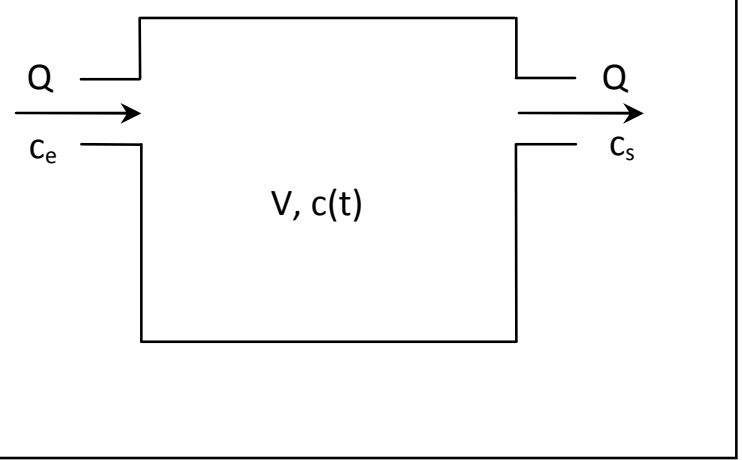

Figura 20. Diagrama esquemático do balanço de massa na sala de aula e suas principais variáveis.

Em que,

- $Q$ = vazão de ar na entrada e na saída do sistema;

- $c_{\mathrm{e}}=$ concentração de gás carbônico no ar exterior de entrada;

- $\quad c(t)=$ concentração de gás carbônico em função do tempo;

- $\quad \mathrm{c}_{\mathrm{s}}=$ concentração de gás carbônico na corrente de saída de ar.

- $\quad \mathrm{V}=$ volume da sala de aula;

Para este caso, como já salientado, o volume da sala é constante e, como a concentração de $\mathrm{CO}_{2}$ em seu interior está igualmente distribuída, a concentração do gás na corrente de saída, $\mathrm{c}_{\mathrm{s}}$, é a mesma que a encontrada no interior da sala variando ao longo do tempo, c(t). Portanto, a partir do balanço de massa e sabendo que o volume da sala é constante, obtém-se a equação a seguir:

$$
\frac{\mathrm{d}(\mathrm{Vc})}{\mathrm{dt}}=\mathrm{V} \frac{\mathrm{dc}}{\mathrm{dt}}=\mathrm{Qc} \mathrm{e}_{-}-\mathrm{Q} \quad \text { Equação (3) }
$$

Como $c_{\mathrm{s}}$ varia em função do tempo, ele passa a ser chamado de c(t) e integrando-se a Equação (3) no intervalo de tempo, t, considerando a concentração de $\mathrm{CO}_{2}$ em cada período de análise, são obtidas as equações:

$$
\frac{\mathrm{dc}}{\mathrm{dt}}=\frac{\mathrm{Q}}{\mathrm{V}}\left(\mathrm{c}_{\mathrm{e}}-\mathrm{c}\right) \quad \text { Equação (4) }
$$




$$
\begin{array}{ll}
\int_{c_{0}}^{c_{t}} \frac{\mathrm{dc}}{\left(\mathrm{c}_{\mathrm{e}}-\mathrm{c}\right)}=\int_{0}^{\mathrm{t}} \frac{\mathrm{Q}}{\mathrm{V}} \cdot \mathrm{dt} & \text { Equação (5) } \\
-\ln \left(\frac{\mathrm{c}_{\mathrm{e}}-\mathrm{c}_{\mathrm{t}}}{\mathrm{c}_{\mathrm{e}}-\mathrm{c}_{0}}\right)=\frac{\mathrm{Q}}{\mathrm{V}} \cdot \mathrm{t} & \text { Equação (6) } \\
\mathrm{Q}=\frac{\mathrm{V}}{\mathrm{t}} \cdot-\ln \left(\frac{\mathrm{c}_{\mathrm{e}}-\mathrm{c}_{\mathrm{t}}}{\mathrm{c}_{\mathrm{e}}-\mathrm{c}_{0}}\right) & \text { Equação (7) }
\end{array}
$$

Assim, a partir da Equação (7) proposta, a taxa de ventilação para a sala foi obtida com a determinação da vazão de ar que entra e, posteriormente, comparada com valores encontrados na RN02 da ABRAVA.

\subsection{Aplicação de questionário}

Com o intuito de avaliar as principais queixas e reclamações dos funcionários e freqüentadores da Biblioteca Pública, foi aplicado um questionário com perguntas relacionadas ao tema.

Elaborou-se um conjunto curto de questões relacionando os potenciais problemas de qualidade do ar interior e os efeitos sobre a satisfação dos ocupantes do recinto. As perguntas foram elaboradas com base em trabalhos relacionados à saúde de ocupantes em Unidades de Terapia Intensiva (MIYAGUSKO, 2008) e à influência do ruído na comunicação interpessoal (SOUSA, 2006).

Com o resultado desse questionário, metas mais específicas poderão ser traçadas para a mitigação dos possíveis problemas a serem evidenciados. Uma cópia do questionário entregue no local encontra-se no ANEXO I. 


\section{Resultados e Discussão}

Esta seção apresenta os principais resultados obtidos durante o desenvolvimento do presente projeto com o monitoramento das variáveis previamente escolhidas e uma análise das suas tendências e valores, comparando-os com as normas em vigor. Há resultados de temperatura, umidade relativa, material particulado em suspensão, bioaerossóis, ruído e uma análise do questionário sobre qualidade do ar.

\subsection{Temperatura e umidade relativa}

Nos três pisos da Biblioteca foram realizadas medições de temperatura e umidade relativa em determinados dias, ao longo dos anos de 2009 e 2010 . A cada 30 minutos, uma amostra de temperatura e de umidade relativa no interior de cada piso e, também, no ambiente externo foi tomada e anotada. Ao final do período de coleta de 4 horas, uma média desses valores foi calculada, assumindo uma média diária de temperatura e umidade relativa.

As Tabelas 11 a 13 apresentam todos os valores médios diários de temperatura para os Pisos 1, 2 e 3, respectivamente, comparando-os com a média externa. As Tabelas 14 a 16 apresentam tabelas com os valores médios de umidade relativa no interior e na porção exterior de ambiente em análise. Além disso, foi calculada uma razão entre as temperaturas médias interna e externa, e também os valores de umidade relativa interna e externa. 
Tabela 11 - Valores médios da temperatura interna (TI) no Piso 1 e da temperatura externa (TE).

\begin{tabular}{|c|c|c|c|}
\hline Data & $\begin{array}{l}\text { Temperatura } \\
\text { Interna }\end{array}$ & $\begin{array}{c}\text { Temperatura } \\
\text { Externa }\end{array}$ & $\begin{array}{l}\text { Razão } \\
\text { TI/TE }\end{array}$ \\
\hline $02 / 06 / 2009$ & 17,4 & 16,6 & 1,05 \\
\hline 09/06/2009 & 22,0 & 21,9 & 1,01 \\
\hline 19/06/2009 & 20,5 & 20,5 & 1,00 \\
\hline $03 / 07 / 2009$ & 20,5 & 20,3 & 1,01 \\
\hline 06/07/2009 & 22,3 & 22,2 & 1,00 \\
\hline $16 / 07 / 2009$ & 19,7 & 19,5 & 1,01 \\
\hline 05/08/2009 & 25,0 & 25,1 & 0,99 \\
\hline 06/08/2009 & 23,5 & 23,7 & 0,99 \\
\hline $04 / 05 / 2010$ & 24,5 & 24,1 & 1,02 \\
\hline $05 / 05 / 2010$ & 25,1 & 24,7 & 1,01 \\
\hline $07 / 05 / 2010$ & 26,6 & 26,5 & 1,00 \\
\hline $11 / 05 / 2010$ & 21,2 & 19,3 & 1,10 \\
\hline $12 / 05 / 2010$ & 20,3 & 19,3 & 1,05 \\
\hline $13 / 05 / 2010$ & 18,7 & 15,6 & 1,20 \\
\hline $18 / 05 / 2010$ & 24,6 & 24,4 & 1,01 \\
\hline $20 / 05 / 2010$ & 19,1 & 16,9 & 1,13 \\
\hline $21 / 05 / 2010$ & 19,9 & 17,9 & 1,11 \\
\hline $25 / 05 / 2010$ & 25,0 & 26,7 & 0,94 \\
\hline $26 / 05 / 2010$ & 24,9 & 26,3 & 0,94 \\
\hline $28 / 05 / 2010$ & 20,7 & 19,3 & 1,07 \\
\hline $31 / 05 / 2010$ & 20,4 & 19,3 & 1,06 \\
\hline $01 / 06 / 2010$ & 22,0 & 21,6 & 1,02 \\
\hline $02 / 06 / 2010$ & 20,0 & 18,0 & 1,11 \\
\hline $08 / 06 / 2010$ & 21,8 & 23,7 & 0,92 \\
\hline 09/06/2010 & 19,3 & 18,6 & 1,04 \\
\hline $10 / 06 / 2010$ & 19,9 & 18,2 & 1,09 \\
\hline $14 / 06 / 2010$ & 18,5 & 17,1 & 1,08 \\
\hline $15 / 06 / 2010$ & 19,9 & 18,8 & 1,06 \\
\hline $16 / 06 / 2010$ & 22,3 & 23,9 & 0,93 \\
\hline $21 / 06 / 2010$ & 22,8 & 23,2 & 0,98 \\
\hline $22 / 06 / 2010$ & 24,4 & 25,6 & 0,95 \\
\hline $24 / 06 / 2010$ & 24,2 & 26,7 & 0,91 \\
\hline $29 / 06 / 2010$ & 20,5 & 18,9 & 1,08 \\
\hline $30 / 06 / 2010$ & 21,3 & 19,5 & 1,10 \\
\hline $01 / 07 / 2010$ & 21,3 & 20,0 & 1,06 \\
\hline $06 / 07 / 2010$ & 23,4 & 25,7 & 0,91 \\
\hline $07 / 07 / 2010$ & 21,5 & 20,4 & 1,06 \\
\hline $08 / 07 / 2010$ & 23,2 & 25,5 & 0,91 \\
\hline $13 / 07 / 2010$ & 22,8 & 22,3 & 1,02 \\
\hline $14 / 07 / 2010$ & 21,8 & 20,0 & 1,09 \\
\hline $15 / 07 / 2010$ & 22,0 & 23,4 & 0,94 \\
\hline $20 / 07 / 2010$ & 24,5 & 26,8 & 0,92 \\
\hline $21 / 07 / 2010$ & 24,9 & 27,2 & 0,91 \\
\hline $22 / 07 / 2010$ & 26,0 & 27,9 & 0,93 \\
\hline
\end{tabular}


Tabela 11 - Valores médios da temperatura interna (TI) no Piso 1 e da temperatura externa (TE) (Continuação).

\begin{tabular}{|c|c|c|c|}
\hline Data & $\begin{array}{l}\text { Temperatura } \\
\text { Interna }\end{array}$ & $\begin{array}{c}\text { Temperatura } \\
\text { Externa }\end{array}$ & $\begin{array}{l}\text { Razão } \\
\text { TI/TE }\end{array}$ \\
\hline $23 / 07 / 2010$ & 23,8 & 23,5 & 1,01 \\
\hline 03/08/2010 & 23,2 & 24,9 & 0,93 \\
\hline 05/08/2010 & 20,3 & 18,7 & 1,08 \\
\hline 06/08/2010 & 19,2 & 16,6 & 1,16 \\
\hline 09/08/2010 & 21,6 & 22,8 & 0,95 \\
\hline $10 / 08 / 2010$ & 24,3 & 27,6 & 0,88 \\
\hline $11 / 08 / 2010$ & 23,9 & 26,7 & 0,90 \\
\hline $17 / 08 / 2010$ & 20,7 & 22,0 & 0,94 \\
\hline 19/08/2010 & 19,5 & 18,7 & 1,04 \\
\hline $20 / 08 / 2010$ & 23,3 & 25,5 & 0,91 \\
\hline $24 / 08 / 2010$ & 26,4 & 28,5 & 0,93 \\
\hline 26/08/2010 & 28,0 & 30,3 & 0,92 \\
\hline $27 / 08 / 2010$ & 25,1 & 25,5 & 0,98 \\
\hline $30 / 08 / 2010$ & 25,8 & 26,5 & 0,97 \\
\hline 03/09/2010 & 26,5 & 26,9 & 0,99 \\
\hline 08/09/2010 & 24,4 & 26,5 & 0,92 \\
\hline 15/09/2010 & 26,0 & 27,1 & 0,96 \\
\hline & & MÁXIMO & 1,20 \\
\hline & & MÍNIMO & 0,88 \\
\hline
\end{tabular}

Tabela 12 - Valores médios da temperatura interna (TI) no Piso 2 e da temperatura externa (TE).

\begin{tabular}{|c|c|c|c|}
\hline Data & $\begin{array}{c}\text { Temperatura } \\
\text { Interna }\end{array}$ & $\begin{array}{c}\text { Temperatura } \\
\text { Externa }\end{array}$ & $\begin{array}{c}\text { Razão } \\
\text { TI/TE }\end{array}$ \\
\hline $09 / 12 / 2009$ & 26,5 & 25,8 & 1,03 \\
\hline $10 / 12 / 2009$ & 25,8 & 25,0 & 1,03 \\
\hline $15 / 12 / 2009$ & 27,9 & 29,3 & 0,95 \\
\hline $16 / 12 / 2009$ & 28,5 & 28,9 & 0,99 \\
\hline $04 / 05 / 2010$ & 24,6 & 24,1 & 1,02 \\
\hline $05 / 05 / 2010$ & 25,1 & 24,7 & 1,02 \\
\hline $07 / 05 / 2010$ & 26,8 & 26,5 & 1,01 \\
\hline $11 / 05 / 2010$ & 21,3 & 19,3 & 1,10 \\
\hline $12 / 05 / 2010$ & 20,2 & 19,3 & 1,05 \\
\hline $13 / 05 / 2010$ & 17,5 & 15,6 & 1,12 \\
\hline $18 / 05 / 2010$ & 25,0 & 24,4 & 1,03 \\
\hline $20 / 05 / 2010$ & 19,0 & 16,9 & 1,12 \\
\hline $21 / 05 / 2010$ & 19,6 & 17,9 & 1,10 \\
\hline $25 / 05 / 2010$ & 25,5 & 26,7 & 0,96 \\
\hline $26 / 05 / 2010$ & 25,4 & 26,3 & 0,96 \\
\hline $28 / 05 / 2010$ & 20,8 & 19,3 & 1,08 \\
\hline $31 / 05 / 2010$ & 21,3 & 19,3 & 1,11 \\
\hline $01 / 06 / 2010$ & 22,2 & 21,6 & 1,03 \\
\hline $02 / 06 / 2010$ & 19,7 & 18,0 & 1,09 \\
\hline $08 / 06 / 2010$ & 22,4 & 23,7 & 0,95 \\
\hline $09 / 06 / 2010$ & 19,7 & 18,6 & 1,06 \\
\hline $10 / 06 / 2010$ & 20,2 & 18,2 & 1,11 \\
\hline $14 / 06 / 2010$ & 18,1 & 17,1 & 1,06 \\
\hline
\end{tabular}


Tabela 12 - Valores médios da temperatura interna (TI) no Piso 2 e da temperatura externa (TE) (Continuação).

\begin{tabular}{|c|c|c|c|}
\hline Data & $\begin{array}{c}\text { Temperatura } \\
\text { Interna }\end{array}$ & $\begin{array}{c}\text { Temperatura } \\
\text { Externa }\end{array}$ & $\begin{array}{l}\text { Razão } \\
\text { TI/TE }\end{array}$ \\
\hline $15 / 06 / 2010$ & 19,6 & 18,8 & 1,05 \\
\hline $16 / 06 / 2010$ & 22,9 & 23,9 & 0,96 \\
\hline $21 / 06 / 2010$ & 23,1 & 23,2 & 1,00 \\
\hline $22 / 06 / 2010$ & 25,1 & 25,6 & 0,98 \\
\hline $24 / 06 / 2010$ & 25,1 & 26,7 & 0,94 \\
\hline $29 / 06 / 2010$ & 20,9 & 18,9 & 1,11 \\
\hline $30 / 06 / 2010$ & 21,5 & 19,5 & 1,11 \\
\hline $01 / 07 / 2010$ & 21,7 & 20,0 & 1,09 \\
\hline $06 / 07 / 2010$ & 24,4 & 25,7 & 0,95 \\
\hline $07 / 07 / 2010$ & 22,0 & 20,4 & 1,08 \\
\hline $08 / 07 / 2010$ & 23,9 & 25,5 & 0,94 \\
\hline $13 / 07 / 2010$ & 23,3 & 22,3 & 1,04 \\
\hline $14 / 07 / 2010$ & 22,2 & 20,0 & 1,11 \\
\hline $15 / 07 / 2010$ & 22,9 & 23,4 & 0,98 \\
\hline $20 / 07 / 2010$ & 25,3 & 26,8 & 0,94 \\
\hline $21 / 07 / 2010$ & 25,7 & 27,2 & 0,94 \\
\hline $22 / 07 / 2010$ & 26,7 & 27,9 & 0,96 \\
\hline $23 / 07 / 2010$ & 24,3 & 23,5 & 1,04 \\
\hline 03/08/2010 & 24,4 & 24,9 & 0,98 \\
\hline $05 / 08 / 2010$ & 20,7 & 18,7 & 1,11 \\
\hline $06 / 08 / 2010$ & 19,1 & 16,6 & 1,15 \\
\hline $09 / 08 / 2010$ & 22,1 & 22,8 & 0,97 \\
\hline $10 / 08 / 2010$ & 25,2 & 27,6 & 0,91 \\
\hline $11 / 08 / 2010$ & 25,1 & 26,7 & 0,94 \\
\hline $17 / 08 / 2010$ & 21,4 & 22,0 & 0,97 \\
\hline $19 / 08 / 2010$ & 20,0 & 18,7 & 1,07 \\
\hline $20 / 08 / 2010$ & 24,4 & 25,5 & 0,96 \\
\hline $24 / 08 / 2010$ & 27,1 & 28,5 & 0,95 \\
\hline $26 / 08 / 2010$ & 29,0 & 30,3 & 0,95 \\
\hline $27 / 08 / 2010$ & 25,9 & 25,5 & 1,01 \\
\hline $30 / 08 / 2010$ & 26,3 & 26,5 & 0,99 \\
\hline $03 / 09 / 2010$ & 27,2 & 26,9 & 1,01 \\
\hline $08 / 09 / 2010$ & 25,3 & 26,5 & 0,95 \\
\hline $15 / 09 / 2010$ & 26,5 & 27,1 & 0,98 \\
\hline \multirow{2}{*}{ 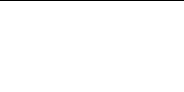 } & & MÁXIMO & 1,15 \\
\hline & & MÍNIMO & 0,91 \\
\hline
\end{tabular}


Tabela 13 - Valores médios da temperatura interna (TI) no Piso 3 e da temperatura externa (TE).

\begin{tabular}{|c|c|c|c|}
\hline Data & $\begin{array}{l}\text { Temperatura } \\
\text { Interna }\end{array}$ & $\begin{array}{c}\text { Temperatura } \\
\text { Externa }\end{array}$ & $\begin{array}{l}\text { Razão } \\
\text { TI/TE }\end{array}$ \\
\hline $20 / 08 / 2009$ & 21,6 & 21,0 & 1,03 \\
\hline $02 / 09 / 2009$ & 29,7 & 30,5 & 0,97 \\
\hline $09 / 09 / 2009$ & 23,7 & 22,7 & 1,04 \\
\hline 16/09/2009 & 26,0 & 23,6 & 1,10 \\
\hline $21 / 09 / 2009$ & 25,0 & 23,6 & 1,06 \\
\hline $30 / 09 / 2009$ & 24,7 & 24,6 & 1,00 \\
\hline $07 / 10 / 2009$ & 28,3 & 26,4 & 1,08 \\
\hline $08 / 10 / 2009$ & 23,5 & 21,8 & 1,08 \\
\hline $14 / 10 / 2009$ & 27,6 & 30,9 & 0,89 \\
\hline $21 / 10 / 2009$ & 28,8 & 30,6 & 0,94 \\
\hline $28 / 10 / 2009$ & 27,3 & 28,6 & 0,95 \\
\hline $11 / 11 / 2009$ & 29,7 & 31,7 & 0,94 \\
\hline $12 / 11 / 2009$ & 30,2 & 31,9 & 0,95 \\
\hline $18 / 11 / 2009$ & 31,1 & 33,7 & 0,92 \\
\hline $19 / 11 / 2009$ & 31,5 & 33,2 & 0,95 \\
\hline $04 / 05 / 2010$ & 24,7 & 24,1 & 1,03 \\
\hline $05 / 05 / 2010$ & 25,2 & 24,7 & 1,02 \\
\hline $07 / 05 / 2010$ & 26,9 & 26,5 & 1,02 \\
\hline $11 / 05 / 2010$ & 21,0 & 19,3 & 1,09 \\
\hline $12 / 05 / 2010$ & 21,0 & 19,3 & 1,08 \\
\hline $13 / 05 / 2010$ & 18,8 & 15,6 & 1,21 \\
\hline $18 / 05 / 2010$ & 24,6 & 24,4 & 1,01 \\
\hline $20 / 05 / 2010$ & 19,3 & 16,9 & 1,14 \\
\hline $21 / 05 / 2010$ & 19,2 & 17,9 & 1,07 \\
\hline $25 / 05 / 2010$ & 25,0 & 26,7 & 0,94 \\
\hline $26 / 05 / 2010$ & 25,2 & 26,3 & 0,96 \\
\hline $28 / 05 / 2010$ & 20,9 & 19,3 & 1,08 \\
\hline $31 / 05 / 2010$ & 21,3 & 19,3 & 1,10 \\
\hline $01 / 06 / 2010$ & 22,2 & 21,6 & 1,02 \\
\hline $02 / 06 / 2010$ & 19,6 & 18,0 & 1,09 \\
\hline 08/06/2010 & 21,9 & 23,7 & 0,93 \\
\hline $09 / 06 / 2010$ & 19,4 & 18,6 & 1,04 \\
\hline $10 / 06 / 2010$ & 20,0 & 18,2 & 1,10 \\
\hline $14 / 06 / 2010$ & 18,3 & 17,1 & 1,07 \\
\hline $15 / 06 / 2010$ & 19,4 & 18,8 & 1,03 \\
\hline $16 / 06 / 2010$ & 22,2 & 23,9 & 0,93 \\
\hline $21 / 06 / 2010$ & 23,0 & 23,2 & 1,00 \\
\hline $22 / 06 / 2010$ & 25,1 & 25,6 & 0,98 \\
\hline $24 / 06 / 2010$ & 24,9 & 26,7 & 0,93 \\
\hline $29 / 06 / 2010$ & 21,2 & 18,9 & 1,12 \\
\hline $30 / 06 / 2010$ & 21,6 & 19,5 & 1,11 \\
\hline $01 / 07 / 2010$ & 21,7 & 20,0 & 1,09 \\
\hline $06 / 07 / 2010$ & 24,2 & 25,7 & 0,94 \\
\hline $07 / 07 / 2010$ & 22,0 & 20,4 & 1,08 \\
\hline 08/07/2010 & 24,0 & 25,5 & 0,94 \\
\hline $13 / 07 / 2010$ & 23,5 & 22,3 & 1,05 \\
\hline $14 / 07 / 2010$ & 22,1 & 20,0 & 1,11 \\
\hline
\end{tabular}


Tabela 13 - Valores médios da temperatura interna (TI) no Piso 3 e da temperatura externa (TE) (Continuação).

\begin{tabular}{|c|c|c|c|}
\hline Data & $\begin{array}{c}\text { Temperatura } \\
\text { Interna }\end{array}$ & $\begin{array}{c}\text { Temperatura } \\
\text { Externa }\end{array}$ & $\begin{array}{c}\text { Razão } \\
\text { TI/TE }\end{array}$ \\
\hline $15 / 07 / 2010$ & 22,6 & 23,4 & 0,97 \\
\hline $20 / 07 / 2010$ & 25,1 & 26,8 & 0,93 \\
\hline $21 / 07 / 2010$ & 25,6 & 27,2 & 0,94 \\
\hline $22 / 07 / 2010$ & 26,5 & 27,9 & 0,95 \\
\hline $23 / 07 / 2010$ & 24,7 & 23,5 & 1,05 \\
\hline $03 / 08 / 2010$ & 24,2 & 24,9 & 0,97 \\
\hline $05 / 08 / 2010$ & 20,6 & 18,7 & 1,10 \\
\hline $06 / 08 / 2010$ & 19,3 & 16,6 & 1,16 \\
\hline $09 / 08 / 2010$ & 22,1 & 22,8 & 0,97 \\
\hline $10 / 08 / 2010$ & 25,2 & 27,6 & 0,91 \\
\hline $11 / 08 / 2010$ & 24,6 & 26,7 & 0,92 \\
\hline $17 / 08 / 2010$ & 21,4 & 22,0 & 0,97 \\
\hline $19 / 08 / 2010$ & 20,0 & 18,7 & 1,07 \\
\hline $20 / 08 / 2010$ & 24,4 & 25,5 & 0,96 \\
\hline $24 / 08 / 2010$ & 27,1 & 28,5 & 0,95 \\
\hline $26 / 08 / 2010$ & 29,0 & 30,3 & 0,95 \\
\hline $27 / 08 / 2010$ & 25,9 & 25,5 & 1,01 \\
\hline $30 / 08 / 2010$ & 26,3 & 26,5 & 0,99 \\
\hline $03 / 09 / 2010$ & 27,2 & 26,9 & 1,01 \\
\hline $08 / 09 / 2010$ & 25,3 & 26,5 & 0,95 \\
\hline $15 / 09 / 2010$ & 26,5 & 27,1 & 0,98 \\
\hline & & MÁXIMO & 1,21 \\
\cline { 3 - 4 } & & MÍNIMO & 0,89 \\
\hline
\end{tabular}

Tabela 14 - Valores médios de umidade relativa interna (URI) no Piso 1 e umidade relativa externa (URE).

\begin{tabular}{|c|c|c|c|}
\hline Data & UR Interna & UR Externa & $\begin{array}{c}\text { Razão } \\
\text { URI/URE }\end{array}$ \\
\hline $02 / 06 / 2009$ & 49,3 & 49,9 & 0,99 \\
\hline $09 / 06 / 2009$ & 54,7 & 55,0 & 1,00 \\
\hline $19 / 06 / 2009$ & 45,8 & 44,8 & 1,02 \\
\hline $03 / 07 / 2009$ & 73,6 & 75,6 & 0,97 \\
\hline $06 / 07 / 2009$ & 55,3 & 56,0 & 0,99 \\
\hline $16 / 07 / 2009$ & 64,5 & 66,0 & 0,98 \\
\hline $05 / 08 / 2009$ & 53,0 & 53,2 & 1,00 \\
\hline $06 / 08 / 2009$ & 50,3 & 48,2 & 1,04 \\
\hline $04 / 05 / 2010$ & 54,3 & 56,4 & 0,96 \\
\hline $05 / 05 / 2010$ & 59,3 & 59,9 & 0,99 \\
\hline $07 / 05 / 2010$ & 51,7 & 50,0 & 1,03 \\
\hline $11 / 05 / 2010$ & 58,3 & 63,5 & 0,92 \\
\hline $12 / 05 / 2010$ & 38,4 & 41,1 & 0,93 \\
\hline $13 / 05 / 2010$ & 54,2 & 64,3 & 0,84 \\
\hline $18 / 05 / 2010$ & 56,8 & 58,3 & 0,98 \\
\hline $20 / 05 / 2010$ & 55,5 & 59,8 & 0,93 \\
\hline $21 / 05 / 2010$ & 59,8 & 67,4 & 0,89 \\
\hline $25 / 05 / 2010$ & 55,9 & 51,0 & 1,10 \\
\hline
\end{tabular}


Tabela 14 - Valores médios de umidade relativa interna (URI) no Piso 1 e umidade relativa externa (URE) (Continuação).

\begin{tabular}{|c|c|c|c|}
\hline Data & UR Interna & UR Externa & $\begin{array}{c}\text { Razão } \\
\text { URI/URE }\end{array}$ \\
\hline $26 / 05 / 2010$ & 55,2 & 50,9 & 1,08 \\
\hline $28 / 05 / 2010$ & 60,7 & 65,5 & 0,93 \\
\hline $31 / 05 / 2010$ & 54,4 & 59,8 & 0,91 \\
\hline $01 / 06 / 2010$ & 47,0 & 46,8 & 1,00 \\
\hline $02 / 06 / 2010$ & 59,3 & 66,7 & 0,89 \\
\hline $08 / 06 / 2010$ & 35,3 & 29,2 & 1,21 \\
\hline 09/06/2010 & 60,3 & 63,4 & 0,95 \\
\hline $10 / 06 / 2010$ & 68,3 & 77,2 & 0,88 \\
\hline $14 / 06 / 2010$ & 52,8 & 55,2 & 0,96 \\
\hline $15 / 06 / 2010$ & 54,9 & 55,2 & 0,99 \\
\hline $16 / 06 / 2010$ & 46,2 & 38,9 & 1,19 \\
\hline $21 / 06 / 2010$ & 49,8 & 42,5 & 1,17 \\
\hline $22 / 06 / 2010$ & 54,7 & 50,4 & 1,09 \\
\hline $24 / 06 / 2010$ & 59,3 & 50,2 & 1,18 \\
\hline $29 / 06 / 2010$ & 57,6 & 63,7 & 0,90 \\
\hline $30 / 06 / 2010$ & 52,2 & 55,8 & 0,94 \\
\hline $01 / 07 / 2010$ & 49,4 & 51,1 & 0,97 \\
\hline 06/07/2010 & 47,8 & 38,9 & 1,23 \\
\hline $07 / 07 / 2010$ & 52,1 & 53,3 & 0,98 \\
\hline 08/07/2010 & 35,5 & 28,6 & 1,24 \\
\hline $13 / 07 / 2010$ & 72,2 & 79,2 & 0,91 \\
\hline $14 / 07 / 2010$ & 75,9 & 85,8 & 0,88 \\
\hline $15 / 07 / 2010$ & 72,2 & 65,3 & 1,10 \\
\hline $20 / 07 / 2010$ & 51,7 & 42,1 & 1,23 \\
\hline $21 / 07 / 2010$ & 40,1 & 32,6 & 1,23 \\
\hline $22 / 07 / 2010$ & 44,6 & 34,8 & 1,28 \\
\hline $23 / 07 / 2010$ & 49,5 & 49,4 & 1,00 \\
\hline $03 / 08 / 2010$ & 53,8 & 47,4 & 1,13 \\
\hline 05/08/2010 & 59,3 & 65,0 & 0,91 \\
\hline 06/08/2010 & 57,6 & 68,1 & 0,85 \\
\hline 09/08/2010 & 40,3 & 32,1 & 1,25 \\
\hline $10 / 08 / 2010$ & 33,4 & 25,1 & 1,33 \\
\hline $11 / 08 / 2010$ & 45,0 & 35,9 & 1,25 \\
\hline $17 / 08 / 2010$ & 33,8 & 28,6 & 1,18 \\
\hline 19/08/2010 & 43,4 & 43,8 & 0,99 \\
\hline $20 / 08 / 2010$ & 30,9 & 23,9 & 1,29 \\
\hline $24 / 08 / 2010$ & 23,7 & 19,3 & 1,23 \\
\hline 26/08/2010 & 22,8 & 17,5 & 1,31 \\
\hline $27 / 08 / 2010$ & 30,9 & 29,1 & 1,06 \\
\hline $30 / 08 / 2010$ & 38,1 & 36,3 & 1,05 \\
\hline 03/09/2010 & 31,3 & 29,1 & 1,08 \\
\hline $08 / 09 / 2010$ & 46,8 & 40,7 & 1,15 \\
\hline $15 / 09 / 2010$ & 48,7 & 45,7 & 1,06 \\
\hline \multirow{2}{*}{\multicolumn{2}{|c|}{+2}} & MÁXIMO & 1,33 \\
\hline & & MÍNIMO & 0,84 \\
\hline
\end{tabular}


Tabela 15 - Valores médios de umidade relativa interna (URI) no Piso 2 e umidade relativa externa (URE).

\begin{tabular}{|c|c|c|c|}
\hline Data & UR Interna & UR Externa & $\begin{array}{c}\text { Razão } \\
\text { URI/URE }\end{array}$ \\
\hline $09 / 12 / 2009$ & 74,6 & 79,7 & 0,94 \\
\hline $10 / 12 / 2009$ & 74,1 & 78,1 & 0,95 \\
\hline $15 / 12 / 2009$ & 60,5 & 52,4 & 1,15 \\
\hline $16 / 12 / 2009$ & 54,3 & 53,1 & 1,02 \\
\hline $04 / 05 / 2010$ & 54,7 & 56,4 & 0,97 \\
\hline $05 / 05 / 2010$ & 57,5 & 59,9 & 0,96 \\
\hline $07 / 05 / 2010$ & 49,9 & 50,0 & 1,00 \\
\hline $11 / 05 / 2010$ & 56,6 & 63,5 & 0,89 \\
\hline $12 / 05 / 2010$ & 39,0 & 41,1 & 0,95 \\
\hline $13 / 05 / 2010$ & 56,5 & 64,3 & 0,88 \\
\hline $18 / 05 / 2010$ & 55,4 & 58,3 & 0,95 \\
\hline $20 / 05 / 2010$ & 53,6 & 59,8 & 0,90 \\
\hline $21 / 05 / 2010$ & 59,0 & 67,4 & 0,88 \\
\hline $25 / 05 / 2010$ & 54,1 & 51,0 & 1,06 \\
\hline $26 / 05 / 2010$ & 54,5 & 50,9 & 1,07 \\
\hline $28 / 05 / 2010$ & 60,5 & 65,5 & 0,92 \\
\hline $31 / 05 / 2010$ & 54,8 & 59,8 & 0,92 \\
\hline $01 / 06 / 2010$ & 46,0 & 46,8 & 0,98 \\
\hline $02 / 06 / 2010$ & 59,3 & 66,7 & 0,89 \\
\hline 08/06/2010 & 33,3 & 29,2 & 1,14 \\
\hline $09 / 06 / 2010$ & 57,7 & 63,4 & 0,91 \\
\hline $10 / 06 / 2010$ & 67,9 & 77,2 & 0,88 \\
\hline $14 / 06 / 2010$ & 53,3 & 55,2 & 0,96 \\
\hline $15 / 06 / 2010$ & 53,4 & 55,2 & 0,97 \\
\hline $16 / 06 / 2010$ & 43,0 & 38,9 & 1,11 \\
\hline $21 / 06 / 2010$ & 44,6 & 42,5 & 1,05 \\
\hline $22 / 06 / 2010$ & 51,9 & 50,4 & 1,03 \\
\hline $24 / 06 / 2010$ & 55,8 & 50,2 & 1,11 \\
\hline $29 / 06 / 2010$ & 56,2 & 63,7 & 0,88 \\
\hline $30 / 06 / 2010$ & 50,5 & 55,8 & 0,91 \\
\hline $01 / 07 / 2010$ & 47,8 & 51,1 & 0,94 \\
\hline $06 / 07 / 2010$ & 45,3 & 38,9 & 1,17 \\
\hline $07 / 07 / 2010$ & 49,4 & 53,3 & 0,93 \\
\hline 08/07/2010 & 33,7 & 28,6 & 1,18 \\
\hline $13 / 07 / 2010$ & 68,5 & 79,2 & 0,86 \\
\hline $14 / 07 / 2010$ & 73,1 & 85,8 & 0,85 \\
\hline $15 / 07 / 2010$ & 68,3 & 65,3 & 1,04 \\
\hline $20 / 07 / 2010$ & 49,6 & 42,1 & 1,18 \\
\hline $21 / 07 / 2010$ & 38,3 & 32,6 & 1,18 \\
\hline $22 / 07 / 2010$ & 38,9 & 34,8 & 1,12 \\
\hline $23 / 07 / 2010$ & 47,6 & 49,4 & 0,96 \\
\hline 03/08/2010 & 50,3 & 47,4 & 1,06 \\
\hline $05 / 08 / 2010$ & 57,2 & 65,0 & 0,88 \\
\hline 06/08/2010 & 57,6 & 68,1 & 0,85 \\
\hline $09 / 08 / 2010$ & 35,5 & 32,1 & 1,10 \\
\hline $10 / 08 / 2010$ & 29,3 & 25,1 & 1,17 \\
\hline
\end{tabular}


Tabela 15 - Valores médios de umidade relativa interna (URI) no Piso 2 e umidade relativa externa (URE) (Continuação).

\begin{tabular}{|c|c|c|c|}
\hline Data & UR Interna & UR Externa & $\begin{array}{c}\text { Razão } \\
\text { URI/URE }\end{array}$ \\
\hline $11 / 08 / 2010$ & 42,4 & 35,9 & 1,18 \\
\hline $17 / 08 / 2010$ & 31,7 & 28,6 & 1,11 \\
\hline $19 / 08 / 2010$ & 41,4 & 43,8 & 0,94 \\
\hline $20 / 08 / 2010$ & 27,4 & 23,9 & 1,15 \\
\hline $24 / 08 / 2010$ & 22,7 & 19,3 & 1,17 \\
\hline $26 / 08 / 2010$ & 21,1 & 17,5 & 1,21 \\
\hline $27 / 08 / 2010$ & 28,8 & 29,1 & 0,99 \\
\hline $30 / 08 / 2010$ & 36,7 & 36,3 & 1,01 \\
\hline $03 / 09 / 2010$ & 29,5 & 29,1 & 1,01 \\
\hline $08 / 09 / 2010$ & 45,3 & 40,7 & 1,11 \\
\hline $15 / 09 / 2010$ & 46,4 & 45,7 & 1,01 \\
\hline & & MÁXIMO & 1,21 \\
\cline { 2 - 4 } & & MÍNIMO & 0,85 \\
\cline { 2 - 4 } & & &
\end{tabular}

Tabela 16 - Valores médios de umidade relativa interna (URI) no Piso 3 e umidade relativa externa (URE).

\begin{tabular}{|c|c|c|c|}
\hline Data & UR Interna & UR Externa & $\begin{array}{c}\text { Razão } \\
\text { URI/URE }\end{array}$ \\
\hline $20 / 08 / 2009$ & 75,6 & 80,9 & 0,94 \\
\hline $02 / 09 / 2009$ & 33,9 & 30,7 & 1,10 \\
\hline $09 / 09 / 2009$ & 70,6 & 77,7 & 0,91 \\
\hline $16 / 09 / 2009$ & 57,9 & 61,7 & 0,94 \\
\hline $21 / 09 / 2009$ & 70,6 & 78,8 & 0,90 \\
\hline $30 / 09 / 2009$ & 49,5 & 49,8 & 0,99 \\
\hline $07 / 10 / 2009$ & 58,0 & 70,1 & 0,83 \\
\hline $08 / 10 / 2009$ & 64,6 & 72,7 & 0,89 \\
\hline $14 / 10 / 2009$ & 53,7 & 42,5 & 1,26 \\
\hline 21/10/2009 & 51,9 & 45,9 & 1,13 \\
\hline 28/10/2009 & 55,7 & 50,9 & 1,09 \\
\hline $11 / 11 / 2009$ & 55,7 & 48,7 & 1,14 \\
\hline $12 / 11 / 2009$ & 48,4 & 42,7 & 1,14 \\
\hline $18 / 11 / 2009$ & 46,5 & 38,2 & 1,22 \\
\hline $19 / 11 / 2009$ & 50,4 & 46,1 & 1,09 \\
\hline $04 / 05 / 2010$ & 54,0 & 56,4 & 0,96 \\
\hline $05 / 05 / 2010$ & 57,9 & 59,9 & 0,97 \\
\hline 07/05/2010 & 48,8 & 50,0 & 0,97 \\
\hline $11 / 05 / 2010$ & 58,2 & 63,5 & 0,92 \\
\hline $12 / 05 / 2010$ & 38,2 & 41,1 & 0,93 \\
\hline $13 / 05 / 2010$ & 52,2 & 64,3 & 0,81 \\
\hline $18 / 05 / 2010$ & 57,0 & 58,3 & 0,98 \\
\hline $20 / 05 / 2010$ & 53,4 & 59,8 & 0,89 \\
\hline $21 / 05 / 2010$ & 61,2 & 67,4 & 0,91 \\
\hline $25 / 05 / 2010$ & 56,3 & 51,0 & 1,10 \\
\hline 26/05/2010 & 54,5 & 50,9 & 1,07 \\
\hline 28/05/2010 & 60,9 & 65,5 & 0,93 \\
\hline $31 / 05 / 2010$ & 53,9 & 59,8 & 0,90 \\
\hline
\end{tabular}


Tabela 16 - Valores médios de umidade relativa interna (URI) no Piso 3 e umidade relativa externa (URE) (Continuação).

\begin{tabular}{|c|c|c|c|}
\hline Data & UR Interna & UR Externa & $\begin{array}{c}\text { Razão } \\
\text { URI/URE }\end{array}$ \\
\hline $01 / 06 / 2010$ & 47,4 & 46,8 & 1,01 \\
\hline $02 / 06 / 2010$ & 60,0 & 66,7 & 0,90 \\
\hline $08 / 06 / 2010$ & 36,6 & 29,2 & 1,25 \\
\hline $09 / 06 / 2010$ & 59,3 & 63,4 & 0,94 \\
\hline $10 / 06 / 2010$ & 67,7 & 77,2 & 0,88 \\
\hline $14 / 06 / 2010$ & 53,1 & 55,2 & 0,96 \\
\hline $15 / 06 / 2010$ & 54,1 & 55,2 & 0,98 \\
\hline $16 / 06 / 2010$ & 46,4 & 38,9 & 1,19 \\
\hline $21 / 06 / 2010$ & 44,3 & 42,5 & 1,04 \\
\hline $22 / 06 / 2010$ & 51,8 & 50,4 & 1,03 \\
\hline $24 / 06 / 2010$ & 56,6 & 50,2 & 1,13 \\
\hline $29 / 06 / 2010$ & 55,2 & 63,7 & 0,87 \\
\hline $30 / 06 / 2010$ & 49,9 & 55,8 & 0,90 \\
\hline $01 / 07 / 2010$ & 47,4 & 51,1 & 0,93 \\
\hline $06 / 07 / 2010$ & 46,6 & 38,9 & 1,20 \\
\hline $07 / 07 / 2010$ & 49,5 & 53,3 & 0,93 \\
\hline $08 / 07 / 2010$ & 34,4 & 28,6 & 1,20 \\
\hline $13 / 07 / 2010$ & 69,1 & 79,2 & 0,87 \\
\hline $14 / 07 / 2010$ & 73,8 & 85,8 & 0,86 \\
\hline $15 / 07 / 2010$ & 68,6 & 65,3 & 1,05 \\
\hline $20 / 07 / 2010$ & 50,6 & 42,1 & 1,20 \\
\hline $21 / 07 / 2010$ & 39,0 & 32,6 & 1,20 \\
\hline $22 / 07 / 2010$ & 40,1 & 34,8 & 1,15 \\
\hline $23 / 07 / 2010$ & 46,4 & 49,4 & 0,94 \\
\hline $03 / 08 / 2010$ & 50,7 & 47,4 & 1,07 \\
\hline $05 / 08 / 2010$ & 57,1 & 65,0 & 0,88 \\
\hline $06 / 08 / 2010$ & 56,8 & 68,1 & 0,83 \\
\hline $09 / 08 / 2010$ & 36,9 & 32,1 & 1,15 \\
\hline $10 / 08 / 2010$ & 31,9 & 25,1 & 1,27 \\
\hline $11 / 08 / 2010$ & 44,6 & 35,9 & 1,24 \\
\hline $17 / 08 / 2010$ & 33,8 & 28,6 & 1,18 \\
\hline $19 / 08 / 2010$ & 41,4 & 43,8 & 0,94 \\
\hline $20 / 08 / 2010$ & 27,4 & 23,9 & 1,15 \\
\hline $24 / 08 / 2010$ & 22,7 & 19,3 & 1,17 \\
\hline $26 / 08 / 2010$ & 21,1 & 17,5 & 1,21 \\
\hline $27 / 08 / 2010$ & 28,8 & 29,1 & 0,99 \\
\hline $30 / 08 / 2010$ & 36,7 & 36,3 & 1,01 \\
\hline $03 / 09 / 2010$ & 29,5 & 29,1 & 1,01 \\
\hline $08 / 09 / 2010$ & 45,3 & 40,7 & 1,11 \\
\hline $15 / 09 / 2010$ & 46,4 & 45,7 & 1,01 \\
\hline \multirow{2}{*}{ 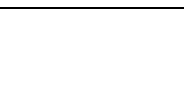 } & & MÁXIMO & 1,27 \\
\hline & & MÍNIMO & 0,81 \\
\hline
\end{tabular}


Em uma análise dos resultados apresentados, denota-se que os valores de temperatura média interna e externa variaram muito pouco, sendo que a média interna se apresentou muito próxima da média externa na maior parte dos dias analisados. Esses valores devem ser avaliados com maior cautela para a suposição das condições de conforto térmico do ambiente. Uma vez que essa variação é muito baixa e os valores encontram-se próximos, há indícios de desconforto térmico, pois a variação no interior é aproximadamente igual ao exterior, quando isso não deveria acontecer.

Essa baixa variação da temperatura interna e externa é evidenciada em todas as tabelas descritas acima, de acordo com a razão TI/TE. Quando o valor dessa razão está próximo de 1,0, denota-se que o ambiente interno está com as mesmas condições do ambiente externo. Nos resultados apresentados, esses valores estiveram próximos de 1,0 e isso é outro fator que denota a falta de conforto térmico nos ambientes estudados.

Sobre o conforto térmico do ambiente, torna-se relevante destacar que, quando a temperatura média externa está abaixo da faixa de $20^{\circ} \mathrm{C}$ a $23^{\circ} \mathrm{C}$, as temperaturas médias internas são maiores do que a externa. Porém, se a temperatura média externa está acima dessa faixa, a interna é menor do que a externa.

Ainda em relação à temperatura, como já salientado, a RE/AVISA nº de 2003 estipula uma faixa recomendável de temperatura visando o conforto térmico humano, sendo, para o verão entre $23^{\circ} \mathrm{C}$ e $26^{\circ} \mathrm{C}$ e, para o inverno, entre $20^{\circ} \mathrm{C}$ e $22^{\circ} \mathrm{C}$. É importante relembrar que essa norma trata de ambientes climatizados, que não é o caso da Biblioteca em estudo.

Um manual sobre conservação de acervos bibliográficos para as Bibliotecas do Rio de Janeiro, desenvolvido por Silva Filho et al. (1994), informa valores adequadoss de temperatura e umidade relativa, entre outras variáveis, para evitar a deterioração do material. As faixas indicadas correspondem à manutenção da temperatura entre $19^{\circ} \mathrm{C}$ e $23^{\circ} \mathrm{C}$, e a umidade relativa entre $50 \%$ a $60 \%$, sendo o ideal de $55 \%$.

Considerando essas duas referências, nota-se que, no verão, a temperatura excede os $26^{\circ} \mathrm{C}$ no Piso 3 e isso torna o ambiente inadequado tanto para o conforto térmico humano, quanto para a conservação preventiva do acervo bibliográfico. Porém, analisando os resultados de temperatura dos Pisos 1 e 2, observa-se que a temperatura no verão é um pouco mais amena se comparada com o Piso 3. Mas, ainda assim, os resultados de temperatura nos Pisos 1 e 2 estão em desacordo com o manual de conservação preventiva de acervo 
bibliográfico. É importante relembrar que o acervo infantil da Biblioteca é situado no Piso 2 e o acervo do Projeto "Barganha-Book" fica armazenado no Piso 1.

Já em uma observação dos valores de umidade relativa, a variação foi diferente se comparada à variação de temperatura média. Porém, diante os valores obtidos, não é possível traçar um padrão de comportamento dessa variação.

Em relação à razão URI/URE, os valores são próximos de 1,0 em todos os pisos analisados. Esse fator também reflete o desconforto térmico do ambiente, evidenciando a falta de isolamento adequado entre o ambiente interno e externo.

A RE/ANVISA n ${ }^{\circ} 9$ de 2003 sugere que os valores de umidade relativa sejam mantidos na faixa de $40 \%$ a $65 \%$ no verão e $35 \%$ a $65 \%$ no inverno. Em relação aos valores recomendados tanto para conforto térmico humano, quanto para conservação de acervo bibliográfico, pode-se notar que há ocorrências de valores fora dos padrões tanto no inverno, quanto no verão.

Os dados de umidade relativa trazem outra importante consideração. No estado de São Paulo, durante os meses de junho a setembro, é comum a ocorrência de um período de estiagem. Esse evento foi diagnosticado nas medições do ano de 2010, de acordo com as Figuras acima e os valores anotados. Porém, no ano de 2009, tal período de estiagem foi bem mais curto se comparado ao de 2010. O ano de 2009 foi marcado por ocorrência de chuvas no período de julho a setembro e isso é comprovado com valores relativamente elevados de umidade relativa, quando comparados com os valores desta variável para o mesmo período no ano de 2010.

\subsection{Material particulado}

As amostras de material particulado foram realizadas em cada dia específico, sendo traçado um perfil diário da variação da concentração em cada 2 minutos, para um tempo total de coleta de 4 horas.

Portanto, as Figuras 21 e 22 apresentam perfis de concentração de particulado total e suas frações respiráveis de um dia específico de medição. 


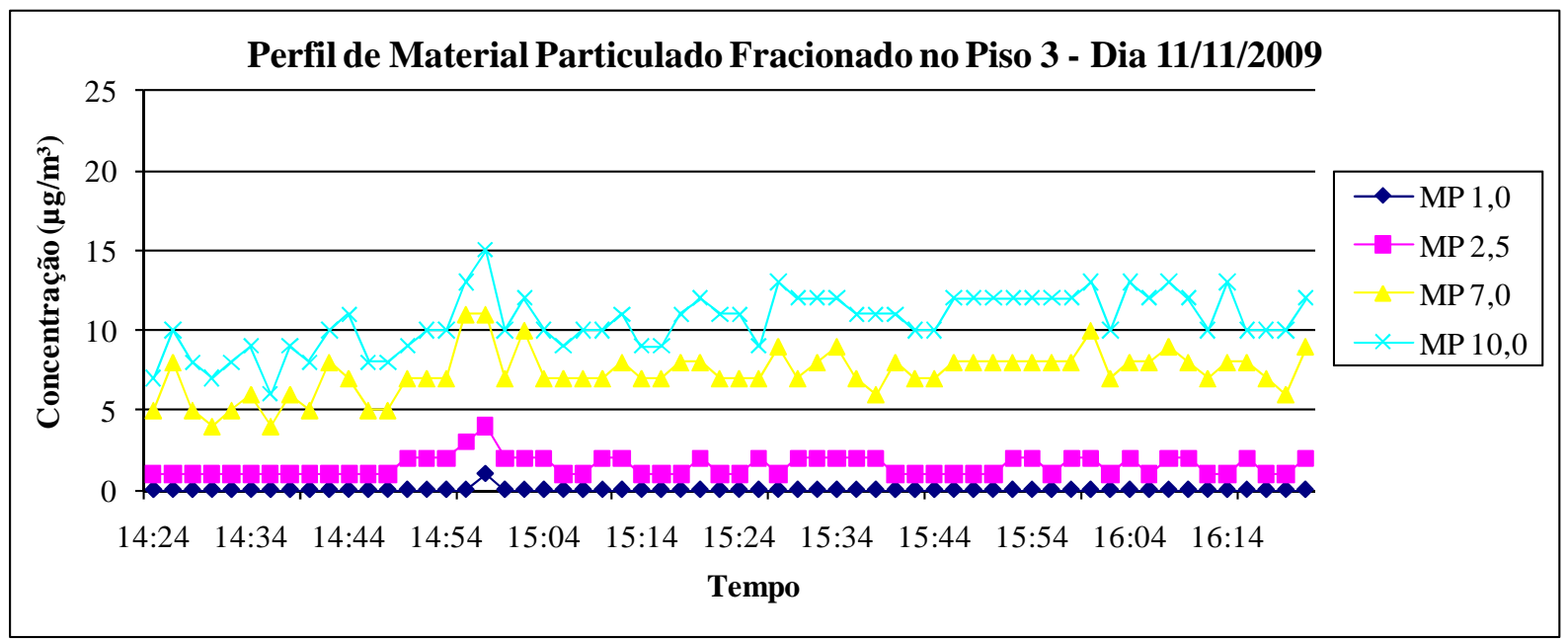

Figura 21. Perfil da concentração de material particulado fracionado em uma medição no Piso 3, no dia 11/11/2009.

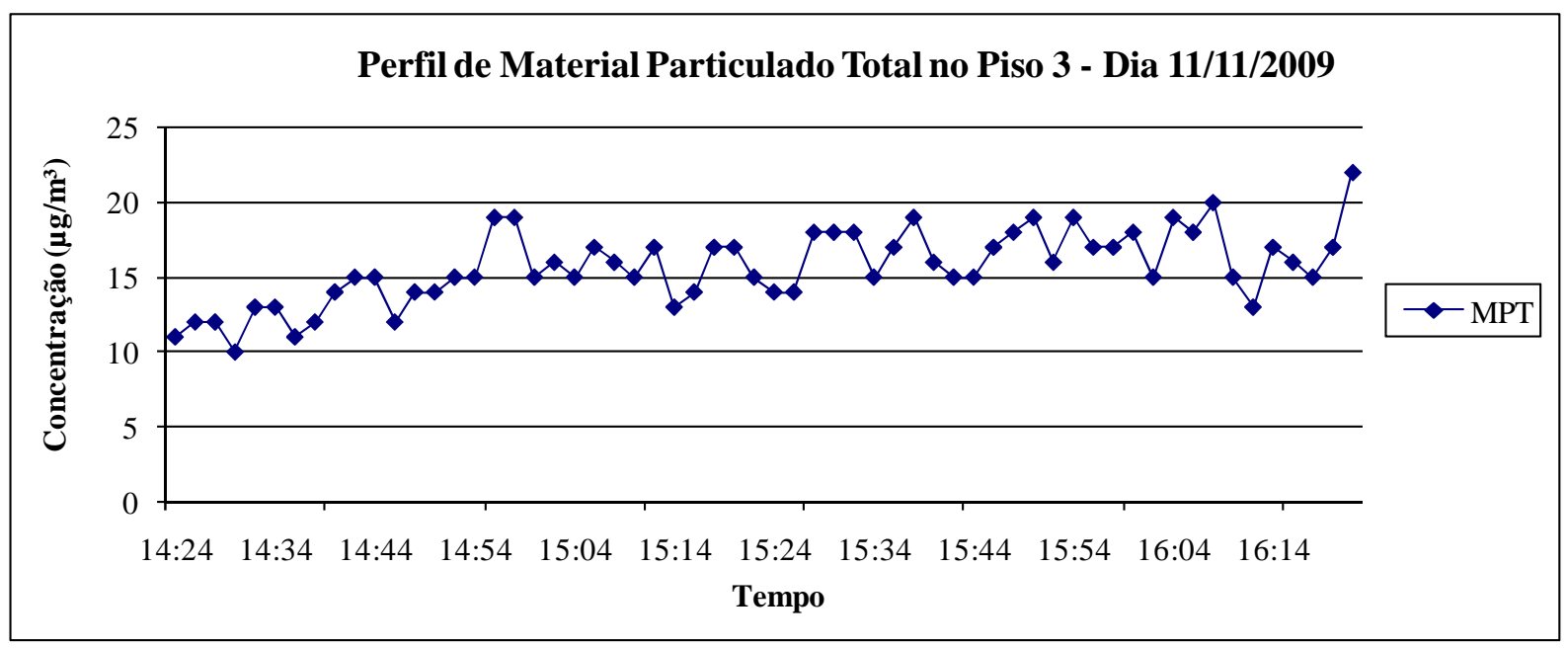

Figura 22. Perfil da concentração de material particulado total em uma medição no Piso 3, no dia 11/11/2009.

Para uma análise da concentração em períodos maiores, uma média desses valores foi obtida para cada dia de monitoramento.

Assim, os valores médios para cada dia em cada ambiente de monitoramento foram agrupados em gráficos e encontram-se dispostos nas Figuras 23 a 26.

O Anexo II apresenta todos os dados de médias diárias de concentração obtidas em cada ambiente interno monitorado e também na porção externa. 


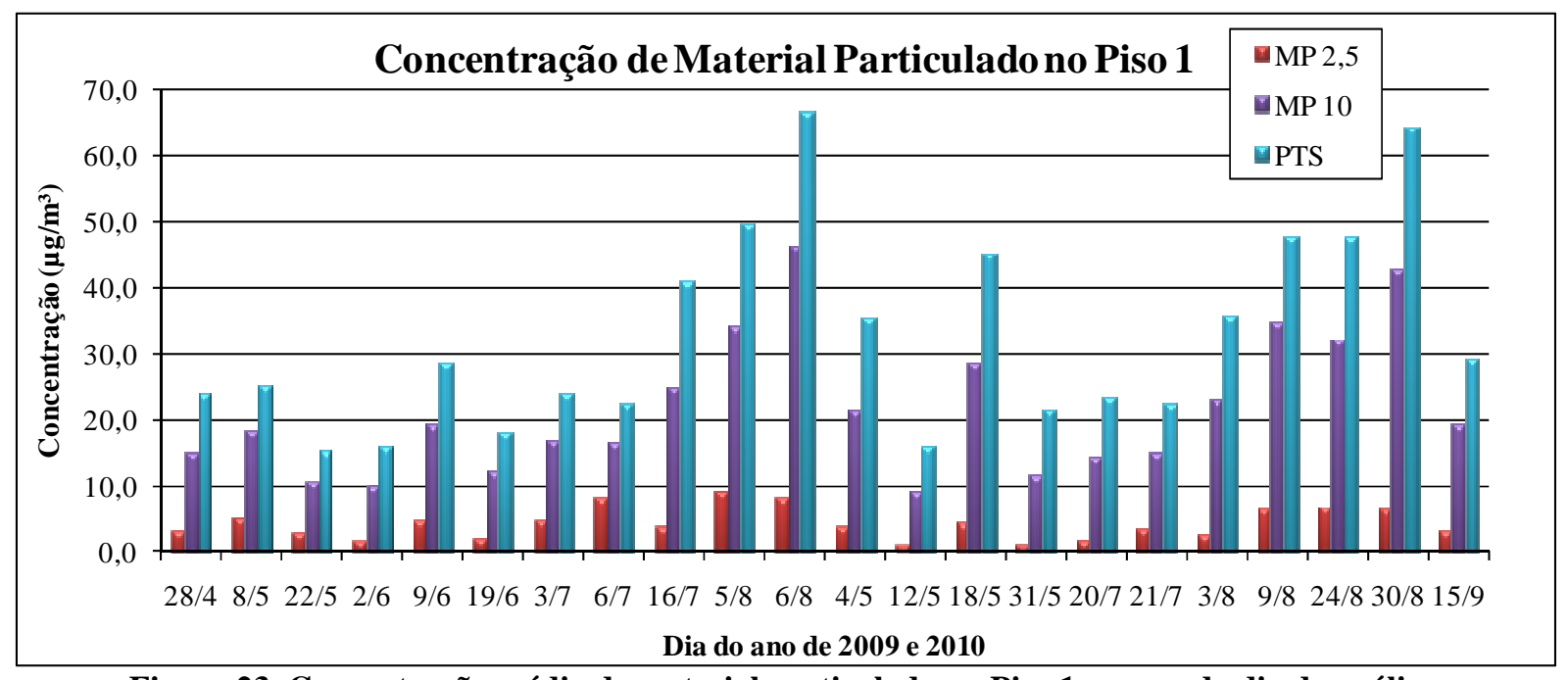

Figura 23. Concentração média de material particulado no Piso 1 para cada dia de análise.

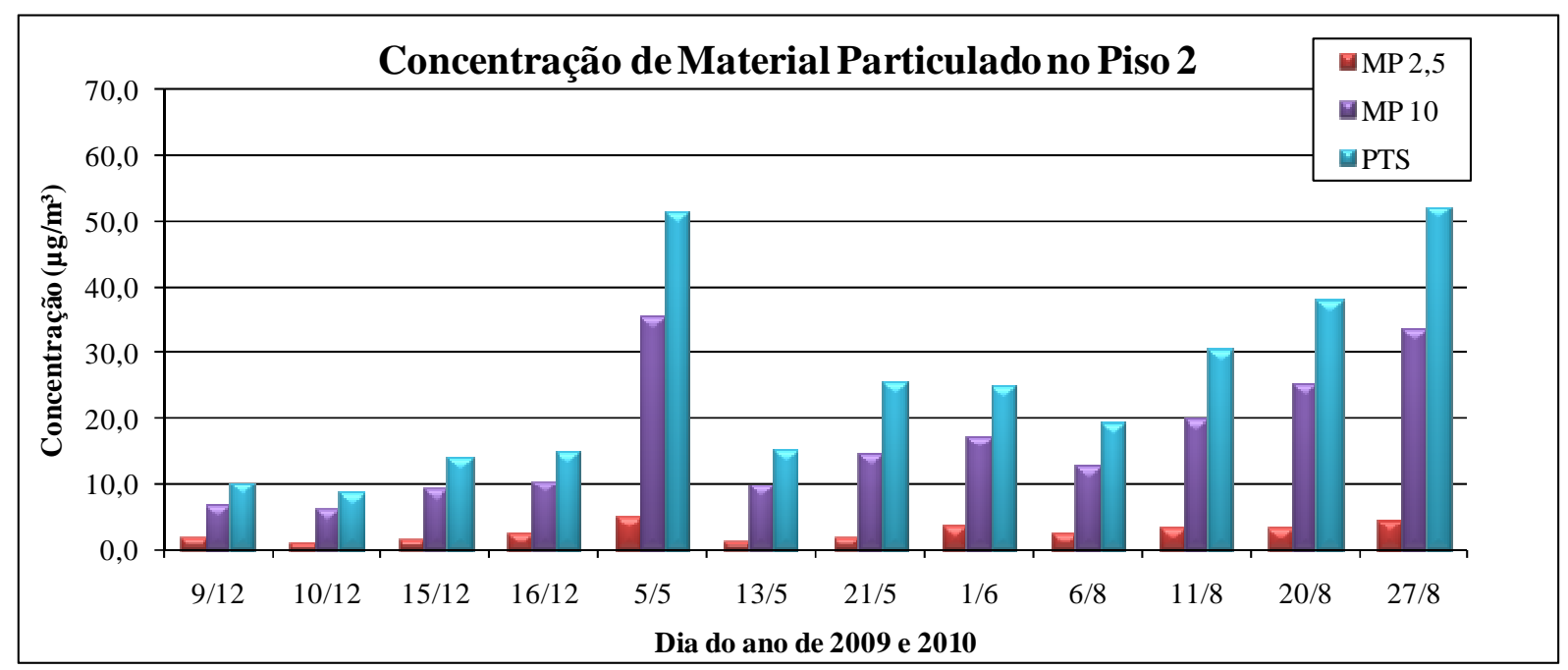

Figura 24. Concentração média de material particulado no Piso 2 para cada dia de análise.

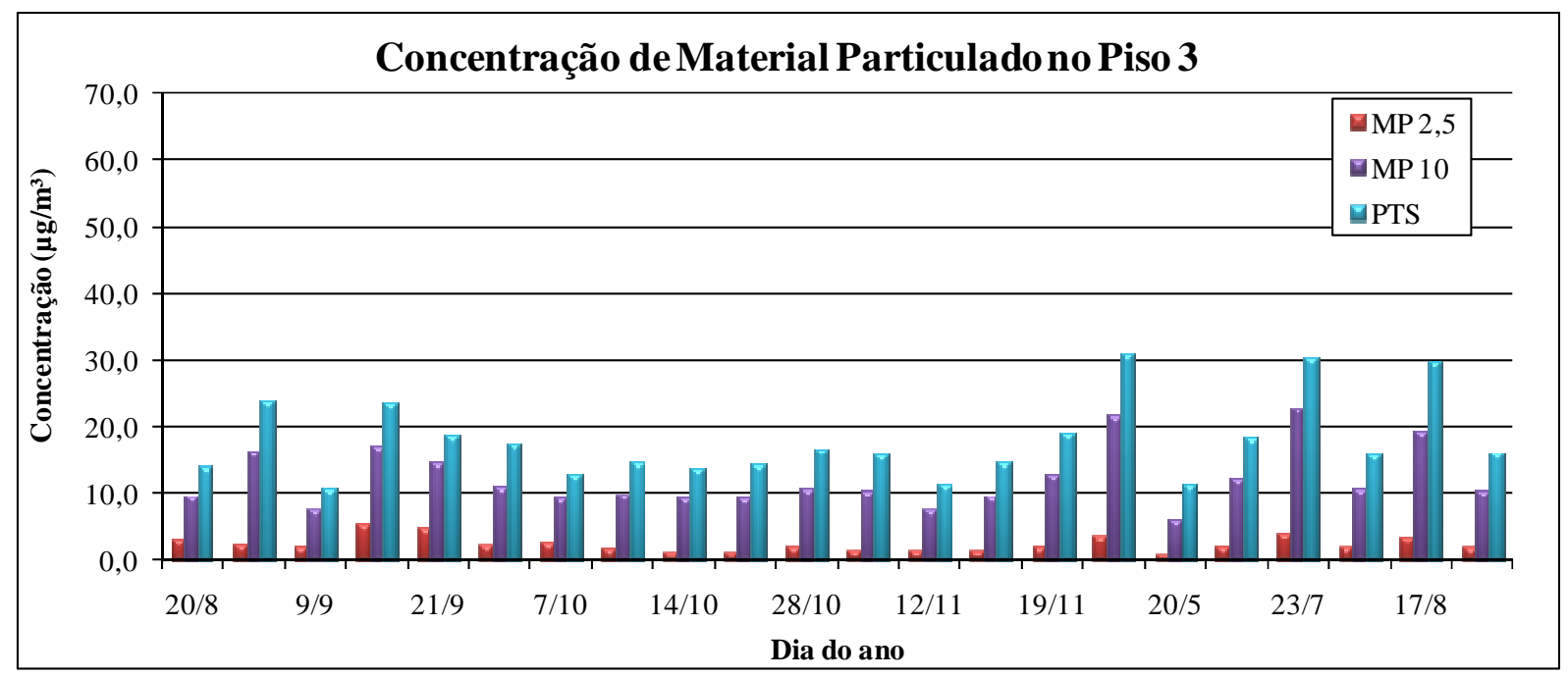

Figura 25. Concentração média de material particulado no Piso 3 para cada dia de análise. 


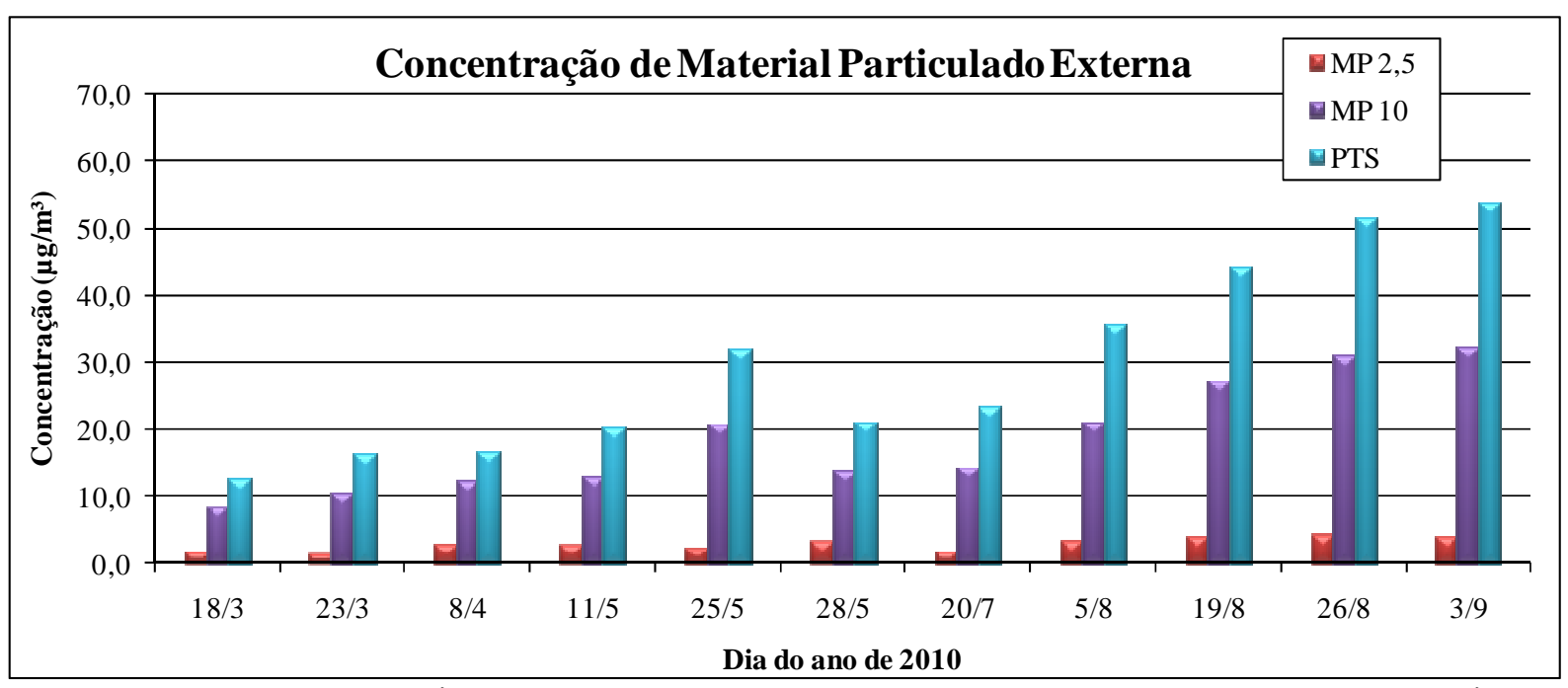

Figura 26. Concentração média de material particulado no Ambiente Externo para cada dia de análise.

A RE/ANVISA $n^{\circ} 9$ traz como recomendação de Valor Máximo Recomendável (VMR) quantidade menor ou igual a $80 \mu \mathrm{g} / \mathrm{m}^{3}$ de material particulado total em um ambiente climatizado como indicador do grau de pureza do ar. Para o $\mathrm{MP}_{2,5}$ e o $\mathrm{MP}_{10}$, a $\mathrm{OMS}$ recomenda como média diárias os valores de $25 \mu \mathrm{g} / \mathrm{m}^{3}$ e $50 \mu \mathrm{g} / \mathrm{m}^{3}$, respectivamente.

A partir desses resultados, de uma maneira geral, não foram encontrados grandes problemas em relação ao particulado em suspensão. Nos ambientes internos, na maioria dos casos, o valor de particulado total em suspensão não ultrapassou $50 \mu \mathrm{g} / \mathrm{m}^{3}$. Na Figura 23, observa-se a ocorrência de dois picos de valores acima do limite de $50 \mu \mathrm{g} / \mathrm{m}^{3}$. É importante notar que no dia 06/08/2009 foi realizada uma limpeza do acervo no interior da sala de processamento de dados. Esse trabalho é geralmente realizado na porção externa da sala, porém, neste dia, o serviço foi realizado no interior da sala em questão e isso fez com que ocorresse o pico caracterizado pelo equipamento. O outro pico aconteceu no dia 30/08/2010, em que uma reorganização dos livros foi realizada e gerou dados acima do normal.

A Figura 24 indica os valores respectivos ao Piso 2, em que duas medições de material particulado total atingiram a média de $50 \mu \mathrm{g} / \mathrm{m}^{3}$. Nesses dias (05/05/2010 e 27/08/2010), houve uma reorganização e limpeza das prateleiras de livros na parte da manhã, coincidindo com o pico de concentração. Esse trabalho é sempre realizado no período da manhã e o ponto de coleta encontrava-se bem próximo das prateleiras.

O ano de 2010 foi marcado por um período de seca nos meses de julho a setembro. Esse período não aconteceu no ano de 2009, quando ocorreram chuvas nestes meses. A concentração de material particulado externo teve um aumento significativo no período de 
seca correspondente ao ano de 2010. A Figura 26 aponta o incremento desses valores, que aumentou consideravelmente nos últimos dias de coleta. Esse aumento de concentração é explicado pelo período de estiagem, evidenciado nas medidas de umidade relativa já apresentadas.

O monitoramento do material particulado no centro da cidade de São Carlos foi realizado por Pozza (2009). Em seu trabalho, no ano de 2004, a concentração de $\mathrm{MP}_{10}$ atingiu valores próximos a $30 \mu \mathrm{g} / \mathrm{m}^{3}$. A Biblioteca Municipal está situada em um local próximo à estação utilizada por Pozza (2009). Sendo assim, torna-se possível comparar estes dados com os obtidos com o monitoramento externo à Biblioteca.

Observa-se na Figura 32 que, no mês de agosto de 2010, as concentrações de $\mathrm{MP}_{10}$ atingiram a faixa de $20 \mu \mathrm{g} / \mathrm{m}^{3}$, até, no final do mês de setembro do mesmo ano, atingir valores próximos a $30 \mu \mathrm{g} / \mathrm{m}^{3}$. Comparando esses valores com o resultado de Pozza (2009), nota-se que a ordem de grandeza desses valores apresentou uma semelhança, apesar da distância temporal entre o ano de 2004 e 2010.

Em paralelo à utilização do contador de partículas, algumas coletas de material particulado foram realizadas, por meio da filtração do ar em membranas de $47 \mathrm{~mm}$ de Teflon®. Vários testes foram realizados para utilizar uma metodologia alternativa para a determinação da concentração de material particulado. Previa-se utilizar análises gravimétricas para uma comparação dos resultados. Porém, alguns problemas foram identificados e não foi possível concluir tais análises. No entanto, torna-se relevante destacar a quantidade de material particulado acumulado em uma membrana, durante 4 horas de coleta e, assim, chamando a atenção para a importância do tema na Biblioteca. A Figura 27 apresenta uma foto de uma membrana com material particulado acumulado. 


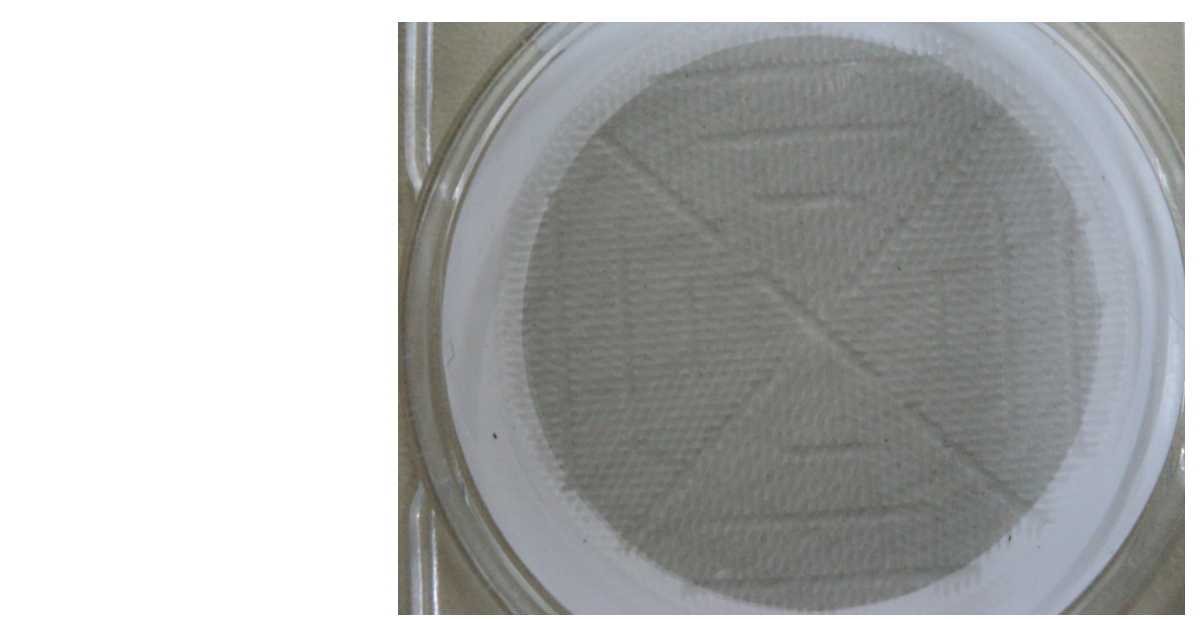

Figura 27. Acúmulo de material particulado em membrana de 47mm de Teflon® após coleta de 4 horas.

\subsection{Bioaerossóis}

Esta seção do texto apresenta os principais resultados para a determinação da concentração de contaminação biológica e, também, os resultados de identificação de microrganismos por coloração de Gram das bactérias.

\subsubsection{Análise da concentração de bioaerossóis}

Para a coleta de bioaerossóis por filtração em membranas, a contagem das colônias de fungos e bactérias presentes nas placas com meio de cultura era realizada após $48 \mathrm{~h}$ de incubação à temperatura ambiente, visto que esse foi o período em que elas cresciam de forma individual e em quantidade suficiente para a contagem.

O crescimento das colônias foi mais bem caracterizado com $48 \mathrm{~h}$ de incubação. A partir desse período, foi possível contar as colônias isoladas para o cálculo da concentração final de bioaerossóis. A Figura 28 mostra a sequência de incubação da membrana de $47 \mathrm{~mm}$ e a adoção do período de 48 h como ideal. 


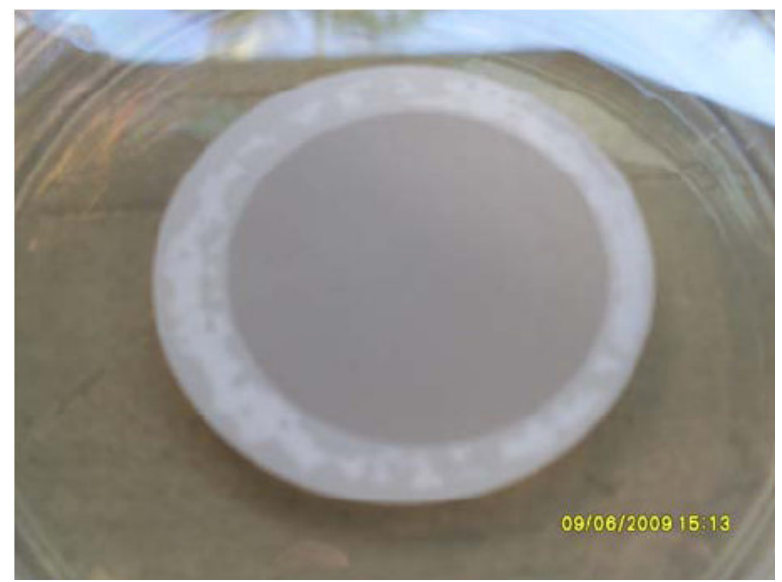

(a) Início da incubação

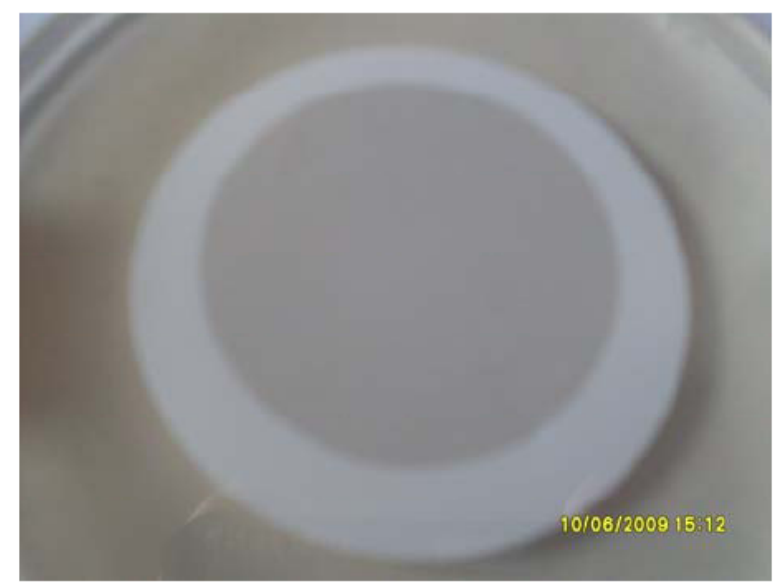

(b) $24 \mathrm{~h}$ de incubação

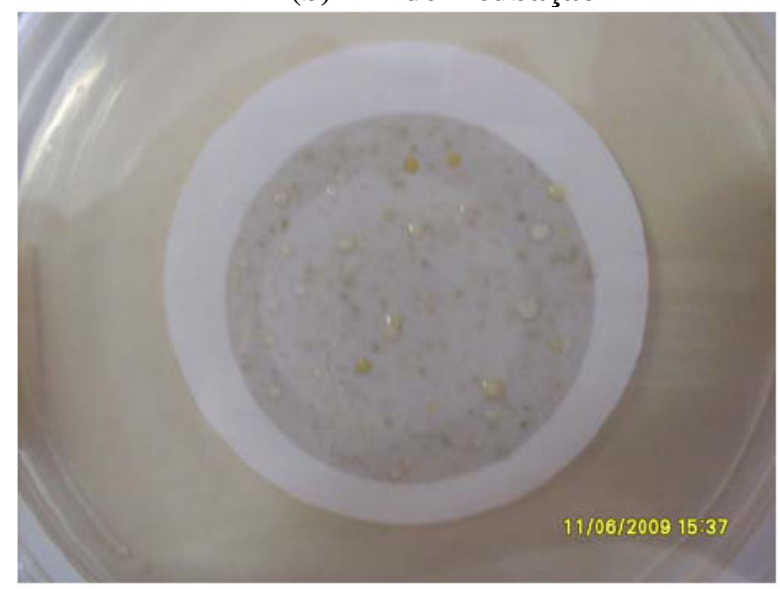

(d) 48 h de incubação

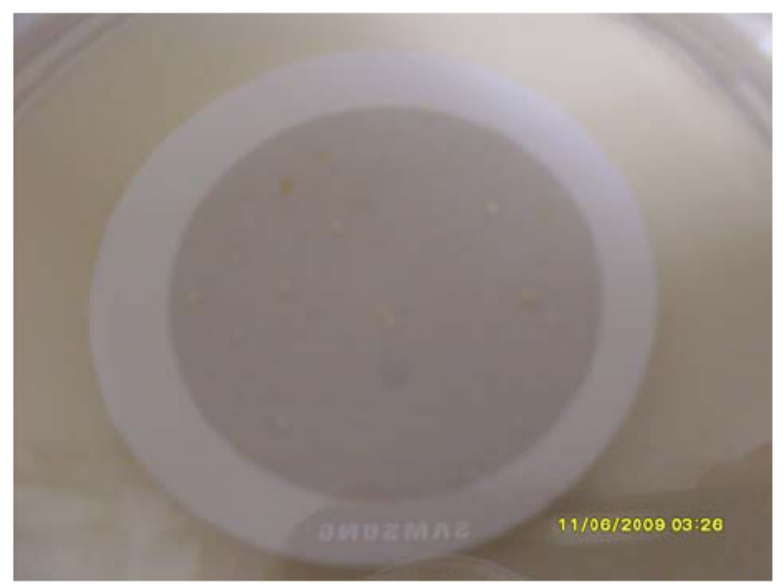

(c) 36h de incubação

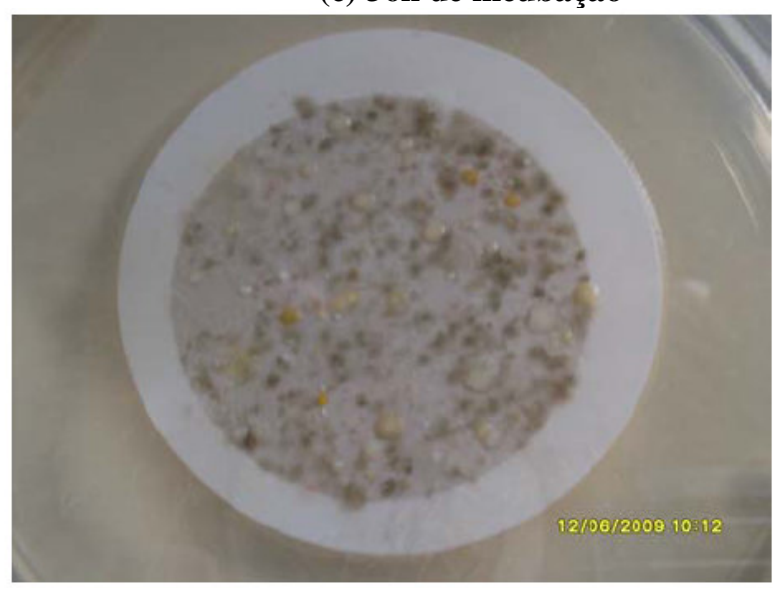

(e) $64 \mathrm{~h}$ de incubação

Figura 28. Desenvolvimento das colônias de bactérias em função do tempo de incubação para a coleta do dia 09/06/2009. (a) início da incubação; (b) 24 h; (c) 36 h; (d) 48h; (e) 64 h.

Foram testados dois períodos de filtração, sendo eles 60 e 120 minutos. Observou-se que o período de filtração não alterou de forma significativa a contagem final de colônias. Além disso, testes de vazão foram realizados, com valores de 600 e 1.000 L/h. Notou-se, 
também, que essa variação não gerou grandes variações na contagem final de colônias. Portanto, padronizou-se o tempo de coleta de 120 minutos, com uma vazão de $1.000 \mathrm{~L} / \mathrm{h}$.

Para a quantificação final da contaminação biológica, realizou-se uma soma da concentração de fungos com a de bactérias, resultando valores finais e, dessa forma, comparando-se com a norma RE/ANVISA ${ }^{\circ} 9$ e a RN02-2003. Elas estabelecem um limite de $750 \mathrm{UFC} / \mathrm{m}^{3}$ como indicação de pureza do ar para contaminantes biológicos. As Figuras 29 a 32 apresentam os resultados para a filtração com membrana de $47 \mathrm{~mm}$ em cada ambiente avaliado.

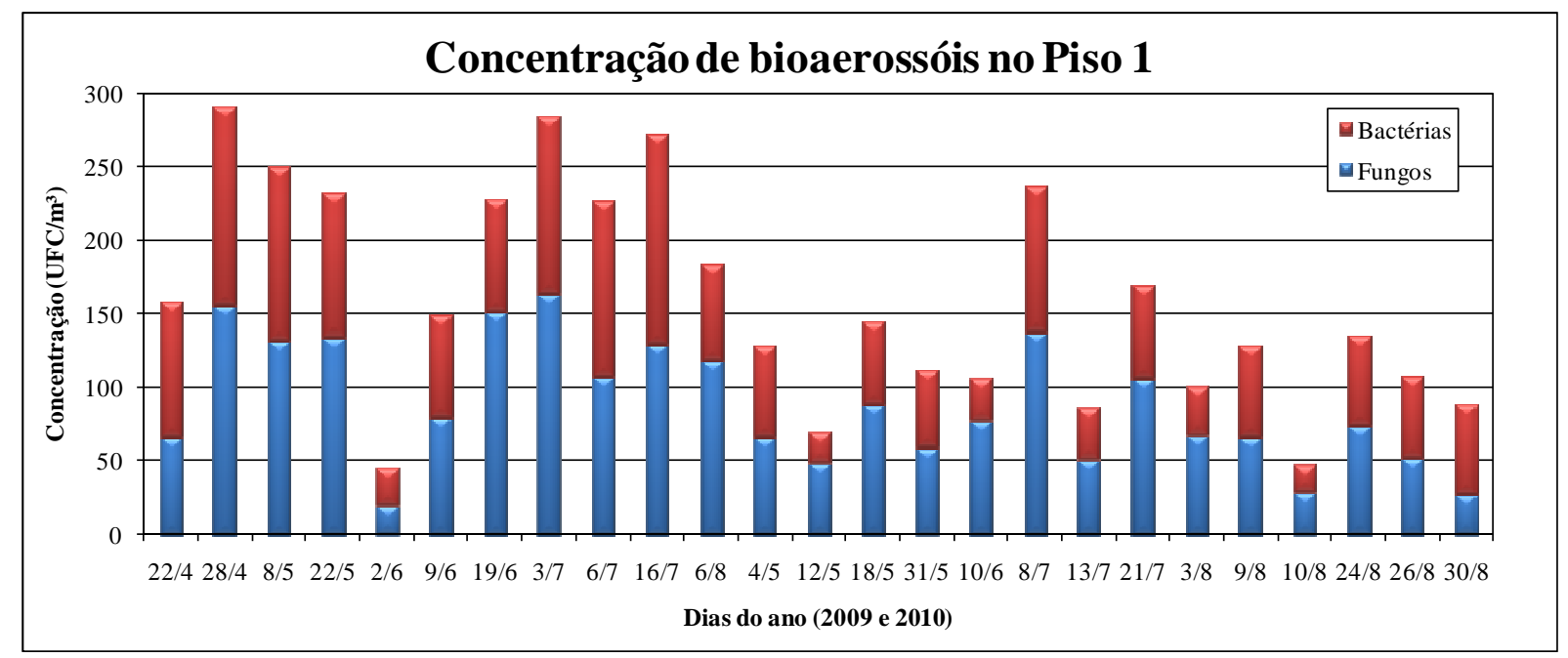

Figura 29. Contaminação biológica no Piso 1 com análise por filtração em membrana.

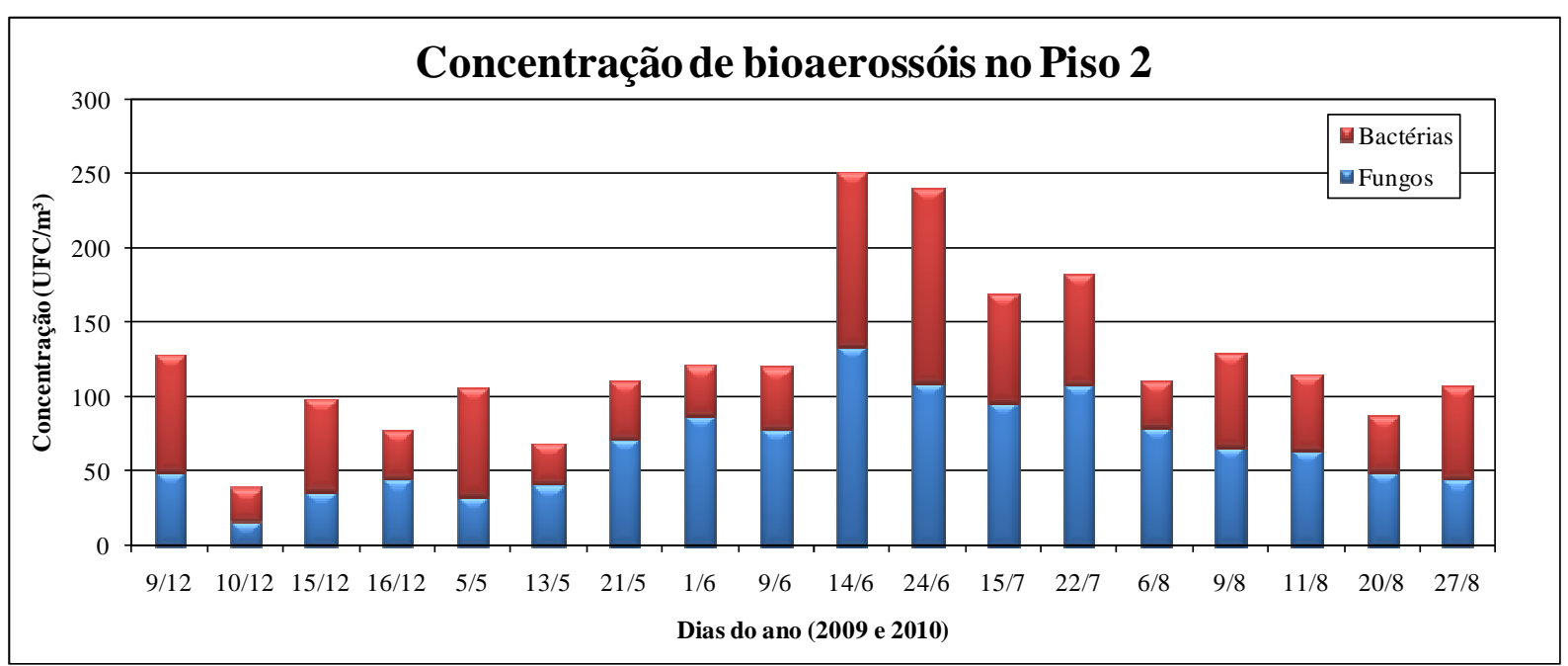

Figura 30. Contaminação biológica no Piso 2 com análise por filtração em membrana. 


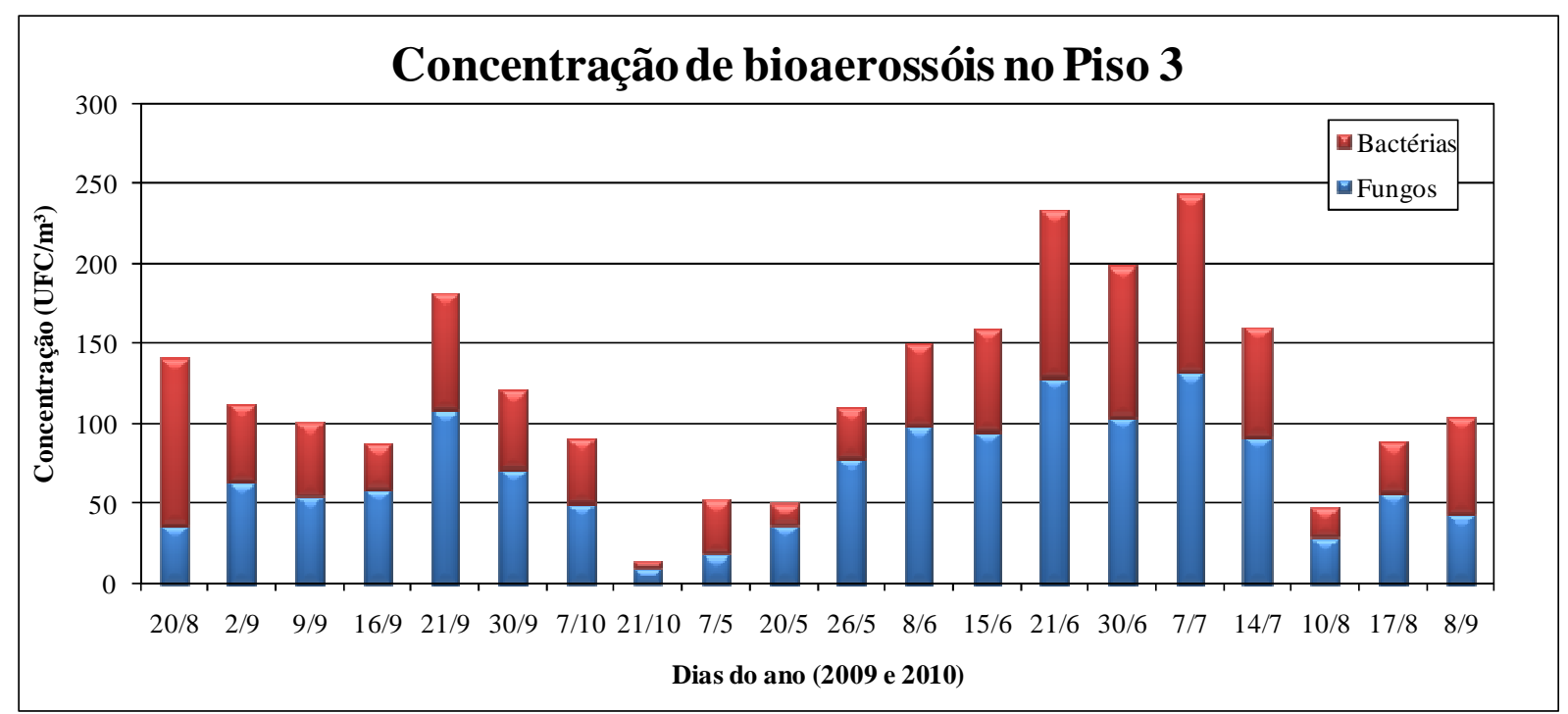

Figura 31. Contaminação biológica no Piso 3 com análise por filtração em membrana.

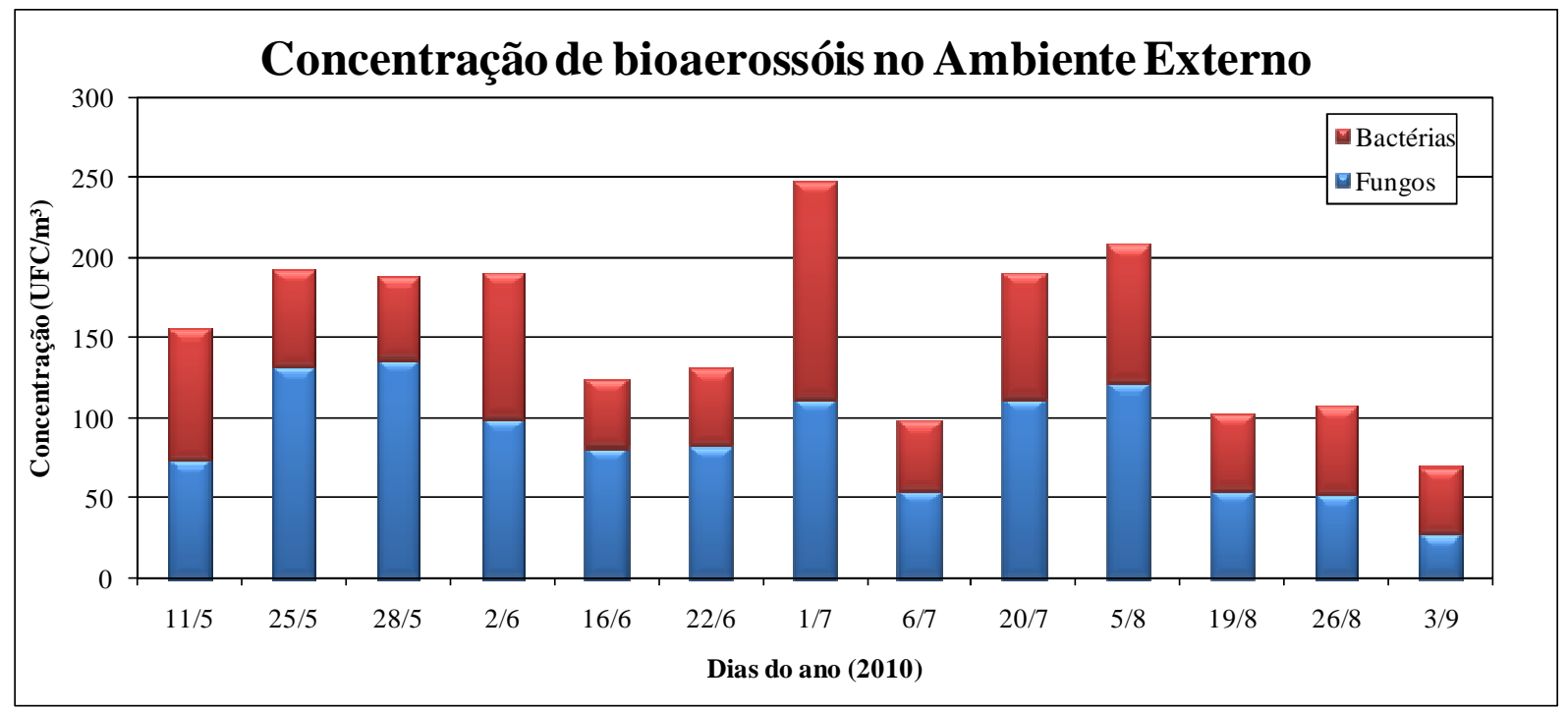

Figura 32. Contaminação biológica no ambiente externo com análise por filtração em membrana.

Encontram-se agrupado no Anexo III todos os valores relativos à concentração de bioaerossóis, para cada dia de coleta nos ambientes selecionados.

A RE/ANVISA nº de 2003 recomenda para contaminação biológica o Valor Máximo Recomendável (VMR) de $750 \mathrm{UFC} / \mathrm{m}^{3}$. A partir desse valor e os resultados apresentados nas Figuras anteriores, denota-se que não há inadequações quanto à contaminação biológica do ambiente. Para uma análise da relação entre a concentração interna e externa (I/E), o ideal seria a realização de medições ao mesmo tempo, mas isso não foi realizado devido à quantidade de material disponível. Mesmo assim, é possível notar que a maioria dos valores 
estão muito próximos, na faixa de 50 a $250 \mathrm{UFC} / \mathrm{m}^{3}$ no ambiente interno e 100 a $250 \mathrm{UFC} / \mathrm{m}^{3}$ no ambiente externo.

Mentese et al. (2009) realizaram estudos da concentração de bioaerossóis em nove bibliotecas na Turquia. Os valores encontrados estão na média de $113 \mathrm{UFC} / \mathrm{m}^{3}$ neste tipo de ambiente. Comparando esses resultados com os obtidos no presente estudo, observa-se que esses valores estão relativamente próximos e bem abaixo do recomendado pela ANVISA.

Já em Singapura, Obbard et al. (2000) elaboraram um estudo sobre a concentração de bioaerossóis em uma biblioteca. Os valores resultantes do monitoramento variaram na faixa de 800 a 3.000 UFC/m³ em média. Em comparação com o presente trabalho, esses resultados estão muito acima do encontrado e em desacordo com as normas vigentes no Brasil.

\subsubsection{Coloração de Gram das bactérias}

Algumas coletas foram reservadas para a análise das colônias de bactérias com a realização da coloração de Gram. O principal intuito desse método é a separação das bactérias em dois grupos: as Gram Positivas e as Gram Negativas. A partir dessa primeira identificação, outros testes poderão ser realizados para a identificação mais detalhada das bactérias, porém, para o projeto em questão, a coloração Gram já foi suficiente.

Constatou-se a presença de bacilos Gram positivos e bacilos Gram negativos, na maioria das amostras. Também se observou a presença de cocos gram positivos, que podem ser leveduras. As Figuras 33 e 34 apresentam os resultados obtidos com algumas das colônias submetidas ao processo. 


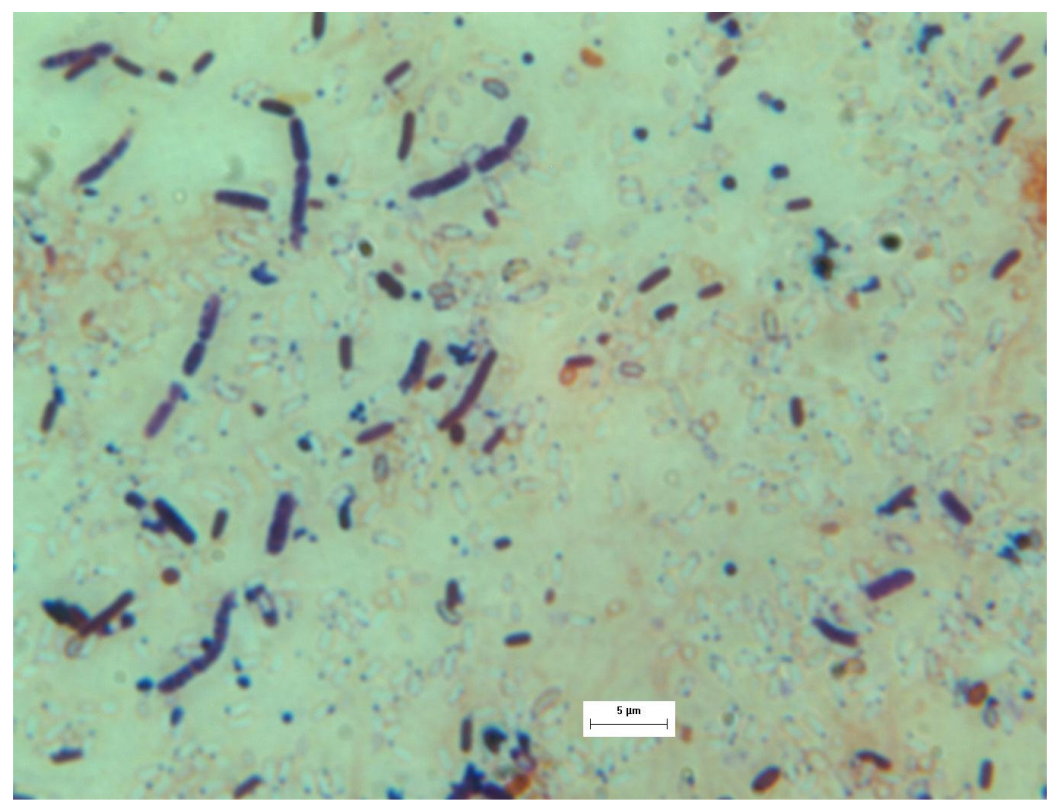

Figura 33. Presença de bacilos Gram positivos, em coleta do dia 07/10/2009; presença de esporos.

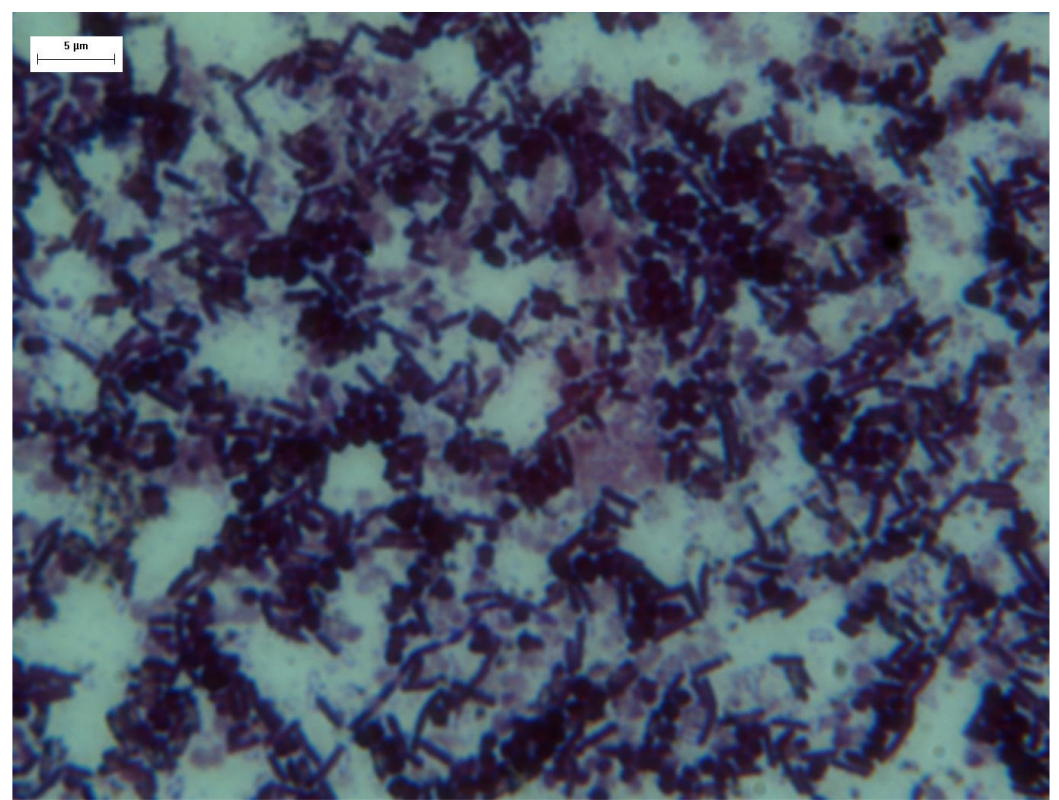

Figura 34. Presença de bacilos e cocos Gram positivos, em coleta do dia 21/10/2009.

Uma grande quantidade de bactérias gram-positivas encontra-se dispersa no ar, amplamente distribuídas em ambientes aquáticos e terrestres, sendo que muitos compõem a microbiota normal da pele e mucosas de humanos e de diversos animais (KONEMAN, 2001). Raramente esses microorganismos são prejudiciais, mas altas concentrações de bactérias no ar de ambientes fechados em relação aos encontrados no ar exterior têm sido utilizadas como indicadores de taxa de ocupação elevada, ventilação deficiente ou inadequada manutenção de edifícios (HEINSOHN e YANG, 2007). 
Dentre os bacilos gram-positivos mais comumente isolados em laboratórios, destacamse os gêneros Bacillus, Corynebacterium e Lactobacillus. A virulência dos bacilos grampositivos é muito variável, podendo ser comuns no ambiente e não causar problemas ou serem patógenos oportunistas (KONEMAM, 2001). Outro gênero de bacilos gram-positivos de grande importância é o gênero Mycobacterium, que engloba espécies causadoras da tuberculose, micobacteriose (Mycobacterium tuberculosis, complexo M. avium e outros) e lepra (Mycobacterium leprae), as quais são adquiridas normalmente pela inalação dos microrganismos presentes no ar (HEINSOHN e YANG, 2007).

\subsection{Ruído}

O decibelímetro DEC-490 descrito anteriormente foi utilizado para as medições de ruído em todos os pisos da Biblioteca Municipal e também na parte externa. Com o auxílio da função de armazenamento de dados do equipamento, amostragens com duração de 4 horas foram realizadas para posterior análise dos resultados. Os dados relativos ao ruído no ambiente foram aferidos e salvos pelo instrumento em intervalos de 30 segundos.

A norma NBR 10152 da ABNT de 1987 estipula que, para bibliotecas, o nível de ruído deve estar situado na faixa de 35 e $45 \mathrm{~dB}(\mathrm{~A})$. Como o limite mínimo de detecção do equipamento é de $30 \mathrm{~dB}(\mathrm{~A})$, tornou-se possível a comparação desses valores com a norma. A Figura 35 apresenta o perfil de ruído resultante de uma amostragem com duração de 4 horas, com a exibição dos dados armazenados no intervalo de 30 segundos. Com o intuito de analisar detalhadamente a distribuição dos valores de ruído nos ambientes monitorados, gráficos do tipo "box-plot" foram elaborados e encontram-se apresentados nas Figuras 36 a 39 em cada local de análise. Dessa forma, é possível identificar os valores médios das medições, bem como os limites máximos e mínimos. 


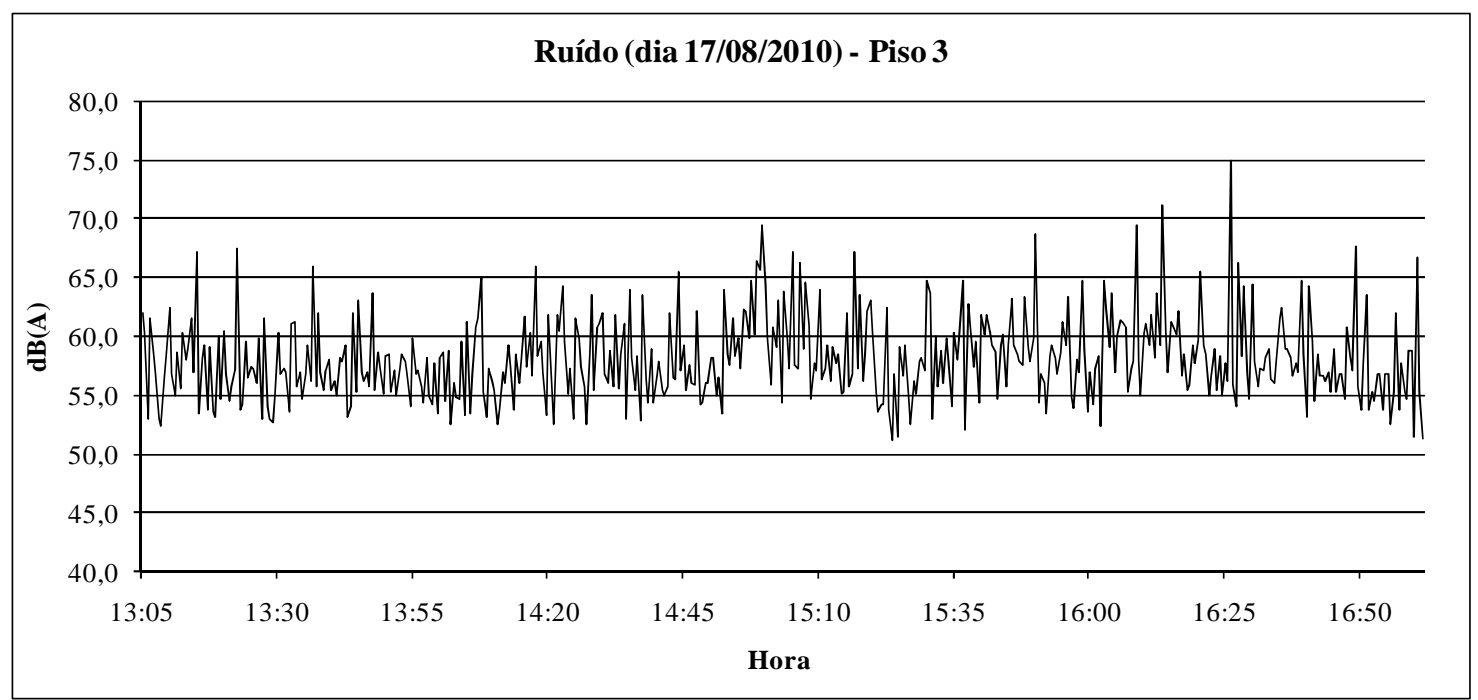

Figura 35. Perfil de ruído em dB(A) durante 4 horas de coleta no Piso 3 no dia 17/08/2010.

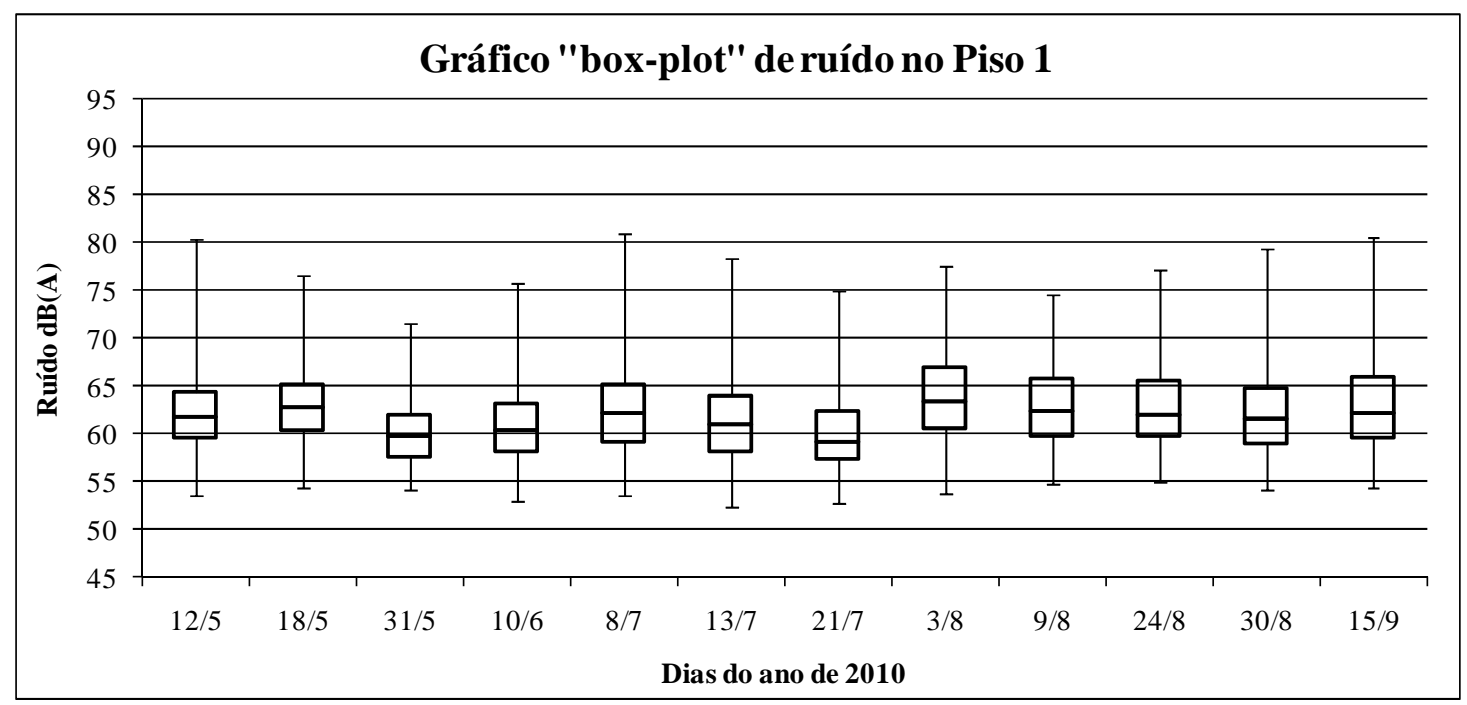

Figura 36. Gráfico de ruído em dB(A) no Piso 1 para $o$ ano de 2010.

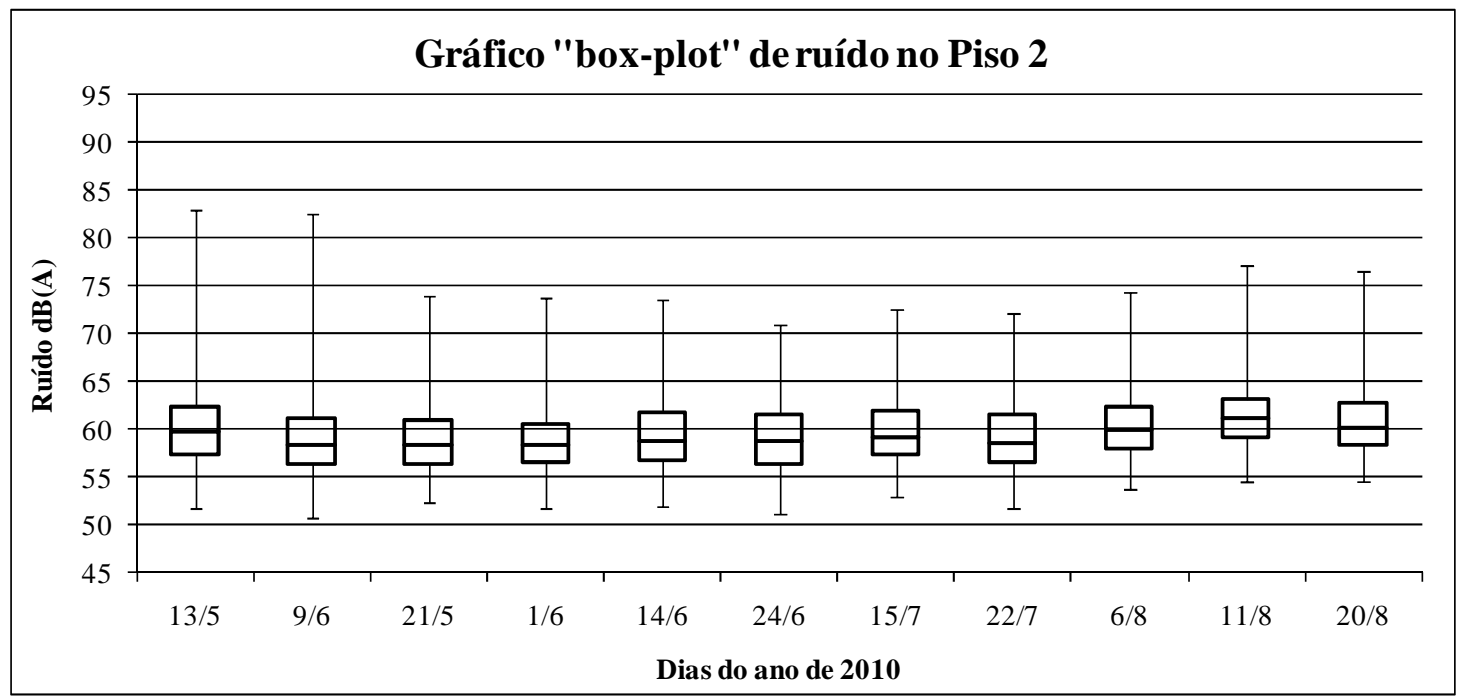

Figura 37. Gráfico de ruído em dB(A) no Piso 2 para o ano de 2010. 


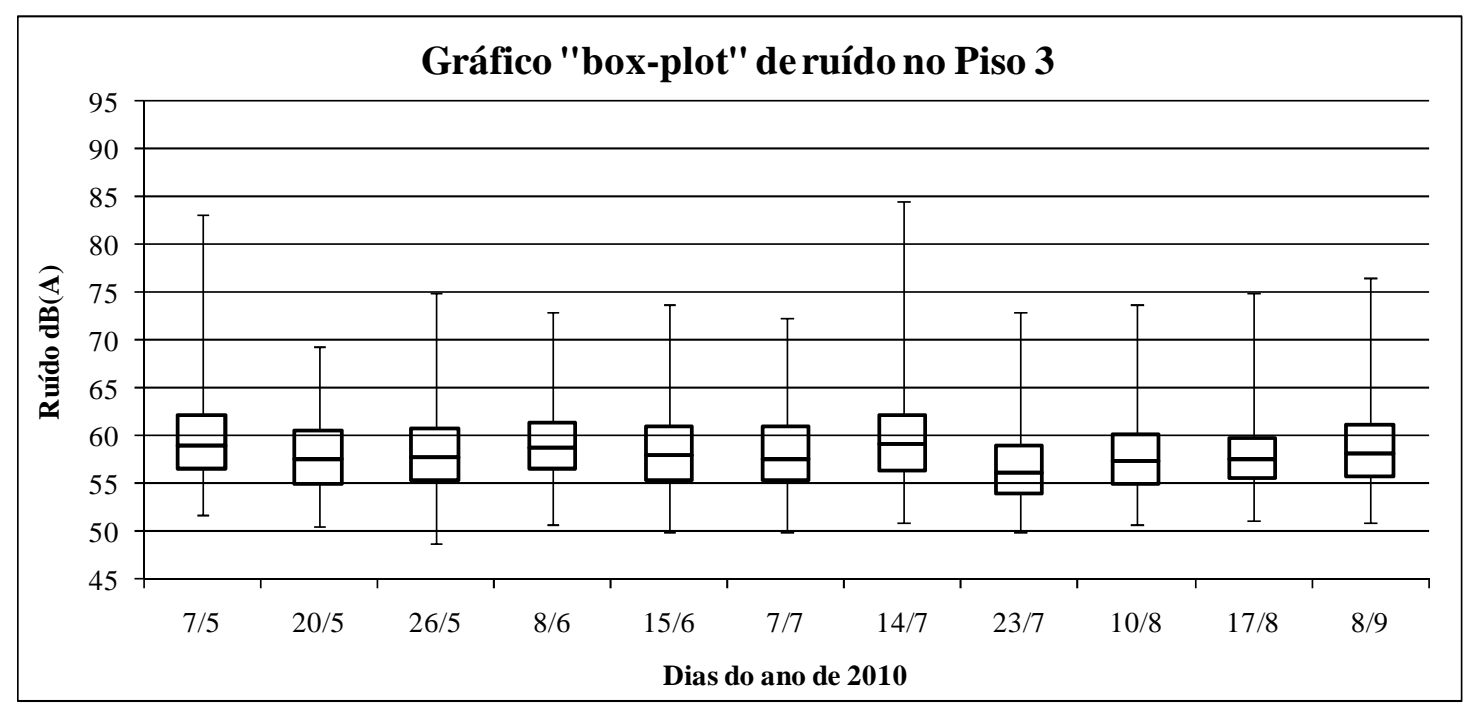

Figura 38. Gráfico de ruído em dB(A) no Piso 3 para o ano de 2010.

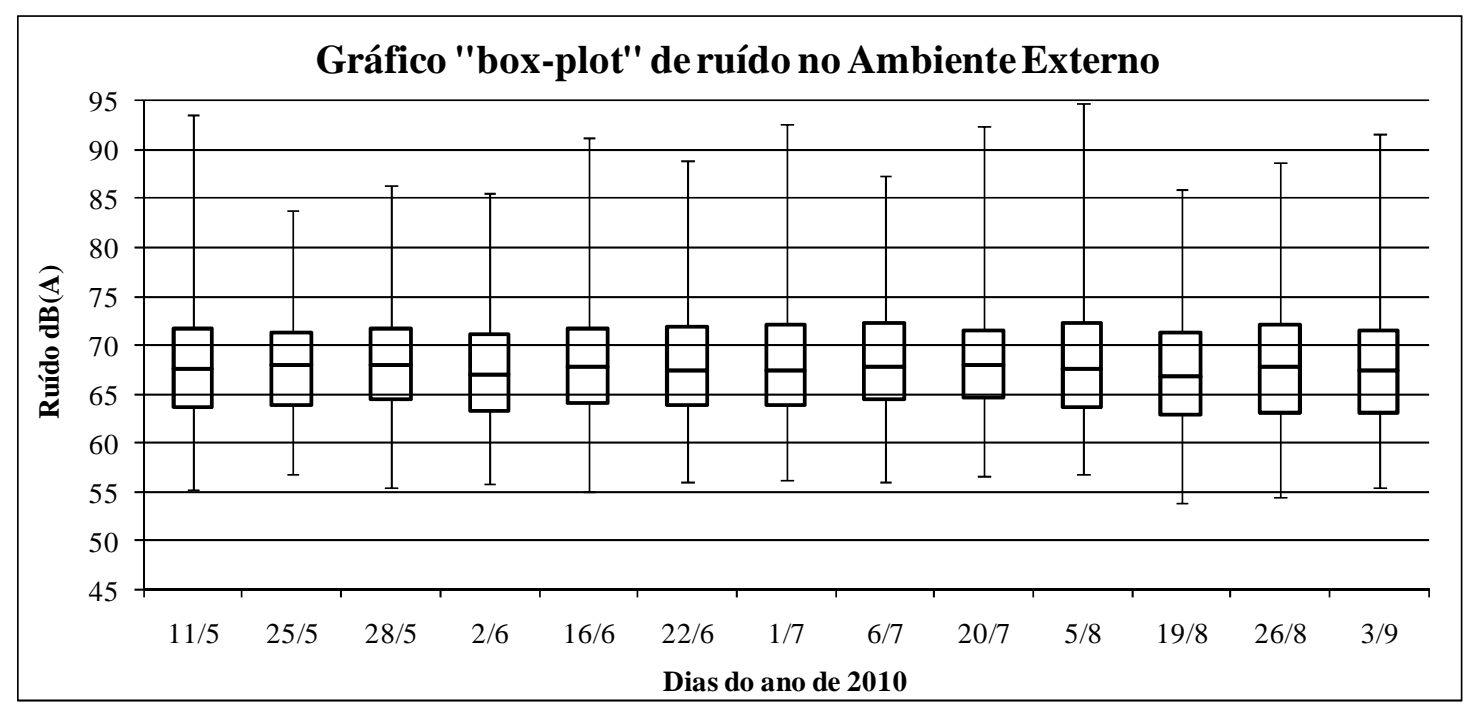

Figura 39. Gráfico de ruído em dB(A) no Ambiente Externo para o ano de 2010.

O Anexo IV traz todos os dados de ruído monitorados ao longo dos anos de 2010 nos ambientes escolhidos.

Os resultados apresentados acima demonstram que o ruído no ambiente interno não obedece à norma da ABNT. Além disso, foi possível observar que não há um isolamento adequado do ruído externo, já que há uma diferença da ordem de $10 \mathrm{~dB}(\mathrm{~A})$ entre os valores médios encontrados dentro e fora da Biblioteca. A Figura 39 mostra que, em média, os valores de ruído da porção externa encontram-se majoritariamente distribuídos na faixa de 65 a $70 \mathrm{~dB}(\mathrm{~A})$. Enquanto isso, nas Figuras 36, 37 e 38 os valores estão predominantemente distribuídos na faixa de 55 a $65 \mathrm{~dB}(\mathrm{~A})$. Sendo assim, observa-se a falta de um isolamento 
acústico adequado para a Biblioteca, pois a influência do ruído externo no interior do prédio é elevada.

Outro ponto importante a ser considerado é em relação aos valores máximos encontrados. Pelo fato da Biblioteca estar situada em um trajeto ascendente da Avenida São Carlos, muitos veículos passam pelo local com altas rotações no motor, contribuindo excessivamente para os altos índices de ruído. No ambiente externo, com valores representados na Figura 39, em muitos momentos, há uma extrapolação da faixa de $90 \mathrm{~dB}(\mathrm{~A})$, mostrando a ocorrência de um pico elevado de ruído em cada amostra. Devido às características da Biblioteca, em muitos eventos, os picos podem ser observados no ambiente interno, atingindo a faixa de $80 \mathrm{~dB}(\mathrm{~A})$, observando as Figuras 36, 37 e 38. Esses picos são provenientes da passagem de carros na Avenida São Carlos. Quando carros, caminhões, motos e ônibus passam na Avenida, logo após a abertura do semáforo próximo à biblioteca, o arranque dos motores é elevado, resultando nesses picos de ruído evidenciados.

A partir da análise desses valores e de acordo com as observações propostas, o ruído está inadequado para o ambiente estudado e os dados comprovam uma das principais queixas do local. O ruído é um fator que interfere diretamente na saúde do ser humano e também está relacionada indiretamente com outros fatores relativos à qualidade do ar em ambientes internos.

No estado brasileiro do Rio Grande do Norte, Leite et al. (1997) realizaram um monitoramento dos níveis de ruído em oito bibliotecas. Os valores médios resultantes encontram-se na faixa de 60 a $75 \mathrm{~dB}(\mathrm{~A})$, evidenciando um problema nestes locais também. Há registros de valores máximos da ordem de $88 \mathrm{~dB}(\mathrm{~A})$. Esses dados são semelhantes aos encontrados na Biblioteca Pública Amadeu Amaral e configuração uma inadequação de isolamento acústico.

\subsection{Intensidade luminosa}

A coleta de dados relativos à taxa de iluminação dos pisos da Biblioteca ocorreu no período da tarde. A Tabela 17 abaixo destaca os valores encontrados nas medições em cada ponto anteriormente descrito, os parâmetros inseridos na Equação (1) e o resultado final do cálculo da Iluminância Média (IM), em LUX, para cada piso.

Foi selecionado o período da tarde para a realização das medidas, visto que no período da manhã não há incidência solar direta pelas janelas. No período da tarde, constata-se tal 
ocorrência e, para evidenciar se essa incidência influi nas condições de iluminação interior, o período da tarde foi escolhido para a realização das amostragens.

A NBR 5413 informa os valores recomendados de iluminação para cada tipo de ambiente e sua atividade predominante em cada local. Para uma sala de leitura da Biblioteca, a iluminância recomendada deve ser de 500 LUX, enquanto para o recinto das estantes, ela deve ser de 300 LUX. É importante salientar que, na Biblioteca Municipal Amadeu Amaral, a sala de leitura é encontra-se alocada juntamente com o recinto das estantes.

Tabela 17 - Dados de coleta de iluminância em cada Piso.

\begin{tabular}{cccc}
\hline Ponto de coleta & Piso 1 & Piso 2 & Piso 3 \\
\hline p-1 (LUX) & 108 & 91 & 117 \\
p-2 (LUX) & 1730 & 387 & 188 \\
q-1 (LUX) & 163 & 118 & 217 \\
q-2 (LUX) & 2320 & 4660 & 266 \\
t-1 (LUX) & 136 & 174 & 166 \\
t-2 (LUX) & 157 & 163 & 190 \\
t-3 (LUX) & 146 & 97 & 113 \\
t-4 (LUX) & 125 & 113 & 76 \\
r-1 (LUX) & 177 & 166 & 270 \\
r-2 (LUX) & 96 & 66 & 267 \\
r-3 (LUX) & 167 & 156 & 265 \\
r-4 (LUX) & 158 & 44 & 238 \\
P (LUX) & 919 & 239 & 153 \\
Q (LUX) & 1242 & 2389 & 242 \\
T (LUX) & 141 & 137 & 136 \\
R (LUX) & 150 & 108 & 260 \\
N & 5 & 5 & 11 \\
M & 10 & 10 & 3 \\
IM (LUX) & 252 & 305 & 244 \\
\hline
\end{tabular}

A última linha da Tabela 17 apresenta o valor respectivo de Iluminância Média (IM), em LUX, para cada piso em análise. Comparando esses valores com o recomendado pela ABNT, denota-se uma inadequação da taxa de iluminação nos três pisos. A norma recomenda valores na faixa de 300 a 500 LUX, de acordo com o tipo de atividade desenvolvida em cada ambiente. Como a Biblioteca conta com área de leitura nos Pisos 2 e 3, o valor recomendado pela norma é de 500 LUX. A partir das medidas realizadas no ambiente, observa-se que os resultados estão em desacordo com a norma, sendo a IM para o Piso 2 de 305 LUX e para o Piso 3 de 244 LUX. No Piso 1, não há uma área reservada para leitura, porém, é um local destinado à organização do acervo da Biblioteca. Tendo em vista que tipo de atividade 
realizada requer prática de leitura, o índice recomendado pela ABNT é de 500 LUX, e a IM para o Piso 1 é de 252 LUX.

\subsection{Análise de gás carbônico}

A contaminação química por gás carbônico foi avaliada a partir da determinação da concentração deste gás no ambiente interno e comparada com a situação do ambiente externo. As Figuras 40 a 43 apresentam gráficos do tipo "box-plot" resultantes das medições realizadas na Biblioteca.

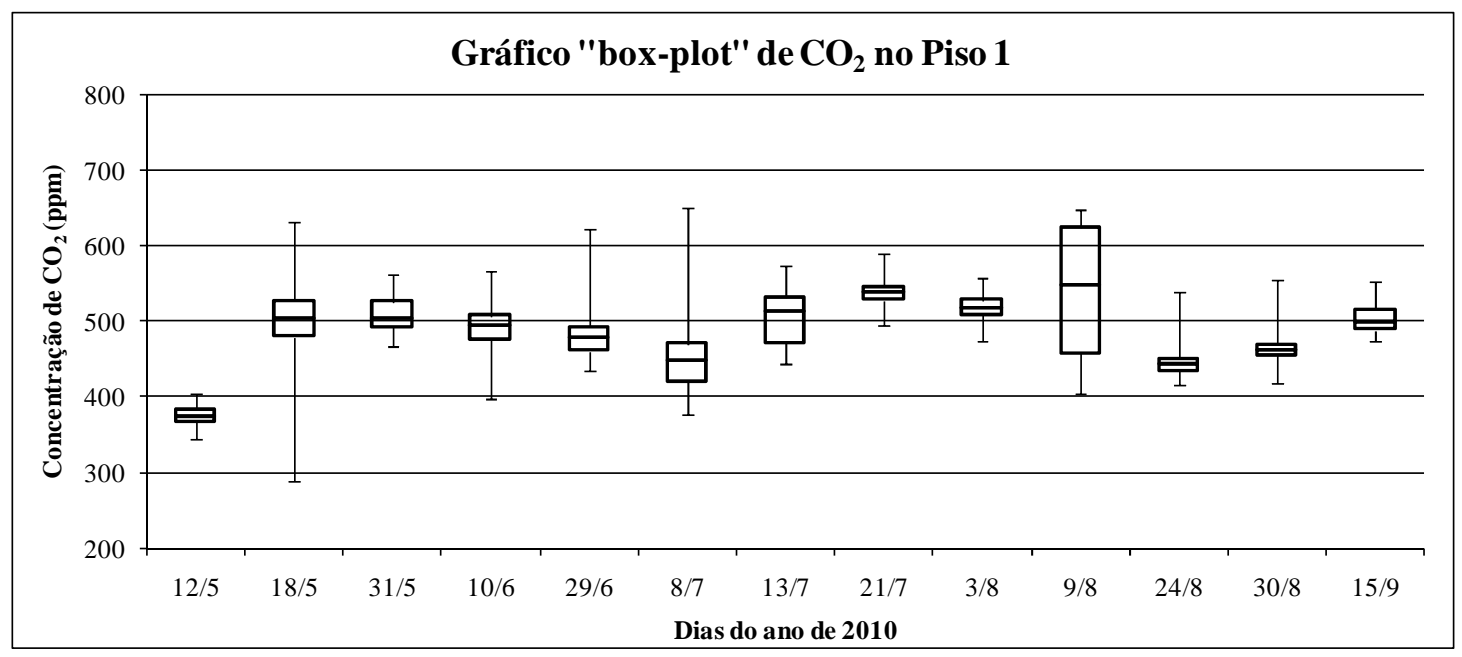

Figura 40. Concentração de gás carbônico no Piso 1 para o ano de 2010.

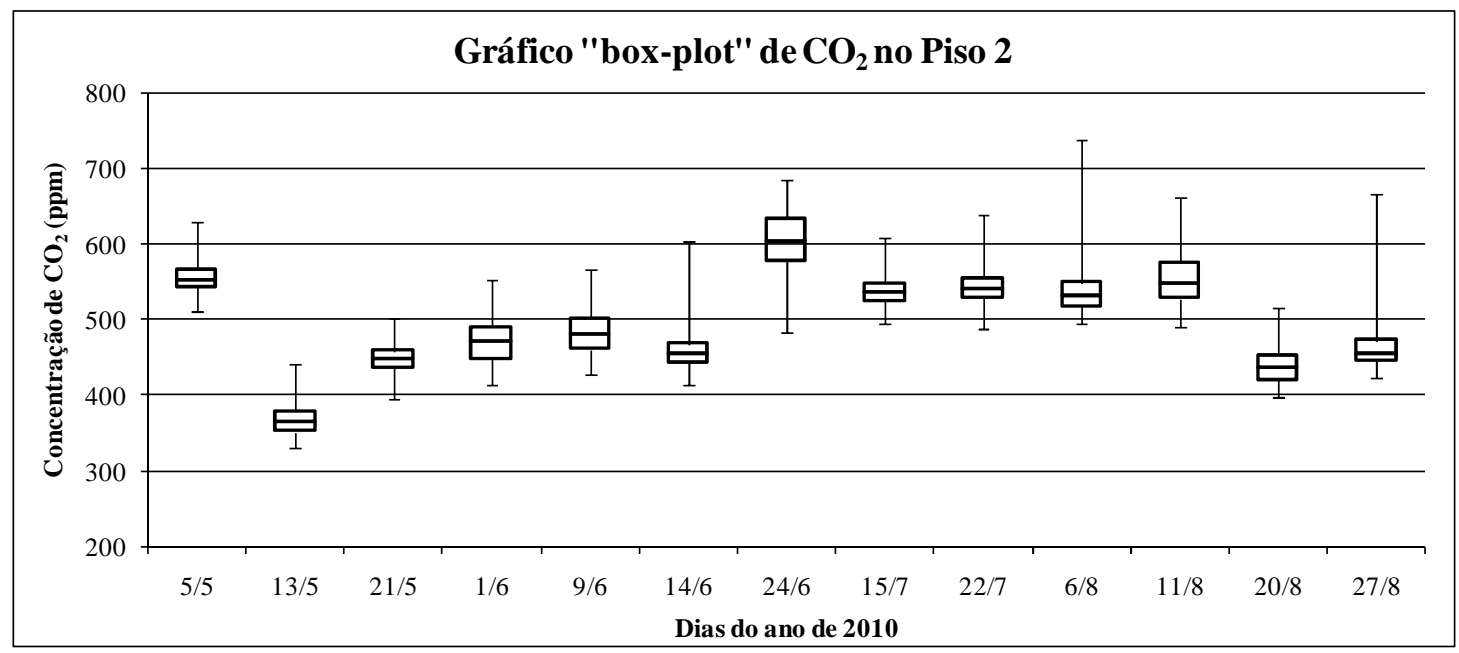

Figura 41. Concentração de gás carbônico no Piso 2 para o ano de 2010. 


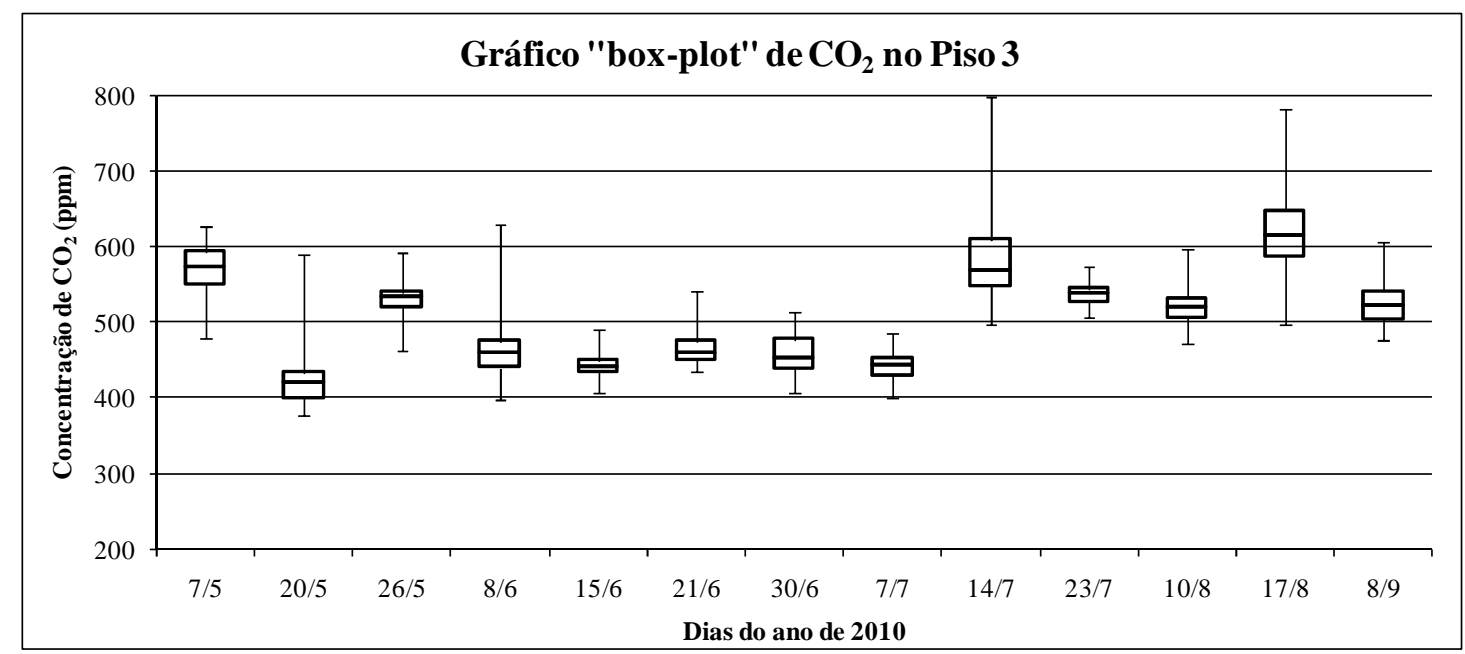

Figura 42. Concentração de gás carbônico no Piso 3 para o ano de 2010.

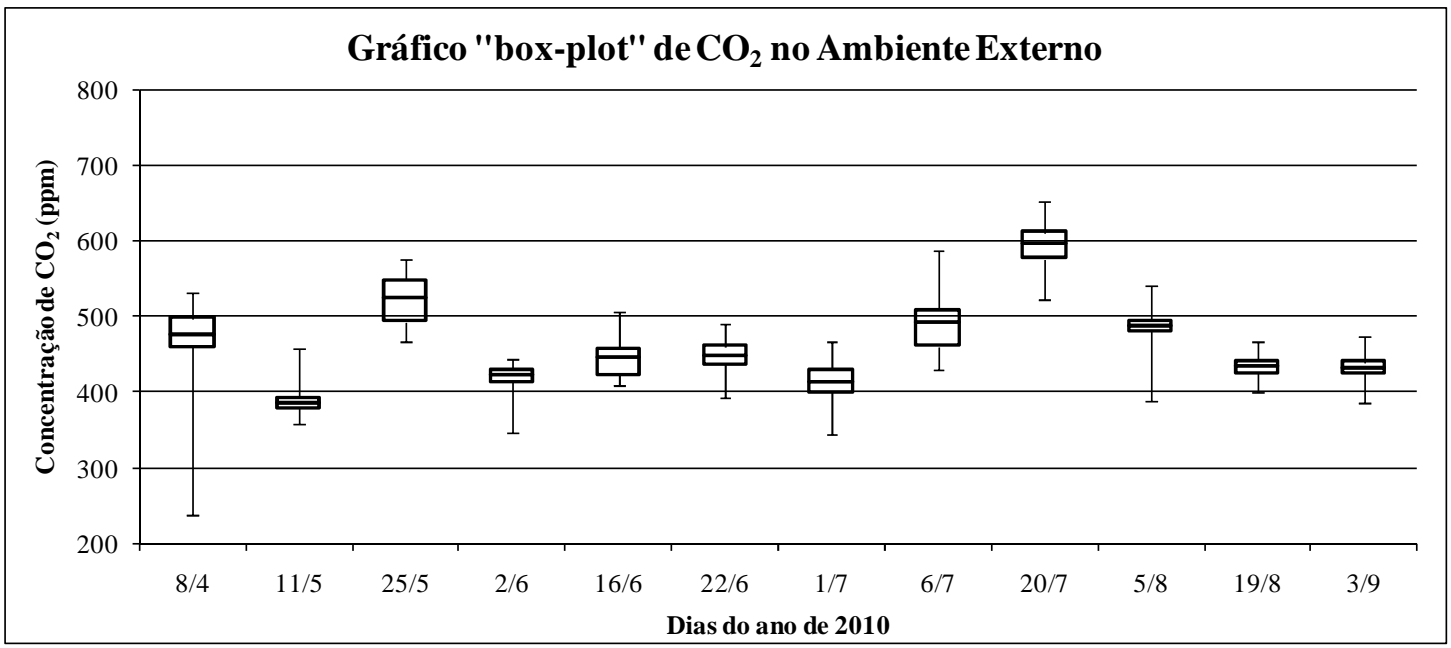

Figura 43. Concentração de gás carbônico no Ambiente Externo para o ano de 2010.

No Anexo V estão apresentados todos os dados relativos ao monitoramento da concentração de dióxido de carbono nos ambientes selecionados.

Para a avaliação da concentração de gás carbônico, foram utilizadas a RE/ANVISA n9 de 2003 e a RN 02 de 2003 da ABRAVA. A primeira estipula um máximo de 1.000 ppm no ambiente interno, enquanto a segunda faz uma correlação entre as concentrações interna e externa. A ABRAVA sugere que a concentração de gás carbônico no ar interior deve ser, no máximo, 700 ppm maior em comparação com a concentração no ambiente exterior.

As Figuras acima destacam os resultados obtidos com as medições e elas comprovam que os três pisos analisados estão de acordo com as recomendações da ANVISA e da ABRAVA. Nos três pisos, a concentração não excedeu em nenhuma medição o valor de 800 ppm. Observa-se a ocorrência de alguns picos de concentração próximos a 800 ppm. É 
importante analisar esse acontecimento e correlacionar com o restante dos dados para o mesmo dia, pois o analisador de gás carbônico é muito sensível às variações e a proximidade de alguma pessoa no ponto de coleta pode ocasionar um pico de concentração. Mesmo com a existência desses pontos elevados, eles não ultrapassaram o valor recomendado pela ANVISA. Já em relação à ABRAVA, os Pisos estão adequados, pois a concentração média de gás carbônico no ambiente externo se manteve na faixa de 400 a 600 ppm e, dessa forma, a concentração aceitável no ambiente interno seria de 1.100 a 1.300 ppm.

Assim, os Pisos estão em acordo com ambas as normas de contaminação por gás carbônico e tal fato pode ser esclarecido pela inexistência de sistema de condicionamento de ar. Como a Biblioteca possui ventilação natural, torna-se previsível a proximidade dos valores de concentração de gás carbônico nos ambientes internos e externo.

\subsection{Taxa de ocupação}

A ABRAVA faz recomendações sobre a taxa de ocupação de ambientes interiores a partir de uma relação entre área construída e o número de pessoas no local. Para o caso da Biblioteca Pública Amadeu Amaral, é importante salientar que, nos Pisos 2 e 3, a maior parcela de ocupantes possui um período de 5 a 10 minutos de permanência no local. A quantidade de pessoas que vão a estes pisos para realizar apenas a locação ou devolução de livros é elevada. Essas considerações são importantes para a análise da taxa de ocupação do local, pois há um grande número de pessoas que circulam pelo ambiente, porém, não acontecendo ao mesmo tempo. Sendo assim, duas análises foram realizadas em relação a este tópico.

Primeiramente, foi realizado um levantamento da quantidade de pessoas que circularam no Piso 3 durante uma parte do dia. Durante oito horas de um dia, foi monitorada a quantidade de pessoas que circularam no ambiente, considerando os próprios funcionários, usuários com tempo de permanência inferior a 15 minutos e leitores que permaneceram por períodos de tempo superiores a 15 minutos.

No período da manhã, das $8 \mathrm{~h}$ às $12 \mathrm{~h}$, houve a ocorrência de 43 pessoas no local, tanto para locação ou devolução, quanto para estudo e leitura no local e incluindo os funcionários. No período da tarde, das $14 \mathrm{~h}$ às $18 \mathrm{~h}, 63$ pessoas circularam no local sob essas mesmas condições anteriormente explicitadas. Portanto, em 8 h de observação, 106 pessoas passaram pelo local ou permaneceram lendo ou estudando. 
O Piso 3 possui uma área aproximada de $285 \mathrm{~m}^{2} \mathrm{e}$, de acordo com a norma, a taxa de ocupação máxima é de 57 pessoas. No Piso 3, foram registradas 106 pessoas durante as $8 \mathrm{~h}$ de monitoramento, porém, esses ocupantes não permaneceram no recinto ao mesmo tempo.

A Tabela 2 da RN02 de 2003 da ABRAVA apresenta o conceito de Densidade de Ocupação Esperada. Este dado é referente ao total da área passível de ocupação e este é o valor considerado para o cálculo da taxa de ocupação de um lugar. A partir desse ponto de vista, foi realizada uma análise em cada piso sobre a capacidade de ocupação de sua respectiva área.

No Piso 1, há uma área construída de $134,4 \mathrm{~m}^{2}$ e, considerando o número de cadeiras e mesas do local, uma densidade de 26 pessoas. Este é o número que pode ser suportado nesse piso, de acordo com o número de cadeiras para os funcionários. Para esta área, a recomendação máxima é de 26 pessoas de acordo com a norma. Sendo assim, observa-se que a densidade de ocupação está no limite para o piso em questão. Porém, é importante salientar que o local possui essa capacidade máxima de ocupação, no entanto, não é sempre que o local é completamente utilizado. Esta é uma sala de reunião também, com uma mesa e cadeiras para todos os participantes. Apesar de o resultado estar no limite recomendado pela norma, a ocupação real não atinge o valor máximo estipulado para o local. Outra ressalva válida é que o cálculo da densidade de ocupação do local foi realizada após a mudança do setor de informática, portanto, para uma quantidade menor de pessoas no local.

Em relação ao Piso 2, de acordo com uma análise das cadeiras disponíveis para espera, estudo e consulta à internet, a ocupação máxima do local é de 50 pessoas. Segundo a norma, ocupação máxima em uma área de $127,5 \mathrm{~m}^{2}$ é de 25 pessoas. Considerando esses valores, se o Piso 2 estiver completamente ocupado, o ambiente em questão estaria em desacordo com a ABRAVA, pois a sua área passível de ocupação é maior do que o recomendado. Para este piso, é importante salientar que há um fluxo intenso de pessoas ao Acessa São Paulo, que é o posto de internet gratuita. No acervo infantil, há um fluxo considerável de pessoas que permanecem por, no máximo, 5 minutos. Porém, neste ambiente, não há uma permanência considerável de pessoas para estudo e leitura.

Por fim, no Piso 3, a ocupação máxima, considerando a disposição de cadeiras, mesas e poltronas, é de 56 pessoas. Este piso é o que possui o maior fluxo de pessoas, tanto para estudo e leitura, quanto para empréstimo e devolução de livros. A ABRAVA recomenda para o total de 57 pessoas como densidade de ocupação esperada. Ao comparar os valores, nota-se 
que eles encontram-se muito próximos. Assim, o piso está adequado perante a norma, mas é importante avaliar essa situação com cautela, pois a densidade de ocupação real se encontra muito próxima da sugerida.

A Tabela 18 apresenta um resumo dos valores e condições acima destacados para a avaliação da taxa de ocupação dos pisos da Biblioteca Amadeu Amaral.

Tabela 18 - Avaliação da densidade de ocupação em cada piso.

\begin{tabular}{cccc}
\hline & Piso 1 & Piso 2 & Piso 3 \\
\hline $\begin{array}{c}\text { Área }\left(\mathbf{m}^{2}\right) \\
\text { Densidade de Ocupação Desejada } \\
\text { (RN02-2003 ABRA VA) }\end{array}$ & 134,4 & 127,5 & 285 \\
$\begin{array}{c}\text { Densidade de Ocupação Real } \\
\text { (Capacidade máxima) } \\
\text { Situação }\end{array}$ & 26 & 25 & 57 \\
\hline
\end{tabular}

\subsection{Taxa de ventilação}

De acordo com a metodologia descrita acima, adaptada de Heinsohn e Cimbala (2003), efetuou-se a análise da taxa de ventilação no Piso 1 da Biblioteca Amadeu Aramal. O monitoramente teve início antes da inserção de gás carbônico com o cilindro, com a finalidade de serem observadas as condições padrões do local. Após a estabilização das medidas, foram fechadas todas as janelas e portas e foi liberada uma quantidade de gás proveniente do cilindro. Houve uma mistura do ar interior da sala com o auxílio de um ventilador e, após atingir um pico superior a 1.800 ppm, as janelas e portas foram abertas. Este procedimento foi realizado duas vezes, denominadas Amostras 1 e 2, no período da manhã do dia 20/11/2010.

As Figuras 44 e 45 apresentam os gráficos resultantes do monitoramento da concentração de gás carbônico durante a realização do experimento. 


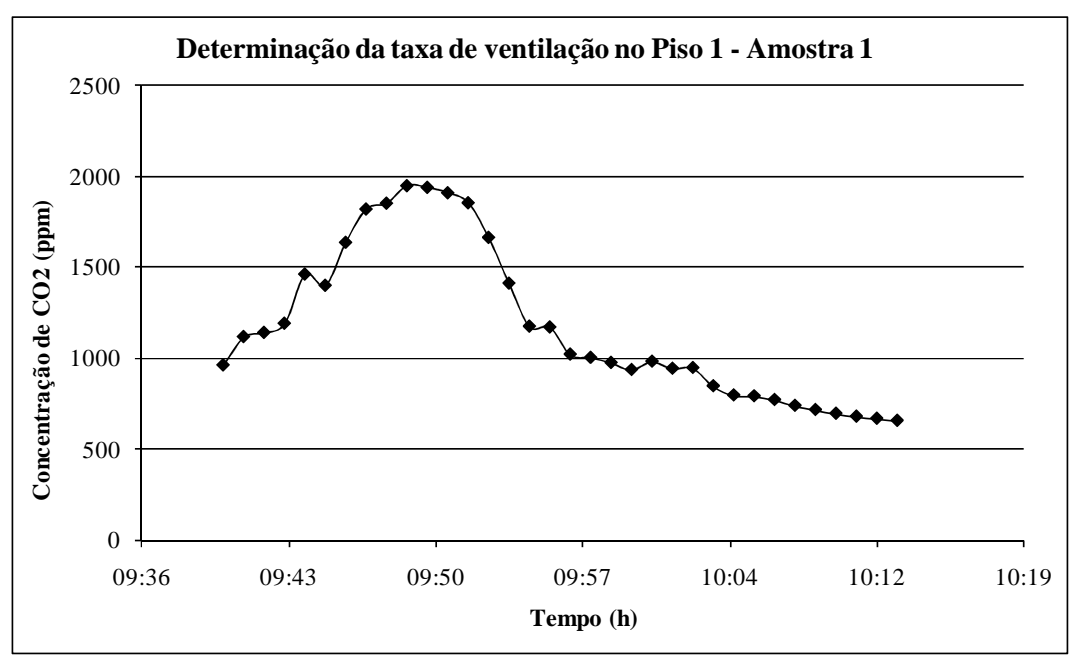

Figura 44. Concentração de gás carbônico para determinação da taxa de ventilação; Amostra 1.

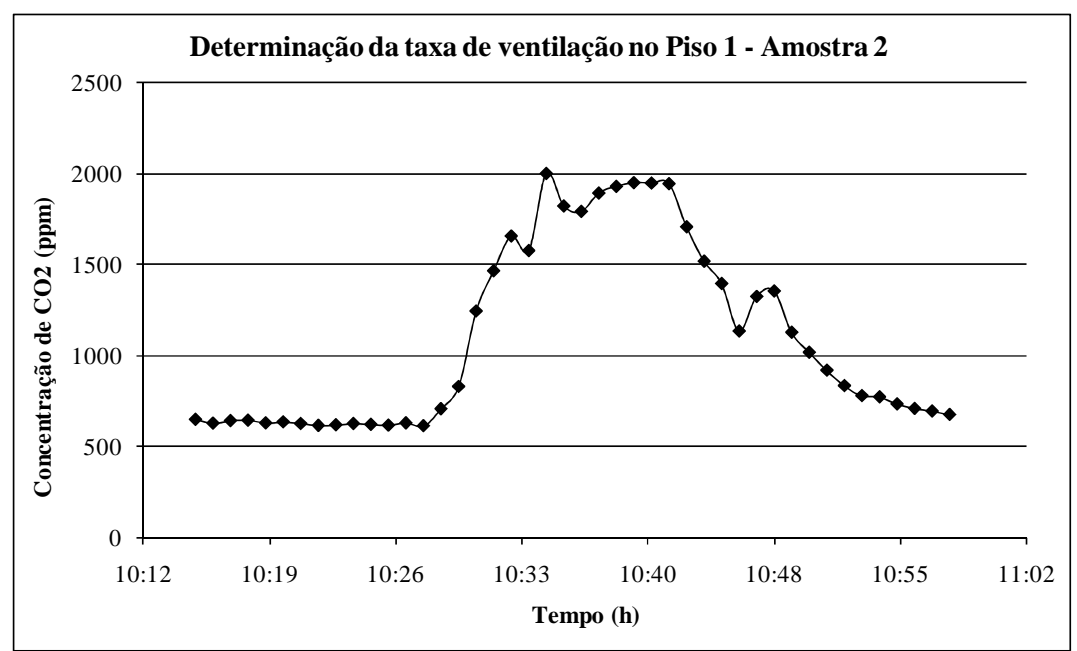

Figura 45. Concentração de gás carbônico para determinação da taxa de ventilação; Amostra 2.

A Equação (7) descrita anteriormente foi utilizada para a determinação da taxa de ventilação, em função do tempo de decaimento da concentração e a concentração de gás carbônico que entra no ambiente. O volume da sala foi estimado em 403,2 $\mathrm{m}^{3}$ e inserido na equação.

A Tabela 19 reúne os valores escolhidos para o cálculo da vazão afluente ao piso, relacionando o período analisado, a concentração de gás carbônico na corrente de entrada $\left(c_{\mathrm{e}}\right)$, o pico de concentração $\left(c_{0}\right)$ e a concentração ao final do tempo " $t$ " decorrido $\left(c_{t}\right)$. 
Tabela 19 - Dados utilizados para determinação da taxa de ventilação no Piso 1.

\begin{tabular}{ccc}
\hline & Amostra 1 & Amostra 2 \\
\hline $\mathbf{t}$ (min) & 34 & 18 \\
$\mathbf{c}_{\mathbf{e}}(\mathbf{p p m})$ & 610 & 610 \\
$\mathbf{c}_{\mathbf{o}}(\mathbf{p p m})$ & 1.950 & 1.950 \\
$\mathbf{c}_{\mathbf{t}}(\mathbf{p p m})$ & 616 & 673 \\
$\mathbf{Q}\left(\mathbf{m}^{\mathbf{3}} \mathbf{m i n}\right)$ & 64,1 & 68,5 \\
$\mathbf{Q}(\mathbf{L} / \mathbf{s})$ & 1.069 & 1.141 \\
\hline
\end{tabular}

A RN02 de 2003 da ABRAVA traz recomendações sobre a taxa de ventilação em bibliotecas, levando em consideração a quantidade de pessoas no ambiente. A norma recomenda um valor mínimo de vazão de ar afluente ao ambiente interior, a fim de que seja garantido um número mínimo de trocas de ar no local. Para a determinação dessa taxa mínima sugerida para o Piso 1, tomou-se como base a densidade ocupacional de 26 pessoas no local, a fim de se estabelecer a vazão ideal de ar que entra na sala. $O$ valor recomendado para biblioteca é de 7,5 L/s por pessoa e, para este ambiente, recomenda-se no mínimo uma vazão de $196 \mathrm{~L} / \mathrm{s}$.

Analisando a Tabela 19, observa-se que a vazão de ar afluente à sala supera o valor mínimo recomendado pela ABRAVA. O valor resultante da amostragem é extremamente elevado se comparado ao recomendado. Tal fato se deve ao tipo de ventilação existente no Piso 1. Devido ao fato deste ambiente possuir ventilação natural, a troca de ar entre os ambientes interno e externo é elevada e, sendo assim, a vazão de ar afluente ao Piso 1 também é alta.

\subsection{Aplicação de questionário}

Após a aplicação das questões aos usuários e funcionários, resultados foram obtidos e foi realizado um levantamento das principais queixas e reclamações relativas à ocupação da Biblioteca Municipal. No total, 18 pessoas responderam ao questionário, no mês de novembro de 2010, sendo 9 usuários e 9 funcionários.

O primeiro ponto a ser considerado é em relação à queixa desses problemas aos órgãos responsáveis pela administração do prédio. Do total de entrevistados, 13 pessoas nunca fizeram reclamação alguma à administração do prédio e à prefeitura, enquanto 5 pessoas realizaram tais observações. Alguns entrevistados citaram reclamações relativas ao "ruído, 
iluminação, ventilação inadequada, calor insuportável, barulho proveniente da avenida, muito quente no calor e muito frio no inverno, poeira”, entre outros.

A proximidade do questionado com um ponto de desconforto também foi levantada. A Figura 46 resume todos os resultados sobre essa pergunta, levando em conta que 18 pessoas responderam ao questionário. Uma pessoa poderia marcar mais de uma opção de para sua localização em relação a um ponto de desconforto e, por isso, foi indicada uma proporção em relação a cada resposta e sua incidência no total final de questionários.

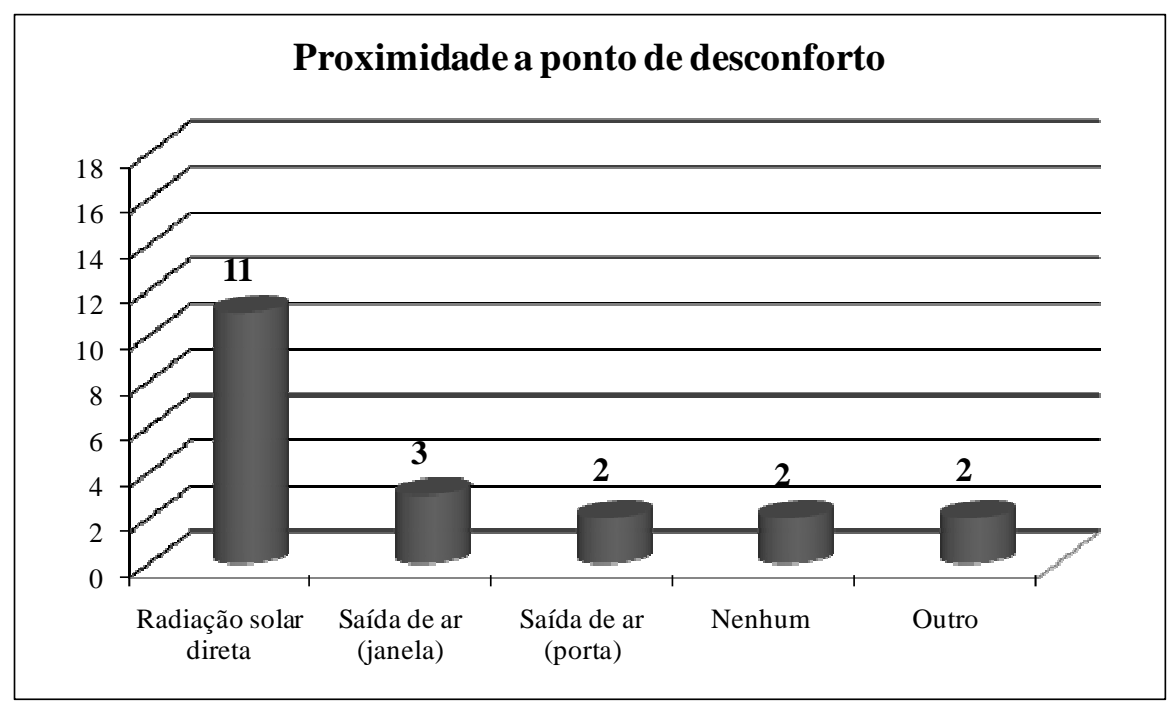

Figura 46. Respostas para a proximidade do questionado a um ponto de desconforto.

Observando a Figura 46, evidencia-se que a maioria dos questionados (61\%) indicaram como proximidade a um ponto de desconforto um local com incidência direta de radiação solar. Denota-se a proximidade com saídas de ar, nas janelas e nas portas, porém, dos 18 entrevistados, 11 evidenciaram a exposição à radiação solar direta. Outros pontos foram levantados, como a proximidade a fontes de "poeira" e, também, a existência de ruído proveniente da avenida.

Com o intuito de conhecer a opinião das pessoas sobre o conforto térmico do local, foram sugeridos 3 cenários para caracterização deste conforto no local: Dias Quente, Dias Frios e Em Geral. As respostas para cada cenário estão apresentadas nas Figuras 47 a 49. 


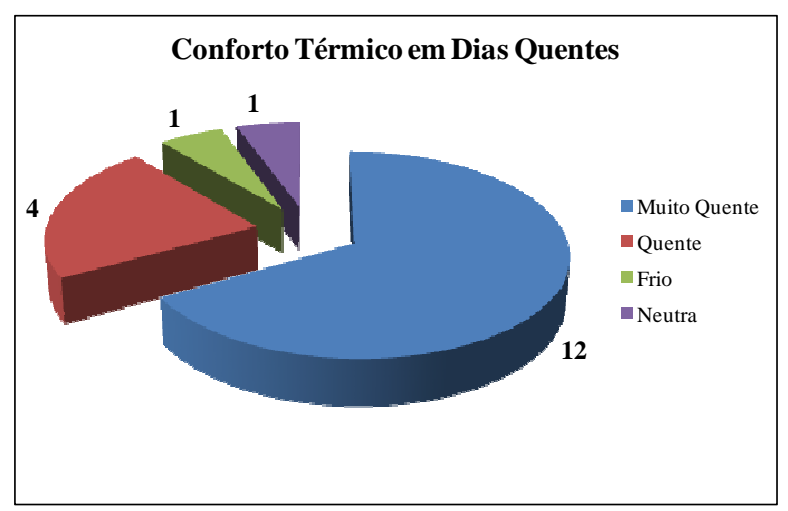

Figura 47. Respostas referentes ao conforto térmico em dias quentes.

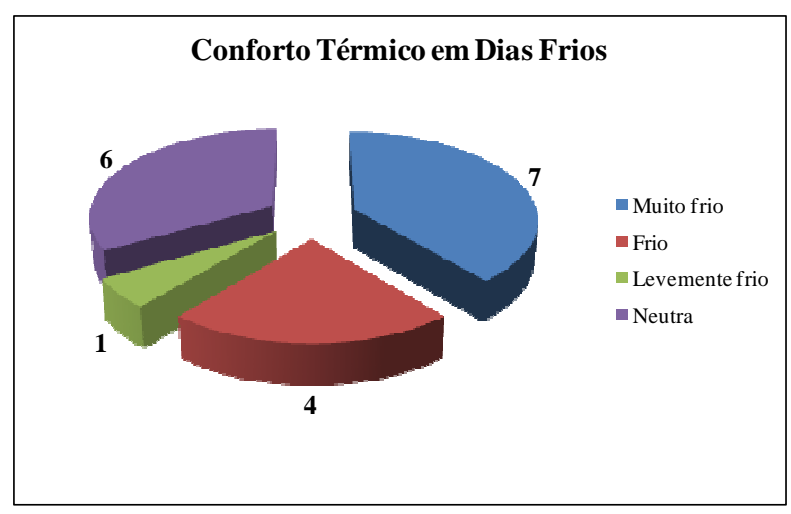

Figura 48. Respostas referentes ao conforto térmico em dias frio.

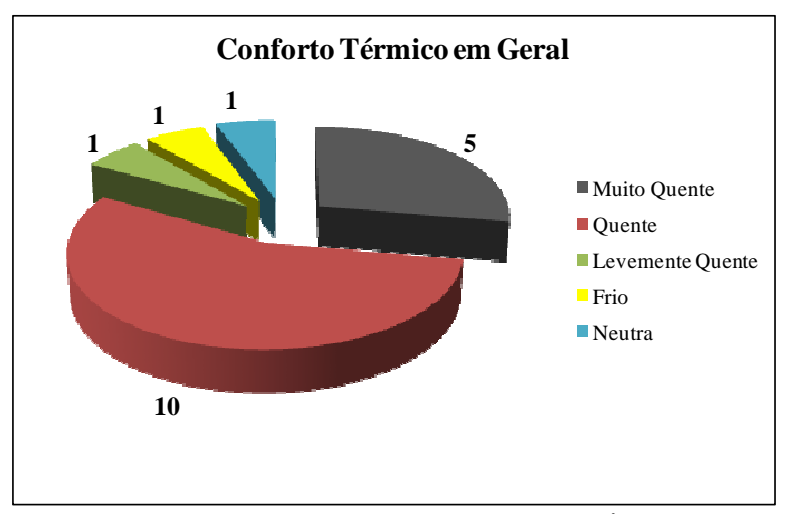

Figura 49. Respostas referentes ao conforto térmico em geral.

Os resultados expostos na Figura 47 mostram que a grande maioria dos entrevistados (89\%) considera o local como quente ou muito quente no verão. Já na Figura 48, evidencia-se $61 \%$ dos questionados consideram o local como frio ou muito frio no inverno. $\mathrm{Na}$ análise geral apresentada na Figura 49, 83\% dos entrevistados consideram a Biblioteca como um local muito quente ou quente. Esses resultados são interessantes, pois comprovam alguns fatores apontados pelos dados. Na seção 5.1 anterior, destaca-se a possível existência de desconforto térmico no local, pois a variação de temperatura e umidade relativa do ambiente 
interno e externo é comparativamente pequena. Esse fator é também comprovado com a aplicação do questionário, em que a maioria dos ocupantes destaca a ocorrência de "muito calor nos dias quentes e muito frio nos dias frios". Apesar da Biblioteca ser classificada de uma maneira geral como um local quente, houve uma considerável quantia de relatos da ocorrência de frio no inverno.

A influência do conforto térmico no desempenho do estudo ou trabalho também foi questionada e a Figura 50 demonstra os principais resultados.

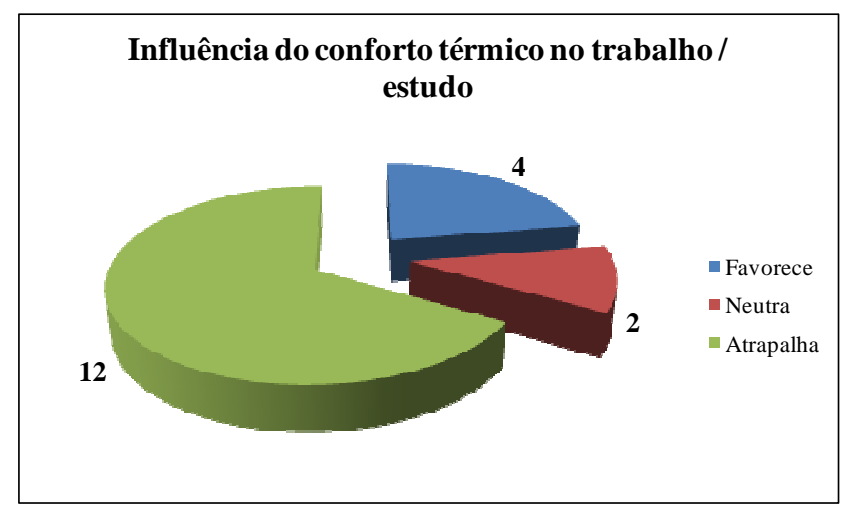

Figura 50. Influência do conforto térmico na realização das atividades do questionado.

É possível observar que a maioria dos entrevistados (67\%) se sente prejudicada pelas más condições de conforto térmico no local de realização de suas atividades, destacando a importância da adoção de medidas corretivas visando a melhora do conforto.

Com o intuito de verificar as condições do ar no ambiente de estudo ou trabalho do questionado, uma classificação do ar foi indagada de acordo com alguns possíveis poluentes. O entrevistado tinha a possibilidade de responder a mais de uma alternativa por questão. Assim, foi realizada uma verificação de maior ocorrência em comparação a todos os questionários. A Figura 51 apresenta os resultados obtidos.

A maior incidência de reclamação foi respectiva a um local com ar empoeirado. Um total de $67 \%$ dos entrevistados relatou essa condição, enquanto outras condições como presença de odor proveniente de mofo, mobiliário e comida também foram destacados por alguns entrevistados. $\mathrm{O}$ ar parado também foi destacado por 7 dos 18 entrevistados. 


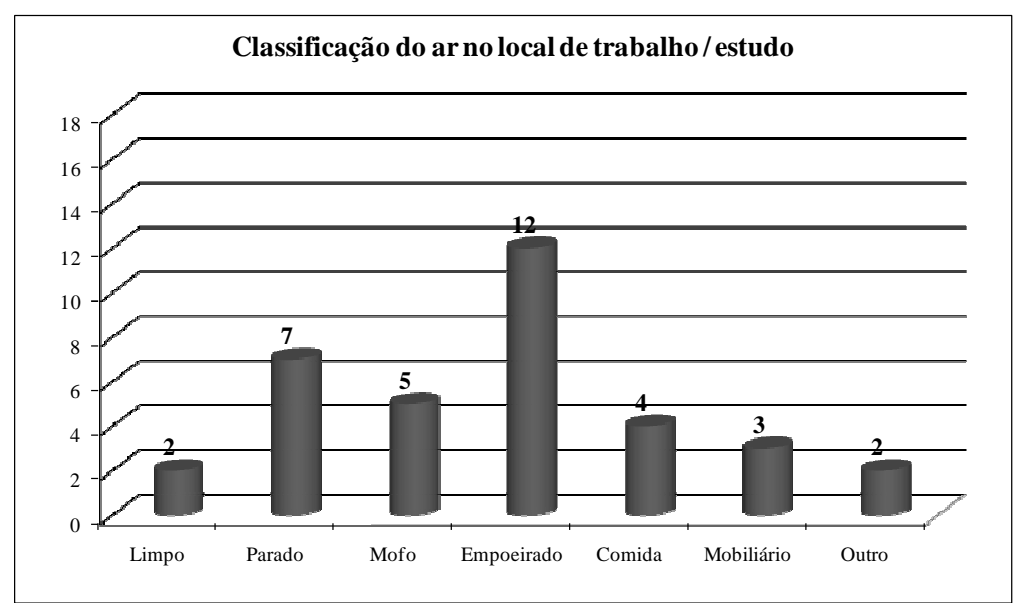

Figura 51. Classificação do ar no local de atividade do questionado.

Para uma avaliação dos efeitos na saúde dos ocupantes, alguns sintomas ligados à má qualidade do ar interior foram questionados. A incidência de sintomas nos entrevistados encontra-se na Figura 52, lembrando que um entrevistado pode apresentar mais de um sintoma.

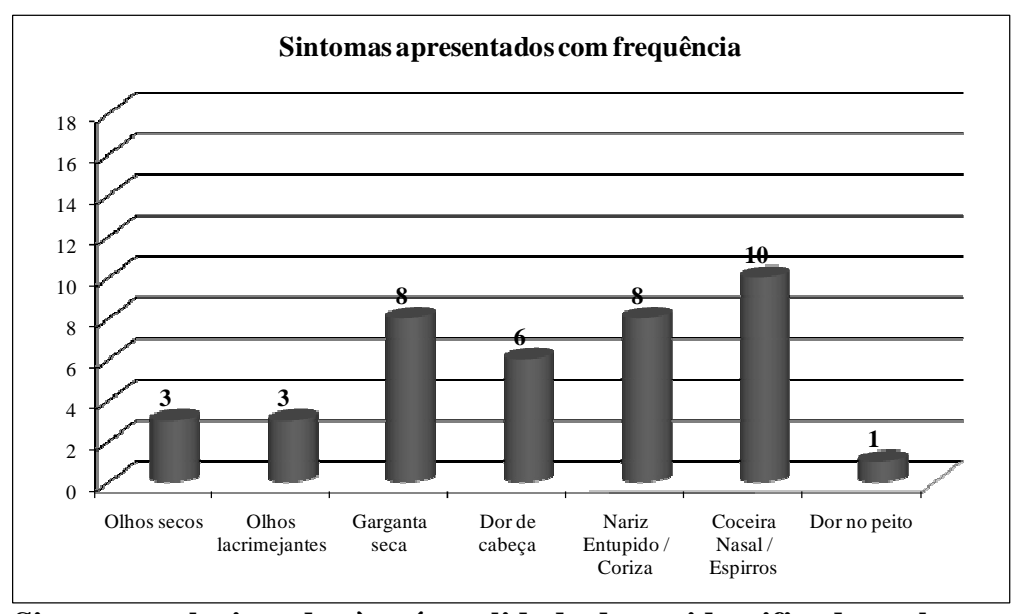

Figura 52. Sintomas relacionados à má qualidade do ar, identificados pelos questionados.

Os principais sintomas identificados são relativos ao trato respiratório superior, como a presença de coceira nasal, ocorrência de nariz entupido e garganta seca. Esses sintomas estão presentes na maioria dos entrevistados e podem ser associados à má qualidade do ar interior.

Por fim, foi realizada uma análise das condições de ruído no ambiente. Quatro perguntas foram elaboradas sobre esse parâmetro. Em uma classificação do ruído no local de trabalho, dos 18 entrevistados, 9 o classificaram como extremo e 9, como alto. Além disso, os entrevistados foram perguntados sobre a influência do ruído no desempenho de suas 
atividades. As respostas estão sintetizadas na Figura 53. A interferência do ruído na comunicação interpessoal também foi avaliada e as respostas encontram-se descritas na Figura 54. Por fim, os questionados fizeram uma avaliação da necessidade de controle das fontes de ruído, e os resultados são apresentados na Figura 55.

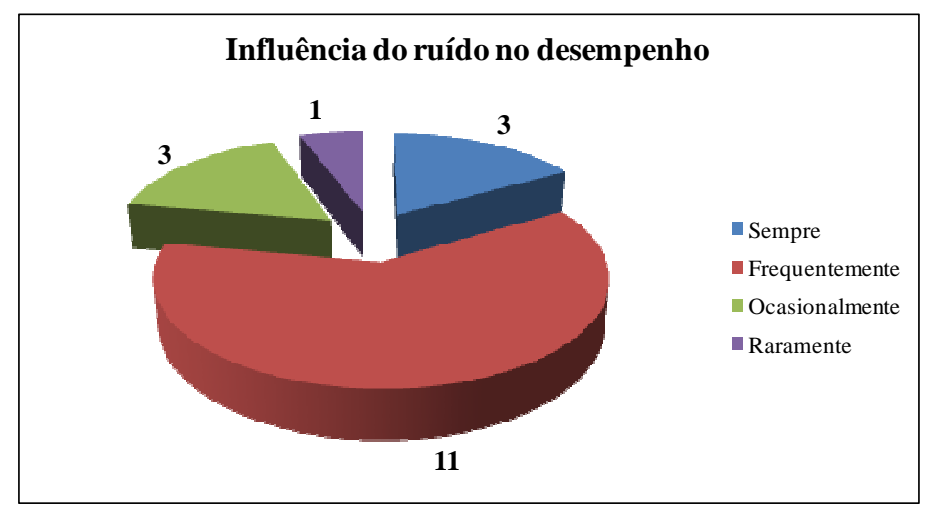

Figura 53. Influência do ruído no desempenho dos questionados.

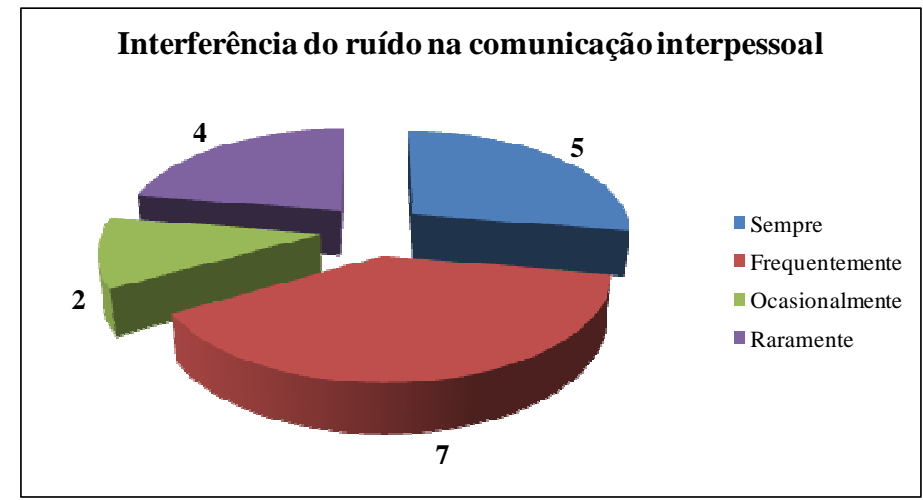

Figura 54. Interferência do ruído na comunicação interpessoal dos entrevistados.

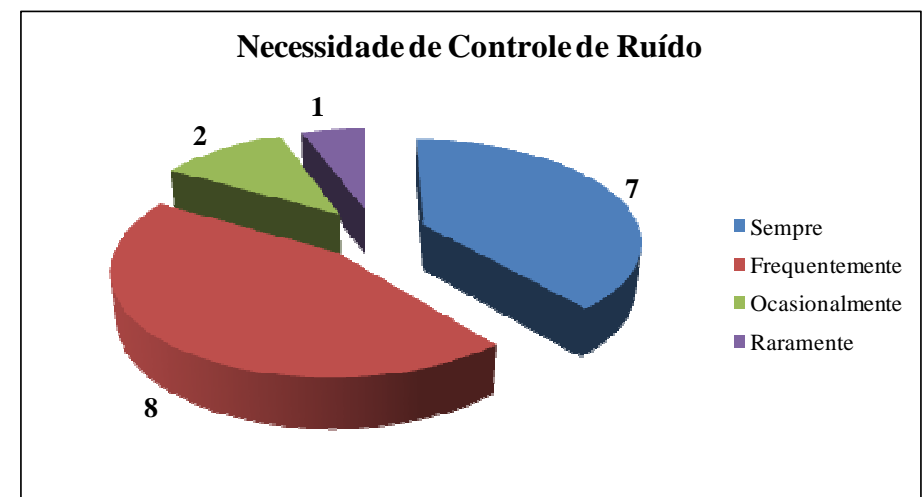

Figura 55. Necessidade de adoção de medidas para controle do ruído.

A maior parte dos entrevistados (78\%) considerou que a presença do ruído sempre ou frequentemente atrapalha o desenvolvimento de suas atividades em seu posto de trabalho. 
Para $67 \%$, a presença do ruído no ambiente sempre ou frequentemente atrapalha a comunicação interpessoal do entrevistado. Por fim, 83\% dos questionados necessitam adotar medidas para controlar o ruído no seu ambiente de estudo ou trabalho. Esses valores, adicionados à classificação do ruído, corroboram os dados anteriormente comentados. O ruído é um grande problema na Biblioteca Pública Amadeu Amaral, conforme os dados obtidos em campo com o decibelímetro e as queixas provenientes dos usuários e funcionários do local.

Como uma última pergunta, foi solicitado para o entrevistado descrever algum ponto que ele considerava relevante para a qualidade do ar e do conforto térmico e acústico do ambiente. A seguir, encontram-se algumas citações.

"Não existe relevância nem conforto" - Feminino.

"Há necessidade de ar condicionado, para os vidros poderem ser fechados; separar os estudantes, pois ficam conversando na ala de leitura próxima aos sofás; eles poderiam ficar somente na ala de entrada ou até nas prateleiras dos livros” - Masculino.

“O prédio não se encontra em local adequado, uma verdadeira poluição sonora. Não foi construído para ser uma Biblioteca, portanto, tudo que ele oferece não corresponde para uma boa qualidade de vida e desenvolvimento do nosso trabalho. Nada é adequado. Por isso, não existe nada que colabore com o conforto, para desenvolvermos bem nosso trabalho." Feminino.

"Sem o calor excessivo e o frio excessivo em dias mais quentes ou frios, poderia ser melhor, pois até as mãos ficam duras no frio e no calor, bebe-se mais água, consequentemente vai mais no banheiro. Por mais que limpem sempre fica poeira de um dia para o outro por causa da avenida. O pior mesmo é o ruído, muitas vezes é impossível falar ao telefone nas horas de pico.” - Feminino.

"Infelizmente, estamos trabalhando num prédio localizado em local inadequado (muito barulho) para uma biblioteca. A Avenida São Carlos é uma das ruas mais barulhentas e ainda mais na subida. E este prédio não oferece nada para que tenhamos uma qualidade de ar e conforto térmico adequados." - Feminino.

“O calor e a umidade favorecem a presença de insetos, como escorpião.” - Feminino.

"Há necessidade de ventiladores e bebedouros." - Masculino.

Tendo em vista esses relatos, o questionário sobre QAI evidenciou as principais queixas dos ocupantes do local, corroborando os resultados encontrados com o monitoramento das variáveis. 
O questionário assume um papel fundamental na comparação com os valores obtidos cientificamente com o monitoramente. Muitos dados numéricos avaliados estão em desacordo com as normas em vigor e isso é evidenciado pelos usuários e funcionários do local. Assim, este questionário cumpre seu papel de evidenciar e categorizar as queixas. Além disso, ressalta-se que este simples conjunto de perguntas possui o intuito de levantar as principais reclamações. Um questionário mais elaborado, baseados em normas rigorosas de instituições internacionais e com um número maior de participantes pode trazer resultados mais profundos e representativos em relação a outros diversos problemas. 


\section{Conclusões}

No presente tópico, há um quadro-resumo de todos os parâmetros avaliados ao longo da pesquisa, com uma comparação em relação aos valores padronizados e breves considerações a respeito do tema, representado pela Tabela 20.

A partir da análise dos resultados e as normas em vigor, conclui-se que:

- A temperatura, a umidade relativa, o ruído e a taxa de iluminação estão em desacordo com os critérios estabelecidos em normas;

- A taxa de ocupação deve ser observada com ressalvas em cada Piso, principalmente no Piso 2;

- A concentração de bioaerossóis, o material particulado em suspensão, a contaminação por gás carbônico e a taxa de ventilação estão de acordo com os valores estabelecidos pelas normas.

As respostas provenientes do questionário correspondem a um papel importante, pois elas estão de acordo com os problemas evidenciados com a coleta de dados. As queixas relatadas são comprovadas e reforçam a idéia de veracidade das reivindicações registradas, de acordo com os objetivos propostos.

Os valores obtidos com o monitoramento ressaltam as características de uma biblioteca típica de países tropicais com o sistema de ventilação natural. A relação entre os valores obtidos no ambiente interno e externo é sempre próxima de 1,00. Isso mostra que o comportamento do ambiente externo influi diretamente no interior da biblioteca. 
Tabela 20 - Quadro síntese de parâmetros avaliados nos ambientes.

\begin{tabular}{|c|c|c|c|c|c|}
\hline Parâmetro & Piso 1 & Piso 2 & Piso 3 & Norma/Referência & Observações \\
\hline Temperatura & Inadequado & Inadequado & Inadequado & RE/ANVISA n ${ }^{\circ} 9$ & $\begin{array}{l}\text { Valores fora da faixa de } \\
\text { recomendação e constatação de } \\
\text { desconforto térmico. }\end{array}$ \\
\hline Umidade relativa & Inadequado & Inadequado & Inadequado & RE/ANVISA n ${ }^{\circ} 9$ & $\begin{array}{l}\text { Valores fora da faixa de } \\
\text { recomendação e constatação de } \\
\text { desconforto térmico. }\end{array}$ \\
\hline Temperatura & Inadequado & Inadequado & Inadequado & SILVA FILHO et al. (1994) & $\begin{array}{c}\text { Valores fora da faixa de } \\
\text { recomendação para conservação } \\
\text { de acervos. }\end{array}$ \\
\hline Umidade relativa & Inadequado & Inadequado & Inadequado & SILVA FILHO et al. (1994) & $\begin{array}{l}\text { Valores fora da faixa de } \\
\text { recomendação para conservação } \\
\text { de acervos. }\end{array}$ \\
\hline $\begin{array}{c}\text { Material } \\
\text { particulado }\end{array}$ & Adequado & Adequado & Adequado & RE/ANVISA n ${ }^{\circ} 9$ e OMS (2005) & $\begin{array}{l}\text { Valores abaixo do máximo } \\
\text { recomendado. }\end{array}$ \\
\hline Bioaerossóis & Adequado & Adequado & Adequado & RE/ANVISA n ${ }^{\circ} 9$ & $\begin{array}{l}\text { Valores abaixo do máximo } \\
\text { recomendado. }\end{array}$ \\
\hline Ruído & Inadequado & Inadequado & Inadequado & NBR 10.152 & $\begin{array}{l}\text { Ruído acima do máximo } \\
\text { recomendado. }\end{array}$ \\
\hline $\begin{array}{c}\text { Taxa de } \\
\text { Iluminação }\end{array}$ & Inadequado & Inadequado & Inadequado & NBR 5.413 & $\begin{array}{l}\text { Iluminação inadequada para o } \\
\text { tipo de atividade exercida. }\end{array}$ \\
\hline Gás carbônico & Adequado & Adequado & Adequado & $\begin{array}{l}\text { RE/ANVISA n }{ }^{\circ} 9 \mathrm{e} \\
\text { RN02/ABRAVA }\end{array}$ & $\begin{array}{l}\text { Concentração abaixo do } \\
\text { máximo recomendado. }\end{array}$ \\
\hline Taxa de Ocupação & Adequado & Inadequado & Adequado & RN02/ABRAVA & $\begin{array}{l}\text { Ressalvas importantes sobre a } \\
\text { taxa de ocupação em cada piso. }\end{array}$ \\
\hline $\begin{array}{c}\text { Taxa de } \\
\text { Ventilação }\end{array}$ & Adequado & - & - & RN02/ABRAVA & $\begin{array}{c}\text { Vazão de ar afluente ao Piso } 1 \\
\text { superior ao mínimo } \\
\text { recomendado. }\end{array}$ \\
\hline
\end{tabular}




\section{Recomendações}

\subsection{Gerais}

As principais recomendações encontram-se elencadas a seguir:

- Sugere-se a realização de um estudo aprofundado sobre material particulado no local. Apesar de o valor estar adequado perante a norma, o questionário evidencia um problema relacionado à poeira e fuligem proveniente de veículos. Análises gravimétricas de material particulado em suspensão são indicadas para investigação detalhada deste parâmetro;

- O ruído é um fator relevante para os ocupantes da Biblioteca, visto que a mesma não conta com isolamento adequado. Recomenda-se a elaboração de estudos para amenizar a poluição sonora do local, de acordo com as queixas dos ocupantes do local;

- O desconforto térmico foi evidenciado pelos ocupantes do local e é relevante para a realização das atividades dos mesmos. Aconselha-se a proposição de estudos para a mudança de configuração do conforto térmico do ambiente, considerando os níveis de temperatura e umidade relativa monitorados. É importante lembrar que a conservação do acervo necessita de níveis de temperatura e umidade relativa específicos, bem como o conforto térmico;

- A análise sazonal do comportamento dos parâmetros avaliados no presente estudo é importante para a realização de um diagnóstico detalhado do ambiente. A realização de amostragens periódicas e concomitantes nos ambientes interno e externo é relevante para a confecção de estudos aprofundados;

- A análise química do material particulado em suspensão é importante para identificar quais os principais compostos dispersos no ar e, consequentemente, interferindo na saúde dos ocupantes. 


\subsection{Trabalhos Posteriores}

Encontram-se dispostas a seguir algumas sugestões para a execução de trabalhos de monitoramento posteriores, em função da experiência adquirida neste estudo:

- É desejável que o monitoramento seja executado ao mesmo tempo tanto no ambiente interno, quanto no ambiente externo. Este quesito é importante para a realização de uma razão interna e externa em um mesmo intervalo de tempo;

- É relevante o monitoramento com um caráter sazonal, ou seja, ao longo de um período superior a um ano. O monitoramento constante por intervalos superiores ao de um ano proporciona uma análise da variação temporal dos parâmetros investigados;

- A comparação de dados existentes de outros estudos deve ser realizada sempre com a ressalva específica das condições do ambiente analisado. É interessante reiterar que o tipo de ocupação, as características de projeto, o sistema de ventilação e outros fatores interferem diretamente no comportamento dos parâmetros de qualidade do ar. 


\section{Referências Bibliográficas}

ABNT - Associação Brasileira de Normas Técnicas. NORMA - NBR 10.152 de 2000 Níveis de ruído para conforto acústico.

ABNT - Associação Brasileira de Normas Técnicas. NORMA - NBR 10.151 de 2000 Avaliação do ruído em áreas habitadas, visando o conforto da comunidade Procedimento.

ABNT - Associação Brasileira de Normas Técnicas. NORMA - NBR 5.382 de 1985 Verificação de iluminância de interiores.

ABNT - Associação Brasileira de Normas Técnicas. NORMA - NBR 5.413 de 1992 Iluminância de interiores.

ABRAVA - Associação Brasileira de Refrigeração, Ar Condicionado, Ventilação e Aquecimento. RECOMENDAÇÃO NORMATIVA RN 02 - 2003. Disponível em: http://www.portalabrava.com.br

ALLOU, L.; MARCHAND, C.; MIRABEL, PH.; LE CALVÉ, S. Aldehydes and BTEX measurements in university libraries in Strasbourg (France). Indoor and Built Environment, 17; 2:138-145, 2008.

AL-REHALI, A. M. Outdoor-indoor air quality in Riyadh: $\mathrm{SO}_{2}, \mathrm{NH}_{3}$ and HCHO. Environmental Monitoring and Assessment, 79; 287-300, 2002.

ANVISA - Agência Nacional de Vigilância Sanitária. PORTARIA No 3.523 de 28 de agosto de 1998. Disponível em: http://www.anvisa.gov.br

ANVISA - Agência Nacional de Vigilância Sanitária. RESOLUÇÃO - RE/ANVISA N¹76 de 24 de outubro de 2000. Disponível em: http://www.anvisa.gov.br

ANVISA - Agência Nacional de Vigilância Sanitária. RESOLUÇÃO - RE/ANVISA Nº9 de 16 de janeiro de 2003. Disponível em: http://www.anvisa.gov.br

AYDOGDU, H.; ASAN, A.; OTKUN, M. T. Indoor and outdoor airborne bacteria in child day-care centers in Edirne City (Turkey), seasonal distribution and influence of meteorological factors. Environmental Monitoring and Assessment, 164; 53-66, 2010.

BAKÓ-BIRÓ, Z.; WARGOCKI, P.; WESCHLER, C.J.; FANGER, P.O. Effects of pollution from personal computers on perceived air quality, SBS symptoms and productivity in offices. Indoor Air, 14, 178-187, 2004.

BARTLETT, K.H.; KENNEDY, S.M.; BRAUER, M.; VAN NETTEN, C.; DILL, B. Evaluation and Determinants of Airborne Bacterial Concentrations in Schools Classrooms. Journal of Occupational and Environmental Hygiene, 1; 639-647, 2004.

BERNSTEIN, J. A. Health effects of air pollution. J. Allergy. Clin. Immunol., 14, № 5, 1116-1123, 2004. 
BHATTACHARYA, K.; RAHA, S.; MAJUMDAR, M. R. Measuring indoor fungal contaminants in rural west Bengal, India, with reference to allergy symptoms. Indoor and Built Environment, 10; 40-47, 2001.

BLONDEAU, P.; IORDACHE, V.; POUPARD, O.; GENIN, D.; ALLARD; F. Relationship between outdoor and indoor air quality in eight French schools. Indoor Air, 15, 2-12, 2005 .

BONETTA, S.; BONNETA, S.; MOSSO, S.; SAMPO, S.; CARRARO, E. Assessment of microbiological indoor air quality in an Italian office building equipped with an HVAC system. Environmental Monitoring and Assessment, 161; 473-483, 2010.

BRICKUS, L. S. R.; AQUINO NETO, F. R. A qualidade do ar de interiores e a química. Química Nova, 22(1), 65-74, 1999.

BRICKUS, L. S. R.; CARDOSO, J. N.; AQUINO NETO, F. R. Distributions of indoor and outdoor air pollutants in Rio de Janeiro, Brazil: implications to indoor air quality in bayside offices. Environ. Sci. Technol., 32: 3485-3490, 1998.

BRUCE, N.; PEREZ-PADILLA, R.; ALBALAK, R. Indoor air pollution in developing countries: a major environmental and public health challenge. Bulletin of the World Health Organization, 78 (9), 1078-1092, 2000.

BRUNO, P. ; CASELLI, M. ; GENNARO, G. ; IACOBELLIS, S. ; TUTINO, M. Monitoring of volatile organic compounds in non-residential indoor environments. Indoor Air, $18 ; 250-256,2008$.

CAI, W.; WANG, D.; WEN, X., YU, X. Indoor air quality assessment in an art gallery with an HVAC system. $4^{\text {th }}$ Internacional Conference on Bioinformatics and Biomedical Engineering, 2151-7614, 2010.

CATRANIS, C. M.; ANAGNOST, S. E.; ZHANG, L.; ZHOU, S.; FERNANDO, A.; MOREY, S.; WANG, C. J. K. A new sub-sampling method for analysis of air samples collected with the Andersen single-stage sampler. Aerobiologia, 22, 177-184, 2006.

CAVALCANTE, R. M.; SEYFFERT, B. H.; D’ORCA, M. G. M.; NASCIMENTO, R. F.; CAMPELO, C. S.; PINTO, I. S.; ANJOS, F. B.; COSTA, A. H. R. Exposure assessment for formaldehyde and acetaldehyde in the workplace. Indoor and Built Environment, 14; 2: 165-172, 2005.

CHAN, D. W. T.; TAM, C. S. Y.; JONES, A. P. An inter-comparison of VOC types and distribution in different indoor environments in a university campus. Indoor and Built Environment, 16; 4: 376-382, 2007.

CHAN, W. C.; LEE, S.C.; CHEN, Y.; MAK, B.; WONG, K.; CHAN,C.S.; ZHENG, C.; GUO, X. Indoor air quality in new hotels' guest rooms of the major world factory region. International Journal of Hospitality Management, 28, 26-32, 2009.

CHAO, C. Y.; WONG, K. K.; CHENG, E. C. Size distribution of indoor particulate matter in 60 homes in Hong Kong. Indoor and Built Environment, 11: 18-26, 2002. 
CHATZIS, C.; ALEXOPOULOS, E. C.; LINOS, A. Indoor and outdoor personal exposure to benzene in Athenas, Greece. Science of Total Environment, 349; 72-80, 2005.

CONAMA - Conselho Nacional de Meio Ambiente. RESOLUÇÃO - CONAMA No 003 de 28 de junho de 1990. Disponível em: http://www.mma.gov.br/port/conama

CONAMA - Conselho Nacional de Meio Ambiente. RESOLUÇÃO - CONAMA Nº05 de 15 de junho de 1989. Disponível em: http://www.mma.gov.br/port/conama

DSM - Scientific Services of Culture Collections. Curso ministrado na Fundação Tropical de Pesquisas e Tecnologia “André Tosello”, Campinas, 1991.

EPA - Environmental Protection Agency. Particle pollution and your health. Disponível em: http://www.epa.gov/airnow/particle/pm-color.pdf; 2003.

EVCI, E. D.; BILGIN, M. D.; AKGÖR, S.; ZENCIRCI, S. G.; ERGIN, F.; BESER, E. Measurement of selected indoor physical environmental factors in hairdressers salons in a Turkish city. Environmental Monitoring Assessment, 134: 471-477, 2007.

FENECH, A.; STRLIC, M.; CIGIC, I. K.; LEVART, A.; GIBSON, L. T.; BRUIN, G.; NTANOS, K.; KOLAR, J.; CASSAR, M. Volatile aldehydes in libraries and archives. Atmospheric Environment, 44; 2067-2073, 2010.

FREW, J.A. Advances in environmental and occupational diseases 2004. J. Allergy. Clin.Immunol., 115, No. 6, 1197-1202, 2005.

GERRITY, T. R. Regional deposition of gases and particles in the lung: implications for mixtures. Toxicology, 105; 327-334, 1995.

GODISH, T. Air Quality. $2^{\text {nd }}$ Ed., Lewis Publishers, 1991.

GODWIN, C.; BATTERMAN, S. Indoor air quality in Michigan schools. Indoor Air, 17, 109-121, 2006.

GUO, H.; LEE, S.C.; CHAN, L.Y.; LI, W.M. Risk assessment of exposure to volatile organic compounds in different indoor environments. Environmental Research, 94, 57-66, 2004.

HANOUNE, B.; LEBRIS, T.; ALLOU, L.; MARCHAND, C.; CALVÉ, S. L. Formaldehyde measurement in libraries: comparison between infrared diode laser spectroscopy and DNPH-derivatization method. Atmospheric Environment, 40; 5768-5775, 2006.

HEINSOHN, P. A., YANG, C. S. Sampling and analysis of indoor microorganisms . John Wiley \& Sons, Inc, Hoboken, New Jersey.2007.

HEINSOHN, R. J., CIMBALA, J. M. Indoor Air Quality Engineering - Environmental Health and Control of Indoor Pollutants. Marcel Dekker, INC, University Park, The Pennsylvania State University, Pennsylvania, U.S.A., 2003.

HUSSEIN, T.; HÄMERI, K.; HEIKKINEN, M.S.A.; KULMALA, M. Indoor and outdoor particle size characterization at a family house in Espoo - Finland. Atmospheric Environment, 39, 3697-3709, 2005. 
ITO, L. X.; AGUIAR, M. L. Indoor air quality of libraries in São Paulo, Brazil. Indoor Built Environ, 16, 1:1-4, 2007.

JAGLBAUER, V. Contribuição à melhora das condições ambientais de trabalho através do aprimoramento da iluminação em galpões e pátios cobertos na indústria mineral. Dissertação (Mestrado em Engenharia Mineral). Escola Politécnica, Universidade de São Paulo, USP. São Paulo, SP, 188 p., 2007.

JANSSEN, N.A.H.; HOCK, G.; BRUNEKREEF, B.; HARSSEMA, H. Mass concentration and elemental composition of $\mathrm{PM}_{10}$ in classrooms. Occup. Environ. Med., 56, 482$487,1999$.

JIA, C.; BATTERMAN, S.; GODWIN, C.; CHARLES, S.; CHIN, J. Y. Sources and migration of volatile organic compounds in mixed-use buildings. Indoor Air, 20: 357$369,2010$.

JONES-OTAZO, H. A.; CLARKE, J. P.; DIAMOND, M. L.; ARCHBOLD, J. A.; FERGUSON, G.; HARNER, T.; RICHARDSON, G. M., RYAN, J. J.; WILFORD, B. Is house dust the missing exposure pathway for PBDEs? An analysis of the urban fate and human exposure to PBDEs. Environ Sci Technol, 39:5121-30, 2005.

KAGAWA, J. Health effects of diesel exhaust emissions - a mixture of air pollutants of worldwide concern. Toxicology, 181-182, 349-353, 2002.

KALOGERAKIS, N.; PACHALI, D.; LEKADITIS, V.; PANTIDOU, A.; ELEFTHERIADIS, K.; LAZADIRIS, M. Indoor air quality - bioaerosol measurements in domestic and office premises. Journal of Aerosol Science, 36, 751-761, 2005.

KARIMIPANAH, T.; AWBI, H. B.; SANDBERG, M.; BLOMQVIST, C. Investigation of air quality, comfort parameters and effectiveness for two floor-level air supply systems in classrooms. Building and Envorinment, 42, 647-655, 2007.

KELLER-OLAMAN, S.J.; EYLES, J.D.; ELLIOTT, S.J.; WILSON, K.; DOSTROVSKY, N.; JERRETT, M. Individual and Neighborhood Characteristics Associated with Environmental Exposure: Exploring Relationships at Home and Work in a Canadian City. Environment and Behavior, 37, No. 4, 441-464, 2005.

KIM, K. Y.; KIM, C. N. Airborne microbiological characteristics in public buildings of Korea. Building and Environment, 42: 2188-2196, 2007.

KONEMAN, M.D.; ALLEN, S.D.; JANDA, W.M.; SCHRECKENBERGER, P.C.; WINN JR, W.C. Diagnóstico Microbiológico. Editora Guanabara Koogan S.A., $5^{\text {a }}$ edição, Rio de Janeiro, 2001.

KOTZIAS, D. Indoor air and human exposure assessment - needs and approaches. Experimental and Toxicologic Pathology, 57, 5-7, 2005.

LAHTINEN, M.; HUUHTANEN, P.; KÄHKÖNEN, E.; REIJULA, K. Psychosocial dimensions of solving an indoor air problem. Indoor Air, 12: 33-36, 2002. 
LEE, S.C.; CHANG, M. Indoor and outdoor air quality investigation at schools in Hong Kong. Chemosphere, 41, 109-113, 2000.

LEE, S.C.; GUO, H.; LI, W.M.; CHAN, L.Y. Inter-comparison of air pollutant concentrations in different indoor environments in Hong Kong. Atmospheric Environment, 36, 1929-1940, 2002.

LEITE, J. Y. P.; LOPES, R. L.; AMARAL, E. S.; SANTOS, J. C.; FERNANDES, M. R. Nível de ruído - uma medida de qualidade nas bibliotecas. $1^{\circ}$ Congresso Brasileiro de Engenharia Sanitária, Foz do Iguaçu, 1997.

LI, A.; SCHOONOVER, T.M.; ZOU, Q.; NORLOCK, F.; CONROY, L.M.; SCHEFF, P.A.; WADDEN, R.A. Polycyclic aromatic hydrocarbons in residential air of ten Chicago area homes: Concentrations and influencing factors. Atmospheric Environment, 39, 3491-3501, 2005.

MARCHAND, C.; BULLIOT, B.; CALVÉ, S. L.; MIRABEL, PH. Aldehyde measurement in indoor environment in Strasbourg (France). Atmospheric Environment, 40; 1336$1345,2006$.

MATSON, U. Indoor and outdoor concentrations of ultrafine particles in some scandinavian rural and urban areas. Science of the Total Environment, 343, 169-176, 2005.

MENG, Q.Y.; TURPIN, B.J.; POLIDORI, A.; LEE, J.H.; WEISEL, C.; MORANDI, M.; COLOME, S.; STOCK, T.; WINER, A.; ZHANG, J.J. PM 2.5 of Ambient Origin: Estimates and Exposure Errors Relevant to PM Epidemiology. Environmental Science \& Technology, 39; 14:5105-5112, 2005.

MENTESE, S.; ARISOY, M.; RAD, A. Y.; GULLU, G. Bacteria and fungi levels in various indoor and outdoor environments in Ankara, Turkey. Clean, 37(6); 487-493, 2009.

MEYER, B. Indoor air quality. $1^{\text {st }}$ Ed. Massachusetts: Addison-Wesley Publishing Company, Inc., 434 p, 1983.

MIHAILOVIC, A.; GRUJIC, S. D.; KIURSKI, J.; KRSTIC, J.; OROS, I.; KOVACEVIC, I. Occupational noise in printing companies. Environmental Monitoring Assessment, 2010.

MIYAGUSKO, M. J. Avaliação da qualidade do ar em Unidades de Terapia Intensiva e sua correlação com o ambiente externo e a saúde dos trabalhadores. Tese (Doutorado em Patologia). Faculdade de Medicina, Universidade de São Paulo, USP. São Paulo, SP, 127p., 2008.

MORAES, A. P. Qualidade do ar interno com ênfase na concentração de aerodispersóides nos edifícios. Dissertação (Mestrado em Engenharia de Construção Civil). Escola Politécnica, Universidade de São Paulo, USP. São Paulo, SP, 159 p., 2006.

MYERS, I.; MAYNARD, R.L. Polluted air - outdoors and indoors. Occupational Medicine, $55,432-438,2005$. 
MYSEN, M.; BERNTSEN, S.; NAFSTAD, P.; SCHILD, P. G. Occupancy density and benefits of demand-controlled ventilation in Norwegian primary schools. Energy and Buildings, 37, 1234-1240, 2005.

NAZAROFF, W.W. Indoor particle dynamics. Indoor Air, 14 (Suppl. 7), 175-183, 2004.

OBBARD, G. I.; VISWANATHAN, J. P.; HUANG, S. Y. Airborne bacteria and fungal spores in the indoor environment - a case of study in Singapore. Acta Biotechnology, $20 ; 1: 67-73,2000$.

OMS - Organização Mundial de Saúde. Guia de qualidade do ar para material particulado, ozônio, dióxido de nitrogênio e dióxido de enxofre. Atualização Global de 2005. Disponível em: http://whqlibdoc.who.int/hq/2006/WHO_SDE_PHE_OEH_06.02_eng.pdf

PASTUSZKA, J. S.; PAW, U. K. T. P.; LIS, D. O.; WLAZLO, A.; ULFIG, K. Bacterial and fungal aerosol in indoor environment in Upper Silesia, Poland. Atmospheric Environment, 34; 3833-3842, 2000.

PETERS, J.M. et al. A Study of Twelve Southern California Communities with Differing Levels ands Types of air Pollution: Prevalence of respiratory morbidity. Am. J. Respir. Crit.Care Med., 159, 760-767, 1999.

POKHREL, A.K.; SMITH, K.R.; KHALAKDINA, A.; DEUJA, A.; BATES, M.N. Casecontrol study of indoor cooking smoke exposure and cataract in Nepal and India. International Journal Of Epidemiology, 34, 702-708, 2005.

POZZA, S. A. Características temporais da concentração de material particulado na atmosfera da cidade de São Carlos - SP. Tese (Doutorado em Engenharia Química). Departamento de Engenharia Química, Universidade Federal de São Carlos. São Carlos, SP, 141 p., 2009.

REDDY, M. K.; SUNEELA, M.; SUMATHI, M.; REDDY, R. C. Indoor air quality at Salarjung Museum, Hyderabad, India. Environment Monitoring Assessment, 105: 359-367, 2005.

RICHARDSON, G.; EICK, S.; JONES, R. How is the indoor environment related to asthma?: literature review. Journal of Advanced Nursing, 53 (3), 328-339, 2005.

RIGHI, E.; AGGAZZOTTI, G.; FANTUZZI, G.; CICCARESE, V.; PREDIERI, G. Air quality and well-being perception in subjects attending university libraries in Modena (Italy). The Science of the Total Environment, 286; 41-50, 2002.

RIOS, A. L. Efeito tardio do ruído na audição e na qualidade do sono em indivíduos expostos a níveis elevados. Dissertação (Mestrado em Biociências Aplicadas à Clínica Médica). Faculdade de Medicina de Ribeirão Preto, Universidade de São Paulo, USP. Ribeirão Preto, SP, 155 p., 2003. 
RODRIGUES, M. A. Condições de trabalho e conforto em bibliotecas do Ensino Superior. Dissertação (Mestrado em Engenharia Humana). Escola de Engenharia, Universidade do Minho. Portugal, 156 p., 2009.

ROSS, C.; MENEZES, J. R.; SVIDZINSKI, T. I. E.; ALBINO, U.; ANDRADE, G. Studies on fungal and bacterial population of air-conditioned environments. Brazilian Archives of Biology and Technology, 47; 5:827-835, 2004.

SALDIVA, P. Air pollution and our lung disease patients. J Bras Pneumol., 34(1):1, 2008.

SCHEFF, P.A.; PAULIUS, V.K.; CURTIS, L.; CONROY, L.M. Indoor Air Quality in a Middle School, Part II: Development of Emission Factors for Particulate Matter and Bioaerosols. Applied Occupational and Environmental Hygiene, Volume 15 (11); 835-842, 2000.

SELTZER, J. M. Biological contaminants. J. Allergy Clin. Immunol., 94; 2:318-326, 1994.

SEN, B.; ASAN, A. Fungal flora in indoor and outdoor air of different residential houses in Tekirdag City (Turkey): seasonal distribution and relationship with climatic factors. Environment Monitoring Assessment, 151:209-219, 2009.

SHENDELL, D. G.; PRILL, R.; FISK, W. J.; APTE, M.G.; BLAKE, D.; FAULKNER, D. Associations between classroom $\mathrm{CO} 2$ concentration and student attendance in Washington and Idaho. Indoor Air, 14, 333-341, 2004.

SILVA FILHO, J. T.; ALMEIDA, M. S. F.; GONÇALVES, P. R. Manual de conservação de acervos bibliográficos. Rio de Janeiro: Universidade Federal do Rio de Janeiro, Sistema de Bibliotecas e Informação - SiBI, 1994. Disponível em: http://www.forum.ufrj.br/biblioteca/artigo.html

SOUSA, F. M. C. Influência do ruído na comunicação interpessoal - percepção de profissionais de saúde numa Unidade de Cuidados Intensivos. Dissertação (Mestrado em Comunicação em Saúde). Universidade Aberta, Lisboa. Lisboa, Portugal, 88 p., 2006.

SUNDELL, J. On the history of indoor air quality and health. Indoor Air, 14 (Suppl. 7), 5158, 2004.

TANEJA, A.; SAINI, R.; MASIH, A. Indoor air quality of houses located in the urban environment of Agra, India. New York Academic Science, 1140: 228-245, 2008.

TUOMAINEN, A.; SEURI, M.; SIEPPI, A. Indoor air quality and health problems associated with damp floor coverings. Int. Arch. Occup. Environ. Health, 77, 222-226, 2004.

VALAVANIDIS, A.; VATISTA, M. Indoor air quality measurements in the Chemistry Department Building of the University of Athens. Indoor and Built Environment, 15, 6: 595-605, 2006.

WALSH, P. J.; DUDNEY, C. S.; CPOENHAVER, E. D. Indoor air quality. $1^{\text {st }}$ Ed. Florida: CRC Press, Inc, 207 p., 1984. 
WESCHLER, C.J. Ozone in Indoor Environments: Concentration and Chemistry. Indoor Air, 10, 269-288, 2000.

WHEELER, A.J.; WILLIAMS, I.; BEAUMONT, R.A.; HAMILTON, R.S. Characterization of Particulate Matter Sampled During a Study of Children's Exposure to Airborne Particulate Matter in a UK Urban Environment. Environmental Monitoring and Assessment, 65, 69-77, 2000.

WILLIAMS, E. O.; LIDWELL, O. M.; HIRCH, A. The bacterial flora of the air of occupied rooms. J Hyg, 54; 4:512-523, 1956.

YE, X.; LIAN, Z.; JIANG, C.; ZHOU, Z.; CHEN, H. Investigation of indoor environmental quality in Shangai metro stations, China. Environmental Monitoring Assessment, 167:643-651, 2010. 
ANEXO I

QUESTIONÁRIO DE CONFORTO TÉRMICO, ACÚSTICO E QUALIDADE DO AR 


\begin{tabular}{|c|c|c|}
\hline \multicolumn{3}{|c|}{ Questionário de Conforto Térmico, Acústico e Qualidade do Ar } \\
\hline Data: & Hora: & \\
\hline 1 - Respondente & (não colocar nome) & \\
\hline Sexo: & Idade: & \\
\hline \multicolumn{3}{|l|}{2 - Localização: } \\
\hline $1^{\circ}$ Piso $[\mathrm{PT}] \quad(\quad)$ & $2^{\circ}$ Piso [Acervo Infantil] $(\quad)$ & $\mathbf{3}^{\circ}$ Piso [Acervo Principal] $(\quad)$ \\
\hline \multicolumn{3}{|c|}{ ( ) Funcionário/Administração ( ) Usuário/Frequentador } \\
\hline \multicolumn{3}{|l|}{4 - Vestimenta Usual: } \\
\hline ( ) Calça comprida & ( ) Blusa Manga Curta & ( ) Blusa Manga Comprida \\
\hline ( ) Saia & ( ) Agasalho & ( ) Meia \\
\hline ( ) Sapato Fechado & ( ) Sapato Aberto & \\
\hline \multicolumn{3}{|c|}{5 - Proximidade a ponto de desconforto: } \\
\hline ( ) Saída de ar no piso [porta] & ( ) Radiação solar direta & ( ) Outro: \\
\hline ( ) Saída de ar na janela & ( ) Nenhum & \\
\hline \multicolumn{3}{|c|}{6 - Já se queixou sobre o conforto térmico/qualidade do ar à administração do prédio ou prefeitura? } \\
\hline ( ) Não & ( ) Sim. Qual queixa? & \\
\hline \multicolumn{3}{|c|}{$\begin{array}{l}7 \text { - Classifique o conforto térmico em relação ao seu ponto de trabalho / estudo. } \\
\text { a) Em dias muito quentes: }\end{array}$} \\
\hline ( ) Muito quente & ( ) Quente & ( ) Levemente quente \\
\hline ( ) Muito fria & ( ) Fria & ( ) Levemente fria \\
\hline \multicolumn{3}{|l|}{ ( ) Neutra } \\
\hline \multicolumn{3}{|l|}{ b) Em dias muito frios: } \\
\hline ( ) Muito quente & ( ) Quente & ( ) Levemente quente \\
\hline ( ) Muito fria & ( ) Fria & ( ) Levemente fria \\
\hline \multicolumn{3}{|l|}{ ( ) Neutra } \\
\hline c) Em geral: & & \\
\hline ( ) Muito quente & ( ) Quente & ( ) Levemente quente \\
\hline ( ) Muito fria & ( ) Fria & ( ) Levemente fria \\
\hline ( ) Neutra & & \\
\hline
\end{tabular}


8 - Classifique como o conforto térmico do seu local contribui com seu trabalho / estudo:

( ) Favorece ( ) Neutra ( ) Atrapalha

9 - Em geral, como você classifica o ar em seu local de trabalho / estudo?

( ) Limpo ( ) Parado ( ) Odores: Mofo

( ) Empoeirado ( ) Odores:Comida ( ) Odores: Mobiliário

( ) Odores: Outro

10 - Antes de ocupar o prédio você já apresentou:

( ) Problemas respiratórios: asma, bronquite

( ) Sinusite

( ) Uso de lentes de contato

( ) Hábito de fumar (últimos 2 anos)

11- Quantas horas por dia você utiliza o computador em seu local de trabalho / estudo na Biblioteca? ( ) Período Integral ( ) Mais do que meio período ( ) Menos do que meio período 12 - Você apresenta alguns destes sintomas com freqüência?

( ) Olhos secos

( ) Dor de cabeça

( ) Olhos lacrimejantes

( ) Nariz entupido / Coriza

( ) Dor no peito / Falta de ar

13 - Como você classifica o ruído existente no seu posto de trabalho ou estudo?
( ) Extremo
( ) Alto
( ) Moderado
( ) Baixo

14 - Você considera seu desempenho afetado pelos efeitos do ruído?
( ) Sempre
( ) Frequentemente
( ) Ocasionalmente
( ) Raramente

15 - A sua comunicação com as pessoas ao redor é afetada pelo ruído?
( ) Sempre
( ) Frequentemente
( ) Ocasionalmente
( ) Raramente

16 - Você sente necessidade de controlar o ruído ao seu redor?

( ) Sempre ( ) Frequentemente ( ) Ocasionalmente ( ) Raramente 17 - Descreva algum ponto que considere relevante relativo à qualidade do ar e do conforto térmico e acústico de sua estação de trabalho: 


\begin{abstract}
ANEXO II
CONCENTRAÇÃO MÉDIA DIÁRIA DE MATERIAL PARTICULADO NOS PISOS 1, 2, 3 E NO AMBIENTE EXTERNO $\left(\mathrm{MP}_{1,0} ; \mathrm{MP}_{2,5} ; \mathrm{MP}_{7,0} ; \mathrm{MP}_{10,0} \mathrm{E} \mathrm{MPT}\right)$
\end{abstract}


Tabela 1 - Concentração média diária de material particulado no Piso 1.

\begin{tabular}{|c|c|c|c|c|c|}
\cline { 2 - 6 } \multicolumn{1}{c|}{} & $\mathrm{MP}_{1,0}$ & $\mathrm{MP}_{2,5}$ & $\mathrm{MP}_{7,0}$ & $\mathrm{MP}_{10,0}$ & $\mathrm{MPT}$ \\
\hline $28 / 04 / 2009$ & 0,5 & 3,2 & 11,3 & 15,2 & 23,7 \\
\hline $08 / 05 / 2009$ & 1,4 & 5,1 & 13,9 & 18,2 & 25,0 \\
\hline $22 / 05 / 2009$ & 0,8 & 3,0 & 7,7 & 10,5 & 15,2 \\
\hline $02 / 06 / 2009$ & 0,0 & 1,7 & 7,5 & 10,0 & 15,9 \\
\hline $09 / 06 / 2009$ & 1,1 & 4,8 & 14,2 & 19,2 & 28,6 \\
\hline $19 / 06 / 2009$ & 0,0 & 2,1 & 8,7 & 12,0 & 17,8 \\
\hline $03 / 07 / 2009$ & 0,9 & 4,7 & 12,9 & 16,8 & 23,8 \\
\hline $06 / 07 / 2009$ & 3,5 & 8,2 & 13,7 & 16,6 & 22,3 \\
\hline $16 / 07 / 2009$ & 0,2 & 3,8 & 17,1 & 24,9 & 40,9 \\
\hline $05 / 08 / 2009$ & 2,5 & 9,2 & 25,9 & 34,0 & 49,4 \\
\hline $06 / 08 / 2009$ & 1,3 & 8,2 & 33,4 & 46,4 & 66,6 \\
\hline $04 / 05 / 2010$ & 0,6 & 3,9 & 15,2 & 21,4 & 35,3 \\
\hline $12 / 05 / 2010$ & 0,0 & 1,1 & 6,2 & 9,2 & 15,8 \\
\hline $18 / 05 / 2010$ & 0,8 & 4,5 & 19,0 & 28,5 & 45,1 \\
\hline $31 / 05 / 2010$ & 0,0 & 1,1 & 8,0 & 11,5 & 21,4 \\
\hline $20 / 07 / 2010$ & 0,1 & 1,9 & 9,3 & 14,3 & 23,3 \\
\hline $21 / 07 / 2010$ & 0,8 & 3,5 & 10,7 & 15,1 & 22,4 \\
\hline $03 / 08 / 2010$ & 0,0 & 2,8 & 15,2 & 22,9 & 35,8 \\
\hline $09 / 08 / 2010$ & 1,1 & 6,5 & 25,4 & 34,6 & 47,6 \\
\hline $24 / 08 / 2010$ & 1,8 & 6,8 & 21,7 & 32,0 & 47,6 \\
\hline $30 / 08 / 2010$ & 1,2 & 6,4 & 28,8 & 42,7 & 64,1 \\
\hline $15 / 09 / 2010$ & 1,0 & 3,3 & 13,0 & 19,0 & 29,2 \\
\hline
\end{tabular}

Tabela 2 - Concentração média diária de material particulado no Piso 2.

\begin{tabular}{|c|c|c|c|c|c|}
\cline { 2 - 6 } \multicolumn{1}{c|}{} & $\mathrm{MP}_{1,0}$ & $\mathrm{MP}_{2,5}$ & $\mathrm{MP}_{7,0}$ & $\mathrm{MP}_{10,0}$ & $\mathrm{MPT}$ \\
\hline Dia & $\mu \mathrm{g} / \mathrm{m}^{3}$ & $\mu \mathrm{g} / \mathrm{m}^{3}$ & $\mu \mathrm{g} / \mathrm{m}^{3}$ & $\mu \mathrm{g} / \mathrm{m}^{3}$ & $\mu \mathrm{g} / \mathrm{m}^{3}$ \\
\hline $09 / 12 / 2009$ & 0,0 & 1,8 & 5,6 & 7,0 & 10,1 \\
\hline $10 / 12 / 2009$ & 0,0 & 1,0 & 4,6 & 6,2 & 8,8 \\
\hline $15 / 12 / 2009$ & 0,0 & 1,4 & 6,7 & 9,1 & 13,9 \\
\hline $16 / 12 / 2009$ & 0,1 & 2,4 & 7,7 & 10,3 & 14,8 \\
\hline $05 / 05 / 2010$ & 0,7 & 5,1 & 25,0 & 35,5 & 51,3 \\
\hline $13 / 05 / 2010$ & 0,0 & 1,2 & 6,8 & 9,7 & 15,1 \\
\hline $21 / 05 / 2010$ & 0,0 & 1,8 & 9,9 & 14,5 & 25,5 \\
\hline $01 / 06 / 2010$ & 0,0 & 3,5 & 12,3 & 17,2 & 25,0 \\
\hline $06 / 08 / 2010$ & 0,5 & 2,4 & 8,9 & 12,6 & 19,3 \\
\hline $11 / 08 / 2010$ & 0,4 & 3,3 & 13,7 & 20,0 & 30,5 \\
\hline $20 / 08 / 2010$ & 0,1 & 3,2 & 16,5 & 25,3 & 38,0 \\
\hline $27 / 08 / 2010$ & 0,8 & 4,6 & 21,3 & 33,4 & 52,2 \\
\hline
\end{tabular}


Tabela 3 - Concentração média diária de material particulado no Piso 3.

\begin{tabular}{|c|c|c|c|c|c|}
\cline { 2 - 6 } \multicolumn{1}{c|}{} & $\mathrm{MP}_{1,0}$ & $\mathrm{MP}_{2,5}$ & $\mathrm{MP}_{7,0}$ & $\mathrm{MP}_{10,0}$ & $\mathrm{MPT}$ \\
\hline $20 / 08 / 2009$ & 0,6 & 3,2 & 7,8 & 9,7 & 14,1 \\
\hline $02 / 09 / 2009$ & 0,0 & 2,4 & 11,3 & 16,3 & 24,0 \\
\hline $09 / 09 / 2009$ & 0,1 & 2,1 & 5,7 & 7,6 & 10,9 \\
\hline $16 / 09 / 2009$ & 1,9 & 5,5 & 13,3 & 17,2 & 23,6 \\
\hline $21 / 09 / 2009$ & 1,4 & 5,0 & 11,9 & 14,7 & 18,7 \\
\hline $30 / 09 / 2009$ & 0,1 & 2,3 & 7,9 & 11,1 & 17,6 \\
\hline $07 / 10 / 2009$ & 0,3 & 2,7 & 7,4 & 9,4 & 12,8 \\
\hline $08 / 10 / 2009$ & 0,0 & 1,8 & 7,0 & 9,8 & 14,6 \\
\hline $14 / 10 / 2009$ & 0,0 & 1,2 & 6,5 & 9,4 & 13,8 \\
\hline $21 / 10 / 2009$ & 0,0 & 1,1 & 6,4 & 9,3 & 14,2 \\
\hline $28 / 10 / 2009$ & 0,1 & 2,1 & 7,7 & 10,9 & 16,6 \\
\hline $11 / 11 / 2009$ & 0,0 & 1,5 & 7,3 & 10,6 & 15,7 \\
\hline $12 / 11 / 2009$ & 0,1 & 1,5 & 5,4 & 7,6 & 11,4 \\
\hline $18 / 11 / 2009$ & 0,0 & 1,4 & 6,7 & 9,6 & 14,7 \\
\hline $19 / 11 / 2009$ & 0,1 & 2,0 & 9,1 & 12,9 & 19,0 \\
\hline $07 / 05 / 2010$ & 0,5 & 3,6 & 15,3 & 21,7 & 31,0 \\
\hline $20 / 05 / 2010$ & 0,0 & 1,0 & 4,6 & 6,2 & 11,3 \\
\hline $26 / 05 / 2010$ & 0,1 & 2,1 & 8,8 & 12,2 & 18,3 \\
\hline $23 / 07 / 2010$ & 0,5 & 4,1 & 16,4 & 22,7 & 30,3 \\
\hline $10 / 08 / 2010$ & 0,1 & 2,0 & 7,6 & 10,8 & 15,7 \\
\hline $17 / 08 / 2010$ & 0,6 & 3,5 & 13,4 & 19,3 & 29,7 \\
\hline $08 / 09 / 2010$ & 0,1 & 1,9 & 7,5 & 10,6 & 16,0 \\
\hline
\end{tabular}

Tabela 4 - Concentração média diária de material particulado no ambiente externo.

\begin{tabular}{|c|c|c|c|c|c|}
\cline { 2 - 6 } \multicolumn{1}{c|}{} & $\mathrm{MP}_{1,0}$ & $\mathrm{MP}_{2,5}$ & $\mathrm{MP}_{7,0}$ & $\mathrm{MP}_{10,0}$ & $\mathrm{MPT}$ \\
\hline Dia & $\mu \mathrm{g} / \mathrm{m}^{3}$ & $\mu \mathrm{g} / \mathrm{m}^{3}$ & $\mu \mathrm{g} / \mathrm{m}^{3}$ & $\mu \mathrm{g} / \mathrm{m}^{3}$ & $\mu \mathrm{g} / \mathrm{m}^{3}$ \\
\hline $18 / 03 / 2010$ & 0,2 & 1,7 & 6,2 & 8,5 & 12,5 \\
\hline $23 / 03 / 2010$ & 0,0 & 1,3 & 7,4 & 10,6 & 16,3 \\
\hline $08 / 04 / 2010$ & 0,1 & 3,0 & 9,6 & 12,2 & 16,7 \\
\hline $11 / 05 / 2010$ & 0,4 & 2,8 & 9,9 & 12,8 & 20,1 \\
\hline $25 / 05 / 2010$ & 0,1 & 2,5 & 13,7 & 20,7 & 31,8 \\
\hline $28 / 05 / 2010$ & 0,1 & 3,4 & 10,9 & 13,8 & 21,2 \\
\hline $20 / 07 / 2010$ & 0,1 & 1,9 & 9,3 & 14,3 & 23,3 \\
\hline $05 / 08 / 2010$ & 0,4 & 3,5 & 14,5 & 21,1 & 35,7 \\
\hline $19 / 08 / 2010$ & 0,6 & 4,1 & 18,3 & 27,1 & 44,1 \\
\hline $26 / 08 / 2010$ & 0,5 & 4,2 & 19,8 & 30,9 & 51,4 \\
\hline $03 / 09 / 2010$ & 0,6 & 4,2 & 20,9 & 32,1 & 53,7 \\
\hline
\end{tabular}




\section{ANEXO III}

CONCENTRAÇÃO DE BIOAEROSSÓIS NOS PISOS 1, 2, 3 E NO AMBIENTE EXTERNO 
Tabela 1 - Concentração de bioaerossóis no Piso 1.

\begin{tabular}{|c|c|c|c|c|c|}
\hline $\begin{array}{c}\text { Data da } \\
\text { coleta }\end{array}$ & $\begin{array}{c}\text { Colônias } \\
\text { Fungos } \\
\end{array}$ & $\begin{array}{l}\text { Colônias } \\
\text { Bactérias }\end{array}$ & $\begin{array}{l}\mathrm{UFC}^{\prime} \mathrm{m}^{3} \\
\text { Fungos } \\
\end{array}$ & $\begin{array}{c}\mathrm{UFC} / \mathrm{m}^{3} \\
\text { Bactérias }\end{array}$ & $\begin{array}{c}\mathrm{UFC}^{\mathrm{m}} \mathbf{m}^{3} \\
\text { Total } \\
\end{array}$ \\
\hline $22 / 04 / 09$ & 66 & \begin{tabular}{|l|}
92 \\
\end{tabular} & 66 & 92 & 158 \\
\hline $28 / 04 / 09$ & 155 & 136 & 155 & 136 & 291 \\
\hline $08 / 05 / 09$ & 132 & 118 & 132 & 118 & 250 \\
\hline $22 / 05 / 09$ & 134 & 98 & 134 & 98 & 232 \\
\hline 02/06/09 & 39 & 51 & 20 & 26 & 45 \\
\hline 09/06/09 & 158 & 139 & 79 & 70 & 149 \\
\hline $19 / 06 / 09$ & 181 & 92 & 151 & 77 & 228 \\
\hline 03/07/09 & 196 & 146 & 163 & 122 & 285 \\
\hline 06/07/09 & 129 & 142 & 108 & 118 & 226 \\
\hline $16 / 07 / 09$ & 156 & 171 & 130 & 143 & 273 \\
\hline 06/08/09 & 142 & 78 & 118 & 65 & 183 \\
\hline $04 / 05 / 10$ & 132 & 125 & 66 & 63 & 129 \\
\hline $12 / 05 / 10$ & 98 & 41 & 49 & 21 & 70 \\
\hline $18 / 05 / 10$ & 177 & 112 & 89 & 56 & 145 \\
\hline $31 / 05 / 10$ & 117 & 106 & 59 & 53 & 112 \\
\hline $10 / 06 / 10$ & 154 & 58 & 77 & 29 & 106 \\
\hline $08 / 07 / 10$ & 276 & 197 & 138 & 99 & 237 \\
\hline $13 / 07 / 10$ & 103 & 68 & 52 & 34 & 86 \\
\hline $21 / 07 / 10$ & 212 & 126 & 106 & 63 & 169 \\
\hline $03 / 08 / 10$ & 134 & 66 & 67 & 33 & 100 \\
\hline $09 / 08 / 10$ & 132 & 126 & 66 & 63 & 129 \\
\hline $10 / 08 / 10$ & 58 & 37 & 29 & 19 & 48 \\
\hline $24 / 08 / 10$ & 146 & 124 & 73 & 62 & 135 \\
\hline $26 / 08 / 10$ & 105 & 109 & 53 & 55 & 107 \\
\hline $30 / 08 / 10$ & 54 & 122 & 27 & 61 & 88 \\
\hline
\end{tabular}


Tabela 2 - Concentração de bioaerossóis no Piso 2.

\begin{tabular}{|c|c|c|c|c|c|}
\hline $\begin{array}{c}\text { Data da } \\
\text { coleta }\end{array}$ & $\begin{array}{c}\text { Colônias } \\
\text { Fungos }\end{array}$ & $\begin{array}{c}\text { Colônias } \\
\text { Bactérias }\end{array}$ & $\begin{array}{c}\mathbf{U F C}^{3} \mathbf{m}^{3} \\
\text { Fungos }\end{array}$ & $\begin{array}{c}\mathbf{U F C}^{3} \mathbf{m}^{3} \\
\text { Bactérias }\end{array}$ & $\begin{array}{c}\mathbf{U F C}^{3} \\
\text { Total }\end{array}$ \\
\hline $09 / 12 / 09$ & 97 & 158 & 49 & 79 & 128 \\
\hline $10 / 12 / 09$ & 33 & 45 & 17 & 23 & 39 \\
\hline $15 / 12 / 09$ & 73 & 123 & 37 & 62 & 98 \\
\hline $16 / 12 / 09$ & 88 & 66 & 44 & 33 & 77 \\
\hline $05 / 05 / 10$ & 66 & 146 & 33 & 73 & 106 \\
\hline $13 / 05 / 10$ & 81 & 56 & 41 & 28 & 69 \\
\hline $21 / 05 / 10$ & 142 & 80 & 71 & 40 & 111 \\
\hline $01 / 06 / 10$ & 173 & 68 & 87 & 34 & 121 \\
\hline $09 / 06 / 10$ & 156 & 83 & 78 & 42 & 120 \\
\hline $14 / 06 / 10$ & 267 & 235 & 134 & 118 & 251 \\
\hline $24 / 06 / 10$ & 220 & 259 & 110 & 130 & 240 \\
\hline $15 / 07 / 10$ & 193 & 146 & 97 & 73 & 170 \\
\hline $22 / 07 / 10$ & 217 & 149 & 109 & 75 & 183 \\
\hline $06 / 08 / 10$ & 158 & 63 & 79 & 32 & 111 \\
\hline $09 / 08 / 10$ & 132 & 126 & 66 & 63 & 129 \\
\hline $11 / 08 / 10$ & 127 & 103 & 64 & 52 & 115 \\
\hline $20 / 08 / 10$ & 98 & 76 & 49 & 38 & 87 \\
\hline $27 / 08 / 10$ & 88 & 126 & 44 & 63 & 107 \\
\hline
\end{tabular}


Tabela 3 - Concentração de bioaerossóis no Piso 3.

\begin{tabular}{|c|c|c|c|c|c|}
\hline $\begin{array}{c}\text { Data da } \\
\text { coleta }\end{array}$ & $\begin{array}{c}\text { Colônias } \\
\text { Fungos }\end{array}$ & $\begin{array}{c}\text { Colônias } \\
\text { Bactérias }\end{array}$ & $\begin{array}{c}\text { UFC/m } \\
\text { Fungos }\end{array}$ & $\begin{array}{c}\mathbf{U F C}^{3} \mathbf{m}^{3} \\
\text { Bactérias }\end{array}$ & $\begin{array}{c}\text { UFC/m } \\
\text { Total }\end{array}$ \\
\hline $20 / 08 / 09$ & 73 & 209 & 37 & 105 & 141 \\
\hline $02 / 09 / 09$ & 127 & 97 & 64 & 49 & 112 \\
\hline $09 / 09 / 09$ & 109 & 91 & 55 & 46 & 100 \\
\hline $16 / 09 / 09$ & 117 & 58 & 59 & 29 & 88 \\
\hline $21 / 09 / 09$ & 217 & 146 & 109 & 73 & 182 \\
\hline $30 / 09 / 09$ & 142 & 99 & 71 & 50 & 121 \\
\hline $07 / 10 / 09$ & 99 & 81 & 50 & 41 & 90 \\
\hline $21 / 10 / 09$ & 19 & 10 & 10 & 5 & 15 \\
\hline $07 / 05 / 10$ & 37 & 67 & 19 & 34 & 52 \\
\hline $20 / 05 / 10$ & 74 & 26 & 37 & 13 & 50 \\
\hline $26 / 05 / 10$ & 157 & 63 & 79 & 32 & 110 \\
\hline $08 / 06 / 10$ & 196 & 103 & 98 & 52 & 150 \\
\hline $15 / 06 / 10$ & 189 & 129 & 95 & 65 & 159 \\
\hline $21 / 06 / 10$ & 258 & 207 & 129 & 104 & 233 \\
\hline $30 / 06 / 10$ & 208 & 188 & 104 & 94 & 198 \\
\hline $07 / 07 / 10$ & 263 & 223 & 132 & 112 & 243 \\
\hline $14 / 07 / 10$ & 183 & 137 & 92 & 69 & 160 \\
\hline $10 / 08 / 10$ & 58 & 37 & 29 & 19 & 48 \\
\hline $17 / 08 / 10$ & 113 & 63 & 57 & 32 & 88 \\
\hline $08 / 09 / 10$ & 87 & 120 & 44 & 60 & 104 \\
\hline
\end{tabular}

Tabela 4 - Concentração de bioaerossóis no ambiente externo.

\begin{tabular}{|c|c|c|c|c|c|}
\hline $\begin{array}{c}\text { Data da } \\
\text { coleta }\end{array}$ & $\begin{array}{c}\text { Colônias } \\
\text { Fungos }\end{array}$ & $\begin{array}{c}\text { Colônias } \\
\text { Bactérias }\end{array}$ & $\begin{array}{c}\mathbf{U F C / m}^{3} \\
\text { Fungos }\end{array}$ & $\begin{array}{c}{\mathbf{U F C} / \mathbf{m}^{3}}^{3} \\
\text { Bactérias }\end{array}$ & $\begin{array}{c}\mathbf{U F C}^{3} \mathbf{m}^{3} \\
\text { Total }\end{array}$ \\
\hline $11 / 05 / 10$ & 146 & 165 & 73 & 83 & 156 \\
\hline $25 / 05 / 10$ & 263 & 122 & 132 & 61 & 193 \\
\hline $28 / 05 / 10$ & 273 & 104 & 137 & 52 & 189 \\
\hline $02 / 06 / 10$ & 198 & 183 & 99 & 92 & 191 \\
\hline $16 / 06 / 10$ & 163 & 85 & 82 & 43 & 124 \\
\hline $22 / 06 / 10$ & 165 & 97 & 83 & 49 & 131 \\
\hline $01 / 07 / 10$ & 223 & 273 & 112 & 137 & 248 \\
\hline $06 / 07 / 10$ & 109 & 87 & 55 & 44 & 98 \\
\hline $20 / 07 / 10$ & 224 & 156 & 112 & 78 & 190 \\
\hline $05 / 08 / 10$ & 243 & 173 & 122 & 87 & 208 \\
\hline $19 / 08 / 10$ & 108 & 97 & 54 & 49 & 103 \\
\hline $26 / 08 / 10$ & 105 & 109 & 53 & 55 & 107 \\
\hline $03 / 09 / 10$ & 56 & 83 & 28 & 42 & 70 \\
\hline
\end{tabular}




\section{ANEXO IV}

DADOS DE RUÍDO PARA OS PISOS 1, 2, 3 E AMBIENTE EXTERNO 
Tabela 1 - Dados de ruído, em $\operatorname{dB}(A)$, no Piso 1.

\begin{tabular}{|c|c|c|c|c|c|c|c|c|c|c|}
\hline $18 / 05 / 10$ & $31 / 05 / 10$ & $10 / 06 / 10$ & $08 / 07 / 10$ & $13 / 07 / 10$ & $21 / 07 / 10$ & $03 / 08 / 10$ & $09 / 08 / 10$ & $24 / 08 / 10$ & $30 / 08 / 10$ & $15 / 09 / 10$ \\
\hline 54,8 & 61,2 & 64,2 & 56,2 & 65,1 & 60,3 & 59,3 & 64,9 & 58,2 & 66,9 & 68,5 \\
\hline 54,4 & 58,5 & 61,0 & 56,8 & 52,7 & 58,2 & 54,4 & 56,2 & 67,8 & 74,6 & 67,1 \\
\hline 56,5 & 62,1 & 54,7 & 56,8 & 61,4 & 56,2 & 59,3 & 64,5 & 68,7 & 74,1 & 62,4 \\
\hline 64,8 & 58,5 & 57,4 & 55,4 & 53,9 & 59,6 & 59,5 & 61,3 & 68,9 & 75,7 & 71,8 \\
\hline 62,7 & 61,6 & 58,9 & 60,5 & 52,3 & 53,7 & 59,2 & 54,8 & 61,5 & 79,4 & 67,4 \\
\hline 55,8 & 65,1 & 54,2 & 54,8 & 65,5 & 55,1 & 56,1 & 58,2 & 60,5 & 73,1 & 62,0 \\
\hline 59,6 & 59,3 & 58,9 & 58,4 & 60,8 & 61,5 & 54,8 & 68,2 & 67,9 & 67,5 & 69,4 \\
\hline 61,2 & 61,9 & 54,9 & 58,1 & 61,3 & 59,0 & 65,1 & 73,6 & 66,2 & 71,0 & 69,1 \\
\hline 59,1 & 58,2 & 58,5 & 55,0 & 62,3 & 74,9 & 62,2 & 64,4 & 65,1 & 75,7 & 60,9 \\
\hline 56,2 & 66,1 & 59,1 & 59,0 & 55,3 & 57,4 & 66,0 & 72,1 & 61,6 & 74,9 & 62,4 \\
\hline 59,1 & 64,6 & 64,4 & 65,9 & 60,1 & 58,8 & 56,7 & 63,8 & 58,1 & 73,6 & 61,8 \\
\hline 54,8 & 64,4 & 59,4 & 57,3 & 61,6 & 63,1 & 56,6 & 68,5 & 63,6 & 62,4 & 64,0 \\
\hline 62,4 & 59,5 & 55,2 & 61,1 & 67,7 & 60,5 & 63,9 & 74,5 & 59,3 & 64,4 & 68,0 \\
\hline 63,3 & 63,3 & 55,3 & 62,8 & 58,7 & 61,4 & 57,2 & 56,6 & 62,2 & 60,9 & 70,5 \\
\hline 64,0 & 67,1 & 69,3 & 61,2 & 67,1 & 63,0 & 59,5 & 71,3 & 66,7 & 64,4 & 62,0 \\
\hline 67,1 & 63,5 & 61,7 & 62,4 & 60,9 & 54,9 & 65,0 & 61,4 & 59,3 & 69,1 & 67,1 \\
\hline 69,4 & 61 & 58,1 & 64,6 & 53,8 & 55,6 & 53,8 & 56,5 & 63,0 & 60,1 & 60,7 \\
\hline 66,8 & 61,9 & 60,5 & 60,0 & 74,6 & 60,0 & 62,3 & 60,1 & 57,3 & 65,0 & 68,4 \\
\hline 67,7 & 58,4 & 56,5 & 62,9 & 60,7 & 57,5 & 56,2 & 65,8 & 68,2 & 60,7 & 66,7 \\
\hline 63,2 & 61,1 & 59,7 & 58,9 & 59,7 & 59,1 & 66,8 & 58,6 & 69,0 & 62,8 & 63,6 \\
\hline 66,3 & 58,4 & 61,8 & 59,7 & 58,9 & 60,5 & 56,0 & 66,5 & 58,1 & 61,8 & 66,2 \\
\hline 68,9 & 59,3 & 64,7 & 62,4 & 58,0 & 59,5 & 55,5 & 58,1 & 60,1 & 60,0 & 59,3 \\
\hline 70,8 & 56,2 & 62,4 & 68,6 & 66,9 & 60,1 & 57,7 & 61,2 & 59,1 & 66,2 & 60,9 \\
\hline 69,4 & 56,7 & 59,2 & 65,9 & 57,9 & 58,2 & 58,1 & 63,1 & 62,2 & 65,4 & 74,7 \\
\hline 64,8 & 57,7 & 61,2 & 70,2 & 62,2 & 57,0 & 67,3 & 66,5 & 59,7 & 69,4 & 67,3 \\
\hline 66,7 & 62,2 & 56,8 & 61,0 & 63,5 & 59,2 & 62,0 & 70,2 & 59,3 & 60,9 & 61,0 \\
\hline 65,5 & 58,8 & 62,1 & 69,1 & 53,8 & 67,5 & 58,7 & 68,6 & 66,9 & 62,9 & 67,8 \\
\hline 62,0 & 71,6 & 61,3 & 60,1 & 66,7 & 55,8 & 59,3 & 62,6 & 65,9 & 66,5 & 68,7 \\
\hline 65,1 & 61,5 & 60,6 & 58,4 & 60,4 & 67,3 & 57,9 & 64,3 & 73,7 & 67,6 & 70,2 \\
\hline 61,5 & 63,1 & 63,6 & 62,9 & 56,1 & 55,7 & 70,2 & 66,3 & 60,1 & 76,4 & 73,4 \\
\hline 62,4 & 59,5 & 57,1 & 62,3 & 66,6 & 61,6 & 67,1 & 62,3 & 61,3 & 61,8 & 68,7 \\
\hline 62,3 & 58 & 73,3 & 68,7 & 55,2 & 58,5 & 56,9 & 65,5 & 68,6 & 59,8 & 71,7 \\
\hline 62,2 & 65 & 59,3 & 58,4 & 58,2 & 60,7 & 59,2 & 59,9 & 59,3 & 71,7 & 61,4 \\
\hline 63,2 & 58,7 & 56,8 & 71,0 & 60,7 & 57,9 & 61,4 & 65,4 & 66,7 & 67,1 & 71,0 \\
\hline 60,6 & 61,6 & 65,9 & 61,5 & 59,3 & 62,9 & 57,7 & 70,6 & 67,1 & 71,5 & 67,3 \\
\hline 65,5 & 61,6 & 57,1 & 62,1 & 61,6 & 59,9 & 58,0 & 69,3 & 60,9 & 59,9 & 58,4 \\
\hline 60,8 & 67,4 & 67,0 & 62,2 & 63,0 & 64,3 & 60,9 & 61,2 & 67,7 & 71,0 & 67,9 \\
\hline 59,3 & 59,6 & 64,4 & 59,3 & 60,9 & 58,5 & 64,5 & 62,4 & 62,4 & 69,3 & 59,3 \\
\hline 69,4 & 59,1 & 58,2 & 55,8 & 56,2 & 59,3 & 59,0 & 69,2 & 74,0 & 60,9 & 62,2 \\
\hline 62,2 & 59,9 & 59,6 & 61,5 & 57,3 & 56,8 & 68,7 & 65,2 & 65,1 & 70,4 & 57,4 \\
\hline 69,0 & 64,2 & 54,6 & 63,5 & 62,8 & 60,3 & 58,9 & 60,0 & 62,0 & 63,6 & 66,1 \\
\hline 61,8 & 65,2 & 61,6 & 68,7 & 55,7 & 57,4 & 57,5 & 63,2 & 62,4 & 70,9 & 59,2 \\
\hline 55,3 & 61,2 & 59,3 & 58,8 & 66,9 & 58,1 & 59,5 & 61,4 & 62,4 & 64,4 & 61,8 \\
\hline 64,3 & 60,3 & 54,6 & 56,2 & 55,3 & 60,8 & 62,2 & 74,3 & 74,0 & 67,5 & 62,8 \\
\hline 67,5 & 56,2 & 60,8 & 63,7 & 57,2 & 59,1 & 68,1 & 66,7 & 62,9 & 74,1 & 66,3 \\
\hline 63,2 & 63,2 & 56,6 & 54,6 & 57,3 & 59,7 & 60,8 & 63,5 & 65,0 & 65,0 & 63,5 \\
\hline 61,9 & 65,2 & 63,4 & 64,4 & 58,3 & 58,0 & 58,3 & 69,1 & 66,6 & 66,9 & 70,8 \\
\hline 56,6 & 56,1 & 56,1 & 60,4 & 59,8 & 57,2 & 63,5 & 66,3 & 69,0 & 66,0 & 69,2 \\
\hline 58,1 & 59,3 & 60,0 & 58,2 & 58,9 & 61,6 & 63,0 & 65,1 & 58,3 & 71,3 & 73,6 \\
\hline 64,4 & 59,7 & 59,3 & 57,5 & 58,6 & 58,0 & 72,8 & 63,9 & 70,7 & 73,7 & 69,8 \\
\hline 57,5 & 60,5 & 61,0 & 62,4 & 57,4 & 59,8 & 57,3 & 60,2 & 59,2 & 62,0 & 67,3 \\
\hline 60,7 & 62,7 & 57,7 & 57,7 & 54,3 & 61,1 & 62,3 & 59,9 & 63,3 & 61,0 & 70,6 \\
\hline 60,7 & 63,1 & 57,7 & 59,9 & 57,5 & 60,8 & 66,3 & 66,3 & 59,1 & 58,5 & 64,0 \\
\hline 62,8 & 60,1 & 62,3 & 57,9 & 62,8 & 65,2 & 60,2 & 66,3 & 67,7 & 63,8 & 68,4 \\
\hline 66,9 & 66,9 & 55,1 & 63,7 & 55,8 & 57,5 & 70,4 & 64,0 & 62,4 & 69,3 & 70,2 \\
\hline 76,5 & 61,7 & 53,8 & 54,6 & 57,7 & 66,6 & 63,9 & 60,0 & 62,6 & 55,1 & 65,2 \\
\hline 58,1 & 64,9 & 58,5 & 65,5 & 56,8 & 57,7 & 63,5 & 63,1 & 70,2 & 62,4 & 59,3 \\
\hline 62,4 & 61,6 & 65,2 & 57,1 & 62,4 & 56,0 & 66,7 & 60,7 & 64,5 & 67,9 & 61,0 \\
\hline 62,4 & 64,8 & 57,7 & 57,7 & 56,4 & 64,6 & 58,5 & 65,2 & 72,3 & 59,0 & 66,3 \\
\hline 62,4 & 60,6 & 63,6 & 66,2 & 55,8 & 58,9 & 62,4 & 63,1 & 62,9 & 64,5 & 61,0 \\
\hline 62,1 & 61,2 & 59,0 & 55,8 & 65,2 & 57,5 & 63,0 & 65,4 & 60,2 & 67,9 & 57,9 \\
\hline 64,2 & 64,8 & 63,2 & 57,3 & 54,6 & 56,6 & 63,8 & 62,8 & 67,1 & 65,7 & 64,0 \\
\hline 65,5 & 62,8 & 56,2 & 59,9 & 61,1 & 54,6 & 67,9 & 60,8 & 58,8 & 59,6 & 58,5 \\
\hline 66,6 & 62 & 55,5 & 61,5 & 55,4 & 55,7 & 66,1 & 64,6 & 58,9 & 58,5 & 60,7 \\
\hline 60,4 & 57,1 & 63,4 & 65,1 & 56,7 & 62,3 & 66,2 & 60,5 & 60,2 & 67,8 & 56,4 \\
\hline 63,0 & 60,3 & 62,7 & 65,5 & 56,4 & 54,6 & 65,2 & 61,2 & 59,6 & 66,5 & 57,7 \\
\hline 65,5 & 55,5 & 60,9 & 66,9 & 56,9 & 59,9 & 59,6 & 58,1 & 70,6 & 56,5 & 61,1 \\
\hline 62,6 & 64,3 & 64,6 & 55,2 & 68,2 & 59,0 & 59,8 & 61,6 & 60,3 & 66,3 & 60,8 \\
\hline 67,8 & 60 & 53,8 & 55,7 & 57,4 & 56,9 & 65,1 & 66,5 & 64,8 & 56,8 & 70,4 \\
\hline 63,4 & 70,9 & 57,7 & 62,0 & 54,0 & 58,5 & 67,1 & 62,0 & 64,2 & 68,1 & 59,4 \\
\hline 64,2 & 64,6 & 53,7 & 66,7 & 58,5 & 58,5 & 65,9 & 56,9 & 58,9 & 64,4 & 62,8 \\
\hline 61,0 & 61,9 & 64,6 & 62,0 & 56,2 & 58,4 & 61,3 & 57,1 & 62,3 & 59,6 & 59,0 \\
\hline 60,3 & 60,2 & 58,1 & 59,0 & 62,8 & 54,2 & 61,2 & 63,6 & 56,6 & 56,5 & 70,5 \\
\hline 61,8 & 60,9 & 55,5 & 55,9 & 62,0 & 64,2 & 59,1 & 57,6 & 65,5 & 59,4 & 65,5 \\
\hline 69,4 & 61,2 & 57,7 & 62,3 & 55,5 & 58,7 & 65,9 & 62,0 & 57,3 & 64,7 & 63,4 \\
\hline 65,9 & 60,7 & 54,2 & 59,9 & 56,9 & 56,8 & 65,2 & 63,7 & 56,8 & 57,3 & 64,8 \\
\hline 63,6 & 60,9 & 57,2 & 63,6 & 53,4 & 56,9 & 56,0 & 59,8 & 64,4 & 59,1 & 67,8 \\
\hline
\end{tabular}


Tabela 1 - Dados de ruído, em dB(A), no Piso 1 (Continuação).

\begin{tabular}{|c|c|c|c|c|c|c|c|c|c|c|}
\hline $18 / 05 / 10$ & $31 / 05 / 10$ & $10 / 06 / 10$ & $08 / 07 / 10$ & $13 / 07 / 10$ & $21 / 07 / 10$ & $03 / 08 / 10$ & $09 / 08 / 10$ & $24 / 08 / 10$ & $30 / 08 / 10$ & $15 / 09 / 10$ \\
\hline 63,0 & 56,9 & 56,1 & 69,4 & 55,3 & 52,8 & 65,4 & 59,3 & 56,4 & 61,2 & 64,0 \\
\hline 64,6 & 61,6 & 53,0 & 54,4 & 59,2 & 58,3 & 59,0 & 65,0 & 61,2 & 59,5 & 61,8 \\
\hline 61,3 & 60,7 & 62,0 & 59,3 & 55,7 & 59,6 & 73,7 & 67,8 & 59,0 & 66,9 & 62,4 \\
\hline 71,3 & 64,4 & 58,3 & 59,5 & 66,9 & 55,0 & 63,8 & 66,5 & 58,3 & 65,3 & 60,7 \\
\hline 65,7 & 60,1 & 61,1 & 57,7 & 58,7 & 55,3 & 66,6 & 67,0 & 62,2 & 57,3 & 58,9 \\
\hline 61,5 & 65,1 & 65,1 & $\begin{array}{ll}60,7 \\
\end{array}$ & 65,5 & 53,3 & 66,6 & 71,0 & 56,9 & 60,5 & 62,6 \\
\hline 66,2 & 56,8 & 63,5 & 57,9 & 58,5 & 57,9 & 61,8 & 70,8 & 69,8 & 57,4 & 60,6 \\
\hline 65,5 & $\begin{array}{l}57,3 \\
\end{array}$ & 65,2 & 60,8 & $\begin{array}{l}55,8 \\
\end{array}$ & 64,0 & 66,7 & 69,3 & 59,8 & 68,7 & 59,5 \\
\hline 67,6 & 62,2 & 60,9 & 59,8 & 62,2 & 54,6 & 64,8 & 67,7 & 59,6 & 62,2 & 58,2 \\
\hline 61,6 & 60,4 & 72,7 & 65,2 & 56,9 & 63,9 & 59,5 & 67,9 & 66,7 & 56,9 & 65,0 \\
\hline 60,4 & 63,7 & 60,4 & 55,6 & 66,7 & 58,5 & 70,2 & 60,6 & 64,3 & 66,7 & 69,6 \\
\hline 61,2 & 57,9 & 62,4 & 54,6 & 59,7 & 62,4 & 70,1 & 65,9 & 62,0 & 64,6 & 71,7 \\
\hline 61,5 & 62,4 & 63,9 & 64,0 & 59,3 & 55,6 & 69,4 & 58,4 & 60,1 & 59,1 & 67,5 \\
\hline 60,3 & 57,1 & 67,3 & 57,5 & 65,2 & 57,2 & 62,4 & 69,4 & 65,2 & 59,5 & 64,1 \\
\hline 63,2 & 62,9 & 62,3 & 69,5 & 57,7 & 58,7 & 60,9 & 60,9 & 65,9 & 59,3 & 73,5 \\
\hline 66,7 & 56,1 & 64,7 & 55,7 & 63,0 & 54,5 & 68,9 & 65,2 & 60,9 & 67,1 & 70,6 \\
\hline 63,2 & 63,9 & 75,7 & 55,5 & 62,4 & 68,9 & 60,6 & 66,1 & 67,1 & 56,6 & 71,6 \\
\hline 63,7 & 58,8 & 62,1 & 59,0 & 56,8 & 60,0 & 68,7 & 58,6 & 62,6 & 67,3 & 75,2 \\
\hline 67,1 & 60 & 62,4 & $\begin{array}{l}56,1 \\
\end{array}$ & 60,4 & $\begin{array}{l}63,0 \\
\end{array}$ & 63,5 & 65,4 & 61,6 & 55,8 & 80,5 \\
\hline 68,2 & 55,5 & 57,9 & 70,2 & 55,9 & 56,0 & 63,7 & 60,1 & 62,8 & 58,0 & 69,7 \\
\hline 70,9 & 55,3 & 62,0 & 60,9 & 64,9 & 55,6 & 64,4 & 68,5 & 73,4 & 57,1 & $\begin{array}{l}69,7 \\
\end{array}$ \\
\hline 66,9 & 59 & 63,2 & $\begin{array}{l}59,1 \\
\end{array}$ & $\begin{array}{l}63,0 \\
\end{array}$ & 60,1 & 70,0 & 68,9 & 62,0 & $\begin{array}{l}73,7 \\
\end{array}$ & 74,5 \\
\hline $\begin{array}{ll}66,3 \\
\end{array}$ & 56,2 & 63,8 & 64,6 & 56,2 & 55,7 & 74,1 & 66,6 & 60,0 & 56,6 & 67,6 \\
\hline 62,6 & 56,2 & 63,0 & 56,9 & $\begin{array}{l}58,9 \\
\end{array}$ & $\begin{array}{l}57,7 \\
\end{array}$ & 59,3 & 71,8 & 59,5 & 65,2 & 69,6 \\
\hline 63,5 & 61,2 & 64,0 & 66,9 & 59,2 & 55,9 & 57,9 & 66,5 & 61,2 & 58,1 & 62,2 \\
\hline 62,2 & 59,9 & 60,3 & 67,5 & 59,1 & 61,2 & 61,6 & 68,5 & 59,8 & 68,7 & 63,5 \\
\hline 66,7 & 59,8 & 65,9 & 62,8 & $\begin{array}{l}63,0 \\
\end{array}$ & 70,2 & 65,9 & 67,3 & 63,2 & 62,8 & $\begin{array}{l}60,8 \\
\end{array}$ \\
\hline 59,2 & 59,5 & 65,3 & 64,1 & 60,2 & $\begin{array}{l}58,7 \\
\end{array}$ & 60,1 & 67,3 & 62,1 & 60,1 & 69,8 \\
\hline 60,4 & 59 & 58,5 & $\begin{array}{l}56,8 \\
\end{array}$ & 58,5 & 57,1 & 60,9 & 66,3 & $\begin{array}{l}56,8 \\
\end{array}$ & 59,2 & 61,4 \\
\hline 61,3 & $\begin{array}{l}58,3 \\
\end{array}$ & 60,5 & 60,9 & 56,2 & 62,0 & 59,3 & 67,1 & 70,6 & 63,7 & 66,8 \\
\hline 64,2 & 57,3 & 60,6 & 59,3 & 65,0 & 62,4 & 61,8 & 68,3 & 60,3 & 62,1 & 68,7 \\
\hline 60,3 & 61,2 & 63,9 & $\begin{array}{ll}60,8 \\
\end{array}$ & 62,2 & 66,1 & 57,9 & 67,3 & 62,3 & 57,1 & 63,4 \\
\hline 58,5 & 59,6 & 59,1 & 67,3 & $\begin{array}{l}55,9 \\
\end{array}$ & 60,3 & $\begin{array}{l}59,9 \\
\end{array}$ & $\begin{array}{l}65,9 \\
\end{array}$ & 70,0 & 66,9 & 65,5 \\
\hline 59,1 & 55,8 & 62,2 & 58,2 & 59,3 & 61,5 & 60,9 & 69,0 & 61,5 & 61,1 & 62,4 \\
\hline 62,0 & 62,2 & 62,4 & 61,5 & $\begin{array}{l}56,1 \\
\end{array}$ & 61,7 & 56,8 & 66,7 & 61,2 & 62,1 & 64,7 \\
\hline 58,1 & 58 & 60,8 & 61,4 & 58,8 & 57,1 & 62,4 & 66,6 & 64,8 & 62,4 & 61,6 \\
\hline 61,9 & 58,3 & 64,4 & 59,4 & 56,2 & 70,6 & 61,6 & 67,9 & 62,4 & 60,5 & 67,1 \\
\hline 62,7 & 57,7 & 67,1 & $\begin{array}{l}59,8 \\
\end{array}$ & 56,2 & 61,6 & 59,8 & 68,7 & 58,6 & 58,7 & 66,1 \\
\hline 60,1 & 58,5 & 66,7 & 55,5 & 64,6 & 62,8 & 61,2 & 68,4 & 57,3 & 58,1 & 62,0 \\
\hline 64,9 & $\begin{array}{l}56,1 \\
\end{array}$ & 63,6 & 64,5 & 61,3 & $\begin{array}{l}59,1 \\
\end{array}$ & $\begin{array}{l}59,9 \\
\end{array}$ & 69,0 & 61,2 & 61,9 & $\begin{array}{l}59,9 \\
\end{array}$ \\
\hline 60,5 & 61,8 & 65,1 & 63,0 & 61,8 & 66,6 & 62,4 & 71,4 & $\begin{array}{l}56,8 \\
\end{array}$ & 61,9 & 70,0 \\
\hline 58,9 & 56,2 & 62,2 & 64,3 & 56,8 & 59,6 & 65,1 & 69,1 & 66,1 & 61,6 & 62,4 \\
\hline 64,6 & 55 & 70,4 & 63,5 & 60,4 & 56,2 & 65,9 & 67,1 & 63,7 & 71,0 & 75,5 \\
\hline 61,2 & 63,7 & 65,0 & 61,5 & $\begin{array}{l}59,7 \\
\end{array}$ & 56,2 & 70,0 & 64,0 & 56,2 & 63,2 & 67,3 \\
\hline $\begin{array}{l}57,7 \\
\end{array}$ & 59 & 64,4 & 71,0 & $\begin{array}{l}57,9 \\
\end{array}$ & 59,0 & 63,8 & 67,0 & 64,4 & 62,4 & $\begin{array}{l}76,7 \\
\end{array}$ \\
\hline 58,5 & 59,8 & 59,3 & 65,3 & 66,5 & 58,9 & 66,1 & 67,3 & 60,3 & 62,3 & 66,3 \\
\hline 59,6 & 55,7 & 64,5 & 61,6 & 61,7 & $\begin{array}{l}59,8 \\
\end{array}$ & 62,9 & 68,2 & 69,4 & 59,0 & 63,3 \\
\hline 64,0 & $\begin{array}{l}57,9 \\
\end{array}$ & $\begin{array}{l}58,7 \\
\end{array}$ & $\begin{array}{l}58,4 \\
\end{array}$ & $\begin{array}{l}55,4 \\
\end{array}$ & 68,0 & 67,9 & 63,4 & $\begin{array}{l}59,1 \\
\end{array}$ & 64,2 & 68,5 \\
\hline 63,6 & 61,2 & 66,5 & 59,2 & $\begin{array}{l}58,8 \\
\end{array}$ & 58,0 & 60,1 & 65,8 & 61,6 & $\begin{array}{l}59,8 \\
\end{array}$ & $\begin{array}{l}58,3 \\
\end{array}$ \\
\hline 64,6 & 55,5 & 66,9 & 59,6 & 62,4 & 61,6 & 59,7 & 64,2 & 69,3 & 58,3 & 58,0 \\
\hline 61,8 & 56 & 64,7 & 63,4 & $\begin{array}{l}58,8 \\
\end{array}$ & 62,6 & 67,1 & 69,4 & 61,0 & 57,5 & 67,0 \\
\hline 63,9 & 60,7 & 60,5 & 64,5 & 57,7 & 60,3 & 69,4 & 69,6 & 63,7 & 61,6 & 61,4 \\
\hline 66,9 & 55,7 & 62,4 & 64,5 & $\begin{array}{l}56,2 \\
\end{array}$ & $\begin{array}{l}57,4 \\
\end{array}$ & 68,3 & 67,1 & 62,9 & 61,5 & 59,0 \\
\hline 65,0 & 60,9 & 63,4 & $\begin{array}{l}57,1 \\
\end{array}$ & $\begin{array}{l}57,7 \\
\end{array}$ & 63,5 & 62,3 & 66,5 & 63,5 & 68,2 & 65,2 \\
\hline 60,0 & 54,8 & 65,8 & 59,5 & 78,3 & 56,2 & 60,8 & 61,2 & 69,8 & 65,8 & $\begin{array}{l}58,9 \\
\end{array}$ \\
\hline $\begin{array}{l}57,7 \\
\end{array}$ & 57,6 & 65,9 & $\begin{array}{l}58,3 \\
\end{array}$ & $\begin{array}{l}66,3 \\
\end{array}$ & 54,2 & 61,0 & 62,0 & 61,6 & 63,1 & 67,5 \\
\hline 63,4 & 62 & 69,4 & 53,6 & 68,2 & 61,6 & 62,1 & 57,2 & 68,7 & 57,7 & 59,6 \\
\hline 61,2 & 57,7 & 64,8 & 59,1 & $\begin{array}{l}58,6 \\
\end{array}$ & $\begin{array}{l}58,7 \\
\end{array}$ & 73,2 & 62,8 & 60,7 & $\begin{array}{l}59,9 \\
\end{array}$ & 64,0 \\
\hline 63,8 & 57,9 & 66,5 & $\begin{array}{l}58,1 \\
\end{array}$ & 65,7 & 60,4 & 60,5 & 59,6 & 58,1 & 61,0 & 63,6 \\
\hline 60,4 & 63 & 69,2 & 55,4 & 59,2 & 63,9 & 57,5 & 61,3 & 65,5 & 62,8 & 62,9 \\
\hline 59,5 & 54,8 & 66,3 & 666,7 & 61,6 & 60,5 & 63,8 & 56,2 & 59,2 & $\begin{array}{l}57,9 \\
\end{array}$ & 61,6 \\
\hline 60,0 & 58,4 & 69,8 & 54,8 & 63,9 & 59,2 & 60,3 & 59,5 & 61,4 & 57,3 & 70,4 \\
\hline 58,5 & 57,4 & 67,4 & 59,0 & 57,6 & 58,0 & 60,9 & 58,3 & 59,9 & 59,8 & 67,6 \\
\hline 56,1 & 62,2 & 68,4 & 58,1 & 65,4 & 61,8 & 63,0 & 65,9 & 71,2 & 62,4 & 56,5 \\
\hline 55,5 & 65,2 & 74,9 & 70,1 & 65,5 & 58,5 & 63,1 & 67,6 & 65,0 & 60,0 & 66,7 \\
\hline $\begin{array}{l}59,1 \\
\end{array}$ & 54,6 & 63,2 & 65,2 & 75,9 & 65,7 & 60,3 & 67,7 & 62,2 & 60,9 & $\begin{array}{l}58,3 \\
\end{array}$ \\
\hline $\begin{array}{l}59,3 \\
\end{array}$ & $\begin{array}{l}55,9 \\
\end{array}$ & 57,6 & 61,6 & $\begin{array}{l}59,3 \\
\end{array}$ & 60,3 & 65,5 & 57,1 & 64,0 & $\begin{array}{l}68,5 \\
\end{array}$ & $\begin{array}{l}60,6 \\
\end{array}$ \\
\hline 65,3 & 64 & 58,7 & 63,5 & 62,4 & 54,9 & 63,9 & 62,0 & 57,5 & 67,1 & 62,4 \\
\hline 61,3 & 62,8 & $\begin{array}{l}59,7 \\
\end{array}$ & 61,2 & $\begin{array}{l}59,0 \\
\end{array}$ & 60,0 & 64,0 & 61,7 & 64,8 & $\begin{array}{l}59,6 \\
\end{array}$ & 71,8 \\
\hline 60,5 & 61,3 & $\begin{array}{l}57,6 \\
\end{array}$ & 63,5 & $\begin{array}{l}62,0 \\
\end{array}$ & 58,0 & 66,8 & 66,9 & 61,5 & 63,8 & 67,4 \\
\hline 67,5 & 59 & 65,9 & 64,0 & 66,7 & 58,7 & 61,3 & 61,2 & 59,5 & 59,5 & 64,4 \\
\hline 63,6 & 57,1 & 61,6 & 64,3 & $\begin{array}{l}59,2 \\
\end{array}$ & 59,3 & 61,0 & 61,6 & 67,4 & 58,4 & 61,0 \\
\hline 62,4 & 56,2 & 62,4 & 64,3 & 57,0 & 57,7 & 66,7 & 58,5 & 67,5 & 60,9 & 59,3 \\
\hline $\begin{array}{l}58,7 \\
\end{array}$ & 61,4 & 61,3 & 69,0 & 61,0 & $\begin{array}{l}56,4 \\
\end{array}$ & 68,1 & $\begin{array}{l}56,9 \\
\end{array}$ & 63,7 & 64,8 & 61,4 \\
\hline 60,0 & 57 & 71,0 & 70,1 & 61,0 & 60,0 & 61,1 & 61,3 & 68,3 & 63,7 & 61,0 \\
\hline 66,5 & 62,3 & 66,5 & 63,3 & 62,4 & 61,2 & 65,9 & 61,6 & 59,0 & 68,3 & 73,2 \\
\hline 59,3 & 57,7 & 64,4 & 62,7 & 55,4 & 66,5 & 60,8 & 62,4 & 66,1 & $\begin{array}{l}58,9 \\
\end{array}$ & 59,5 \\
\hline
\end{tabular}


Tabela 1 - Dados de ruído, em dB(A), no Piso 1 (Continuação).

\begin{tabular}{|c|c|c|c|c|c|c|c|c|c|c|}
\hline $18 / 05 / 10$ & $31 / 05 / 10$ & $10 / 06 / 10$ & $08 / 07 / 10$ & $13 / 07 / 10$ & $21 / 07 / 10$ & $03 / 08 / 10$ & $09 / 08 / 10$ & $24 / 08 / 10$ & $30 / 08 / 10$ & $15 / 09 / 10$ \\
\hline 59,9 & 60,7 & 67,1 & 66,3 & 55,8 & 60,6 & 60,8 & 60,1 & 62,4 & 63,4 & 63,6 \\
\hline 58,7 & 57,3 & 60,9 & 67,1 & 56,9 & 64,6 & 66,7 & 66,3 & 59,6 & 65,0 & 56,7 \\
\hline 59,3 & 62,1 & 60,9 & 63,9 & 61,8 & 66,1 & 64,4 & 58,1 & 68,2 & 63,1 & 63,2 \\
\hline 62,3 & 61,6 & 61,4 & 58,7 & 65,2 & 65,2 & 67,5 & 56,9 & 58,5 & 63,2 & 60,1 \\
\hline 63,8 & 63,1 & 61,9 & 58,5 & 62,7 & 65,0 & 65,8 & 61,7 & 65,5 & 69,7 & 60,5 \\
\hline 65,0 & 60,1 & 58,2 & 65,1 & 67,7 & 60,5 & 66,9 & 71,3 & 60,7 & 61,2 & 58,0 \\
\hline 57,6 & 63,4 & 60,0 & 64,4 & 63,4 & 56,8 & 64,8 & 66,7 & 57,9 & 64,5 & 63,9 \\
\hline 68,2 & 58,8 & 61,4 & 69,7 & 59,3 & 63,0 & 60,9 & 63,0 & 62,3 & 63,5 & 66,3 \\
\hline 66,5 & 58,7 & 64,8 & 58,9 & 60,8 & 61,6 & 65,4 & 59,4 & 58,5 & 61,4 & 57,0 \\
\hline 68,2 & 59,3 & 62,4 & 62,4 & 58,3 & 67,0 & 58,7 & 65,3 & 68,6 & 63,4 & 60,2 \\
\hline 60,3 & 54,9 & 67,0 & 68,6 & 65,5 & 64,3 & 65,4 & 71,6 & 61,6 & 62,6 & 61,0 \\
\hline 67,8 & 65,5 & 58,5 & 64,6 & 61,6 & 63,2 & 63,8 & 60,4 & 62,2 & 63,2 & 60,5 \\
\hline 63,9 & 56,9 & 71,4 & 64,8 & 61,3 & 65,5 & 60,6 & 61,4 & 60,7 & 60,1 & 58,5 \\
\hline 62,7 & 59,8 & 63,0 & 62,3 & 70,6 & 61,1 & 65,3 & 66,0 & 59,9 & 66,7 & 63,8 \\
\hline 62,9 & 57,3 & 64,7 & 65,5 & 61,5 & 66,7 & 62,4 & 60,8 & 64,2 & 62,8 & 63,4 \\
\hline 63,6 & 60,8 & 61,3 & 69,9 & 59,0 & 60,4 & 61,2 & 62,4 & 59,3 & 63,9 & 68,5 \\
\hline 71,3 & 54,6 & 59,9 & 66,9 & 61,0 & 57,3 & 57,7 & 63,5 & 59,2 & 59,3 & 63,5 \\
\hline 65,4 & 63 & 58,8 & 66,9 & 60,5 & 60,1 & 59,0 & 61,8 & 66,2 & 60,5 & 63,5 \\
\hline 62,7 & 57,9 & 55,3 & 62,8 & 66,6 & 61,6 & 60,5 & 60,0 & 58,5 & 57,6 & 63,5 \\
\hline 62,4 & 57,3 & 60,5 & 63,0 & 64,8 & 64,8 & 60,7 & 58,7 & 59,3 & 63,5 & 60,3 \\
\hline 62,2 & 62,7 & 56,2 & 62,0 & 61,9 & 62,6 & 60,8 & 61,6 & 59,6 & 57,5 & 58,1 \\
\hline 65,0 & 57,1 & 58,9 & 74,1 & 62,4 & 65,1 & 57,3 & 64,2 & 64,5 & 59,3 & 61,0 \\
\hline 65,4 & 55,3 & 62,8 & 62,8 & 61,6 & 62,3 & 56,9 & 62,6 & 58,9 & 62,4 & 66,1 \\
\hline 61,0 & 54,9 & 59,7 & 70,7 & 64,3 & 54,4 & 62,3 & 61,6 & 69,8 & 60,7 & 56,4 \\
\hline 61,4 & 64 & 53,5 & 60,6 & 58,2 & 56,8 & 57,1 & 57,7 & 72,2 & 63,4 & 65,9 \\
\hline 64,8 & 55 & 61,6 & 66,3 & 58,1 & 56,2 & 69,3 & 62,8 & 57,2 & 56,9 & 55,7 \\
\hline 70,1 & 65,4 & 64,8 & 61,6 & 62,2 & 56,7 & 72,8 & 56,2 & 60,4 & 68,0 & 72,1 \\
\hline 65,2 & 62,1 & 60,2 & 64,3 & 58,7 & 58,5 & 61,2 & 64,8 & 60,9 & 56,9 & 57,7 \\
\hline 62,4 & 65,9 & 60,4 & 63,0 & 67,1 & 56,7 & 59,1 & 63,2 & 62,0 & 60,3 & 66,1 \\
\hline 69,8 & 63,6 & 56,8 & 58,7 & 56,7 & 63,2 & 59,2 & 60,1 & 77,2 & 58,5 & 62,0 \\
\hline 67,1 & 58,3 & 58,1 & 59,5 & 66,3 & 62,0 & 62,4 & 58,5 & 74,1 & 66,5 & 72,2 \\
\hline 63,9 & 56,5 & 60,0 & 67,3 & 62,4 & 58,4 & 60,7 & 59,3 & 56,2 & 58,5 & 67,7 \\
\hline 64,3 & 65,3 & 59,9 & 67,7 & 58,5 & 64,2 & 61,5 & 61,5 & 59,6 & 59,3 & 67,0 \\
\hline 67,8 & 56,8 & 62,4 & 57,7 & 59,1 & 56,2 & 62,4 & 66,3 & 61,2 & 56,6 & 64,1 \\
\hline 65,0 & 66,7 & 64,3 & 57,5 & 58,7 & 59,7 & 67,5 & 63,6 & 69,4 & 62,4 & 61,6 \\
\hline 63,7 & 63,4 & 58,9 & 62,0 & 63,7 & 61,2 & 73,3 & 62,8 & 59,1 & 67,3 & 64,6 \\
\hline 67,9 & 57,9 & 57,7 & 56,2 & 58,2 & 67,1 & 74,6 & 68,0 & 56,9 & 63,4 & 65,0 \\
\hline 65,3 & 58,9 & 63,5 & 65,2 & 56,5 & 63,7 & 65,7 & 59,6 & 67,3 & 58,4 & 61,2 \\
\hline 62,6 & 59,6 & 62,8 & 60,5 & 61,5 & 56,9 & 67,1 & 61,1 & 62,4 & 58,5 & 68,4 \\
\hline 60,2 & 59,2 & 59,2 & 61,2 & 67,1 & 58,0 & 57,4 & 58,7 & 65,5 & 61,6 & 70,6 \\
\hline 64,0 & 56,8 & 60,5 & 58,3 & 58,5 & 57,7 & 68,3 & 65,8 & 58,9 & 59,3 & 67,3 \\
\hline 61,8 & 56,8 & 59,8 & 57,9 & 60,4 & 64,2 & 62,7 & 57,7 & 59,9 & 67,6 & 76,9 \\
\hline 67,0 & 55,9 & 62,0 & 65,0 & 56,9 & 55,4 & 56,8 & 67,4 & 63,0 & 58,7 & 69,2 \\
\hline 61,2 & 66,9 & 65,0 & 68,3 & 56,9 & 61,8 & 57,7 & 63,5 & 64,0 & 70,0 & 67,8 \\
\hline 65,1 & 66,7 & 60,1 & 58,7 & 61,5 & 58,5 & 59,2 & 63,6 & 76,1 & 64,4 & 67,6 \\
\hline 64,1 & 59,6 & 62,0 & 64,4 & 56,1 & 55,2 & 57,7 & 60,0 & 70,5 & 66,3 & 69,0 \\
\hline 61,1 & 57,3 & 61,0 & 60,7 & 61,5 & 59,8 & 57,9 & 59,2 & 64,9 & 64,8 & 71,7 \\
\hline 64,6 & 58,3 & 62,2 & 67,9 & 59,1 & 58,1 & 61,1 & 61,5 & 65,9 & 61,2 & 65,8 \\
\hline 63,2 & 65,1 & 58,3 & 66,5 & 56,5 & 57,9 & 66,2 & 62,4 & 62,4 & 64,8 & 65,5 \\
\hline 57,7 & 68,3 & 64,5 & 61,8 & 62,1 & 56,8 & 60,1 & 64,7 & 68,6 & 61,3 & 58,5 \\
\hline 63,1 & 63,9 & 62,6 & 60,9 & 64,2 & 58,7 & 60,8 & 63,2 & 61,6 & 60,6 & 70,8 \\
\hline 64,7 & 58,8 & 61,7 & 62,4 & 63,2 & 59,7 & 61,0 & 65,2 & 59,2 & 63,4 & 58,5 \\
\hline 68,3 & 59,8 & 60,1 & 67,5 & 55,1 & 57,2 & 58,3 & 68,3 & 60,0 & 73,0 & 60,3 \\
\hline 68,1 & 60,3 & 58,2 & 60,9 & 65,5 & 56,4 & 61,2 & 68,7 & 59,5 & 63,8 & 55,1 \\
\hline 63,5 & 62 & 62,4 & 62,1 & 61,8 & 59,1 & 65,2 & 64,6 & 73,7 & 68,4 & 60,8 \\
\hline 71,0 & 57,7 & 63,5 & 65,9 & 56,6 & 64,0 & 67,0 & 62,3 & 66,5 & 62,9 & 56,0 \\
\hline 59,9 & 67,5 & 65,2 & 63,2 & 60,3 & 57,1 & 64,0 & 63,1 & 60,7 & 62,9 & 65,0 \\
\hline 63,1 & 57,1 & 60,5 & 63,5 & 61,2 & 59,7 & 60,3 & 63,0 & 71,7 & 64,8 & 60,1 \\
\hline 66,9 & 57,2 & 60,5 & 66,9 & 58,7 & 56,6 & 59,0 & 67,4 & 60,2 & 59,6 & 55,8 \\
\hline 65,0 & 58,2 & 56,6 & 71,4 & 56,6 & 61,9 & 58,1 & 64,4 & 62,0 & 62,8 & 56,1 \\
\hline 57,7 & 61,2 & 61,1 & 67,4 & 60,5 & 57,7 & 60,0 & 66,4 & 60,9 & 56,9 & 62,2 \\
\hline 58,1 & 61,2 & 60,1 & 66,1 & 69,9 & 59,0 & 67,8 & 63,9 & 60,3 & 58,9 & 61,0 \\
\hline 62,4 & 57,9 & 63,8 & 68,5 & 57,9 & 58,7 & 59,3 & 65,7 & 70,0 & 57,2 & 54,3 \\
\hline 62,8 & 57,5 & 56,2 & 63,4 & 61,2 & 57,1 & 62,4 & 67,9 & 66,7 & 58,5 & 60,0 \\
\hline 61,5 & 56,4 & 60,6 & 64,6 & 56,8 & 60,9 & 55,9 & 65,9 & 60,3 & 58,9 & 54,4 \\
\hline 59,3 & 62,4 & 65,9 & 64,8 & 63,3 & 58,9 & 67,1 & 66,3 & 61,4 & 64,3 & 55,3 \\
\hline 65,2 & 65,2 & 60,7 & 65,5 & 63,9 & 58,0 & 58,5 & 68,9 & 68,4 & 60,0 & 56,4 \\
\hline 69,0 & 64,8 & 58,0 & 73,0 & 60,0 & 60,3 & 59,0 & 67,9 & 60,6 & 57,1 & 65,3 \\
\hline 60,8 & 62,6 & 60,1 & 65,1 & 60,1 & 58,1 & 70,6 & 66,6 & 59,8 & 66,1 & 54,8 \\
\hline 56,9 & 69,2 & 59,3 & 62,4 & 58,1 & 59,6 & 59,6 & 67,4 & 62,2 & 59,8 & 63,5 \\
\hline 59,5 & 67,9 & 58,1 & 63,2 & 57,2 & 63,6 & 62,4 & 65,7 & 61,8 & 63,4 & 62,7 \\
\hline 67,1 & 62,4 & 61,4 & 61,9 & 57,1 & 63,0 & 61,4 & 66,5 & 59,0 & 65,4 & 58,9 \\
\hline 64,7 & 66 & 59,9 & 67,6 & 53,2 & 56,9 & 59,2 & 61,2 & 64,0 & 60,1 & 62,0 \\
\hline 61,6 & 65,1 & 61,0 & 64,5 & 56,0 & 57,7 & 58,6 & 58,9 & 58,7 & 59,9 & 56,8 \\
\hline 56,9 & 60,1 & 56,0 & 64,0 & 59,9 & 56,7 & 61,3 & 62,8 & 65,2 & 61,6 & 58,6 \\
\hline 64,4 & 60,5 & 63,2 & 66,5 & 54,6 & 63,0 & 69,4 & 62,4 & 60,8 & 60,5 & 58,7 \\
\hline 60,4 & 59,1 & 61,0 & 61,8 & 61,6 & 69,1 & 64,9 & 61,4 & 61,6 & 55,8 & 61,2 \\
\hline
\end{tabular}


Tabela 1 - Dados de ruído, em dB(A), no Piso 1 (Continuação).

\begin{tabular}{|c|c|c|c|c|c|c|c|c|c|c|}
\hline $18 / 05 / 10$ & $31 / 05 / 10$ & $10 / 06 / 10$ & $08 / 07 / 10$ & $13 / 07 / 10$ & $21 / 07 / 10$ & $03 / 08 / 10$ & $09 / 08 / 10$ & $24 / 08 / 10$ & $30 / 08 / 10$ & $15 / 09 / 10$ \\
\hline 64,8 & 61,8 & 65,2 & 61,8 & 54,8 & 63,8 & 61,4 & 64,7 & 61,0 & 64,7 & 65,1 \\
\hline 58,7 & 62,4 & 59,2 & 64,8 & 57,6 & 56,8 & 59,6 & 61,0 & 57,7 & 58,5 & 60,5 \\
\hline 66,5 & $\begin{array}{l}58,4 \\
\end{array}$ & 60,6 & 62,8 & $\begin{array}{l}59,3 \\
\end{array}$ & 64,4 & 60,5 & 61,3 & 60,9 & 60,1 & $\begin{array}{l}59,7 \\
\end{array}$ \\
\hline 65,0 & 66,5 & 62,0 & 66,6 & 54,6 & 55,6 & 61,5 & 57,5 & 68,5 & 55,2 & 59,2 \\
\hline 61,8 & 55,1 & 58,5 & 59,2 & 58,0 & 55,6 & 68,5 & 60,9 & 63,2 & 66,8 & 55,0 \\
\hline 62,9 & 60,5 & 63,2 & 63,8 & 58,3 & 59,8 & 74,1 & 60,0 & 62,4 & 56,1 & 55,2 \\
\hline 62,4 & 58,7 & 57,5 & 63,0 & 58,7 & 57,7 & 61,2 & 59,6 & 70,2 & 58,5 & 59,8 \\
\hline 60,4 & 61,2 & 59,3 & 61,4 & 56,2 & 60,3 & 66,7 & 59,0 & 60,8 & 60,1 & 59,8 \\
\hline 56,0 & 59,7 & 56,7 & 67,4 & 54,0 & 67,6 & 64,8 & 59,9 & 59,3 & 58,3 & 65,3 \\
\hline $\mathrm{X}$ & 58,5 & 62,6 & 66,0 & 55,4 & 58,6 & 60,9 & 60,6 & 62,3 & 59,8 & 56,0 \\
\hline $\mathrm{X}$ & 54,5 & 64,4 & 63,8 & 64,4 & 54,6 & 63,5 & 56,9 & 63,9 & 58,0 & 59,5 \\
\hline $\mathrm{X}$ & 62,3 & 61,6 & 60,8 & 60,5 & 54,6 & 62,4 & 65,7 & 60,0 & 62,1 & 56,5 \\
\hline $\mathrm{X}$ & 59,1 & 65,2 & 60,0 & 60,3 & 64,3 & 64,7 & 59,9 & 65,5 & 58,9 & 59,2 \\
\hline $\mathrm{X}$ & 59,3 & 59,1 & 69,4 & 60,2 & 55,9 & 66,3 & 64,6 & 61,5 & 67,8 & 67,9 \\
\hline $\mathrm{X}$ & 59,9 & 57,4 & 71,2 & 60,4 & 61,1 & 71,8 & 59,7 & 58,1 & 59,2 & 60,9 \\
\hline $\mathrm{X}$ & 64,5 & 59,3 & 66,3 & 64,5 & 57,2 & 62,8 & 66,0 & 67,7 & 61,6 & 58,0 \\
\hline $\mathrm{X}$ & 67,1 & 58,0 & 60,5 & 61,1 & 54,6 & 62,1 & 65,3 & 58,1 & 58,6 & 62,2 \\
\hline $\mathrm{X}$ & 56,5 & 65,5 & 66,9 & 62,1 & 69,0 & 65,3 & 68,3 & 60,9 & 59,5 & 70,4 \\
\hline $\mathrm{X}$ & 64,1 & 59,0 & 60,9 & 59,8 & 55,6 & 65,9 & 64,7 & 60,7 & 58,3 & 66,7 \\
\hline $\mathrm{X}$ & 58,2 & 54,5 & 65,2 & 61,0 & 65,2 & 58,5 & 62,9 & 63,6 & 63,0 & 56,8 \\
\hline $\mathrm{X}$ & 60,4 & 63,3 & 61,4 & 56,6 & 58,1 & 62,6 & 58,2 & 67,3 & 57,2 & 67,1 \\
\hline $\mathrm{X}$ & 60,4 & 62,9 & 63,9 & 60,7 & 55,1 & 65,4 & 56,7 & 56,8 & 60,6 & $\begin{array}{l}59,7 \\
\end{array}$ \\
\hline$X$ & 60 & 58,1 & 59,7 & 70,2 & 60,6 & 62,6 & 63,7 & 67,0 & 58,5 & 55,4 \\
\hline $\mathrm{X}$ & 66 & 60,8 & 70,4 & 60,1 & 55,0 & 68,7 & 62,3 & 66,7 & 55,2 & 59,0 \\
\hline$X$ & 58,2 & 61,1 & 66,4 & 60,0 & 54,6 & 67,9 & 71,1 & 58,4 & 65,1 & 55,8 \\
\hline $\mathrm{X}$ & 57,3 & 59,7 & 66,5 & 59,8 & 57,1 & 63,1 & 62,7 & 60,1 & 59,2 & 62,2 \\
\hline $\mathrm{X}$ & 64 & 63,8 & 61,0 & 57,5 & 55,1 & 61,0 & 64,3 & 55,6 & 59,5 & 55,4 \\
\hline$X$ & 63,6 & 58,5 & 62,7 & 60,1 & 58,3 & 65,1 & 64,2 & 62,8 & 56,7 & 65,2 \\
\hline $\mathrm{X}$ & 56 & 60,3 & 65,9 & 54,6 & 59,3 & 68,7 & 64,2 & 67,0 & 61,6 & 58,7 \\
\hline $\mathrm{X}$ & 56,8 & $\begin{array}{l}59,9 \\
\end{array}$ & 58,3 & 60,9 & 55,5 & 66,5 & 67,3 & 59,0 & 55,8 & 60,0 \\
\hline $\mathrm{X}$ & 56,8 & 58,7 & 62,3 & 56,8 & 58,7 & 67,1 & 58,7 & 70,2 & 59,8 & 62,8 \\
\hline $\mathrm{X}$ & 58,5 & 56,4 & 64,3 & 52,9 & 55,1 & 66,5 & 58,9 & 59,3 & 62,9 & 72,0 \\
\hline$X$ & 55,4 & 59,7 & 61,6 & 68,3 & 57,7 & 66,3 & 65,0 & 59,8 & 57,3 & 65,5 \\
\hline $\mathrm{X}$ & 57 & 59,6 & 58,4 & 64,9 & 60,3 & 65,0 & 62,4 & 61,8 & 57,7 & 60,0 \\
\hline $\mathrm{X}$ & 60,7 & 60,0 & $\begin{array}{l}57,7 \\
\end{array}$ & 62,8 & 62,0 & 64,8 & 65,9 & 59,6 & 55,4 & $\begin{array}{l}58,3 \\
\end{array}$ \\
\hline$X$ & 55,6 & 61,3 & 61,8 & 59,5 & 65,1 & 63,0 & 61,6 & 61,4 & 60,8 & 57,4 \\
\hline $\mathrm{X}$ & 58,4 & 56,7 & 62,4 & 65,5 & 58,4 & 64,2 & 63,2 & 57,9 & 65,0 & 60,3 \\
\hline $\mathrm{X}$ & 56,4 & 64,0 & 62,0 & 62,4 & 64,5 & 60,7 & 57,8 & 60,5 & 62,0 & 55,3 \\
\hline $\mathrm{X}$ & 61,3 & 59,3 & 60,1 & 58,5 & 55,9 & 66,3 & 59,3 & 71,4 & 56,2 & 58,2 \\
\hline $\mathrm{X}$ & 61,4 & 62,2 & $\begin{array}{l}57,1 \\
\end{array}$ & 65,0 & 57,3 & 66,0 & 70,8 & 58,1 & 59,5 & 66,1 \\
\hline$X$ & 56,9 & 59,1 & 61,5 & 66,6 & 59,0 & 65,3 & 57,1 & 60,9 & 63,5 & 70,1 \\
\hline$X$ & 60,7 & 59,0 & 61,2 & 64,5 & 62,3 & 62,6 & 64,2 & 63,5 & 66,5 & 59,5 \\
\hline $\mathrm{X}$ & 61,1 & 62,0 & 55,1 & 64,0 & 58,9 & 65,5 & 58,7 & 63,7 & 59,5 & 63,1 \\
\hline $\mathrm{X}$ & 61,6 & 64,5 & 56,2 & 65,7 & 63,5 & 64,8 & 67,5 & 64,9 & 60,2 & 57,7 \\
\hline $\mathrm{X}$ & 63,7 & 63,8 & 57,2 & 68,7 & 57,9 & 71,7 & 61,8 & 63,0 & 57,3 & 62,7 \\
\hline$X$ & 66,7 & $\begin{array}{l}60,9 \\
\end{array}$ & 69,6 & 70,2 & 62,4 & 65,2 & 58,5 & 64,6 & 63,2 & 57,7 \\
\hline $\mathrm{X}$ & 57,6 & 60,3 & 63,8 & 71,7 & 54,6 & 67,1 & 56,2 & 58,3 & 63,7 & 60,6 \\
\hline $\mathrm{X}$ & 56,2 & 58,4 & 66,6 & 64,6 & 63,3 & 69,3 & 57,7 & 60,9 & 61,0 & 60,1 \\
\hline$X$ & 57,7 & 60,0 & 59,1 & 64,8 & 57,7 & 72,2 & 59,1 & 56,0 & 59,2 & 63,4 \\
\hline $\mathrm{X}$ & 56,9 & 55,8 & 60,5 & 63,5 & 55,2 & 72,1 & 56,9 & 56,7 & 61,6 & 63,1 \\
\hline$X$ & 58,3 & 64,7 & 62,2 & 59,8 & 64,6 & 65,9 & 61,5 & 69,9 & 57,7 & 63,9 \\
\hline $\mathrm{X}$ & 58,6 & 61,6 & 67,0 & 61,8 & 55,4 & 73,6 & 61,6 & 63,6 & 57,6 & 64,7 \\
\hline $\mathrm{X}$ & 57,9 & 65,7 & $\begin{array}{l}58,8 \\
\end{array}$ & 69,8 & $\begin{array}{l}58,9 \\
\end{array}$ & 67,4 & 65,5 & 62,1 & 60,9 & $\begin{array}{l}59,3 \\
\end{array}$ \\
\hline$X$ & 58,1 & 58,9 & 60,6 & 66,5 & 63,2 & 67,1 & 59,6 & 64,0 & 64,2 & 65,3 \\
\hline $\mathrm{X}$ & 63 & 66,7 & 56,2 & 67,7 & 62,8 & 75,3 & 67,4 & 66,1 & 61,8 & 61,8 \\
\hline $\mathrm{X}$ & 62,4 & 64,7 & 72,6 & 63,2 & 61,6 & 69,5 & 60,6 & 59,7 & $\begin{array}{l}57,1 \\
\end{array}$ & 64,6 \\
\hline $\mathrm{X}$ & 57,3 & $\begin{array}{l}56,9 \\
\end{array}$ & 56,5 & 68,0 & 57,7 & 67,4 & 64,4 & 60,1 & 66,5 & 59,1 \\
\hline $\mathrm{X}$ & 61,8 & 62,3 & 59,3 & 61,5 & 57,1 & 69,4 & 60,5 & 60,3 & 65,9 & 65,5 \\
\hline$X$ & 54,3 & 65,2 & 57,6 & 66,2 & 64,4 & 69,0 & 58,6 & 58,1 & 60,0 & 61,7 \\
\hline $\mathrm{X}$ & 55,6 & 62,8 & 60,7 & 66,2 & 61,5 & 71,7 & 59,6 & 63,6 & 63,8 & 56,8 \\
\hline $\mathrm{X}$ & $\begin{array}{l}55,7 \\
\end{array}$ & 60,3 & 62,4 & $\begin{array}{l}59,9 \\
\end{array}$ & 59,5 & 66,9 & $\begin{array}{l}56,1 \\
\end{array}$ & 61,8 & 62,6 & $\begin{array}{l}60,3 \\
\end{array}$ \\
\hline$X$ & 56,7 & 68,5 & $\begin{array}{l}57,9 \\
\end{array}$ & $\begin{array}{l}59,0 \\
\end{array}$ & 57,5 & 73,4 & 60,9 & 61,0 & $\begin{array}{l}59,7 \\
\end{array}$ & 57,3 \\
\hline $\mathrm{X}$ & 58,9 & 59,1 & 59,3 & 60,8 & 60,8 & 70,4 & 60,9 & 59,2 & 59,5 & 58,1 \\
\hline $\mathrm{X}$ & 55,9 & 63,8 & 64,0 & 54,9 & 63,6 & 76,0 & 65,3 & 58,9 & 60,1 & 56,8 \\
\hline $\mathrm{X}$ & 60,5 & 60,5 & 56,8 & 64,3 & 56,9 & 70,7 & 60,7 & 60,9 & 58,3 & 62,0 \\
\hline $\mathrm{X}$ & 66,3 & 67,3 & 59,5 & $\begin{array}{l}67,4 \\
\end{array}$ & 57,5 & 72,6 & 60,8 & 63,2 & $\begin{array}{l}58,9 \\
\end{array}$ & $\begin{array}{l}59,2 \\
\end{array}$ \\
\hline$X$ & 60,1 & 62,7 & 61,8 & 63,2 & 54,5 & 71,7 & $\begin{array}{l}59,9 \\
\end{array}$ & 62,4 & 59,3 & 62,0 \\
\hline$X$ & 60,1 & 63,9 & 55,7 & 63,5 & 65,2 & 67,3 & 60,4 & 71,8 & 61,5 & $\begin{array}{l}60,9 \\
\end{array}$ \\
\hline $\mathrm{X}$ & 59 & 66,2 & 63,0 & 62,2 & 60,5 & 71,0 & 63,7 & 59,5 & 61,4 & 63,6 \\
\hline$X$ & 55,5 & 66,5 & 57,6 & 71,7 & 56,6 & 70,4 & 63,3 & $\begin{array}{l}58,9 \\
\end{array}$ & 72,2 & $\begin{array}{l}63,7 \\
\end{array}$ \\
\hline $\mathrm{X}$ & 56 & 63,6 & 61,2 & 66,9 & 65,3 & 67,5 & 63,5 & 65,2 & $\begin{array}{l}59,8 \\
\end{array}$ & 71,8 \\
\hline$X$ & 57,5 & 61,0 & 65,5 & 70,6 & 57,1 & 65,1 & 62,4 & 63,6 & 63,2 & 63,0 \\
\hline $\mathrm{X}$ & 62,4 & 68,9 & 64,5 & 64,0 & 65,2 & 67,7 & 62,8 & 60,2 & 60,3 & 61,5 \\
\hline $\mathrm{X}$ & 56,2 & 62,7 & 55,0 & 57,4 & 57,7 & 66,3 & 66,2 & 59,6 & 59,9 & 64,2 \\
\hline$X$ & 56,6 & 68,7 & 60,6 & $\begin{array}{l}59,6 \\
\end{array}$ & 61,5 & 70,8 & 67,6 & 58,5 & 65,8 & 62,4 \\
\hline $\mathrm{X}$ & 56,1 & 60,1 & 67,0 & 54,6 & 64,0 & 75,5 & 66,9 & 69,1 & 57,7 & 58,3 \\
\hline$X$ & 57,6 & 59,5 & 58,2 & 56,2 & 60,4 & 70,2 & 66,7 & 60,7 & 59,6 & 76,5 \\
\hline
\end{tabular}


Tabela 1 - Dados de ruído, em dB(A), no Piso 1 (Continuação).

\begin{tabular}{|c|c|c|c|c|c|c|c|c|c|c|}
\hline $18 / 05 / 10$ & $31 / 05 / 10$ & $10 / 06 / 10$ & $08 / 07 / 10$ & $13 / 07 / 10$ & $21 / 07 / 10$ & $03 / 08 / 10$ & $09 / 08 / 10$ & $24 / 08 / 10$ & $30 / 08 / 10$ & $15 / 09 / 10$ \\
\hline $\mathrm{X}$ & 61,2 & 57,9 & 57,1 & 61,2 & 65,4 & 68,0 & 66,2 & 69,1 & 56,5 & 62,8 \\
\hline $\mathrm{X}$ & 62 & 63,8 & 63,2 & 53,0 & 56,1 & 69,6 & 63,7 & 57,3 & 65,5 & 61,6 \\
\hline $\mathrm{X}$ & 66,5 & $\begin{array}{l}58,7 \\
\end{array}$ & 60,7 & 65,0 & $\begin{array}{l}55,7 \\
\end{array}$ & 68,6 & 62,6 & 57,2 & 57,1 & 62,2 \\
\hline $\mathrm{X}$ & 69,3 & 56,5 & 61,8 & 59,7 & 56,8 & 65,5 & 64,2 & 65,7 & 62,3 & 67,0 \\
\hline $\mathrm{X}$ & 60,8 & 58,3 & 57,7 & 65,4 & 57,7 & 70,9 & 63,6 & 57,7 & 57,2 & 62,4 \\
\hline $\mathrm{X}$ & 57,6 & 57,3 & 57,3 & 65,8 & 58,7 & 70,9 & 57,1 & 66,3 & 64,0 & 59,5 \\
\hline $\mathrm{X}$ & 59,6 & 56,8 & 56,9 & 56,6 & 54,1 & 74,9 & 61,0 & 67,6 & 57,7 & 64,2 \\
\hline $\mathrm{X}$ & 54,8 & 57,9 & 64,7 & 61,4 & 54,4 & 68,3 & 66,4 & 62,2 & 58,9 & 55,5 \\
\hline $\mathrm{X}$ & 58,4 & 59,3 & 62,7 & 57,4 & 55,4 & 69,8 & 65,0 & 64,2 & 66,5 & 59,9 \\
\hline$X$ & 59,7 & 58,4 & 64,0 & 61,6 & 62,8 & 74,0 & 64,9 & 61,0 & 58,3 & 60,8 \\
\hline $\mathrm{X}$ & 56,4 & 57,7 & 59,6 & 68,1 & 58,7 & 62,6 & 62,2 & 59,5 & 65,7 & 61,2 \\
\hline $\mathrm{X}$ & 65,9 & 57,9 & 57,2 & 64,4 & 62,4 & 71,0 & 64,6 & 64,0 & 70,0 & 65,8 \\
\hline $\mathrm{X}$ & 62,4 & 63,3 & 62,8 & 63,2 & 57,4 & 71,8 & 70,1 & 68,3 & 62,4 & 61,4 \\
\hline $\mathrm{X}$ & 58,6 & 57,2 & 64,0 & 61,4 & 62,1 & 58,5 & 70,0 & 66,8 & 65,4 & 62,2 \\
\hline $\mathrm{X}$ & 57,7 & 64,9 & 62,4 & 60,3 & 58,9 & 63,0 & 73,0 & 59,6 & 61,1 & 60,1 \\
\hline $\mathrm{X}$ & 62 & 57,3 & 63,3 & 62,6 & 57,3 & 58,6 & 66,5 & 63,6 & 57,5 & 63,1 \\
\hline $\mathrm{X}$ & 60,5 & 59,9 & 61,0 & 59,9 & 55,7 & 69,4 & 65,2 & 57,9 & 66,5 & 58,4 \\
\hline $\mathrm{X}$ & 59,1 & 60,1 & 65,2 & 66,4 & 63,9 & 70,6 & 64,1 & 62,4 & 63,4 & 66,9 \\
\hline $\mathrm{X}$ & 58,3 & 56,4 & 61,1 & $\begin{array}{l}60,0 \\
\end{array}$ & 56,4 & 63,2 & 65,2 & 63,6 & 62,8 & 59,6 \\
\hline $\mathrm{X}$ & 62,8 & 64,9 & 58,5 & 73,2 & 53,0 & 65,0 & 65,0 & 63,6 & 66,7 & 64,6 \\
\hline $\mathrm{X}$ & 57,3 & $\begin{array}{l}57,7 \\
\end{array}$ & 58,7 & 68,7 & 55,9 & 60,5 & 58,7 & 73,4 & 60,5 & 56,8 \\
\hline $\mathrm{X}$ & 59,7 & 61,0 & 58,5 & 60,1 & 55,3 & 67,5 & 60,9 & 59,9 & 64,4 & 67,3 \\
\hline$X$ & 60 & 59,7 & 63,6 & 60,9 & 62,0 & 70,6 & 65,2 & 59,7 & 64,8 & 60,3 \\
\hline $\mathrm{X}$ & 63,1 & 60,8 & 54,5 & 61,0 & 60,7 & 63,1 & 60,3 & 67,4 & 68,7 & 60,9 \\
\hline $\mathrm{X}$ & 57,9 & 65,5 & 77,5 & 66,6 & 58,5 & 65,7 & 61,0 & 60,5 & 68,3 & 58,5 \\
\hline $\mathrm{X}$ & $\begin{array}{l}60,9 \\
\end{array}$ & 56,5 & 63,6 & 61,5 & 58,9 & 63,2 & 65,9 & 67,7 & 58,0 & 63,4 \\
\hline $\mathrm{X}$ & 60,7 & $\begin{array}{l}57,9 \\
\end{array}$ & 65,4 & 63,1 & 58,8 & 69,1 & 63,7 & 58,1 & 65,5 & $\begin{array}{l}60,7 \\
\end{array}$ \\
\hline$X$ & 57,7 & 65,2 & $\begin{array}{l}57,7 \\
\end{array}$ & 64,2 & 55,8 & 65,1 & 68,1 & 58,1 & 67,1 & 62,4 \\
\hline $\mathrm{X}$ & 64 & 61,2 & 61,6 & 65,2 & 59,9 & 64,4 & 62,8 & 67,7 & 60,4 & 63,0 \\
\hline $\mathrm{X}$ & 58,7 & 56,2 & 58,5 & 65,3 & 59,1 & 68,7 & 63,4 & 59,3 & 62,7 & 62,8 \\
\hline $\mathrm{X}$ & 58,5 & 62,7 & 54,3 & 62,0 & 64,0 & 66,6 & 57,3 & 59,8 & 60,4 & 64,6 \\
\hline $\mathrm{X}$ & 58,5 & 57,9 & 68,1 & 56,2 & 64,5 & 69,1 & 66,2 & 61,4 & 63,2 & 58,5 \\
\hline$X$ & 61 & 60,4 & 61,6 & 59,3 & 61,8 & 65,1 & 61,8 & 57,1 & 66,5 & 63,1 \\
\hline $\mathrm{X}$ & 64,6 & 58,9 & 68,9 & 66,3 & 60,6 & 76,7 & 63,4 & 69,4 & 67,7 & 60,5 \\
\hline $\mathrm{X}$ & 63,7 & 58,6 & $\begin{array}{l}57,9 \\
\end{array}$ & 65,9 & 66,3 & 67,5 & 63,0 & 61,3 & 76,7 & 60,9 \\
\hline $\mathrm{X}$ & 61,3 & 63,4 & 56,6 & 69,6 & 66,1 & 71,4 & 63,2 & 63,0 & 67,7 & 61,6 \\
\hline$X$ & 54,9 & 59,9 & 62,8 & 60,1 & 62,8 & 63,8 & 68,6 & 55,4 & 62,1 & 69,6 \\
\hline$X$ & 67,9 & 64,2 & 64,4 & 66,6 & 60,9 & 63,0 & 63,0 & 59,0 & 60,9 & 63,3 \\
\hline $\mathrm{X}$ & 58,1 & 60,7 & 65,2 & 59,9 & 60,3 & 57,1 & 66,3 & 63,1 & 59,1 & 57,1 \\
\hline $\mathrm{X}$ & 57,6 & 61,0 & 61,6 & 67,7 & 58,9 & 60,3 & 60,5 & 59,1 & $\begin{array}{l}57,7 \\
\end{array}$ & $\begin{array}{l}58,6 \\
\end{array}$ \\
\hline $\mathrm{X}$ & 54,2 & 69,4 & 57,9 & 59,6 & 65,2 & 68,6 & 68,5 & 62,4 & 60,0 & 59,8 \\
\hline$X$ & 58,1 & 60,5 & 64,5 & 59,5 & 68,2 & 71,4 & 59,2 & 58,8 & 57,7 & 73,4 \\
\hline $\mathrm{X}$ & 58,3 & 64,9 & $\begin{array}{l}57,7 \\
\end{array}$ & 62,3 & 61,4 & 68,1 & 65,8 & 56,2 & 59,0 & 63,1 \\
\hline $\mathrm{X}$ & 60,7 & 63,0 & 58,5 & 61,9 & 66,6 & 56,2 & 64,9 & 69,4 & 65,0 & 60,3 \\
\hline $\mathrm{X}$ & 62,4 & 59,7 & 60,2 & 63,9 & 63,3 & 65,2 & 64,8 & 75,3 & $\begin{array}{l}56,7 \\
\end{array}$ & 65,4 \\
\hline $\mathrm{X}$ & 64,2 & 64,9 & 58,3 & 63,2 & 64,9 & 59,3 & 65,7 & 69,6 & 57,5 & 65,2 \\
\hline $\mathrm{X}$ & 61,4 & 59,3 & 61,8 & 63,7 & 66,6 & 65,9 & 68,2 & 62,7 & 56,6 & 62,7 \\
\hline $\mathrm{X}$ & 59,9 & 60,0 & $\begin{array}{l}58,9 \\
\end{array}$ & 63,5 & 59,6 & 63,8 & 64,3 & 60,0 & $\begin{array}{l}58,5 \\
\end{array}$ & 64,5 \\
\hline$X$ & 59,8 & 58,4 & 68,1 & 63,3 & 61,7 & 65,5 & 64,4 & 64,3 & 58,8 & 68,2 \\
\hline $\mathrm{X}$ & 65,2 & 59,5 & 60,3 & 63,6 & 57,7 & 67,5 & 66,2 & 61,6 & 59,3 & 62,8 \\
\hline$X$ & 59,9 & 64,0 & 60,3 & 64,0 & 62,8 & 59,0 & 64,6 & 63,7 & 56,4 & 61,8 \\
\hline $\mathrm{X}$ & 60,7 & 64,7 & 57,0 & 61,4 & 59,1 & 69,4 & 66,2 & 57,8 & 65,5 & 73,0 \\
\hline $\mathrm{X}$ & 63,8 & 60,5 & 56,1 & 64,2 & 63,3 & 58,4 & 58,7 & 56,9 & 61,0 & $\begin{array}{l}57,2 \\
\end{array}$ \\
\hline$X$ & 65,5 & 65,9 & 72,6 & $\begin{array}{l}59,8 \\
\end{array}$ & 62,4 & 60,9 & 62,8 & 60,9 & 63,6 & $\begin{array}{l}58,5 \\
\end{array}$ \\
\hline $\mathrm{X}$ & 59,7 & 61,8 & 71,3 & 63,7 & 67,9 & 63,2 & 60,9 & 58,9 & 58,9 & 59,5 \\
\hline $\mathrm{X}$ & 59 & 60,8 & 64,3 & 62,0 & 60,4 & 69,6 & 67,1 & 65,9 & $\begin{array}{l}58,7 \\
\end{array}$ & 65,5 \\
\hline $\mathrm{X}$ & 61,3 & $\begin{array}{l}57,9 \\
\end{array}$ & 62,8 & 59,5 & 71,5 & 62,4 & 59,2 & 60,2 & 59,6 & 61,0 \\
\hline $\mathrm{X}$ & 60,3 & 55,3 & $\begin{array}{l}56,7 \\
\end{array}$ & 66,3 & 60,1 & 59,3 & 59,4 & 60,3 & 63,6 & 62,4 \\
\hline$X$ & 65,2 & 56,4 & $\begin{array}{l}58,7 \\
\end{array}$ & 62,1 & 65,0 & 59,6 & 57,7 & 64,8 & 57,1 & $\begin{array}{l}60,8 \\
\end{array}$ \\
\hline $\mathrm{X}$ & 56,2 & 58,5 & 65,9 & 61,6 & 67,9 & 65,2 & 61,1 & 60,2 & 57,4 & 66,3 \\
\hline $\mathrm{X}$ & 60,1 & 61,0 & $\begin{array}{l}59,3 \\
\end{array}$ & $\begin{array}{l}60,6 \\
\end{array}$ & 65,1 & 61,9 & 60,9 & 65,5 & 56,5 & $\begin{array}{l}67,7 \\
\end{array}$ \\
\hline$X$ & 60,9 & 57,5 & $\begin{array}{l}58,9 \\
\end{array}$ & 61,2 & 61,8 & 60,8 & 57,9 & 63,3 & 56,5 & 61,4 \\
\hline $\mathrm{X}$ & 65 & 58,5 & 59,3 & 65,4 & 57,5 & 63,2 & 61,4 & 58,1 & 59,7 & 58,2 \\
\hline$X$ & 56,9 & 55,0 & 60,7 & 66,0 & 62,8 & 62,4 & 56,8 & 60,0 & 62,9 & 60,2 \\
\hline $\mathrm{X}$ & 61,8 & 61,1 & 61,3 & 69,3 & 65,1 & 70,2 & 60,7 & 55,1 & 69,4 & 63,4 \\
\hline $\mathrm{X}$ & $\begin{array}{l}58,5 \\
\end{array}$ & 57,3 & 61,9 & $\begin{array}{l}63,7 \\
\end{array}$ & 60,9 & 61,2 & $\begin{array}{l}56,9 \\
\end{array}$ & 59,3 & 57,5 & 61,6 \\
\hline$X$ & $\begin{array}{l}59,5 \\
\end{array}$ & 57,9 & $\begin{array}{ll}65,3 \\
\end{array}$ & $\begin{array}{ll}62,8 \\
\end{array}$ & 57,7 & 68,6 & $\begin{array}{l}59,5 \\
\end{array}$ & $\begin{array}{l}59,9 \\
\end{array}$ & 62,4 & $\begin{array}{l}60,7 \\
\end{array}$ \\
\hline $\mathrm{X}$ & 62 & 60,8 & 58,5 & 70,5 & 58,5 & 64,4 & 57,9 & 57,5 & 59,0 & 57,3 \\
\hline $\mathrm{X}$ & 61,8 & 62,0 & $\begin{array}{l}58,9 \\
\end{array}$ & $\begin{array}{l}60,8 \\
\end{array}$ & 64,5 & 64,0 & 66,3 & 63,5 & 63,2 & $\begin{array}{l}60,3 \\
\end{array}$ \\
\hline$X$ & 63,9 & 65,0 & 57,5 & 64,0 & 60,6 & 70,2 & 59,5 & 57,5 & 66,0 & $\begin{array}{l}58,8 \\
\end{array}$ \\
\hline $\mathrm{X}$ & 55,7 & $\begin{array}{l}55,8 \\
\end{array}$ & $\begin{array}{l}57,7 \\
\end{array}$ & 68,7 & 70,4 & 63,8 & 57,7 & 70,4 & $\begin{array}{l}63,8 \\
\end{array}$ & 62,4 \\
\hline$X$ & 58,7 & 57,9 & 62,2 & 62,3 & 63,9 & 68,3 & 60,8 & 64,5 & 70,1 & 66,1 \\
\hline $\mathrm{X}$ & 61,5 & 58,3 & 56,2 & 62,4 & 57,7 & 63,2 & 56,2 & 61,6 & 69,1 & 69,0 \\
\hline $\mathrm{X}$ & 60,7 & 59,0 & 63,6 & $\begin{array}{l}56,1 \\
\end{array}$ & $\begin{array}{l}58,7 \\
\end{array}$ & 64,2 & $\begin{array}{l}59,3 \\
\end{array}$ & 66,9 & 69,4 & 64,4 \\
\hline$X$ & 56,9 & 59,0 & 80,9 & 64,6 & 59,8 & 68,2 & 60,9 & 60,8 & 63,0 & 65,8 \\
\hline $\mathrm{X}$ & 55 & 65,0 & 67,3 & 65,5 & 64,3 & 61,3 & 62,2 & 67,1 & 64,0 & 63,1 \\
\hline$X$ & 58,8 & 60,3 & 68,3 & $\begin{array}{l}59,3 \\
\end{array}$ & 67,0 & 62,0 & 57,9 & 64,2 & 60,4 & 59,0 \\
\hline
\end{tabular}


Tabela 1 - Dados de ruído, em dB(A), no Piso 1 (Continuação).

\begin{tabular}{|c|c|c|c|c|c|c|c|c|c|c|}
\hline $18 / 05 / 10$ & $31 / 05 / 10$ & $10 / 06 / 10$ & $08 / 07 / 10$ & $13 / 07 / 10$ & $21 / 07 / 10$ & $03 / 08 / 10$ & $09 / 08 / 10$ & $24 / 08 / 10$ & $30 / 08 / 10$ & $15 / 09 / 10$ \\
\hline $\mathrm{X}$ & 54,6 & 62,3 & 72,1 & 68,3 & 59,2 & 59,1 & 62,4 & 58,1 & 59,5 & 62,7 \\
\hline $\mathrm{X}$ & 59,7 & 63,1 & 78,2 & 57,3 & 62,8 & 63,5 & 61,2 & 65,7 & 60,7 & 59,6 \\
\hline $\mathrm{X}$ & 54,9 & 66,5 & 61,6 & 56,9 & 59,5 & 60,7 & 67,3 & 62,4 & 62,4 & 64,3 \\
\hline $\mathrm{X}$ & 63,5 & 56,6 & 67,4 & 55,9 & 64,7 & 62,4 & 60,9 & 68,4 & 60,5 & 62,2 \\
\hline $\mathrm{X}$ & 57,3 & 57,9 & 66,9 & 57,1 & 55,5 & 64,3 & 60,1 & 63,5 & 65,2 & 69,6 \\
\hline $\mathrm{X}$ & 64,7 & 56,6 & 61,8 & 63,4 & 59,3 & 66,3 & 58,1 & 60,9 & $\begin{array}{l}58,7 \\
\end{array}$ & 59,3 \\
\hline $\mathrm{X}$ & 56,2 & 55,4 & 66,9 & 62,4 & 58,2 & 55,7 & 64,8 & 65,5 & 59,7 & 59,6 \\
\hline $\mathrm{X}$ & 68,2 & 58,8 & 64,4 & 64,4 & 60,3 & 67,4 & 56,1 & 65,2 & 58,7 & 56,9 \\
\hline $\mathrm{X}$ & 57,2 & 58,5 & 58,9 & 56,1 & 61,9 & 60,1 & 60,1 & 69,6 & 58,5 & 60,5 \\
\hline$X$ & 64,5 & 56,7 & 66,2 & 58,0 & 59,1 & 67,7 & 59,3 & 73,4 & 60,1 & 59,3 \\
\hline $\mathrm{X}$ & 62 & 56,0 & 63,2 & 60,5 & 60,0 & 64,5 & 60,0 & 66,6 & 63,1 & 64,2 \\
\hline $\mathrm{X}$ & 58,8 & 58,2 & 66,5 & 59,3 & 67,3 & 70,2 & 67,1 & 67,9 & 61,8 & 60,5 \\
\hline $\mathrm{X}$ & 57,1 & 56,0 & 65,5 & 58,9 & 58,2 & 73,6 & 59,0 & 65,9 & 63,6 & 67,5 \\
\hline $\mathrm{X}$ & 54,8 & 59,8 & 63,6 & 66,2 & 63,6 & 65,7 & 59,6 & 69,1 & 67,4 & 67,9 \\
\hline $\mathrm{X}$ & 63,2 & 56,0 & 67,4 & 78,0 & 53,8 & 67,5 & 56,5 & 65,7 & 67,9 & 61,0 \\
\hline $\mathrm{X}$ & 57,9 & 59,3 & 60,9 & 67,8 & 59,5 & 67,3 & 61,2 & 71,4 & 71,3 & 60,1 \\
\hline $\mathrm{X}$ & 57,3 & 59,2 & 69,4 & 70,1 & 63,1 & 59,5 & 58,5 & 63,0 & 63,3 & 61,6 \\
\hline $\mathrm{X}$ & 58,3 & 55,7 & 72,5 & 70,2 & 59,7 & 64,6 & 64,3 & 74,9 & 70,1 & 62,8 \\
\hline $\mathrm{X}$ & 59,6 & 61,0 & 65,4 & 63,5 & $\begin{array}{l}59,7 \\
\end{array}$ & 62,8 & 57,6 & 67,4 & 64,7 & 65,5 \\
\hline $\mathrm{X}$ & 57,7 & 55,9 & 69,7 & 61,6 & 58,4 & 64,4 & 60,6 & 64,7 & 67,1 & 63,9 \\
\hline $\mathrm{X}$ & 60,5 & $\begin{array}{l}58,8 \\
\end{array}$ & 67,0 & 64,0 & 59,0 & 63,2 & 57,2 & 64,6 & 62,7 & 61,2 \\
\hline $\mathrm{X}$ & $\begin{array}{l}57,9 \\
\end{array}$ & 55,3 & 62,8 & 64,4 & 66,3 & 61,8 & 61,4 & 70,4 & 64,4 & 66,0 \\
\hline$X$ & 57,7 & 57,6 & 62,3 & 62,8 & $\begin{array}{l}56,8 \\
\end{array}$ & 65,9 & 62,4 & 69,8 & 60,2 & 58,2 \\
\hline$X$ & 57,2 & 58,4 & 62,4 & 59,6 & 57,0 & 62,7 & 65,3 & 68,4 & 65,7 & 62,1 \\
\hline$X$ & 59,1 & $\begin{array}{l}58,9 \\
\end{array}$ & 64,6 & 59,1 & 64,4 & 65,9 & 64,6 & 63,6 & 65,9 & 60,7 \\
\hline $\mathrm{X}$ & 60,9 & 55,3 & 62,1 & 60,9 & 62,2 & 68,2 & 60,5 & 68,7 & 65,9 & 61,8 \\
\hline $\mathrm{X}$ & 58,3 & 61,2 & 65,0 & 64,0 & 55,2 & $\begin{array}{l}58,7 \\
\end{array}$ & 60,9 & 61,5 & 63,0 & 66,5 \\
\hline$X$ & 60,1 & 56,4 & 66,6 & 64,3 & 60,1 & 59,6 & 61,8 & 60,0 & $\begin{array}{l}58,1 \\
\end{array}$ & 60,9 \\
\hline $\mathrm{X}$ & $\begin{array}{l}57,9 \\
\end{array}$ & $\begin{array}{l}56,9 \\
\end{array}$ & 61,2 & 55,8 & 62,7 & 58,7 & 59,6 & 58,1 & 71,2 & 66,3 \\
\hline$X$ & 60,9 & 60,0 & 68,3 & 57,1 & $\begin{array}{l}58,9 \\
\end{array}$ & 61,5 & 63,9 & 64,2 & 58,5 & 64,6 \\
\hline $\mathrm{X}$ & 58,7 & 65,2 & 67,7 & 67,1 & 55,8 & 59,9 & 63,7 & 60,9 & 64,5 & 61,0 \\
\hline$X$ & $\begin{array}{l}56,9 \\
\end{array}$ & 60,5 & 64,0 & $\begin{array}{l}66,7 \\
\end{array}$ & 54,6 & 58,1 & 67,9 & 60,5 & 58,5 & 61,4 \\
\hline$X$ & $\begin{array}{l}58,8 \\
\end{array}$ & 59,7 & 69,2 & 64,2 & 55,4 & 63,4 & $\begin{array}{l}60,9 \\
\end{array}$ & 67,5 & 72,9 & 60,1 \\
\hline $\mathrm{X}$ & 56,4 & 59,3 & 63,4 & 66,7 & 60,7 & 60,9 & 62,8 & 58,5 & 68,0 & 57,4 \\
\hline $\mathrm{X}$ & 56,6 & 62,4 & 61,6 & 61,3 & 57,2 & $\begin{array}{l}60,8 \\
\end{array}$ & $\begin{array}{l}55,8 \\
\end{array}$ & 60,6 & 65,2 & 62,3 \\
\hline $\mathrm{X}$ & 57,1 & 62,6 & 60,6 & 70,4 & 60,5 & 61,6 & 61,0 & 59,3 & 62,1 & 57,2 \\
\hline $\mathrm{X}$ & 58,9 & 59,8 & 68,3 & 62,0 & 66,6 & 63,8 & 58,1 & 57,7 & 58,4 & 59,7 \\
\hline$X$ & 56,2 & 61,8 & 62,8 & 59,9 & 63,1 & 62,3 & 58,8 & 59,5 & 58,3 & 59,3 \\
\hline $\mathrm{X}$ & 56,1 & 68,9 & 62,7 & 63,3 & 64,6 & $\begin{array}{l}63,1 \\
\end{array}$ & 66,5 & 58,7 & 59,1 & 59,5 \\
\hline $\mathrm{X}$ & 62,4 & 62,3 & 63,2 & 61,3 & 60,4 & 63,8 & 64,9 & 55,0 & 61,5 & 60,8 \\
\hline$X$ & 63,1 & 57,7 & $\begin{array}{l}65,7 \\
\end{array}$ & 62,2 & 55,8 & 63,2 & $\begin{array}{l}56,8 \\
\end{array}$ & 57,7 & $\begin{array}{l}58,7 \\
\end{array}$ & 60,0 \\
\hline$X$ & 57,1 & 64,8 & 67,3 & 59,1 & 64,0 & 62,8 & 56,7 & 61,9 & 69,4 & 69,6 \\
\hline $\mathrm{X}$ & 68,6 & 58,1 & 68,4 & 61,7 & 60,2 & 65,5 & 59,7 & 61,2 & 56,8 & 67,8 \\
\hline $\mathrm{X}$ & 60 & 59,3 & 63,2 & 60,1 & 56,4 & 71,8 & 61,2 & 60,9 & 57,3 & 61,8 \\
\hline$X$ & 61,3 & 62,0 & $\begin{array}{l}63,3 \\
\end{array}$ & $\begin{array}{l}57,7 \\
\end{array}$ & 63,3 & 77,6 & 63,4 & 61,5 & $\begin{array}{l}57,4 \\
\end{array}$ & $\begin{array}{l}58,5 \\
\end{array}$ \\
\hline$X$ & 58,5 & 70,2 & 63,2 & 67,6 & 59,1 & 65,5 & 67,5 & 63,3 & 57,7 & 62,4 \\
\hline $\mathrm{X}$ & 60,1 & 62,3 & 73,9 & 59,1 & 63,5 & 66,2 & 61,6 & 65,3 & 63,7 & 60,7 \\
\hline$X$ & 59,8 & $\begin{array}{l}56,9 \\
\end{array}$ & 68,1 & 65,7 & 57,5 & 65,1 & $\begin{array}{l}57,7 \\
\end{array}$ & 69,1 & 61,0 & 66,6 \\
\hline$X$ & 59,3 & 56,8 & 66,7 & $\begin{array}{l}58,9 \\
\end{array}$ & 55,8 & $\begin{array}{l}60,9 \\
\end{array}$ & 61,8 & 59,3 & 62,8 & $\begin{array}{l}58,6 \\
\end{array}$ \\
\hline$X$ & 62,4 & 55,4 & 62,9 & 56,8 & 59,3 & 67,8 & 61,3 & 65,1 & 56,5 & 59,0 \\
\hline$X$ & 61,4 & 63,2 & 64,0 & $\begin{array}{l}58,9 \\
\end{array}$ & $\begin{array}{l}59,7 \\
\end{array}$ & 72,0 & 61,8 & 58,4 & 61,8 & 64,8 \\
\hline $\mathrm{X}$ & 59,7 & 59,8 & 59,5 & 55,3 & 59,3 & 63,2 & 63,1 & 60,0 & 57,7 & 60,4 \\
\hline$X$ & 61,9 & 67,1 & 64,7 & $\begin{array}{l}58,3 \\
\end{array}$ & $\begin{array}{l}63,9 \\
\end{array}$ & 60,7 & 60,0 & 59,0 & 61,7 & 64,7 \\
\hline$X$ & 67,1 & 56,5 & 60,3 & 57,2 & 64,6 & 63,0 & 56,5 & 67,7 & $\begin{array}{l}58,1 \\
\end{array}$ & 57,5 \\
\hline $\mathrm{X}$ & 60,1 & 65,5 & 69,8 & 58,6 & 69,1 & 69,3 & 59,1 & 60,7 & 64,4 & 59,3 \\
\hline$X$ & 61,3 & 60,5 & 60,1 & $\begin{array}{l}67,7 \\
\end{array}$ & 57,5 & 66,8 & $\begin{array}{l}56,9 \\
\end{array}$ & 64,2 & 68,4 & 62,8 \\
\hline $\mathrm{X}$ & 62,1 & 57,7 & 63,7 & 61,5 & 58,1 & 64,9 & 60,9 & 55,6 & 54,2 & 57,2 \\
\hline $\mathrm{X}$ & 58,7 & 64,7 & 70,2 & 59,5 & 68,1 & 69,2 & 61,8 & 68,1 & 63,4 & 69,4 \\
\hline$X$ & 56,4 & 60,5 & 67,5 & $\begin{array}{l}60,3 \\
\end{array}$ & 68,5 & 59,6 & 62,0 & 64,4 & 56,0 & 62,2 \\
\hline $\mathrm{X}$ & 60,9 & 64,2 & 67,1 & 61,2 & 65,5 & 66,3 & 59,5 & 66,6 & 60,9 & 60,9 \\
\hline $\mathrm{X}$ & $\begin{array}{l}58,6 \\
\end{array}$ & 55,2 & $\begin{array}{l}70,7 \\
\end{array}$ & $\begin{array}{l}68,9 \\
\end{array}$ & $\begin{array}{l}59,3 \\
\end{array}$ & 61,6 & 62,0 & 64,3 & 60,9 & 64,2 \\
\hline$X$ & 56,9 & 60,6 & 72,9 & 74,6 & 60,4 & 59,6 & 62,0 & 60,5 & 54,6 & 57,5 \\
\hline $\mathrm{X}$ & 65,5 & 57,7 & 71,0 & 61,2 & 55,4 & 72,9 & 59,2 & 60,1 & 63,9 & 58,9 \\
\hline$X$ & 59,9 & 56,0 & 64,2 & 65,9 & $\begin{array}{l}57,7 \\
\end{array}$ & 61,0 & 57,5 & 64,5 & 58,4 & 60,2 \\
\hline $\mathrm{X}$ & 61,8 & 61,9 & 66,1 & 61,6 & 59,3 & 59,7 & 56,7 & 62,0 & 73,0 & 63,0 \\
\hline $\mathrm{X}$ & 59,4 & 58,6 & 66,3 & $\begin{array}{l}57,9 \\
\end{array}$ & 55,6 & $\begin{array}{l}58,1 \\
\end{array}$ & 64,5 & 61,1 & $\begin{array}{l}58,3 \\
\end{array}$ & $\begin{array}{l}68,7 \\
\end{array}$ \\
\hline$X$ & $\begin{array}{l}56,9 \\
\end{array}$ & 55,7 & 60,2 & $\begin{array}{l}59,2 \\
\end{array}$ & $\begin{array}{l}59,6 \\
\end{array}$ & 56,4 & $\begin{array}{l}59,5 \\
\end{array}$ & 61,9 & 60,0 & 56,0 \\
\hline $\mathrm{X}$ & 55,9 & 61,6 & 63,7 & 76,2 & 55,4 & 63,4 & 60,9 & 58,4 & 58,9 & 65,5 \\
\hline $\mathrm{X}$ & 55,6 & 60,1 & 62,3 & $\begin{array}{l}58,0 \\
\end{array}$ & $\begin{array}{l}59,3 \\
\end{array}$ & 61,6 & 61,2 & $\begin{array}{l}58,7 \\
\end{array}$ & $\begin{array}{l}59,1 \\
\end{array}$ & 56,2 \\
\hline$X$ & 58,3 & 60,5 & 65,5 & 65,5 & 57,3 & 68,6 & 69,1 & 60,9 & 61,2 & $\begin{array}{l}56,4 \\
\end{array}$ \\
\hline $\mathrm{X}$ & 57,7 & 58,4 & 67,1 & 68,7 & 64,2 & 61,8 & 58,2 & 61,9 & 62,0 & 60,2 \\
\hline$X$ & 61,6 & 58,4 & 67,1 & $\begin{array}{l}55,9 \\
\end{array}$ & 61,2 & 75,9 & $\begin{array}{l}60,9 \\
\end{array}$ & 62,9 & 58,4 & 61,2 \\
\hline $\mathrm{X}$ & 60,4 & 58,4 & 62,4 & 55,9 & 59,3 & 63,9 & 57,2 & 65,9 & 59,2 & 67,5 \\
\hline $\mathrm{X}$ & 58,3 & 55,3 & 61,0 & 62,8 & 62,0 & 57,2 & $\begin{array}{l}59,3 \\
\end{array}$ & $\begin{array}{l}57,6 \\
\end{array}$ & 65,9 & 65,5 \\
\hline$X$ & 61,8 & $\begin{array}{l}58,9 \\
\end{array}$ & 64,2 & 62,0 & 56,6 & 68,2 & 62,4 & 67,5 & 71,6 & 62,4 \\
\hline $\mathrm{X}$ & 58,3 & 60,4 & 60,9 & 62,2 & 60,0 & 66,1 & 59,6 & 61,8 & 60,9 & 60,9 \\
\hline$X$ & $\mathrm{X}$ & $\begin{array}{l}57,9 \\
\end{array}$ & 62,4 & 64,2 & 63,8 & 59,3 & $\begin{array}{l}58,7 \\
\end{array}$ & 59,8 & 59,8 & 59,6 \\
\hline
\end{tabular}


Tabela 1 - Dados de ruído, em dB(A), no Piso 1 (Continuação).

\begin{tabular}{|c|c|c|c|c|c|c|c|c|c|c|}
\hline $18 / 05 / 10$ & $31 / 05 / 10$ & $10 / 06 / 10$ & $08 / 07 / 10$ & $13 / 07 / 10$ & $21 / 07 / 10$ & $03 / 08 / 10$ & $09 / 08 / 10$ & $24 / 08 / 10$ & $30 / 08 / 10$ & $15 / 09 / 10$ \\
\hline $\mathrm{X}$ & $\mathrm{X}$ & 57,0 & 65,2 & 60,5 & 61,4 & 63,8 & 59,2 & 61,0 & 59,2 & 59,3 \\
\hline $\mathrm{X}$ & $\mathrm{X}$ & 56,2 & 63,6 & 61,5 & 60,8 & 60,5 & 64,6 & 60,9 & 58,3 & 57,5 \\
\hline $\mathrm{X}$ & $\mathrm{X}$ & 61,9 & 64,9 & 58,6 & 54,6 & 56,8 & 58,3 & 65,2 & 60,5 & 58,3 \\
\hline $\mathrm{X}$ & $\mathrm{X}$ & 56,2 & 59,8 & 60,8 & 57,7 & 60,4 & 60,4 & 63,8 & 61,8 & 57,7 \\
\hline $\mathrm{X}$ & $\mathrm{X}$ & 60,6 & 64,0 & 63,0 & 59,1 & 56,8 & 58,5 & 63,3 & 59,7 & 60,3 \\
\hline $\mathrm{X}$ & $x$ & 62,0 & 62,4 & 59,6 & 59,2 & 56,2 & 59,3 & 57,5 & 62,7 & 65,3 \\
\hline $\mathrm{X}$ & $\mathrm{X}$ & 55,8 & 61,0 & 63,7 & 57,7 & 57,3 & 59,3 & 68,3 & 60,8 & 60,7 \\
\hline $\mathrm{X}$ & $\mathrm{X}$ & 57,9 & 60,8 & 57,2 & 58,1 & 61,6 & 58,5 & 59,9 & 61,2 & 56,4 \\
\hline $\mathrm{X}$ & $\mathrm{X}$ & 57,1 & 60,9 & 62,4 & 53,8 & 65,9 & 62,4 & 62,2 & 64,8 & 61,4 \\
\hline $\mathrm{X}$ & $\mathrm{X}$ & 58,9 & 62,4 & 59,7 & 61,2 & 61,5 & 60,2 & 66,5 & 58,1 & 61,0 \\
\hline $\mathrm{X}$ & $\mathrm{X}$ & 59,1 & 56,6 & 57,3 & 66,7 & 58,2 & 57,9 & 60,6 & 63,2 & 61,1 \\
\hline $\mathrm{X}$ & $\mathrm{X}$ & 56,5 & 59,2 & 54,0 & 58,1 & 57,5 & 65,2 & 65,1 & 58,2 & 59,0 \\
\hline $\mathrm{X}$ & $\mathrm{X}$ & 58,1 & 61,8 & 60,9 & 57,4 & 63,8 & 61,8 & 61,2 & 64,0 & $\mathrm{X}$ \\
\hline $\mathrm{X}$ & $\mathrm{X}$ & 60,3 & 57,9 & 60,9 & 58,6 & 64,8 & 62,7 & 59,9 & 56,8 & $\mathrm{X}$ \\
\hline$X$ & $\mathrm{X}$ & 65,2 & 66,7 & 59,1 & 56,8 & 73,6 & 57,9 & 62,0 & 64,0 & $\mathrm{X}$ \\
\hline $\mathrm{X}$ & $\mathrm{X}$ & 63,0 & 58,9 & $\mathrm{X}$ & 67,1 & 65,4 & 69,1 & 63,4 & 62,4 & $\mathrm{X}$ \\
\hline $\mathrm{X}$ & $\mathrm{X}$ & 57,7 & 57,7 & $\mathrm{X}$ & 58,3 & 63,7 & 64,8 & 67,4 & 57,1 & $\mathrm{X}$ \\
\hline $\mathrm{X}$ & $\mathrm{X}$ & 60,4 & 61,8 & $\mathrm{X}$ & $\mathrm{X}$ & 62,8 & 59,5 & 66,2 & 63,9 & $\mathrm{X}$ \\
\hline $\mathrm{X}$ & $x$ & 57,3 & 55,4 & $\mathrm{X}$ & $\mathrm{X}$ & 62,4 & 58,3 & 59,8 & 64,0 & $\mathrm{X}$ \\
\hline $\mathrm{X}$ & $\mathrm{X}$ & $\mathrm{X}$ & 61,8 & $\mathrm{X}$ & $\mathrm{X}$ & 63,6 & 63,0 & 58,8 & 55,8 & $\mathrm{X}$ \\
\hline$X$ & $X$ & $X$ & 60,1 & $X$ & $\mathrm{X}$ & 62,4 & 69,3 & 67,7 & 59,6 & $\mathrm{X}$ \\
\hline $\mathrm{X}$ & $\mathrm{X}$ & $\mathrm{X}$ & 56,6 & $\mathrm{X}$ & $\mathrm{X}$ & 62,8 & 59,2 & 62,7 & $\mathrm{X}$ & $\mathrm{X}$ \\
\hline $\mathrm{X}$ & $\mathrm{X}$ & $\mathrm{X}$ & 62,4 & $X$ & $\mathrm{X}$ & 62,7 & 60,8 & 60,7 & $\mathrm{X}$ & $\mathrm{X}$ \\
\hline $\mathrm{X}$ & $\mathrm{X}$ & $\mathrm{X}$ & 62,1 & $\mathrm{X}$ & $\mathrm{X}$ & 67,4 & 60,9 & 65,7 & $\mathrm{X}$ & $X$ \\
\hline $\mathrm{X}$ & $\mathrm{X}$ & $\mathrm{X}$ & 69,4 & $\mathrm{X}$ & $\mathrm{X}$ & 62,4 & 57,5 & 61,6 & $\mathrm{X}$ & $\mathrm{X}$ \\
\hline $\mathrm{X}$ & $\mathrm{X}$ & $X$ & $\mathrm{X}$ & $X$ & $\mathrm{X}$ & 61,6 & $\mathrm{X}$ & 59,6 & $\mathrm{X}$ & $\mathrm{X}$ \\
\hline$X$ & $\mathrm{X}$ & $\mathrm{X}$ & $X$ & $X$ & $X$ & 66,1 & $\mathrm{X}$ & 70,8 & $X$ & $\mathrm{X}$ \\
\hline $\mathrm{X}$ & $\mathrm{X}$ & $\mathrm{X}$ & $\mathrm{X}$ & $\mathrm{X}$ & $\mathrm{X}$ & 73,4 & $\mathrm{X}$ & 60,5 & $\mathrm{X}$ & $\mathrm{X}$ \\
\hline $\mathrm{X}$ & $\mathrm{X}$ & $\mathrm{X}$ & $\mathrm{X}$ & $\mathrm{X}$ & $\mathrm{X}$ & 65,3 & $\mathrm{X}$ & 60,5 & $\mathrm{X}$ & $\mathrm{X}$ \\
\hline $\mathrm{X}$ & $\mathrm{X}$ & $\mathrm{X}$ & $\mathrm{X}$ & $\mathrm{X}$ & $\mathrm{X}$ & 67,1 & $\mathrm{X}$ & 65,9 & $\mathrm{X}$ & $\mathrm{x}$ \\
\hline
\end{tabular}


Tabela 2 - Dados de ruído, em dB(A), no Piso 2.

\begin{tabular}{|c|c|c|c|c|c|c|c|c|}
\hline $21 / 05 / 10$ & $01 / 06 / 10$ & $14 / 06 / 10$ & $24 / 06 / 10$ & $15 / 07 / 10$ & $22 / 07 / 10$ & $06 / 08 / 10$ & $11 / 08 / 10$ & $20 / 08 / 10$ \\
\hline 53,8 & 58,2 & 63,6 & 58,6 & 54,8 & 57,7 & 60,1 & 56,5 & $\begin{array}{l}60,9 \\
\end{array}$ \\
\hline 66,3 & 62,0 & 54,9 & 56,8 & 57,5 & 56,4 & 60,1 & 64,8 & 58,0 \\
\hline 60,3 & 61,2 & 68,1 & 57,2 & 65,5 & 57,5 & 56,9 & 57,3 & 59,3 \\
\hline 56,2 & 60,7 & 62,0 & 56,5 & 61,1 & 61,3 & 64,4 & 68,5 & 60,9 \\
\hline 64,6 & 62,8 & 59,3 & 60,6 & 64,7 & 54,4 & 61,0 & 62,4 & 61,6 \\
\hline 57,0 & 54,2 & 56,0 & 52,5 & 60,7 & $\begin{array}{l}57,1 \\
\end{array}$ & 74,3 & 56,0 & 63,2 \\
\hline 65,3 & 60,5 & 61,4 & 55,3 & 56,7 & 61,2 & 57,9 & 61,3 & 58,5 \\
\hline 57,7 & 53,8 & 66,6 & 58,7 & 65,4 & 57,4 & 56,8 & 60,1 & 63,4 \\
\hline 54,4 & 60,5 & 62,8 & 53,9 & 59,4 & 62,0 & 59,2 & 68,5 & 58,6 \\
\hline 59,8 & 53,5 & 62,1 & 63,6 & 66,7 & 55,5 & 62,9 & 59,0 & 61,6 \\
\hline 56,0 & 64,4 & 57,9 & 68,7 & 67,1 & 62,9 & 65,2 & 67,1 & 61,9 \\
\hline 59,3 & 57,6 & 62,2 & 54,6 & 56,8 & 70,2 & 62,3 & 59,3 & 57,7 \\
\hline 60,9 & 55,5 & 60,7 & 59,2 & 65,1 & 55,1 & 62,8 & 65,2 & 65,7 \\
\hline 55,9 & 61,5 & 69,4 & 67,7 & 57,7 & 67,1 & 60,9 & 64,2 & 64,4 \\
\hline 60,9 & 58,1 & 55,1 & 65,9 & 69,4 & 54,8 & 59,5 & 60,3 & 69,4 \\
\hline 62,6 & 51,8 & 61,5 & 56,2 & 54,5 & 60,1 & 60,6 & 57,1 & 61,3 \\
\hline 58,5 & 58,5 & 55,5 & 54,6 & 56,2 & 58,5 & 59,1 & 58,4 & 57,7 \\
\hline 58,5 & 52,1 & 65,7 & 57,7 & 67,4 & 57,7 & 59,3 & 59,2 & 60,6 \\
\hline 56,5 & 59,5 & 58,7 & 57,1 & 56,0 & 66,9 & 61,5 & 67,3 & 59,0 \\
\hline 61,2 & 57,9 & 55,1 & 56,9 & 60,2 & 56,0 & 65,4 & 62,2 & 66,1 \\
\hline 56,7 & 58,5 & 65,2 & 53,6 & 60,0 & 55,8 & 61,8 & 57,3 & 56,2 \\
\hline 63,1 & 60,5 & 58,0 & 54,3 & 61,2 & 62,9 & 65,3 & 61,4 & 65,2 \\
\hline 61,4 & 57,7 & 62,1 & 57,0 & 58,9 & 55,9 & 64,4 & 58,8 & 62,8 \\
\hline 56,2 & 56,6 & 65,7 & 58,1 & 61,6 & 59,3 & 64,2 & 60,5 & 60,1 \\
\hline 63,4 & 56,0 & 60,3 & 69,1 & 55,3 & 55,6 & 60,5 & 61,5 & 66,6 \\
\hline 54,6 & 53,7 & 62,0 & 66,1 & 58,3 & 71,8 & 58,1 & 57,2 & 57,7 \\
\hline 62,3 & 59,3 & 61,8 & 60,0 & 55,6 & 56,7 & 59,6 & 60,1 & 68,1 \\
\hline 55,3 & 68,3 & 63,8 & 60,1 & 55,4 & 55,5 & 72,8 & 61,5 & 65,9 \\
\hline 60,5 & 65,2 & 55,0 & 58,5 & 56,9 & 62,4 & 63,9 & 62,0 & 60,6 \\
\hline 61,2 & 60,1 & 61,2 & 65,2 & 65,0 & 56,6 & 59,2 & 63,6 & 58,3 \\
\hline 60,9 & 57,1 & 69,1 & 64,8 & 56,8 & 55,5 & 66,3 & 72,9 & 67,5 \\
\hline 63,0 & 58,4 & 69,3 & 59,1 & 62,3 & 57,6 & 62,4 & 64,2 & 58,1 \\
\hline 58,2 & 52,8 & 73,6 & 57,9 & 56,4 & 71,2 & 62,2 & 61,4 & 67,9 \\
\hline 58,4 & 59,9 & 58,7 & 53,8 & 59,9 & 56,7 & 69,1 & 63,2 & 57,6 \\
\hline 61,7 & 58,1 & 62,0 & 63,4 & 66,8 & 56,5 & 60,3 & 61,2 & 66,9 \\
\hline 56,5 & 58,3 & 59,2 & 54,6 & 59,1 & 57,3 & 61,0 & 56,9 & 60,1 \\
\hline 62,4 & 60,3 & 54,3 & 58,1 & 58,3 & 66,0 & 59,6 & 62,3 & 56,9 \\
\hline 59,3 & 58,4 & 57,9 & 62,0 & 60,0 & 57,9 & 58,8 & 61,8 & 63,9 \\
\hline 59,0 & 59,7 & 54,4 & 56,5 & 57,5 & 64,4 & 57,2 & 69,6 & 58,5 \\
\hline 65,8 & 58,1 & 56,9 & 63,6 & 59,0 & 56,8 & 56,8 & 65,4 & 60,3 \\
\hline 57,9 & 53,6 & 59,9 & 59,0 & 63,2 & 57,1 & 59,2 & 68,4 & 59,6 \\
\hline 62,7 & 58,9 & 56,2 & 63,7 & 58,3 & 59,7 & 65,0 & 61,5 & 61,2 \\
\hline 60,0 & 54,4 & 65,9 & 61,7 & 58,9 & 61,6 & 64,1 & 59,1 & 59,0 \\
\hline 57,0 & 60,4 & 69,9 & 56,2 & 62,2 & 63,4 & 58,8 & 64,4 & 57,9 \\
\hline 54,6 & 58,2 & 56,0 & 65,4 & 64,5 & 61,4 & 66,3 & 65,9 & 59,9 \\
\hline 57,3 & 58,1 & 57,2 & 58,4 & 59,6 & 64,6 & 61,5 & 62,2 & 61,0 \\
\hline 57,2 & 56,6 & 58,3 & 61,7 & 72,5 & 59,5 & 64,2 & 63,1 & 59,6 \\
\hline 56,9 & 54,5 & 66,3 & 58,5 & 62,0 & 54,4 & 63,1 & 63,1 & 61,9 \\
\hline 56,9 & 60,3 & 68,4 & 58,3 & 58,4 & 59,6 & 60,9 & 64,8 & 62,2 \\
\hline 56,7 & 58,1 & 57,1 & 63,2 & 58,3 & 54,4 & 63,6 & 60,3 & 60,4 \\
\hline 54,2 & 54,2 & 57,5 & 57,9 & 57,4 & 54,4 & 68,7 & 69,3 & 59,5 \\
\hline 63,1 & 56,5 & 58,1 & 56,7 & 55,3 & 61,1 & 64,5 & 66,3 & 58,3 \\
\hline 58,7 & 65,0 & 60,6 & 57,2 & 57,6 & 55,0 & 59,9 & 62,8 & 58,7 \\
\hline 56,9 & 65,2 & 63,2 & 54,0 & 53,8 & 59,8 & 58,9 & 69,3 & 58,1 \\
\hline 61,6 & 59,8 & 55,3 & 61,4 & 58,5 & 56,8 & 64,8 & 61,2 & 58,3 \\
\hline 63,0 & 56,5 & 59,3 & 57,6 & 56,2 & 64,2 & 56,7 & 60,7 & 60,1 \\
\hline 63,3 & 59,2 & 56,9 & 57,9 & 56,2 & 65,1 & 55,7 & 65,0 & 56,8 \\
\hline 66,9 & 54,4 & 57,6 & 59,4 & 57,7 & 56,7 & 58,1 & 64,4 & 61,4 \\
\hline 55,5 & 62,1 & 57,5 & 56,5 & 57,6 & 69,8 & 58,2 & 67,5 & 57,5 \\
\hline 61,1 & 56,8 & 61,0 & 66,4 & 70,2 & 59,5 & 58,9 & 59,5 & 62,0 \\
\hline 57,2 & 51,8 & 61,3 & 62,4 & 60,8 & 62,7 & 62,4 & 60,9 & 60,7 \\
\hline 56,6 & 56,2 & 60,1 & 59,1 & 62,0 & 61,9 & 61,8 & 61,0 & 63,8 \\
\hline 54,4 & 52,1 & 59,3 & 59,1 & 61,1 & 54,3 & 62,4 & 59,6 & 60,0 \\
\hline 67,8 & 58,9 & 62,1 & 54,2 & 59,7 & 62,4 & 57,1 & 67,5 & 62,8 \\
\hline 54,7 & 59,5 & 55,6 & 55,6 & 66,1 & 59,9 & 63,6 & 58,2 & 61,4 \\
\hline 57,2 & 55,0 & 60,3 & 55,5 & 60,9 & 60,6 & 61,8 & 59,8 & 60,0 \\
\hline 61,0 & 67,2 & 64,5 & 55,8 & 61,0 & 62,8 & 56,4 & 62,3 & 56,2 \\
\hline 59,1 & 57,7 & 63,4 & 57,6 & 64,2 & 58,4 & 59,9 & 63,9 & 65,2 \\
\hline 61,6 & 59,2 & 69,6 & 58,5 & 60,7 & 65,4 & 60,3 & 60,6 & 59,7 \\
\hline 60,7 & 58,7 & 60,4 & 59,3 & 64,9 & 57,7 & 61,0 & 58,2 & 63,8 \\
\hline 60,7 & 52,0 & 58,3 & 63,0 & 59,1 & 58,3 & 66,9 & 60,7 & 59,9 \\
\hline 59,5 & 73,7 & 59,5 & 54,2 & 57,4 & 62,8 & 56,8 & 63,1 & 61,3 \\
\hline 62,6 & 56,5 & 62,2 & 62,8 & 68,5 & 60,1 & 59,6 & 70,8 & 58,7 \\
\hline 61,2 & 60,9 & 58,5 & 63,1 & 63,2 & 61,8 & 58,8 & 66,1 & 58,8 \\
\hline 63,7 & 60,7 & 62,4 & 59,7 & 62,2 & 61,7 & 58,5 & 61,6 & 61,2 \\
\hline 56,9 & 56,7 & 59,4 & 66,3 & 55,8 & 59,2 & 63,4 & 59,5 & 65,3 \\
\hline 59,3 & 55,6 & 58,5 & 61,2 & 62,4 & 60,7 & 58,9 & 59,1 & 57,2 \\
\hline
\end{tabular}


Tabela 2 - Dados de ruído, em dB(A), no Piso 2 (Continuação).

\begin{tabular}{|c|c|c|c|c|c|c|c|c|}
\hline $21 / 05 / 10$ & $01 / 06 / 10$ & $14 / 06 / 10$ & $24 / 06 / 10$ & $15 / 07 / 10$ & $22 / 07 / 10$ & $06 / 08 / 10$ & $11 / 08 / 10$ & $20 / 08 / 10$ \\
\hline 59,7 & 58,0 & 60,5 & 56,9 & 58,8 & 59,3 & 56,6 & 62,4 & 61,0 \\
\hline 57,7 & 59,9 & 56,9 & 61,0 & 56,6 & 64,7 & 55,4 & 62,4 & 60,2 \\
\hline 57,7 & 58,7 & 69,3 & 62,7 & 67,0 & 58,5 & 61,5 & 61,4 & 60,5 \\
\hline 61,6 & 57,9 & 60,8 & $\begin{array}{l}58,8 \\
\end{array}$ & 61,6 & 59,7 & 61,2 & 60,5 & 64,0 \\
\hline 60,3 & 69,7 & 59,0 & 61,3 & 67,1 & 60,5 & 60,8 & 63,5 & 56,4 \\
\hline 63,2 & 64,8 & 70,6 & 58,2 & 57,6 & 57,5 & 60,1 & 61,6 & 58,5 \\
\hline 62,4 & 65,5 & 66,9 & 57,1 & 56,9 & 72,2 & 58,7 & 64,3 & 65,0 \\
\hline 55,6 & 62,9 & 55,5 & 61,8 & 60,5 & 60,5 & 61,9 & 61,4 & 65,7 \\
\hline 65,3 & 56,8 & 62,3 & 58,9 & 60,2 & 61,8 & 56,1 & 62,8 & 67,9 \\
\hline 56,8 & 58,0 & 61,3 & 55,7 & 58,9 & 63,5 & 56,7 & 64,9 & 60,0 \\
\hline 62,0 & 58,0 & 66,4 & 59,4 & 57,1 & 58,2 & 57,7 & 59,8 & 61,5 \\
\hline 63,4 & 61,1 & 65,4 & 60,6 & 56,2 & 66,6 & 56,8 & 62,0 & 58,1 \\
\hline 60,1 & 58,5 & 62,4 & 70,2 & 62,6 & 56,9 & 64,0 & 64,5 & 62,0 \\
\hline 56,2 & 59,3 & 65,3 & 58,7 & 57,3 & 59,5 & 59,5 & 63,0 & 57,1 \\
\hline 59,3 & 60,9 & 58,3 & 56,5 & 64,3 & 63,2 & 54,8 & 65,0 & 61,2 \\
\hline 59,2 & 56,9 & 69,0 & 64,8 & 63,0 & 57,5 & 62,4 & 59,6 & 64,2 \\
\hline 55,4 & 64,9 & 56,2 & 60,5 & 60,9 & 60,6 & 56,5 & 64,1 & 59,3 \\
\hline 57,9 & 68,7 & 58,2 & 63,2 & 58,4 & 55,4 & 65,5 & 60,9 & 62,8 \\
\hline 54,2 & 56,0 & 54,2 & 62,4 & 60,1 & 63,2 & 60,7 & 60,1 & 59,7 \\
\hline 57,4 & 59,6 & 52,0 & 57,9 & 57,7 & 62,3 & 59,9 & 63,6 & 58,1 \\
\hline 63,5 & 60,0 & 57,9 & 62,0 & 60,1 & 61,2 & 60,9 & 61,8 & 57,7 \\
\hline 62,0 & 64,6 & 58,6 & 57,7 & 57,7 & 65,5 & 56,5 & 61,1 & 59,3 \\
\hline 56,5 & 65,7 & 56,1 & 64,0 & 61,9 & 59,2 & 59,3 & 65,2 & 68,3 \\
\hline 62,4 & 57,6 & 62,4 & 58,6 & 58,6 & 62,1 & 56,2 & 60,2 & 60,6 \\
\hline 59,2 & 58,5 & 56,8 & 63,1 & 59,9 & 64,3 & 55,4 & 62,4 & 64,6 \\
\hline 60,4 & 57,3 & 57,3 & 62,4 & 57,1 & 54,8 & 57,1 & 61,6 & 64,6 \\
\hline 54,8 & 56,2 & 58,1 & 56,8 & 56,7 & 60,0 & 57,9 & 61,4 & 64,8 \\
\hline 57,3 & 66,2 & 54,2 & 63,2 & 60,1 & 58,3 & 61,0 & 59,5 & 65,1 \\
\hline 58,9 & 53,7 & 59,7 & 67,1 & 61,0 & 56,9 & 59,5 & 59,3 & 63,3 \\
\hline 57,0 & 61,6 & 55,2 & 52,5 & 55,0 & 64,8 & 59,2 & 64,2 & 61,5 \\
\hline 63,9 & 66,9 & 58,0 & 66,6 & 60,3 & 59,0 & 56,8 & 59,7 & 68,6 \\
\hline 63,8 & 60,9 & 55,4 & 60,1 & $\begin{array}{ll}53,8 \\
\end{array}$ & 60,6 & 64,4 & 63,7 & 62,9 \\
\hline 63,9 & 58,4 & 59,9 & 62,3 & 59,9 & 60,1 & 56,9 & 60,8 & 72,6 \\
\hline 55,2 & 53,5 & 59,2 & 61,2 & 54,3 & 62,0 & 56,5 & 62,1 & 58,4 \\
\hline 60,1 & 59,5 & 57,0 & 56,2 & 59,5 & 60,4 & 56,5 & 63,2 & 59,2 \\
\hline 56,4 & 60,6 & 57,2 & 61,0 & 60,5 & 61,2 & 58,1 & 58,5 & 63,2 \\
\hline 56,8 & 64,0 & 56,4 & 53,8 & 60,7 & 65,5 & 59,7 & 61,5 & 57,2 \\
\hline 56,2 & 58,1 & 56,5 & 65,7 & 60,4 & 59,5 & 57,7 & 59,3 & 66,9 \\
\hline 55,6 & 51,7 & 59,1 & 61,2 & 55,4 & 57,8 & 59,6 & 74,5 & 64,5 \\
\hline 56,6 & 60,1 & 57,5 & 53,2 & 60,7 & 60,5 & 59,1 & 61,6 & 59,3 \\
\hline 58,1 & 58,3 & 56,8 & 64,3 & 58,9 & 60,3 & 64,5 & 59,5 & 61,4 \\
\hline 56,9 & 54,9 & 64,8 & 56,4 & 54,2 & 58,5 & 65,5 & 61,9 & 58,1 \\
\hline 58,9 & 67,7 & 61,4 & 65,0 & 58,4 & 58,9 & 66,6 & 62,2 & 65,9 \\
\hline 55,9 & 59,9 & 62,3 & 56,6 & 63,8 & 58,2 & 66,5 & 60,0 & 61,5 \\
\hline 63,1 & 55,2 & 56,0 & 56,9 & 61,8 & 61,2 & 66,3 & 61,5 & 59,3 \\
\hline 57,6 & 64,2 & 64,8 & 66,1 & 60,1 & 57,6 & 60,7 & 59,9 & 62,0 \\
\hline 53,6 & 65,0 & 55,6 & 56,6 & 61,0 & 57,1 & 57,3 & 65,0 & 61,5 \\
\hline 60,3 & 56,9 & 63,9 & 55,3 & 61,6 & 57,1 & 55,2 & 61,6 & 59,9 \\
\hline 54,0 & 61,6 & 56,9 & 60,4 & 57,6 & 60,0 & 55,2 & 59,3 & 62,2 \\
\hline 58,9 & 58,1 & 57,9 & 55,6 & 60,9 & 57,2 & 60,3 & 60,7 & 58,7 \\
\hline 62,9 & 52,6 & 58,3 & \begin{tabular}{|l}
53,8 \\
\end{tabular} & 57,7 & 54,8 & 56,8 & 59,7 & 62,9 \\
\hline 57,3 & 55,7 & 55,1 & 57,7 & 60,1 & 65,0 & 57,7 & 63,0 & 57,3 \\
\hline 56,8 & 53,6 & 55,1 & 59,6 & 62,9 & 60,1 & 59,0 & 64,0 & 60,1 \\
\hline 57,0 & 56,9 & 57,3 & 62,4 & 61,2 & 57,3 & 61,7 & 59,6 & 59,8 \\
\hline 62,6 & 64,6 & 64,9 & 56,2 & 62,4 & 56,9 & 56,2 & 64,2 & 62,4 \\
\hline 57,3 & 58,5 & 61,1 & 60,4 & 62,3 & 54,8 & 59,0 & 59,9 & 58,5 \\
\hline 64,4 & 57,5 & 62,2 & 56,2 & 62,4 & 56,6 & 56,9 & 62,4 & 57,1 \\
\hline 55,6 & 55,6 & 53,9 & 60,5 & 59,7 & 55,5 & 60,7 & 60,3 & 63,0 \\
\hline 56,1 & 58,0 & 58,9 & 56,9 & 61,6 & 58,7 & 57,5 & 65,1 & 62,8 \\
\hline 55,2 & 61,4 & 57,7 & 59,0 & 60,2 & 56,4 & 55,8 & 63,2 & 59,0 \\
\hline 60,7 & 55,1 & 54,9 & 59,1 & 58,9 & 54,9 & 5 & 61,8 & 62,4 \\
\hline 61,0 & 57,4 & 57,3 & 59,4 & 56,5 & 60,1 & 55,8 & 61,6 & 56,9 \\
\hline 55,5 & 69,1 & 56,1 & 60,1 & 57,9 & 55,7 & 58,5 & 61,2 & 61,2 \\
\hline 57,3 & 59,9 & 57,3 & 64,7 & 63,5 & 57,5 & 59,3 & 61,0 & 61,8 \\
\hline 54,4 & 55,6 & 56,8 & 61,6 & 58,4 & 60,5 & 64,9 & 66,2 & 60,2 \\
\hline 54,1 & 57,3 & 56,4 & 57,7 & 54,4 & 56,7 & 67,8 & 58,6 & 66,9 \\
\hline 55,2 & 55,2 & 61,3 & 55,3 & 58,5 & 64,3 & 56,8 & 62,2 & 58,9 \\
\hline 60,9 & 56,4 & 56,8 & 60,6 & 58,7 & 57,7 & 65,3 & 61,9 & 66,7 \\
\hline 60,1 & 64,2 & 55,6 & 70,9 & 59,5 & 63,8 & 62,7 & 60,6 & 59,5 \\
\hline 62,8 & 60,1 & 59,3 & 63,8 & 68,7 & 58,1 & 62,1 & 61,0 & 60,4 \\
\hline 58,9 & 63,8 & 56,7 & 61,2 & 58,7 & 58,2 & 58,5 & 61,0 & 63,4 \\
\hline 59,1 & 60,6 & 61,8 & 59,3 & 57,2 & 60,9 & 57,3 & 61,4 & 58,3 \\
\hline 55,7 & 55,4 & 57,7 & 64,3 & 62,8 & 58,4 & 56,9 & 61,1 & 59,7 \\
\hline 61,2 & 59,3 & 61,7 & 58,1 & 58,5 & 65,0 & 63,0 & 60,0 & 58,1 \\
\hline 56,2 & 59,3 & 58,0 & 56,7 & 58,7 & 57,1 & 56,8 & 63,6 & 63,1 \\
\hline 55,6 & 52,5 & 57,2 & 63,8 & 56,5 & 58,3 & 62,4 & 62,1 & 61,2 \\
\hline 54,5 & 64,9 & 56,8 & 62,4 & 57,0 & 63,9 & 55,0 & 62,8 & 58,5 \\
\hline
\end{tabular}


Tabela 2 - Dados de ruído, em dB(A), no Piso 2 (Continuação).

\begin{tabular}{|c|c|c|c|c|c|c|c|c|}
\hline $21 / 05 / 10$ & $01 / 06 / 10$ & $14 / 06 / 10$ & $24 / 06 / 10$ & $15 / 07 / 10$ & $22 / 07 / 10$ & $06 / 08 / 10$ & $11 / 08 / 10$ & $20 / 08 / 10$ \\
\hline 54,5 & 62,8 & 53,0 & 62,2 & 58,8 & 62,9 & 69,6 & 62,7 & 59,8 \\
\hline 56,6 & 58,8 & 58,0 & 58,4 & 54,9 & 59,5 & 58,7 & 60,3 & 62,2 \\
\hline 55,3 & 58,5 & 58,4 & 61,5 & 64,7 & 60,0 & 57,7 & 59,7 & 63,8 \\
\hline 55,8 & 64,6 & 59,3 & 63,1 & 61,4 & 56,4 & 58,1 & 60,7 & 63,1 \\
\hline 53,8 & 59,7 & 57,9 & 63,6 & 56,6 & 64,0 & 60,1 & 64,7 & 60,9 \\
\hline 61,9 & 56,4 & 60,5 & 65,3 & 62,8 & 63,4 & 55,9 & 60,1 & 60,9 \\
\hline 55,7 & 60,5 & 56,8 & 59,5 & 58,9 & 57,5 & 59,3 & 59,3 & 59,5 \\
\hline 56,8 & 53,0 & 58,4 & 61,1 & 59,3 & 57,7 & 62,9 & 63,0 & 59,7 \\
\hline 57,6 & $\mathrm{X}$ & 61,6 & 62,0 & 59,1 & 58,0 & 56,9 & 63,8 & 57,9 \\
\hline 59,9 & $\mathrm{X}$ & 55,4 & 65,9 & 63,1 & 62,4 & 59,6 & 68,9 & 60,2 \\
\hline 57,1 & $\mathrm{X}$ & 55,9 & 68,3 & 61,0 & 54,5 & 57,9 & 62,0 & 63,7 \\
\hline 58,3 & $\mathrm{X}$ & 56,9 & 63,8 & 58,7 & 54,4 & 62,2 & 61,0 & 63,4 \\
\hline 56,8 & $\mathrm{X}$ & 58,0 & 58,9 & 58,1 & 56,4 & 60,9 & 62,2 & 63,5 \\
\hline 59,8 & $\mathrm{X}$ & 56,7 & 65,7 & 61,2 & 60,3 & 57,7 & 58,3 & 58,9 \\
\hline 56,7 & $\mathrm{X}$ & 61,2 & 60,3 & 55,9 & 58,1 & 58,2 & 65,5 & 58,1 \\
\hline 55,4 & $\mathrm{X}$ & 55,6 & 63,1 & 67,3 & 55,5 & 61,6 & 61,6 & 61,3 \\
\hline 54,9 & $X$ & 53,8 & 60,4 & 65,2 & 58,1 & 58,7 & 59,7 & 65,3 \\
\hline 53,4 & $\mathrm{X}$ & 54,8 & 60,1 & 60,7 & 59,8 & 59,8 & 60,7 & 58,0 \\
\hline 56,8 & $\mathrm{X}$ & 62,1 & 61,0 & 57,7 & 55,4 & 57,9 & 59,3 & 65,2 \\
\hline 55,0 & $\mathrm{X}$ & 59,0 & 61,5 & 55,2 & 65,5 & 69,0 & 63,8 & 59,5 \\
\hline 61,2 & $X$ & 63,4 & 60,9 & 59,3 & 58,3 & 58,0 & 61,3 & 65,7 \\
\hline 58,4 & $\mathrm{X}$ & 58,4 & 60,2 & 56,9 & 61,1 & 59,3 & 61,0 & 58,6 \\
\hline 61,8 & $X$ & 62,8 & 59,3 & 67,7 & 56,2 & 58,8 & 62,3 & 60,1 \\
\hline 56,1 & $X$ & 59,5 & 66,8 & 64,0 & 55,4 & 55,2 & 63,2 & 62,0 \\
\hline 60,9 & $\mathrm{X}$ & 60,9 & 57,0 & 54,6 & 59,7 & 58,8 & 62,8 & 58,0 \\
\hline 58,6 & $\mathrm{X}$ & 58,6 & 57,4 & 62,2 & 60,0 & 57,3 & 68,3 & 62,1 \\
\hline 57,5 & $X$ & 54,2 & 57,9 & 63,8 & 60,1 & 58,2 & 62,2 & 58,8 \\
\hline 57,6 & $X$ & 57,6 & 57,7 & 62,7 & 62,1 & 56,1 & 64,2 & 58,5 \\
\hline 55,3 & $\mathrm{X}$ & 58,8 & 53,0 & 60,6 & 54,5 & 58,3 & 60,6 & 58,8 \\
\hline 56,6 & $X$ & 62,0 & 51,7 & 57,7 & 64,8 & 58,7 & 66,7 & 57,7 \\
\hline 58,0 & $\mathrm{X}$ & 56,8 & 69,3 & 60,3 & 56,6 & 55,8 & 61,5 & 59,6 \\
\hline 62,4 & $\mathrm{X}$ & 58,4 & 56,2 & 63,1 & $\begin{array}{l}57,1 \\
\end{array}$ & 57,5 & 58,9 & 58,1 \\
\hline 56,9 & $\mathrm{X}$ & 57,1 & 58,5 & 59,3 & 63,8 & 57,3 & 64,0 & 60,5 \\
\hline 63,4 & $\mathrm{X}$ & 67,7 & 60,2 & 64,4 & 56,0 & 58,4 & 58,9 & 59,8 \\
\hline 56,9 & $X$ & 59,5 & 55,1 & 60,8 & 66,0 & 56,8 & 64,8 & 58,9 \\
\hline 59,9 & $X$ & 65,0 & 58,5 & 61,4 & 55,7 & 59,0 & 62,4 & 67,7 \\
\hline 53,2 & $X$ & 66,1 & 59,3 & 59,7 & 58,2 & 56,4 & 57,7 & 59,5 \\
\hline 61,0 & $\mathrm{X}$ & 62,4 & 58,0 & 61,2 & 57,5 & 58,5 & 62,8 & 56,7 \\
\hline 55,6 & $\mathrm{X}$ & 58,9 & 63,8 & 58,8 & 55,6 & 56,5 & 60,9 & 65,0 \\
\hline 56,8 & $X$ & 58,1 & 56,5 & 60,6 & 59,0 & 62,4 & 60,7 & 67,9 \\
\hline 58,1 & $\mathrm{X}$ & 56,0 & 62,8 & 63,7 & 55,0 & 58,5 & 62,3 & 58,9 \\
\hline 64,8 & $X$ & 63,1 & 61,7 & 59,3 & 58,5 & 64,9 & 63,8 & 65,1 \\
\hline 60,8 & $\mathrm{X}$ & 58,1 & 58,5 & 56,8 & 53,8 & 64,6 & 66,3 & 61,6 \\
\hline 61,3 & $\mathrm{X}$ & 66,2 & 57,7 & 58,5 & 56,1 & 67,6 & 64,0 & 61,4 \\
\hline 58,2 & $X$ & 59,0 & 56,2 & 57,5 & 65,0 & 57,1 & 63,8 & 57,9 \\
\hline 55,8 & $\mathrm{X}$ & 63,5 & 58,0 & 59,0 & 67,2 & 61,2 & 65,2 & 67,1 \\
\hline 63,1 & $\mathrm{X}$ & 63,6 & 59,2 & 56,6 & 59,5 & 66,6 & 61,2 & 64,7 \\
\hline 56,8 & $x$ & 60,9 & 58,6 & $\begin{array}{l}59,8 \\
\end{array}$ & 60,5 & 60,6 & 58,5 & $\begin{array}{l}57,7 \\
\end{array}$ \\
\hline 63,4 & $\mathrm{X}$ & 62,0 & 60,3 & 60,9 & 62,4 & 61,6 & 63,2 & 61,0 \\
\hline 58,8 & $X$ & 60,3 & 60,3 & 57,7 & 63,2 & 60,1 & 60,9 & 63,0 \\
\hline 63,8 & $X$ & 55,4 & 65,9 & 58,1 & 58,0 & 62,4 & 61,0 & 71,7 \\
\hline 55,5 & $X$ & 57,3 & 64,0 & 57,1 & 58,1 & 58,9 & 58,5 & 58,5 \\
\hline 58,9 & $\mathrm{X}$ & 59,3 & 58,9 & 59,3 & 64,2 & 65,8 & 61,4 & 59,7 \\
\hline 55,5 & $\mathrm{X}$ & 54,6 & 59,9 & 68,2 & 55,6 & 58,5 & 58,0 & 62,4 \\
\hline 61,4 & $\mathrm{X}$ & 60,8 & 56,1 & 57,5 & 58,9 & 61,2 & 60,6 & 56,2 \\
\hline 56,8 & $\mathrm{X}$ & 60,1 & 65,5 & 62,9 & 54,2 & 64,8 & 61,5 & 63,8 \\
\hline 54,0 & $\mathrm{X}$ & 57,5 & 58,5 & 57,1 & 58,9 & 61,4 & 58,1 & 59,7 \\
\hline 60,1 & $\mathrm{X}$ & 57,0 & 54,6 & 58,9 & 60,0 & 62,3 & 60,9 & 56,2 \\
\hline 53,0 & $X$ & 55,1 & 60,9 & 58,0 & 56,8 & 59,7 & 61,2 & 59,0 \\
\hline 58,3 & $\mathrm{X}$ & 61,9 & 58,4 & 58,2 & 60,8 & 58,1 & 59,3 & 57,1 \\
\hline 59,9 & $\mathrm{X}$ & 58,1 & 67,1 & 56,7 & 59,5 & 5 & 60,5 & 61,0 \\
\hline 56,9 & $X$ & 60,8 & 62,4 & 58,7 & 64,2 & 57,1 & 64,1 & 55,4 \\
\hline 56,8 & $\mathrm{X}$ & 57,0 & 58,0 & 70,4 & 60,1 & 58,9 & 62,9 & 57,4 \\
\hline 59,3 & $\mathrm{X}$ & 60,0 & 63,2 & 56,7 & 59,5 & 60,1 & 68,2 & 58,4 \\
\hline 58,1 & $X$ & 56,7 & 60,7 & 53,4 & 61,6 & 57,3 & 68,1 & 57,1 \\
\hline 60,9 & $\mathrm{X}$ & 61,6 & 59,7 & 63,6 & 56,9 & 67,1 & 62,1 & 62,8 \\
\hline 56,2 & $X$ & 59,3 & 60,6 & 58,6 & 55,6 & 61,9 & 56,2 & 66,1 \\
\hline 53,8 & $\mathrm{X}$ & 61,1 & 61,0 & 63,2 & 61,3 & 62,4 & 62,4 & 57,5 \\
\hline 64,5 & $x$ & 56,6 & 62,4 & 58,5 & 58,1 & 56,0 & 59,7 & 60,2 \\
\hline 55,0 & $X$ & 56,2 & 59,3 & 56,1 & 58,8 & 68,7 & 59,7 & 57,3 \\
\hline 58,9 & $\mathrm{X}$ & 57,7 & 62,4 & 57,5 & 58,3 & 56,9 & 60,5 & 57,1 \\
\hline 55,3 & $\mathrm{X}$ & 57,5 & 58,4 & 59,3 & 61,2 & 60,1 & 55,6 & 56,8 \\
\hline 59,6 & $\mathrm{X}$ & 58,9 & 54,9 & 61,7 & 58,1 & 64,4 & 63,6 & 56,4 \\
\hline 53,6 & $x$ & 59,4 & 60,5 & 59,5 & 56,0 & 59,6 & 59,6 & 5,5 \\
\hline 57,4 & $X$ & 58,5 & 60,9 & 60,7 & 61,4 & 58,5 & 59,5 & 58,9 \\
\hline 59,3 & $\mathrm{X}$ & 62,7 & 64,4 & 62,0 & 57,9 & 59,2 & 58,7 & 61,1 \\
\hline 61,4 & $\mathrm{X}$ & 57,2 & 61,2 & 57,9 & 58,5 & 62,0 & 61,2 & 59,1 \\
\hline
\end{tabular}


Tabela 2 - Dados de ruído, em dB(A), no Piso 2 (Continuação).

\begin{tabular}{|c|c|c|c|c|c|c|c|c|}
\hline $21 / 05 / 10$ & $01 / 06 / 10$ & $14 / 06 / 10$ & $24 / 06 / 10$ & $15 / 07 / 10$ & $22 / 07 / 10$ & $06 / 08 / 10$ & $11 / 08 / 10$ & $20 / 08 / 10$ \\
\hline 60,9 & $\mathrm{X}$ & 57,4 & 57,7 & 64,0 & 56,0 & 57,5 & 60,6 & 55,2 \\
\hline 73,9 & $\mathrm{X}$ & 58,5 & 57,2 & 56,9 & 64,3 & 59,8 & 66,7 & 65,2 \\
\hline 61,2 & $X$ & 60,9 & 55,6 & 63,4 & 58,0 & 58,8 & 68,3 & 56,9 \\
\hline 60,3 & $X$ & 63,1 & 61,2 & 61,1 & 55,6 & 59,2 & 63,2 & 61,2 \\
\hline 65,4 & $\mathrm{X}$ & 57,2 & 56,9 & 62,2 & 61,6 & 56,9 & 63,2 & 60,4 \\
\hline 59,3 & $\mathrm{X}$ & 62,9 & 55,1 & 68,7 & $\begin{array}{l}57,3 \\
\end{array}$ & 59,7 & 63,7 & 68,1 \\
\hline 57,9 & $\mathrm{X}$ & 58,9 & 56,4 & 62,7 & 58,0 & 58,1 & 61,6 & 59,9 \\
\hline 56,4 & $\mathrm{X}$ & 61,1 & 55,4 & 60,1 & 68,1 & 64,5 & 66,3 & 61,9 \\
\hline 58,1 & $x$ & 61,1 & 60,0 & 64,0 & 63,4 & 60,1 & 60,9 & 60,5 \\
\hline 63,5 & $X$ & 64,3 & 60,0 & 58,1 & 59,3 & 64,0 & 64,9 & 58,8 \\
\hline 64,8 & $X$ & 57,5 & 54,3 & 63,1 & 61,2 & 57,5 & 60,5 & 58,0 \\
\hline 56,2 & $\mathrm{X}$ & 59,3 & 58,1 & 62,1 & 67,5 & 60,9 & 60,9 & 60,7 \\
\hline 62,4 & $\mathrm{X}$ & 62,7 & 56,2 & 59,2 & 64,6 & 58,1 & 62,8 & 55,8 \\
\hline 55,4 & $\mathrm{X}$ & 65,9 & 59,2 & 70,2 & 55,2 & 54,8 & 57,3 & 60,4 \\
\hline 58,1 & $X$ & 63,8 & 59,8 & 60,2 & 61,6 & 63,6 & 60,2 & 56,6 \\
\hline 56,2 & $\mathrm{X}$ & 58,6 & 60,9 & 64,2 & 59,5 & 56,6 & 60,1 & 55,9 \\
\hline 57,1 & $X$ & 58,0 & 56,9 & 66,5 & 64,6 & 65,2 & 67,3 & 62,7 \\
\hline 59,5 & $\mathrm{X}$ & 58,0 & 57,6 & 60,1 & 64,3 & 60,4 & 61,6 & 63,2 \\
\hline 60,3 & $\mathrm{X}$ & 64,0 & 59,3 & 63,0 & 60,9 & 56,2 & 62,0 & 64,8 \\
\hline 56,6 & $\mathrm{X}$ & 57,6 & 57,3 & 61,7 & 57,5 & 56,9 & 60,1 & 63,0 \\
\hline 55,8 & $X$ & 60,5 & 53,3 & 62,3 & 61,5 & 55,9 & 63,0 & 57,7 \\
\hline 64,5 & $X$ & 57,6 & 60,5 & 65,3 & 56,7 & 59,0 & 59,1 & 57,7 \\
\hline 56,9 & $X$ & 62,6 & 54,2 & 63,2 & 61,2 & 61,2 & 66,9 & 67,0 \\
\hline 59,8 & $X$ & 56,5 & 64,5 & 60,1 & 60,5 & 61,5 & 66,8 & 62,4 \\
\hline 58,7 & $\mathrm{X}$ & 59,1 & 54,6 & 55,5 & 62,0 & 61,7 & 56,9 & 57,7 \\
\hline 63,1 & $\mathrm{X}$ & 58,3 & 54,8 & 55,8 & 56,9 & 60,1 & 65,0 & 55,4 \\
\hline 61,6 & $X$ & 57,3 & 54,0 & 58,5 & 57,4 & 57,4 & 59,0 & 57,7 \\
\hline 58,2 & $X$ & 58,9 & 53,7 & 55,3 & 58,9 & 63,7 & 62,4 & 60,4 \\
\hline 60,3 & $\mathrm{X}$ & 58,2 & 59,5 & 58,5 & 55,1 & 61,6 & 59,8 & 63,5 \\
\hline 57,7 & $X$ & 61,0 & 55,0 & 59,2 & 55,9 & 65,9 & 59,5 & 59,8 \\
\hline 58,9 & $\mathrm{X}$ & 60,1 & 55,4 & 65,9 & 58,1 & 59,3 & 61,0 & 59,8 \\
\hline 59,1 & $\mathrm{X}$ & 59,7 & 59,8 & 65,7 & 61,1 & 61,4 & 59,1 & 58,1 \\
\hline 66,7 & $\mathrm{X}$ & 68,7 & 53,6 & 67,1 & 67,8 & 61,2 & 64,7 & 59,9 \\
\hline 52,9 & $\mathrm{X}$ & 64,2 & 63,8 & 58,3 & 59,8 & 57,4 & 62,7 & 60,3 \\
\hline 60,4 & $X$ & 56,8 & 63,1 & 63,8 & 56,8 & 57,2 & 62,4 & 61,2 \\
\hline 57,9 & $X$ & 65,9 & 55,8 & 63,6 & 56,7 & 56,7 & 63,6 & 58,4 \\
\hline 59,9 & $X$ & 57,3 & 60,9 & 59,0 & 58,7 & 59,3 & 62,4 & 60,5 \\
\hline 55,6 & $\mathrm{X}$ & 58,7 & 56,6 & 57,1 & 56,6 & 56,9 & 60,7 & 56,2 \\
\hline 58,8 & $\mathrm{X}$ & 65,0 & 59,6 & 57,7 & 62,0 & 58,5 & 59,3 & 64,0 \\
\hline 59,3 & $X$ & 55,0 & 54,1 & 57,2 & 55,3 & 59,9 & 63,5 & 60,7 \\
\hline 62,4 & $\mathrm{X}$ & 57,6 & 60,1 & 61,0 & 57,2 & 66,1 & 61,8 & 59,7 \\
\hline 56,6 & $\mathrm{X}$ & 53,4 & 62,4 & 57,4 & 60,2 & 58,9 & 58,5 & 61,7 \\
\hline 58,0 & $X$ & 57,0 & 56,4 & 62,1 & 64,9 & 63,5 & 64,0 & 58,7 \\
\hline 56,1 & $\mathrm{X}$ & 54,8 & 62,8 & 62,4 & 60,0 & 57,2 & 58,3 & 58,9 \\
\hline 63,3 & $X$ & 55,6 & 55,8 & 56,9 & 58,1 & 63,0 & 59,2 & 60,5 \\
\hline 58,0 & $\mathrm{X}$ & 54,3 & 59,7 & 56,9 & 60,5 & 57,5 & 60,6 & 61,6 \\
\hline 55,2 & $X$ & 64,6 & 63,7 & 59,7 & 65,9 & 67,0 & 61,0 & 58,1 \\
\hline 65,9 & $\mathrm{X}$ & 56,2 & 57,6 & 57,3 & 66,5 & 60,6 & 61,0 & 61,0 \\
\hline 66,7 & $\mathrm{X}$ & 52,6 & 56,9 & 54,7 & 61,8 & 58,5 & 66,1 & 63,2 \\
\hline 61,9 & $\mathrm{X}$ & 58,9 & 62,0 & 61,6 & 57,4 & 60,9 & 57,9 & 63,5 \\
\hline 62,4 & $\mathrm{X}$ & 58,1 & 58,3 & 60,4 & 64,0 & 57,0 & 62,0 & 61,2 \\
\hline 60,3 & $X$ & 57,6 & 59,7 & 57,9 & 57,3 & 61,5 & 60,9 & 59,5 \\
\hline 58,3 & $\mathrm{X}$ & 59,4 & 59,7 & 56,8 & 57,1 & 60,4 & 60,9 & 59,3 \\
\hline 58,6 & $X$ & 62,4 & 62,2 & 60,4 & 62,4 & 56,6 & 66,4 & 66,1 \\
\hline 58,1 & $\mathrm{X}$ & 56,2 & 58,6 & 62,7 & 61,8 & 56,8 & 57,7 & 64,7 \\
\hline 59,5 & $\mathrm{X}$ & 54,2 & 58,3 & 58,9 & 59,5 & 59,9 & 60,8 & 59,1 \\
\hline 57,4 & $\mathrm{X}$ & 53,7 & 57,7 & 56,5 & 56,9 & 59,0 & 65,2 & 68,7 \\
\hline 54,6 & $\mathrm{X}$ & 61,0 & 57,7 & 60,7 & 58,1 & 60,9 & 71,1 & 5,5 \\
\hline 63,4 & $X$ & 56,6 & 64,8 & 59,5 & 59,5 & 58,9 & 66,8 & 62,4 \\
\hline 55,4 & $\mathrm{X}$ & 63,1 & 61,4 & 66,7 & 58,0 & 60,9 & 64,4 & 59,5 \\
\hline 62,4 & $\mathrm{X}$ & 56,7 & 56,5 & 56,1 & 61,6 & 55,3 & 64,8 & 55,0 \\
\hline 59,1 & $X$ & 58,8 & 54,9 & 56,9 & 55,4 & 59,8 & 57,9 & 61,2 \\
\hline 57,7 & $\mathrm{X}$ & 58,2 & 55,3 & 59,6 & 62,4 & 62,3 & 59,3 & 60,8 \\
\hline 57,7 & $\mathrm{X}$ & 58,4 & 56,9 & 53,3 & 54,6 & 59,7 & 71,4 & 62,8 \\
\hline 64,5 & $X$ & 54,7 & 61,2 & 58,3 & 55,8 & 59,1 & 67,4 & 60,3 \\
\hline 57,9 & $\mathrm{X}$ & 59,7 & 51,1 & 60,2 & 57,5 & 57,3 & 66,2 & 60,5 \\
\hline 55,7 & $X$ & 56,9 & 67,2 & 57,8 & 57,6 & 58,9 & 63,6 & 63,8 \\
\hline 62,6 & $X$ & 55,0 & 53,8 & 63,2 & 62,2 & 61,6 & 63,2 & 62,3 \\
\hline 55,5 & $\mathrm{X}$ & 57,6 & 54,5 & 55,5 & 57,5 & 65,0 & 59,8 & 66,7 \\
\hline 56,7 & $X$ & 54,8 & 61,2 & 58,2 & 59,9 & 60,8 & 60,7 & 63,2 \\
\hline 59,0 & $X$ & 58,9 & 52,9 & 55,6 & 62,4 & 61,9 & 59,8 & 62,1 \\
\hline 58,3 & $\mathrm{X}$ & 54,0 & 62,0 & 55,6 & 54,1 & 59,7 & 59,9 & 61,7 \\
\hline 54,9 & $\mathrm{X}$ & 64,3 & 57,5 & 62,1 & 56,2 & 64,0 & 63,8 & 58,8 \\
\hline 61,4 & $x$ & 61,1 & 60,1 & 58,2 & 56,4 & 61,4 & 63,2 & 58,6 \\
\hline 55,6 & $X$ & 60,5 & 56,5 & 63,7 & 60,8 & 58,2 & 65,0 & 68,9 \\
\hline 62,1 & $\mathrm{X}$ & 59,1 & 54,2 & 58,3 & 57,1 & 60,8 & 60,0 & 56,8 \\
\hline 55,6 & $X$ & 56,9 & 61,0 & 56,6 & 55,8 & 58,3 & 63,0 & 62,7 \\
\hline
\end{tabular}


Tabela 2 - Dados de ruído, em dB(A), no Piso 2 (Continuação).

\begin{tabular}{|c|c|c|c|c|c|c|c|c|}
\hline $21 / 05 / 10$ & $01 / 06 / 10$ & $14 / 06 / 10$ & $24 / 06 / 10$ & $15 / 07 / 10$ & $22 / 07 / 10$ & $06 / 08 / 10$ & $11 / 08 / 10$ & $20 / 08 / 10$ \\
\hline 64,6 & $\mathrm{X}$ & 59,9 & 57,0 & 61,3 & 62,0 & 60,9 & 66,7 & 59,1 \\
\hline 55,7 & $\mathrm{X}$ & 56,8 & 60,3 & 62,0 & 57,2 & 60,1 & 60,4 & 64,0 \\
\hline 55,4 & $X$ & 59,1 & 56,5 & 61,1 & 56,9 & 66,3 & 60,1 & 57,3 \\
\hline 56,8 & $X$ & 58,4 & 56,5 & 55,1 & 58,9 & 63,2 & 66,3 & $\begin{array}{l}56,8 \\
\end{array}$ \\
\hline 55,3 & $\mathrm{X}$ & 62,6 & 61,9 & 64,3 & 58,1 & 60,8 & 58,5 & 60,7 \\
\hline 59,8 & $\mathrm{X}$ & 54,4 & 57,6 & 64,0 & 61,0 & 62,4 & 58,3 & 58,3 \\
\hline 56,5 & $\mathrm{X}$ & 58,7 & 61,2 & 57,7 & 58,2 & 62,3 & 62,4 & 58,4 \\
\hline 58,5 & $\mathrm{X}$ & 55,3 & 64,2 & 58,9 & 60,3 & 58,3 & 64,4 & 57,3 \\
\hline 56,9 & $x$ & 67,6 & 56,4 & $\begin{array}{l}59,3 \\
\end{array}$ & 57,7 & 68,3 & 66,2 & 55,2 \\
\hline 57,1 & $X$ & 61,2 & 60,4 & 60,5 & 62,4 & 63,9 & 59,3 & 59,3 \\
\hline 59,9 & $X$ & 64,7 & 55,0 & 55,6 & 64,8 & 63,5 & 65,7 & 57,7 \\
\hline 54,1 & $\mathrm{X}$ & 55,6 & 66,7 & 61,8 & 58,9 & 58,7 & 58,3 & 65,4 \\
\hline 59,1 & $\mathrm{X}$ & 57,7 & 55,8 & 60,9 & 57,3 & 61,2 & 56,8 & 57,7 \\
\hline 55,1 & $\mathrm{X}$ & 56,2 & 54,4 & 54,8 & 65,9 & 60,2 & 67,3 & 63,2 \\
\hline 52,4 & $X$ & 53,4 & 59,3 & 55,5 & 54,5 & 57,9 & 61,2 & 76,5 \\
\hline 52,6 & $X$ & 57,1 & 56,9 & 63,4 & 61,6 & 63,2 & 63,5 & 58,3 \\
\hline 55,0 & $X$ & 53,0 & 59,9 & 58,3 & 65,3 & 60,8 & 61,6 & 57,9 \\
\hline 54,7 & $X$ & 63,6 & 55,4 & 58,8 & 61,6 & 70,2 & 58,0 & 56,7 \\
\hline 59,1 & $\mathrm{X}$ & 56,5 & 57,1 & 56,1 & $\begin{array}{l}58,9 \\
\end{array}$ & 60,8 & 58,6 & 56,8 \\
\hline 64,0 & $\mathrm{X}$ & 57,7 & 58,9 & 55,8 & 68,1 & 61,2 & 58,5 & 62,7 \\
\hline 61,0 & $X$ & 60,5 & 53,9 & 63,0 & 65,2 & 57,1 & 63,7 & 57,2 \\
\hline 61,3 & $X$ & 62,4 & 57,7 & 60,1 & 55,1 & 63,5 & 66,8 & 65,5 \\
\hline 65,1 & $X$ & 57,1 & 56,9 & 72,6 & 54,8 & 61,7 & 59,5 & 59,7 \\
\hline 59,0 & $X$ & 59,1 & 56,8 & 64,9 & 60,1 & 57,9 & 61,6 & 60,5 \\
\hline 58,7 & $\mathrm{X}$ & 57,1 & 59,2 & 58,7 & 56,2 & 60,1 & 58,5 & 58,3 \\
\hline 59,5 & $\mathrm{X}$ & 59,9 & 58,3 & 65,1 & 63,6 & 71,4 & 61,7 & 57,0 \\
\hline 61,6 & $X$ & 61,6 & 61,5 & 59,1 & 55,9 & 57,9 & 60,3 & 65,7 \\
\hline 59,0 & $X$ & 55,4 & 58,9 & 64,4 & 62,4 & 60,4 & 59,7 & 63,1 \\
\hline 57,6 & $\mathrm{X}$ & 57,7 & 60,5 & 60,6 & 59,7 & 62,8 & 60,7 & 58,9 \\
\hline 56,8 & $\mathrm{X}$ & 57,3 & 61,9 & 57,3 & 64,5 & 68,7 & 59,7 & 60,9 \\
\hline 66,3 & $\mathrm{X}$ & 59,6 & 59,6 & 57,7 & 60,9 & 60,4 & 59,8 & 56,2 \\
\hline 55,5 & $\mathrm{X}$ & 59,1 & 64,0 & 57,9 & $\begin{array}{l}58,9 \\
\end{array}$ & 66,1 & 57,4 & 65,2 \\
\hline 61,0 & $\mathrm{X}$ & 61,6 & 60,5 & 58,1 & 59,8 & 58,1 & 57,9 & 59,8 \\
\hline 58,1 & $\mathrm{X}$ & 60,4 & 59,3 & 58,6 & 55,2 & 55,8 & 59,3 & 56,2 \\
\hline 62,8 & $X$ & 59,6 & 58,0 & 60,7 & 56,2 & 63,1 & 58,8 & 59,7 \\
\hline 53,2 & $X$ & 57,4 & 59,8 & 62,4 & 58,5 & 62,4 & 67,4 & 64,4 \\
\hline 63,5 & $\mathrm{X}$ & 61,3 & 62,2 & 59,8 & 56,8 & 58,5 & 60,6 & 58,7 \\
\hline 57,6 & $\mathrm{X}$ & 54,2 & 65,8 & 61,2 & 58,6 & 58,5 & 59,1 & 60,2 \\
\hline 55,0 & $\mathrm{X}$ & 57,3 & 68,2 & 60,8 & 55,3 & 57,3 & 62,4 & 59,1 \\
\hline 56,6 & $X$ & 57,3 & 58,3 & 55,9 & 57,2 & 70,5 & 60,7 & 68,2 \\
\hline 56,0 & $\mathrm{X}$ & 59,1 & 55,9 & 58,8 & 60,6 & 60,5 & 65,5 & 56,2 \\
\hline 56,9 & $\mathrm{X}$ & 61,2 & 65,1 & 60,1 & 60,0 & 65,5 & 59,3 & 56,7 \\
\hline 55,5 & $X$ & 53,4 & 58,1 & 63,2 & 64,0 & 60,4 & 60,7 & 58,9 \\
\hline 59,5 & $\mathrm{X}$ & 58,7 & 53,0 & 64,0 & 58,7 & 60,7 & 58,4 & 55,7 \\
\hline 54,6 & $X$ & 59,6 & 54,9 & 60,6 & 55,2 & 59,2 & 60,7 & 59,3 \\
\hline 63,1 & $\mathrm{X}$ & 64,7 & 61,8 & 56,6 & 64,1 & 59,3 & 59,2 & 60,3 \\
\hline 60,8 & $\mathrm{X}$ & 61,6 & 62,0 & 58,2 & 55,8 & 65,1 & 63,8 & 59,7 \\
\hline 61,4 & $\mathrm{X}$ & 61,7 & 56,7 & 62,0 & 55,4 & 67,0 & 59,9 & 59,3 \\
\hline 60,1 & $\mathrm{X}$ & 63,6 & 58,6 & 59,6 & 66,3 & 64,2 & 66,3 & 56,6 \\
\hline 58,5 & $\mathrm{X}$ & 69,6 & 57,6 & 55,4 & 56,9 & 60,5 & 62,4 & 65,5 \\
\hline 56,9 & $\mathrm{X}$ & 56,5 & 53,9 & 60,9 & 55,8 & 60,3 & 57,6 & 56,2 \\
\hline 58,4 & $X$ & 54,6 & 57,6 & 53,8 & 54,0 & 62,3 & 61,3 & 58,2 \\
\hline 59,1 & $\mathrm{X}$ & 61,0 & 58,2 & 57,2 & 58,9 & 58,5 & 56,4 & 55,7 \\
\hline 55,4 & $\mathrm{X}$ & 60,1 & 62,4 & 56,8 & 60,9 & 61,1 & 67,6 & 55,8 \\
\hline 57,0 & $\mathrm{X}$ & 60,3 & 58,0 & 58,7 & 55,4 & 63,5 & 64,1 & 61,1 \\
\hline 58,7 & $\mathrm{X}$ & 61,4 & 55,4 & 58,1 & 59,6 & 60,9 & 61,0 & 61,0 \\
\hline 65,5 & $\mathrm{X}$ & 63,7 & 66,3 & 56,6 & 64,3 & 65,0 & 62,4 & 63,7 \\
\hline 59,2 & $\mathrm{X}$ & 57,9 & 58,9 & 64,0 & 57,3 & 62,1 & 57,1 & 60,1 \\
\hline 57,9 & $X$ & 59,5 & 56,1 & 60,0 & 58,8 & 60,7 & 63,1 & 56,8 \\
\hline 58,6 & $\mathrm{X}$ & 5,5 & 56,8 & 63,3 & 59,7 & 61,6 & 57,3 & 59,7 \\
\hline 63,1 & $\mathrm{X}$ & 65,1 & 64,4 & 64,6 & 57,6 & 60,8 & 61,6 & 55,2 \\
\hline 56,0 & $X$ & 55,6 & 56,7 & 60,2 & 55,4 & 60,6 & 56,9 & 62,1 \\
\hline 68,7 & $\mathrm{X}$ & 66,5 & 53,2 & 59,7 & 55,3 & 63,0 & 54,9 & 57,3 \\
\hline 63,0 & $\mathrm{X}$ & 62,1 & 54,3 & 60,8 & 53,2 & 56,7 & 67,3 & 60,3 \\
\hline 59,1 & $X$ & 59,1 & 56,6 & 56,4 & 56,7 & 58,5 & 57,1 & 67,7 \\
\hline 65,9 & $\mathrm{X}$ & 56,7 & 57,1 & 58,7 & 62,1 & 62,3 & 64,5 & 59,3 \\
\hline 53,4 & $X$ & 56,9 & 64,3 & 60,6 & 56,5 & 57,7 & 57,4 & 62,4 \\
\hline 62,4 & $X$ & 64,2 & 60,1 & 64,8 & 54,4 & 59,1 & 56,8 & 64,3 \\
\hline 60,3 & $\mathrm{X}$ & 56,2 & 57,0 & 58,1 & 62,6 & 56,6 & 5 5,3 & 58,6 \\
\hline 61,0 & $X$ & 56,1 & 58,2 & 58,7 & 56,8 & 60,4 & 54,6 & 65,0 \\
\hline 57,3 & $X$ & 55,9 & 53,8 & 57,9 & 60,3 & 62,4 & 59,2 & 58,9 \\
\hline 59,3 & $X$ & 58,6 & 66,8 & 55,8 & 58,7 & 59,7 & 59,2 & 64,6 \\
\hline 55,0 & $\mathrm{X}$ & 63,7 & 55,0 & 57,9 & 57,7 & 57,9 & 57,3 & 56,7 \\
\hline 67,1 & $x$ & 63,8 & 58,6 & 61,4 & 58,5 & 65,3 & 63,2 & 58,0 \\
\hline 55,9 & $X$ & 70,9 & 69,0 & 56,4 & 56,5 & 62,1 & 62,4 & 66,5 \\
\hline 63,6 & $\mathrm{X}$ & 70,7 & 58,8 & 57,6 & 61,2 & 60,9 & 60,7 & 60,5 \\
\hline 59,2 & $\mathrm{X}$ & 61,5 & 57,9 & 56,0 & 55,3 & 62,2 & 64,1 & 64,4 \\
\hline
\end{tabular}


Tabela 2 - Dados de ruído, em dB(A), no Piso 2 (Continuação).

\begin{tabular}{|c|c|c|c|c|c|c|c|c|}
\hline $21 / 05 / 10$ & $01 / 06 / 10$ & $14 / 06 / 10$ & $24 / 06 / 10$ & $15 / 07 / 10$ & $22 / 07 / 10$ & $06 / 08 / 10$ & $11 / 08 / 10$ & $20 / 08 / 10$ \\
\hline 53,8 & $\mathrm{X}$ & 56,0 & 59,3 & 63,7 & 58,2 & 59,7 & 56,2 & 64,2 \\
\hline 58,1 & $\mathrm{X}$ & 62,1 & 54,4 & 57,9 & 62,2 & 65,5 & 65,2 & 60,8 \\
\hline 59,2 & $X$ & 57,3 & 59,7 & 56,9 & 60,7 & 57,7 & 61,2 & 69,8 \\
\hline 62,4 & $X$ & 60,4 & 55,8 & 62,0 & 63,8 & 59,0 & 63,9 & 58,7 \\
\hline 55,8 & $\mathrm{X}$ & 58,4 & 57,7 & 59,7 & 59,9 & 56,6 & 61,0 & 69,4 \\
\hline 59,1 & $\mathrm{X}$ & 61,6 & 58,2 & $\begin{array}{l}58,8 \\
\end{array}$ & 57,2 & 57,7 & 60,2 & 66,5 \\
\hline 55,7 & $\mathrm{X}$ & 60,3 & 57,4 & 58,1 & 59,3 & 69,1 & 67,5 & 58,8 \\
\hline 67,0 & $\mathrm{X}$ & 62,4 & 63,6 & 55,7 & 57,2 & 57,5 & 58,1 & 60,9 \\
\hline 55,7 & $x$ & 57,6 & 62,6 & $\begin{array}{l}59,0 \\
\end{array}$ & 65,5 & 59,5 & 61,7 & 58,9 \\
\hline 62,2 & $X$ & 69,1 & 58,9 & 58,3 & 56,0 & 65,7 & 61,8 & 68,2 \\
\hline 56,8 & $X$ & 55,8 & 58,0 & 58,5 & 60,6 & 57,7 & 58,1 & 59,7 \\
\hline 69,4 & $\mathrm{X}$ & 56,8 & 53,8 & 60,8 & 59,9 & 62,4 & 58,9 & 66,7 \\
\hline 58,1 & $\mathrm{X}$ & 56,1 & 56,6 & 57,4 & 54,4 & 57,1 & 56,9 & 60,7 \\
\hline 52,5 & $\mathrm{X}$ & 60,0 & 54,8 & 64,4 & 65,3 & 55,3 & 58,6 & 58,5 \\
\hline 64,7 & $X$ & 56,8 & 57,6 & 57,9 & 56,9 & 57,7 & 65,2 & 60,6 \\
\hline 58,1 & $X$ & 58,4 & 62,1 & 62,4 & 56,2 & 59,1 & 57,3 & 59,2 \\
\hline 61,1 & $X$ & 60,3 & 55,1 & 62,3 & 56,4 & 61,5 & 60,1 & 55,9 \\
\hline 56,4 & $X$ & 65,5 & 54,2 & 59,8 & 56,2 & 60,7 & 56,0 & 62,0 \\
\hline 56,9 & $X$ & 56,0 & 57,6 & 60,4 & 61,8 & 67,5 & 58,1 & 59,6 \\
\hline 61,3 & $\mathrm{X}$ & 55,1 & 59,0 & 56,1 & 54,7 & 61,8 & 60,2 & 66,9 \\
\hline 56,1 & $X$ & 57,5 & 59,3 & 61,7 & 55,8 & 68,6 & 57,3 & 59,3 \\
\hline 62,0 & $X$ & 59,3 & 58,0 & 62,1 & 61,9 & 64,8 & 58,5 & 56,8 \\
\hline 65,8 & $\mathrm{X}$ & 68,7 & 59,6 & 63,2 & 54,3 & 61,3 & 55,4 & 63,6 \\
\hline 58,4 & $X$ & 63,8 & 57,3 & 60,7 & 63,2 & 57,7 & 56,6 & 57,7 \\
\hline 57,9 & $\mathrm{X}$ & 57,9 & 62,2 & 58,9 & 58,9 & 58,9 & 62,0 & 58,8 \\
\hline 63,7 & $\mathrm{X}$ & 54,4 & 57,6 & 57,8 & 57,2 & 58,6 & 58,4 & 65,4 \\
\hline 54,8 & $X$ & 57,3 & 55,6 & 57,3 & 59,8 & 61,0 & 58,7 & 66,8 \\
\hline 63,8 & $X$ & 59,7 & 57,7 & 60,2 & 54,9 & 63,7 & 56,1 & 67,1 \\
\hline 60,1 & $\mathrm{X}$ & 59,5 & 56,6 & 57,4 & 57,1 & 60,1 & 63,0 & 63,2 \\
\hline 64,0 & $\mathrm{X}$ & 68,7 & 63,8 & 54,2 & 53,5 & 58,9 & 57,9 & 60,7 \\
\hline 58,5 & $\mathrm{X}$ & 55,0 & 60,0 & 55,4 & 54,7 & 58,1 & 56,9 & 61,1 \\
\hline 67,5 & $\mathrm{X}$ & 56,8 & 55,8 & $\begin{array}{l}58,8 \\
\end{array}$ & $\begin{array}{l}56,9 \\
\end{array}$ & 62,2 & 58,5 & 67,9 \\
\hline 64,3 & $\mathrm{X}$ & 56,5 & 59,3 & 60,3 & 53,0 & 62,0 & 60,1 & 71,8 \\
\hline 54,0 & $\mathrm{X}$ & 62,0 & 55,6 & 59,2 & 68,0 & 61,0 & 65,9 & 59,5 \\
\hline 58,5 & $X$ & 62,7 & 62,7 & 54,6 & 58,9 & 62,7 & 58,9 & 64,0 \\
\hline 54,3 & $X$ & 61,2 & 53,6 & 54,5 & 55,8 & 66,3 & 58,9 & 63,0 \\
\hline 68,1 & $\mathrm{X}$ & 55,4 & 54,8 & 62,3 & 56,2 & 59,6 & 62,1 & 58,3 \\
\hline 60,1 & $\mathrm{X}$ & 61,4 & 59,7 & 59,8 & 63,8 & 59,5 & 61,0 & 60,8 \\
\hline 53,3 & $\mathrm{X}$ & 55,2 & 55,6 & 64,2 & 61,8 & 60,1 & 59,2 & 57,6 \\
\hline 60,1 & $X$ & 58,7 & 67,7 & 65,5 & 54,4 & 62,0 & 59,3 & 66,5 \\
\hline 55,0 & $X$ & 54,9 & 61,2 & 55,9 & 54,6 & 57,6 & 62,4 & 56,5 \\
\hline 59,3 & $X$ & 56,9 & 57,9 & 55,2 & 55,6 & 62,8 & 57,1 & 60,3 \\
\hline 53,7 & $X$ & 61,4 & 63,5 & 70,6 & 52,8 & 62,2 & 62,8 & 61,9 \\
\hline 53,4 & $\mathrm{X}$ & 54,9 & 57,3 & 57,6 & 62,4 & 61,6 & 72,1 & 59,8 \\
\hline 55,3 & $X$ & 58,5 & 66,2 & 62,8 & 64,2 & 64,8 & 61,2 & 63,5 \\
\hline 52,6 & $\mathrm{X}$ & 56,4 & 55,5 & 54,1 & 60,6 & 62,4 & 62,8 & 59,0 \\
\hline 59,6 & $\mathrm{X}$ & 62,7 & 56,2 & 52,9 & 58,3 & 65,5 & 57,3 & 57,7 \\
\hline 57,2 & $x$ & 68,2 & 62,2 & 56,6 & 55,1 & 62,4 & 57,7 & 61,0 \\
\hline 56,6 & $\mathrm{X}$ & 64,0 & 59,2 & 56,0 & 59,3 & 63,7 & 59,8 & 61,5 \\
\hline 57,6 & $X$ & 63,5 & 64,0 & 54,0 & 59,8 & 63,2 & 55,7 & 59,5 \\
\hline 54,6 & $X$ & 61,8 & 56,8 & 57,3 & 59,3 & 61,5 & 61,7 & 62,0 \\
\hline 62,4 & $X$ & 59,5 & 52,2 & 56,2 & 54,5 & 55,7 & 58,8 & 63,7 \\
\hline 59,8 & $\mathrm{X}$ & 57,5 & 65,0 & 55,4 & 52,8 & 60,0 & 62,8 & 62,8 \\
\hline 60,3 & $\mathrm{X}$ & 58,9 & 54,2 & 58,5 & 64,6 & 71,3 & 62,4 & 61,2 \\
\hline 56,8 & $\mathrm{X}$ & 56,6 & 66,1 & 58,3 & 55,3 & 62,9 & 62,4 & 63,1 \\
\hline 57,7 & $\mathrm{X}$ & 58,5 & 66,3 & 65,4 & 57,7 & 63,8 & 55,9 & 58,1 \\
\hline 62,2 & $\mathrm{X}$ & 57,3 & 53,4 & 67,1 & 59,8 & 56,8 & 58,1 & 62,4 \\
\hline 60,1 & $\mathrm{X}$ & 64,7 & 55,7 & 63,2 & 60,1 & 63,4 & 57,6 & 58,9 \\
\hline 54,5 & $\mathrm{X}$ & 58,1 & 57,9 & 60,3 & 58,1 & 59,6 & 58,6 & 57,1 \\
\hline 56,1 & $\mathrm{X}$ & 56,4 & 56,2 & 59,0 & 55,4 & 69,1 & 59,7 & 57,3 \\
\hline 53,0 & $x$ & 59,0 & 52,4 & 58,5 & 58,1 & 56,4 & 5 & 61,2 \\
\hline 55,7 & $X$ & 54,6 & 56,6 & 59,9 & 62,0 & 59,9 & 57,5 & 63,2 \\
\hline 59,9 & $\mathrm{X}$ & 60,9 & 61,3 & 56,2 & 56,2 & 64,2 & 61,0 & 56,8 \\
\hline 60,1 & $\mathrm{X}$ & 60,3 & 55,8 & 57,1 & 65,2 & 57,2 & 59,1 & 61,2 \\
\hline 63,4 & $X$ & 54,6 & 60,7 & 59,6 & 58,2 & 57,2 & 59,8 & 57,4 \\
\hline 58,5 & $\mathrm{X}$ & 56,6 & 56,4 & 54,5 & 59,2 & 56,6 & 68,7 & 61,5 \\
\hline 62,7 & $X$ & 62,6 & 58,2 & 58,9 & 62,3 & 63,2 & 56,8 & 58,0 \\
\hline 57,2 & $X$ & 65,8 & 62,2 & 60,2 & 57,9 & 57,1 & 67,3 & 55,8 \\
\hline 56,9 & $x$ & 55,3 & 57,0 & 56,7 & 58,9 & 65,0 & 61,6 & 63,8 \\
\hline 61,0 & $X$ & 67,1 & 62,4 & 58,2 & 63,8 & 67,9 & 55,5 & 59,9 \\
\hline 57,7 & $\mathrm{X}$ & 62,4 & 59,4 & 60,6 & 56,5 & 63,2 & 65,7 & 56,1 \\
\hline 57,6 & $X$ & 59,5 & 53,8 & 59,3 & 54,1 & 54,9 & 59,3 & 62,2 \\
\hline 58,0 & $\mathrm{X}$ & 62,8 & 62,2 & 61,2 & 54,5 & 61,0 & 58,8 & 58,5 \\
\hline 60,2 & $x$ & 63,1 & 53,4 & 57,0 & 52,2 & 5 & 56,2 & 61,3 \\
\hline 59,3 & $X$ & 56,0 & 62,4 & 55,3 & 51,7 & 60,1 & 58,9 & 59,7 \\
\hline 56,2 & $\mathrm{X}$ & 61,0 & 62,9 & 68,7 & 59,6 & 56,6 & 58,1 & 67,1 \\
\hline 58,7 & $\mathrm{X}$ & 57,7 & 56,5 & 54,2 & 58,0 & 58,7 & 62,4 & 56,9 \\
\hline
\end{tabular}


Tabela 2 - Dados de ruído, em dB(A), no Piso 2 (Continuação).

\begin{tabular}{|c|c|c|c|c|c|c|c|c|}
\hline $21 / 05 / 10$ & $01 / 06 / 10$ & $14 / 06 / 10$ & $24 / 06 / 10$ & $15 / 07 / 10$ & $22 / 07 / 10$ & $06 / 08 / 10$ & $11 / 08 / 10$ & $20 / 08 / 10$ \\
\hline 59,0 & $\mathrm{X}$ & 61,9 & 56,0 & 55,2 & 55,7 & 66,5 & 59,9 & 61,0 \\
\hline 61,0 & $\mathrm{X}$ & 71,4 & 52,7 & 62,8 & 58,5 & 58,8 & 56,9 & 55,3 \\
\hline 61,8 & $\mathrm{X}$ & 56,6 & 60,2 & 55,2 & 55,3 & 65,2 & 61,4 & 59,9 \\
\hline 55,4 & $\mathrm{X}$ & 58,8 & 56,9 & 60,6 & 64,3 & 61,8 & 58,7 & 54,6 \\
\hline 63,9 & $\mathrm{X}$ & 58,8 & 57,2 & 59,9 & 56,1 & 58,9 & 62,4 & 64,6 \\
\hline $\mathrm{X}$ & $\mathrm{X}$ & 64,5 & 55,7 & 63,2 & 58,5 & 60,9 & 61,0 & 59,2 \\
\hline $\mathrm{X}$ & $\mathrm{X}$ & 56,9 & 61,6 & 55,8 & 57,9 & 55,0 & 55,9 & 61,1 \\
\hline $\mathrm{X}$ & $\mathrm{X}$ & 60,7 & 56,2 & 58,4 & 54,8 & 59,3 & 65,9 & 60,1 \\
\hline $\mathrm{X}$ & $\mathrm{X}$ & 59,7 & 55,4 & 61,2 & 53,9 & 62,8 & 77,1 & 60,3 \\
\hline $\mathrm{X}$ & $\mathrm{X}$ & 54,4 & 53,4 & 53,6 & 59,8 & 53,8 & 56,8 & 58,4 \\
\hline $\mathrm{X}$ & $\mathrm{X}$ & $\mathrm{X}$ & 59,7 & 56,4 & 57,5 & 57,3 & $\mathrm{X}$ & 57,7 \\
\hline $\mathrm{X}$ & $\mathrm{X}$ & $\mathrm{X}$ & 55,0 & 63,0 & 65,9 & 57,1 & $\mathrm{X}$ & 62,0 \\
\hline $\mathrm{X}$ & $\mathrm{X}$ & $\mathrm{X}$ & 60,0 & 59,7 & 62,3 & 61,0 & $\mathrm{X}$ & 59,9 \\
\hline $\mathrm{X}$ & $\mathrm{X}$ & $\mathrm{X}$ & $\mathrm{X}$ & 57,7 & 59,7 & 59,8 & $\mathrm{X}$ & 61,1 \\
\hline $\mathrm{X}$ & $\mathrm{X}$ & $\mathrm{X}$ & $\mathrm{X}$ & 63,2 & 57,7 & 55,3 & $\mathrm{X}$ & 58,5 \\
\hline $\mathrm{X}$ & $\mathrm{X}$ & $\mathrm{X}$ & $\mathrm{X}$ & $\mathrm{X}$ & 62,3 & 59,3 & $\mathrm{X}$ & 58,1 \\
\hline $\mathrm{X}$ & $\mathrm{X}$ & $\mathrm{X}$ & $\mathrm{X}$ & $\mathrm{X}$ & 54,6 & $\mathrm{X}$ & $\mathrm{X}$ & 59,3 \\
\hline $\mathrm{X}$ & $\mathrm{X}$ & $\mathrm{X}$ & $\mathrm{X}$ & $\mathrm{X}$ & 54,8 & $\mathrm{X}$ & $\mathrm{X}$ & 63,5 \\
\hline $\mathrm{X}$ & $\mathrm{X}$ & $\mathrm{X}$ & $\mathrm{X}$ & $\mathrm{X}$ & 56,8 & $\mathrm{X}$ & $\mathrm{X}$ & 60,1 \\
\hline $\mathrm{X}$ & $\mathrm{X}$ & $\mathrm{X}$ & $\mathrm{X}$ & $\mathrm{X}$ & 59,9 & $\mathrm{X}$ & $\mathrm{X}$ & 58,9 \\
\hline $\mathrm{X}$ & $\mathrm{X}$ & $\mathrm{X}$ & $\mathrm{X}$ & $\mathrm{X}$ & 55,6 & $\mathrm{X}$ & $\mathrm{X}$ & 63,5 \\
\hline $\mathrm{X}$ & $\mathrm{X}$ & $\mathrm{X}$ & $\mathrm{X}$ & $\mathrm{X}$ & 54,0 & $\mathrm{X}$ & $\mathrm{X}$ & 58,7 \\
\hline $\mathrm{X}$ & $\mathrm{X}$ & $\mathrm{X}$ & $\mathrm{X}$ & $\mathrm{X}$ & 56,0 & $\mathrm{X}$ & $\mathrm{X}$ & $\mathrm{X}$ \\
\hline $\mathrm{X}$ & $\mathrm{X}$ & $\mathrm{X}$ & $\mathrm{X}$ & $\mathrm{X}$ & 67,3 & $\mathrm{X}$ & $\mathrm{X}$ & $\mathrm{X}$ \\
\hline $\mathrm{X}$ & $\mathrm{X}$ & $\mathrm{X}$ & $\mathrm{X}$ & $\mathrm{X}$ & 67,5 & $\mathrm{X}$ & $\mathrm{X}$ & $\mathrm{X}$ \\
\hline $\mathrm{X}$ & $\mathrm{X}$ & $\mathrm{X}$ & $\mathrm{X}$ & $\mathrm{X}$ & 52,8 & $\mathrm{X}$ & $\mathrm{X}$ & $\mathrm{X}$ \\
\hline $\mathrm{X}$ & $\mathrm{X}$ & $\mathrm{X}$ & $\mathrm{X}$ & $\mathrm{X}$ & 61,8 & $\mathrm{X}$ & $\mathrm{X}$ & $\mathrm{X}$ \\
\hline $\mathrm{X}$ & $\mathrm{X}$ & $\mathrm{X}$ & $\mathrm{X}$ & $\mathrm{X}$ & 53,4 & $\mathrm{X}$ & $\mathrm{X}$ & $\mathrm{X}$ \\
\hline
\end{tabular}


Tabela 3 - Dados de ruído, em dB(A), no Piso 3.

\begin{tabular}{|c|c|c|c|c|c|c|c|c|c|}
\hline $20 / 05 / 10$ & $26 / 05 / 10$ & $08 / 06 / 10$ & $15 / 06 / 10$ & $07 / 07 / 10$ & $14 / 07 / 10$ & $23 / 07 / 10$ & $10 / 08 / 10$ & $17 / 08 / 10$ & $08 / 09 / 10$ \\
\hline 59,8 & 58,1 & 57,6 & 54,5 & 56,6 & 55,2 & 60,7 & 58,5 & 62,0 & 61,4 \\
\hline 58,7 & 52,2 & 59,3 & 54,4 & 63,5 & 55,2 & 51,1 & 54,2 & 60,3 & 59,3 \\
\hline 59 & 55,4 & $\begin{array}{l}56,9 \\
\end{array}$ & 60,0 & 54,9 & $\begin{array}{ll}62,8 \\
\end{array}$ & 60,1 & $\begin{array}{l}55,3 \\
\end{array}$ & 53,0 & 58,7 \\
\hline 54,4 & 63,0 & 56,6 & 56,2 & 61,6 & 57,0 & 56,0 & 58,5 & 61,6 & 55,2 \\
\hline 59,3 & 53,4 & 56,4 & 62,2 & 62,2 & 53,0 & 54,1 & 61,1 & 58,5 & 62,7 \\
\hline 58,8 & 57,4 & 52,6 & 57,2 & 54,5 & 59,6 & 59,5 & 57,3 & 56,9 & 56,1 \\
\hline 59,7 & 58,9 & 60,9 & 58,9 & 66,3 & 58,7 & 54,8 & 56,0 & 53,0 & 57,7 \\
\hline 59,3 & 58,6 & 62,6 & 59,6 & 55,1 & 56,2 & $\begin{array}{l}58,9 \\
\end{array}$ & 59,0 & 52,3 & 64,0 \\
\hline $\begin{array}{l}56,4 \\
\end{array}$ & $\begin{array}{ll}66,3 \\
\end{array}$ & $\begin{array}{ll}61,2 \\
\end{array}$ & 55,1 & 65,5 & 72,0 & $\begin{array}{l}55,2 \\
\end{array}$ & $\begin{array}{l}57,7 \\
\end{array}$ & 56,6 & 54,8 \\
\hline 54,9 & 61,3 & 60,9 & 60,9 & 50,5 & 55,3 & 56,2 & 63,0 & 58,3 & 53,8 \\
\hline 62,4 & 59,2 & 62,4 & 53,2 & 59,2 & 58,5 & 58,5 & 59,6 & 62,4 & 58,3 \\
\hline 59,1 & 65,5 & 59,8 & $\begin{array}{l}53,3 \\
\end{array}$ & 55,5 & 58,5 & 56,2 & 58,1 & $\begin{array}{l}56,8 \\
\end{array}$ & 61,2 \\
\hline 60,9 & 55,6 & 58,1 & 61,1 & 64,8 & 57,7 & 58,7 & 62,8 & 55,0 & 59,1 \\
\hline 58,9 & 59,3 & 60,3 & 59,6 & 55,8 & 66,7 & 55,2 & 54,0 & 58,7 & 65,9 \\
\hline 55,5 & 52,9 & 67,5 & 55,4 & 64,4 & 59,7 & 55,6 & 66,3 & 55,6 & 58,2 \\
\hline 53,4 & 66,7 & 56,9 & 55,4 & 68,0 & 65,2 & 64,9 & 56,6 & 60,3 & 62,3 \\
\hline 60 & 66,8 & 62,7 & 55,4 & 57,4 & 62,8 & 59,1 & 54,8 & 58,0 & 52,1 \\
\hline 57,7 & 51,0 & 60,8 & 60,3 & 69,6 & 58,9 & 65,0 & 62,2 & 59,0 & 56,6 \\
\hline 57,7 & 57,1 & 59,5 & 54,6 & 53,8 & 61,4 & 54,9 & 54,3 & 61,6 & 59,0 \\
\hline 60,6 & 53,9 & 60,9 & 59,7 & 64,0 & 55,2 & 56,0 & 67,0 & 56,9 & 60,7 \\
\hline 62,4 & 56,6 & 56,6 & 65,5 & 57,5 & 59,3 & 61,5 & 53,3 & 67,1 & 66,5 \\
\hline 62,6 & 54,0 & 62,4 & 62,1 & 62,4 & 64,4 & 57,5 & 58,1 & 53,5 & 57,1 \\
\hline 60,5 & 54,6 & 62,8 & 60,0 & 60,7 & 50,9 & 60,4 & 53,6 & 58,1 & 60,4 \\
\hline 59,1 & 58,9 & 56,2 & 63,2 & 58,9 & 60,9 & 58,8 & 56,9 & 59,3 & 64,4 \\
\hline 62,4 & 55,9 & 57,6 & 68,0 & 56,4 & 56,7 & 63,7 & 67,7 & 53,8 & 55,8 \\
\hline 55 & 66,5 & 54,9 & 56,8 & 69,6 & 56,8 & 57,5 & 58,6 & 59,1 & 57,9 \\
\hline 59,5 & 63,8 & 55,0 & 55,8 & 56,6 & 58,5 & 60,3 & 53,9 & 53,6 & 54,4 \\
\hline 57,7 & 56,7 & 55,4 & 60,1 & 55,3 & 60,6 & 57,9 & 58,8 & 53,2 & 67,6 \\
\hline 54,6 & 64,2 & 58,9 & 59,7 & 54,8 & 62,4 & 55,0 & 57,3 & 60,0 & 59,3 \\
\hline 56,5 & 56,2 & 59,2 & 61,4 & 56,9 & 58,1 & 52,0 & 53,8 & 54,6 & 59,3 \\
\hline 61,7 & 60,3 & 56,0 & 58,7 & 56,4 & 54,8 & 56,2 & 56,5 & 60,4 & 56,4 \\
\hline 58,7 & 60,7 & 68,7 & 54,9 & 52,2 & 61,8 & 55,0 & 52,3 & 56,8 & 54,0 \\
\hline 58,3 & 61,2 & 58,9 & 57,1 & 61,1 & 55,7 & 64,3 & 59,5 & 54,5 & 61,6 \\
\hline 60,1 & 60,0 & 57,7 & 60,7 & 55,6 & 60,2 & 63,2 & 53,0 & 55,7 & 62,7 \\
\hline 56,4 & 57,2 & 71,0 & 57,7 & 64,4 & 57,2 & 55,9 & 60,8 & 57,1 & 60,4 \\
\hline 63,7 & 58,6 & 63,9 & 55,4 & 60,9 & 60,6 & 60,7 & 53,5 & 67,5 & 56,6 \\
\hline 55,9 & 60,9 & 57,1 & 55,0 & 59,3 & 69,4 & 56,2 & 55,4 & 53,8 & 55,4 \\
\hline 57,4 & 56,4 & 56,7 & 61,8 & 51,3 & 55,8 & 60,6 & 57,2 & 54,2 & 64,2 \\
\hline 53,3 & 59,3 & 56,2 & 60,5 & 62,3 & 61,5 & 58,4 & 52,8 & 59,6 & 57,7 \\
\hline 58,6 & 61,4 & 59,3 & 62,6 & 54,3 & 56,8 & 53,0 & 58,7 & 56,5 & 69,1 \\
\hline 61,3 & 60,9 & 59,7 & 65,7 & 67,1 & 55,9 & 56,0 & 54,8 & 57,4 & 58,9 \\
\hline 57,7 & 58,9 & 60,9 & 56,9 & 51,5 & 70,2 & 56,5 & 61,2 & 57,3 & 58,1 \\
\hline 60,2 & 58,9 & 56,9 & 58,3 & 55,7 & 61,2 & 56,4 & 58,1 & 56,0 & 61,2 \\
\hline 59,4 & 58,7 & 56,4 & 56,2 & 56,4 & 67,7 & 63,6 & 55,0 & 59,9 & 52,6 \\
\hline 59,7 & $\begin{array}{l}59,2 \\
\end{array}$ & 64,0 & 66,7 & 57,6 & 56,2 & 51,9 & 54,2 & 53,0 & 54,8 \\
\hline 64 & 56,7 & 58,4 & 56,6 & 57,6 & 65,0 & 57,7 & 54,4 & 61,5 & 58,1 \\
\hline 56,7 & 62,3 & 59,2 & 63,0 & 57,7 & 58,3 & 54,6 & 53,4 & 54,0 & 53,4 \\
\hline 57 & 58,5 & 66,3 & 60,3 & 61,6 & 54,0 & 62,4 & 60,3 & 53,0 & 59,3 \\
\hline 61,9 & 62,8 & 65,1 & 60,9 & 60,9 & 67,6 & 61,3 & 64,7 & 52,7 & 59,8 \\
\hline 55,7 & 60,7 & 66,9 & 61,8 & 63,4 & 57,7 & 56,6 & 65,0 & 55,0 & 67,3 \\
\hline 57,3 & 58,9 & 62,0 & 65,2 & 63,9 & 62,6 & 67,1 & 58,1 & 60,3 & 64,6 \\
\hline 69,4 & 56,7 & 67,5 & 58,9 & 59,7 & 56,5 & 58,1 & 53,4 & 56,8 & 55,5 \\
\hline 65,2 & 55,6 & 62,0 & 58,1 & 56,1 & 54,9 & 58,1 & 58,2 & 57,2 & 55,0 \\
\hline 60,8 & 66,3 & 58,9 & 60,7 & 64,7 & 56,8 & 55,4 & 65,0 & 56,9 & 57,3 \\
\hline 61 & 59,7 & 60,3 & 63,8 & 57,2 & 53,8 & 55,2 & 60,0 & 53,6 & 56,9 \\
\hline 62,8 & 61,5 & 60,8 & 53,5 & 57,9 & 54,0 & 65,2 & 63,9 & 61,1 & 57,2 \\
\hline 60,1 & 58,9 & 65,8 & 55,6 & 57,2 & 58,7 & 62,1 & 57,2 & 61,2 & 58,7 \\
\hline 58,5 & 52,7 & 58,5 & 59,3 & 56,7 & 53,0 & 58,5 & 59,7 & 55,7 & 54,9 \\
\hline 56,5 & 73,1 & 57,4 & 56,6 & 63,6 & 57,5 & 56,6 & 54,1 & 56,9 & 56,8 \\
\hline 55,2 & 54,8 & 57,7 & 58,4 & 52,2 & 64,8 & 62,0 & 66,7 & 54,7 & 64,4 \\
\hline 58,5 & 64,5 & 61,0 & 61,2 & 63,1 & 54,6 & 62,4 & 54,4 & 56,8 & 62,8 \\
\hline 54,8 & 58,6 & 59,1 & 63,8 & 53,0 & 58,7 & 60,3 & 54,8 & 59,3 & 55,2 \\
\hline 66,2 & 54,3 & 61,0 & 61,6 & 62,4 & 53,8 & 58,4 & 55,6 & 56,2 & 61,4 \\
\hline 54,6 & 57,9 & 56,5 & 63,2 & 56,8 & 65,9 & 61,8 & 53,6 & 65,9 & 57,3 \\
\hline 56,4 & 54,2 & 59,3 & 60,0 & 62,0 & 54,3 & 55,2 & 63,1 & 55,8 & 61,2 \\
\hline 61,4 & 56,6 & 55,6 & 64,2 & 54,0 & 61,0 & 63,6 & 55,8 & 62,0 & 58,1 \\
\hline 66,1 & 56,2 & 60,0 & 57,2 & 58,5 & 54,6 & 57,4 & 54,6 & 57,0 & 54,2 \\
\hline 57,2 & 53,9 & 58,3 & 59,6 & 57,5 & 54,3 & 60,6 & 54,6 & 55,5 & 59,5 \\
\hline 55 & 69,0 & 55,4 & 56,9 & 55,8 & 65,2 & 54,6 & 53,8 & 57,1 & 53,2 \\
\hline 55,5 & 57,1 & 60,7 & 65,2 & 65,8 & 53,8 & 57,1 & 65,0 & 58,0 & 59,1 \\
\hline 57,2 & 53,6 & 54,4 & $\begin{array}{l}62,0 \\
\end{array}$ & 56,6 & 60,3 & 55,3 & 54,9 & 55,4 & 55,2 \\
\hline 61,1 & 59,4 & 66,6 & 58,1 & 56,4 & 61,4 & 53,8 & 53,2 & 56,2 & 52,6 \\
\hline 60,8 & 55,5 & 60,4 & 63,8 & 57,4 & 53,3 & 59,5 & 58,5 & 55,0 & 57,2 \\
\hline 54,6 & 61,3 & 58,0 & 58,1 & 59,7 & 63,7 & 58,1 & 56,6 & 58,1 & 56,1 \\
\hline 59,8 & 55,5 & 60,1 & 65,1 & 51,9 & 56,2 & 53,9 & 57,7 & 57,9 & 59,7 \\
\hline 62,1 & 64,8 & 58,5 & 62,1 & 63,7 & 84,6 & 60,1 & 54,2 & 59,3 & 56,0 \\
\hline 60,8 & 61,0 & 65,3 & 57,1 & 54,0 & 57,7 & 58,1 & 68,7 & 53,2 & 53,9 \\
\hline
\end{tabular}


Tabela 3 - Dados de ruído, em dB(A), no Piso 3 (Continuação).

\begin{tabular}{|c|c|c|c|c|c|c|c|c|c|}
\hline $20 / 05 / 10$ & $26 / 05 / 10$ & $08 / 06 / 10$ & $15 / 06 / 10$ & $07 / 07 / 10$ & $14 / 07 / 10$ & $23 / 07 / 10$ & $10 / 08 / 10$ & $17 / 08 / 10$ & $08 / 09 / 10$ \\
\hline 65,5 & 55,7 & 55,9 & 60,3 & 62,8 & 58,2 & 51,8 & 67,5 & 54,0 & 61,2 \\
\hline 60,1 & 64,8 & 54,1 & 53,3 & 61,8 & 55,5 & 64,9 & 57,1 & 62,0 & 57,3 \\
\hline 57,7 & 53,4 & 55,4 & 65,3 & 61,6 & 54,1 & 50,8 & 64,6 & 55,3 & 56,2 \\
\hline 56,8 & 61,1 & 58,2 & 58,8 & 56,9 & 53,0 & 62,0 & 54,6 & 63,0 & 64,7 \\
\hline 55,4 & 60,9 & 60,9 & 57,5 & 56,8 & 61,6 & 50,7 & 54,9 & 56,9 & 54,3 \\
\hline 56,4 & 56,4 & 61,8 & 60,0 & 59,9 & 57,5 & 58,0 & 60,3 & 56,2 & 64,2 \\
\hline 56,9 & 58,5 & 58,3 & 57,6 & 53,3 & 60,5 & 60,3 & 54,8 & 56,9 & 59,2 \\
\hline 64,6 & 52,6 & 59,7 & 59,9 & 53,4 & 57,7 & 54,9 & 57,4 & 55,8 & 59,3 \\
\hline 62,3 & 61,8 & 60,7 & 61,2 & 59,3 & 55,7 & 59,0 & 56,0 & 63,7 & 59,0 \\
\hline 63,4 & 57,3 & 64,1 & 62,3 & 56,6 & 58,6 & 57,3 & 53,6 & 55,5 & 58,5 \\
\hline 60,5 & 54,3 & 57,3 & 60,2 & 52,7 & 56,2 & 55,9 & 61,9 & 58,6 & 63,5 \\
\hline 58,7 & 63,1 & 55,1 & 56,9 & 59,3 & 59,9 & 54,0 & 53,0 & 57,4 & 61,6 \\
\hline 60,1 & 56,9 & 65,1 & 63,7 & 53,0 & 56,6 & 63,8 & 64,4 & 55,1 & 65,2 \\
\hline 56,9 & 65,5 & 63,0 & 56,7 & 62,4 & 54,2 & 51,9 & 57,1 & 58,3 & 62,8 \\
\hline 60,9 & 55,5 & 58,7 & 56,8 & 53,8 & 58,9 & 59,6 & 57,3 & 58,5 & 56,6 \\
\hline 61 & 55,5 & 59,9 & 57,2 & 62,9 & 55,6 & 59,5 & 60,5 & 55,2 & 57,7 \\
\hline 62,1 & 66,0 & 54,4 & 57,4 & 54,6 & 67,8 & 64,7 & 54,1 & 57,1 & 55,5 \\
\hline 60,4 & 57,7 & 61,0 & 55,0 & 61,1 & 63,6 & 69,3 & 62,9 & 55,0 & 56,0 \\
\hline 57,3 & 66,3 & 57,4 & 55,2 & 60,7 & 65,5 & 56,5 & 58,3 & 57,2 & 54,6 \\
\hline 61 & 72,6 & 60,6 & 63,6 & 60,7 & 65,0 & 54,8 & 64,6 & 58,5 & 53,8 \\
\hline 63,6 & 56,6 & 62,3 & 62,4 & 61,7 & 55,4 & 60,5 & 59,8 & 57,9 & 56,9 \\
\hline 61,8 & 62,0 & 55,6 & 60,2 & 55,7 & 63,7 & 56,9 & 56,6 & 56,8 & 64,3 \\
\hline 65,9 & 57,3 & 57,9 & 57,2 & 61,1 & 55,8 & 53,3 & 61,6 & 54,0 & 64,2 \\
\hline 58,9 & 60,8 & 57,6 & 60,4 & 54,2 & 71,4 & 56,2 & 58,1 & 59,9 & 56,6 \\
\hline $\begin{array}{l}56,7 \\
\end{array}$ & 60,7 & $\begin{array}{l}58,9 \\
\end{array}$ & 63,0 & $\begin{array}{l}58,8 \\
\end{array}$ & 59,7 & 51,7 & 56,9 & 56,8 & 52,6 \\
\hline 55,5 & 60,2 & 56,9 & 60,8 & 52,9 & 57,4 & 53,7 & 62,4 & 57,1 & 56,9 \\
\hline 56,8 & 69,4 & 54,6 & 62,0 & 58,8 & 58,5 & 56,7 & 54,6 & 55,8 & 54,4 \\
\hline 60,8 & 65,5 & 67,1 & 58,8 & 54,2 & 57,3 & 53,5 & 56,0 & 54,3 & 53,0 \\
\hline 58,7 & 59,2 & 56,2 & 59,3 & 59,2 & 61,4 & 53,7 & 54,0 & 58,1 & $\begin{array}{l}58,7 \\
\end{array}$ \\
\hline 59,6 & 56,2 & 55,7 & 56,0 & 57,3 & 53,8 & 54,6 & 52,1 & 54,9 & 52,9 \\
\hline 63,4 & 65,2 & 59,7 & 55,6 & 53,5 & 54,3 & 58,2 & 59,5 & 54,2 & 58,8 \\
\hline 51,9 & 67,7 & 56,5 & 55,3 & $\begin{array}{l}55,9 \\
\end{array}$ & 65,4 & 54,6 & 54,2 & 57,7 & 58,7 \\
\hline 52,9 & 59,5 & 61,5 & 62,8 & 53,4 & 58,9 & 63,4 & 64,4 & 53,4 & 61,4 \\
\hline 59,5 & 58,5 & 59,8 & 61,0 & 63,9 & 58,4 & 60,9 & 60,2 & 58,1 & 57,6 \\
\hline 56,6 & 60,6 & 58,1 & 62,0 & 54,6 & 58,7 & 58,3 & $\begin{array}{l}56,9 \\
\end{array}$ & 58,7 & 52,9 \\
\hline 57,9 & 59,2 & 56,8 & 58,6 & 62,2 & 54,8 & 61,2 & 56,2 & 54,5 & 64,3 \\
\hline 60,9 & 70,6 & 54,8 & 51,2 & $\begin{array}{l}59,6 \\
\end{array}$ & 57,7 & 56,1 & 60,8 & 58,8 & 55,7 \\
\hline 62 & 56,4 & 61,2 & 53,6 & 61,3 & 59,8 & 53,3 & 59,3 & 52,5 & 61,8 \\
\hline 58,2 & 69,2 & 57,2 & 58,7 & 57,7 & 54,6 & 54,4 & 55,7 & 56,0 & 65,2 \\
\hline 57,8 & 63,0 & 54,9 & 58,1 & 59,7 & 57,5 & 54,3 & $\begin{array}{l}58,5 \\
\end{array}$ & 54,8 & 54,6 \\
\hline $\begin{array}{l}56,8 \\
\end{array}$ & 53,2 & 60,5 & 54,0 & 60,4 & 54,2 & 57,5 & 59,1 & 54,6 & 57,6 \\
\hline 55,2 & 58,8 & 52,3 & $\begin{array}{l}58,6 \\
\end{array}$ & 65,2 & 66,1 & 54,0 & 55,4 & 59,5 & 59,8 \\
\hline 60,1 & 55,2 & 68,7 & 65,0 & 55,6 & 56,8 & 55,2 & 59,3 & 53,3 & 60,1 \\
\hline 57,9 & 63,3 & 61,0 & 56,2 & 58,1 & 62,3 & 55,0 & 58,5 & 61,2 & 59,3 \\
\hline 57,2 & 64,9 & 63,7 & 54,2 & $\begin{array}{l}56,9 \\
\end{array}$ & 55,7 & 63,0 & 59,6 & 53,4 & 62,8 \\
\hline 52,4 & 55,0 & 62,0 & 58,4 & 54,2 & 56,2 & 60,5 & 60,0 & 56,6 & 61,6 \\
\hline 53,8 & 59,2 & 56,0 & 55,3 & 64,9 & 59,6 & 62,4 & 61,4 & 60,7 & 64,2 \\
\hline 52,2 & 55,2 & 57,1 & 51,3 & 56,1 & 57,7 & 51,5 & 64,8 & 61,6 & 61,0 \\
\hline 56,7 & 66,5 & 59,5 & 61,1 & 60,3 & 66,7 & 57,7 & 58,3 & 65,0 & 55,7 \\
\hline 58,1 & 62,7 & 61,6 & 59,1 & 54,2 & 60,2 & 53,4 & 54,0 & 55,3 & 52,3 \\
\hline 62,8 & $\begin{array}{l}58,1 \\
\end{array}$ & 59,5 & 55,4 & 68,3 & 59,9 & 51,0 & 56,8 & 53,2 & 56,8 \\
\hline 55,8 & 62,4 & 61,2 & 53,6 & 57,1 & 61,0 & 73,0 & 60,3 & 57,2 & 54,8 \\
\hline 59,7 & 62,4 & 61,9 & 55,5 & 60,9 & 59,7 & 53,0 & 60,9 & 56,2 & 62,4 \\
\hline 61,1 & 59,9 & 58,3 & 52,7 & 59,1 & 62,9 & 51,4 & 53,7 & 55,5 & 70,0 \\
\hline 61,8 & 56,1 & 66,2 & 59,6 & 67,3 & 71,5 & 51,5 & 53,5 & 52,6 & 60,9 \\
\hline 63,1 & 58,1 & 65,9 & 54,2 & 58,7 & 61,6 & 54,2 & 62,4 & 53,7 & 59,2 \\
\hline 59,6 & 57,9 & 64,8 & 59,3 & 53,2 & 69,3 & 55,2 & 60,1 & 56,9 & 54,5 \\
\hline 59,6 & 65,3 & 68,4 & 54,8 & 57,5 & 60,7 & 55,2 & 62,4 & 56,0 & 58,9 \\
\hline 66 & 65,7 & 69,1 & 60,7 & 55,5 & 60,1 & 59,7 & 54,8 & 59,3 & 64,2 \\
\hline 55,8 & 59,5 & 61,6 & 56,1 & 57,6 & 62,4 & 51,9 & 53,0 & 57,6 & 66,3 \\
\hline 65,1 & 52,6 & 59,9 & 56,4 & 56,0 & 59,2 & 55,1 & 60,1 & 53,8 & 58,9 \\
\hline 64,7 & 57,1 & 55,7 & 53,0 & 58,4 & $\begin{array}{l}60,9 \\
\end{array}$ & 56,2 & 56,2 & 58,5 & 59,0 \\
\hline 63,4 & 59,1 & 62,4 & 52,6 & 54,4 & 62,4 & 58,1 & 60,7 & 56,1 & 54,5 \\
\hline 59,8 & 60,1 & 59,7 & 65,7 & 58,7 & 56,0 & 52,4 & 58,8 & 57,9 & 55,3 \\
\hline 62 & 61,8 & 54,3 & 51,6 & 56,7 & 54,8 & 55,2 & 56,2 & 61,7 & 52,2 \\
\hline 56,5 & 60,1 & 67,7 & 54,2 & 56,9 & 55,4 & 52,5 & 55,9 & 57,4 & 68,9 \\
\hline 56 & 56,5 & 50,7 & 53,7 & 54,4 & 64,4 & 56,9 & 55,2 & 60,3 & 56,2 \\
\hline 54,4 & 52,3 & 65,5 & 62,2 & 55,0 & 63,1 & 51,7 & 56,6 & 56,6 & 60,5 \\
\hline 54,8 & 55,9 & 54,2 & 57,5 & 57,7 & 59,2 & 65,7 & 54,9 & 65,9 & 59,6 \\
\hline $\begin{array}{l}54,9 \\
\end{array}$ & 56,8 & 54,7 & 62,4 & 55,7 & 66,2 & 55,3 & 57,0 & 58,4 & 59,8 \\
\hline 55,3 & 55,0 & 61,1 & 51,2 & 55,3 & 60,5 & 60,9 & 58,5 & 59,5 & 58,1 \\
\hline 67,9 & 55,9 & 64,2 & 50,3 & 64,0 & 74,1 & 55,0 & 62,8 & 56,9 & 60,9 \\
\hline 61,9 & 52,1 & 60,7 & 56,5 & 59,1 & 58,2 & 53,2 & 67,5 & 53,3 & 56,5 \\
\hline 58,1 & 56,4 & 54,4 & 53,6 & 54,5 & 61,6 & 57,7 & 55,1 & 61,9 & 59,8 \\
\hline 56,2 & 60,6 & 55,6 & 54,0 & 61,4 & 62,0 & 54,2 & 58,1 & 55,4 & 56,7 \\
\hline 57,6 & 53,6 & 60,9 & 51,2 & 57,9 & 63,8 & 54,9 & 62,4 & 52,6 & 63,8 \\
\hline 54 & 60,9 & 60,2 & 57,1 & 60,0 & 59,7 & 56,2 & 55,6 & 61,9 & 63,5 \\
\hline
\end{tabular}


Tabela 3 - Dados de ruído, em dB(A), no Piso 3 (Continuação).

\begin{tabular}{|c|c|c|c|c|c|c|c|c|c|}
\hline $20 / 05 / 10$ & $26 / 05 / 10$ & $08 / 06 / 10$ & $15 / 06 / 10$ & $07 / 07 / 10$ & $14 / 07 / 10$ & $23 / 07 / 10$ & $10 / 08 / 10$ & $17 / 08 / 10$ & $08 / 09 / 10$ \\
\hline 52,5 & 58,8 & 58,1 & 55,0 & 55,0 & 55,1 & 55,3 & 61,8 & 60,4 & 63,2 \\
\hline 51,7 & 53,8 & 67,1 & 54,6 & 57,3 & 60,2 & 54,6 & 52,5 & 64,2 & 58,1 \\
\hline 52,6 & 56,6 & 56,5 & 51,5 & 54,2 & 65,5 & 59,3 & 52,1 & 59,6 & 62,4 \\
\hline 52,1 & 56,7 & 57,9 & 55,6 & 62,9 & 57,7 & 60,6 & 58,3 & 55,1 & 68,3 \\
\hline 54,5 & 54,6 & 54,6 & 57,8 & 61,6 & 72,8 & 55,9 & 53,6 & 57,2 & 58,3 \\
\hline 60,2 & 56,9 & 62,8 & 65,7 & 61,4 & 56,6 & 54,9 & 61,8 & 53,0 & 63,0 \\
\hline 59,3 & 62,4 & 58,2 & 53,8 & 61,0 & 60,7 & 58,7 & 54,8 & 61,6 & 76,5 \\
\hline 56,7 & 57,7 & 64,0 & 65,2 & 58,9 & 63,1 & 53,8 & 54,2 & 59,9 & 56,8 \\
\hline 59,5 & 51,5 & 63,1 & 56,2 & 59,5 & 56,2 & 54,8 & 62,8 & 57,4 & 63,1 \\
\hline 54,2 & 68,3 & 56,6 & 52,4 & 55,3 & 65,9 & 55,2 & 56,6 & 55,7 & 56,7 \\
\hline 61,2 & 51,5 & 62,4 & 57,1 & 58,4 & 55,1 & 52,5 & 57,9 & 52,6 & 58,5 \\
\hline 53,6 & 63,8 & 55,0 & 53,7 & 62,4 & 62,0 & 53,5 & 56,0 & 58,6 & 62,4 \\
\hline 53 & 53,8 & 57,3 & 55,2 & 62,6 & 63,5 & 54,0 & 57,4 & 63,5 & 56,2 \\
\hline 54 & 50,9 & 58,9 & 52,8 & 53,9 & 58,7 & 55,4 & 59,5 & 55,4 & 56,5 \\
\hline 55,3 & 59,8 & 54,6 & 64,3 & 60,1 & 58,9 & 55,6 & 53,4 & 60,8 & 60,6 \\
\hline 55,3 & 54,6 & 64,6 & 58,1 & 54,4 & 60,9 & 58,1 & 64,8 & 61,0 & 57,9 \\
\hline 55,7 & 55,0 & 60,5 & 56,8 & 60,5 & 68,9 & 55,1 & 53,7 & 62,0 & 57,5 \\
\hline 56,5 & 58,0 & 63,8 & 51,0 & 56,8 & 61,4 & 58,1 & 55,3 & 56,8 & 60,5 \\
\hline 55,4 & 51,3 & 59,3 & 56,2 & 51,3 & 55,5 & 53,9 & 66,6 & 56,1 & 59,5 \\
\hline 59,5 & 56,2 & 56,6 & 62,3 & 59,6 & 62,4 & 55,0 & 53,4 & 58,8 & 63,5 \\
\hline 55 & 67,5 & 65,2 & 57,0 & 57,3 & 59,6 & 60,0 & 56,2 & 55,7 & 61,5 \\
\hline 61,6 & 64,1 & 61,4 & 52,4 & 57,3 & 54,6 & 56,2 & 60,0 & 61,8 & 60,3 \\
\hline 53,3 & 55,7 & 58,5 & 52,5 & 51,9 & 67,6 & 53,6 & 56,0 & 55,6 & 54,6 \\
\hline 54,2 & 54,7 & 57,7 & 56,0 & 63,1 & 54,6 & 53,3 & 60,5 & 58,5 & 62,0 \\
\hline 57,2 & 55,9 & 54,8 & 52,9 & 54,0 & 60,9 & 52,2 & 54,0 & 61,0 & 55,8 \\
\hline 54,4 & 53,2 & 65,0 & 55,0 & 57,9 & 58,8 & 53,0 & 59,2 & 53,0 & 60,9 \\
\hline 52,4 & 59,5 & 58,1 & 59,2 & 55,2 & 59,5 & 53,8 & 56,5 & 64,0 & 63,6 \\
\hline 51 & 64,0 & 56,7 & 57,9 & 60,4 & 64,9 & 59,5 & 56,6 & 58,1 & 58,5 \\
\hline 52,8 & 51,5 & 60,4 & 64,2 & 54,9 & 53,0 & 56,2 & 53,6 & 55,4 & 63,4 \\
\hline 60,4 & 62,9 & 57,7 & 60,1 & 56,2 & 59,7 & 54,9 & 52,3 & 58,4 & 59,8 \\
\hline 53 & 51,3 & 66,4 & 52,1 & 53,8 & 58,3 & 59,7 & 66,0 & 52,8 & 64,5 \\
\hline 60,4 & 56,0 & 60,8 & 59,9 & 52,5 & 71,2 & 54,5 & 55,2 & 63,5 & 66,5 \\
\hline 51,9 & 57,5 & 62,4 & 52,8 & 55,7 & 57,7 & 58,4 & 56,9 & 56,4 & 53,9 \\
\hline 50,7 & 51,8 & 58,9 & 54,6 & 58,1 & 58,6 & 55,7 & $\begin{array}{l}60,7 \\
\end{array}$ & 54,4 & 67,4 \\
\hline 53,4 & 55,1 & 63,2 & 55,3 & 70,5 & 59,1 & 50,4 & 52,3 & 59,0 & 58,2 \\
\hline 55,8 & 53,8 & 60,1 & 55,1 & 58,2 & 62,2 & 59,0 & 68,7 & 54,3 & 69,3 \\
\hline 53,8 & 55,4 & 61,0 & 56,0 & 56,5 & 55,8 & 51,5 & 66,5 & 56,7 & 62,8 \\
\hline 62,3 & 57,1 & 61,4 & 51,5 & 52,1 & 59,3 & 53,0 & 56,4 & 57,8 & 61,5 \\
\hline 59,9 & 54,9 & 63,5 & 57,5 & 60,7 & 57,0 & 51,4 & 59,2 & 55,4 & 62,1 \\
\hline 60,9 & 67,7 & 64,1 & 52,3 & 56,1 & 60,9 & 53,6 & 56,9 & 55,0 & 58,7 \\
\hline 53 & 64,2 & 60,4 & 56,8 & 57,5 & 55,3 & 57,2 & 61,8 & 55,7 & 62,3 \\
\hline 56,2 & 63,8 & 54,4 & 55,1 & 59,1 & 54,2 & 55,7 & 55,2 & 62,0 & 59,1 \\
\hline 55 & 56,5 & 62,2 & 59,8 & 65,3 & 66,4 & 53,3 & 55,1 & 56,5 & 59,0 \\
\hline 64,2 & 56,4 & 64,6 & 52,3 & 52,6 & 54,4 & 55,7 & 60,1 & 56,4 & 62,0 \\
\hline 56,7 & 63,9 & 62,9 & 57,1 & 53,4 & 65,3 & 64,6 & 57,8 & 65,5 & 55,8 \\
\hline 52,5 & 55,6 & 68,6 & 52,1 & $\begin{array}{l}58,9 \\
\end{array}$ & 60,3 & 52,3 & 60,3 & 57,1 & 64,3 \\
\hline 50,7 & 59,5 & 64,4 & 54,6 & 54,8 & 58,0 & 54,0 & 55,3 & 59,3 & 67,4 \\
\hline 53 & 59,0 & 61,4 & 53,2 & 64,3 & 63,0 & 51,7 & 56,2 & 55,4 & 63,4 \\
\hline 58,5 & 59,6 & 60,3 & 54,2 & 51,2 & 62,4 & 55,3 & 60,2 & 57,5 & 65,2 \\
\hline 56,2 & 67,6 & 59,2 & 53,4 & 59,3 & 61,5 & 53,0 & 55,6 & 56,0 & 54,8 \\
\hline 54,8 & 66,6 & 56,9 & 51,3 & 57,4 & 62,2 & 62,4 & 58,3 & 55,9 & 59,8 \\
\hline 59,7 & 57,9 & 54,8 & 55,1 & 64,9 & 60,4 & 55,1 & 54,2 & 62,2 & 67,7 \\
\hline 65,5 & 60,5 & $\begin{array}{l}60,9 \\
\end{array}$ & 64,0 & 53,3 & 59,2 & 59,7 & 55,6 & 54,2 & 56,5 \\
\hline 55,1 & 56,5 & 52,8 & 56,7 & 62,0 & 53,2 & 52,6 & 60,2 & 54,4 & 60,9 \\
\hline 53,2 & 59,8 & 59,5 & 51,6 & 52,4 & 70,2 & 52,2 & 57,6 & 56,1 & 58,0 \\
\hline 52,8 & 56,0 & 63,7 & 57,1 & 63,8 & 56,0 & 56,6 & 60,0 & 56,1 & 64,7 \\
\hline 56,5 & 62,7 & 57,7 & 52,2 & 56,7 & 55,0 & 55,5 & 55,0 & 58,1 & 60,3 \\
\hline 53,4 & 53,0 & 61,5 & 64,1 & 53,6 & 58,5 & 50,7 & 58,1 & 58,2 & 56,2 \\
\hline 60 & 54,5 & 58,8 & 63,1 & 57,3 & 53,6 & 60,0 & 58,7 & 55,0 & 60,6 \\
\hline 53,3 & 59,3 & 54,1 & 56,5 & 59,6 & 59,1 & 51,4 & 59,5 & 56,5 & 56,8 \\
\hline $\begin{array}{l}50,9 \\
\end{array}$ & 55,4 & 61,9 & 61,0 & 61,2 & 53,4 & 49,9 & 67,1 & 53,4 & 65,1 \\
\hline 53,3 & 54,0 & 60,9 & 58,7 & 63,2 & 59,9 & 53,8 & 62,8 & 64,0 & 55,1 \\
\hline 64,2 & 60,9 & 54,8 & 56,7 & 55,9 & 72,4 & 51,5 & 56,6 & 58,5 & 55,3 \\
\hline 58,2 & 50,5 & 60,9 & 63,2 & 57,7 & 56,5 & 53,9 & 60,6 & 57,5 & 61,6 \\
\hline 53,6 & 59,3 & 54,6 & 58,7 & 59,5 & 60,1 & 50,9 & 53,0 & 61,6 & 59,3 \\
\hline 57,7 & 56,5 & 60,6 & 54,2 & 52,3 & 63,6 & 55,9 & 67,8 & 58,3 & 62,6 \\
\hline 54 & 67,1 & 58,3 & 57,5 & 53,4 & 56,0 & 53,0 & 54,2 & 59,9 & 60,1 \\
\hline 54,8 & 57,6 & 60,0 & 55,9 & 51,5 & 56,5 & 63,2 & 52,6 & 57,3 & 56,9 \\
\hline 52,2 & 59,1 & 59,7 & 55,7 & 69,4 & 54,9 & 58,9 & 54,4 & 62,3 & 59,9 \\
\hline 51,9 & 60,5 & 58,4 & 56,8 & 53,6 & 58,5 & 60,4 & 53,7 & 62,2 & 57,6 \\
\hline 53,2 & 59,5 & 60,2 & 62,4 & 56,2 & 60,1 & 56,8 & 58,0 & 59,9 & 54,0 \\
\hline 64,8 & 53,0 & 58,9 & 58,0 & 54,3 & 57,3 & 59,9 & 58,8 & 64,8 & 54,8 \\
\hline 59,9 & 56,5 & 62,6 & 62,7 & 52,4 & 59,6 & 55,6 & 55,0 & 60,1 & 54,0 \\
\hline 51,8 & 60,7 & 58,1 & 54,6 & 59,8 & 53,0 & 56,8 & 55,9 & 66,4 & 65,5 \\
\hline 53 & 64,8 & 58,5 & 55,9 & 56,4 & 59,0 & 57,6 & 53,8 & 65,7 & 56,2 \\
\hline 50,6 & 58,9 & 64,0 & 54,2 & 57,6 & 60,6 & 51,7 & 61,6 & 69,4 & 60,1 \\
\hline 66,5 & 57,9 & 57,6 & 56,6 & 49,9 & 54,9 & 59,2 & 63,8 & 64,4 & 56,2 \\
\hline
\end{tabular}


Tabela 3 - Dados de ruído, em dB(A), no Piso 3 (Continuação).

\begin{tabular}{|c|c|c|c|c|c|c|c|c|c|}
\hline $20 / 05 / 10$ & $26 / 05 / 10$ & $08 / 06 / 10$ & $15 / 06 / 10$ & $07 / 07 / 10$ & $14 / 07 / 10$ & $23 / 07 / 10$ & $10 / 08 / 10$ & $17 / 08 / 10$ & $08 / 09 / 10$ \\
\hline 55,3 & 66,2 & 60,3 & 55,1 & 57,7 & 64,0 & 58,9 & 56,4 & 59,9 & 55,0 \\
\hline 60,8 & 56,0 & 59,9 & 56,2 & 54,6 & 60,0 & 53,7 & 58,3 & 55,9 & 58,4 \\
\hline 53,4 & 68,7 & 64,6 & 59,3 & 61,6 & 64,2 & 53,4 & 56,9 & 60,8 & 61,8 \\
\hline 54,4 & 55,7 & 57,9 & 58,7 & 54,7 & 58,7 & 54,9 & 68,7 & 59,1 & 61,2 \\
\hline 59,8 & 65,7 & 57,0 & 56,1 & 59,1 & 57,4 & 51,7 & 64,2 & 63,0 & 64,8 \\
\hline 63,9 & 55,9 & 58,9 & 53,8 & 61,4 & 61,0 & 57,0 & 53,3 & 54,3 & 57,1 \\
\hline 57,3 & 56,0 & 60,6 & 62,3 & 53,3 & 59,0 & 53,8 & 56,7 & 63,8 & 56,6 \\
\hline 54,7 & 60,3 & 56,8 & 62,8 & 54,8 & 67,7 & 60,2 & 58,9 & 59,7 & 60,2 \\
\hline 55 & 56,7 & 67,5 & 60,0 & 54,6 & 59,3 & 58,0 & 60,7 & 57,3 & 56,2 \\
\hline 61,8 & 56,2 & 55,8 & 58,4 & 61,4 & 55,1 & 59,6 & 60,0 & 67,1 & 56,8 \\
\hline 58,2 & 60,1 & 58,9 & 60,5 & 54,8 & 60,9 & 58,3 & 62,6 & 57,5 & 58,0 \\
\hline $\mathrm{X}$ & 57,1 & 58,1 & 65,7 & 57,7 & 59,3 & 51,4 & 58,1 & 57,2 & 64,3 \\
\hline $\mathrm{X}$ & 58,5 & 54,8 & 58,3 & 51,2 & 62,0 & 60,5 & 59,0 & 66,3 & 57,1 \\
\hline $\mathrm{X}$ & 53,0 & 57,6 & 57,9 & 61,6 & 56,2 & 55,6 & 57,3 & 58,9 & 58,2 \\
\hline $\mathrm{X}$ & 62,8 & 56,8 & 67,9 & 56,0 & 54,4 & 58,1 & 58,1 & 64,6 & 65,2 \\
\hline $\mathrm{X}$ & 60,5 & 54,2 & 61,0 & 66,1 & 61,8 & 55,2 & 59,6 & 60,9 & 60,1 \\
\hline $\mathrm{X}$ & 51,2 & 57,5 & 62,0 & 59,9 & 53,4 & 66,5 & 64,7 & 54,6 & 64,0 \\
\hline $\mathrm{X}$ & 56,7 & 56,6 & 63,9 & 55,3 & 61,9 & 56,2 & 61,0 & 57,7 & 65,3 \\
\hline $\mathrm{X}$ & 53,0 & 63,9 & $\begin{array}{l}58,9 \\
\end{array}$ & 60,1 & 59,9 & 53,7 & 62,4 & 57,1 & 67,7 \\
\hline $\mathrm{X}$ & 54,0 & 55,3 & 67,0 & 52,7 & 58,5 & 51,3 & 62,4 & 64,0 & 56,8 \\
\hline $\mathrm{X}$ & 59,0 & 60,1 & 61,9 & 61,2 & 60,8 & 53,7 & 66,0 & 56,4 & 57,7 \\
\hline $\mathrm{X}$ & 58,5 & 61,2 & 71,0 & $\begin{array}{l}57,7 \\
\end{array}$ & 55,1 & 57,5 & 58,9 & 57,3 & 60,3 \\
\hline $\mathrm{X}$ & 65,5 & 72,9 & 59,1 & 56,0 & 62,0 & 52,6 & 64,8 & 59,2 & 65,7 \\
\hline $\mathrm{X}$ & 54,6 & 59,8 & 54,3 & 57,9 & 56,8 & 58,8 & 64,3 & 56,2 & 59,9 \\
\hline $\mathrm{X}$ & 60,7 & 58,1 & 59,3 & 60,3 & 67,9 & 53,8 & 60,9 & 59,1 & 65,9 \\
\hline $\mathrm{X}$ & 56,2 & 57,6 & 57,3 & 62,8 & 62,0 & 58,0 & 55,4 & 57,7 & 54,8 \\
\hline $\mathrm{X}$ & 54,8 & 59,7 & 56,5 & 59,7 & 59,8 & 53,4 & 59,2 & 58,5 & 62,7 \\
\hline $\mathrm{X}$ & 65,4 & 60,7 & 58,1 & 55,3 & 62,3 & 59,3 & 58,7 & 55,1 & 56,2 \\
\hline$X$ & 69,1 & 64,1 & 59,3 & 61,1 & 57,2 & 54,6 & 64,5 & 55,2 & 54,2 \\
\hline $\mathrm{X}$ & 60,6 & 61,8 & 54,1 & 68,9 & 56,8 & 61,4 & 56,0 & 62,0 & 58,5 \\
\hline $\mathrm{X}$ & 61,0 & 60,9 & 59,1 & 62,0 & 56,2 & 54,1 & 56,7 & 55,8 & 57,3 \\
\hline $\mathrm{X}$ & 60,5 & 59,3 & 54,4 & 58,8 & 61,1 & 54,8 & 57,2 & 56,8 & 59,3 \\
\hline $\mathrm{X}$ & 60,9 & 54,2 & 61,6 & 58,7 & 62,4 & 57,9 & 55,6 & 67,1 & 54,4 \\
\hline$X$ & 58,7 & 66,5 & 55,2 & 61,6 & 65,5 & 56,2 & 57,4 & 57,2 & 61,6 \\
\hline $\mathrm{X}$ & 56,2 & 55,1 & 63,6 & 55,9 & 57,5 & 54,8 & 54,0 & 63,5 & 60,1 \\
\hline $\mathrm{X}$ & 59,7 & 56,7 & 59,9 & 59,6 & 66,0 & 53,2 & 51,9 & 56,2 & 55,0 \\
\hline$X$ & 51,8 & 59,6 & 58,2 & 57,6 & 57,3 & 53,8 & 61,0 & 58,7 & 55,2 \\
\hline $\mathrm{X}$ & 57,1 & 62,3 & 55,6 & 65,7 & 60,0 & 53,5 & 52,4 & 62,2 & 57,5 \\
\hline $\mathrm{X}$ & 54,0 & 63,9 & 53,4 & 54,0 & 56,2 & 57,6 & 62,6 & 63,0 & 58,3 \\
\hline $\mathrm{X}$ & 56,8 & 58,4 & 60,8 & 58,1 & 62,2 & 54,5 & 59,0 & 60,5 & $\begin{array}{l}58,7 \\
\end{array}$ \\
\hline $\mathrm{X}$ & 64,0 & 69,1 & $\begin{array}{l}51,9 \\
\end{array}$ & $\begin{array}{l}56,4 \\
\end{array}$ & 58,4 & 56,2 & 52,6 & 55,3 & 54,6 \\
\hline $\mathrm{X}$ & 54,6 & 59,0 & 57,9 & 70,8 & 57,6 & 55,1 & 62,0 & 53,6 & 59,3 \\
\hline $\mathrm{X}$ & 60,4 & 53,0 & 56,2 & 56,1 & 62,2 & 59,9 & 58,8 & 54,2 & 54,5 \\
\hline $\mathrm{X}$ & 56,6 & 61,4 & 61,2 & 59,2 & 60,3 & 52,5 & 60,5 & 54,2 & 61,3 \\
\hline $\mathrm{X}$ & 66,1 & 53,0 & 57,2 & 53,4 & 59,2 & 53,8 & 57,7 & 62,4 & 64,9 \\
\hline $\mathrm{X}$ & 63,9 & 56,8 & 64,7 & 58,2 & 64,2 & 57,1 & 54,2 & 53,8 & 53,0 \\
\hline $\mathrm{X}$ & 59,4 & 60,7 & 61,2 & 56,6 & 56,0 & 56,9 & 60,0 & 51,1 & 61,2 \\
\hline $\mathrm{X}$ & 58,4 & 61,5 & 54,2 & 55,2 & 62,2 & 54,2 & 59,2 & 56,8 & 54,8 \\
\hline $\mathrm{X}$ & 53,7 & 63,2 & 56,0 & 61,0 & 64,8 & 57,7 & 65,3 & 51,5 & 60,7 \\
\hline$X$ & 57,5 & 55,9 & 56,7 & 52,6 & 67,5 & 51,0 & 60,9 & 59,1 & 62,3 \\
\hline $\mathrm{X}$ & 60,3 & 55,6 & 57,1 & 62,8 & 65,5 & 53,8 & 61,9 & 56,7 & 58,5 \\
\hline $\mathrm{X}$ & 55,5 & 63,4 & 57,3 & 56,4 & 56,8 & 59,5 & 64,4 & 59,3 & 66,0 \\
\hline $\mathrm{X}$ & 64,0 & 68,0 & 64,0 & 64,4 & 62,7 & 53,9 & 56,5 & 54,8 & 55,5 \\
\hline $\mathrm{X}$ & 55,7 & 62,4 & 54,2 & 52,1 & 57,3 & 56,2 & 56,8 & 52,6 & 62,3 \\
\hline $\mathrm{X}$ & 61,0 & 59,3 & 57,9 & 64,6 & 60,6 & 51,5 & 62,9 & 56,2 & 55,2 \\
\hline $\mathrm{X}$ & 60,7 & 56,5 & 54,6 & 56,1 & 58,5 & 58,7 & 57,2 & 55,1 & 57,9 \\
\hline $\mathrm{X}$ & 58,7 & 57,9 & 57,5 & 60,9 & 60,6 & 54,0 & 63,2 & 57,9 & 61,6 \\
\hline $\mathrm{X}$ & 66,5 & 56,4 & 57,3 & 56,1 & 63,4 & 62,4 & 61,6 & 58,1 & 55,6 \\
\hline $\mathrm{X}$ & 54,5 & 58,1 & 62,0 & 64,7 & 63,4 & 54,0 & 61,1 & 57,1 & 63,4 \\
\hline $\mathrm{X}$ & 56,8 & 53,4 & 59,0 & 61,8 & 56,9 & 60,3 & 56,8 & 64,7 & 60,9 \\
\hline $\mathrm{X}$ & 60,4 & 58,5 & 58,2 & 57,3 & 68,3 & 57,7 & 54,6 & 63,7 & 61,3 \\
\hline $\mathrm{X}$ & 53,7 & 56,5 & 61,6 & 58,0 & 55,2 & 57,5 & 58,5 & 53,0 & 60,4 \\
\hline $\mathrm{X}$ & 61,8 & 55,0 & 53,8 & 53,2 & 64,4 & 52,1 & 57,9 & 60,0 & 59,7 \\
\hline $\mathrm{X}$ & 56,8 & 57,7 & 53,0 & 55,0 & 61,0 & 57,1 & 55,9 & 55,7 & 56,9 \\
\hline $\mathrm{X}$ & 60,7 & 55,4 & 51,2 & 58,3 & 63,1 & 55,2 & 54,0 & 58,8 & 55,8 \\
\hline $\mathrm{X}$ & 61,7 & 58,7 & 55,4 & 57,8 & 60,6 & 60,5 & 53,6 & 56,0 & 58,9 \\
\hline $\mathrm{X}$ & 57,2 & 55,3 & 55,1 & 56,5 & 55,9 & 57,4 & 54,0 & 59,9 & 63,1 \\
\hline $\mathrm{X}$ & 67,5 & 60,3 & 54,6 & 62,7 & 64,0 & 52,9 & 54,0 & 57,9 & 54,8 \\
\hline $\mathrm{X}$ & 58,9 & 66,7 & 57,3 & $\begin{array}{l}56,9 \\
\end{array}$ & 58,5 & 63,6 & 62,0 & 54,0 & 54,9 \\
\hline $\mathrm{X}$ & 65,2 & 63,4 & 52,3 & 60,7 & 61,6 & 63,8 & 59,3 & 60,3 & 59,6 \\
\hline $\mathrm{X}$ & 60,8 & 53,4 & 53,6 & 60,6 & 66,8 & 57,7 & 58,1 & 58,0 & 56,8 \\
\hline $\mathrm{X}$ & 59,3 & 52,9 & 55,8 & $\begin{array}{l}56,8 \\
\end{array}$ & 56,0 & 56,2 & 61,7 & 60,1 & 58,5 \\
\hline $\mathrm{X}$ & 66,2 & 53,0 & 56,0 & 66,2 & 60,1 & 56,6 & 56,2 & 64,7 & 59,1 \\
\hline $\mathrm{X}$ & 59,4 & 58,6 & 58,4 & 59,1 & 62,8 & 68,1 & 58,4 & 52,0 & 57,1 \\
\hline $\mathrm{X}$ & 64,8 & 53,6 & 59,3 & $\begin{array}{l}58,9 \\
\end{array}$ & 66,5 & 55,3 & 60,4 & 62,8 & 65,3 \\
\hline $\mathrm{X}$ & 57,5 & 53,9 & 57,9 & 55,4 & 61,5 & 59,6 & 58,1 & 60,7 & 55,4 \\
\hline $\mathrm{X}$ & 59,1 & 68,7 & 63,3 & $\begin{array}{l}58,8 \\
\end{array}$ & 66,2 & 51,7 & 73,7 & 57,4 & 60,1 \\
\hline
\end{tabular}


Tabela 3 - Dados de ruído, em dB(A), no Piso 3 (Continuação).

\begin{tabular}{|c|c|c|c|c|c|c|c|c|c|}
\hline $20 / 05 / 10$ & $26 / 05 / 10$ & $08 / 06 / 10$ & $15 / 06 / 10$ & $07 / 07 / 10$ & $14 / 07 / 10$ & $23 / 07 / 10$ & $10 / 08 / 10$ & $17 / 08 / 10$ & $08 / 09 / 10$ \\
\hline $\mathrm{X}$ & 57,5 & 55,3 & 57,9 & 57,2 & 61,7 & 57,4 & 54,5 & 59,6 & 64,6 \\
\hline $\mathrm{X}$ & 57,4 & 58,8 & 56,7 & 58,9 & 63,2 & 53,0 & 61,7 & 54,3 & 55,0 \\
\hline $\mathrm{X}$ & 57,7 & 59,1 & 56,2 & 58,9 & 61,3 & 63,4 & 54,5 & 61,9 & 60,7 \\
\hline $\mathrm{X}$ & 56,9 & 55,9 & 58,3 & 58,5 & 61,4 & 53,2 & 52,6 & 60,1 & 57,1 \\
\hline $\mathrm{X}$ & 51,8 & 63,7 & 56,2 & 55,0 & 65,1 & 64,4 & 58,2 & 61,9 & 60,6 \\
\hline $\mathrm{X}$ & 59,3 & 58,5 & 59,7 & 58,1 & 69,6 & 52,5 & 54,6 & 60,3 & 59,3 \\
\hline$X$ & 53,5 & 63,0 & 56,2 & 54,5 & 64,8 & 63,5 & 57,7 & 59,3 & 56,5 \\
\hline $\mathrm{X}$ & 60,5 & 61,4 & 65,5 & 52,9 & 61,4 & 53,4 & 54,8 & 58,6 & 60,3 \\
\hline $\mathrm{X}$ & 54,8 & 55,8 & 54,4 & 61,2 & 56,9 & 57,2 & 54,2 & 54,7 & 53,9 \\
\hline $\mathrm{X}$ & 51,4 & 58,7 & 63,0 & 54,9 & 67,9 & 54,0 & 57,9 & 59,3 & 67,9 \\
\hline $\mathrm{X}$ & 60,6 & 55,3 & 64,2 & 57,5 & 56,2 & 58,3 & 56,7 & 60,1 & 55,1 \\
\hline $\mathrm{X}$ & 55,0 & 63,6 & 59,7 & 54,5 & 54,2 & 57,7 & 63,6 & 55,8 & 55,2 \\
\hline $\mathrm{X}$ & 53,5 & 54,6 & 57,7 & 57,3 & 61,2 & 53,7 & 57,5 & 59,3 & 58,3 \\
\hline $\mathrm{X}$ & 63,5 & 54,8 & 63,7 & 56,0 & 59,2 & 55,2 & 52,2 & 63,2 & 55,5 \\
\hline $\mathrm{X}$ & 53,2 & 68,7 & 56,6 & 65,5 & 61,6 & 57,2 & 58,0 & 59,2 & 64,3 \\
\hline $\mathrm{X}$ & 55,5 & 62,8 & 54,6 & 68,1 & 60,2 & 67,7 & 55,3 & 58,5 & 53,6 \\
\hline $\mathrm{X}$ & 62,7 & 65,7 & 65,9 & 56,9 & 58,1 & 58,7 & 56,9 & 57,9 & 54,2 \\
\hline $\mathrm{X}$ & 59,2 & 60,2 & 53,0 & 55,5 & 58,7 & 58,6 & 56,4 & 57,5 & 56,4 \\
\hline $\mathrm{X}$ & 55,9 & 60,9 & 59,1 & 60,7 & 57,3 & 57,7 & 54,0 & 63,4 & 60,5 \\
\hline $\mathrm{X}$ & 52,6 & 62,4 & 55,5 & 69,3 & 56,9 & 65,9 & 58,9 & 59,1 & 63,1 \\
\hline $\mathrm{X}$ & 56,2 & 59,7 & 60,1 & 56,2 & 60,1 & 53,4 & 55,6 & 57,9 & 55,6 \\
\hline $\mathrm{X}$ & 52,5 & 63,8 & 57,4 & 62,8 & 56,5 & 59,9 & 64,6 & 59,8 & 58,5 \\
\hline $\mathrm{X}$ & 66,9 & 68,6 & 61,1 & 55,1 & 63,1 & 60,1 & 60,0 & 68,7 & 52,7 \\
\hline $\mathrm{X}$ & 57,9 & 57,7 & 59,3 & 72,3 & 54,8 & 62,7 & 54,0 & 54,4 & 51,0 \\
\hline $\mathrm{X}$ & 62,4 & 62,2 & 57,9 & 55,9 & 68,2 & 58,9 & 57,5 & 56,8 & 62,8 \\
\hline $\mathrm{X}$ & 56,2 & 66,2 & 73,7 & 58,3 & 66,4 & 55,7 & 55,9 & 56,1 & 56,9 \\
\hline $\mathrm{X}$ & 54,3 & 58,6 & 61,9 & 58,1 & 59,6 & 56,9 & 55,1 & 53,4 & 58,7 \\
\hline $\mathrm{X}$ & 57,3 & 63,2 & 59,7 & 61,8 & 57,7 & 56,0 & 55,0 & 58,3 & 57,6 \\
\hline $\mathrm{X}$ & 63,4 & 58,9 & 58,3 & 53,8 & 55,9 & 56,6 & 55,3 & 59,3 & 52,3 \\
\hline $\mathrm{X}$ & 59,5 & 61,0 & 61,0 & 57,3 & 61,6 & 60,2 & 62,2 & 58,1 & 66,3 \\
\hline$X$ & 59,3 & 62,0 & 58,0 & 61,0 & 57,7 & 58,4 & 67,1 & 56,8 & 59,1 \\
\hline $\mathrm{X}$ & 60,0 & 65,1 & 59,3 & 60,4 & 52,6 & 55,5 & 66,3 & 58,7 & 60,4 \\
\hline $\mathrm{X}$ & 56,0 & 61,5 & 53,8 & 59,9 & 65,3 & 59,2 & 55,7 & 61,2 & 59,1 \\
\hline $\mathrm{X}$ & 58,4 & 58,6 & 63,1 & 72,1 & 58,5 & 55,8 & 54,9 & 59,2 & 57,0 \\
\hline $\mathrm{X}$ & 54,6 & 56,2 & 59,1 & 56,8 & 65,2 & 56,7 & 56,4 & 63,3 & 61,9 \\
\hline $\mathrm{X}$ & 62,3 & 66,4 & 57,7 & 56,4 & 68,1 & 54,1 & 55,6 & 54,8 & 54,1 \\
\hline $\mathrm{X}$ & 53,8 & 64,0 & 57,6 & 59,8 & 57,3 & 59,9 & 58,9 & 53,9 & 69,4 \\
\hline $\mathrm{X}$ & 60,1 & 59,1 & 60,8 & 54,5 & 62,0 & 57,9 & 60,9 & 58,0 & 63,4 \\
\hline $\mathrm{X}$ & 54,3 & 61,5 & 61,6 & 60,1 & 51,5 & 53,3 & 57,7 & 56,9 & 55,4 \\
\hline $\mathrm{X}$ & 57,3 & 66,3 & 60,5 & 57,4 & 65,5 & 55,6 & 57,9 & 64,7 & 57,7 \\
\hline $\mathrm{X}$ & 57,7 & 60,2 & 62,4 & 57,3 & 54,8 & 54,6 & 53,8 & 58,9 & 56,8 \\
\hline $\mathrm{X}$ & 59,9 & 61,7 & 53,4 & 56,0 & 55,7 & 60,7 & 65,5 & 53,6 & 58,1 \\
\hline $\mathrm{X}$ & 60,8 & 55,9 & 67,9 & 57,3 & 59,9 & 52,6 & 66,2 & 56,9 & 58,0 \\
\hline $\mathrm{X}$ & 54,6 & 55,4 & 54,0 & 58,9 & 53,5 & 64,6 & 56,2 & 54,2 & 52,9 \\
\hline $\mathrm{X}$ & 53,8 & 56,8 & 61,5 & 58,7 & 61,4 & 53,4 & 57,7 & 57,3 & 55,9 \\
\hline $\mathrm{X}$ & 64,8 & 56,8 & 56,7 & 54,2 & 56,2 & 59,7 & 61,1 & 58,3 & 54,9 \\
\hline $\mathrm{X}$ & 56,1 & 63,2 & 71,2 & 58,5 & 53,8 & 56,5 & 57,5 & 52,3 & 54,1 \\
\hline $\mathrm{X}$ & 62,8 & 67,2 & 54,4 & 68,0 & 55,7 & 57,9 & 55,4 & 64,8 & 57,7 \\
\hline $\mathrm{X}$ & 65,2 & 57,9 & 52,5 & 55,4 & 54,5 & $\mathrm{X}$ & 55,9 & 62,4 & 57,7 \\
\hline $\mathrm{X}$ & 52,6 & 63,0 & 58,3 & 57,1 & 59,8 & $\mathrm{X}$ & 59,8 & 59,1 & 61,4 \\
\hline $\mathrm{X}$ & 58,9 & 56,8 & 53,2 & 57,7 & 56,6 & $\mathrm{X}$ & 56,8 & 63,7 & 53,5 \\
\hline$X$ & 58,5 & 57,3 & 61,9 & 62,0 & 55,6 & $X$ & 61,4 & 56,9 & 56,7 \\
\hline $\mathrm{X}$ & $\begin{array}{l}58,1 \\
\end{array}$ & 55,5 & $\begin{array}{l}51,5 \\
\end{array}$ & 53,5 & 61,1 & $\mathrm{X}$ & 58,5 & 60,0 & 56,0 \\
\hline $\mathrm{X}$ & 60,0 & 54,6 & 62,4 & 65,4 & 58,5 & $X$ & 53,2 & 61,4 & 54,2 \\
\hline $\mathrm{X}$ & 53,8 & 64,0 & 52,7 & 61,0 & 58,9 & $\mathrm{X}$ & 55,0 & 61,2 & 59,6 \\
\hline $\mathrm{X}$ & 65,8 & 59,5 & 59,5 & $\mathrm{X}$ & 57,5 & $\mathrm{X}$ & 56,5 & 60,7 & 55,3 \\
\hline $\mathrm{X}$ & 59,5 & 61,8 & 66,6 & $\mathrm{X}$ & 57,7 & $\mathrm{X}$ & 57,6 & 55,2 & 57,2 \\
\hline $\mathrm{X}$ & 53,5 & 57,5 & 64,4 & $\mathrm{X}$ & 59,1 & $\mathrm{X}$ & 54,5 & 57,3 & 61,8 \\
\hline $\mathrm{X}$ & 57,9 & 56,2 & 53,0 & $\mathrm{X}$ & 57,0 & $\mathrm{X}$ & 59,9 & 57,9 & 53,3 \\
\hline $\mathrm{X}$ & 53,5 & 59,6 & 56,2 & $\mathrm{X}$ & 63,1 & $\mathrm{X}$ & 57,5 & 69,4 & 59,3 \\
\hline $\mathrm{X}$ & 62,8 & 61,0 & 54,7 & $X$ & 60,7 & $\mathrm{X}$ & 59,2 & 57,9 & 60,9 \\
\hline $\mathrm{X}$ & 53,5 & 67,1 & 59,9 & $\mathrm{X}$ & 56,2 & $\mathrm{X}$ & 61,5 & 55,0 & 54,6 \\
\hline $\mathrm{X}$ & 56,8 & 52,2 & 55,3 & $\mathrm{X}$ & 55,3 & $\mathrm{X}$ & 59,3 & 60,3 & 61,0 \\
\hline $\mathrm{X}$ & 61,6 & 63,5 & 58,5 & $\mathrm{X}$ & 54,0 & $\mathrm{X}$ & 56,7 & 61,0 & 60,9 \\
\hline $\mathrm{X}$ & 52,5 & 65,8 & 59,5 & $X$ & 62,4 & $\mathrm{X}$ & 59,9 & 59,3 & 61,2 \\
\hline $\mathrm{X}$ & 57,7 & 59,7 & 52,4 & $\mathrm{X}$ & 59,5 & $\mathrm{X}$ & 58,9 & 61,8 & 55,9 \\
\hline $\mathrm{X}$ & 50,9 & 63,0 & 53,4 & $\mathrm{X}$ & 56,6 & $\mathrm{X}$ & 60,5 & 58,1 & 61,0 \\
\hline $\mathrm{X}$ & 64,4 & 54,3 & 54,1 & $\mathrm{X}$ & 63,4 & $\mathrm{X}$ & 56,1 & 63,7 & 67,1 \\
\hline $\mathrm{X}$ & 58,1 & 55,1 & 58,5 & $\mathrm{X}$ & 56,1 & $\mathrm{X}$ & 55,1 & 59,3 & 55,6 \\
\hline $\mathrm{X}$ & 55,6 & 63,2 & 60,5 & $X$ & 66,3 & $\mathrm{X}$ & 58,4 & 71,2 & 58,9 \\
\hline $\mathrm{X}$ & 59,9 & 52,6 & 63,4 & $\mathrm{X}$ & 63,8 & $\mathrm{X}$ & 54,6 & 60,5 & 56,0 \\
\hline $\mathrm{X}$ & 55,3 & 60,8 & 59,1 & $\mathrm{X}$ & 55,5 & $\mathrm{X}$ & 64,2 & 56,9 & 62,0 \\
\hline$X$ & 64,0 & 58,9 & 65,0 & $X$ & 65,3 & $\mathrm{X}$ & 54,8 & 61,2 & 66,3 \\
\hline $\mathrm{X}$ & 58,2 & 52,3 & $\begin{array}{l}58,4 \\
\end{array}$ & $\mathrm{X}$ & 60,1 & $\mathrm{X}$ & 53,3 & 60,9 & 57,3 \\
\hline $\mathrm{X}$ & 59,2 & 57,7 & 59,3 & $\mathrm{X}$ & 65,4 & $\mathrm{X}$ & 60,8 & 60,2 & 63,0 \\
\hline $\mathrm{X}$ & 58,9 & 58,4 & 61,8 & $\mathrm{X}$ & 54,7 & $\mathrm{X}$ & 53,8 & 62,1 & 53,7 \\
\hline $\mathrm{X}$ & 56,4 & 57,5 & 61,3 & $\mathrm{X}$ & 58,7 & $\mathrm{X}$ & 59,8 & 56,6 & 55,6 \\
\hline
\end{tabular}


Tabela 3 - Dados de ruído, em dB(A), no Piso 3 (Continuação).

\begin{tabular}{|c|c|c|c|c|c|c|c|c|c|}
\hline $20 / 05 / 10$ & $26 / 05 / 10$ & $08 / 06 / 10$ & $15 / 06 / 10$ & $07 / 07 / 10$ & $14 / 07 / 10$ & $23 / 07 / 10$ & $10 / 08 / 10$ & $17 / 08 / 10$ & $08 / 09 / 10$ \\
\hline $\mathrm{X}$ & 61,3 & 56,8 & 58,7 & $\mathrm{X}$ & 61,6 & $\mathrm{X}$ & 55,8 & 58,5 & 55,8 \\
\hline $\mathrm{X}$ & 62,4 & 56,2 & 54,1 & $\mathrm{X}$ & 58,2 & $\mathrm{X}$ & 53,6 & 55,5 & 54,1 \\
\hline $\mathrm{X}$ & 54,5 & 59,8 & 59,8 & $\mathrm{X}$ & 60,9 & $\mathrm{X}$ & 58,2 & 55,9 & 60,4 \\
\hline$X$ & 61,5 & 54,7 & 55,8 & $X$ & 55,7 & $X$ & 56,8 & 59,2 & 57,5 \\
\hline $\mathrm{X}$ & 54,7 & 61,7 & 62,4 & $\mathrm{X}$ & 51,8 & $\mathrm{X}$ & 66,3 & 57,7 & 53,8 \\
\hline $\mathrm{X}$ & 56,6 & 61,4 & 62,1 & $\mathrm{X}$ & 62,4 & $X$ & 57,4 & 59,7 & 58,0 \\
\hline $\mathrm{X}$ & 58,9 & 55,0 & 60,8 & $\mathrm{X}$ & 53,4 & $\mathrm{X}$ & 55,0 & 65,5 & 53,6 \\
\hline $\mathrm{X}$ & 55,8 & 58,5 & 56,1 & $\mathrm{X}$ & 67,5 & $\mathrm{X}$ & 58,7 & 59,3 & 60,8 \\
\hline $\mathrm{X}$ & 61,4 & 53,4 & 60,7 & $\mathrm{X}$ & 58,5 & $\mathrm{X}$ & 54,3 & 58,5 & 53,6 \\
\hline$X$ & 55,2 & 60,8 & 59,0 & $\mathrm{X}$ & 63,9 & $X$ & 58,5 & 55,0 & 56,9 \\
\hline $\mathrm{X}$ & 53,8 & 56,8 & 58,9 & $\mathrm{X}$ & 60,6 & $\mathrm{X}$ & 56,2 & 56,6 & 56,1 \\
\hline $\mathrm{X}$ & 55,8 & 59,9 & 58,6 & $\mathrm{X}$ & 57,2 & $\mathrm{X}$ & 54,7 & 58,9 & 59,2 \\
\hline $\mathrm{X}$ & 52,8 & 58,0 & 56,5 & $\mathrm{X}$ & 68,4 & $\mathrm{X}$ & 56,2 & 55,4 & 65,2 \\
\hline $\mathrm{X}$ & 59,6 & 56,0 & 60,6 & $\mathrm{X}$ & 61,1 & $\mathrm{X}$ & 56,0 & 58,3 & 55,4 \\
\hline $\mathrm{X}$ & 55,3 & 58,4 & 52,6 & $\mathrm{X}$ & 61,0 & $X$ & 58,5 & 55,0 & 54,0 \\
\hline $\mathrm{X}$ & 67,3 & 56,2 & 58,0 & $\mathrm{X}$ & 60,0 & $\mathrm{X}$ & 56,9 & 57,7 & 65,5 \\
\hline $\mathrm{X}$ & 60,9 & 56,6 & 59,5 & $\mathrm{X}$ & 60,9 & $\mathrm{X}$ & 56,8 & 56,2 & 54,2 \\
\hline $\mathrm{X}$ & 54,5 & 57,6 & 57,7 & $\mathrm{X}$ & 66,1 & $\mathrm{X}$ & 59,5 & 74,9 & 67,1 \\
\hline $\mathrm{X}$ & 65,5 & 55,0 & 56,4 & $\mathrm{X}$ & 62,9 & $\mathrm{X}$ & 57,7 & 55,9 & 56,6 \\
\hline $\mathrm{X}$ & 56,9 & 65,0 & 61,2 & $X$ & 59,2 & $X$ & 59,1 & 54,1 & 63,9 \\
\hline $\mathrm{X}$ & 56,0 & 55,1 & $\begin{array}{l}60,9 \\
\end{array}$ & $\mathrm{X}$ & 68,6 & $\mathrm{X}$ & 55,6 & 66,2 & 55,8 \\
\hline $\mathrm{X}$ & 55,5 & 56,2 & 57,1 & $\mathrm{X}$ & 58,7 & $\mathrm{X}$ & 51,9 & 58,4 & 57,2 \\
\hline$X$ & 52,1 & 56,8 & 58,1 & $\mathrm{X}$ & 67,1 & $X$ & 54,2 & 64,3 & 62,9 \\
\hline $\mathrm{X}$ & 55,1 & 59,3 & 60,1 & $\mathrm{X}$ & 56,1 & $\mathrm{X}$ & 55,6 & 56,9 & 56,5 \\
\hline$X$ & 54,1 & $\begin{array}{l}58,9 \\
\end{array}$ & 62,4 & $\mathrm{X}$ & 56,7 & $X$ & 64,4 & 54,7 & 54,9 \\
\hline $\mathrm{X}$ & 54,2 & 57,3 & 59,3 & $\mathrm{X}$ & 64,2 & $\mathrm{X}$ & 60,6 & 64,5 & 55,4 \\
\hline $\mathrm{X}$ & 57,3 & 59,1 & 58,7 & $\mathrm{X}$ & 53,9 & $\mathrm{X}$ & 55,9 & 57,9 & 53,0 \\
\hline$X$ & 62,4 & 57,3 & 60,3 & $\mathrm{X}$ & 66,5 & $\mathrm{X}$ & 62,2 & 55,7 & 59,2 \\
\hline $\mathrm{X}$ & 59,3 & 54,5 & 60,2 & $\mathrm{X}$ & 57,6 & $\mathrm{X}$ & 55,6 & 57,3 & $\begin{array}{l}56,8 \\
\end{array}$ \\
\hline $\mathrm{X}$ & 54,0 & 59,3 & 55,2 & $\mathrm{X}$ & 57,2 & $\mathrm{X}$ & 63,2 & 57,1 & 60,0 \\
\hline $\mathrm{X}$ & 55,8 & 56,8 & 63,1 & $\mathrm{X}$ & 67,3 & $\mathrm{X}$ & 56,1 & 58,1 & 56,0 \\
\hline $\mathrm{X}$ & 57,2 & 57,2 & 56,8 & $\mathrm{X}$ & 60,8 & $\mathrm{X}$ & 54,9 & 58,9 & 54,2 \\
\hline $\mathrm{X}$ & 59,5 & 60,3 & 60,3 & $X$ & 64,0 & $X$ & 56,4 & 56,4 & 58,1 \\
\hline $\mathrm{X}$ & 62,4 & 56,2 & 54,5 & $\mathrm{X}$ & 65,2 & $\mathrm{X}$ & 55,4 & 56,0 & 54,6 \\
\hline $\mathrm{X}$ & 53,0 & 55,9 & 65,7 & $\mathrm{X}$ & 56,9 & $\mathrm{X}$ & 57,4 & 57,9 & 55,4 \\
\hline$X$ & 57,1 & 58,6 & 55,6 & $\mathrm{X}$ & 63,6 & $X$ & 53,3 & 61,6 & 58,1 \\
\hline $\mathrm{X}$ & 55,2 & 57,6 & 61,0 & $\mathrm{X}$ & 59,0 & $\mathrm{X}$ & 53,2 & 62,4 & 53,2 \\
\hline $\mathrm{X}$ & 51,9 & 59,3 & 61,2 & $\mathrm{X}$ & 63,1 & $X$ & 60,1 & 58,9 & 55,2 \\
\hline $\mathrm{X}$ & 63,1 & 52,9 & 54,2 & $\mathrm{X}$ & 60,9 & $\mathrm{X}$ & 52,1 & 59,0 & 54,9 \\
\hline $\mathrm{X}$ & 53,7 & 56,8 & 58,1 & $\mathrm{X}$ & 57,4 & $\mathrm{X}$ & 56,8 & 58,1 & 57,0 \\
\hline $\mathrm{X}$ & 60,8 & 59,6 & 56,8 & $X$ & 61,9 & $\mathrm{X}$ & 51,3 & 56,6 & 54,1 \\
\hline $\mathrm{X}$ & 49,8 & 59,3 & 58,8 & $\mathrm{X}$ & 54,6 & $\mathrm{X}$ & 50,7 & 57,7 & 57,5 \\
\hline $\mathrm{X}$ & 50,2 & 62,8 & 60,5 & $\mathrm{X}$ & 58,1 & $X$ & 53,3 & 56,9 & 57,2 \\
\hline $\mathrm{X}$ & 61,8 & 55,2 & 62,9 & $\mathrm{X}$ & 59,6 & $\mathrm{X}$ & 52,7 & 64,8 & 59,1 \\
\hline $\mathrm{X}$ & 55,0 & 56,5 & 58,8 & $\mathrm{X}$ & 56,1 & $\mathrm{X}$ & 55,8 & 58,5 & 54,2 \\
\hline$X$ & 50,6 & 58,2 & 60,1 & $\mathrm{X}$ & 62,8 & $\mathrm{X}$ & 55,4 & 53,2 & 57,5 \\
\hline $\mathrm{X}$ & 56,9 & 54,2 & 66,3 & $\mathrm{X}$ & 57,2 & $\mathrm{X}$ & 53,0 & 64,2 & 53,8 \\
\hline $\mathrm{X}$ & 53,5 & 54,2 & 57,3 & $\mathrm{X}$ & 58,7 & $\mathrm{X}$ & 59,3 & 59,5 & 53,4 \\
\hline$X$ & 50,2 & 56,2 & 60,3 & $\mathrm{X}$ & 62,1 & $X$ & 53,8 & 54,5 & 62,8 \\
\hline $\mathrm{X}$ & 68,1 & 59,1 & 62,1 & $\mathrm{X}$ & 54,2 & $\mathrm{X}$ & 59,1 & 58,5 & 53,4 \\
\hline$X$ & 56,0 & 56,2 & $\begin{array}{l}58,1 \\
\end{array}$ & $\mathrm{X}$ & 63,1 & $\mathrm{X}$ & 62,6 & 56,6 & 60,5 \\
\hline $\mathrm{X}$ & 48,8 & 57,6 & 55,8 & $\mathrm{X}$ & 55,5 & $\mathrm{X}$ & 55,7 & 56,7 & 61,8 \\
\hline $\mathrm{X}$ & 54,4 & 65,5 & 54,7 & $\mathrm{X}$ & 62,4 & $\mathrm{X}$ & 54,4 & 56,2 & 57,4 \\
\hline$X$ & 56,9 & 59,0 & 55,3 & $\mathrm{X}$ & 59,2 & $X$ & 59,9 & 56,9 & 55,0 \\
\hline $\mathrm{X}$ & 51,4 & 60,1 & 63,3 & $\mathrm{X}$ & 53,4 & $\mathrm{X}$ & 54,7 & 55,3 & 59,9 \\
\hline $\mathrm{X}$ & 60,6 & 56,9 & 57,1 & $\mathrm{X}$ & 62,0 & $\mathrm{X}$ & 60,0 & 59,0 & 59,7 \\
\hline $\mathrm{X}$ & 55,2 & 56,2 & 65,5 & $\mathrm{X}$ & 59,1 & $\mathrm{X}$ & 55,7 & 55,2 & 60,0 \\
\hline $\mathrm{X}$ & 51,0 & 57,7 & 52,8 & $\mathrm{X}$ & 61,1 & $\mathrm{X}$ & 62,2 & 56,8 & 58,9 \\
\hline$X$ & 56,6 & 52,6 & 71,3 & $\mathrm{X}$ & 60,9 & $X$ & 55,4 & 56,8 & 58,3 \\
\hline $\mathrm{X}$ & 48,8 & 61,2 & 55,4 & $\mathrm{X}$ & 52,8 & $\mathrm{X}$ & 62,0 & 54,6 & 54,6 \\
\hline $\mathrm{X}$ & 60,9 & 55,7 & 64,7 & $\mathrm{X}$ & 63,8 & $\mathrm{X}$ & 61,9 & 60,8 & 54,9 \\
\hline $\mathrm{X}$ & 51,4 & 53,8 & 58,3 & $\mathrm{X}$ & 54,1 & $\mathrm{X}$ & 64,6 & 58,1 & 58,7 \\
\hline $\mathrm{X}$ & 51,4 & 61,0 & 67,7 & $\mathrm{X}$ & 56,4 & $\mathrm{X}$ & 55,7 & 57,1 & 58,2 \\
\hline$X$ & 74,9 & 56,6 & 56,2 & $\mathrm{X}$ & 61,5 & $\mathrm{X}$ & 52,5 & 67,6 & 56,5 \\
\hline $\mathrm{X}$ & 55,6 & 58,5 & 58,6 & $\mathrm{X}$ & 64,0 & $\mathrm{X}$ & 58,7 & 55,7 & 56,8 \\
\hline $\mathrm{X}$ & 50,5 & 56,9 & 56,4 & $\mathrm{X}$ & 54,6 & $\mathrm{X}$ & 56,0 & 53,7 & 64,0 \\
\hline$X$ & 62,6 & 60,4 & 49,9 & $\mathrm{X}$ & 59,7 & $X$ & 56,2 & 57,7 & 58,5 \\
\hline $\mathrm{X}$ & 64,4 & 56,2 & 60,1 & $\mathrm{X}$ & 57,7 & $\mathrm{X}$ & 63,3 & 63,5 & 56,9 \\
\hline $\mathrm{X}$ & 58,9 & 58,7 & 52,6 & $\mathrm{X}$ & 59,2 & $\mathrm{X}$ & 54,5 & 53,8 & 61,8 \\
\hline$X$ & 62,4 & 56,0 & 61,0 & $X$ & 61,4 & $X$ & 52,9 & 55,3 & 59,9 \\
\hline $\mathrm{X}$ & 61,7 & 56,2 & 58,1 & $\mathrm{X}$ & 53,0 & $\mathrm{X}$ & 60,2 & 54,5 & 54,2 \\
\hline$X$ & 55,8 & 55,4 & 54,9 & $\mathrm{X}$ & 57,7 & $X$ & 54,6 & 56,8 & 60,4 \\
\hline $\mathrm{X}$ & 56,6 & 60,4 & 66,7 & $\mathrm{X}$ & 58,6 & $\mathrm{X}$ & 50,9 & 56,8 & 54,8 \\
\hline $\mathrm{X}$ & 52,1 & 57,3 & $\begin{array}{l}62,0 \\
\end{array}$ & $\mathrm{X}$ & 59,8 & $\mathrm{X}$ & 57,5 & $\begin{aligned} 53,8 \\
\end{aligned}$ & 54,2 \\
\hline$X$ & $\begin{array}{l}51,9 \\
\end{array}$ & 57,3 & 58,3 & $\mathrm{X}$ & 56,8 & $X$ & 52,8 & 56,8 & 57,7 \\
\hline $\mathrm{X}$ & 57,7 & 61,4 & 64,7 & $\mathrm{X}$ & 53,4 & $\mathrm{X}$ & 54,8 & 56,8 & 57,5 \\
\hline $\mathrm{X}$ & 56,0 & 59,7 & 55,4 & $\mathrm{X}$ & 53,6 & $X$ & 52,8 & 52,6 & 59,2 \\
\hline
\end{tabular}


Tabela 3 - Dados de ruído, em dB(A), no Piso 3 (Continuação).

\begin{tabular}{|c|c|c|c|c|c|c|c|c|c|}
\hline $20 / 05 / 10$ & $26 / 05 / 10$ & $08 / 06 / 10$ & $15 / 06 / 10$ & $07 / 07 / 10$ & $14 / 07 / 10$ & $23 / 07 / 10$ & $10 / 08 / 10$ & $17 / 08 / 10$ & $08 / 09 / 10$ \\
\hline $\mathrm{X}$ & 57,9 & 61,0 & 61,6 & $\mathrm{X}$ & 69,2 & $\mathrm{X}$ & 51,7 & 55,3 & 57,3 \\
\hline $\mathrm{X}$ & 56,8 & 60,6 & 58,5 & $\mathrm{X}$ & 59,9 & $\mathrm{X}$ & 57,2 & 62,0 & 64,3 \\
\hline $\mathrm{X}$ & 53,4 & 66,0 & 63,6 & $\mathrm{X}$ & 53,6 & $\mathrm{X}$ & 55,0 & 53,8 & 62,6 \\
\hline $\mathrm{X}$ & 65,2 & 57,3 & 54,2 & $\mathrm{X}$ & 58,1 & $\mathrm{X}$ & 52,2 & 57,7 & 60,4 \\
\hline $\mathrm{X}$ & 55,7 & 55,3 & 67,4 & $\mathrm{X}$ & 56,2 & $\mathrm{X}$ & 58,1 & 55,2 & 56,5 \\
\hline $\mathrm{X}$ & 57,5 & 58,1 & 58,1 & $\mathrm{X}$ & 56,0 & $\mathrm{X}$ & 63,0 & 54,6 & 69,4 \\
\hline $\mathrm{X}$ & $\mathrm{X}$ & 58,1 & 54,9 & $\mathrm{X}$ & 67,7 & $\mathrm{X}$ & 52,6 & 58,8 & 53,7 \\
\hline $\mathrm{X}$ & $\mathrm{X}$ & 55,8 & 61,8 & $\mathrm{X}$ & 58,7 & $\mathrm{X}$ & 55,9 & 58,8 & 57,7 \\
\hline $\mathrm{X}$ & $\mathrm{X}$ & 59,2 & 59,5 & $\mathrm{X}$ & $\mathrm{X}$ & $\mathrm{X}$ & 56,2 & 51,5 & 64,9 \\
\hline $\mathrm{X}$ & $\mathrm{X}$ & 59,2 & 53,4 & $\mathrm{X}$ & $\mathrm{X}$ & $\mathrm{X}$ & 59,5 & 66,7 & 52,9 \\
\hline $\mathrm{X}$ & $\mathrm{X}$ & 58,0 & 61,4 & $\mathrm{X}$ & $\mathrm{X}$ & $\mathrm{X}$ & 66,8 & 55,2 & 54,7 \\
\hline $\mathrm{X}$ & $\mathrm{X}$ & 60,4 & 54,9 & $\mathrm{X}$ & $\mathrm{X}$ & $\mathrm{X}$ & 56,2 & 51,3 & 55,8 \\
\hline $\mathrm{X}$ & $\mathrm{X}$ & 58,5 & 57,3 & $\mathrm{X}$ & $\mathrm{X}$ & $\mathrm{X}$ & 63,6 & $\mathrm{X}$ & 53,2 \\
\hline $\mathrm{X}$ & $\mathrm{X}$ & 61,8 & 56,9 & $\mathrm{X}$ & $\mathrm{X}$ & $\mathrm{X}$ & 60,5 & $\mathrm{X}$ & 56,8 \\
\hline $\mathrm{X}$ & $\mathrm{X}$ & 56,9 & 53,4 & $\mathrm{X}$ & $\mathrm{X}$ & $\mathrm{X}$ & 60,5 & $\mathrm{X}$ & 63,4 \\
\hline $\mathrm{X}$ & $\mathrm{X}$ & 58,0 & 58,5 & $\mathrm{X}$ & $\mathrm{X}$ & $\mathrm{X}$ & 63,4 & $\mathrm{X}$ & 55,1 \\
\hline $\mathrm{X}$ & $\mathrm{X}$ & 64,3 & 54,7 & $\mathrm{X}$ & $\mathrm{X}$ & $\mathrm{X}$ & 57,9 & $\mathrm{X}$ & 60,7 \\
\hline $\mathrm{X}$ & $\mathrm{X}$ & 56,1 & 62,6 & $\mathrm{X}$ & $\mathrm{X}$ & $\mathrm{X}$ & 65,3 & $\mathrm{X}$ & $\mathrm{X}$ \\
\hline $\mathrm{X}$ & $\mathrm{X}$ & 55,2 & $\mathrm{X}$ & $\mathrm{X}$ & $\mathrm{X}$ & $\mathrm{X}$ & 59,4 & $\mathrm{X}$ & $\mathrm{X}$ \\
\hline $\mathrm{X}$ & $\mathrm{X}$ & 61,6 & $\mathrm{X}$ & $\mathrm{X}$ & $\mathrm{X}$ & $\mathrm{X}$ & 60,7 & $\mathrm{X}$ & $\mathrm{X}$ \\
\hline $\mathrm{X}$ & $\mathrm{X}$ & 59,9 & $\mathrm{X}$ & $\mathrm{X}$ & $\mathrm{X}$ & $\mathrm{X}$ & 65,7 & $\mathrm{X}$ & $\mathrm{X}$ \\
\hline $\mathrm{X}$ & $\mathrm{X}$ & 55,5 & $\mathrm{X}$ & $\mathrm{X}$ & $\mathrm{X}$ & $\mathrm{X}$ & 59,4 & $\mathrm{X}$ & $\mathrm{X}$ \\
\hline $\mathrm{X}$ & $\mathrm{X}$ & 66,3 & $\mathrm{X}$ & $\mathrm{X}$ & $\mathrm{X}$ & $\mathrm{X}$ & 56,4 & $\mathrm{X}$ & $\mathrm{X}$ \\
\hline $\mathrm{X}$ & $\mathrm{X}$ & 63,2 & $\mathrm{X}$ & $\mathrm{X}$ & $\mathrm{X}$ & $\mathrm{X}$ & 55,6 & $\mathrm{X}$ & $\mathrm{X}$ \\
\hline $\mathrm{X}$ & $\mathrm{X}$ & 65,8 & $\mathrm{X}$ & $\mathrm{X}$ & $\mathrm{X}$ & $\mathrm{X}$ & 61,6 & $\mathrm{X}$ & $\mathrm{X}$ \\
\hline $\mathrm{X}$ & $\mathrm{X}$ & 58,9 & $\mathrm{X}$ & $\mathrm{X}$ & $\mathrm{X}$ & $\mathrm{X}$ & $\mathrm{X}$ & $\mathrm{X}$ & $\mathrm{X}$ \\
\hline
\end{tabular}


Tabela 4 - Dados de ruído, em dB(A), no ambiente externo.

\begin{tabular}{|c|c|c|c|c|c|c|c|c|c|c|c|}
\hline $25 / 05 / 10$ & $28 / 05 / 10$ & $02 / 06 / 10$ & $16 / 06 / 10$ & $22 / 06 / 10$ & $01 / 07 / 10$ & $06 / 07 / 10$ & $20 / 07 / 10$ & $05 / 08 / 10$ & $19 / 08 / 10$ & $26 / 08 / 10$ & $03 / 09 / 10$ \\
\hline 68,1 & 64,0 & 70,2 & 70,0 & 69,4 & 65,4 & 63,6 & 73,7 & 60,9 & 65,7 & 63,5 & 70,6 \\
\hline 66,9 & 71,0 & 63,0 & 64,4 & 70,2 & 72,4 & 67,1 & 66,3 & 70,8 & 76,5 & 70,8 & 60,8 \\
\hline 61,0 & 64,5 & 71,7 & 70,7 & 72,4 & 68,7 & 70,0 & 78,7 & 65,2 & 63,6 & 71,5 & 67,8 \\
\hline 73,9 & 69,6 & 68,1 & 57,2 & 65,9 & 66,1 & 77,3 & 73,9 & 60,4 & 63,4 & 65,5 & 60,1 \\
\hline 69,4 & 67,4 & 65,9 & 70,6 & 71,4 & 64,9 & 66,6 & 67,0 & 75,7 & 69,5 & 67,4 & 78,5 \\
\hline 60,9 & 60,3 & 64,3 & 67,5 & 78,0 & 59,7 & 64,8 & 70,8 & 61,3 & 66,8 & 62,2 & 72,2 \\
\hline 75,5 & 72,6 & 67,6 & 70,5 & 68,3 & 61,9 & 66,9 & 66,9 & 75,5 & 79,5 & 71,2 & 61,9 \\
\hline 77,1 & 62,8 & 68,6 & 76,2 & 65,2 & 61,2 & 61,2 & 74,3 & 72,5 & 62,6 & 64,7 & 76,3 \\
\hline 67,4 & 68,1 & 62,4 & 61,4 & 61,6 & 60,6 & 67,6 & 66,2 & 61,5 & 70,2 & 61,4 & 83,4 \\
\hline 61,6 & 74,9 & 68,7 & 75,5 & 73,4 & 72 & 63,2 & 67,6 & 70,2 & 67,5 & 63,2 & 76,7 \\
\hline 69,3 & 67,5 & 63,6 & 69,7 & 60,7 & 70,2 & 71,3 & 65,5 & 78,2 & 62,3 & 64,9 & 66,1 \\
\hline 63,6 & 77,5 & 64,5 & 73,2 & 69,7 & 77,4 & 71,8 & 87,1 & 69,8 & 77,6 & 71,4 & 73,4 \\
\hline 58,5 & 60,0 & 66,9 & 75,4 & 69,1 & 68,1 & 58,8 & 79,4 & 65,7 & 61,8 & 66,8 & 67,7 \\
\hline 69,6 & 68,3 & 71,5 & 59,1 & 62,8 & 65,1 & 86,8 & 65,9 & 65,0 & 63,9 & 59,5 & 63,2 \\
\hline 61,9 & 68,3 & 64,2 & 73,6 & 73,6 & 66,9 & 74,8 & 65,9 & 75,3 & 71,8 & 70,4 & 71,6 \\
\hline 66,7 & 60,7 & 65,7 & 63,0 & 67,1 & 72,7 & 64,2 & 79,2 & 66,8 & 60,3 & 63,7 & 57,5 \\
\hline 63,7 & 79,1 & 64,8 & 60,3 & 65,4 & 63,9 & 74,1 & 71,0 & 68,1 & 77,2 & 72,5 & 69,4 \\
\hline 58,3 & 73,2 & 74,9 & 67,4 & 70,2 & 62 & 70,4 & 74,7 & 68,7 & 60,5 & 64,0 & 79,1 \\
\hline 71,7 & 64,6 & 66,9 & 60,9 & 62,8 & 65,8 & 74,7 & 74,5 & 62,4 & 61,1 & 60,9 & 62,6 \\
\hline 66,3 & 73,5 & 67,1 & 82,1 & 66,5 & 72,3 & 69,3 & 69,6 & 80,8 & 67,7 & 72,8 & 76,8 \\
\hline 76,2 & 63,3 & 69,4 & 73,1 & 73,0 & 61,8 & 69,8 & 68,5 & 77,3 & 64,0 & 59,9 & 85,9 \\
\hline 67,5 & 66,5 & 61,6 & 68,7 & 73,2 & 69,1 & 70,6 & 61,6 & 73,0 & 73,9 & 74,1 & 72,2 \\
\hline 67,7 & 77,8 & 73,2 & 69,1 & 69,6 & 74,9 & 73,9 & 75,7 & 72,6 & 74,5 & 70,0 & 65,2 \\
\hline 77,3 & 68,4 & 73,4 & 64,2 & 62,4 & 60,1 & 80,3 & 63,7 & 70,4 & 64,2 & 70,0 & 62,8 \\
\hline 65,7 & 70,0 & 60,5 & 78,0 & 72,4 & 70,4 & 73,0 & 71,4 & 82,1 & 62,4 & 71,8 & 82,7 \\
\hline 75,3 & 69,8 & 63,6 & 75,7 & 68,6 & 59 & 65,3 & 66,5 & 73,6 & 63,1 & 61,6 & 69,1 \\
\hline 67,5 & 71,8 & 67,0 & 60,3 & 65,9 & 72,1 & 59,8 & 62,2 & 73,0 & 75,6 & 69,3 & 65,5 \\
\hline 63,5 & 61,0 & 73,9 & 68,5 & 71,4 & 59,3 & 75,2 & 70,2 & 63,1 & 60,3 & 72,8 & 71,8 \\
\hline 74,6 & 61,5 & 62,6 & 65,9 & 66,3 & 59,3 & 76,9 & 69,4 & 64,0 & 77,1 & 60,3 & 59,2 \\
\hline 60,7 & 63,4 & 65,7 & 63,6 & 68,1 & 78 & 66,3 & 67,7 & 67,2 & 77,8 & 70,0 & 72,6 \\
\hline 71,5 & 58,5 & 64,0 & 68,2 & 60,7 & 60,9 & 71,8 & 67,7 & 80,8 & 59,2 & 66,2 & 74,9 \\
\hline 69,8 & 77,3 & 66,3 & 60,9 & 73,4 & 70,6 & 65,0 & 60,5 & 69,4 & 69,1 & 74,3 & 69,4 \\
\hline 70,2 & 67,3 & 80,6 & 62,4 & 71,8 & 69,3 & 68,7 & 78,7 & 69,8 & 85,7 & 73,3 & 59,1 \\
\hline 63,2 & 69,4 & 63,2 & 63,9 & 61,6 & 61,2 & 70,4 & 78,4 & 60,1 & 63,8 & 65,5 & 68,3 \\
\hline 80,7 & 61,8 & 64,5 & 72,8 & 70,6 & 67,9 & 70,8 & 62,6 & 79,1 & 73,2 & 66,1 & 68,5 \\
\hline 70,7 & 60,9 & 68,7 & 62,4 & 63,5 & 61 & 64,2 & 78,8 & 62,0 & 64,2 & 62,4 & 60,4 \\
\hline 69,6 & 68,1 & 60,7 & 62,4 & 70,4 & 86,2 & 71,1 & 62,0 & 66,3 & 73,4 & 72,8 & 71,6 \\
\hline 74,8 & 68,4 & 68,0 & 69,0 & 65,1 & 66,3 & 66,0 & 70,8 & 64,0 & 67,1 & 65,0 & 65,5 \\
\hline 69,2 & 66,5 & 69,2 & 65,7 & 61,0 & 61,4 & 71,3 & 64,0 & 60,1 & 77,9 & 62,3 & 70,1 \\
\hline 64,0 & 69,4 & 58,7 & 69,4 & 66,2 & 71,2 & 63,8 & 62,0 & 68,1 & 72,6 & 66,5 & 62,8 \\
\hline 62,4 & 72,6 & 72,0 & 70,4 & 57,3 & 79,5 & 65,8 & 75,7 & 60,1 & 64,8 & 59,9 & 62,8 \\
\hline 69,8 & 82,0 & 58,3 & 65,4 & 77,7 & 70,1 & 81,2 & 60,8 & 72,2 & 79,2 & 72,4 & 69,6 \\
\hline 63,6 & 78,0 & 76,4 & 64,5 & 65,0 & 74,1 & 62,4 & 92,3 & 66,6 & 62,4 & 66,5 & 64,6 \\
\hline 70,6 & 63,2 & 62,4 & 59,6 & 62,4 & 61,5 & 80,3 & 69,6 & 67,3 & 66,3 & 64,0 & 70,7 \\
\hline 58,7 & 69,4 & 69,3 & 74,5 & 74,8 & 72,4 & 65,2 & 62,0 & 84,3 & 63,0 & 71,8 & 78,0 \\
\hline 67,3 & 63,6 & 60,7 & 71,8 & 61,8 & 61,1 & 67,5 & 66,1 & 61,3 & 61,6 & 65,7 & 68,9 \\
\hline 70,6 & 74,1 & 59,5 & 64,7 & 58,4 & 65,2 & 71,7 & 73,6 & 79,4 & 84,2 & 83,5 & 69,8 \\
\hline 63,2 & 69,9 & 65,3 & 91,3 & 63,5 & 71,2 & 61,2 & 69,4 & 65,4 & 78,0 & 66,0 & 64,6 \\
\hline 73,4 & 63,0 & 60,5 & 69,5 & 64,8 & 59,7 & 76,3 & 68,3 & 63,1 & 70,9 & 58,5 & 72,1 \\
\hline 62,2 & 71,1 & 72,8 & 81,8 & 69,1 & 72,6 & 63,4 & 60,7 & 85,7 & 71,4 & 76,4 & 79,8 \\
\hline 67,9 & 70,2 & 65,1 & 68,7 & 57,7 & 75,3 & 65,2 & 80,4 & 67,6 & 68,4 & 62,6 & 60,6 \\
\hline 76,2 & 81,2 & 64,3 & 62,8 & 73,6 & 78 & 76,7 & 61,8 & 65,3 & 78,4 & 73,7 & 72,2 \\
\hline 60,9 & 72,6 & 69,8 & 69,3 & 63,0 & 74,5 & 65,2 & 71,4 & 71,8 & 60,4 & 73,4 & 76,5 \\
\hline 70,2 & 69,6 & 60,4 & 65,5 & 57,6 & 60,1 & 67,1 & 68,3 & 61,0 & 63,9 & 61,1 & 72,5 \\
\hline 70,1 & 67,3 & 63,5 & 78,0 & 69,4 & 79,2 & 70,6 & 61,5 & 71,2 & 65,9 & 74,3 & 58,5 \\
\hline 70,6 & 69,1 & 69,3 & 65,3 & 62,0 & 57,3 & 63,8 & 69,2 & 61,8 & 64,7 & 67,1 & 69,5 \\
\hline 75,7 & 73,6 & 61,3 & 64,0 & 66,3 & 66,3 & 71,6 & 69,1 & 86,2 & 77,6 & 83,7 & 62,4 \\
\hline 62,1 & 63,4 & 68,1 & 76,7 & 70,1 & 67,7 & 70,4 & 73,1 & 64,4 & 58,3 & 66,6 & 58,7 \\
\hline 78,8 & 73,2 & 64,5 & 62,4 & 59,5 & 62,1 & 70,0 & 76,3 & 64,2 & 65,3 & 62,8 & 63,4 \\
\hline 61,4 & 61,8 & 58,9 & 68,1 & 80,2 & 68 & 67,4 & 68,1 & 72,4 & 70,2 & 71,8 & 75,5 \\
\hline 66,3 & 73,9 & 64,0 & 83,3 & 61,2 & 62,8 & 73,4 & 82,7 & 67,3 & 64,4 & 62,8 & 58,5 \\
\hline 69,4 & 60,1 & 68,5 & 71,0 & 66,7 & 74,4 & 65,7 & 66,5 & 80,1 & 71,4 & 75,5 & 78,0 \\
\hline 60,2 & 65,1 & 70,4 & 72,5 & 76,4 & 67,1 & 67,4 & 69,1 & 61,3 & 59,1 & 69,2 & 60,1 \\
\hline 69,8 & 68,0 & 67,8 & 59,7 & 61,8 & 57,6 & 73,0 & 61,8 & 60,2 & 60,1 & 65,7 & 72,9 \\
\hline 60,2 & 77,3 & 61,6 & 82,1 & 83,1 & 69,3 & 63,6 & 72,6 & 74,4 & 63,5 & 79,2 & 76,4 \\
\hline 65,5 & 64,8 & 71,5 & 68,3 & 62,8 & 63,5 & 66,4 & 76,9 & 62,0 & 63,1 & 62,0 & 65,1 \\
\hline 65,9 & 63,9 & 69,0 & 78,0 & 70,6 & 81 & 69,0 & 64,2 & 72,3 & 72,0 & 73,7 & 66,5 \\
\hline 66,2 & 67,6 & 74,5 & 66,8 & 68,6 & 67,7 & 61,4 & 72,9 & 59,1 & 61,9 & 66,6 & 65,5 \\
\hline 70,4 & 66,5 & 66,9 & 62,4 & 74,7 & 65,5 & 71,7 & 66,8 & 59,7 & 60,7 & 59,9 & 66,1 \\
\hline 59,4 & 70,2 & 78,8 & 79,6 & 77,7 & 80,3 & 66,1 & 65,5 & 70,7 & 69,4 & 69,7 & 63,7 \\
\hline 60,8 & 68,1 & 78,6 & 65,4 & 76,9 & 64,7 & 58,9 & 72,8 & 62,7 & 66,8 & 63,0 & 76,9 \\
\hline 73,0 & 72,0 & 72,9 & 62,6 & 67,6 & 75,3 & 66,2 & 67,3 & 63,6 & 79,8 & 74,5 & 71,4 \\
\hline 62,4 & 68,7 & 65,9 & 77,5 & 80,5 & 65,2 & 65,5 & 82,2 & 64,4 & 73,4 & 67,9 & 64,1 \\
\hline 72,0 & 78,8 & 63,4 & 62,4 & 62,2 & 59,9 & 78,2 & 71,2 & 58,9 & 69,1 & 64,4 & 64,3 \\
\hline 78,9 & 59,5 & 69,4 & 82,0 & 72,3 & 68,9 & 67,4 & 64,3 & 72,0 & 65,9 & 70,9 & 63,2 \\
\hline 66,8 & 70,2 & 64,6 & 63,4 & 64,4 & 77,1 & 66,1 & 68,7 & 65,7 & 60,2 & 60,9 & 58,3 \\
\hline 72,2 & 68,1 & 61,8 & 61,0 & 75,2 & 66 & 80,8 & 62,1 & 72,8 & 71,7 & 68,5 & 63,0 \\
\hline
\end{tabular}


Tabela 4 - Dados de ruído, em dB(A), no ambiente externo (Continuação).

\begin{tabular}{|c|c|c|c|c|c|c|c|c|c|c|c|}
\hline $25 / 05 / 10$ & $28 / 05 / 10$ & $02 / 06 / 10$ & $16 / 06 / 10$ & $22 / 06 / 10$ & $01 / 07 / 10$ & $06 / 07 / 10$ & $20 / 07 / 10$ & $05 / 08 / 10$ & $19 / 08 / 10$ & $26 / 08 / 10$ & $03 / 09 / 10$ \\
\hline 66,5 & 70,0 & 67,8 & 67,1 & 62,6 & 66,8 & 73,2 & 74,3 & 64,2 & 58,3 & 70,2 & 63,0 \\
\hline 72,2 & 67,7 & 74,5 & 60,9 & 64,7 & 61,4 & 76,1 & 68,7 & 63,3 & 64,6 & 65,8 & 77,8 \\
\hline 64,4 & 66,1 & 62,6 & 73,2 & 70,8 & 70,6 & 64,6 & 70,0 & 78,3 & 75,2 & 77,9 & 57,9 \\
\hline 71,4 & 74,1 & 76,1 & 71,4 & 61,5 & 67,5 & 60,5 & 72,3 & 61,2 & 61,2 & 60,7 & 79,6 \\
\hline 62,4 & 68,4 & 64,4 & 64,2 & 67,5 & 78,6 & 68,7 & 63,8 & 80,3 & 75,9 & 70,4 & 62,0 \\
\hline 67,4 & 63,6 & 78,7 & 71,5 & 66,9 & 78,8 & 66,5 & 72,2 & 66,3 & 56,6 & 71,0 & 69,0 \\
\hline 70,4 & 68,5 & 66,1 & 59,3 & 66,3 & 74,8 & 80,2 & 77,1 & 61,4 & 76,1 & 64,5 & 60,3 \\
\hline 64,4 & 71,0 & 81,1 & 78,7 & 81,2 & 67 & 70,2 & 64,2 & 71,2 & 74,8 & 69,8 & 69,0 \\
\hline 74,7 & 71,7 & 72,0 & 69,3 & 60,2 & 57,7 & 65,7 & 75,6 & 59,0 & 72,2 & 61,4 & 80,0 \\
\hline 71,4 & 79,2 & 63,0 & 64,4 & 73,6 & 69,1 & 69,3 & 64,0 & 68,9 & 75,3 & 72,0 & 64,6 \\
\hline 58,3 & 64,8 & 65,0 & 76,2 & 67,3 & 62,8 & 65,2 & 71,8 & 64,4 & 64,8 & 65,5 & 67,0 \\
\hline 79,2 & 68,2 & 60,8 & 64,4 & 63,5 & 64,4 & 74,9 & 68,6 & 64,0 & 70,5 & 60,4 & 66,3 \\
\hline 67,2 & 81,2 & 64,3 & 67,7 & 72,8 & 64,8 & 78,8 & 65,2 & 79,8 & 67,1 & 69,1 & 83,5 \\
\hline 66,3 & 76,9 & 60,7 & 67,7 & 64,9 & 61,7 & 64,5 & 69,1 & 78,0 & 69,1 & 62,8 & 63,0 \\
\hline 66,0 & 68,3 & 71,1 & 63,9 & 70,0 & 77 & 68,1 & 68,1 & 72,3 & 58,7 & 79,3 & 64,8 \\
\hline 62,2 & 60,0 & 62,0 & 77,2 & 68,5 & 66,8 & 62,0 & 74,3 & 60,4 & 76,5 & 76,5 & 67,2 \\
\hline 73,0 & 62,1 & 75,9 & 62,4 & 59,9 & 56,6 & 72,9 & 70,2 & 57,7 & 62,9 & 60,7 & 67,4 \\
\hline 58,5 & 62,9 & 70,4 & 66,9 & 79,6 & 70,2 & 75,2 & 69,3 & 73,9 & 67,4 & 70,7 & 60,4 \\
\hline 65,0 & 62,4 & 60,8 & 69,6 & 71,4 & 59,1 & 64,4 & 65,8 & 65,5 & 58,3 & 59,5 & 76,9 \\
\hline 64,8 & 60,5 & 59,0 & 74,4 & 71,8 & 76,7 & 69,1 & 63,6 & 60,1 & 69,4 & 65,1 & 67,9 \\
\hline 69,6 & 66,9 & 78,0 & 70,5 & 64,6 & 81 & 64,7 & 71,2 & 76,8 & 67,3 & 64,9 & 66,2 \\
\hline 67,1 & 67,3 & 79,6 & 69,2 & 61,2 & 66,3 & 74,1 & 69,1 & 70,6 & 67,6 & 64,8 & 59,6 \\
\hline 73,0 & 76,3 & 63,0 & 73,4 & 70,0 & 70 & 68,7 & 63,4 & 66,1 & 56,9 & 75,3 & 72,0 \\
\hline 71,2 & 71,1 & 63,8 & 61,2 & 60,9 & 74,5 & 63,4 & 73,0 & 76,5 & 59,9 & 63,6 & 55,4 \\
\hline 66,1 & 69,6 & 61,0 & 59,3 & 69,0 & 70,2 & 69,6 & 59,3 & 65,9 & 71,0 & 73,4 & 58,3 \\
\hline 58,9 & 80,6 & 64,0 & 69,6 & 66,2 & 72,2 & 66,3 & 71,6 & 66,3 & 55,3 & 66,3 & 61,8 \\
\hline 67,8 & 66,1 & 65,0 & 63,0 & 70,1 & 71,2 & 74,1 & 62,7 & 75,3 & 72,2 & 60,1 & 68,1 \\
\hline 58,7 & 59,6 & 71,2 & 75,7 & 69,6 & 67,6 & 64,8 & 65,7 & 81,1 & 66,2 & 66,6 & 79,1 \\
\hline 62,2 & 69,8 & 64,4 & 69,4 & 63,7 & 64,4 & 71,5 & 73,7 & 58,3 & 69,6 & 58,3 & 72,8 \\
\hline 62,7 & 64,6 & 74,9 & 62,2 & 69,7 & 76 & 74,1 & 70,9 & 74,1 & 61,6 & 74,1 & 68,1 \\
\hline 62,8 & 58,6 & 62,0 & 72,3 & 65,2 & 80,2 & 72,3 & 67,9 & 71,7 & 77,8 & 70,2 & 61,5 \\
\hline 69,7 & 68,2 & 67,8 & 80,8 & 65,0 & 63,2 & 71,0 & 67,5 & 59,3 & 61,0 & 81,2 & 78,8 \\
\hline 64,0 & 56,9 & 55,8 & 71,8 & 72,1 & 72,4 & 67,6 & 63,6 & 73,7 & 71,0 & 67,8 & 60,2 \\
\hline 62,8 & 69,5 & 64,0 & 69,1 & 63,2 & 66,9 & 63,5 & 70,6 & 65,5 & 65,8 & 61,1 & 64,2 \\
\hline 67,9 & 79,2 & 67,5 & 60,0 & 79,8 & 69,1 & 82,3 & 66,0 & 82,5 & 65,3 & 66,5 & 57,2 \\
\hline 61,6 & 64,0 & 62,2 & 80,6 & 65,2 & 62,6 & 64,0 & 68,4 & 68,2 & 69,1 & 81,7 & 63,4 \\
\hline 70,8 & 67,9 & 68,7 & 60,6 & 69,4 & 79,3 & 76,0 & 73,6 & 77,3 & 64,6 & 61,6 & 65,5 \\
\hline 83,8 & 71,3 & 59,5 & 71,2 & 71,4 & 62,3 & 72,1 & 64,4 & 65,8 & 66,8 & 67,0 & 67,7 \\
\hline 65,0 & 81,2 & 74,3 & 76,5 & 65,5 & 66,7 & 62,2 & 69,8 & 70,5 & 63,5 & 62,4 & 61,0 \\
\hline 64,0 & 64,8 & 57,1 & 63,5 & 64,0 & 56,2 & 69,8 & 72,1 & 60,8 & 74,5 & 75,3 & 70,6 \\
\hline 67,1 & 61,2 & 72,1 & 72,2 & 60,1 & 75,2 & 62,0 & 67,7 & 72,2 & 56,6 & 78,2 & 66,7 \\
\hline 69,2 & 64,7 & 63,5 & 70,2 & 61,8 & 65,5 & 70,2 & 61,6 & 67,4 & 73,2 & 59,1 & 76,0 \\
\hline 78,5 & 66,5 & 79,1 & 80,6 & 69,7 & 59,2 & 68,5 & 66,5 & 70,6 & 66,7 & 72,1 & 59,9 \\
\hline 62,8 & 58,5 & 60,9 & 62,4 & 66,9 & 71,3 & 68,9 & 65,5 & 61,8 & 60,3 & 60,7 & 74,4 \\
\hline 68,5 & 81,2 & 67,3 & 63,7 & 75,5 & 62,3 & 80,8 & 72,2 & 60,8 & 58,9 & 67,3 & 59,8 \\
\hline 66,2 & 63,4 & 69,4 & 75,5 & 62,0 & 75,7 & 60,3 & 69,9 & 61,6 & 83,1 & 67,3 & 67,8 \\
\hline 77,1 & 64,0 & 61,6 & 61,8 & 61,0 & 63,9 & 85,0 & 64,4 & 66,1 & 73,3 & 62,4 & 71,6 \\
\hline 64,8 & 62,1 & 66,3 & 72,2 & 67,8 & 76,1 & 67,7 & 65,3 & 61,2 & 68,1 & 66,3 & 63,8 \\
\hline 70,8 & 82,0 & 57,5 & 66,2 & 61,6 & 61,6 & 61,2 & 70,6 & 69,6 & 58,9 & 63,8 & 82,3 \\
\hline 69,3 & 65,9 & 67,7 & 67,5 & 88,8 & 74,5 & 72,9 & 66,2 & 70,7 & 67,6 & 74,1 & 64,2 \\
\hline 69,1 & 62,8 & 62,4 & 68,7 & 62,4 & 61,9 & 70,9 & 68,2 & 63,4 & 69,4 & 73,0 & 71,6 \\
\hline 68,0 & 69,8 & 73,4 & 65,7 & 63,6 & 76,4 & 78,4 & 60,6 & 75,3 & 62,4 & 59,8 & 59,8 \\
\hline 70,4 & 70,4 & 62,0 & 66,1 & 74,1 & 67,1 & 59,6 & 60,5 & 58,5 & 82,0 & 69,0 & 70,2 \\
\hline 65,9 & 68,0 & 61,0 & 71,0 & 61,6 & 66,6 & 65,2 & 70,6 & 71,7 & 60,8 & 71,0 & 69,6 \\
\hline 66,1 & 66,1 & 67,1 & 63,8 & 65,5 & 61,8 & 73,7 & 71,5 & 61,3 & 65,1 & 68,0 & 64,8 \\
\hline 64,4 & 67,4 & 72,5 & 70,6 & 65,7 & 64 & 65,5 & 74,7 & 79,2 & 80,7 & 69,1 & 59,7 \\
\hline 65,0 & 63,6 & 60,7 & 68,7 & 56,1 & 81,2 & 80,4 & 79,4 & 66,6 & 71,6 & 65,5 & 70,6 \\
\hline 63,2 & 71,0 & 74,9 & 75,2 & 81,9 & 65,7 & 77,2 & 65,0 & 67,5 & 61,6 & 64,8 & 63,3 \\
\hline 58,7 & 62,4 & 59,6 & 74,7 & 67,8 & 67,6 & 66,3 & 67,8 & 70,0 & 83,4 & 62,8 & 68,4 \\
\hline 73,2 & 67,1 & 67,7 & 63,9 & 71,4 & 67,5 & 66,8 & 65,9 & 65,5 & 64,3 & 74,8 & 59,7 \\
\hline 64,4 & 57,3 & 59,0 & 78,4 & 65,1 & 72,6 & 66,2 & 79,6 & 70,8 & 62,3 & 65,7 & 68,9 \\
\hline 74,5 & 67,1 & 59,7 & 66,9 & 60,6 & 72,9 & 77,1 & 63,5 & 66,9 & 60,9 & 61,0 & 57,1 \\
\hline 59,6 & 60,1 & 63,7 & 74,1 & 71,0 & 80,4 & 64,1 & 61,5 & 81,2 & 61,2 & 69,3 & 71,5 \\
\hline 70,9 & 71,8 & 62,1 & 72,2 & 70,4 & 77,6 & 67,7 & 62,4 & 62,8 & 70,0 & 57,4 & 78,7 \\
\hline 70,2 & 60,1 & 78,2 & 64,5 & 69,4 & 62,4 & 70,8 & 65,3 & 82,6 & 61,8 & 69,2 & 62,7 \\
\hline 64,8 & 64,3 & 69,6 & 69,8 & 66,3 & 72,2 & 64,0 & 73,6 & 67,9 & 71,6 & 70,8 & 64,4 \\
\hline 65,4 & 63,2 & 72,6 & 60,7 & 63,6 & 69,6 & 76,1 & 64,9 & 77,8 & 69,3 & 64,6 & 74,4 \\
\hline 65,9 & 63,3 & 65,9 & 70,2 & 73,8 & 77,3 & 66,3 & 64,4 & 62,4 & 70,1 & 67,4 & 63,6 \\
\hline 66,1 & 69,1 & 78,8 & 68,9 & 63,5 & 62,4 & 63,2 & 65,7 & 66,9 & 64,0 & 59,7 & 61,4 \\
\hline 66,7 & 55,5 & 60,8 & 62,1 & 72,2 & 71,4 & 68,7 & 62,4 & 72,5 & 67,3 & 76,1 & 69,4 \\
\hline 69,8 & 68,3 & 71,2 & 70,0 & 63,0 & 60,3 & 60,5 & 65,9 & 64,6 & 58,7 & 62,2 & 58,5 \\
\hline 65,7 & 61,7 & 74,1 & 68,3 & 64,0 & 72,2 & 87,3 & 66,6 & 68,5 & 82,3 & 63,2 & 68,7 \\
\hline 63,0 & 75,7 & 67,1 & 63,6 & 80,8 & 66,7 & 66,7 & 73,6 & 60,2 & 61,2 & 66,8 & 73,4 \\
\hline 70,9 & 69,7 & 71,2 & 70,2 & 76,4 & 66 & 61,8 & 70,1 & 79,6 & 67,1 & 56,5 & 58,8 \\
\hline 78,8 & 74,4 & 67,3 & 62,4 & 61,1 & 63,2 & 69,4 & 60,9 & 63,1 & 70,2 & 67,7 & 59,8 \\
\hline 66,1 & 62,4 & 62,4 & 71,4 & 67,1 & 75,7 & 65,3 & 77,3 & 70,0 & 60,5 & 75,3 & 70,6 \\
\hline 73,0 & 70,0 & 62,4 & 65,2 & 64,8 & 75,9 & 83,5 & 65,5 & 72,1 & 68,3 & 59,0 & 62,0 \\
\hline
\end{tabular}


Tabela 4 - Dados de ruído, em dB(A), no ambiente externo (Continuação).

\begin{tabular}{|c|c|c|c|c|c|c|c|c|c|c|c|}
\hline $25 / 05 / 10$ & $28 / 05 / 10$ & $02 / 06 / 10$ & $16 / 06 / 10$ & $22 / 06 / 10$ & $01 / 07 / 10$ & $06 / 07 / 10$ & $20 / 07 / 10$ & $05 / 08 / 10$ & $19 / 08 / 10$ & $26 / 08 / 10$ & 03/09/10 \\
\hline 64,8 & 61,2 & 61,6 & 77,8 & 73,3 & 70,2 & 69,7 & 64,6 & 73,8 & 57,6 & 69,1 & 64,3 \\
\hline 66,0 & 62,7 & 60,7 & 78,9 & 64,0 & 77,5 & 62,6 & 64,7 & 60,5 & 70,2 & 68,6 & 62,8 \\
\hline 73,7 & 64,2 & 71,4 & 69,7 & 73,0 & 65 & 69,3 & 65,3 & 70,4 & 65,8 & 73,6 & 68,7 \\
\hline 66,9 & 74,1 & 60,7 & 81,2 & 68,7 & 62,7 & 69,9 & 77,1 & 66,7 & 79,9 & 58,5 & 62,8 \\
\hline 71,2 & 70,4 & 68,7 & 73,6 & 64,0 & 63,2 & 81,2 & 68,4 & 63,7 & 68,6 & 73,6 & 70,9 \\
\hline 59,9 & 69,6 & 56,6 & 64,3 & 71,8 & 70,6 & 62,1 & 65,8 & 67,8 & 70,6 & 65,7 & 72,0 \\
\hline 65,2 & 69,4 & 71,3 & 61,2 & 70,8 & 59,9 & 64,8 & 68,7 & 62,7 & 60,9 & 78,2 & 74,5 \\
\hline 72,8 & 68,1 & 66,9 & 70,2 & 78,7 & 65,3 & 69,4 & 63,1 & 62,8 & 72,2 & 67,1 & 66,4 \\
\hline 57,7 & 78,4 & 73,0 & 71,2 & 69,0 & 64,8 & 71,8 & 68,1 & 67,8 & 62,2 & 63,4 & 66,3 \\
\hline 72,4 & 66,4 & 64,6 & 67,3 & 63,9 & 70,7 & 69,8 & 65,5 & 67,5 & 69,2 & 65,3 & 67,9 \\
\hline 68,1 & 68,7 & 65,9 & 72,3 & 73,4 & 63,8 & 69,0 & 73,0 & 58,1 & 80,6 & 75,5 & 62,8 \\
\hline 71,0 & 69,4 & 69,8 & 64,8 & 60,8 & 66,3 & 66,3 & 67,4 & 78,0 & 63,4 & 71,4 & 65,2 \\
\hline 61,5 & 69,4 & 63,9 & 63,2 & 67,3 & 76,1 & 67,7 & 63,8 & 60,8 & 68,6 & 81,8 & 63,8 \\
\hline 65,0 & 70,9 & 69,7 & 67,5 & 66,7 & 73,9 & 67,1 & 63,4 & 69,6 & 60,0 & 66,2 & 72,0 \\
\hline 76,5 & 74,0 & 58,5 & 61,2 & 60,9 & 70,6 & 72,0 & 73,4 & 58,1 & 68,3 & 59,6 & 59,5 \\
\hline 59,6 & 65,2 & 64,8 & 69,8 & 70,1 & 69,6 & 65,7 & 71,5 & 74,0 & 71,5 & 76,9 & 74,6 \\
\hline 70,0 & 63,4 & 59,7 & 70,6 & 60,8 & 74,1 & 63,6 & 67,6 & 69,8 & 73,3 & 57,2 & 69,7 \\
\hline 64,7 & 60,9 & 67,8 & 70,0 & 69,4 & 84,2 & 70,0 & 67,3 & 64,0 & 64,6 & 67,5 & 69,2 \\
\hline 60,9 & 62,6 & 60,1 & 76,5 & 69,2 & 74,5 & 65,0 & 73,6 & 66,9 & 67,8 & 67,8 & 69,8 \\
\hline 67,4 & 70,1 & 77,5 & 72,2 & 64,6 & 70,7 & 60,9 & 67,1 & 61,8 & 61,4 & 68,3 & 69,4 \\
\hline 58,7 & 58,4 & 58,2 & 72,0 & 73,6 & 67,1 & 66,4 & 85,6 & 63,2 & 68,5 & 68,0 & 65,0 \\
\hline 68,9 & 65,5 & 66,1 & 69,6 & 81,6 & 66,1 & 62,4 & 69,3 & 64,4 & 66,6 & 68,7 & 71,5 \\
\hline 64,8 & 62,4 & 71,7 & 63,6 & 72,0 & 69,4 & 69,1 & 65,2 & 67,9 & 65,1 & 77,0 & 67,5 \\
\hline 67,9 & 71,6 & 59,7 & 73,7 & 66,5 & 61,6 & 65,3 & 68,9 & 65,7 & 63,8 & 61,3 & 63,0 \\
\hline 80,2 & 62,8 & 62,7 & 68,2 & 69,6 & 79,1 & 74,1 & 71,7 & 70,4 & 60,5 & 55,9 & 76,4 \\
\hline 67,1 & 62,4 & 60,6 & 71,1 & 76,7 & 68,7 & 65,5 & 78,8 & 63,1 & 75,7 & 63,2 & 66,7 \\
\hline 74,0 & 61,5 & 76,2 & 68,0 & 65,9 & 63,6 & 61,2 & 66,7 & 77,6 & 60,7 & 58,8 & 70,2 \\
\hline 69,9 & 61,2 & 66,3 & 65,3 & 65,9 & 66,2 & 68,0 & 69,0 & 61,0 & 71,8 & 72,2 & 63,4 \\
\hline 62,3 & 71,7 & 70,4 & 70,6 & 67,5 & 61,6 & 68,7 & 70,4 & 79,6 & 69,3 & 68,6 & 67,8 \\
\hline 70,2 & 61,0 & 62,0 & 83,7 & 62,7 & 66,3 & 78,6 & 82,3 & 62,8 & 70,6 & 60,2 & 62,0 \\
\hline 64,0 & 70,4 & 73,2 & 73,1 & 71,2 & 63,7 & 61,0 & 60,8 & 67,5 & 60,1 & 79,4 & 65,2 \\
\hline 64,8 & 57,7 & 71,0 & 62,4 & 81,5 & 68 & 73,9 & 56,6 & 72,5 & 70,7 & 63,5 & 68,1 \\
\hline 69,8 & 61,0 & 75,5 & 65,9 & 61,8 & 56,5 & 67,1 & 67,1 & 58,1 & 60,1 & 72,6 & 72,6 \\
\hline 60,5 & 59,1 & 74,5 & 67,1 & 64,0 & 69,8 & 62,0 & 62,0 & 62,4 & 77,3 & 70,5 & 66,2 \\
\hline 78,6 & 83,9 & 69,8 & 63,0 & 62,1 & 61 & 85,4 & 72,6 & 61,2 & 60,6 & 62,0 & 72,1 \\
\hline 62,3 & 83,1 & 76,3 & 73,4 & 81,2 & 70,6 & 71,8 & 65,9 & 70,2 & 62,8 & 68,3 & 63,4 \\
\hline 61,0 & 70,1 & 64,0 & 64,9 & 60,3 & 57,9 & 62,7 & 69,9 & 63,4 & 59,1 & 59,1 & 70,1 \\
\hline 70,8 & 73,9 & 78,3 & 63,2 & 66,3 & 80,7 & 67,4 & 79,4 & 84,2 & 73,4 & 70,5 & 60,9 \\
\hline 59,8 & 76,2 & 61,6 & 71,6 & 64,8 & 67,7 & 65,7 & 65,3 & 63,2 & 66,5 & 65,5 & 71,2 \\
\hline 74,9 & 69,0 & 77,7 & 65,2 & 73,2 & 68,6 & 72,0 & 72,7 & 74,6 & 66,3 & 70,9 & 82,3 \\
\hline 74,6 & 67,5 & 70,4 & 79,4 & 73,0 & 64,8 & 77,5 & 66,5 & 63,1 & 65,9 & 67,7 & 67,1 \\
\hline 78,6 & 77,2 & 67,0 & 71,4 & 57,7 & 69,4 & 65,9 & 61,4 & 72,4 & 63,8 & 59,3 & 69,4 \\
\hline 73,9 & 66,1 & 75,7 & 65,5 & 76,4 & 59,3 & 76,0 & 67,9 & 75,9 & 68,9 & 73,2 & 73,2 \\
\hline 69,3 & 67,5 & 79,6 & 78,2 & 68,3 & 60,1 & 60,9 & 61,0 & 72,0 & 59,0 & 74,9 & 58,5 \\
\hline 76,8 & 70,1 & 61,9 & 59,0 & 65,8 & 83 & 73,6 & 68,2 & 79,1 & 71,8 & 66,9 & 78,5 \\
\hline 80,8 & 74,1 & 71,1 & 65,9 & 79,1 & 64,4 & 77,3 & 65,8 & 62,9 & 81,0 & 69,6 & 68,1 \\
\hline 60,7 & 71,0 & 73,7 & 65,8 & 62,8 & 66,5 & 70,1 & 64,6 & 70,9 & 74,8 & 59,2 & 67,1 \\
\hline 68,4 & 70,9 & 68,3 & 59,6 & 70,0 & 69,8 & 72,4 & 74,9 & 66,5 & 67,5 & 73,6 & 81,0 \\
\hline 75,3 & 66,7 & 66,6 & 81,8 & 64,4 & 74,9 & 68,3 & 80,0 & 77,2 & 70,6 & 73,3 & 66,1 \\
\hline 74,3 & 86,3 & 60,5 & 67,3 & 58,7 & 62 & 74,3 & 72,0 & 69,4 & 77,1 & 67,7 & 67,9 \\
\hline 62,7 & 66,3 & 64,1 & 72,1 & 73,6 & 84,1 & 68,3 & 65,1 & 69,2 & 65,7 & 76,1 & 59,6 \\
\hline 65,9 & 68,3 & 59,9 & 65,9 & 70,2 & 67,1 & 64,7 & 66,5 & 65,7 & 69,4 & 67,9 & 85,3 \\
\hline 67,8 & 66,7 & 70,0 & 60,7 & 75,5 & 66,6 & 70,6 & 74,7 & 76,7 & 66,8 & 72,6 & 65,3 \\
\hline 64,0 & 79,8 & 60,8 & 63,6 & 69,6 & 80,6 & 72,4 & 58,7 & 70,6 & 60,0 & 61,2 & 65,5 \\
\hline 81,5 & 68,6 & 69,5 & 59,1 & 63,6 & 61 & 67,3 & 70,0 & 70,5 & 65,7 & 59,9 & 59,3 \\
\hline 59,3 & 65,0 & 64,0 & 73,0 & 66,7 & 71,4 & 67,8 & 66,7 & 65,2 & 70,1 & 65,5 & 76,8 \\
\hline 64,2 & 71,2 & 60,5 & 69,5 & 76,5 & 62,8 & 64,0 & 69,3 & 66,1 & 64,3 & 64,0 & 62,0 \\
\hline 67,9 & 69,6 & 61,6 & 74,9 & 71,5 & 68,6 & 71,4 & 67,7 & 58,7 & 70,6 & 71,7 & 69,8 \\
\hline 66,7 & 67,0 & 78,0 & 72,9 & 63,2 & 59,9 & 62,3 & 69,6 & 72,6 & 62,0 & 65,4 & 68,9 \\
\hline 69,4 & 65,8 & 66,7 & 62,6 & 62,6 & 75,3 & 81,9 & 75,9 & 65,4 & 66,2 & 59,5 & 77,6 \\
\hline 66,3 & 66,3 & 68,7 & 68,7 & 67,8 & 63,2 & 68,2 & 66,2 & 61,5 & 67,3 & 73,0 & 67,1 \\
\hline 65,3 & 60,8 & 62,4 & 69,1 & 59,7 & 68,2 & 67,4 & 66,5 & 67,0 & 72,2 & 59,7 & 67,9 \\
\hline 68,2 & 80,4 & 62,4 & 59,6 & 70,6 & 67,6 & 74,8 & 71,0 & 60,1 & 69,6 & 70,8 & 64,2 \\
\hline 83,8 & 62,0 & 63,8 & 76,5 & 65,0 & 67,3 & 67,6 & 58,9 & 67,9 & 62,4 & 70,6 & 63,2 \\
\hline 69,4 & 69,3 & 66,2 & 70,2 & 73,6 & 76,7 & 64,4 & 69,8 & 59,1 & 65,1 & 70,4 & 64,5 \\
\hline 71,0 & 65,1 & 62,6 & 63,2 & 70,0 & 70 & 69,7 & 65,0 & 72,0 & 58,9 & 76,2 & 61,8 \\
\hline 61,2 & 66,5 & 65,7 & 64,5 & 59,9 & 66,1 & 71,4 & 63,4 & 66,3 & 63,5 & 69,8 & 66,1 \\
\hline 71,1 & 71,7 & 69,8 & 68,2 & 62,4 & 61,6 & 79,6 & 65,7 & 69,4 & 56,9 & 75,3 & 66,5 \\
\hline 60,1 & 64,3 & 59,1 & 73,6 & 69,6 & 63,7 & 71,2 & 59,7 & 63,1 & 70,7 & 73,6 & 68,4 \\
\hline 70,5 & 71,4 & 72,1 & 65,9 & 64,2 & 59,9 & 77,7 & 64,4 & 71,4 & 67,1 & 63,6 & 68,2 \\
\hline 65,2 & 63,6 & 65,8 & 78,8 & 73,7 & 67,5 & 65,0 & 66,5 & 70,8 & 79,6 & 78,8 & 65,4 \\
\hline 69,4 & 76,2 & 71,2 & 74,1 & 62,8 & 68,4 & 73,3 & 64,2 & 63,0 & 67,3 & 70,9 & 62,4 \\
\hline 66,5 & 63,0 & 65,2 & 63,6 & 75,5 & 73,2 & 73,6 & 66,9 & 64,3 & 59,3 & 75,6 & 67,9 \\
\hline 68,7 & 68,3 & 72,6 & 72,7 & 67,4 & 64,6 & 74,1 & 68,3 & 62,0 & 70,1 & 80,5 & 70,6 \\
\hline 80,6 & 69,6 & 74,2 & 62,0 & 63,6 & 70,2 & 68,3 & 68,3 & 74,8 & 63,2 & 65,1 & 56,9 \\
\hline 61,7 & 71,8 & 70,6 & 71,2 & 76,8 & 65,5 & 66,5 & 74,0 & 59,9 & $\begin{array}{r}74,9 \\
\end{array}$ & 72,6 & 68,7 \\
\hline 63,0 & 80,6 & 75,2 & 65,9 & 67,1 & 79,5 & 59,3 & 65,5 & 72,3 & 64,7 & 81,2 & 64,1 \\
\hline
\end{tabular}


Tabela 4 - Dados de ruído, em dB(A), no ambiente externo (Continuação).

\begin{tabular}{|c|c|c|c|c|c|c|c|c|c|c|c|}
\hline $25 / 05 / 10$ & $28 / 05 / 10$ & $02 / 06 / 10$ & $16 / 06 / 10$ & $22 / 06 / 10$ & $01 / 07 / 10$ & $06 / 07 / 10$ & $20 / 07 / 10$ & $05 / 08 / 10$ & $19 / 08 / 10$ & $26 / 08 / 10$ & $03 / 09 / 10$ \\
\hline 70,2 & 68,6 & 68,3 & 65,7 & 70,0 & 72,2 & 73,4 & 70,6 & 67,1 & 65,5 & 67,4 & 65,4 \\
\hline 66,4 & 73,1 & 74,4 & 66,1 & 62,0 & 74,8 & 74,3 & 70,0 & 79,5 & 61,9 & 69,3 & 59,7 \\
\hline 68,7 & 67,9 & 69,0 & 62,1 & 64,6 & 74,9 & 69,1 & 80,8 & 75,6 & 67,8 & 61,4 & 68,1 \\
\hline 58,9 & 81,9 & 78,0 & 71,0 & 69,7 & 65,3 & 61,3 & 69,7 & 65,5 & 60,4 & 70,0 & 65,3 \\
\hline 59,3 & 62,8 & 71,0 & 65,5 & 60,0 & 71 & 65,5 & 61,8 & 65,0 & 77,4 & 57,0 & 66,1 \\
\hline 83,4 & 66,6 & 71,8 & 64,6 & 67,1 & 64 & 72,2 & 67,4 & 84,0 & 59,8 & 66,9 & 62,4 \\
\hline 63,5 & 68,1 & 81,9 & 73,2 & 66,5 & 71 & 63,4 & 64,1 & 74,7 & 85,9 & 63,4 & 60,4 \\
\hline 82,7 & 73,0 & 75,2 & 65,2 & 65,4 & 65,5 & 76,5 & 76,4 & 65,5 & 65,1 & 62,2 & 74,7 \\
\hline 66,3 & 67,5 & 59,2 & 75,4 & 66,2 & 71,4 & 78,8 & 71,4 & 66,3 & 70,4 & 82,3 & 60,7 \\
\hline 63,2 & 69,0 & 62,4 & 58,9 & 64,3 & 65,7 & 60,9 & 65,1 & 61,8 & 66,4 & 61,1 & 68,7 \\
\hline 66,6 & 61,7 & 68,7 & 65,5 & 66,8 & 76,3 & 72,6 & 69,8 & 74,1 & 67,3 & 68,3 & 58,9 \\
\hline 68,9 & 65,1 & 64,4 & 67,1 & 67,5 & 62,4 & 69,4 & 69,8 & 68,7 & 73,9 & 68,7 & 66,3 \\
\hline 69,6 & 67,9 & 60,3 & 67,6 & 64,8 & 78,6 & 78,0 & 77,5 & 70,6 & 68,1 & 56,4 & 62,6 \\
\hline 61,4 & 72,9 & 65,1 & 67,1 & 64,4 & 72,2 & 80,6 & 66,7 & 65,2 & 67,7 & 75,4 & 66,1 \\
\hline 74,1 & 67,5 & 64,1 & 69,9 & 74,4 & 68,7 & 60,5 & 59,5 & 81,2 & 64,2 & 68,7 & 60,5 \\
\hline 65,1 & 62,4 & 70,8 & 60,4 & 67,3 & 66,3 & 66,1 & 68,6 & 62,0 & 70,4 & 77,0 & 66,5 \\
\hline 70,6 & 80,0 & 67,5 & 69,1 & 73,0 & 62 & 66,9 & 59,8 & 76,9 & 68,1 & 70,0 & 72,6 \\
\hline 69,3 & 66,0 & 58,9 & 65,9 & 58,1 & 66,3 & 83,1 & 68,1 & 63,8 & 74,1 & 60,9 & 70,6 \\
\hline 59,1 & 82,7 & 72,1 & 68,2 & 70,8 & 67,9 & 76,7 & 64,8 & 70,5 & 63,4 & 73,6 & 66,3 \\
\hline 64,7 & 69,4 & 74,9 & 77,0 & 60,8 & 71,2 & 64,9 & 64,6 & 66,9 & 73,4 & 60,4 & 59,3 \\
\hline 61,6 & 81,0 & 64,4 & 61,2 & 81,2 & 65,5 & 72,2 & 68,2 & 67,8 & 75,6 & 67,0 & 79,0 \\
\hline 66,3 & 72,3 & 61,0 & 66,1 & 74,8 & 71,6 & 67,1 & 67,1 & 69,4 & 65,9 & 68,4 & 69,3 \\
\hline 73,2 & 76,8 & 71,6 & 62,1 & 63,7 & 63,5 & 71,3 & 70,2 & 64,5 & 68,7 & 65,9 & 73,6 \\
\hline 67,8 & 73,0 & 72,9 & 74,9 & 71,0 & 74,9 & 67,8 & 80,9 & 67,1 & 59,1 & 65,1 & 58,7 \\
\hline 65,1 & 75,4 & 62,1 & 73,0 & 64,2 & 67,5 & 62,7 & 65,4 & 61,2 & 70,4 & 60,4 & 68,7 \\
\hline 69,5 & 67,9 & 70,2 & 62,6 & 74,9 & 68,3 & 73,7 & 73,8 & 76,5 & 63,6 & 68,6 & 66,6 \\
\hline 64,0 & 65,1 & 67,5 & 65,8 & 77,1 & 60,6 & 66,5 & 60,6 & 65,2 & 68,3 & 80,8 & 75,6 \\
\hline 72,5 & 68,4 & 74,1 & 60,9 & 63,5 & 73,6 & 72,5 & 70,8 & 66,3 & 62,6 & 58,8 & 64,6 \\
\hline 68,5 & 65,9 & 66,9 & 68,0 & 71,7 & 63,8 & 61,8 & 64,9 & 64,8 & 68,2 & 73,3 & 68,7 \\
\hline 70,6 & 76,8 & 68,6 & 80,8 & 60,7 & 63,9 & 58,9 & 64,8 & 80,0 & 61,1 & 66,2 & 69,7 \\
\hline 65,4 & 60,9 & 68,2 & 71,0 & 69,4 & 66,3 & 72,4 & 66,0 & 64,0 & 63,1 & 83,5 & 69,7 \\
\hline 63,1 & 62,8 & 70,8 & 68,9 & 69,6 & 61,1 & 63,8 & 67,1 & 82,0 & 73,4 & 71,0 & 74,9 \\
\hline 73,0 & 59,2 & 64,6 & 62,4 & 61,3 & 66,8 & 66,7 & 71,2 & 67,6 & 70,2 & 64,0 & 61,6 \\
\hline 70,0 & 72,0 & 72,2 & 75,7 & 70,1 & 62,2 & 67,5 & 60,3 & 65,9 & 70,0 & 64,0 & 69,1 \\
\hline 72,8 & 62,6 & 70,2 & 64,7 & 81,7 & 64,9 & 62,8 & 60,5 & 68,4 & 72,9 & 59,6 & 65,2 \\
\hline 77,5 & 75,7 & 74,7 & 71,4 & 66,2 & 65,5 & 74,5 & 69,6 & 69,5 & 82,7 & 70,6 & 73,7 \\
\hline 63,6 & 67,8 & 69,6 & 67,1 & 71,8 & 70,2 & 67,3 & 63,7 & 68,7 & 64,8 & 79,6 & 61,0 \\
\hline 76,5 & 71,3 & 63,8 & 67,9 & 65,0 & 66,2 & 80,8 & 67,9 & 60,5 & 65,5 & 66,3 & 77,2 \\
\hline 71,0 & 79,2 & 67,1 & 69,8 & 69,8 & 70,6 & 63,7 & 68,5 & 72,8 & 64,7 & 71,4 & 69,3 \\
\hline 67,5 & 73,6 & 61,3 & 67,6 & 64,6 & 63,1 & 64,5 & 69,4 & 65,4 & 68,4 & 64,0 & 68,3 \\
\hline 72,8 & 64,7 & 68,7 & 66,2 & 75,3 & 66,6 & 67,5 & 69,1 & 94,7 & 78,2 & 78,6 & 67,8 \\
\hline 68,7 & 62,7 & 70,4 & 76,3 & 68,2 & 62 & 59,9 & 69,0 & 80,3 & 69,1 & 67,8 & 65,9 \\
\hline 67,9 & 70,0 & 71,1 & 61,2 & 59,9 & 63,9 & 78,4 & 68,6 & 69,2 & 61,2 & 61,6 & 68,0 \\
\hline 64,2 & 60,5 & 61,8 & 71,6 & 72,9 & 71,6 & 69,4 & 63,1 & 69,8 & 67,9 & 70,0 & 60,6 \\
\hline 61,9 & 76,1 & 68,6 & 67,4 & 60,8 & 67,1 & 59,3 & 62,0 & 70,6 & 65,9 & 64,0 & 68,3 \\
\hline 64,0 & 64,8 & 63,6 & 60,7 & 63,8 & 69,3 & 65,3 & 75,9 & 65,2 & 66,9 & 79,4 & 63,2 \\
\hline 62,0 & 69,9 & 74,9 & 68,3 & 69,6 & 69,1 & 64,7 & 67,3 & 65,2 & 59,2 & 77,1 & 66,1 \\
\hline 70,4 & 59,3 & 62,7 & 65,2 & 61,8 & 73,2 & 68,7 & 75,7 & 64,6 & 71,6 & 61,8 & 61,7 \\
\hline 63,5 & 77,4 & 71,0 & 67,5 & 79,0 & 60,3 & 63,5 & 58,8 & 60,3 & 75,2 & 71,5 & 79,9 \\
\hline 70,4 & 78,8 & 65,5 & 71,8 & 61,2 & 70,2 & 64,0 & 62,8 & 64,4 & 68,2 & 64,6 & 69,4 \\
\hline 63,9 & 70,4 & 59,6 & 64,0 & 69,1 & 61,2 & 73,2 & 68,0 & 68,7 & 77,6 & 66,1 & 72,0 \\
\hline 64,7 & 67,7 & 65,9 & 70,6 & 67,1 & 60,8 & 73,4 & 68,1 & 66,1 & 66,9 & 71,0 & 64,9 \\
\hline 76,7 & 64,4 & 62,8 & 69,8 & 65,5 & 65,1 & 74,0 & 71,0 & 62,2 & 71,8 & 66,9 & 61,6 \\
\hline 63,2 & 70,2 & 76,7 & 66,0 & 69,2 & 68,7 & 71,0 & 72,0 & 64,7 & 54,0 & 69,8 & 63,0 \\
\hline 62,6 & 64,3 & 63,8 & 71,2 & 61,0 & 69,6 & 58,1 & 62,8 & 65,3 & 74,9 & 70,2 & 65,5 \\
\hline 72,2 & 70,0 & 59,2 & 67,7 & 70,2 & 58,7 & 68,3 & 69,4 & 80,3 & 64,0 & 68,6 & 74,5 \\
\hline 62,4 & 62,8 & 58,9 & 67,9 & 73,7 & 76,1 & 64,5 & 62,4 & 65,1 & 62,8 & 64,8 & 63,8 \\
\hline 72,5 & 77,1 & 76,2 & 63,1 & 58,4 & 57,7 & 77,3 & 67,7 & 66,3 & 76,5 & 60,7 & 67,3 \\
\hline 60,1 & 62,0 & 75,7 & 64,8 & 73,4 & 59,5 & 66,4 & 70,0 & 72,8 & 72,0 & 82,3 & 61,9 \\
\hline 67,4 & 71,2 & 70,9 & 71,8 & 71,8 & 72,9 & 67,0 & 68,3 & 66,8 & 61,5 & 63,9 & 64,0 \\
\hline 76,3 & 63,2 & 74,9 & 65,1 & 76,5 & 68,5 & 72,3 & 69,6 & 72,8 & 59,3 & 68,1 & 72,3 \\
\hline 66,1 & 74,1 & 65,7 & 66,7 & 64,9 & 77,1 & 66,2 & 63,2 & 72,0 & 72,5 & 74,1 & 68,1 \\
\hline 70,9 & 73,0 & 70,8 & 61,0 & 77,7 & 81,5 & 79,6 & 70,2 & 70,4 & 73,0 & 66,1 & 62,1 \\
\hline 67,9 & 69,7 & 68,4 & 65,3 & 67,1 & 67,9 & 71,4 & 63,2 & 63,2 & 65,1 & 68,6 & 71,5 \\
\hline 61,6 & 80,6 & 67,4 & 74,1 & 64,5 & 74,9 & 62,4 & 68,4 & 68,2 & 61,6 & 63,7 & 77,7 \\
\hline 79,2 & 65,2 & 66,4 & 58,3 & 78,0 & 69,7 & 74,1 & 75,5 & 62,3 & 65,5 & 66,3 & 68,7 \\
\hline 62,0 & 64,5 & 78,6 & 75,5 & 66,5 & 68,9 & 65,4 & 65,5 & 79,5 & 82,4 & 72,0 & 72,3 \\
\hline 62,8 & 62,3 & 64,0 & 66,2 & 64,3 & 63 & 72,6 & 78,7 & 60,9 & 71,6 & 63,7 & 67,1 \\
\hline 70,7 & 69,3 & 77,5 & 73,1 & 77,1 & 71,8 & 67,3 & 66,3 & 80,2 & 62,6 & 72,2 & 68,1 \\
\hline 71,4 & 64,9 & 62,0 & 70,2 & 64,0 & 77,2 & 61,4 & 64,2 & 69,4 & 70,6 & 69,4 & 62,4 \\
\hline 61,7 & 67,3 & 69,0 & 64,1 & 67,7 & 59,2 & 73,3 & 81,1 & 65,3 & 66,9 & 76,7 & 71,8 \\
\hline 64,0 & 66,3 & 69,4 & 77,7 & 69,1 & 69,2 & 71,3 & 62,3 & 65,9 & 68,1 & 68,4 & 59,1 \\
\hline 70,2 & 73,4 & 69,4 & 63,4 & 66,3 & 57,7 & 68,7 & 64,6 & 71,4 & 58,8 & 59,1 & 71,2 \\
\hline 64,3 & 68,5 & 65,8 & 70,0 & 80,3 & 72,7 & 70,0 & 77,3 & 67,4 & 76,4 & 67,6 & 70,6 \\
\hline 61,2 & 70,8 & 62,7 & 72,6 & 72,4 & 73,7 & 68,4 & 62,3 & 66,4 & 61,7 & 73,3 & 65,7 \\
\hline 71,0 & 71,6 & 65,8 & 64,3 & 69,8 & 79,5 & 73,6 & 71,8 & 63,1 & 67,1 & 73,0 & 58,0 \\
\hline 60,9 & 73,7 & 65,3 & 67,1 & 69,4 & 68,1 & 66,2 & 60,9 & 65,3 & 63,6 & 66,3 & 68,0 \\
\hline
\end{tabular}


Tabela 4 - Dados de ruído, em dB(A), no ambiente externo (Continuação).

\begin{tabular}{|c|c|c|c|c|c|c|c|c|c|c|c|}
\hline $25 / 05 / 10$ & $28 / 05 / 10$ & $02 / 06 / 10$ & $16 / 06 / 10$ & $22 / 06 / 10$ & $01 / 07 / 10$ & $06 / 07 / 10$ & $20 / 07 / 10$ & $05 / 08 / 10$ & $19 / 08 / 10$ & $26 / 08 / 10$ & $03 / 09 / 10$ \\
\hline 73,0 & 65,0 & 68,9 & 70,8 & 60,0 & 80,1 & 72,5 & 73,9 & 74,8 & 61,4 & 60,3 & 61,2 \\
\hline 72,8 & 69,4 & 60,7 & 69,8 & 74,2 & 64,4 & 71,8 & 65,7 & 69,4 & 66,1 & 69,8 & 61,8 \\
\hline 66,7 & 78,8 & 75,9 & 61,4 & 63,6 & 70,6 & 66,3 & 62,9 & 73,7 & 59,5 & 64,3 & 64,7 \\
\hline 69,2 & 71,7 & 66,5 & 63,2 & 66,7 & 64,2 & 68,7 & 63,1 & 63,2 & 68,4 & 73,4 & 62,0 \\
\hline 74,0 & 62,8 & 73,4 & 67,8 & 65,3 & 66,8 & 63,8 & 81,8 & 73,7 & 64,8 & 81,2 & 70,9 \\
\hline 73,2 & 69,5 & 61,2 & 63,4 & 65,5 & 70,6 & 71,4 & 65,7 & 63,7 & 73,4 & 79,2 & 67,0 \\
\hline 61,5 & 68,7 & 69,1 & 66,5 & 76,4 & 61,9 & 71,7 & 67,3 & 60,6 & 73,3 & 73,3 & 63,2 \\
\hline 71,2 & 63,9 & 73,3 & 69,2 & 64,0 & 81,6 & 68,3 & 62,2 & 74,0 & 75,3 & 63,0 & 55,5 \\
\hline 81,2 & 67,0 & 69,5 & 66,3 & 64,5 & 64,2 & 76,5 & 70,4 & 82,9 & 66,9 & 65,2 & 77,2 \\
\hline 60,1 & 64,3 & 65,5 & 75,3 & 70,4 & 74,1 & 68,7 & 61,7 & 69,9 & 70,6 & 63,2 & 69,1 \\
\hline 66,7 & 79,6 & 61,4 & 62,2 & 63,1 & 63,9 & 71,8 & 86,1 & 61,8 & 61,6 & 63,2 & 91,7 \\
\hline 71,0 & 67,1 & 73,4 & 73,1 & 77,1 & 66,9 & 68,6 & 71,3 & 68,1 & 69,4 & 71,5 & 67,8 \\
\hline 70,6 & 67,0 & 65,5 & 71,0 & 64,4 & 62,4 & 60,8 & 63,6 & 68,3 & 76,1 & 65,1 & 69,7 \\
\hline 70,7 & 77,8 & 74,6 & 70,2 & 72,9 & 80,6 & 67,3 & 69,4 & 67,5 & 70,1 & 69,9 & 70,2 \\
\hline 62,8 & 72,6 & 69,2 & 69,6 & 66,8 & 77,2 & 65,4 & 78,4 & 65,2 & 76,3 & 65,5 & 71,4 \\
\hline 73,6 & 72,4 & 62,8 & 78,8 & 65,3 & 74,9 & 70,2 & 67,9 & 76,5 & 61,2 & 62,7 & 71,4 \\
\hline 71,0 & 63,9 & 63,8 & 80,1 & 74,5 & 74,3 & 71,7 & 73,6 & 65,5 & 71,8 & 71,0 & 76,4 \\
\hline 63,1 & 73,0 & 70,8 & 64,9 & 63,5 & 63,7 & 63,2 & 65,0 & 73,9 & 67,1 & 69,6 & 69,4 \\
\hline 67,0 & 63,1 & 61,2 & 64,6 & 69,4 & 69,4 & 65,5 & 72,9 & 62,2 & 70,9 & 74,6 & 59,2 \\
\hline 60,6 & 65,4 & 72,5 & 68,2 & 75,3 & 60,7 & 65,9 & 71,2 & 74,5 & 63,8 & 77,8 & 68,3 \\
\hline 67,9 & 68,4 & 63,3 & 70,2 & 60,7 & 68,5 & 78,4 & 68,7 & 68,2 & 69,4 & 56,5 & 65,9 \\
\hline 61,8 & 71,3 & 70,6 & 70,2 & 69,8 & 71,3 & 70,9 & 71,0 & 65,5 & 61,6 & 68,6 & 66,3 \\
\hline 78,0 & 64,8 & 60,0 & 66,9 & 64,4 & 71 & 78,5 & 66,2 & 61,8 & 78,0 & 60,1 & 57,7 \\
\hline 70,5 & 67,1 & 66,0 & 65,8 & 73,2 & 60,3 & 73,0 & 75,9 & 68,5 & 60,0 & 68,2 & 76,5 \\
\hline 66,1 & 65,1 & 76,9 & 76,5 & 71,3 & 79,8 & 67,9 & 65,8 & 72,4 & 65,5 & 69,3 & 60,1 \\
\hline 79,6 & 68,2 & 63,8 & 63,8 & 67,3 & 66,3 & 76,3 & 85,9 & 69,4 & 74,0 & 61,3 & 74,9 \\
\hline 75,7 & 65,2 & 67,1 & 76,2 & 82,7 & 69,4 & 64,4 & 72,1 & 70,9 & 62,6 & 80,3 & 68,7 \\
\hline 64,9 & 75,5 & 58,0 & 66,9 & 65,4 & 60 & 61,1 & 70,0 & 70,0 & 65,5 & 62,3 & 75,2 \\
\hline 67,7 & 60,5 & 64,3 & 65,0 & 63,7 & 70,6 & 68,3 & 74,1 & 74,1 & 61,4 & 64,0 & 70,8 \\
\hline 61,4 & 65,4 & 59,0 & 65,2 & 71,8 & 63,1 & 70,8 & 60,6 & 71,0 & 66,9 & 81,7 & 62,8 \\
\hline 72,2 & 65,0 & 72,2 & 58,1 & 60,3 & 64,9 & 66,3 & 71,5 & 80,4 & 56,2 & 63,9 & 76,7 \\
\hline 59,6 & 63,4 & 67,9 & 72,6 & 74,2 & 59,9 & 72,6 & 75,2 & 63,6 & 74,1 & 72,2 & 67,0 \\
\hline 66,7 & 74,4 & 71,8 & 75,9 & 64,6 & 61,9 & 63,5 & 63,6 & 63,2 & 59,7 & 61,0 & 67,9 \\
\hline 73,2 & 63,3 & 65,9 & 65,4 & 66,2 & 67,1 & 67,4 & 71,0 & 67,7 & 69,7 & 68,4 & 63,7 \\
\hline 63,6 & 83,2 & 74,1 & 73,4 & 64,2 & 58,5 & 64,5 & 70,6 & 65,5 & 62,9 & 67,1 & 65,0 \\
\hline 68,7 & 71,4 & 72,1 & 65,3 & 70,5 & 81,6 & 74,5 & 73,6 & 75,5 & 66,3 & 58,7 & 58,2 \\
\hline 63,7 & 65,9 & 65,9 & 79,0 & 66,1 & 65,9 & 62,0 & 63,6 & 62,0 & 69,5 & 78,4 & 67,8 \\
\hline 60,7 & 60,4 & 68,1 & 67,1 & 71,6 & 78 & 63,7 & 60,4 & 82,3 & 69,8 & 63,3 & 63,4 \\
\hline 61,4 & 74,4 & 62,9 & 69,3 & 63,8 & 69,8 & 66,6 & 69,3 & 64,8 & 72,1 & 74,5 & 68,7 \\
\hline 58,7 & 67,9 & 70,6 & 68,5 & 73,3 & 68,7 & 65,9 & 61,1 & 71,2 & 60,9 & 62,6 & 73,1 \\
\hline 70,2 & 70,2 & 56,9 & 70,2 & 79,2 & 65,9 & 78,5 & 70,6 & 63,2 & 74,9 & 60,9 & 68,9 \\
\hline 64,7 & 73,7 & 65,0 & 69,4 & 69,4 & 70,4 & 65,8 & 66,7 & 68,1 & 63,0 & 71,2 & 73,6 \\
\hline 70,4 & 67,8 & 62,3 & 69,2 & 66,3 & 67,4 & 60,4 & 60,6 & 63,4 & 74,1 & 61,6 & 64,2 \\
\hline 67,9 & 70,2 & 66,8 & 61,6 & 73,2 & 58,2 & 69,6 & 75,2 & 73,2 & 63,6 & 77,2 & 62,4 \\
\hline 63,0 & 66,7 & 56,2 & 73,7 & 65,5 & 67,1 & 62,0 & 65,3 & 71,0 & 74,1 & 74,5 & 57,1 \\
\hline 74,9 & 65,3 & 74,5 & 70,2 & 62,8 & 60,5 & 73,2 & 70,2 & 65,2 & 64,6 & 58,1 & 71,2 \\
\hline 66,6 & 66,7 & 64,2 & 76,7 & 78,0 & 66,1 & 64,4 & 67,8 & 65,0 & 67,3 & 65,7 & 62,8 \\
\hline 63,4 & 76,3 & 68,1 & 72,6 & 65,0 & 62,4 & 65,7 & 63,0 & 64,9 & 64,8 & 79,4 & 74,9 \\
\hline 74,8 & 69,6 & 68,3 & 65,2 & 68,1 & 66,2 & 74,8 & 74,8 & 73,6 & 69,0 & 71,4 & 57,1 \\
\hline 62,2 & 68,7 & 66,7 & 67,4 & 64,6 & 65,7 & 68,7 & 60,5 & 64,0 & 62,8 & 61,9 & 77,6 \\
\hline 74,5 & 64,1 & 72,0 & 61,6 & 64,0 & 71 & 69,8 & 78,6 & 70,4 & 64,5 & 54,5 & 64,4 \\
\hline 74,1 & 79,2 & 66,7 & 78,0 & 67,8 & 63,2 & 66,9 & 72,8 & 61,0 & 66,2 & 75,5 & 59,3 \\
\hline 69,8 & 78,3 & 63,9 & 63,1 & 57,9 & 76,7 & 60,4 & 64,4 & 73,7 & 60,1 & 63,7 & 73,0 \\
\hline 67,7 & 70,1 & 62,2 & 58,5 & 66,0 & 67,7 & 67,2 & 73,0 & 58,9 & 69,2 & 74,1 & 61,3 \\
\hline 69,1 & 72,9 & 66,8 & 70,2 & 67,0 & 80,1 & 59,9 & 66,7 & 67,5 & 55,8 & 67,9 & 61,1 \\
\hline 70,2 & 69,4 & 67,9 & 63,4 & 62,7 & 67,8 & 74,1 & 73,0 & 66,8 & 69,4 & 64,3 & 63,8 \\
\hline 73,0 & 70,2 & 71,0 & 70,0 & 69,1 & 63,9 & 69,6 & 73,4 & 68,5 & 64,6 & 71,7 & 70,8 \\
\hline 70,0 & 70,4 & 65,3 & 71,2 & 75,7 & 71,8 & 62,0 & 70,2 & 64,9 & 70,4 & 63,5 & 62,4 \\
\hline 68,7 & 70,0 & 78,5 & 62,4 & 74,1 & 60,9 & 68,4 & 69,7 & 73,0 & 58,9 & 74,9 & 70,6 \\
\hline 68,4 & 63,1 & 65,5 & 82,0 & 62,7 & 70,4 & 61,5 & 65,8 & 77,4 & 78,4 & 70,2 & 65,3 \\
\hline 72,8 & 75,3 & 74,1 & 65,7 & 62,4 & 63,5 & 66,3 & 75,6 & 63,0 & 62,1 & 68,1 & 63,4 \\
\hline 71,7 & 69,4 & 65,5 & 73,7 & 74,9 & 70,2 & 66,5 & 73,8 & 72,7 & 67,1 & 68,9 & 67,7 \\
\hline 64,2 & 73,7 & 63,5 & 71,0 & 63,6 & 68,3 & 63,2 & 63,6 & 62,6 & 66,5 & 72,9 & 64,1 \\
\hline 65,2 & 66,7 & 69,4 & 64,3 & 65,5 & 80,7 & 73,0 & 71,2 & 79,2 & 64,1 & 71,8 & 62,0 \\
\hline 64,8 & 65,2 & 61,2 & 69,8 & 68,6 & 66,5 & 63,6 & 61,2 & 69,3 & 70,2 & 70,2 & 70,1 \\
\hline 71,3 & 64,0 & 70,2 & 64,2 & 67,5 & 92,5 & 71,0 & 69,3 & 65,8 & 60,1 & 63,9 & 62,4 \\
\hline 65,9 & 67,1 & 62,1 & 71,4 & 73,3 & 66,7 & 78,0 & 66,3 & 64,0 & 82,3 & 71,6 & 78,3 \\
\hline 65,5 & 66,9 & 71,4 & 70,6 & 79,8 & 72,2 & 80,9 & 61,2 & 74,9 & 61,2 & 62,8 & 69,4 \\
\hline 75,7 & 62,0 & 63,4 & 64,4 & 63,6 & 63,2 & 69,6 & 66,0 & 63,7 & 73,8 & 74,9 & 83,1 \\
\hline 66,7 & 67,9 & 76,3 & 70,4 & 73,9 & 63,6 & 66,2 & 67,1 & 71,7 & 62,8 & 65,5 & 68,9 \\
\hline 71,7 & 68,1 & 60,8 & 63,1 & 61,5 & 70,4 & 68,1 & 65,2 & 68,7 & 75,9 & 56,4 & 69,6 \\
\hline 72,0 & 71,1 & 78,0 & 68,5 & 70,4 & 62,3 & 73,1 & 61,0 & 78,4 & 61,2 & 72,2 & 59,5 \\
\hline 69,2 & 58,8 & 65,4 & 61,2 & 65,7 & 70 & 59,8 & 60,9 & 70,5 & 71,2 & 60,4 & 69,8 \\
\hline 76,0 & 69,5 & 68,6 & 60,4 & 68,6 & 64,1 & 68,6 & 63,9 & 60,3 & 63,6 & 77,3 & 65,9 \\
\hline 71,2 & 65,8 & 67,7 & 80,6 & 66,8 & 77 & 58,9 & 61,3 & 79,2 & 79,8 & 71,7 & 71,8 \\
\hline 76,5 & 71,5 & 66,9 & 64,1 & 65,2 & 79 & 70,0 & 71,6 & 61,2 & 63,1 & 71,0 & 73,3 \\
\hline 70,9 & 62,4 & 58,2 & 75,1 & 73,0 & 72,9 & 72,1 & 69,6 & 76,5 & 66,5 & 72,2 & 74,9 \\
\hline
\end{tabular}


Tabela 4 - Dados de ruído, em dB(A), no ambiente externo (Continuação).

\begin{tabular}{|c|c|c|c|c|c|c|c|c|c|c|c|}
\hline $25 / 05 / 10$ & $28 / 05 / 10$ & $02 / 06 / 10$ & $16 / 06 / 10$ & $22 / 06 / 10$ & $01 / 07 / 10$ & $06 / 07 / 10$ & $20 / 07 / 10$ & $05 / 08 / 10$ & $19 / 08 / 10$ & $26 / 08 / 10$ & $03 / 09 / 10$ \\
\hline 69,4 & 70,9 & 62,8 & 67,7 & 62,3 & 64,8 & 63,8 & 61,0 & 72,1 & 62,4 & 73,0 & 68,7 \\
\hline 71,4 & 64,5 & 69,0 & 67,1 & 65,0 & 69,1 & 63,2 & 64,3 & 78,6 & 64,8 & 67,1 & 68,1 \\
\hline 65,2 & 78,5 & 67,5 & 70,0 & 70,2 & 67,3 & 61,0 & 68,3 & 63,7 & 67,7 & 68,1 & 77,2 \\
\hline 78,8 & 69,4 & 70,4 & 71,6 & 61,4 & 76,5 & 73,9 & 72,7 & 81,4 & 63,7 & 68,5 & 66,7 \\
\hline 72,2 & 66,7 & 73,9 & 75,5 & 67,6 & 71 & 65,9 & 67,1 & 71,8 & 76,7 & 81,6 & 67,8 \\
\hline 67,7 & 65,3 & 73,0 & 67,5 & 69,1 & 64,7 & 60,9 & 65,7 & 77,1 & 70,8 & 64,0 & 65,5 \\
\hline 68,7 & 61,9 & 57,7 & 73,4 & 71,1 & 63,8 & 65,2 & 74,9 & 67,5 & 81,9 & 76,9 & 66,1 \\
\hline 70,7 & 68,1 & 77,5 & 72,2 & 66,0 & 64,2 & 61,9 & 64,8 & 68,6 & 70,7 & 64,8 & 63,4 \\
\hline 72,2 & 63,2 & 65,9 & 61,2 & 69,1 & 67,9 & 64,6 & 70,0 & 72,0 & 82,7 & 59,7 & 74,1 \\
\hline 68,6 & 76,4 & 68,0 & 72,5 & 70,1 & 65,2 & 63,4 & 70,1 & 66,7 & 70,0 & 71,5 & 70,1 \\
\hline 70,0 & 63,5 & 61,6 & 59,9 & 77,8 & 64,5 & 68,4 & 66,7 & 70,0 & 69,6 & 81,2 & 75,3 \\
\hline 70,2 & 79,4 & 65,9 & 58,8 & 70,4 & 67 & 71,1 & 69,4 & 66,1 & 64,4 & 64,0 & 72,2 \\
\hline 66,8 & 65,5 & 77,9 & 65,9 & 70,2 & 70,2 & 61,8 & 69,9 & 70,9 & 63,8 & 88,6 & 73,2 \\
\hline 69,8 & 85,3 & 62,7 & 67,8 & 67,9 & 60,4 & 76,4 & 72,4 & 64,5 & 68,6 & 59,6 & 66,3 \\
\hline 72,2 & 60,7 & 67,7 & 70,7 & 76,9 & 73,5 & 72,4 & 67,1 & 69,7 & 72,8 & 69,2 & 62,2 \\
\hline 71,6 & 73,4 & 68,4 & 60,6 & 59,6 & 72,6 & 66,5 & 61,8 & 69,8 & 61,8 & 59,1 & 78,5 \\
\hline 78,8 & 72,6 & 68,7 & 74,9 & 64,9 & 79,2 & 69,1 & 71,8 & 73,6 & 60,8 & 70,8 & 65,0 \\
\hline 68,7 & 64,7 & 70,0 & 66,1 & 66,0 & 80 & 63,2 & 58,1 & 66,1 & 67,0 & 72,1 & 73,7 \\
\hline 71,0 & 74,7 & 77,2 & 60,4 & 71,7 & 65 & 73,6 & 65,5 & 66,0 & 63,8 & 60,5 & 64,0 \\
\hline 73,2 & 58,9 & 63,9 & 77,1 & 72,1 & 71,5 & 76,1 & 67,7 & 69,0 & 73,9 & 70,7 & 69,6 \\
\hline 68,3 & 70,6 & 69,6 & 69,9 & 67,3 & 64,2 & 65,8 & 63,1 & 61,2 & 57,7 & 74,5 & 64,0 \\
\hline 73,7 & 62,1 & 60,7 & 65,8 & 65,2 & 68,5 & 63,7 & 74,9 & 76,9 & 77,9 & 61,8 & 79,8 \\
\hline 67,7 & 74,5 & 77,3 & 65,9 & 74,9 & 64,5 & 69,4 & 64,4 & 62,9 & 62,1 & 76,7 & 81,1 \\
\hline 69,8 & 65,5 & 71,8 & 64,6 & 63,1 & 76,9 & 68,7 & 67,3 & 64,0 & 66,3 & 73,0 & 72,2 \\
\hline 71,2 & 67,1 & 72,1 & 69,4 & 74,6 & 66,6 & 70,1 & 70,4 & 59,1 & 65,3 & 65,9 & 66,5 \\
\hline 69,4 & 63,5 & 63,6 & 65,7 & 76,5 & 70,6 & 63,2 & 71,7 & 73,0 & 63,4 & 82,9 & 63,9 \\
\hline 75,4 & 69,8 & 63,1 & 64,0 & 72,1 & 63,9 & 72,8 & 72,8 & 68,1 & 68,7 & 56,5 & 71,4 \\
\hline 67,4 & 78,5 & 67,1 & 67,5 & 63,8 & 77,3 & 74,9 & 66,0 & 69,3 & 70,1 & 69,3 & 64,0 \\
\hline 81,1 & 63,2 & 66,7 & 64,4 & 56,6 & 63,6 & 78,4 & 73,0 & 60,1 & 71,1 & 71,8 & 65,3 \\
\hline 74,5 & 68,5 & 72,5 & 66,6 & 71,2 & 73,4 & 67,5 & 70,8 & 69,2 & 63,0 & 63,9 & 64,0 \\
\hline 73,6 & 70,2 & 67,6 & 70,4 & 63,6 & 81,7 & 63,7 & 67,8 & 64,8 & 66,7 & 67,1 & 67,5 \\
\hline 75,5 & 82,0 & 71,1 & 62,0 & 61,4 & 62,4 & 67,1 & 64,9 & 69,1 & 66,2 & 65,5 & 62,3 \\
\hline 70,2 & 66,5 & 63,0 & 67,5 & 74,9 & 64,5 & 63,6 & 63,5 & 62,4 & 74,1 & 60,9 & 72,6 \\
\hline 68,7 & 62,7 & 67,6 & 57,3 & 60,2 & 63,1 & 81,0 & 68,3 & 67,6 & 63,4 & 70,6 & 70,2 \\
\hline 69,3 & 69,8 & 64,5 & 69,1 & 70,2 & 64,8 & 79,0 & 67,5 & 65,8 & 67,8 & 72,4 & 81,5 \\
\hline 73,7 & 66,8 & 76,5 & 66,2 & 62,0 & 65,9 & 63,4 & 68,0 & 63,4 & 71,0 & 60,3 & 67,1 \\
\hline 72,8 & 73,6 & 65,4 & 58,9 & 66,7 & 66,5 & 72,3 & 62,9 & 71,0 & 77,1 & 67,9 & 72,3 \\
\hline 72,0 & 69,9 & 66,5 & 69,5 & 72,1 & 63,5 & 64,3 & 68,7 & 63,5 & 62,8 & 75,9 & 66,2 \\
\hline 69,6 & 81,2 & 71,2 & 66,3 & 67,4 & 68,6 & 70,8 & 76,1 & 68,7 & 77,1 & 55,6 & 63,8 \\
\hline 74,0 & 70,6 & 62,7 & 74,9 & 75,5 & 64,6 & 61,6 & 72,1 & 73,1 & 66,7 & 77,8 & 62,4 \\
\hline 66,7 & 67,3 & 73,2 & 68,2 & 58,7 & 76,4 & 62,6 & 70,2 & 70,5 & 63,5 & 72,6 & 63,1 \\
\hline 76,0 & 75,6 & 69,9 & 68,3 & 62,0 & 63,3 & 70,6 & 60,7 & 67,7 & 63,2 & 62,9 & 69,4 \\
\hline 67,0 & 69,8 & 77,6 & 66,9 & 79,2 & 73,7 & 61,5 & 58,5 & 67,8 & 61,1 & 62,4 & 59,5 \\
\hline 69,6 & 65,4 & 67,9 & 56,6 & 69,4 & 64,2 & 64,8 & 68,5 & 63,6 & 66,3 & 60,2 & 76,9 \\
\hline 61,0 & 74,5 & 65,5 & 74,8 & 75,3 & 60,4 & 68,2 & 66,3 & 71,6 & 65,5 & 68,7 & 62,2 \\
\hline 64,0 & 74,9 & 79,2 & 70,6 & 69,5 & 69,8 & 56,9 & 60,0 & 63,0 & 72,6 & 65,4 & 69,3 \\
\hline 67,1 & 74,9 & 67,1 & 63,0 & 65,7 & 62,4 & 68,5 & 76,5 & 56,9 & 60,8 & 66,5 & 65,2 \\
\hline 61,6 & 67,2 & 66,6 & 73,9 & 74,3 & 70,6 & 67,5 & 64,1 & 74,7 & 64,6 & 67,1 & 64,7 \\
\hline 80,3 & 67,2 & 77,7 & 65,9 & 65,4 & 64,5 & 74,9 & 66,1 & 64,5 & 62,4 & 69,6 & 60,3 \\
\hline 58,7 & 68,3 & 63,8 & 67,9 & 79,6 & 83,5 & 67,0 & 65,2 & 81,7 & 71,8 & 56,8 & 63,6 \\
\hline 65,8 & 68,7 & 74,6 & 76,2 & 75,4 & 60,7 & 65,9 & 62,7 & 64,0 & 64,3 & 69,3 & 68,3 \\
\hline 81,0 & 69,4 & 72,2 & 66,5 & 86,4 & 68 & 80,8 & 67,8 & 73,0 & 71,5 & 68,1 & 59,1 \\
\hline 61,6 & 65,9 & 69,1 & 64,8 & 67,1 & 77,7 & 73,6 & 73,6 & 60,3 & 62,9 & 58,5 & 78,0 \\
\hline 70,5 & 66,2 & 62,2 & 60,2 & 65,8 & 67,5 & 79,4 & 69,3 & 68,4 & 65,2 & 69,7 & 61,0 \\
\hline 70,6 & 72,5 & 56,9 & 79,6 & 74,5 & 66,5 & 78,6 & 69,4 & 80,3 & 63,6 & 70,5 & 60,9 \\
\hline 67,1 & 64,3 & 66,1 & 67,7 & 79,6 & 80,7 & 67,4 & 72,1 & 69,8 & 61,8 & 55,5 & 72,9 \\
\hline 70,8 & 80,6 & 64,3 & 70,9 & 66,7 & 65,7 & 76,9 & 68,6 & 61,2 & 74,9 & 65,3 & 72,8 \\
\hline 63,5 & 72,9 & 85,5 & 66,6 & 73,6 & 61,2 & 68,1 & 76,3 & 79,2 & 61,2 & 60,4 & 77,5 \\
\hline 76,0 & 66,9 & 63,9 & 68,7 & 61,2 & 62,8 & 67,3 & 73,4 & 70,7 & 65,0 & 76,5 & 73,1 \\
\hline 83,2 & 68,1 & 63,0 & 80,2 & 74,0 & 67 & 63,5 & 67,4 & 63,8 & 73,7 & 76,1 & 78,0 \\
\hline 72,2 & 72,6 & 66,1 & 70,4 & 69,4 & 69,4 & 63,7 & 66,7 & 78,7 & 65,5 & 56,2 & 71,5 \\
\hline 68,7 & 77,3 & 63,8 & 62,0 & 70,8 & 68 & 67,6 & 74,7 & 72,2 & 79,1 & 61,9 & 64,2 \\
\hline 68,7 & 60,8 & 75,7 & 80,9 & 70,6 & 71,8 & 63,6 & 60,4 & 66,1 & 70,4 & 64,8 & 70,4 \\
\hline 60,6 & 66,1 & 72,2 & 59,2 & 61,4 & 64,8 & 81,6 & 71,6 & 60,1 & 67,1 & 59,3 & 63,6 \\
\hline 70,2 & 69,1 & 67,3 & 66,3 & 77,3 & 82 & 60,0 & 64,7 & 75,2 & 69,1 & 73,6 & 79,4 \\
\hline 67,0 & 67,5 & 70,8 & 74,2 & 69,8 & 66,3 & 65,0 & 62,4 & 60,5 & 60,2 & 66,6 & 66,0 \\
\hline 63,7 & 65,3 & 63,1 & 58,5 & 69,6 & 67,5 & 63,4 & 66,5 & 77,8 & 70,2 & 58,1 & 68,0 \\
\hline 64,6 & 67,7 & 71,3 & 66,7 & 69,3 & 80,4 & 65,9 & 63,8 & 61,0 & 63,7 & 66,8 & 67,4 \\
\hline 66,7 & 61,5 & 59,3 & 61,8 & 63,0 & 73,4 & 65,5 & 70,0 & 71,0 & 64,3 & 63,1 & 63,6 \\
\hline 58,5 & 68,1 & 67,1 & 71,7 & 69,0 & 66,3 & 67,1 & 68,1 & 67,6 & 69,1 & 61,2 & 62,0 \\
\hline 66,5 & 67,4 & 65,9 & 61,9 & 63,2 & 65,9 & 57,6 & 62,2 & 74,0 & 61,7 & 76,5 & 74,8 \\
\hline 77,3 & 77,1 & 69,4 & 60,7 & 81,2 & 68,2 & 68,2 & 72,1 & 60,6 & 81,9 & 67,4 & 58,4 \\
\hline 56,9 & 68,4 & 76,9 & 70,2 & 66,7 & 66,1 & 60,5 & 65,1 & 77,8 & 62,9 & 60,3 & 66,2 \\
\hline 73,2 & 65,5 & 76,1 & 63,8 & 61,0 & 70,1 & 72,8 & 66,5 & 67,3 & 60,9 & 69,3 & 62,4 \\
\hline 67,3 & 71,4 & 67,3 & 55,1 & 68,6 & 63,2 & 61,9 & 74,4 & 69,8 & 73,1 & 71,6 & 75,5 \\
\hline 61,4 & 76,3 & 70,6 & 61,8 & 63,6 & 74,4 & 62,2 & 71,2 & 64,4 & 62,4 & 56,1 & 68,7 \\
\hline 74,7 & 71,8 & 64,4 & 61,7 & 69,0 & 65,5 & 63,0 & 65,5 & 70,6 & 79,6 & 68,7 & 60,9 \\
\hline
\end{tabular}


Tabela 4 - Dados de ruído, em dB(A), no ambiente externo (Continuação).

\begin{tabular}{|c|c|c|c|c|c|c|c|c|c|c|c|}
\hline $25 / 05 / 10$ & $28 / 05 / 10$ & $02 / 06 / 10$ & $16 / 06 / 10$ & $22 / 06 / 10$ & $01 / 07 / 10$ & $06 / 07 / 10$ & $20 / 07 / 10$ & $05 / 08 / 10$ & $19 / 08 / 10$ & $26 / 08 / 10$ & $03 / 09 / 10$ \\
\hline 59,7 & 65,8 & 69,6 & 58,7 & 65,1 & 73,9 & 67,3 & 82,3 & 67,7 & 69,0 & 64,3 & 81,0 \\
\hline 63,1 & 64,4 & 62,8 & 73,7 & 77,1 & 61 & 70,8 & 74,4 & 64,0 & 61,5 & 71,2 & 64,0 \\
\hline 69,8 & 68,5 & 60,6 & 68,1 & 72,0 & 76,2 & 65,3 & 64,0 & 72,6 & 76,1 & 75,3 & 66,5 \\
\hline 57,1 & 66,9 & 62,4 & 75,4 & 69,8 & 63,8 & 56,5 & 68,9 & 63,6 & 60,1 & 66,7 & 67,6 \\
\hline 71,6 & 83,5 & 64,2 & 63,8 & 61,3 & 69,4 & 70,5 & $\mathrm{X}$ & 64,6 & 73,8 & 86,2 & 70,4 \\
\hline 64,8 & 69,1 & 75,7 & 65,7 & 65,7 & 69,1 & 65,0 & $\mathrm{X}$ & 66,7 & 68,7 & 62,4 & 74,5 \\
\hline 59,8 & 65,5 & 59,7 & 62,3 & 62,0 & 65 & 81,2 & $\mathrm{X}$ & 66,3 & 65,3 & 58,7 & 65,0 \\
\hline 68,5 & 67,8 & 61,9 & 64,8 & 85,9 & 70,4 & 61,0 & $\mathrm{X}$ & 79,4 & 68,3 & 65,3 & 60,1 \\
\hline 70,2 & 63,9 & 69,4 & 75,7 & 72,6 & 63,4 & 63,7 & $\mathrm{X}$ & 62,3 & 63,4 & 67,7 & $\mathrm{X}$ \\
\hline 58,4 & 73,7 & 63,6 & 76,3 & 64,7 & 70,2 & 81,2 & $\mathrm{X}$ & 63,0 & 67,8 & 58,9 & $\mathrm{X}$ \\
\hline 77,3 & 63,9 & 73,7 & 72,6 & 70,6 & 75,7 & 56,0 & $\mathrm{X}$ & 70,2 & 69,1 & 73,7 & $\mathrm{X}$ \\
\hline 64,8 & $\mathrm{X}$ & 67,1 & 61,0 & 62,4 & 64 & 83,0 & $\mathrm{X}$ & 73,6 & 62,2 & 68,0 & $\mathrm{X}$ \\
\hline 61,5 & $\mathrm{X}$ & 65,2 & 77,7 & 58,7 & 73,6 & 66,1 & $X$ & 86,6 & 71,0 & 69,3 & $X$ \\
\hline 79,2 & $\mathrm{X}$ & 68,0 & 73,0 & 74,5 & 66,6 & 63,2 & $\mathrm{X}$ & 57,5 & 74,3 & 73,9 & $\mathrm{X}$ \\
\hline 75,4 & $\mathrm{X}$ & $\mathrm{X}$ & 61,8 & 64,0 & 70,5 & 65,7 & $\mathrm{X}$ & 75,4 & 70,9 & 57,3 & $\mathrm{X}$ \\
\hline 68,2 & $\mathrm{X}$ & $\mathrm{X}$ & 62,8 & 62,1 & 69 & $\mathrm{X}$ & $\mathrm{X}$ & 65,5 & 61,9 & 62,8 & $\mathrm{X}$ \\
\hline 75,9 & $\mathrm{X}$ & $\mathrm{X}$ & 70,6 & 71,2 & 59,4 & $\mathrm{X}$ & $\mathrm{X}$ & 66,5 & 66,1 & $\mathrm{X}$ & $\mathrm{X}$ \\
\hline 60,4 & $\mathrm{X}$ & $\mathrm{X}$ & 60,6 & 68,4 & 73,7 & $\mathrm{X}$ & $X$ & 67,1 & $\mathrm{X}$ & $X$ & $X$ \\
\hline 82,5 & $X$ & $X$ & 77,5 & 60,6 & $\mathrm{X}$ & $\mathrm{X}$ & $X$ & $\mathrm{X}$ & $\mathrm{X}$ & $\mathrm{X}$ & $X$ \\
\hline 67,1 & $\mathrm{X}$ & $X$ & 65,5 & 73,0 & $X$ & $X$ & $X$ & $X$ & $X$ & $\mathrm{X}$ & $X$ \\
\hline 63,0 & $\mathrm{X}$ & $\mathrm{X}$ & 60,5 & 64,6 & $\mathrm{X}$ & $\mathrm{X}$ & $\mathrm{X}$ & $\mathrm{X}$ & $\mathrm{X}$ & $X$ & $\mathrm{X}$ \\
\hline $\mathrm{X}$ & $X$ & $X$ & 75,7 & 63,6 & $X$ & $X$ & $X$ & $\mathrm{X}$ & $\mathrm{X}$ & $\mathrm{X}$ & $\mathrm{X}$ \\
\hline$X$ & $X$ & $X$ & 63,1 & $\mathrm{X}$ & $X$ & $X$ & $X$ & $X$ & $X$ & $X$ & $X$ \\
\hline $\mathrm{X}$ & $\mathrm{X}$ & $\mathrm{X}$ & 62,4 & $X$ & $\mathrm{X}$ & $\mathrm{X}$ & $\mathrm{X}$ & $\mathrm{X}$ & $\mathrm{X}$ & $\mathrm{X}$ & $\mathrm{X}$ \\
\hline $\mathrm{X}$ & $\mathrm{X}$ & $\mathrm{X}$ & 77,7 & $\mathrm{X}$ & $X$ & $\mathrm{X}$ & $X$ & $X$ & $X$ & $\mathrm{X}$ & $X$ \\
\hline $\mathrm{X}$ & $\mathrm{X}$ & $\mathrm{X}$ & 68,9 & $\mathrm{X}$ & $\mathrm{X}$ & $\mathrm{X}$ & $\mathrm{X}$ & $\mathrm{X}$ & $\mathrm{X}$ & $\mathrm{X}$ & $\mathrm{X}$ \\
\hline $\mathrm{X}$ & $\mathrm{X}$ & $X$ & 65,5 & $\mathrm{X}$ & $X$ & $\mathrm{X}$ & $X$ & $\mathrm{X}$ & $X$ & $\mathrm{X}$ & $X$ \\
\hline $\mathrm{X}$ & $X$ & $X$ & 66,5 & $X$ & $X$ & $X$ & $X$ & $\mathrm{X}$ & $X$ & $X$ & $X$ \\
\hline $\mathrm{X}$ & $\mathrm{X}$ & $\mathrm{X}$ & 58,4 & $\mathrm{X}$ & $\mathrm{X}$ & $\mathrm{X}$ & $\mathrm{X}$ & $\mathrm{X}$ & $\mathrm{X}$ & $\mathrm{X}$ & $\mathrm{X}$ \\
\hline
\end{tabular}




\begin{abstract}
ANEXO V
DADOS DE CONCENTRAÇÃO DE GÁS CARBÔNICO NOS PISOS 1, 2, 3 E NO AMBIENTE EXTERNO
\end{abstract}


Tabela 1 - Concentração de $\mathrm{CO}_{2}$, em ppm, no Piso 1 no ano de 2010.

\begin{tabular}{|c|c|c|c|c|c|c|c|c|c|c|c|c|}
\hline $12 / 5 / 10$ & $18 / 5 / 10$ & $31 / 5 / 10$ & $10 / 6 / 10$ & $29 / 6 / 10$ & $8 / 7 / 10$ & $13 / 7 / 10$ & $21 / 7 / 10$ & $3 / 8 / 10$ & $9 / 8 / 10$ & $24 / 8 / 10$ & $30 / 8 / 10$ & $15 / 9 / 10$ \\
\hline 355 & 414 & 593 & 451 & 479 & 431 & 457 & 508 & 498 & 694 & 444 & 470 & 534 \\
\hline 367 & 402 & 595 & 439 & 481 & 426 & 460 & 491 & 493 & 700 & 426 & 452 & 497 \\
\hline 360 & 411 & 657 & 438 & 501 & 434 & 464 & 498 & 502 & 698 & 430 & 452 & 488 \\
\hline 363 & 421 & 626 & 537 & 492 & 435 & 468 & 494 & 496 & 682 & 418 & 459 & 492 \\
\hline 369 & 410 & 592 & 462 & 487 & 421 & 470 & 498 & 491 & 710 & 422 & 467 & 499 \\
\hline 366 & 564 & 604 & 431 & 534 & 440 & 467 & 492 & 499 & 693 & 428 & 520 & 513 \\
\hline 365 & 462 & 617 & 431 & 498 & 452 & 463 & 499 & 505 & 682 & 451 & 485 & 515 \\
\hline 373 & 435 & 601 & 447 & 488 & 437 & 456 & 503 & 501 & 682 & 443 & 479 & 521 \\
\hline 374 & 421 & 592 & 469 & 488 & 432 & 460 & 492 & 500 & 679 & 440 & 487 & 509 \\
\hline 376 & 450 & 583 & 450 & 488 & 421 & 447 & 483 & 497 & 679 & 426 & 492 & 513 \\
\hline 368 & 462 & 581 & 465 & 494 & 418 & 459 & 476 & 498 & 668 & 421 & 484 & 518 \\
\hline 375 & 448 & 574 & 458 & 491 & 418 & 457 & 488 & 494 & 668 & 422 & 490 & 511 \\
\hline 391 & 460 & 578 & 478 & 502 & 427 & 471 & 539 & 496 & 669 & 422 & 476 & 503 \\
\hline 385 & 461 & 585 & 473 & 509 & 421 & 458 & 561 & 495 & 653 & 426 & 474 & 512 \\
\hline 386 & 451 & 581 & 476 & 506 & 422 & 450 & 504 & 494 & 664 & 425 & 488 & 530 \\
\hline 387 & 456 & 577 & 481 & 502 & 416 & 444 & 501 & 494 & 659 & 429 & 479 & 516 \\
\hline 376 & 453 & 570 & 476 & 511 & 406 & 453 & 494 & 491 & 659 & 434 & 494 & 511 \\
\hline 372 & 469 & 573 & 474 & 517 & 398 & 453 & 501 & 495 & 652 & 441 & 487 & 507 \\
\hline 382 & 458 & 582 & 480 & 502 & 406 & 469 & 509 & 494 & 668 & 431 & 492 & 506 \\
\hline 373 & 461 & 573 & 480 & 499 & 404 & 455 & 499 & 505 & 633 & 428 & 483 & 516 \\
\hline 375 & 476 & 565 & 474 & 515 & 406 & 471 & 508 & 505 & 627 & 434 & 503 & 528 \\
\hline 378 & 514 & 562 & 474 & 495 & 404 & 451 & 492 & 496 & 633 & 447 & 493 & 508 \\
\hline 374 & 474 & 553 & 476 & 506 & 403 & 464 & 495 & 497 & 620 & 424 & 514 & 505 \\
\hline 378 & 465 & 577 & 464 & 497 & 394 & 459 & 496 & 493 & 622 & 436 & 493 & 500 \\
\hline 376 & 475 & 575 & 464 & 492 & 395 & 461 & 505 & 499 & 607 & 426 & 501 & 492 \\
\hline 377 & 458 & 579 & 458 & 493 & 402 & 451 & 498 & 493 & 610 & 435 & 495 & 519 \\
\hline 371 & 479 & 570 & 486 & 504 & 396 & 453 & 502 & 493 & 622 & 435 & 494 & 516 \\
\hline 372 & 483 & 564 & 453 & 504 & 388 & 465 & 499 & 506 & 611 & 424 & 497 & 504 \\
\hline 375 & 473 & 575 & 475 & 500 & 394 & 463 & 492 & 499 & 613 & 422 & 492 & 507 \\
\hline 374 & 484 & 586 & 471 & 478 & 402 & 461 & 487 & 504 & 619 & 430 & 462 & 530 \\
\hline 381 & 472 & 593 & 469 & 493 & 401 & 463 & 501 & 511 & 613 & 438 & 459 & 520 \\
\hline 391 & 480 & 582 & 471 & 486 & 406 & 460 & 489 & 504 & 650 & 451 & 458 & 520 \\
\hline 375 & 482 & 591 & 473 & 497 & 400 & 455 & 488 & 501 & 621 & 449 & 475 & 522 \\
\hline 386 & 476 & 587 & 479 & 499 & 401 & 444 & 498 & 505 & 614 & 445 & 468 & 522 \\
\hline 386 & 476 & 574 & 485 & 497 & 404 & 454 & 503 & 497 & 611 & 448 & 464 & 540 \\
\hline 376 & 473 & 567 & 475 & 485 & 410 & 458 & 501 & 502 & 596 & 429 & 456 & 526 \\
\hline 379 & 460 & 561 & 470 & 498 & 400 & 457 & 508 & 516 & 603 & 443 & 462 & 518 \\
\hline 386 & 463 & 567 & 475 & 499 & 398 & 446 & 509 & 521 & 603 & 440 & 457 & 527 \\
\hline 391 & 467 & 570 & 461 & 491 & 416 & 453 & 502 & 507 & 612 & 441 & 471 & 545 \\
\hline 373 & 468 & 585 & 587 & 496 & 403 & 448 & 522 & 515 & 605 & 431 & 467 & 534 \\
\hline 374 & 465 & 584 & 555 & 503 & 408 & 455 & 528 & 521 & 599 & 440 & 457 & 539 \\
\hline 364 & 469 & 600 & 491 & 515 & 414 & 457 & 556 & 506 & 596 & 429 & 479 & 547 \\
\hline 371 & 455 & 612 & 505 & 490 & 393 & 448 & 539 & 521 & 598 & 434 & 449 & 518 \\
\hline 369 & 466 & 602 & 524 & 500 & 412 & 447 & 525 & 514 & 612 & 429 & 467 & 536 \\
\hline 360 & 455 & 580 & 508 & 514 & 420 & 448 & 522 & 513 & 600 & 440 & 470 & 539 \\
\hline 367 & 474 & 592 & 498 & 506 & 417 & 450 & 527 & 516 & 610 & 433 & 467 & 540 \\
\hline 364 & 465 & 585 & 519 & 523 & 408 & 454 & 523 & 511 & 607 & 433 & 461 & 526 \\
\hline 361 & 473 & 590 & 516 & 525 & 403 & 444 & 525 & 530 & 591 & 437 & 459 & 539 \\
\hline 361 & 475 & 601 & 513 & 520 & 405 & 475 & 531 & 519 & 585 & 438 & 460 & 537 \\
\hline 364 & 474 & 601 & 512 & 512 & 401 & 451 & 536 & 519 & 587 & 427 & 444 & 545 \\
\hline 366 & 475 & 608 & 483 & 518 & 410 & 438 & 529 & 524 & 583 & 425 & 463 & 547 \\
\hline 364 & 458 & 586 & 501 & 531 & 420 & 458 & 524 & 534 & 607 & 431 & 450 & 550 \\
\hline 360 & 456 & 547 & 489 & 512 & 407 & 460 & 533 & 521 & 605 & 426 & 452 & 540 \\
\hline 387 & 485 & 518 & 494 & 508 & 400 & 463 & 546 & 522 & 611 & 426 & 461 & 545 \\
\hline 371 & 483 & 512 & 499 & 508 & 403 & 458 & 520 & 521 & 618 & 422 & 464 & 543 \\
\hline 362 & 489 & 512 & 500 & 509 & 411 & 454 & 545 & 532 & 612 & 446 & 449 & 536 \\
\hline 373 & 507 & 513 & 506 & 503 & 399 & 480 & 539 & 531 & 633 & 427 & 450 & 540 \\
\hline 367 & 517 & 513 & 527 & 495 & 395 & 479 & 531 & 518 & 625 & 430 & 453 & 548 \\
\hline 361 & 502 & 522 & 527 & 495 & 402 & 476 & 535 & 519 & 615 & 434 & 465 & 536 \\
\hline 367 & 503 & 514 & 547 & 482 & 395 & 480 & 547 & 517 & 607 & 435 & 457 & 543 \\
\hline 354 & 500 & 503 & 531 & 489 & 402 & 484 & 545 & 527 & 621 & 436 & 455 & 515 \\
\hline 363 & 512 & 499 & 514 & 492 & 388 & 469 & 538 & 530 & 640 & 436 & 462 & 523 \\
\hline 366 & 512 & 514 & 533 & 500 & 399 & 489 & 546 & 529 & 651 & 439 & 469 & 524 \\
\hline 370 & 524 & 503 & 548 & 499 & 400 & 476 & 538 & 524 & 638 & 436 & 460 & 549 \\
\hline 376 & 507 & 519 & 563 & 499 & 416 & 476 & 544 & 523 & 628 & 440 & 449 & 526 \\
\hline 369 & 519 & 526 & 551 & 504 & 396 & 472 & 532 & 516 & 629 & 444 & 443 & 519 \\
\hline 372 & 511 & 528 & 570 & 502 & 396 & 467 & 548 & 522 & 626 & 432 & 449 & 512 \\
\hline 370 & 521 & 518 & 688 & 489 & 404 & 472 & 549 & 526 & 628 & 433 & 454 & 517 \\
\hline 370 & 530 & 521 & 560 & 485 & 403 & 463 & 544 & 528 & 629 & 432 & 444 & 515 \\
\hline 369 & 532 & 502 & 582 & 516 & 421 & 481 & 545 & 515 & 630 & 436 & 446 & 525 \\
\hline 368 & 544 & 505 & 541 & 515 & 428 & 487 & 563 & 512 & 652 & 445 & 455 & 518 \\
\hline 379 & 539 & 529 & 547 & 505 & 420 & 476 & 553 & 519 & 639 & 433 & 439 & 509 \\
\hline 375 & 537 & 514 & 535 & 505 & 421 & 486 & 562 & 519 & 648 & 434 & 478 & 501 \\
\hline 376 & 537 & 522 & 542 & 486 & 443 & 482 & 544 & 521 & 665 & 437 & 466 & 513 \\
\hline 373 & 521 & 509 & 531 & 506 & 442 & 485 & 553 & 522 & 650 & 427 & 455 & 513 \\
\hline 397 & 527 & 496 & 522 & 485 & 459 & 473 & 549 & 530 & 667 & 433 & 467 & 515 \\
\hline 387 & 541 & 526 & 518 & 484 & 433 & 482 & 537 & 516 & 624 & 425 & 461 & 503 \\
\hline
\end{tabular}


Tabela 1 - Concentração de $\mathrm{CO}_{2}$, em ppm, no Piso 1 no ano de 2010 (Continuação).

\begin{tabular}{|c|c|c|c|c|c|c|c|c|c|c|c|c|}
\hline $12 / 5 / 10$ & $18 / 5 / 10$ & $31 / 5 / 10$ & $10 / 6 / 10$ & $29 / 6 / 10$ & $8 / 7 / 10$ & $13 / 7 / 10$ & $21 / 7 / 10$ & $3 / 8 / 10$ & $9 / 8 / 10$ & $24 / 8 / 10$ & $30 / 8 / 10$ & $15 / 9 / 10$ \\
\hline 383 & 538 & 492 & 537 & 496 & 443 & 490 & 526 & 529 & 623 & 434 & 463 & 507 \\
\hline 385 & 519 & 504 & 542 & 483 & 436 & 486 & 527 & 533 & 618 & 434 & 462 & 507 \\
\hline 375 & 539 & 519 & 524 & 487 & 427 & 476 & 527 & 529 & 655 & 432 & 444 & 516 \\
\hline 390 & 517 & 521 & 525 & 489 & 426 & 480 & 519 & 534 & 666 & 418 & 458 & 503 \\
\hline 389 & 551 & 512 & 523 & 476 & 421 & 481 & 524 & 525 & 652 & 443 & 453 & 498 \\
\hline 396 & 544 & 504 & 492 & 479 & 433 & 488 & 537 & 543 & 642 & 436 & 452 & 511 \\
\hline 398 & 524 & 517 & 510 & 485 & 432 & 485 & 531 & 525 & 672 & 445 & 467 & 504 \\
\hline 386 & 550 & 523 & 506 & 481 & 429 & 472 & 538 & 518 & 625 & 437 & 464 & 498 \\
\hline 399 & 579 & 491 & 490 & 478 & 428 & 483 & 545 & 513 & 606 & 438 & 448 & 491 \\
\hline 394 & 545 & 496 & 501 & 485 & 440 & 488 & 539 & 520 & 621 & 444 & 450 & 501 \\
\hline 372 & 558 & 494 & 510 & 486 & 458 & 484 & 548 & 525 & 606 & 451 & 456 & 504 \\
\hline 381 & 566 & 489 & 501 & 469 & 443 & 486 & 538 & 536 & 619 & 435 & 447 & 503 \\
\hline 385 & 547 & 485 & 507 & 490 & 446 & 491 & 546 & 530 & 639 & 440 & 463 & 501 \\
\hline 379 & 573 & 493 & 498 & 490 & 453 & 492 & 546 & 504 & 633 & 437 & 456 & 503 \\
\hline 383 & 547 & 502 & 497 & 480 & 469 & 481 & 552 & 519 & 646 & 442 & 454 & 499 \\
\hline 382 & 566 & 496 & 505 & 471 & 462 & 489 & 558 & 518 & 655 & 437 & 456 & 501 \\
\hline 378 & 550 & 504 & 480 & 479 & 455 & 496 & 551 & 515 & 649 & 447 & 462 & 527 \\
\hline 381 & 553 & 490 & 487 & 473 & 447 & 495 & 542 & 520 & 639 & 454 & 457 & 534 \\
\hline 370 & 554 & 499 & 510 & 484 & 458 & 499 & 539 & 521 & 639 & 442 & 462 & 509 \\
\hline 371 & 577 & 494 & 510 & 466 & 461 & 500 & 547 & 524 & 635 & 454 & 454 & 520 \\
\hline 375 & 569 & 509 & 503 & 459 & 465 & 502 & 544 & 521 & 620 & 451 & 458 & 500 \\
\hline 389 & 585 & 505 & 497 & 474 & 471 & 508 & 550 & 531 & 647 & 445 & 448 & 490 \\
\hline 386 & 586 & 496 & 496 & 461 & 481 & 525 & 546 & 517 & 636 & 454 & 461 & 497 \\
\hline 385 & 582 & 496 & 500 & 462 & 466 & 506 & 541 & 508 & 640 & 452 & 451 & 506 \\
\hline 393 & 561 & 493 & 489 & 468 & 481 & 512 & 558 & 513 & 642 & 449 & 465 & 523 \\
\hline 394 & 549 & 507 & 487 & 467 & 480 & 504 & 547 & 511 & 639 & 444 & 460 & 532 \\
\hline 398 & 562 & 513 & 499 & 461 & 467 & 513 & 549 & 508 & 629 & 452 & 467 & 519 \\
\hline 374 & 555 & 510 & 495 & 450 & 460 & 507 & 555 & 529 & 626 & 445 & 446 & 518 \\
\hline 376 & 555 & 519 & 503 & 448 & 451 & 521 & 544 & 533 & 598 & 444 & 448 & 509 \\
\hline 379 & 566 & 503 & 502 & 459 & 464 & 526 & 545 & 528 & 598 & 437 & 472 & 500 \\
\hline 359 & 526 & 499 & 494 & 457 & 444 & 534 & 538 & 512 & 606 & 439 & 457 & 505 \\
\hline 372 & 555 & 493 & 477 & 453 & 450 & 526 & 544 & 509 & 600 & 444 & 458 & 497 \\
\hline 367 & 538 & 500 & 499 & 450 & 454 & 513 & 553 & 510 & 576 & 446 & 458 & 490 \\
\hline 384 & 543 & 485 & 495 & 445 & 453 & 515 & 560 & 511 & 587 & 477 & 472 & 492 \\
\hline 408 & 548 & 485 & 486 & 448 & 452 & 508 & 549 & 511 & 594 & 447 & 450 & 490 \\
\hline 396 & 567 & 495 & 495 & 442 & 449 & 505 & 542 & 519 & 556 & 449 & 461 & 508 \\
\hline 366 & 572 & 499 & 504 & 448 & 480 & 506 & 549 & 515 & 541 & 445 & 458 & 504 \\
\hline 388 & 556 & 505 & 502 & 461 & 459 & 508 & 535 & 516 & 544 & 460 & 462 & 499 \\
\hline 386 & 562 & 498 & 509 & 453 & 459 & 497 & 545 & 517 & 566 & 466 & 457 & 505 \\
\hline 386 & 543 & 503 & 520 & 464 & 458 & 496 & 536 & 513 & 559 & 457 & 451 & 493 \\
\hline 392 & 522 & 501 & 504 & 448 & 471 & 500 & 548 & 511 & 544 & 451 & 463 & 490 \\
\hline 385 & 516 & 495 & 496 & 449 & 474 & 501 & 552 & 517 & 545 & 448 & 475 & 496 \\
\hline 387 & 526 & 499 & 493 & 448 & 499 & 515 & 551 & 523 & 564 & 459 & 471 & 494 \\
\hline 391 & 527 & 514 & 497 & 455 & 491 & 515 & 568 & 531 & 560 & 441 & 463 & 491 \\
\hline 369 & 523 & 499 & 495 & 473 & 474 & 522 & 546 & 530 & 547 & 446 & 476 & 495 \\
\hline 377 & 517 & 502 & 497 & 489 & 453 & 532 & 550 & 526 & 556 & 436 & 467 & 494 \\
\hline 390 & 517 & 509 & 516 & 466 & 458 & 524 & 538 & 535 & 555 & 452 & 462 & 495 \\
\hline 401 & 500 & 495 & 498 & 461 & 465 & 526 & 543 & 560 & 543 & 450 & 455 & 502 \\
\hline 398 & 509 & 488 & 507 & 485 & 470 & 517 & 537 & 551 & 550 & 442 & 455 & 485 \\
\hline 363 & 499 & 475 & 507 & 450 & 468 & 524 & 541 & 552 & 550 & 446 & 457 & 494 \\
\hline 381 & 512 & 470 & 477 & 468 & 468 & 509 & 546 & 581 & 545 & 434 & 470 & 488 \\
\hline 361 & 512 & 472 & 514 & 461 & 462 & 521 & 530 & 569 & 547 & 441 & 465 & 488 \\
\hline 377 & 528 & 474 & 495 & 472 & 455 & 530 & 531 & 617 & 516 & 432 & 459 & 494 \\
\hline 372 & 528 & 493 & 505 & 482 & 455 & 510 & 529 & 583 & 534 & 423 & 467 & 482 \\
\hline 380 & 524 & 489 & 510 & 482 & 449 & 541 & 526 & 585 & 540 & 436 & 464 & 498 \\
\hline 383 & 536 & 478 & 498 & 454 & 450 & 540 & 535 & 562 & 539 & 433 & 467 & 497 \\
\hline 371 & 536 & 485 & 505 & 463 & 450 & 513 & 522 & 580 & 544 & 442 & 461 & 530 \\
\hline 374 & 552 & 476 & 494 & 481 & 468 & 533 & 534 & 553 & 528 & 438 & 476 & 500 \\
\hline 369 & 553 & 477 & 502 & 479 & 449 & 537 & 523 & 556 & 502 & 450 & 471 & 503 \\
\hline 365 & 551 & 491 & 505 & 486 & 448 & 529 & 528 & 545 & 472 & 438 & 466 & 494 \\
\hline 361 & 559 & 494 & 502 & 487 & 446 & 540 & 526 & 556 & 483 & 437 & 470 & 468 \\
\hline 367 & 571 & 499 & 497 & 481 & 454 & 528 & 530 & 561 & 465 & 434 & 459 & 489 \\
\hline 353 & 568 & 494 & 509 & 478 & 440 & 501 & 545 & 562 & 472 & 444 & 457 & 493 \\
\hline 361 & 563 & 495 & 515 & 490 & 439 & 520 & 527 & 550 & 476 & 438 & 449 & 476 \\
\hline 366 & 555 & 496 & 506 & 471 & 433 & 523 & 523 & 555 & 465 & 444 & 447 & 477 \\
\hline 363 & 542 & 492 & 526 & 485 & 443 & 507 & 532 & 552 & 473 & 442 & 452 & 483 \\
\hline 359 & 540 & 480 & 517 & 519 & 438 & 502 & 543 & 557 & 466 & 448 & 463 & 476 \\
\hline 364 & 520 & 486 & 525 & 487 & 436 & 516 & 537 & 565 & 465 & 440 & 457 & 468 \\
\hline 368 & 509 & 467 & 502 & 468 & 440 & 501 & 540 & 564 & 462 & 436 & 449 & 472 \\
\hline 381 & 498 & 468 & 505 & 486 & 430 & 515 & 544 & 557 & 474 & 434 & 456 & 475 \\
\hline 382 & 498 & 485 & 506 & 484 & 428 & 512 & 531 & 558 & 473 & 433 & 449 & 475 \\
\hline 376 & 487 & 476 & 513 & 473 & 436 & 522 & 547 & 553 & 446 & 421 & 452 & 474 \\
\hline 374 & 474 & 482 & 513 & 460 & 437 & 530 & 543 & 571 & 447 & 435 & 454 & 486 \\
\hline 361 & 486 & 485 & 513 & 467 & 436 & 523 & 544 & 563 & 446 & 423 & 454 & 475 \\
\hline 371 & 493 & 484 & 533 & 474 & 439 & 528 & 540 & 563 & 448 & 428 & 458 & 486 \\
\hline 362 & 489 & 469 & 494 & 484 & 443 & 528 & 538 & 540 & 459 & 423 & 458 & 488 \\
\hline 385 & 489 & 479 & 499 & 459 & 435 & 516 & 534 & 546 & 450 & 438 & 450 & 495 \\
\hline
\end{tabular}


Tabela 1 - Concentração de $\mathrm{CO}_{2}$, em ppm, no Piso 1 no ano de 2010 (Continuação).

\begin{tabular}{|c|c|c|c|c|c|c|c|c|c|c|c|c|}
\hline $12 / 5 / 10$ & $18 / 5 / 10$ & $31 / 5 / 10$ & $10 / 6 / 10$ & $29 / 6 / 10$ & $8 / 7 / 10$ & $13 / 7 / 10$ & $21 / 7 / 10$ & $3 / 8 / 10$ & $9 / 8 / 10$ & $24 / 8 / 10$ & $30 / 8 / 10$ & $15 / 9 / 10$ \\
\hline 370 & 486 & 484 & 496 & 475 & 425 & 521 & 524 & 529 & 434 & 433 & 468 & 498 \\
\hline 382 & 504 & 484 & 498 & 467 & 434 & 507 & 538 & 546 & 437 & 429 & 470 & 482 \\
\hline 380 & 511 & 498 & 522 & 481 & 434 & 522 & 528 & 533 & 421 & 443 & 456 & 488 \\
\hline 390 & 511 & 493 & 529 & 479 & 443 & 533 & 528 & 525 & 435 & 438 & 457 & 485 \\
\hline 381 & 509 & 481 & 511 & 484 & 459 & 517 & 532 & 523 & 448 & 433 & 465 & 490 \\
\hline 367 & 511 & 480 & 492 & 479 & 448 & 526 & 540 & 529 & 455 & 440 & 461 & 494 \\
\hline 362 & 514 & 467 & 514 & 482 & 455 & 535 & 537 & 527 & 458 & 431 & 463 & 495 \\
\hline 368 & 501 & 475 & 486 & 479 & 464 & 530 & 549 & 527 & 463 & 436 & 464 & 489 \\
\hline 360 & 504 & 480 & 519 & 484 & 482 & 522 & 534 & 518 & 458 & 442 & 450 & 495 \\
\hline 370 & 505 & 476 & 506 & 486 & 475 & 523 & 529 & 529 & 448 & 443 & 461 & 485 \\
\hline 375 & 513 & 467 & 507 & 479 & 470 & 533 & 531 & 510 & 453 & 453 & 461 & 494 \\
\hline 358 & 504 & 494 & 483 & 479 & 474 & 536 & 533 & 531 & 454 & 445 & 481 & 485 \\
\hline 383 & 505 & 510 & 493 & 469 & 470 & 529 & 537 & 520 & 450 & 446 & 462 & 478 \\
\hline 375 & 506 & 497 & 503 & 470 & 473 & 529 & 538 & 518 & 444 & 448 & 465 & 485 \\
\hline 372 & 504 & 480 & 516 & 466 & 466 & 540 & 541 & 512 & 444 & 446 & 476 & 496 \\
\hline 370 & 504 & 485 & 473 & 477 & 464 & 531 & 538 & 512 & 448 & 439 & 474 & 484 \\
\hline 380 & 489 & 469 & 471 & 469 & 473 & 549 & 542 & 504 & 443 & 444 & 467 & 485 \\
\hline 366 & 478 & 489 & 480 & 468 & 476 & 541 & 541 & 504 & 458 & 450 & 477 & 504 \\
\hline 355 & 468 & 493 & 473 & 480 & 476 & 546 & 550 & 517 & 453 & 439 & 467 & 495 \\
\hline 362 & 472 & 494 & 499 & 480 & 454 & 538 & 558 & 508 & 443 & 448 & 477 & 480 \\
\hline 373 & 480 & 495 & 496 & 476 & 444 & 525 & 558 & 524 & 435 & 445 & 472 & 475 \\
\hline 376 & 489 & 487 & 471 & 478 & 452 & 534 & 546 & 504 & 439 & 441 & 469 & 496 \\
\hline 363 & 498 & 475 & 468 & 470 & 444 & 543 & 533 & 501 & 438 & 447 & 465 & 507 \\
\hline 365 & 492 & 492 & 469 & 474 & 446 & 540 & 542 & 517 & 452 & 451 & 462 & 499 \\
\hline 355 & 486 & 484 & 478 & 482 & 440 & 543 & 531 & 533 & 447 & 461 & 470 & 507 \\
\hline 346 & 480 & 483 & 469 & 480 & 444 & 547 & 543 & 523 & 430 & 456 & 466 & 497 \\
\hline 364 & 487 & 507 & 491 & 467 & 441 & 524 & 540 & 517 & 448 & 451 & 457 & 501 \\
\hline 346 & 471 & 499 & 485 & 477 & 440 & 522 & 545 & 523 & 454 & 446 & 463 & 507 \\
\hline 341 & 480 & 486 & 478 & 461 & 446 & 522 & 546 & 523 & 448 & 440 & 459 & 506 \\
\hline 360 & 481 & 500 & 488 & 475 & 437 & 542 & 544 & 536 & 447 & 443 & 470 & 517 \\
\hline 377 & 476 & 487 & 477 & 473 & 440 & 529 & 538 & 530 & 442 & 441 & 469 & 508 \\
\hline 383 & 474 & 490 & 477 & 466 & 452 & 544 & 544 & 522 & 451 & 443 & 464 & 499 \\
\hline 383 & 515 & 499 & 477 & 465 & 448 & 517 & 529 & 519 & 448 & 444 & 472 & 500 \\
\hline 372 & 506 & 502 & 463 & 468 & 441 & 530 & 520 & 525 & 455 & 443 & 460 & 497 \\
\hline 367 & 504 & 501 & 457 & 464 & 447 & 535 & 534 & 518 & 443 & 441 & 461 & 486 \\
\hline 361 & 508 & 507 & 469 & 510 & 464 & 550 & 531 & 525 & 447 & 451 & 462 & 487 \\
\hline 361 & 494 & 504 & 466 & 464 & 477 & 538 & 533 & 517 & 443 & 444 & 457 & 494 \\
\hline 360 & 501 & 513 & 476 & 480 & 497 & 531 & 526 & 523 & 467 & 441 & 458 & 498 \\
\hline 372 & 477 & 501 & 463 & 463 & 488 & 537 & 542 & 524 & 439 & 446 & 457 & 480 \\
\hline 373 & 481 & 494 & 470 & 455 & 475 & 539 & 540 & 517 & 483 & 448 & 451 & 477 \\
\hline 360 & 457 & 496 & 472 & 456 & 484 & 536 & 533 & 521 & 472 & 445 & 456 & 487 \\
\hline 360 & 476 & 501 & 458 & 453 & 480 & 524 & 538 & 513 & 462 & 451 & 470 & 496 \\
\hline 344 & 467 & 489 & 474 & 455 & 482 & 533 & 540 & 514 & 452 & 461 & 464 & 494 \\
\hline 355 & 488 & 500 & 463 & 459 & 485 & 540 & 539 & 518 & 449 & 459 & 469 & 477 \\
\hline 350 & 495 & 497 & 458 & 457 & 464 & 538 & 536 & 505 & 457 & 476 & 469 & 480 \\
\hline 356 & 502 & 478 & 463 & 463 & 465 & 538 & 546 & 525 & 447 & 473 & 470 & 487 \\
\hline 354 & 493 & 491 & 483 & 474 & 463 & 541 & 544 & 519 & 480 & 482 & 470 & 490 \\
\hline 372 & $\begin{array}{l}509 \\
\end{array}$ & 506 & 482 & 447 & 463 & 552 & 538 & 507 & 471 & 472 & 462 & 477 \\
\hline 419 & 482 & 502 & 468 & 455 & 482 & 544 & 536 & 512 & 468 & 489 & 467 & 483 \\
\hline 384 & 509 & 508 & 488 & 460 & 486 & 535 & 534 & 510 & 462 & 480 & 475 & 494 \\
\hline 371 & 497 & 494 & 483 & 440 & 483 & 538 & 538 & 513 & 454 & 486 & 481 & 482 \\
\hline 373 & 496 & 503 & 484 & 444 & 479 & 542 & 564 & 532 & 452 & 474 & 474 & 481 \\
\hline 378 & 485 & 483 & 467 & 450 & 471 & 538 & 555 & 503 & 452 & 479 & 469 & 501 \\
\hline 382 & 488 & 521 & 462 & 444 & 468 & 537 & 541 & 505 & 475 & 466 & 475 & 489 \\
\hline 374 & 483 & 510 & 469 & 453 & 472 & 533 & 537 & 503 & 461 & 473 & 461 & 494 \\
\hline 397 & 501 & 500 & 455 & 456 & 495 & 538 & 544 & 505 & 456 & 475 & 468 & 481 \\
\hline 384 & 517 & 505 & 461 & 442 & 482 & 530 & 532 & 508 & 469 & 455 & 456 & 484 \\
\hline 393 & 509 & 525 & 465 & 451 & 486 & 527 & 540 & 528 & 472 & 458 & 460 & 468 \\
\hline 381 & 516 & 515 & 482 & 447 & 483 & 526 & 548 & 509 & 478 & 464 & 458 & 474 \\
\hline 366 & 495 & 514 & 486 & 446 & 506 & 533 & 550 & 500 & 473 & 472 & 463 & 477 \\
\hline 365 & $\begin{array}{l}499 \\
\end{array}$ & 505 & 479 & 448 & 478 & 536 & 547 & 503 & 468 & 459 & 452 & 494 \\
\hline 367 & 501 & 509 & 480 & 443 & 489 & 529 & 546 & 520 & 471 & 467 & 453 & 474 \\
\hline 371 & 500 & 501 & 478 & 461 & 503 & 535 & 540 & 501 & 447 & 457 & 459 & 482 \\
\hline 380 & 505 & 499 & 491 & 444 & 514 & 534 & 540 & 502 & 446 & 472 & 453 & 481 \\
\hline 374 & 482 & 500 & 499 & 456 & 489 & 527 & 540 & 505 & 456 & 466 & 470 & 476 \\
\hline 382 & 490 & 495 & 485 & 449 & 487 & 522 & 544 & 498 & 466 & 465 & 446 & 477 \\
\hline 366 & 506 & 534 & 485 & 443 & 481 & 529 & 542 & 517 & 451 & 478 & 450 & 486 \\
\hline 368 & 506 & 506 & 474 & 442 & 512 & 540 & 544 & 517 & 464 & 480 & 447 & 495 \\
\hline 371 & 503 & 509 & 481 & 459 & $\begin{array}{l}508 \\
08\end{array}$ & 511 & 549 & 524 & 457 & 473 & 456 & 494 \\
\hline 378 & 510 & 510 & 475 & 457 & 483 & 532 & 548 & 515 & 456 & 476 & 447 & 500 \\
\hline 380 & 512 & 508 & 479 & 452 & 500 & 560 & 542 & 525 & 461 & 472 & 450 & 493 \\
\hline 392 & 508 & 513 & 476 & 465 & 479 & 546 & 535 & 521 & 469 & 445 & 442 & 494 \\
\hline 374 & 481 & 499 & 465 & 459 & 483 & 527 & 535 & 526 & 468 & 464 & 446 & 489 \\
\hline 394 & 475 & 510 & 475 & 458 & 483 & 536 & 533 & 518 & 477 & 464 & 449 & 483 \\
\hline 398 & 484 & 501 & 477 & 468 & 476 & 523 & 533 & 522 & 459 & 455 & 456 & 486 \\
\hline 387 & 508 & $\mathrm{X}$ & 478 & 453 & 482 & 537 & 543 & 523 & 446 & 456 & 444 & 482 \\
\hline 386 & 508 & $X$ & 464 & 454 & 484 & 547 & 539 & 511 & 459 & 455 & 439 & 474 \\
\hline
\end{tabular}


Tabela 1 - Concentração de $\mathrm{CO}_{2}$, em ppm, no Piso 1 no ano de 2010 (Continuação).

\begin{tabular}{|c|c|c|c|c|c|c|c|c|c|c|c|c|}
\hline $12 / 5 / 10$ & $18 / 5 / 10$ & $31 / 5 / 10$ & $10 / 6 / 10$ & $29 / 6 / 10$ & $8 / 7 / 10$ & $13 / 7 / 10$ & $21 / 7 / 10$ & $3 / 8 / 10$ & $9 / 8 / 10$ & $24 / 8 / 10$ & $30 / 8 / 10$ & $15 / 9 / 10$ \\
\hline 396 & 501 & $\mathrm{X}$ & 477 & 434 & 481 & 552 & 541 & 511 & 443 & 458 & 444 & 495 \\
\hline 379 & 496 & $\mathrm{X}$ & 480 & 455 & 473 & 550 & 548 & 508 & 456 & 447 & 452 & 495 \\
\hline 372 & 505 & $\mathrm{X}$ & 489 & 451 & 452 & 554 & 538 & 516 & 450 & 449 & 446 & 486 \\
\hline 387 & 507 & $\mathrm{X}$ & 504 & 449 & 450 & 562 & 543 & 503 & 466 & 452 & 452 & 490 \\
\hline 369 & $\mathrm{X}$ & $\mathrm{X}$ & 510 & 455 & 460 & 541 & 548 & 504 & 462 & 447 & 448 & 501 \\
\hline 384 & $\mathrm{X}$ & $\mathrm{X}$ & 492 & 465 & 450 & 541 & 557 & 522 & 467 & 454 & 458 & 492 \\
\hline 384 & $\mathrm{X}$ & $\mathrm{X}$ & 495 & 461 & 463 & $\mathrm{X}$ & 553 & 509 & 457 & 451 & 463 & $\mathrm{X}$ \\
\hline 402 & $\mathrm{X}$ & $\mathrm{X}$ & 510 & 460 & 470 & $\mathrm{X}$ & 557 & 508 & 470 & 458 & 459 & $\mathrm{X}$ \\
\hline 400 & $\mathrm{X}$ & $\mathrm{X}$ & $\mathrm{X}$ & 462 & 471 & $\mathrm{X}$ & $\mathrm{X}$ & 519 & 447 & 478 & 469 & $\mathrm{X}$ \\
\hline $\mathrm{X}$ & $\mathrm{X}$ & $\mathrm{X}$ & $\mathrm{X}$ & $\mathrm{X}$ & 472 & $\mathrm{X}$ & $\mathrm{X}$ & 501 & 438 & 472 & $\mathrm{X}$ & $\mathrm{X}$ \\
\hline $\mathrm{X}$ & $\mathrm{X}$ & $\mathrm{X}$ & $\mathrm{X}$ & $\mathrm{X}$ & $\mathrm{X}$ & $\mathrm{X}$ & $\mathrm{X}$ & 499 & 446 & 470 & $\mathrm{X}$ & $\mathrm{X}$ \\
\hline $\mathrm{X}$ & $\mathrm{X}$ & $\mathrm{X}$ & $\mathrm{X}$ & $\mathrm{X}$ & $\mathrm{X}$ & $\mathrm{X}$ & $\mathrm{X}$ & 517 & 453 & 465 & $\mathrm{X}$ & $\mathrm{X}$ \\
\hline $\mathrm{X}$ & $\mathrm{X}$ & $\mathrm{X}$ & $\mathrm{X}$ & $\mathrm{X}$ & $\mathrm{X}$ & $\mathrm{X}$ & $\mathrm{X}$ & 521 & $\mathrm{X}$ & 476 & $\mathrm{X}$ & $\mathrm{X}$ \\
\hline $\mathrm{X}$ & $\mathrm{X}$ & $\mathrm{X}$ & $\mathrm{X}$ & $\mathrm{X}$ & $\mathrm{X}$ & $\mathrm{X}$ & $\mathrm{X}$ & 514 & $\mathrm{X}$ & $\mathrm{X}$ & $\mathrm{X}$ & $\mathrm{X}$ \\
\hline $\mathrm{X}$ & $\mathrm{X}$ & $\mathrm{X}$ & $\mathrm{X}$ & $\mathrm{X}$ & $\mathrm{X}$ & $\mathrm{X}$ & $\mathrm{X}$ & 525 & $\mathrm{X}$ & $\mathrm{X}$ & $\mathrm{X}$ & $\mathrm{X}$ \\
\hline
\end{tabular}


Tabela 2 - Concentração de $\mathrm{CO}_{2}$, em ppm, no Piso 2 no ano de 2010.

\begin{tabular}{|c|c|c|c|c|c|c|c|c|c|c|c|c|}
\hline $5 / 5 / 10$ & $13 / 5 / 10$ & $21 / 5 / 10$ & $1 / 6 / 10$ & $9 / 6 / 10$ & $14 / 6 / 10$ & $24 / 6 / 10$ & $15 / 7 / 10$ & $22 / 7 / 10$ & $6 / 8 / 10$ & $11 / 8 / 10$ & $20 / 8 / 10$ & $27 / 8 / 10$ \\
\hline 585 & 441 & 496 & 443 & 457 & 603 & 514 & 536 & 491 & 510 & 538 & 449 & 447 \\
\hline 526 & 404 & 481 & 441 & 460 & 479 & 506 & 521 & 489 & 534 & 528 & 461 & 480 \\
\hline 526 & 401 & 474 & 441 & 450 & 486 & 494 & 535 & 501 & 561 & 554 & 447 & 667 \\
\hline 525 & 410 & 468 & 450 & 467 & 484 & 484 & 533 & 524 & 738 & 563 & 443 & 469 \\
\hline 608 & 387 & 462 & 445 & 450 & 457 & 497 & 543 & 532 & 602 & 561 & 453 & 473 \\
\hline 555 & 394 & 462 & 439 & 455 & 459 & 483 & 531 & 526 & 589 & 565 & 430 & 458 \\
\hline 537 & 417 & 467 & 444 & 444 & 453 & 486 & 529 & 547 & 597 & 568 & 440 & 457 \\
\hline 545 & 398 & 470 & 418 & 462 & 466 & 484 & 535 & 536 & 564 & 539 & 440 & 453 \\
\hline 525 & 399 & 462 & 415 & 450 & 468 & 490 & 541 & 522 & 549 & 549 & 435 & 442 \\
\hline 527 & 392 & 450 & 433 & 456 & 477 & 502 & 537 & 531 & 546 & 563 & 447 & 438 \\
\hline 531 & 380 & 461 & 432 & 444 & 469 & 499 & 566 & 520 & 557 & 580 & 437 & 452 \\
\hline 525 & 380 & 464 & 434 & 438 & 466 & 486 & 539 & 542 & 601 & 581 & 430 & 440 \\
\hline 553 & 376 & 463 & 444 & 447 & 468 & 495 & 526 & 540 & 609 & 563 & 412 & 450 \\
\hline 545 & 378 & 458 & 448 & 445 & 477 & 495 & 534 & 535 & 601 & 554 & 416 & 459 \\
\hline 553 & 371 & 455 & 449 & 449 & 477 & 487 & 527 & 549 & 595 & 547 & 410 & 464 \\
\hline 546 & 393 & 477 & 458 & 453 & 469 & 495 & 527 & 545 & 605 & 536 & 425 & 450 \\
\hline 526 & 375 & 469 & 435 & 448 & 462 & 498 & 533 & 505 & 584 & 539 & 433 & 463 \\
\hline 512 & 378 & 460 & 432 & 447 & 445 & 502 & 519 & 513 & 557 & 538 & 430 & 441 \\
\hline 510 & 385 & 448 & 442 & 442 & 442 & 507 & 518 & 559 & 558 & 522 & 435 & 439 \\
\hline 516 & 372 & 461 & 450 & 446 & 439 & 517 & 524 & 533 & 545 & 508 & 418 & 437 \\
\hline 519 & 373 & 471 & 444 & 445 & 437 & 510 & 518 & 548 & 523 & 549 & 404 & 434 \\
\hline 529 & 366 & 475 & 434 & 432 & 456 & 503 & 535 & 544 & 541 & 566 & 407 & 425 \\
\hline 534 & 363 & 451 & 442 & 444 & 451 & 521 & 535 & 544 & 547 & 578 & 403 & 431 \\
\hline 526 & 355 & 455 & 433 & 440 & 454 & 542 & 527 & 526 & 532 & 539 & 408 & 427 \\
\hline 534 & 366 & 441 & 444 & 440 & 465 & 533 & 536 & 502 & 559 & 538 & 412 & 431 \\
\hline 547 & 365 & 436 & 442 & 455 & 476 & 531 & 545 & 511 & 538 & 544 & 429 & 430 \\
\hline 629 & 369 & 439 & 438 & 446 & 459 & 528 & 528 & 537 & 516 & 525 & 442 & 424 \\
\hline 548 & 370 & 434 & 444 & 440 & 459 & 534 & 522 & 506 & 505 & 536 & 440 & 442 \\
\hline 553 & 370 & 428 & 455 & 440 & 468 & 543 & 529 & 503 & 521 & 515 & 413 & 444 \\
\hline 547 & 360 & 447 & 450 & 427 & 455 & 528 & 536 & 510 & 509 & 523 & 417 & 446 \\
\hline 548 & 407 & 450 & 430 & 429 & 455 & 536 & 514 & 514 & 511 & 541 & 433 & 434 \\
\hline 554 & 402 & 462 & 449 & 435 & 459 & 548 & 516 & 529 & 511 & 556 & 448 & 445 \\
\hline 546 & 390 & 451 & 429 & 433 & 447 & 565 & 527 & 538 & 495 & 556 & 444 & 437 \\
\hline 545 & 412 & 448 & 432 & 442 & 450 & 586 & 529 & 547 & 527 & 514 & 447 & 428 \\
\hline 539 & 432 & 448 & 433 & 438 & 449 & 565 & 521 & 519 & 517 & 511 & 430 & 443 \\
\hline 573 & 432 & 445 & 425 & 438 & 478 & 566 & 523 & 519 & 529 & 517 & 419 & 444 \\
\hline 547 & 424 & 438 & 445 & 434 & 453 & 574 & 525 & 527 & 519 & 509 & 441 & 437 \\
\hline 534 & 414 & 449 & 444 & 446 & 444 & 558 & 516 & 518 & 536 & 535 & 435 & 440 \\
\hline 555 & 431 & 454 & 420 & 446 & 454 & 547 & 520 & 500 & 517 & 524 & 436 & 443 \\
\hline 563 & 407 & 472 & 443 & 440 & 472 & 589 & 515 & 526 & 524 & 535 & 436 & 438 \\
\hline 555 & 403 & 480 & 436 & 443 & 457 & 592 & 562 & 541 & 540 & 530 & 421 & 442 \\
\hline 547 & 392 & 463 & 439 & 441 & 438 & 583 & 547 & 540 & 517 & 523 & 414 & 446 \\
\hline 547 & 374 & 447 & 442 & 470 & 438 & 607 & 542 & 538 & 504 & 520 & 435 & 457 \\
\hline 550 & 378 & 453 & 452 & 477 & 433 & 569 & 525 & 524 & 519 & 529 & 405 & 448 \\
\hline 544 & 384 & 459 & 468 & 491 & 428 & 575 & 517 & 532 & 513 & 537 & 432 & 451 \\
\hline 569 & 371 & 451 & 446 & 476 & 431 & 594 & 523 & 546 & 524 & 513 & 434 & 462 \\
\hline 562 & 373 & 439 & 448 & 479 & 431 & 586 & 540 & 550 & 528 & 517 & 421 & 457 \\
\hline $\begin{array}{l}587 \\
8\end{array}$ & 367 & 451 & 452 & 493 & 441 & 589 & 531 & 548 & $\begin{array}{l}499 \\
\end{array}$ & 509 & 438 & 467 \\
\hline 554 & 357 & 436 & 458 & 484 & 426 & 548 & 530 & 574 & 510 & 491 & 447 & 446 \\
\hline 552 & 373 & 428 & 460 & 471 & 449 & 579 & 520 & 570 & 494 & 505 & 444 & 450 \\
\hline 584 & 369 & 446 & 448 & 493 & 437 & 581 & 532 & 549 & 502 & 516 & 441 & 448 \\
\hline 560 & 362 & 449 & 446 & 479 & 433 & 576 & 537 & 539 & 505 & 528 & 447 & 448 \\
\hline 563 & 356 & 431 & 453 & 466 & 428 & 590 & 532 & 520 & 498 & 509 & 421 & 441 \\
\hline 566 & 372 & 438 & 473 & 480 & 441 & 578 & 546 & 545 & 520 & 512 & 416 & 452 \\
\hline 556 & 380 & 448 & 444 & 486 & 436 & 570 & 549 & 532 & 516 & 513 & 436 & 464 \\
\hline 530 & 369 & 451 & 470 & 479 & 423 & 592 & 519 & 544 & 520 & 519 & 490 & 440 \\
\hline 524 & 370 & 447 & 472 & 464 & 415 & 581 & 511 & 542 & 505 & 519 & 473 & 435 \\
\hline 527 & 381 & 443 & 484 & 465 & 422 & 597 & 531 & 548 & 526 & 530 & 440 & 443 \\
\hline 531 & 381 & 434 & 471 & 473 & 433 & 600 & 516 & 580 & 520 & 527 & 414 & 426 \\
\hline 534 & 366 & 436 & 476 & 456 & 444 & 598 & 538 & 574 & 536 & 516 & 408 & 445 \\
\hline 521 & 373 & 433 & 490 & 462 & 429 & 590 & 539 & 558 & 531 & 527 & 427 & 440 \\
\hline 518 & 365 & 418 & 481 & 458 & 443 & 571 & 544 & 553 & 520 & 532 & 437 & 452 \\
\hline 530 & 378 & 436 & 507 & 479 & 434 & 588 & 549 & 543 & 511 & 546 & 435 & 461 \\
\hline 511 & 379 & 431 & 500 & 489 & 437 & 597 & 550 & 545 & 533 & 559 & 442 & 455 \\
\hline 528 & 370 & 429 & 481 & 481 & 435 & 594 & 543 & 536 & 533 & 561 & 439 & 449 \\
\hline 543 & 375 & 434 & 483 & 482 & 442 & 610 & 542 & 541 & 538 & 581 & 464 & 462 \\
\hline 542 & 380 & 428 & 492 & 464 & 441 & 590 & 537 & 541 & 521 & 584 & 432 & 457 \\
\hline 533 & 385 & 447 & 489 & 462 & 441 & 625 & 538 & 534 & 519 & 563 & 445 & 460 \\
\hline 526 & 390 & 437 & 492 & 453 & 425 & 563 & 544 & 541 & 528 & $\begin{array}{l}547 \\
\end{array}$ & 459 & 464 \\
\hline 528 & 391 & 452 & 483 & 469 & 425 & 564 & 542 & 533 & 539 & 548 & 441 & 442 \\
\hline 544 & 392 & 437 & 477 & 475 & 453 & 577 & 533 & 529 & 539 & 566 & 446 & 438 \\
\hline 552 & 388 & 455 & 483 & 461 & 442 & 549 & 530 & 540 & 519 & 569 & 432 & 454 \\
\hline 534 & 397 & 464 & 475 & 471 & 450 & 574 & 518 & 526 & 537 & 557 & 455 & 446 \\
\hline 537 & 396 & 452 & 468 & 461 & 438 & 607 & 517 & 531 & $\begin{array}{l}563 \\
\end{array}$ & 533 & 451 & $\begin{array}{l}438 \\
\end{array}$ \\
\hline 543 & 402 & 447 & 456 & 510 & 444 & 591 & 533 & 538 & 538 & 535 & 475 & 441 \\
\hline 547 & 385 & 454 & 452 & 476 & 432 & 562 & 504 & 533 & 540 & 539 & 490 & 446 \\
\hline 547 & 389 & 452 & 448 & 500 & 440 & 620 & 532 & 542 & 528 & 534 & 460 & 445 \\
\hline
\end{tabular}


Tabela 2 - Concentração de $\mathrm{CO}_{2}$, em ppm, no Piso 2 no ano de 2010 (Continuação).

\begin{tabular}{|c|c|c|c|c|c|c|c|c|c|c|c|c|}
\hline $5 / 5 / 10$ & $13 / 5 / 10$ & $21 / 5 / 10$ & $1 / 6 / 10$ & $9 / 6 / 10$ & $14 / 6 / 10$ & $24 / 6 / 10$ & $15 / 7 / 10$ & $22 / 7 / 10$ & $6 / 8 / 10$ & $11 / 8 / 10$ & $20 / 8 / 10$ & $27 / 8 / 10$ \\
\hline 555 & 399 & 467 & 447 & 495 & 458 & 634 & 543 & 572 & 520 & 537 & 463 & 450 \\
\hline 550 & 424 & 447 & 437 & 494 & 437 & 640 & 538 & 516 & 508 & 536 & 441 & 443 \\
\hline 554 & 404 & 457 & 445 & 496 & 434 & 631 & 521 & 541 & 510 & 571 & 486 & 439 \\
\hline 549 & 406 & 484 & 441 & 487 & 423 & 624 & 522 & 542 & 513 & 640 & 516 & 441 \\
\hline 547 & 385 & 489 & 439 & 478 & 440 & 655 & 511 & 554 & 511 & 578 & 513 & 445 \\
\hline 552 & 381 & 491 & 445 & 481 & 446 & 677 & 528 & 557 & 500 & 570 & 464 & 469 \\
\hline 549 & 379 & 469 & 439 & 493 & 450 & 656 & 583 & 558 & 511 & 568 & 454 & 456 \\
\hline 575 & 368 & 472 & 438 & 474 & 443 & 660 & 554 & 540 & 520 & 576 & 441 & 448 \\
\hline 549 & 385 & 455 & 457 & 458 & 439 & 616 & 516 & 542 & 532 & 572 & 442 & 447 \\
\hline 540 & 381 & 463 & 448 & 472 & 438 & 606 & 528 & 557 & 565 & 555 & 486 & 449 \\
\hline 545 & 379 & 462 & 456 & 464 & 446 & 627 & 514 & 559 & 528 & 570 & 470 & 447 \\
\hline 549 & 379 & 457 & 463 & 476 & 446 & 594 & 501 & 581 & 537 & 574 & 441 & 451 \\
\hline 547 & 368 & 477 & 453 & 470 & 456 & 580 & 509 & 578 & 534 & 582 & 419 & 450 \\
\hline 564 & 370 & 456 & 452 & 454 & 450 & 612 & 496 & 570 & 520 & 551 & 432 & 452 \\
\hline 559 & 371 & 445 & 448 & 464 & 459 & 622 & 500 & 558 & 527 & 537 & 447 & 440 \\
\hline 547 & 379 & 446 & 450 & 475 & 448 & 621 & 516 & 541 & 535 & 556 & 444 & 448 \\
\hline 542 & 366 & 442 & 454 & 493 & 461 & 639 & 508 & 539 & 548 & 563 & 436 & 454 \\
\hline 564 & 369 & 441 & 455 & 494 & 461 & 640 & 521 & 545 & 584 & 572 & 430 & 462 \\
\hline 565 & 357 & 448 & 453 & 496 & 458 & 627 & 506 & 523 & 563 & 570 & 434 & 452 \\
\hline 590 & 368 & 427 & 465 & 486 & 456 & 660 & 524 & 542 & 526 & 544 & 405 & 449 \\
\hline 567 & 355 & 437 & 466 & 480 & 473 & 634 & 528 & 541 & 519 & 588 & 425 & 452 \\
\hline 574 & 384 & 442 & 455 & 470 & 470 & 638 & 510 & 548 & 536 & 591 & 443 & 449 \\
\hline 571 & 387 & 432 & 460 & 445 & 469 & 650 & 527 & 553 & 548 & 583 & 436 & 445 \\
\hline 580 & 376 & 445 & 462 & 452 & 471 & 670 & 536 & 545 & 538 & 599 & 443 & 449 \\
\hline 579 & 369 & 436 & 471 & 468 & 473 & 666 & 531 & 545 & 536 & 583 & 440 & 443 \\
\hline 560 & 368 & 430 & 499 & 480 & 481 & 640 & 532 & 561 & 574 & 578 & 463 & 461 \\
\hline 564 & 354 & 443 & 465 & 473 & 473 & 666 & 529 & 558 & 548 & 616 & 457 & 449 \\
\hline 577 & 364 & 441 & 470 & 463 & 454 & 660 & 529 & 555 & 568 & 561 & 448 & 445 \\
\hline 583 & 363 & 444 & 467 & 465 & 458 & 660 & 520 & 564 & 526 & 554 & 423 & 453 \\
\hline 594 & 372 & 445 & 472 & 487 & 481 & 649 & 528 & 560 & 548 & 545 & 422 & 443 \\
\hline 578 & 364 & 447 & 473 & 490 & 462 & 641 & 522 & 566 & 568 & 599 & 420 & 453 \\
\hline 576 & 355 & 448 & 480 & 481 & 459 & 641 & 502 & 539 & 556 & 589 & 423 & 441 \\
\hline 566 & 347 & 450 & 479 & 473 & 460 & 633 & 515 & 540 & 527 & 551 & 411 & 444 \\
\hline 588 & 354 & 448 & 483 & 464 & 444 & 660 & 530 & 560 & 532 & 548 & 399 & 439 \\
\hline 598 & 346 & 448 & 519 & 471 & 457 & 640 & 534 & 549 & 521 & 561 & 411 & 441 \\
\hline 591 & 353 & 447 & 493 & 460 & 443 & 651 & 530 & 541 & 511 & 575 & 417 & 448 \\
\hline 600 & 344 & 443 & 497 & 483 & 435 & 636 & 526 & 525 & 523 & 548 & 414 & 451 \\
\hline 590 & 358 & 430 & 469 & 478 & 442 & 622 & 518 & 531 & 518 & 556 & 411 & 436 \\
\hline 566 & 356 & 438 & 466 & 482 & 443 & 576 & 526 & 520 & 521 & 617 & 408 & 443 \\
\hline 541 & 348 & 443 & 457 & 486 & 453 & 585 & 526 & 526 & 528 & 617 & 401 & 457 \\
\hline 541 & 361 & 451 & 450 & 508 & 449 & 597 & 533 & 514 & 544 & 600 & 408 & 451 \\
\hline 536 & 366 & 456 & 446 & 508 & 454 & 612 & 543 & 523 & 516 & 565 & 400 & 475 \\
\hline 539 & 370 & 483 & 436 & 512 & 445 & 582 & 540 & 517 & 509 & 588 & 415 & 459 \\
\hline 550 & 356 & 484 & 454 & 531 & 472 & 583 & 541 & 523 & 509 & 593 & 412 & 455 \\
\hline 560 & 353 & 474 & 461 & 545 & 450 & 591 & 533 & 513 & 521 & 620 & 414 & 457 \\
\hline 573 & 354 & 481 & 453 & 522 & 464 & 597 & 553 & 560 & 535 & 587 & 423 & 461 \\
\hline 559 & 363 & 465 & 440 & 513 & 453 & 607 & 547 & 524 & 553 & 621 & 424 & 455 \\
\hline 565 & 368 & 470 & 441 & 517 & 445 & 624 & 537 & 502 & 584 & 618 & 428 & 451 \\
\hline 575 & 375 & 470 & 432 & 547 & 462 & 610 & 537 & 516 & 553 & 610 & 413 & 455 \\
\hline 563 & 378 & 460 & 444 & 537 & 439 & 610 & 542 & 541 & 529 & 656 & 407 & 451 \\
\hline 572 & 349 & 457 & 441 & 519 & 449 & 613 & 555 & 544 & 553 & 662 & 416 & 476 \\
\hline 582 & 372 & 463 & 435 & 535 & 439 & 612 & 545 & 538 & 553 & 629 & 405 & 491 \\
\hline 544 & 354 & 445 & 450 & 546 & 453 & 611 & 530 & 521 & 527 & 632 & 397 & 486 \\
\hline 547 & 350 & 461 & 490 & 537 & 457 & 584 & 538 & 528 & 537 & 612 & 401 & 501 \\
\hline 552 & 347 & 444 & 474 & 504 & 464 & 599 & 548 & 518 & 543 & 598 & 411 & 497 \\
\hline 538 & 353 & 446 & 473 & 515 & 453 & 614 & 516 & 518 & 544 & 622 & 415 & 504 \\
\hline 543 & 369 & 435 & 487 & 501 & 456 & 616 & 515 & 515 & 527 & 618 & 418 & 515 \\
\hline 545 & 376 & 444 & 462 & 508 & 453 & 614 & 513 & 510 & 518 & 580 & 431 & 526 \\
\hline 559 & 359 & 458 & 489 & 517 & 445 & 625 & 517 & 523 & 512 & 594 & 431 & 540 \\
\hline 569 & 362 & 453 & 482 & 500 & 445 & 616 & 510 & 527 & 507 & 595 & 437 & 522 \\
\hline 564 & 375 & 478 & 483 & 511 & 458 & 604 & 507 & 530 & 522 & 589 & 434 & 542 \\
\hline 564 & 383 & 480 & 530 & 532 & 441 & 609 & 519 & 539 & 513 & 578 & 465 & 529 \\
\hline 544 & 371 & 503 & 512 & 511 & 434 & 661 & 529 & 545 & 507 & 557 & 507 & 511 \\
\hline 535 & 367 & 475 & 510 & 499 & 445 & 650 & 541 & 534 & 525 & 560 & 505 & 515 \\
\hline 547 & 370 & 478 & 490 & 512 & 491 & 674 & 531 & 542 & 516 & 559 & 485 & 480 \\
\hline 562 & 376 & 455 & 479 & 543 & 443 & 663 & 526 & 544 & 540 & 535 & 471 & 461 \\
\hline 548 & 359 & 463 & 473 & 531 & 442 & 636 & 536 & 537 & 519 & 554 & 459 & 455 \\
\hline 561 & 367 & 472 & 491 & 520 & 449 & 635 & 527 & 538 & 535 & 580 & 450 & 456 \\
\hline 572 & 360 & 456 & 486 & 524 & 442 & 630 & 533 & 535 & 543 & 593 & 442 & 450 \\
\hline 566 & 363 & 448 & 490 & 552 & 443 & 634 & 532 & 547 & 537 & 592 & 448 & 474 \\
\hline 544 & 361 & 457 & 461 & 564 & 449 & 647 & 523 & 546 & 560 & 590 & 489 & 475 \\
\hline 547 & 366 & 446 & 464 & 567 & 455 & 640 & 524 & 546 & 549 & 600 & 473 & 474 \\
\hline 548 & 371 & 461 & 475 & 538 & 445 & 650 & 519 & 560 & 558 & 616 & 474 & 472 \\
\hline 552 & 362 & 431 & 456 & 541 & 438 & 625 & 525 & 562 & $\begin{array}{l}567 \\
\end{array}$ & 625 & 468 & 456 \\
\hline 550 & 355 & 441 & 473 & 520 & 447 & 636 & 524 & 558 & 547 & 611 & 455 & 468 \\
\hline 551 & 348 & 459 & 485 & 517 & 446 & 634 & 516 & 563 & 550 & 606 & 448 & 457 \\
\hline 556 & 338 & 447 & 490 & 503 & 439 & 609 & 522 & 549 & 538 & 590 & 449 & 448 \\
\hline
\end{tabular}


Tabela 2 - Concentração de $\mathrm{CO}_{2}$, em ppm, no Piso 2 no ano de 2010 (Continuação).

\begin{tabular}{|c|c|c|c|c|c|c|c|c|c|c|c|c|}
\hline $5 / 5 / 10$ & $13 / 5 / 10$ & $21 / 5 / 10$ & $1 / 6 / 10$ & $9 / 6 / 10$ & $14 / 6 / 10$ & $24 / 6 / 10$ & $15 / 7 / 10$ & $22 / 7 / 10$ & $6 / 8 / 10$ & $11 / 8 / 10$ & $20 / 8 / 10$ & $27 / 8 / 10$ \\
\hline 563 & 357 & 436 & 480 & 495 & 445 & 612 & 533 & 543 & 525 & 591 & 440 & 447 \\
\hline 577 & 357 & 454 & 481 & 499 & 472 & 612 & 534 & 566 & 539 & 578 & 421 & 455 \\
\hline 557 & 364 & 454 & 487 & 500 & 455 & 627 & 531 & 563 & 534 & 579 & 420 & 471 \\
\hline 567 & 351 & 437 & 498 & 509 & 455 & 634 & 535 & 566 & 534 & 578 & 422 & 475 \\
\hline 558 & 357 & 442 & 501 & 520 & 468 & 619 & 520 & 561 & 527 & 579 & 406 & 464 \\
\hline 553 & 358 & 435 & 493 & 524 & 468 & 603 & 541 & 561 & 560 & 551 & 411 & 460 \\
\hline 538 & 345 & 430 & 486 & 501 & 482 & 607 & 532 & 571 & 549 & 548 & 421 & 453 \\
\hline 540 & 354 & 436 & 485 & 505 & 463 & 599 & 541 & 586 & 537 & 538 & 417 & 464 \\
\hline 528 & 362 & 436 & 516 & 511 & 464 & 600 & 543 & 563 & 536 & 534 & 416 & 489 \\
\hline 531 & 369 & 422 & 486 & 498 & 468 & 589 & 528 & 576 & 556 & 540 & 411 & 483 \\
\hline 535 & 357 & 420 & 474 & 505 & 457 & 603 & 524 & 578 & 557 & 540 & 434 & 478 \\
\hline 542 & 357 & 431 & 467 & 489 & 459 & 624 & 521 & 568 & 555 & 548 & 434 & 479 \\
\hline 554 & 345 & 446 & 459 & 516 & 457 & 614 & 539 & 560 & 543 & 551 & 445 & 485 \\
\hline 556 & 349 & 460 & 466 & 527 & 465 & 604 & 540 & 558 & 547 & 559 & 438 & 489 \\
\hline 552 & 343 & 445 & 466 & 538 & 486 & 585 & 542 & 561 & 532 & 542 & 453 & 456 \\
\hline 562 & 357 & 453 & 466 & 528 & 485 & 604 & 555 & 538 & 527 & 540 & 451 & 451 \\
\hline 542 & 347 & 459 & 462 & 519 & 473 & 572 & 555 & 561 & 526 & 537 & 461 & 492 \\
\hline 552 & 345 & 467 & 465 & 494 & 465 & 593 & 583 & 538 & 552 & 549 & 435 & 466 \\
\hline 557 & 345 & 464 & 442 & 485 & 461 & 605 & 555 & 550 & 536 & 560 & 429 & 464 \\
\hline 556 & 347 & 464 & 450 & 480 & 455 & 588 & 546 & 539 & 510 & 552 & 431 & 466 \\
\hline 543 & 351 & 451 & 454 & 484 & 449 & 610 & 530 & 524 & 539 & 577 & 428 & 465 \\
\hline 554 & 346 & 448 & 466 & 491 & 445 & 589 & 527 & 531 & 522 & 586 & 413 & 476 \\
\hline 551 & 345 & 451 & 470 & 496 & 450 & 592 & 533 & 525 & 552 & 554 & 411 & 449 \\
\hline 550 & 352 & 442 & 473 & 473 & 450 & 576 & 556 & 534 & 550 & 568 & 420 & 454 \\
\hline 551 & 350 & 450 & 483 & 466 & 443 & 549 & 578 & 532 & 580 & 616 & 406 & 458 \\
\hline 556 & 351 & 442 & 476 & 470 & 448 & 563 & 577 & 540 & 569 & 621 & 411 & 468 \\
\hline 550 & 349 & 464 & 480 & 508 & 468 & 567 & 583 & 539 & 525 & 556 & 408 & 458 \\
\hline 553 & 354 & 460 & 474 & 503 & 481 & 589 & 575 & 528 & 553 & 541 & 419 & 466 \\
\hline 549 & 345 & 470 & 492 & 494 & 481 & 596 & 547 & 522 & 544 & 528 & 429 & 464 \\
\hline 551 & 352 & 457 & 479 & 509 & 476 & 599 & 552 & 524 & 544 & 549 & 410 & 471 \\
\hline 545 & 349 & 447 & 481 & 488 & 461 & 602 & 556 & 532 & 545 & 569 & 414 & 473 \\
\hline 555 & 339 & 450 & 493 & 494 & 484 & 610 & 556 & 526 & 519 & 554 & 431 & 487 \\
\hline 559 & 351 & 452 & 490 & 492 & 485 & 603 & 528 & 518 & 514 & 552 & 456 & 466 \\
\hline 563 & 340 & 444 & 485 & 508 & 480 & 593 & 546 & 524 & 515 & 546 & 443 & 455 \\
\hline 555 & 351 & 442 & 480 & 476 & 450 & 595 & 554 & 582 & 527 & 536 & 451 & 442 \\
\hline 549 & 342 & 436 & 469 & 473 & 471 & 596 & 555 & 554 & 506 & 545 & 464 & 455 \\
\hline 557 & 345 & 444 & 495 & 476 & 457 & 587 & 573 & 582 & 504 & 527 & 444 & 462 \\
\hline 570 & 349 & 437 & 514 & 482 & 469 & 575 & 547 & 574 & 495 & 521 & 448 & 459 \\
\hline 559 & 342 & 431 & 513 & 447 & 463 & 571 & 548 & 568 & 501 & 522 & 451 & 477 \\
\hline 552 & 341 & 423 & 491 & 448 & 478 & 556 & 542 & 561 & 509 & 536 & 461 & 474 \\
\hline 548 & 356 & 413 & 488 & 479 & 507 & 568 & 578 & 579 & 501 & 546 & 468 & 485 \\
\hline 551 & 348 & 417 & 491 & 453 & 495 & 585 & 560 & 638 & 508 & 523 & 442 & 501 \\
\hline 550 & 346 & 442 & 496 & 475 & 479 & 582 & 575 & 561 & 510 & 541 & 430 & 494 \\
\hline 556 & 355 & 439 & 513 & 471 & 466 & 588 & 578 & 598 & 506 & 560 & 410 & 490 \\
\hline 566 & 359 & 430 & 493 & 492 & 452 & 605 & 551 & 565 & 502 & 539 & 427 & 474 \\
\hline 553 & 353 & 439 & 491 & 485 & 463 & 618 & 547 & 565 & 505 & 527 & 422 & 488 \\
\hline 560 & 350 & 454 & 485 & 465 & 453 & 622 & 544 & 568 & 503 & 531 & 423 & 489 \\
\hline \begin{tabular}{|l|l|}
558 \\
\end{tabular} & 359 & 445 & 509 & 478 & 455 & 633 & 550 & 561 & $\begin{array}{l}498 \\
\end{array}$ & 524 & 454 & 490 \\
\hline 540 & 367 & 441 & 505 & 484 & 479 & 634 & 565 & 551 & 506 & 547 & 436 & 501 \\
\hline 550 & 366 & 445 & 502 & 475 & 467 & 632 & 582 & 548 & 504 & 533 & 428 & 475 \\
\hline 544 & 357 & 455 & 536 & 459 & 463 & 603 & 597 & 551 & 506 & 526 & 459 & 482 \\
\hline 537 & 374 & 446 & 524 & 460 & 458 & 599 & 600 & 567 & 505 & 539 & 461 & 483 \\
\hline 546 & 362 & 433 & 517 & 469 & $\begin{array}{l}459 \\
\end{array}$ & 606 & 585 & 584 & 527 & 523 & 477 & 492 \\
\hline 556 & 358 & 441 & 549 & 509 & 498 & 634 & 582 & 580 & 547 & 514 & 454 & 479 \\
\hline 572 & 350 & 439 & 553 & 495 & 483 & 635 & 585 & 542 & 528 & 531 & 438 & 474 \\
\hline 554 & 361 & 449 & 532 & 511 & 462 & 623 & 595 & 544 & 540 & 503 & 471 & 478 \\
\hline 554 & 352 & 446 & 536 & 531 & 472 & 607 & 603 & 537 & 579 & 514 & 476 & 463 \\
\hline 558 & 341 & 453 & 541 & 499 & 512 & 615 & 592 & 535 & 586 & 513 & 460 & 450 \\
\hline 543 & 340 & 417 & 534 & 509 & 487 & 608 & 588 & 530 & 577 & 509 & 465 & 451 \\
\hline 539 & 349 & 432 & 500 & 507 & 468 & 592 & 577 & 526 & 598 & 516 & 479 & 440 \\
\hline 547 & 349 & 435 & 502 & 493 & 469 & 610 & 573 & 521 & $\begin{array}{l}586 \\
8\end{array}$ & 531 & 459 & 452 \\
\hline 559 & 336 & 443 & 498 & 502 & 487 & 606 & 579 & 552 & 593 & 539 & 472 & 460 \\
\hline 560 & 350 & 441 & 494 & 497 & 481 & 615 & 586 & 566 & 592 & 543 & 475 & 461 \\
\hline 574 & 341 & 421 & 504 & 500 & 482 & 635 & 596 & 549 & 570 & 508 & 453 & 467 \\
\hline 567 & 340 & 421 & 493 & 495 & 471 & 642 & 608 & 554 & 555 & 524 & 453 & 461 \\
\hline 565 & 335 & 426 & 489 & 490 & 463 & 652 & 575 & 567 & 586 & 510 & 466 & 468 \\
\hline 583 & 337 & 406 & 496 & 510 & 454 & 672 & 578 & 555 & $\mathrm{X}$ & 512 & 456 & 464 \\
\hline 585 & 354 & 412 & 491 & 507 & 476 & 654 & 549 & 541 & $X$ & 534 & 420 & 469 \\
\hline 590 & 334 & 396 & 514 & 530 & 484 & 610 & 561 & 540 & $\mathrm{X}$ & 530 & 426 & 459 \\
\hline 583 & 330 & 422 & 517 & 506 & 458 & 628 & 568 & 547 & $X$ & 516 & 420 & 454 \\
\hline 595 & 354 & 421 & 505 & 518 & 453 & 628 & 552 & 554 & $X$ & 523 & 450 & 454 \\
\hline 589 & 350 & 410 & 500 & 497 & 443 & 652 & 561 & 556 & $\mathrm{X}$ & 524 & 442 & 470 \\
\hline 585 & 353 & 402 & 501 & 489 & 446 & 685 & 538 & 572 & $\mathrm{X}$ & 515 & 464 & 475 \\
\hline 566 & 356 & 409 & 485 & 446 & 475 & 662 & 540 & 546 & $\mathrm{X}$ & 500 & 448 & 483 \\
\hline 571 & 348 & 402 & 484 & 465 & 467 & 656 & 549 & 527 & $X$ & 499 & 448 & 496 \\
\hline 575 & 348 & 406 & 495 & 455 & 440 & 654 & 561 & 525 & $\mathrm{X}$ & 504 & 448 & 496 \\
\hline 582 & 351 & 411 & 484 & 444 & 438 & 656 & 546 & 537 & $\mathrm{X}$ & 515 & 454 & 504 \\
\hline
\end{tabular}


Tabela 2 - Concentração de $\mathrm{CO}_{2}$, em ppm, no Piso 2 no ano de 2010 (Continuação).

\begin{tabular}{|c|c|c|c|c|c|c|c|c|c|c|c|c|}
\hline $5 / 5 / 10$ & $13 / 5 / 10$ & $21 / 5 / 10$ & $1 / 6 / 10$ & $9 / 6 / 10$ & $14 / 6 / 10$ & $24 / 6 / 10$ & $15 / 7 / 10$ & $22 / 7 / 10$ & $6 / 8 / 10$ & $11 / 8 / 10$ & $20 / 8 / 10$ & $27 / 8 / 10$ \\
\hline 576 & 346 & 414 & 493 & 453 & 442 & 665 & 544 & 526 & $\mathrm{X}$ & 514 & 433 & 462 \\
\hline 569 & 347 & 414 & 479 & 471 & 454 & 654 & 548 & 546 & $\mathrm{X}$ & 522 & 449 & 460 \\
\hline 571 & 346 & 411 & 481 & 439 & 452 & 671 & 544 & 530 & $\mathrm{X}$ & 518 & 450 & 475 \\
\hline 567 & 360 & 414 & 487 & 463 & 473 & 651 & 543 & 540 & $\mathrm{X}$ & 508 & 445 & 475 \\
\hline 568 & 357 & 420 & 491 & 463 & 452 & 645 & 563 & 531 & $\mathrm{X}$ & 508 & 485 & 459 \\
\hline 574 & 361 & $\mathrm{X}$ & 553 & 465 & 477 & 656 & 561 & 542 & $\mathrm{X}$ & $\mathrm{X}$ & 471 & 486 \\
\hline 567 & 366 & $\mathrm{X}$ & $\mathrm{X}$ & 458 & 473 & 637 & 564 & 530 & $\mathrm{X}$ & $\mathrm{X}$ & 479 & 485 \\
\hline 572 & 367 & $\mathrm{X}$ & $\mathrm{X}$ & 465 & $\mathrm{X}$ & $\mathrm{X}$ & $\mathrm{X}$ & 527 & $\mathrm{X}$ & $\mathrm{X}$ & 474 & $\mathrm{X}$ \\
\hline 575 & 370 & $\mathrm{X}$ & $\mathrm{X}$ & 465 & $\mathrm{X}$ & $\mathrm{X}$ & $\mathrm{X}$ & 538 & $\mathrm{X}$ & $\mathrm{X}$ & 456 & $\mathrm{X}$ \\
\hline 584 & 366 & $X$ & $X$ & 467 & $x$ & $\mathrm{X}$ & $\mathrm{X}$ & 541 & $\mathrm{X}$ & $\mathrm{X}$ & 454 & $\mathrm{X}$ \\
\hline $\mathrm{X}$ & 361 & $x$ & $x$ & $\mathrm{X}$ & $\mathrm{X}$ & $\mathrm{X}$ & $\mathrm{X}$ & 534 & $\mathrm{X}$ & $\mathrm{X}$ & $\mathrm{X}$ & $\mathrm{X}$ \\
\hline $\mathrm{X}$ & $\mathrm{X}$ & $\mathrm{X}$ & $\mathrm{X}$ & $\mathrm{X}$ & $\mathrm{X}$ & $\mathrm{X}$ & $\mathrm{X}$ & 537 & $\mathrm{X}$ & $\mathrm{X}$ & $\mathrm{X}$ & $\mathrm{X}$ \\
\hline $\mathrm{X}$ & $\mathrm{X}$ & $\mathrm{X}$ & $\mathrm{X}$ & $\mathrm{X}$ & $\mathrm{X}$ & $\mathrm{X}$ & $\mathrm{X}$ & 534 & $\mathrm{X}$ & $\mathrm{X}$ & $\mathrm{X}$ & $\mathrm{X}$ \\
\hline
\end{tabular}


Tabela 3 - Concentração de $\mathrm{CO}_{2}$, em ppm, no Piso 3 no ano de 2010.

\begin{tabular}{|c|c|c|c|c|c|c|c|c|c|c|c|c|}
\hline $7 / 5 / 10$ & $20 / 5 / 10$ & $26 / 5 / 10$ & $8 / 6 / 10$ & $15 / 6 / 10$ & $21 / 6 / 10$ & $30 / 6 / 10$ & $7 / 7 / 10$ & $14 / 7 / 10$ & $23 / 7 / 10$ & $10 / 8 / 10$ & $17 / 8 / 10$ & $8 / 9 / 10$ \\
\hline 489 & 586 & 462 & 472 & 408 & 538 & 442 & 435 & 538 & 564 & 531 & 523 & 504 \\
\hline 478 & 413 & 469 & 442 & 428 & 523 & 428 & 442 & 541 & 524 & 510 & 542 & 595 \\
\hline 491 & 427 & 520 & 501 & 417 & 541 & 453 & 447 & 559 & 523 & 515 & 531 & 500 \\
\hline 486 & 436 & 508 & 455 & 426 & 521 & 439 & 443 & 556 & 545 & 512 & 542 & 511 \\
\hline 491 & 433 & 490 & 450 & 411 & 525 & 446 & 445 & 551 & 573 & 508 & 550 & 519 \\
\hline 486 & 425 & 480 & 456 & 464 & 536 & 456 & 445 & 586 & 542 & 517 & 534 & 516 \\
\hline 492 & 420 & 496 & 449 & 416 & 533 & 453 & 435 & 549 & 526 & 528 & 534 & 498 \\
\hline 488 & 589 & 490 & 446 & 428 & 525 & 442 & 444 & 542 & 535 & 523 & 542 & 504 \\
\hline 498 & 427 & 483 & 444 & 428 & 540 & 453 & 427 & 539 & 534 & 516 & 552 & 495 \\
\hline 499 & 446 & 488 & 452 & 421 & 541 & 452 & 450 & 520 & 517 & 507 & 533 & 506 \\
\hline 499 & 433 & 495 & 451 & 430 & 535 & 447 & 421 & 529 & 528 & 505 & 529 & 501 \\
\hline 494 & 429 & 515 & 461 & 431 & 538 & 447 & 430 & 522 & 515 & 500 & 520 & 511 \\
\hline 496 & 426 & 509 & 448 & 441 & 534 & 447 & 419 & 514 & 521 & 493 & 514 & 504 \\
\hline 495 & 431 & 503 & 456 & 435 & 529 & 445 & 419 & 506 & 532 & 515 & 507 & 502 \\
\hline 509 & 431 & 497 & 458 & 434 & 518 & 451 & 425 & 514 & 537 & 502 & 514 & 498 \\
\hline 518 & 433 & 492 & 440 & 437 & 520 & 436 & 423 & 498 & 528 & 501 & 516 & 501 \\
\hline 528 & 423 & 482 & 455 & 434 & 513 & 445 & 418 & 510 & 521 & 509 & 516 & 506 \\
\hline 534 & 419 & 486 & 446 & 440 & 518 & 440 & 421 & 521 & 518 & 503 & 519 & 495 \\
\hline 544 & 427 & 538 & 452 & 446 & 529 & 439 & 425 & 528 & 520 & 504 & 534 & 497 \\
\hline 522 & 435 & 494 & 473 & 439 & 520 & 438 & 413 & 521 & 535 & 504 & 525 & 502 \\
\hline 525 & 441 & 479 & 475 & 442 & 510 & 439 & 429 & 536 & 524 & 503 & 525 & 505 \\
\hline 529 & 456 & 496 & 450 & 440 & 505 & 432 & 437 & 533 & 509 & 492 & 510 & 509 \\
\hline 547 & 446 & 492 & 461 & 440 & 504 & 435 & 424 & 523 & 522 & 497 & 551 & 497 \\
\hline 543 & 446 & 493 & 476 & 433 & 508 & 437 & 421 & 521 & 522 & 493 & 517 & 501 \\
\hline 542 & 436 & 483 & 552 & 441 & 492 & 438 & 425 & 522 & 521 & 510 & 517 & 509 \\
\hline 529 & 435 & 496 & 526 & 443 & 485 & 437 & 410 & 520 & 508 & 522 & 520 & 496 \\
\hline 541 & 430 & 497 & 438 & 438 & 486 & 432 & 413 & 515 & 506 & 516 & 520 & 504 \\
\hline 536 & 441 & 496 & 438 & 438 & 486 & 414 & 426 & 516 & 508 & 520 & 512 & 510 \\
\hline 540 & 425 & 521 & 442 & 424 & 495 & 423 & 422 & 515 & 513 & 533 & 507 & 498 \\
\hline 536 & 447 & 505 & 437 & 439 & 497 & 430 & 417 & 508 & 516 & 519 & 501 & 503 \\
\hline 548 & 444 & 512 & 432 & 424 & 481 & 421 & 419 & 531 & 527 & 509 & 507 & 514 \\
\hline 543 & 469 & 505 & 446 & 436 & 490 & 419 & 423 & 532 & 528 & 502 & 501 & 519 \\
\hline 544 & 487 & 492 & 463 & 436 & 479 & 428 & 417 & 539 & 518 & 518 & 502 & 507 \\
\hline 546 & 472 & 498 & 466 & 424 & 492 & 420 & 423 & 539 & 509 & 516 & 506 & 520 \\
\hline 557 & 452 & 495 & 443 & 420 & 479 & 421 & 415 & 548 & 515 & 516 & 503 & 523 \\
\hline 530 & 443 & 490 & 423 & 435 & 486 & 423 & 417 & 546 & 517 & 508 & 497 & 519 \\
\hline 542 & 439 & 507 & 419 & 440 & 465 & 433 & 412 & 549 & 525 & 514 & 507 & 506 \\
\hline 535 & 431 & 516 & 449 & 452 & 466 & 429 & 429 & 537 & 510 & 521 & 509 & 511 \\
\hline 529 & 436 & 497 & 455 & 443 & 471 & 432 & 427 & 565 & 526 & 513 & 517 & 508 \\
\hline 544 & 444 & 515 & 428 & 432 & 464 & 429 & 420 & 563 & 540 & 530 & 519 & 495 \\
\hline 543 & 439 & 505 & 434 & 436 & 465 & 420 & 421 & 546 & 535 & 508 & 513 & 495 \\
\hline 541 & 442 & 510 & 436 & 433 & 463 & 427 & 421 & 539 & 539 & 521 & 538 & 503 \\
\hline 550 & 422 & 518 & 438 & 425 & 453 & 417 & 420 & 543 & 545 & 507 & 533 & 493 \\
\hline 553 & 439 & 521 & 451 & 436 & 461 & 423 & 415 & 543 & 536 & 504 & 539 & 486 \\
\hline 557 & 448 & 527 & 461 & 437 & 457 & 430 & 427 & 539 & 544 & 503 & 543 & 493 \\
\hline 561 & 444 & 524 & 477 & 429 & 459 & 426 & 429 & 547 & 550 & 506 & 543 & 493 \\
\hline 546 & 444 & 523 & 494 & 438 & 451 & 433 & 411 & 539 & 543 & 497 & 562 & 501 \\
\hline 551 & 450 & 535 & 471 & 439 & 456 & 435 & 414 & 534 & 543 & 495 & 563 & 489 \\
\hline 566 & 437 & 593 & 463 & 437 & 456 & 427 & 401 & 540 & 546 & 483 & 544 & 486 \\
\hline 584 & 427 & 531 & 447 & 444 & 465 & 426 & 409 & 562 & 548 & 486 & 550 & 496 \\
\hline 559 & 406 & 549 & 420 & 441 & 454 & 408 & 427 & 533 & 538 & 552 & 561 & 490 \\
\hline 568 & 410 & 538 & 426 & 439 & 463 & 415 & 420 & 548 & 532 & 514 & 577 & 483 \\
\hline 550 & 421 & 551 & 433 & 427 & 456 & 420 & 425 & 549 & 542 & 518 & 590 & 484 \\
\hline 552 & 424 & 540 & 428 & 435 & 450 & 435 & 422 & 546 & 544 & 522 & 594 & 495 \\
\hline 555 & 409 & 546 & 444 & 430 & 462 & 416 & 427 & 549 & 543 & 541 & 590 & 476 \\
\hline 550 & 416 & 536 & 487 & 433 & 466 & 419 & 433 & 556 & 547 & 531 & 584 & 476 \\
\hline 561 & 414 & 529 & 488 & 455 & 451 & 419 & 420 & 576 & 545 & 569 & 602 & 491 \\
\hline 547 & 424 & 535 & 495 & 431 & 442 & 430 & 430 & 561 & 553 & 542 & 609 & 492 \\
\hline 554 & 414 & 532 & 465 & 442 & 455 & 432 & 415 & 556 & 545 & 541 & 624 & 493 \\
\hline 547 & 430 & 516 & 449 & 445 & 465 & 434 & 421 & 569 & 547 & 547 & 620 & 502 \\
\hline 548 & 429 & 560 & 461 & 423 & 456 & 431 & 419 & 551 & 536 & 552 & 622 & 495 \\
\hline 561 & 433 & 505 & 471 & 436 & 457 & 422 & 420 & 553 & 541 & 550 & 625 & 504 \\
\hline 556 & 427 & 508 & 473 & 432 & 444 & 430 & 412 & 581 & 555 & 560 & 626 & 492 \\
\hline 550 & 429 & 497 & 473 & 431 & 466 & 431 & 430 & 561 & 544 & 569 & 635 & 486 \\
\hline 567 & 434 & 488 & 465 & 436 & 442 & 441 & 415 & 562 & 542 & 568 & 634 & 493 \\
\hline 552 & 436 & 510 & 461 & 430 & 453 & 446 & 423 & 556 & 545 & 565 & 630 & 488 \\
\hline 546 & 440 & 511 & 465 & 442 & 453 & 447 & 430 & 563 & 542 & 551 & 623 & 498 \\
\hline 549 & 459 & 499 & 460 & 429 & 469 & 436 & 435 & 554 & 553 & 547 & 622 & 480 \\
\hline 556 & 442 & 500 & 467 & 423 & 448 & 440 & 440 & 562 & 545 & 565 & 633 & 495 \\
\hline 554 & 435 & 503 & 478 & 437 & 456 & 439 & 439 & 544 & 547 & 565 & 611 & 485 \\
\hline 548 & 443 & 510 & 484 & 424 & 457 & 450 & 427 & 542 & 540 & 553 & 599 & 493 \\
\hline 549 & 433 & 503 & 473 & 437 & 469 & 454 & 442 & 536 & 542 & 532 & 618 & 487 \\
\hline 564 & 445 & 508 & 463 & 428 & 450 & 439 & 435 & 546 & 544 & 532 & 612 & 511 \\
\hline 555 & 443 & 511 & 490 & 427 & 458 & 436 & 430 & 553 & 547 & 547 & 641 & 488 \\
\hline 560 & 444 & 505 & 478 & 425 & 456 & 437 & 434 & 555 & 547 & 550 & 641 & 499 \\
\hline 551 & 449 & 518 & 478 & 420 & 471 & 437 & 412 & 550 & 546 & 553 & 634 & 492 \\
\hline 550 & 451 & 518 & 485 & 436 & 465 & 438 & 424 & 544 & 538 & 537 & 621 & 486 \\
\hline
\end{tabular}


Tabela 3 - Concentração de $\mathrm{CO}_{2}$, em ppm, no Piso 3 no ano de 2010 (Continuação).

\begin{tabular}{|c|c|c|c|c|c|c|c|c|c|c|c|c|}
\hline $7 / 5 / 10$ & $20 / 5 / 10$ & $26 / 5 / 10$ & $8 / 6 / 10$ & $15 / 6 / 10$ & $21 / 6 / 10$ & $30 / 6 / 10$ & $7 / 7 / 10$ & $14 / 7 / 10$ & $23 / 7 / 10$ & $10 / 8 / 10$ & $17 / 8 / 10$ & $8 / 9 / 10$ \\
\hline 545 & 435 & 524 & 472 & 430 & 455 & 435 & 411 & 545 & 550 & 530 & 613 & 497 \\
\hline 554 & 446 & 550 & 507 & 427 & 457 & 435 & 428 & 538 & 543 & 533 & 601 & 501 \\
\hline 553 & 431 & 542 & 511 & 415 & 455 & 449 & 439 & 528 & 548 & 541 & 596 & 502 \\
\hline 553 & 435 & 541 & 483 & 419 & 462 & 431 & 429 & 545 & 550 & 537 & 615 & 496 \\
\hline 557 & 410 & 554 & 469 & 419 & 456 & 440 & 430 & 539 & 549 & 542 & 641 & 497 \\
\hline 562 & 411 & 546 & 492 & 424 & 454 & 441 & 429 & 549 & 536 & 534 & 605 & 501 \\
\hline 549 & 410 & 552 & 465 & 435 & 455 & 478 & 442 & 545 & 545 & 525 & 591 & 500 \\
\hline 553 & 412 & 538 & 494 & 431 & 455 & 478 & 429 & 546 & 543 & 503 & 605 & 506 \\
\hline 556 & 410 & 541 & 484 & 433 & 457 & 454 & 435 & 557 & 569 & 539 & 596 & 506 \\
\hline 556 & 414 & 542 & 468 & 440 & 454 & 456 & 439 & 549 & 559 & 541 & 592 & 516 \\
\hline 551 & 399 & 534 & 465 & 444 & 453 & 465 & 427 & 545 & 542 & 530 & 577 & 514 \\
\hline 566 & 409 & 544 & 471 & 447 & 448 & 453 & 445 & 553 & 547 & 555 & 586 & 502 \\
\hline 570 & 411 & 531 & 473 & 442 & 448 & 438 & 435 & 553 & 544 & 520 & 587 & 540 \\
\hline 551 & 432 & 531 & 446 & 439 & 453 & 444 & 432 & 547 & 546 & 521 & 599 & 513 \\
\hline 555 & 418 & 533 & 468 & 446 & 459 & 443 & 447 & 542 & 551 & 515 & 617 & 523 \\
\hline 563 & 520 & 540 & 463 & 436 & 452 & 451 & 463 & 548 & 543 & 521 & 621 & 519 \\
\hline 569 & 436 & 545 & 475 & 440 & 454 & 436 & 446 & 558 & 553 & 525 & 635 & 539 \\
\hline 558 & 403 & 534 & 466 & 427 & 466 & 455 & 465 & 554 & 546 & 532 & 639 & 520 \\
\hline 572 & 408 & 536 & 464 & 442 & 449 & 450 & 451 & 568 & 546 & 531 & 634 & 514 \\
\hline 570 & 411 & 535 & 474 & 441 & 470 & 445 & 448 & 572 & 541 & 512 & 633 & 513 \\
\hline 578 & 427 & 540 & 470 & 436 & 465 & 442 & 452 & 552 & 543 & 527 & 637 & 514 \\
\hline 565 & 422 & 542 & 467 & 433 & 489 & 439 & 455 & 547 & 540 & 524 & 667 & 511 \\
\hline 572 & 431 & 537 & 435 & 427 & 476 & 437 & 452 & 559 & 552 & 523 & 628 & 524 \\
\hline 580 & 431 & 533 & 439 & 442 & 485 & 455 & 455 & 565 & 538 & 534 & 643 & 554 \\
\hline 563 & 429 & 547 & 448 & 430 & 467 & 447 & 455 & 566 & 546 & 521 & 617 & 531 \\
\hline 567 & 426 & 536 & 460 & 446 & 459 & 452 & 458 & 558 & 541 & 522 & 618 & 513 \\
\hline 556 & 431 & 537 & 460 & 442 & 473 & 451 & 442 & 553 & 532 & 521 & 593 & 518 \\
\hline 563 & 418 & 531 & 461 & 444 & 462 & 448 & 444 & 560 & 529 & 524 & 627 & 532 \\
\hline 557 & 426 & 537 & 477 & 440 & 475 & 437 & 448 & 574 & 532 & 530 & 611 & 536 \\
\hline 555 & 431 & 535 & 505 & 444 & 468 & 442 & 452 & 567 & 523 & 538 & 615 & 536 \\
\hline 552 & 427 & 535 & 629 & 452 & 477 & 442 & 451 & 564 & 514 & 527 & 619 & 526 \\
\hline 562 & 423 & 538 & 513 & 471 & 471 & 452 & 450 & 556 & 523 & 530 & 621 & 529 \\
\hline 550 & 421 & 539 & 554 & 447 & 468 & 447 & 445 & 566 & 519 & 512 & 604 & 521 \\
\hline 557 & 412 & 534 & 532 & 459 & 477 & 446 & 463 & 577 & 525 & 508 & 593 & 512 \\
\hline 567 & 409 & 533 & 479 & 449 & 474 & 450 & 454 & 573 & 538 & 520 & 605 & 531 \\
\hline 565 & 429 & 533 & 474 & 461 & 490 & 443 & 455 & 560 & 540 & 513 & 631 & 524 \\
\hline 569 & 414 & 526 & 465 & 465 & 481 & 467 & 451 & 587 & 536 & 504 & 615 & 531 \\
\hline 566 & 424 & 534 & 455 & 483 & 488 & 466 & 451 & 570 & 540 & 498 & 640 & 578 \\
\hline 560 & 432 & 538 & 464 & 465 & 480 & 456 & 451 & 573 & 543 & 522 & 683 & 534 \\
\hline 569 & 412 & 537 & 477 & 472 & 476 & 449 & 460 & 579 & 536 & 509 & 730 & 549 \\
\hline 575 & 411 & 530 & 472 & 460 & 466 & 468 & 460 & 586 & 545 & 526 & 695 & 553 \\
\hline 567 & 416 & 532 & 468 & 489 & 474 & 449 & 459 & 580 & 542 & 502 & 646 & 535 \\
\hline 584 & 436 & 541 & 455 & 490 & 483 & 459 & 458 & 579 & 541 & 518 & 677 & 526 \\
\hline 566 & 462 & 543 & 445 & 474 & 459 & 459 & 462 & 567 & 539 & 527 & 679 & 530 \\
\hline 574 & 430 & 532 & 436 & 479 & 475 & 451 & 463 & 577 & 540 & 514 & 673 & 516 \\
\hline 578 & 437 & 540 & 434 & 475 & 525 & 444 & 459 & 580 & 542 & 518 & 698 & 527 \\
\hline 571 & 427 & 540 & 489 & 461 & 469 & 441 & 456 & 582 & 542 & 516 & 683 & 541 \\
\hline 581 & 457 & 537 & 475 & 455 & 481 & 448 & 461 & 569 & 552 & 512 & 687 & 545 \\
\hline 587 & 435 & 541 & 461 & 461 & 474 & 454 & 465 & 573 & 544 & 524 & 656 & 518 \\
\hline 578 & 437 & 543 & 445 & 450 & 476 & 446 & 449 & 567 & 547 & 513 & 665 & 552 \\
\hline 573 & 417 & 544 & 440 & 460 & 475 & 444 & 463 & 572 & 547 & 534 & 696 & 521 \\
\hline 583 & 431 & 538 & 450 & 446 & 481 & 453 & 473 & 571 & 558 & 510 & 700 & 508 \\
\hline 585 & 428 & 541 & 451 & 456 & 467 & 459 & 470 & 559 & 558 & 515 & 623 & 538 \\
\hline 592 & 426 & 545 & 471 & 450 & 467 & 446 & 476 & 568 & 549 & 512 & 679 & 531 \\
\hline 593 & 420 & 543 & 477 & 454 & 478 & 443 & 473 & 565 & 541 & 526 & 673 & 520 \\
\hline 591 & 426 & 549 & 483 & 467 & 459 & 446 & 471 & 567 & 538 & 535 & 666 & 528 \\
\hline 593 & 429 & 539 & 466 & 456 & 465 & 456 & 485 & 573 & 530 & 539 & 627 & 522 \\
\hline 597 & 428 & 544 & 482 & 465 & 469 & 452 & 476 & 582 & 538 & 516 & 636 & 511 \\
\hline 594 & 433 & 535 & 495 & 448 & 473 & 453 & 475 & 588 & 538 & 526 & 673 & 504 \\
\hline 593 & 428 & 552 & 515 & 451 & 464 & 455 & 465 & 591 & 546 & 512 & 726 & 508 \\
\hline 574 & 433 & 541 & 487 & 450 & 454 & 449 & 469 & 580 & 539 & 505 & 783 & 518 \\
\hline 591 & 427 & 538 & 478 & 454 & 467 & 444 & 465 & 569 & 536 & 520 & 779 & 520 \\
\hline 603 & 426 & 546 & 488 & 449 & 448 & 450 & 461 & 603 & 539 & 505 & 747 & 523 \\
\hline 581 & 422 & 536 & 514 & 446 & 460 & 449 & 456 & 584 & 534 & 507 & 713 & 519 \\
\hline 596 & 416 & 536 & 528 & 454 & 471 & 457 & 465 & 607 & 533 & 522 & 725 & 567 \\
\hline 588 & 432 & 541 & 531 & 443 & 469 & 451 & 462 & 601 & 542 & 552 & 781 & 532 \\
\hline 595 & 429 & 541 & 511 & 451 & 478 & 456 & 465 & 596 & 531 & 516 & 705 & 517 \\
\hline 594 & 420 & 528 & 509 & 443 & 475 & 458 & 452 & 603 & 539 & 516 & 651 & 534 \\
\hline 599 & 427 & 533 & 501 & 463 & 465 & 459 & 454 & 590 & 536 & 534 & 707 & 570 \\
\hline 598 & 424 & 542 & 510 & 455 & 459 & 469 & 460 & 590 & 536 & 510 & 664 & 548 \\
\hline 596 & 417 & 541 & 497 & 462 & 468 & 454 & 464 & 601 & 539 & 529 & 663 & 531 \\
\hline 593 & 422 & 542 & 501 & 450 & 466 & 459 & 460 & 598 & 537 & 521 & 639 & 518 \\
\hline 600 & 423 & 531 & 486 & 450 & 476 & 454 & 450 & 592 & 519 & 532 & 638 & 548 \\
\hline 604 & 415 & 535 & 461 & 444 & 463 & 455 & 455 & 585 & 527 & 522 & 647 & 540 \\
\hline 619 & 399 & 549 & 481 & 458 & 466 & 463 & 455 & 593 & 539 & 509 & 649 & 523 \\
\hline 610 & 406 & 546 & 457 & 456 & 476 & 468 & 449 & 581 & 526 & 510 & 668 & 520 \\
\hline 603 & 400 & 541 & 470 & 462 & 450 & 461 & 460 & 586 & 541 & 525 & 683 & 542 \\
\hline
\end{tabular}


Tabela 3 - Concentração de $\mathrm{CO}_{2}$, em ppm, no Piso 3 no ano de 2010 (Continuação).

\begin{tabular}{|c|c|c|c|c|c|c|c|c|c|c|c|c|}
\hline $7 / 5 / 10$ & $20 / 5 / 10$ & $26 / 5 / 10$ & $8 / 6 / 10$ & $15 / 6 / 10$ & $21 / 6 / 10$ & $30 / 6 / 10$ & $7 / 7 / 10$ & $14 / 7 / 10$ & $23 / 7 / 10$ & $10 / 8 / 10$ & $17 / 8 / 10$ & $8 / 9 / 10$ \\
\hline 604 & 419 & 538 & 459 & 451 & 449 & 462 & 468 & 587 & 532 & 502 & 693 & 545 \\
\hline 628 & 403 & 527 & 454 & 450 & 454 & 461 & 449 & 576 & 525 & 529 & 717 & 533 \\
\hline 593 & 409 & 532 & 462 & 452 & 457 & 466 & 453 & 592 & 535 & 503 & 690 & 535 \\
\hline 603 & 410 & 535 & 487 & 458 & 467 & 459 & 440 & 585 & 550 & 522 & 656 & 526 \\
\hline 611 & 403 & 538 & 459 & 467 & 475 & 464 & 443 & 592 & 529 & 524 & 708 & 537 \\
\hline 605 & 395 & 538 & 457 & 451 & 478 & 467 & 452 & 580 & 537 & 518 & 709 & 528 \\
\hline 604 & 412 & 534 & 463 & 463 & 482 & 470 & 443 & 566 & 536 & 511 & 678 & 528 \\
\hline 602 & 398 & 530 & 465 & 447 & 465 & 481 & 447 & 602 & 517 & 522 & 665 & 543 \\
\hline 602 & 403 & 537 & 462 & 455 & 452 & 475 & 443 & 628 & 537 & 520 & 662 & 547 \\
\hline 604 & 389 & 522 & 446 & 447 & 459 & 486 & 445 & 612 & 522 & 500 & 661 & 530 \\
\hline 595 & 405 & 526 & 491 & 446 & 446 & 479 & 435 & 608 & 536 & 502 & 655 & 525 \\
\hline 589 & 399 & 532 & 504 & 445 & 466 & 471 & 429 & 612 & 536 & 530 & 678 & 539 \\
\hline 589 & 408 & 530 & 463 & 446 & 447 & 486 & 433 & 613 & 526 & 507 & 650 & 555 \\
\hline 589 & 416 & 531 & 457 & 444 & 449 & 484 & 440 & 638 & 523 & 488 & 678 & 541 \\
\hline 597 & 388 & 539 & 477 & 452 & 449 & 470 & 437 & 633 & 522 & 488 & 676 & 540 \\
\hline 585 & 405 & 537 & 457 & 448 & 443 & 477 & 427 & 626 & 523 & 471 & 652 & 534 \\
\hline 587 & 404 & 535 & 446 & 458 & 455 & 483 & 437 & 611 & 529 & 489 & 715 & 515 \\
\hline 581 & 397 & 528 & 450 & 444 & 454 & 467 & 446 & 620 & 520 & 482 & 711 & 541 \\
\hline 586 & 397 & 538 & 460 & 444 & 439 & 499 & 443 & 615 & 519 & 480 & 697 & 536 \\
\hline 594 & 392 & 539 & 445 & 442 & 456 & 490 & 458 & 622 & 543 & 481 & 694 & 540 \\
\hline 606 & 397 & 536 & 457 & 441 & 453 & 480 & 444 & 607 & 537 & 473 & 663 & 548 \\
\hline 598 & 392 & 542 & 446 & 438 & 458 & 478 & 445 & 601 & $\mathrm{X}$ & 482 & 620 & 544 \\
\hline 622 & 399 & 547 & 449 & 447 & 457 & 473 & 440 & 582 & $\mathrm{X}$ & 488 & 618 & 587 \\
\hline 598 & 399 & 539 & 456 & 443 & 446 & 482 & 442 & 551 & $\mathrm{X}$ & 491 & 619 & 537 \\
\hline 604 & 395 & 535 & 451 & 445 & 445 & 486 & 449 & 564 & $\mathrm{X}$ & 490 & 597 & 550 \\
\hline 593 & 402 & 529 & 451 & 450 & 447 & 482 & 448 & 588 & $\mathrm{X}$ & 513 & 643 & 546 \\
\hline 587 & 400 & 530 & 441 & 450 & 454 & 481 & 443 & 595 & $\mathrm{X}$ & 498 & 605 & 551 \\
\hline 591 & 387 & 537 & 444 & 442 & 447 & 481 & 449 & 596 & $X$ & 493 & 585 & 541 \\
\hline 589 & 392 & 535 & 422 & 444 & 445 & 474 & 448 & 615 & $X$ & 495 & 598 & 545 \\
\hline 595 & 402 & 530 & 431 & 437 & 445 & 486 & 445 & 611 & $X$ & 510 & 589 & 544 \\
\hline 591 & 400 & 537 & 431 & 437 & 445 & 480 & 438 & 607 & $X$ & 511 & 584 & 598 \\
\hline 583 & 402 & 539 & 429 & 435 & 452 & 487 & 442 & 606 & $X$ & 528 & 585 & 561 \\
\hline 595 & 401 & 541 & 434 & 435 & 448 & 489 & 447 & 613 & $x$ & 497 & 596 & 555 \\
\hline 595 & 394 & 541 & 429 & 446 & 442 & 488 & 451 & 620 & $X$ & 509 & 602 & 544 \\
\hline 592 & 409 & 536 & 428 & 441 & 450 & 475 & 446 & 629 & $X$ & 506 & 592 & 552 \\
\hline 600 & 399 & 530 & 431 & 452 & 447 & 486 & 436 & 655 & $\mathrm{X}$ & 493 & 600 & 548 \\
\hline 595 & 401 & 536 & 421 & 438 & 448 & 491 & 447 & 642 & $X$ & 497 & 591 & 559 \\
\hline 593 & 392 & 531 & 434 & 450 & 450 & 472 & 441 & 657 & $X$ & 501 & 597 & 549 \\
\hline 600 & 392 & 543 & 438 & 437 & 448 & 482 & 443 & 659 & $X$ & 493 & 602 & 554 \\
\hline 601 & 391 & 533 & 426 & 444 & 463 & 479 & 436 & 676 & $X$ & 502 & 610 & 548 \\
\hline 591 & 398 & 541 & 430 & 443 & 458 & 467 & 437 & 681 & $\mathrm{X}$ & 498 & 580 & 518 \\
\hline 595 & 395 & 524 & 438 & 435 & 450 & 468 & 445 & 707 & $X$ & 499 & 613 & 540 \\
\hline 601 & 388 & 535 & 419 & 438 & 463 & 469 & 437 & 709 & $X$ & 501 & 609 & 540 \\
\hline 593 & 392 & 532 & 424 & 427 & 455 & 474 & 454 & 762 & $X$ & 509 & 617 & 534 \\
\hline 591 & 399 & 539 & 406 & 440 & 448 & 468 & 449 & 757 & $X$ & 506 & 598 & 559 \\
\hline 596 & 391 & 530 & 405 & 440 & 466 & 471 & 443 & 780 & $\mathrm{X}$ & 497 & 591 & 531 \\
\hline 592 & 404 & 532 & 415 & 440 & 473 & 476 & 469 & 785 & $\mathrm{X}$ & 500 & 600 & 533 \\
\hline 595 & 389 & 542 & 409 & 435 & 452 & 472 & 454 & 777 & $X$ & 489 & 619 & 542 \\
\hline 599 & 401 & 537 & 405 & 438 & 447 & 480 & 450 & 798 & $\mathrm{X}$ & 496 & 641 & 559 \\
\hline 596 & 394 & 539 & 414 & 424 & 446 & 479 & 455 & 789 & $X$ & 527 & 629 & 575 \\
\hline 597 & 385 & 520 & 441 & 435 & 447 & 490 & 428 & 785 & $\mathrm{X}$ & 513 & 617 & 572 \\
\hline 592 & 389 & 530 & 434 & 428 & 445 & 467 & 442 & 777 & $X$ & 501 & 608 & 536 \\
\hline 583 & 398 & 539 & 420 & 464 & 444 & 491 & 439 & 768 & $X$ & 530 & 617 & 567 \\
\hline 592 & 394 & 540 & 424 & 432 & 455 & 488 & 444 & 759 & $\mathrm{X}$ & 532 & 610 & 563 \\
\hline 590 & 395 & 550 & 412 & 429 & 443 & 477 & 463 & 761 & $\mathrm{X}$ & 517 & 629 & 532 \\
\hline 584 & 397 & 546 & 405 & 438 & 446 & 479 & 443 & 754 & $X$ & 501 & 603 & 530 \\
\hline 593 & 392 & 534 & 420 & 437 & 434 & 483 & 442 & 754 & $X$ & 527 & 603 & 531 \\
\hline 591 & 403 & 543 & 418 & 431 & 445 & 487 & 432 & 754 & $X$ & 519 & 612 & 529 \\
\hline 596 & 395 & 537 & 411 & 425 & 439 & 481 & 453 & 741 & $X$ & 512 & 601 & 532 \\
\hline 589 & 400 & 523 & 397 & 410 & 442 & 477 & 463 & 736 & $\mathrm{X}$ & 550 & 649 & 528 \\
\hline 590 & 394 & 527 & 399 & 415 & 448 & 477 & 449 & 723 & $X$ & 530 & 677 & 520 \\
\hline 594 & 397 & 547 & 406 & 441 & 450 & 481 & 441 & 718 & $\mathrm{X}$ & 529 & 656 & 521 \\
\hline 580 & 396 & 540 & 413 & 436 & 447 & 486 & 433 & 713 & $X$ & 523 & 655 & 549 \\
\hline 589 & 390 & 535 & 409 & 449 & 440 & 481 & 446 & 703 & $X$ & 534 & 610 & 537 \\
\hline 601 & 388 & 533 & 411 & 433 & 447 & 480 & 449 & 697 & $X$ & 530 & 607 & 546 \\
\hline 602 & 380 & 531 & 406 & 450 & 440 & 474 & 440 & 683 & $X$ & 529 & 614 & 551 \\
\hline 599 & 389 & 536 & 418 & 445 & 454 & 487 & 434 & 700 & $\mathrm{X}$ & 526 & 615 & 535 \\
\hline 587 & 395 & 539 & 423 & 444 & 443 & 495 & 439 & 688 & $\mathrm{X}$ & 540 & 596 & 543 \\
\hline 596 & 377 & 524 & 435 & 441 & 438 & 500 & 440 & 689 & $X$ & 544 & 645 & 606 \\
\hline 590 & 389 & 529 & 447 & 439 & 443 & 488 & 449 & 686 & $X$ & 544 & 612 & 550 \\
\hline 593 & 391 & 544 & 466 & 436 & 455 & 491 & 444 & 686 & $X$ & 539 & 604 & 560 \\
\hline 592 & 388 & 541 & 454 & 440 & 450 & 486 & 450 & 715 & $\mathrm{X}$ & 517 & 613 & 553 \\
\hline 589 & 383 & 540 & 442 & 445 & 445 & 495 & 447 & 666 & $\mathrm{X}$ & 533 & 604 & 535 \\
\hline 596 & 382 & 533 & 443 & 437 & 436 & 497 & 466 & 666 & $X$ & 530 & 621 & 544 \\
\hline 593 & 389 & 543 & 438 & 441 & 445 & 502 & 463 & 656 & $\mathrm{X}$ & 548 & 615 & 540 \\
\hline 591 & 392 & 538 & 433 & 450 & 446 & 494 & 449 & 662 & $X$ & 597 & 590 & 541 \\
\hline 574 & 392 & 532 & 460 & 441 & 465 & 496 & 464 & 639 & $X$ & 551 & 607 & 547 \\
\hline
\end{tabular}


Tabela 3 - Concentração de $\mathrm{CO}_{2}$, em ppm, no Piso 3 no ano de 2010 (Continuação).

\begin{tabular}{|c|c|c|c|c|c|c|c|c|c|c|c|c|}
\hline $7 / 5 / 10$ & $20 / 5 / 10$ & $26 / 5 / 10$ & $8 / 6 / 10$ & $15 / 6 / 10$ & $21 / 6 / 10$ & $30 / 6 / 10$ & $7 / 7 / 10$ & $14 / 7 / 10$ & $23 / 7 / 10$ & $10 / 8 / 10$ & $17 / 8 / 10$ & $8 / 9 / 10$ \\
\hline 589 & 390 & 540 & 458 & 438 & 463 & 493 & 457 & $\mathrm{X}$ & $\mathrm{X}$ & 530 & 624 & 563 \\
\hline 590 & 381 & $\mathrm{X}$ & 455 & 432 & 454 & 500 & 454 & $\mathrm{X}$ & $\mathrm{X}$ & 532 & 657 & 574 \\
\hline 595 & 385 & $\mathrm{X}$ & 473 & 451 & 451 & 502 & 454 & $\mathrm{X}$ & $\mathrm{X}$ & 553 & 614 & 541 \\
\hline 592 & 393 & $\mathrm{X}$ & 497 & 445 & 440 & 499 & $\mathrm{X}$ & $\mathrm{X}$ & $\mathrm{X}$ & 548 & 648 & 537 \\
\hline 599 & 382 & $\mathrm{X}$ & 494 & 449 & 459 & 514 & $\mathrm{X}$ & $\mathrm{X}$ & $\mathrm{X}$ & 556 & 625 & 548 \\
\hline 607 & 385 & $\mathrm{X}$ & 491 & 454 & 445 & 504 & $\mathrm{X}$ & $\mathrm{X}$ & $\mathrm{X}$ & 543 & 588 & 559 \\
\hline $\mathrm{X}$ & $\mathrm{X}$ & $\mathrm{X}$ & 481 & 443 & $\mathrm{X}$ & $\mathrm{X}$ & $\mathrm{X}$ & $\mathrm{X}$ & $\mathrm{X}$ & 542 & 606 & 549 \\
\hline $\mathrm{X}$ & $X$ & $\mathrm{X}$ & 486 & 436 & $\mathrm{X}$ & $\mathrm{X}$ & $\mathrm{X}$ & $\mathrm{X}$ & $\mathrm{X}$ & 532 & $\mathrm{X}$ & $\mathrm{X}$ \\
\hline $\mathrm{X}$ & $\mathrm{X}$ & $\mathrm{X}$ & 497 & $\mathrm{X}$ & $\mathrm{X}$ & $\mathrm{X}$ & $\mathrm{X}$ & $\mathrm{X}$ & $\mathrm{X}$ & 529 & $\mathrm{X}$ & $\mathrm{X}$ \\
\hline $\mathrm{X}$ & $\mathrm{X}$ & $\mathrm{X}$ & 480 & $\mathrm{X}$ & $\mathrm{X}$ & $X$ & $X$ & $\mathrm{X}$ & $X$ & 560 & $X$ & $X$ \\
\hline $\mathrm{X}$ & $X$ & $X$ & 475 & $X$ & $X$ & $X$ & $X$ & $X$ & $\mathrm{X}$ & 561 & $\mathrm{X}$ & $\mathrm{X}$ \\
\hline
\end{tabular}


Tabela 4 - Concentração de $\mathrm{CO}_{2}$, em ppm, no ambiente externo.

\begin{tabular}{|c|c|c|c|c|c|c|c|c|c|c|c|}
\hline $8 / 4 / 10$ & $11 / 5 / 10$ & $25 / 5 / 10$ & $2 / 6 / 10$ & $16 / 6 / 10$ & $22 / 6 / 10$ & $1 / 7 / 10$ & $6 / 7 / 10$ & $20 / 7 / 10$ & $5 / 8 / 10$ & $19 / 8 / 10$ & $3 / 9 / 10$ \\
\hline 487 & 411 & 445 & 466 & 406 & 390 & 509 & 449 & 537 & 492 & 471 & 433 \\
\hline 455 & 397 & 436 & 470 & 397 & 381 & 489 & 438 & 507 & 494 & 462 & 425 \\
\hline 460 & 388 & 427 & 475 & 402 & 386 & 495 & 441 & 508 & 499 & 452 & 423 \\
\hline 460 & 402 & 437 & 470 & 399 & 391 & 488 & 431 & 496 & 483 & 461 & 416 \\
\hline 452 & 394 & 446 & 462 & 398 & 390 & 478 & 440 & 523 & 488 & 476 & 423 \\
\hline 440 & 409 & 449 & 459 & 399 & 393 & 479 & 442 & 563 & 494 & 455 & 411 \\
\hline 442 & 395 & 440 & 479 & 420 & 389 & 466 & 427 & 548 & 490 & 444 & 399 \\
\hline 455 & 384 & 433 & 454 & 407 & 383 & 460 & 441 & 504 & 473 & 455 & 407 \\
\hline 445 & 407 & 436 & 445 & 429 & 386 & 472 & 431 & 491 & 477 & 455 & 415 \\
\hline 459 & 395 & 450 & 454 & 423 & 383 & 462 & 425 & 492 & 477 & 450 & 413 \\
\hline 452 & 411 & 448 & 446 & 436 & 394 & 483 & 460 & 495 & 497 & 448 & 428 \\
\hline 457 & 409 & 464 & 453 & 428 & 399 & 475 & 460 & 505 & 492 & 444 & 416 \\
\hline 454 & 404 & 452 & 471 & 399 & 417 & 477 & 442 & 485 & 471 & 448 & 425 \\
\hline 445 & 402 & 441 & 457 & 429 & 430 & 469 & 423 & 486 & 484 & 460 & 422 \\
\hline 450 & 380 & 438 & 447 & 427 & 415 & 452 & 431 & 502 & 483 & 451 & 426 \\
\hline 456 & 394 & 437 & 453 & 417 & 419 & 469 & 412 & 503 & 472 & 440 & 412 \\
\hline 466 & 382 & 447 & 451 & 413 & 434 & 457 & 417 & 514 & 483 & 435 & 439 \\
\hline 462 & 395 & 464 & 442 & 411 & 412 & 459 & 425 & 544 & 481 & 439 & 451 \\
\hline 461 & 401 & 468 & 424 & 408 & 420 & 450 & 424 & 539 & 464 & 432 & 437 \\
\hline 454 & 392 & 494 & 440 & 394 & 429 & 465 & 425 & 543 & 480 & 432 & 428 \\
\hline 455 & 405 & 505 & 437 & 386 & 417 & 459 & 416 & 538 & 479 & 438 & 424 \\
\hline 448 & 385 & 493 & 422 & 401 & 412 & 460 & 421 & 553 & 481 & 433 & 429 \\
\hline 447 & 386 & 505 & 434 & 395 & 423 & 478 & 429 & 560 & 489 & 440 & 427 \\
\hline 440 & 389 & 509 & 423 & 409 & 423 & 459 & 413 & 556 & 478 & 438 & 434 \\
\hline 447 & 402 & 511 & 422 & 400 & 424 & 463 & 406 & 550 & 496 & 449 & 438 \\
\hline 460 & 412 & 491 & 430 & 394 & 415 & 444 & 412 & 564 & 491 & 436 & 426 \\
\hline 466 & 392 & 506 & 425 & 394 & 431 & 445 & 425 & 574 & 480 & 438 & 440 \\
\hline 475 & 387 & 524 & 423 & 403 & 427 & 455 & 430 & 582 & 471 & 432 & 437 \\
\hline 484 & 380 & 498 & 430 & 411 & 417 & 443 & 433 & 556 & 484 & 436 & 451 \\
\hline 470 & 386 & 518 & 428 & 414 & 428 & 431 & 439 & 569 & 480 & 459 & 447 \\
\hline 461 & 401 & 509 & 428 & 381 & 421 & 439 & 444 & 572 & 486 & 458 & 445 \\
\hline 463 & 399 & 513 & 422 & 392 & 433 & 452 & 435 & 587 & 495 & 437 & 436 \\
\hline $\begin{array}{l}458 \\
\end{array}$ & 395 & 512 & 436 & 390 & 427 & 444 & 446 & 609 & 483 & 433 & 437 \\
\hline 477 & 381 & 525 & 415 & 385 & 427 & 440 & 474 & 611 & 473 & 437 & 418 \\
\hline 467 & 385 & 523 & 421 & 392 & 441 & 434 & 456 & 601 & 486 & 449 & 426 \\
\hline 473 & 419 & 553 & 436 & 381 & 435 & 428 & 460 & 606 & 475 & 440 & 444 \\
\hline 468 & 393 & 539 & 434 & 394 & 431 & 443 & 474 & 650 & 479 & 442 & 447 \\
\hline 468 & 387 & 523 & 413 & 395 & 437 & 430 & 448 & 639 & 474 & 431 & 451 \\
\hline 470 & 398 & 527 & 407 & 401 & 424 & 441 & 453 & 623 & 476 & 444 & 434 \\
\hline 484 & 392 & 507 & 417 & 393 & 432 & 448 & 451 & 640 & 494 & 438 & 444 \\
\hline 480 & 396 & 520 & 427 & 410 & 426 & 431 & 439 & 632 & 473 & 436 & 446 \\
\hline 493 & 386 & 516 & 425 & 415 & 432 & 435 & 453 & 658 & 471 & 447 & 426 \\
\hline 473 & 419 & 512 & 430 & 426 & 441 & 428 & 472 & 637 & 485 & 445 & 437 \\
\hline 468 & 409 & 519 & 413 & 404 & 431 & 417 & 461 & 617 & 484 & 442 & 438 \\
\hline 478 & 401 & 540 & 429 & 428 & 434 & 412 & 450 & 637 & 472 & 435 & 425 \\
\hline 480 & 389 & 522 & 437 & 420 & 429 & 407 & 451 & 617 & 478 & 443 & 439 \\
\hline 469 & 402 & 524 & 438 & 424 & 430 & 428 & 442 & 602 & 479 & 450 & 439 \\
\hline 474 & 407 & 531 & 436 & 419 & 434 & 420 & 436 & 623 & 480 & 439 & 428 \\
\hline 465 & 421 & 541 & 431 & 422 & 437 & 423 & 439 & 654 & 485 & 439 & 438 \\
\hline 492 & 402 & 557 & 414 & 432 & 434 & 413 & 457 & 651 & 497 & 447 & 426 \\
\hline 489 & 387 & 556 & 417 & 426 & 426 & 411 & 491 & 642 & 485 & 440 & 432 \\
\hline 475 & 385 & 550 & 429 & 412 & 439 & 417 & 486 & 636 & 476 & 439 & 439 \\
\hline 461 & 397 & 539 & 430 & 418 & 439 & 419 & 486 & 610 & 472 & 440 & 436 \\
\hline 454 & 395 & 551 & 412 & 421 & 446 & 426 & 480 & 622 & 482 & 445 & 419 \\
\hline 458 & 397 & 543 & 416 & 402 & 439 & 423 & 469 & 637 & 500 & 432 & 433 \\
\hline 448 & 390 & 547 & 412 & 427 & 440 & 414 & 472 & 637 & 489 & 439 & 414 \\
\hline 451 & 410 & 543 & 420 & 435 & 437 & 429 & 496 & 625 & 486 & 440 & 430 \\
\hline 463 & 405 & 548 & 435 & 421 & 441 & 425 & 485 & 655 & 486 & 436 & 439 \\
\hline 480 & 389 & 563 & 418 & 438 & 439 & 420 & 470 & 631 & 492 & 444 & 429 \\
\hline 478 & 380 & 561 & 408 & 440 & 440 & 408 & 486 & 612 & 496 & 438 & 424 \\
\hline 477 & 379 & 559 & 418 & 424 & 432 & 429 & 496 & 621 & 495 & 440 & 420 \\
\hline 458 & 383 & 543 & 414 & 447 & 447 & 447 & 503 & 609 & 492 & 436 & 432 \\
\hline 456 & 394 & 539 & 426 & 422 & 438 & 441 & 487 & 607 & 498 & 428 & 428 \\
\hline 448 & 393 & 545 & 418 & 417 & 448 & 442 & 481 & 619 & 486 & 463 & 447 \\
\hline 460 & 385 & 556 & 424 & 413 & 443 & 423 & 482 & 621 & 488 & 432 & 442 \\
\hline 498 & 378 & 549 & 424 & 417 & 439 & 440 & 504 & 634 & 498 & 444 & 432 \\
\hline 476 & 416 & 543 & 408 & 415 & 430 & 431 & 475 & 616 & 495 & 435 & 447 \\
\hline 476 & 404 & 556 & 408 & 443 & 444 & 443 & 475 & 618 & 496 & 443 & 437 \\
\hline 473 & 381 & 551 & 408 & 448 & 447 & 420 & 488 & 622 & 490 & 443 & 426 \\
\hline 457 & 375 & 546 & 417 & 433 & 436 & 433 & 488 & 604 & 484 & 438 & 427 \\
\hline 483 & 376 & 547 & 435 & 410 & 444 & 437 & 490 & 598 & 492 & 443 & 448 \\
\hline 477 & 375 & 554 & 423 & 426 & 442 & 423 & 490 & 621 & 491 & 451 & 424 \\
\hline 495 & 395 & 548 & 426 & 441 & 459 & 425 & 470 & 610 & 493 & 465 & 428 \\
\hline 460 & 398 & 546 & 405 & 449 & 437 & 424 & 473 & 601 & 497 & 455 & 436 \\
\hline 484 & 408 & 544 & 411 & 444 & 448 & 414 & 488 & 611 & 499 & 435 & 440 \\
\hline 483 & 405 & 551 & 409 & 428 & 445 & 418 & 490 & 628 & 489 & 418 & 416 \\
\hline 477 & 387 & 562 & 421 & 443 & 447 & 424 & 509 & 628 & 489 & 429 & 431 \\
\hline
\end{tabular}


Tabela 4 - Concentração de $\mathrm{CO}_{2}$, em ppm, no ambiente externo(Continuação).

\begin{tabular}{|c|c|c|c|c|c|c|c|c|c|c|c|}
\hline $8 / 4 / 10$ & $11 / 5 / 10$ & $25 / 5 / 10$ & $2 / 6 / 10$ & $16 / 6 / 10$ & $22 / 6 / 10$ & $1 / 7 / 10$ & $6 / 7 / 10$ & $20 / 7 / 10$ & $5 / 8 / 10$ & $19 / 8 / 10$ & $3 / 9 / 10$ \\
\hline 473 & 398 & 542 & 415 & 441 & 446 & 453 & 472 & 615 & 497 & 431 & 431 \\
\hline 472 & 369 & 556 & 401 & 442 & 448 & 420 & 484 & 604 & 493 & 440 & 424 \\
\hline 482 & 384 & 557 & 416 & 441 & 445 & 418 & 522 & 601 & 491 & 430 & 443 \\
\hline 484 & 388 & 551 & 406 & 451 & 454 & 411 & 496 & 616 & 493 & 429 & 435 \\
\hline 475 & 391 & 548 & 409 & 448 & 453 & 425 & 476 & 602 & 489 & 462 & 448 \\
\hline 471 & 399 & 553 & 411 & 458 & 447 & 416 & 490 & 597 & 490 & 417 & 443 \\
\hline 476 & 379 & $\mathrm{X}$ & 403 & 458 & 436 & 434 & 508 & 596 & 514 & 436 & 444 \\
\hline 492 & 375 & $\mathrm{X}$ & 401 & 440 & 447 & 409 & 499 & 600 & 503 & 431 & 421 \\
\hline 501 & 394 & $\mathrm{X}$ & 401 & 462 & 447 & 411 & 481 & 601 & 489 & 425 & 444 \\
\hline 509 & 379 & $X$ & 407 & 449 & 444 & 418 & 485 & 612 & 493 & 433 & 439 \\
\hline 523 & 382 & $\mathrm{X}$ & 418 & 459 & 458 & 409 & 489 & 603 & 503 & 424 & 415 \\
\hline 532 & 377 & $\mathrm{X}$ & 428 & 441 & 459 & 399 & 487 & 593 & 496 & 416 & 428 \\
\hline 531 & 378 & $X$ & 430 & 450 & 459 & 413 & 464 & 583 & 491 & 447 & 426 \\
\hline 510 & 382 & $\mathrm{X}$ & 427 & 432 & 463 & 414 & 467 & 586 & 497 & 438 & 432 \\
\hline 520 & 392 & $X$ & 429 & 436 & 447 & 431 & 488 & 594 & 499 & 424 & 428 \\
\hline 518 & 377 & $\mathrm{X}$ & 415 & 449 & 444 & 435 & 492 & 594 & 491 & 444 & 438 \\
\hline 528 & 382 & $\mathrm{X}$ & 416 & 466 & 464 & 423 & 506 & 613 & 491 & 433 & 433 \\
\hline 532 & 388 & $X$ & 404 & 465 & 463 & 416 & 484 & 592 & 513 & 418 & 434 \\
\hline 540 & 394 & $X$ & 418 & 455 & 457 & 416 & 479 & 603 & 498 & 439 & 435 \\
\hline 546 & 387 & $X$ & 399 & 462 & 453 & 435 & 476 & 584 & 515 & 436 & 427 \\
\hline 520 & 385 & $\mathrm{X}$ & 420 & 468 & 476 & 426 & 482 & 592 & 482 & 422 & 425 \\
\hline 546 & 373 & $\mathrm{X}$ & 430 & 447 & 479 & 417 & 485 & 578 & 480 & 454 & 436 \\
\hline 522 & 383 & $X$ & 427 & 457 & 454 & 422 & 504 & 589 & 492 & 435 & 445 \\
\hline 534 & 391 & $X$ & 423 & 436 & 448 & 429 & 514 & 606 & 490 & 445 & 453 \\
\hline 532 & 384 & $\mathrm{X}$ & 424 & 443 & 472 & 412 & 488 & 590 & 474 & 443 & 448 \\
\hline 524 & 373 & $\mathrm{X}$ & 412 & 438 & 460 & 417 & 490 & 595 & 490 & 446 & 433 \\
\hline 564 & 389 & $\mathrm{X}$ & 406 & 431 & 447 & 425 & 499 & 590 & 484 & 443 & 442 \\
\hline 534 & 398 & $X$ & 416 & 452 & 453 & 403 & 499 & 594 & 494 & 433 & 425 \\
\hline 524 & 383 & $\mathrm{X}$ & 424 & 463 & 453 & 405 & 506 & 590 & 489 & 425 & 423 \\
\hline 504 & 383 & $\mathrm{X}$ & 427 & 449 & 456 & 419 & 493 & 596 & 478 & 425 & 434 \\
\hline 521 & 369 & $\mathrm{X}$ & 404 & 456 & 450 & 412 & 503 & 597 & 477 & 444 & 431 \\
\hline 523 & 377 & $\mathrm{X}$ & 423 & 451 & 462 & 413 & 496 & 577 & 481 & 434 & 433 \\
\hline 508 & 379 & $X$ & 407 & 452 & 466 & 409 & 483 & 574 & 487 & 419 & 428 \\
\hline 523 & 369 & $\mathrm{X}$ & 411 & 452 & 455 & 411 & 499 & 588 & 508 & 451 & 446 \\
\hline 528 & 370 & $\mathrm{X}$ & 421 & 433 & 461 & 411 & 501 & 588 & 488 & 420 & 428 \\
\hline 542 & 373 & $X$ & 407 & 461 & 462 & 428 & 494 & 574 & 481 & 417 & 414 \\
\hline $\mathrm{X}$ & 385 & $\mathrm{X}$ & 406 & 440 & 456 & 432 & 474 & 588 & 477 & 443 & 421 \\
\hline $\mathrm{X}$ & 379 & $\mathrm{X}$ & 414 & 443 & 480 & 408 & 470 & 592 & 492 & 426 & 419 \\
\hline$X$ & 376 & $X$ & 421 & 434 & 473 & 411 & 504 & 613 & 489 & 426 & 434 \\
\hline $\mathrm{X}$ & 378 & $\mathrm{X}$ & 420 & 443 & 458 & 425 & 511 & 616 & 493 & 430 & 434 \\
\hline$X$ & 372 & $X$ & 416 & 445 & 463 & 424 & 525 & 614 & 497 & 424 & 428 \\
\hline $\mathrm{X}$ & 392 & $\mathrm{X}$ & 420 & 442 & 464 & 419 & 514 & 637 & 484 & 427 & 440 \\
\hline $\mathrm{X}$ & 369 & $\mathrm{X}$ & 413 & 446 & 475 & 429 & 530 & 627 & 496 & 442 & 419 \\
\hline $\mathrm{X}$ & 374 & $\mathrm{X}$ & 416 & 446 & 475 & 414 & 504 & 608 & 480 & 430 & 442 \\
\hline$X$ & 389 & $X$ & 407 & 455 & 474 & 418 & 504 & 616 & 482 & 444 & 435 \\
\hline$X$ & 387 & $X$ & 413 & 473 & 482 & 436 & 508 & 618 & 499 & 447 & 429 \\
\hline $\mathrm{X}$ & 386 & $\mathrm{X}$ & 404 & 461 & 458 & 425 & 496 & 626 & 486 & 436 & 433 \\
\hline $\mathrm{X}$ & 393 & $\mathrm{X}$ & 422 & 444 & 454 & 421 & 522 & 606 & 486 & 438 & 443 \\
\hline$X$ & 379 & $X$ & 424 & 444 & 468 & 417 & 506 & 605 & 487 & 427 & 438 \\
\hline$x$ & 378 & $x$ & 431 & 441 & 477 & 419 & 512 & 587 & 501 & 438 & 459 \\
\hline $\mathrm{X}$ & 374 & $\mathrm{X}$ & 422 & 474 & 466 & 407 & 492 & 599 & 487 & 421 & 439 \\
\hline $\mathrm{X}$ & 394 & $\mathrm{X}$ & 419 & 470 & 463 & 398 & 491 & 598 & 480 & 431 & 453 \\
\hline $\mathrm{X}$ & 383 & $\mathrm{X}$ & 421 & 453 & 473 & 402 & 503 & 595 & 476 & 431 & 442 \\
\hline$X$ & 384 & $X$ & 426 & 475 & 466 & 420 & 520 & 596 & 487 & 448 & 434 \\
\hline $\mathrm{X}$ & 386 & $\mathrm{X}$ & 423 & 459 & 468 & 426 & 515 & 602 & 490 & 428 & 447 \\
\hline$X$ & 391 & $\mathrm{X}$ & 414 & 466 & 467 & 409 & 506 & 597 & 486 & 433 & 442 \\
\hline $\mathrm{X}$ & 387 & $\mathrm{X}$ & 410 & 477 & 459 & 405 & 530 & 603 & 520 & 433 & 443 \\
\hline $\mathrm{X}$ & 384 & $\mathrm{X}$ & 406 & 452 & 450 & 413 & 528 & 580 & 500 & 450 & 423 \\
\hline$X$ & 383 & $X$ & 413 & 449 & 459 & 410 & 537 & 613 & 510 & 436 & 433 \\
\hline $\mathrm{X}$ & 375 & $\mathrm{X}$ & 407 & 464 & 476 & 411 & 534 & 623 & 494 & 425 & 429 \\
\hline$X$ & 371 & $\mathrm{X}$ & 414 & 466 & 463 & 422 & 512 & 630 & 502 & 438 & 422 \\
\hline$X$ & 385 & $X$ & 406 & 460 & 480 & 401 & 500 & 632 & $\begin{array}{l}508 \\
\end{array}$ & 437 & 407 \\
\hline $\mathrm{X}$ & 383 & $\mathrm{X}$ & 413 & 447 & 498 & 413 & 505 & 625 & 498 & 435 & 425 \\
\hline $\mathrm{X}$ & 379 & $\mathrm{X}$ & 432 & 466 & 471 & 403 & 548 & 607 & 512 & 441 & 428 \\
\hline $\mathrm{X}$ & 390 & $\mathrm{X}$ & 417 & 452 & 462 & 392 & 535 & 608 & 500 & 422 & 431 \\
\hline$X$ & 386 & $\mathrm{X}$ & 407 & 462 & 463 & 412 & 530 & 622 & 495 & 402 & 429 \\
\hline$X$ & 373 & $X$ & 431 & 451 & 469 & 409 & 527 & 638 & 497 & 417 & 436 \\
\hline $\mathrm{X}$ & 367 & $\mathrm{X}$ & 424 & 467 & 473 & 423 & 522 & 621 & 505 & 435 & 447 \\
\hline $\mathrm{X}$ & 390 & $\mathrm{X}$ & 416 & 445 & 459 & 394 & 510 & 614 & 508 & 439 & 449 \\
\hline$X$ & 388 & $X$ & 411 & 450 & 470 & 404 & 504 & 627 & 480 & 434 & 443 \\
\hline$x$ & 384 & $x$ & 426 & 467 & 466 & 410 & 503 & 623 & 458 & 423 & 450 \\
\hline$X$ & 385 & $X$ & 430 & 453 & 463 & 403 & 501 & 606 & 491 & 430 & 427 \\
\hline $\mathrm{X}$ & 364 & $\mathrm{X}$ & 411 & 450 & 461 & 398 & 511 & 613 & 491 & 428 & 447 \\
\hline $\mathrm{X}$ & 380 & $\mathrm{X}$ & 421 & 435 & 471 & 399 & 502 & 603 & 494 & 412 & 431 \\
\hline$X$ & 388 & $X$ & 413 & 458 & 468 & 394 & 499 & 608 & 475 & 436 & 450 \\
\hline $\mathrm{X}$ & 373 & $\mathrm{X}$ & 406 & 444 & 470 & 392 & 511 & 599 & 472 & 434 & 443 \\
\hline $\mathrm{X}$ & 385 & $\mathrm{X}$ & 412 & 420 & 475 & 419 & 499 & 605 & 467 & 417 & 445 \\
\hline
\end{tabular}


Tabela 4 - Concentração de $\mathrm{CO}_{2}$, em ppm, no ambiente externo(Continuação).

\begin{tabular}{|c|c|c|c|c|c|c|c|c|c|c|c|}
\hline $8 / 4 / 10$ & $11 / 5 / 10$ & $25 / 5 / 10$ & $2 / 6 / 10$ & $16 / 6 / 10$ & $22 / 6 / 10$ & $1 / 7 / 10$ & $6 / 7 / 10$ & $20 / 7 / 10$ & $5 / 8 / 10$ & $19 / 8 / 10$ & $3 / 9 / 10$ \\
\hline $\mathrm{X}$ & 386 & $\mathrm{X}$ & 422 & 439 & 470 & 393 & 505 & 606 & 471 & 422 & 421 \\
\hline $\mathrm{X}$ & 380 & $\mathrm{X}$ & 419 & 453 & 457 & 397 & 536 & 601 & 501 & 439 & 435 \\
\hline $\mathrm{X}$ & 387 & $\mathrm{X}$ & 428 & 442 & 467 & 395 & 517 & 577 & 491 & 436 & 435 \\
\hline $\mathrm{X}$ & 386 & $\mathrm{X}$ & 418 & 451 & 474 & 412 & 516 & 586 & 497 & 440 & 458 \\
\hline $\mathrm{X}$ & 377 & $\mathrm{X}$ & 402 & 441 & 477 & 403 & 515 & 597 & 504 & 424 & 428 \\
\hline $\mathrm{X}$ & 382 & $\mathrm{X}$ & 411 & 447 & 473 & 412 & 503 & 606 & 490 & 427 & 434 \\
\hline $\mathrm{X}$ & 402 & $\mathrm{X}$ & 420 & 463 & 472 & 396 & 512 & 613 & 485 & 437 & 451 \\
\hline $\mathrm{X}$ & 379 & $\mathrm{X}$ & 400 & 451 & 468 & 402 & 523 & 600 & 502 & 433 & 447 \\
\hline $\mathrm{X}$ & 382 & $X$ & 415 & 465 & 465 & 400 & 525 & 593 & 486 & 434 & 437 \\
\hline $\mathrm{X}$ & 387 & $X$ & 425 & 448 & 469 & 400 & 509 & 596 & 477 & 431 & 438 \\
\hline $\mathrm{X}$ & 391 & $\mathrm{X}$ & 410 & 469 & 462 & 416 & 508 & 583 & 506 & 419 & 444 \\
\hline $\mathrm{X}$ & 392 & $\mathrm{X}$ & 410 & 473 & 475 & 403 & 507 & 597 & 499 & 438 & 437 \\
\hline $\mathrm{X}$ & 396 & $X$ & 411 & 470 & 456 & 397 & 529 & 613 & 473 & 420 & 430 \\
\hline $\mathrm{X}$ & 384 & $X$ & 410 & 443 & 456 & 396 & 513 & 597 & 472 & 428 & 424 \\
\hline $\mathrm{X}$ & 391 & $X$ & 423 & 463 & 473 & 406 & 509 & 587 & 463 & 432 & 416 \\
\hline $\mathrm{X}$ & 381 & $\mathrm{X}$ & 424 & 466 & 459 & 407 & 501 & 584 & 462 & 438 & 419 \\
\hline $\mathrm{X}$ & 385 & $\mathrm{X}$ & 426 & 459 & 472 & 390 & 530 & 596 & 484 & 426 & 424 \\
\hline $\mathrm{X}$ & 377 & $\mathrm{X}$ & 415 & 471 & 456 & 402 & 514 & 588 & 492 & 436 & 434 \\
\hline $\mathrm{X}$ & 382 & $X$ & 421 & 460 & 452 & 437 & 506 & 574 & 485 & 434 & 454 \\
\hline $\mathrm{X}$ & 401 & $\mathrm{X}$ & 417 & 463 & 458 & 431 & 514 & 574 & 469 & 416 & 440 \\
\hline $\mathrm{X}$ & 384 & $\mathrm{X}$ & 430 & 480 & 448 & 421 & 495 & 599 & 467 & 421 & 429 \\
\hline $\mathrm{X}$ & 386 & $\mathrm{X}$ & 403 & 463 & 478 & 400 & 486 & 589 & 491 & 417 & 432 \\
\hline $\mathrm{X}$ & 399 & $X$ & 409 & 461 & 474 & 402 & 500 & 599 & 483 & 434 & 422 \\
\hline $\mathrm{X}$ & 379 & $\mathrm{X}$ & 410 & 475 & 461 & 394 & 502 & 605 & 485 & 432 & 425 \\
\hline$x$ & 391 & $\mathrm{X}$ & 426 & 481 & 467 & 394 & 505 & 601 & 490 & 426 & 434 \\
\hline$X$ & 382 & $\mathrm{X}$ & 428 & 470 & 471 & 404 & 501 & 578 & 484 & 418 & 440 \\
\hline $\mathrm{X}$ & 397 & $\mathrm{X}$ & 426 & 454 & 456 & 387 & 501 & 595 & 491 & 425 & 450 \\
\hline $\mathrm{X}$ & 391 & $X$ & 420 & 467 & 461 & 405 & 517 & 593 & 488 & 438 & 444 \\
\hline $\mathrm{X}$ & 393 & $\mathrm{X}$ & 426 & 458 & 452 & 391 & 508 & 581 & 482 & 436 & 420 \\
\hline $\mathrm{X}$ & 385 & $\mathrm{X}$ & 425 & 459 & 454 & 405 & 515 & 577 & 481 & 440 & 415 \\
\hline $\mathrm{X}$ & 382 & $\mathrm{X}$ & 413 & 455 & 461 & 409 & 542 & 589 & 488 & 430 & 424 \\
\hline$X$ & 378 & $X$ & 430 & 455 & 452 & 397 & 540 & 570 & 502 & 434 & 439 \\
\hline$X$ & 376 & $X$ & 422 & 476 & 447 & 385 & 524 & 579 & 491 & 423 & 442 \\
\hline $\mathrm{X}$ & 368 & $\mathrm{X}$ & 429 & 447 & 450 & 399 & 527 & 594 & 481 & 419 & 437 \\
\hline $\mathrm{X}$ & 380 & $\mathrm{X}$ & 434 & 439 & 454 & 394 & 506 & 603 & 496 & 429 & 434 \\
\hline $\mathrm{X}$ & 374 & $\mathrm{X}$ & 432 & 467 & 459 & 375 & 508 & 600 & 483 & 416 & 409 \\
\hline $\mathrm{X}$ & 384 & $\mathrm{X}$ & 440 & 458 & 460 & 390 & 521 & 575 & 503 & 426 & 435 \\
\hline $\mathrm{X}$ & 389 & $\mathrm{X}$ & 425 & 448 & 446 & 387 & 511 & 580 & 506 & 437 & 418 \\
\hline $\mathrm{X}$ & 384 & $\mathrm{X}$ & 421 & 445 & 440 & 398 & 516 & 583 & 505 & 441 & 427 \\
\hline $\mathrm{X}$ & 381 & $\mathrm{X}$ & 420 & 479 & 455 & 384 & 524 & 583 & 502 & 445 & 426 \\
\hline$X$ & 390 & $\mathrm{X}$ & 420 & 470 & 439 & 395 & 523 & 606 & 487 & 451 & 429 \\
\hline $\mathrm{X}$ & 387 & $\mathrm{X}$ & 420 & 460 & 448 & 369 & 517 & 623 & 483 & 454 & 413 \\
\hline $\mathrm{X}$ & 389 & $\mathrm{X}$ & 420 & 450 & 438 & 379 & 521 & 588 & 491 & 428 & 423 \\
\hline $\mathrm{X}$ & 384 & $\mathrm{X}$ & 421 & 447 & 444 & 394 & 515 & 580 & 508 & 434 & 423 \\
\hline $\mathrm{X}$ & 374 & $X$ & 421 & 466 & 462 & 400 & 493 & 591 & 485 & 436 & 417 \\
\hline$x$ & 392 & $\mathrm{X}$ & 422 & 459 & 444 & 393 & 501 & 601 & 502 & 441 & 431 \\
\hline $\mathrm{X}$ & 376 & $\mathrm{X}$ & 425 & 457 & 444 & 395 & 528 & 590 & 491 & 423 & 426 \\
\hline $\mathrm{X}$ & 368 & $\mathrm{X}$ & 428 & 453 & 446 & 409 & 499 & 584 & 472 & 441 & 427 \\
\hline $\mathrm{X}$ & 379 & $\mathrm{X}$ & 420 & 450 & 446 & 402 & 512 & 577 & 497 & 436 & 419 \\
\hline $\mathrm{X}$ & 375 & $\mathrm{X}$ & 428 & 457 & 454 & 388 & 515 & 574 & 496 & 427 & 415 \\
\hline $\mathrm{X}$ & 384 & $\mathrm{X}$ & 408 & 487 & 439 & 416 & 537 & 572 & 499 & 425 & 423 \\
\hline $\mathrm{X}$ & 379 & $\mathrm{X}$ & 411 & 463 & 453 & 401 & 502 & 600 & 488 & 419 & 420 \\
\hline $\mathrm{X}$ & 372 & $\mathrm{X}$ & 409 & 462 & 436 & 416 & 515 & 581 & 483 & 423 & 429 \\
\hline $\mathrm{X}$ & 375 & $\mathrm{X}$ & 428 & 445 & 450 & 387 & 498 & 563 & 486 & 408 & 436 \\
\hline $\mathrm{X}$ & 387 & $\mathrm{X}$ & 417 & 446 & 448 & 394 & 498 & 572 & 492 & 422 & 427 \\
\hline $\mathrm{X}$ & 365 & $\mathrm{X}$ & 405 & 442 & 437 & 392 & 507 & 590 & 501 & 416 & 421 \\
\hline$X$ & 375 & $X$ & 423 & 456 & 440 & 395 & 493 & 603 & 497 & 422 & 418 \\
\hline $\mathrm{X}$ & 383 & $X$ & 432 & 464 & 444 & 397 & 492 & 586 & 488 & 425 & 429 \\
\hline $\mathrm{X}$ & 389 & $\mathrm{X}$ & 425 & 454 & 443 & 399 & 477 & 592 & 484 & 414 & 429 \\
\hline $\mathrm{X}$ & 369 & $\mathrm{X}$ & 431 & 462 & 439 & 396 & 500 & 586 & 484 & 419 & 433 \\
\hline $\mathrm{X}$ & 378 & $\mathrm{X}$ & 426 & 470 & 436 & 387 & 491 & 585 & 503 & 425 & 441 \\
\hline $\mathrm{X}$ & 358 & $X$ & 436 & 451 & 442 & 386 & 480 & 572 & 491 & 419 & 447 \\
\hline $\mathrm{X}$ & 363 & $\mathrm{X}$ & 432 & 448 & 453 & 397 & 489 & 585 & 465 & 411 & 450 \\
\hline $\mathrm{X}$ & 353 & $\mathrm{X}$ & 429 & 445 & 427 & 408 & 490 & 586 & 491 & 411 & 455 \\
\hline $\mathrm{X}$ & 371 & $\mathrm{X}$ & 424 & 450 & 448 & 397 & 487 & 576 & 473 & 407 & 449 \\
\hline $\mathrm{X}$ & 366 & $\mathrm{X}$ & 450 & 456 & 448 & 377 & 486 & 543 & 479 & 399 & 447 \\
\hline $\mathrm{X}$ & 399 & $\mathrm{X}$ & 424 & 449 & 458 & 390 & 484 & 568 & 487 & 410 & 459 \\
\hline $\mathrm{X}$ & 367 & $\mathrm{X}$ & 425 & 450 & 441 & 400 & 468 & 573 & 485 & 412 & 461 \\
\hline $\mathrm{X}$ & 369 & $\mathrm{X}$ & 429 & 445 & 439 & 399 & 482 & 550 & 469 & 396 & 439 \\
\hline$X$ & 364 & $X$ & 421 & 423 & 440 & 391 & 455 & 561 & 475 & 386 & 438 \\
\hline $\mathrm{X}$ & 368 & $\mathrm{X}$ & 425 & 444 & 444 & 398 & 451 & 555 & 493 & 403 & 442 \\
\hline $\mathrm{X}$ & 372 & $x$ & 419 & 443 & 449 & 408 & 460 & 583 & 477 & 398 & 419 \\
\hline $\mathrm{X}$ & 379 & $\mathrm{X}$ & 435 & 451 & 442 & 391 & 455 & 557 & 497 & 397 & 424 \\
\hline $\mathrm{X}$ & 386 & $X$ & 429 & 453 & 434 & 405 & 452 & 541 & 499 & 432 & 416 \\
\hline$X$ & 392 & $X$ & 429 & 447 & 435 & 402 & 455 & 539 & 486 & 417 & 425 \\
\hline $\mathrm{X}$ & 397 & $\mathrm{X}$ & 438 & 423 & 433 & 386 & 460 & 542 & 491 & 410 & 417 \\
\hline $\mathrm{X}$ & 384 & $\mathrm{X}$ & 425 & 434 & 439 & 396 & 465 & 547 & 485 & 417 & 417 \\
\hline
\end{tabular}


Tabela 4 - Concentração de $\mathrm{CO}_{2}$, em ppm, no ambiente externo(Continuação).

\begin{tabular}{|c|c|c|c|c|c|c|c|c|c|c|c|}
\hline $8 / 4 / 10$ & $11 / 5 / 10$ & $25 / 5 / 10$ & $2 / 6 / 10$ & $16 / 6 / 10$ & $22 / 6 / 10$ & $1 / 7 / 10$ & $6 / 7 / 10$ & $20 / 7 / 10$ & $5 / 8 / 10$ & $19 / 8 / 10$ & $3 / 9 / 10$ \\
\hline $\mathrm{X}$ & 380 & $\mathrm{X}$ & 435 & 421 & 434 & 393 & 456 & 530 & 483 & 419 & 419 \\
\hline $\mathrm{X}$ & 376 & $\mathrm{X}$ & 433 & 416 & 446 & 404 & 457 & 536 & 471 & 445 & 431 \\
\hline $\mathrm{X}$ & 373 & $\mathrm{X}$ & 422 & 426 & 435 & 381 & 445 & 531 & 472 & 423 & $\mathrm{X}$ \\
\hline $\mathrm{X}$ & $\mathrm{X}$ & $\mathrm{X}$ & 440 & 431 & 435 & 379 & 456 & 548 & 466 & 426 & $\mathrm{X}$ \\
\hline $\mathrm{X}$ & $\mathrm{X}$ & $\mathrm{X}$ & 428 & 420 & 437 & 389 & 452 & $\mathrm{X}$ & 473 & 441 & $\mathrm{X}$ \\
\hline $\mathrm{X}$ & $\mathrm{X}$ & $\mathrm{X}$ & $\mathrm{X}$ & 415 & 442 & 407 & 453 & $\mathrm{X}$ & 467 & 431 & $\mathrm{X}$ \\
\hline $\mathrm{X}$ & $\mathrm{X}$ & $\mathrm{X}$ & $\mathrm{X}$ & 436 & 424 & 390 & $\mathrm{X}$ & $\mathrm{X}$ & 456 & $\mathrm{X}$ & $\mathrm{X}$ \\
\hline $\mathrm{X}$ & $\mathrm{X}$ & $\mathrm{X}$ & $\mathrm{X}$ & 434 & 435 & 395 & $\mathrm{X}$ & $\mathrm{X}$ & $\mathrm{X}$ & $\mathrm{X}$ & $\mathrm{X}$ \\
\hline $\mathrm{X}$ & $\mathrm{X}$ & $\mathrm{X}$ & $\mathrm{X}$ & 430 & 437 & $\mathrm{X}$ & $\mathrm{X}$ & $\mathrm{X}$ & $\mathrm{X}$ & $\mathrm{X}$ & $\mathrm{X}$ \\
\hline $\mathrm{X}$ & $\mathrm{X}$ & $\mathrm{X}$ & $\mathrm{X}$ & 419 & 443 & $\mathrm{X}$ & $\mathrm{X}$ & $\mathrm{X}$ & $\mathrm{X}$ & $\mathrm{X}$ & $\mathrm{X}$ \\
\hline $\mathrm{X}$ & $\mathrm{X}$ & $\mathrm{X}$ & $\mathrm{X}$ & 421 & $\mathrm{X}$ & $\mathrm{X}$ & $\mathrm{X}$ & $\mathrm{X}$ & $\mathrm{X}$ & $\mathrm{X}$ & $\mathrm{X}$ \\
\hline $\mathrm{X}$ & $\mathrm{X}$ & $\mathrm{X}$ & $\mathrm{X}$ & 403 & $\mathrm{X}$ & $\mathrm{X}$ & $\mathrm{X}$ & $\mathrm{X}$ & $\mathrm{X}$ & $\mathrm{X}$ & $\mathrm{X}$ \\
\hline
\end{tabular}

